Ralf Oberheide

\title{
Die Bekämpfung der Steuerumgehung
}




\section{Ralf Oberheide}

\section{Die Bekämpfung der Steuerumgehung}

In Zeiten, in denen in zunehmendem Maße über eine „zu hohe“ Steuerlast geklagt wird, gewinnen legale und illegale Formen des Steuerwiderstandes an praktischer und auch wissenschaftlicher Bedeutung. Die hier untersuchte mißbräuchliche Steuerumgehung ist als vom Gesetzeswortlaut, nicht jedoch vom Gesetzeszweck gedeckte Form der Steuerersparnis methodisch zwischen der legalen Steuervermeidung und der illegalen Steuerhinterziehung anzusiedeln. Diese Arbeit stellt den vorhandenen Erkenntnissen der Steuerrechtswissenschaft eine neue Ökonomische Theorie der Steuerumgehung zur Seite und entwickelt hieraus konkrete Vorschläge für eine Steuerreform, deren Umsetzung die mißbräuchliche Umgehung von Steuern weitgehend ausschließen könnte.

Ralf Oberheide wurde 1963 in Hamburg geboren. 1986-1991 Studium der Betriebswirtschaftslehre an der Universität Hamburg, 1991-1995 Wissenschaftlicher Mitarbeiter am dortigen Institut für Finanzwissenschaft. 


\section{Die Bekämpfung der Steuerumgehung}




\section{FINANZWISSENSCHAFTLICHE SCHRIFTEN}

Herausgegeben von den Professoren

Albers, Krause-Junk, Littmann, Oberhauser, Pohmer, Schmidt

Band 87

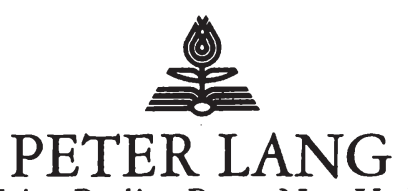

Frankfurt am Main - Berlin - Bern - New York · Paris - Wien

Ralf Oberheide - 978-3-631-75185-5

Downloaded from PubFactory at 01/11/2019 07:21:58AM

via free access 


\section{Ralf Oberheide}

\section{Die Bekämpfung der Steuerumgehung}

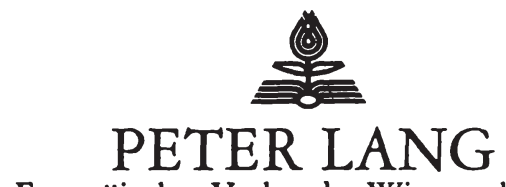

Europäischer Verlag der Wissenschaften

Ralf Oberheide - 978-3-631-75185-5

Downloaded from PubFactory at 01/11/2019 07:21:58AM

via free access 
Die Deutsche Bibliothek - CIP-Einheitsaufnahme

Oberheide, Ralf:

Die Bekämpfung der Steuerumgehung / Ralf Oberheide. Frankfurt am Main ; Berlin ; Bern ; New York ; Paris ; Wien : Lang, 1998

(Finanzwissenschaftliche Schriften ; Bd. 87)

Zugl.: Hamburg, Univ., Diss., 1997

ISBN 3-631-33164-9

Open Access: The online version of this publication is published on www.peterlang.com and www.econstor.eu under the international Creative Commons License CC-BY 4.0. Learn more on how you can use and share this work: http://creativecommons. org/licenses/by/4.0.

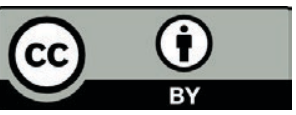

This book is available Open Access thanks to the kind support of ZBW - Leibniz-Informationszentrum Wirtschaft.

\author{
D 18 \\ ISSN 0170-8252 \\ ISBN 3-631-33164-9 \\ ISBN 978-3-631-75185-5 (eBook) \\ (C) Peter Lang GmbH \\ Europäischer Verlag der Wissenschaften \\ Frankfurt am Main 1998 \\ Alle Rechte vorbehalten.
}

Das Werk einschließlich aller seiner Teile ist urheberrechtlich geschützt. Jede Verwertung außerhalb der engen Grenzen des

Urheberrechtsgesetzes ist ohne Zustimmung des Verlages unzulässig und strafbar. Das gilt insbesondere für Vervielfältigungen, Übersetzungen, Mikroverfilmungen und die Einspeicherung und Verarbeitung in elektronischen Systemen.

Printed in Germany 124567 


\section{Meiner Schwägerin}


Ralf Oberheide - 978-3-631-75185-5

Downloaded from PubFactory at 01/11/2019 07:21:58AM

via free access 


\section{"Taxation is the cause of tax avoision." (Christie Davies)}


Ralf Oberheide - 978-3-631-75185-5

Downloaded from PubFactory at 01/11/2019 07:21:58AM

via free access 


\section{VORWORT}

Die vorliegende Arbeit entstand als Dissertation während und unmittelbar nach meiner Tätigkeit als Wissenschaftlicher Mitarbeiter am Institut für Finanzwissenschaft der Universität Hamburg. Eingereicht wurde die Arbeit am 22. Oktober 1996, die Literaturliste spiegelt weitgehend den Stand vom September 1996 wider. Die Bearbeitung des Themas „Steuerumgehung" erfolgte auf Anregung und mit Unterstützung meines Doktorvaters Prof. Dr. Christian Scheer, für dessen fachliche und menschliche Betreuung ich mich an dieser Stelle auf das herzlichste bedanke. Prof. Scheer war bei auftretenden Fragen und Problemen stets zur Stelle, ohne sich jemals aufzudrängen und ohne mir den nötigen Freiraum für die individuelle Abhandlung des Themas zu nehmen. Auch die angenehme Arbeitsatmosphäre am Institut, für die ich mich bei Prof. Scheer, aber auch bei den Professoren G. Engelhardt und G. Tolkemitt sowie bei allen weiteren Kollegen zu bedanken habe, hat zweifellos zum Gelingen der Arbeit beigetragen.

Mein Dank gilt ferner Prof. Cyrille David (Paris) für die Beschaffung französischsprachiger Literatur sowie Frau Francoise Krohn (Großhansdorf) für deren Übersetzung. Des weiteren bin ich Frau Dipl.-Psych. Susanne Horstmann Dank schuldig, die mir insbesondere bei den Literaturrecherchen an der Londoner Universität tatkräftig zur Seite gestanden hat. Bedanken möchte ich mich an dieser Stelle auch bei meinen Eltern für die finanzielle Unterstützung in der Zeit zwischen Ablauf meines befristeten Arbeitsvertrages an der Universität Hamburg und Aufnahme meiner derzeitigen Tätigkeit als Steuerassistent bei der BDO Deutsche Warentreuhand AG. Bei den Professoren G. Krause-Junk und L. Fischer bedanke ich mich für die mit der Erstellung des Zweitgutachtens bzw. mit dem Vorsitz bei der Disputation verbundenen Mühen.

Schließlich gilt mein Dank dem Verlag Peter Lang (Frankfurt/Main u.a.) für die Aufnahme meiner Arbeit in die Reihe der „Finanzwissenschaftlichen Schriften“. 
Ralf Oberheide - 978-3-631-75185-5

Downloaded from PubFactory at 01/11/2019 07:21:58AM

via free access 


\section{Inhaltsverzeichnis}

Vorwort

Abkürzungsverzeichnis

Symbolverzeichnis

Abbildungsverzeichnis

1. Einleitung

2.

Was ist Steuerumgehung?

$2.1 \quad$ Der Begriff der Gesetzesumgehung

3. Soll die Steuerumgehung bekämpft werden?

3.2 Steuerumgehung als Gefahr für die Demokratie?

Fiskalische Auswirkungen der Steuerumgehung

3.4 Allokative Auswirkungen der Steuerumgehung

Direkte Wohlfahrtsverluste aus Steuererhöhungen oder

Kürzungen von Staatsausgaben

$\begin{array}{lll}3.5 .2 & \text { Vertikale Verteilungswirkungen } & 42\end{array}$

3.6 Ergebnis

4. Die Bekämpfung der Steuerumgehung aus rechtswissenschaftlicher Sicht

4.1 Die Diskussion um die Notwendigkeit einer Generalklausel gegen die Steuerumgehung - Alternativen zur Generalklausel

4.1.1 Die Verhinderung der Steuerumgehung durch Gesetzestextanpassungen und Spezialklauseln

4.1.2 Die Bekämpfung der Steuerumgehung im Wege der Gesetzesanwendung ohne Zuhilfenahme einer Generalklausel

4.1.2.1 Zur Abgrenzung zwischen Auslegung und Analogie sowie zwischen Auslegung und teleologischer Reduktion

4.1.2.2 Zur Zulässigkeit von Analogie und teleologischer Reduktion 
4.1.2.2.2 Demokratieprinzip und Gewaltenteilung $\quad 50$

4.1.2.2.3 Sachgesetzlichkeiten im Steuerrecht 51

4.1.2.2.4 Bindung an Recht und Gesetz 51

4.1.2.2.5 Grundsätze der Tatbestandsmäßigkeit und Rechtssicherheit

4.1.2.2.6 Abwägen zwischen Rechtssicherheitspostulat und Gleichheitsgrundsatz? $\quad 54$

4.1.2.2.7 Die Rechtsprechung zur steuerverschärfenden Analogie 55

4.1.2.2.8 Zwischenergebnis $\quad 56$

4.1.2.3 Die wirtschaftliche Betrachtungsweise 57

4.1.3 Die Bekämpfung der Steuerumgehung durch rückwirkende Steuergesetze $\quad 59$

4.1.4 Zwischenergebnis 61

4.2 Die Bekämpfung von Steuerumgehungsaktivitäten ohne Zuhilfenahme einer Generalklausel im Ausland 62

4.2.1 Großbritannien 63

4.2.1.1 Die Rechtsprechung zur Steuerumgehung 63

4.2.1.2 Die Gesetzgebung gegen die Steuerumgehung 67

$\begin{array}{lll}4.2 .2 & \text { USA } & 68\end{array}$

4.2.3 Zwischenergebnis $\quad 70$

4.3 Die Generalklausel gegen die Steuerumgehung in Deutschland: $\S 42 \mathrm{AO}$

4.3.1 Zur Geschichte der Generalklausel $\quad 72$

4.3.2 Der Anwendungsbereich der Generalklausel:

Abgrenzung der Steuerumgehung ( $\$ 42 \mathrm{AO})$ vom

Scheingeschäft (§41 AO)

4.3.3 Die Tatbestandsmerkmale des $\S 42 \mathrm{AO}$ im einzelnen $\quad 76$

4.3.3.1 Umgehung des Gesetzes $\quad 76$

4.3.3.2 Gestaltungsmöglichkeiten des Rechts 77

$\begin{array}{lll}\text { 4.3.3.3 Mißbrauch } & 77\end{array}$

4.3.3.3.1 Die von der Rechtsprechung entwickelten Merkmale
eines Mißbrauchs

$\begin{array}{lll}\text { 4.3.3.3.2 Unangemessenheit } & 78\end{array}$

$\begin{array}{lll}\text { 4.3.3.3.3 Steuerminderungsabsicht } & 80\end{array}$

4.3.3.3.4 Nichtexistenz beachtlicher außersteuerlicher Gründe $\quad 81$

$\begin{array}{lll}\text { 4.3.3.4 Steuerumgehungsabsicht } & 82\end{array}$

$\begin{array}{ll}\text { 4.3.3.5 Minderung der Steuer } & 85\end{array}$

$\begin{array}{lll}\text { 4.3.4 Beweislastverteilung } & 86\end{array}$

$\begin{array}{lll}\text { 4.3.5 } & \text { Rechtsfolgen des } \S 42 \mathrm{AO} & 87\end{array}$

$\begin{array}{lll}\text { 4.3.6 Strafbarkeit der Steuerumgehung } & 89\end{array}$

$\begin{array}{lll}\text { 4.3.6.1 Derzeitige Rechtslage } & 89\end{array}$ 
4.3.6.2 Verfassungsrechtliche Grenzen einer Verschärfung der

Rechtsfolgen

4.3.7 Verfassungsmäßigkeit des $\S 42 \mathrm{AO} \quad 93$

4.4 Die Bekämpfung der Steuerumgehung in Frankreich 94

4.5 Zwischenergebnis 96

5. Ökonomische Theorie der Steuerumgehung 99

$5.1 \quad$ Vorbemerkungen 99

5.2 Das entscheidungstheoretische Modell der Einkommensteuer$\begin{array}{ll}\text { hinterziehung } & 100\end{array}$

$\begin{array}{lll}5.2 .1 & \text { Modellprämissen } & 100\end{array}$

$\begin{array}{lll}\text { 5.2.2 Das Modell } & 101\end{array}$

5.2.3 Der Einfluß von Bruttoeinkommen, Aufdeckungswahrscheinlichkeit, Strafsatz und Steuertarif auf die Höhe des deklarierten Einkommens $\quad 105$

$\begin{array}{lll}\text { 5.2.3.1 Vorüberlegungen } & 105\end{array}$

5.2.3.2 Der Einfluß des tatsächlichen Einkommens auf die Höhe des deklarierten Einkommens 108

5.2.3.3 Der Einfluß der Überprüfungswahrscheinlichkeit auf die Höhe des deklarierten Einkommens

5.2.3.4 Der Einfluß des Strafsatzes auf die Höhe des deklarierten Einkommens 113

5.2.3.5 Der Einfluß des Steuertarifes auf die Höhe des deklarierten Einkommens

5.2.3.5.1 Der Einfluß des Steuersatzes auf die Einkommensdeklaration

5.2.3.5.2 Der Einfluß des Pauschaltransfers bzw. der Kopfsteuer auf die Einkommensdeklaration

5.2.3.5.3 Der Einfluß einer Veränderung der Progressivität des Steuertarifes auf die Einkommensdeklaration

5.3 Empirische Fundierung der Ergebnisse des theoretischen Modells der Hinterziehung Vorbemerkungen Einkommenshöhe

5.3.3 Überprüfungswahrscheinlichkeit 122

$\begin{array}{lll}\text { 5.3.4 Strafsatz } & 123\end{array}$

$\begin{array}{lll}\text { 5.3.5 Grenzsteuersatz } & 124\end{array}$

$\begin{array}{lll}\text { 5.3.6 Sonstige Einflußfaktoren } & 126\end{array}$

5.4 Mögliche Erweiterungen des Grundmodells der Einkommensteuerhinterziehung und ihre Relevanz für ein Modell der Steuerumgehung 
5.5 Entscheidungstheoretisches Modell der Steuerumgehung 135

5.5.1 Vorbemerkungen 135

$\begin{array}{ll}\text { 5.5.2 Allgemeines Modell der Steuerumgehung } & 135\end{array}$

5.5.2.1 Statisches Modell 135

5.5.2.2 Komparativ-statische Analyse:

Die Wirkung von Parametervariationen auf das versteuerte Einkommen

5.5.2.2.1 Variation des ,wahren“ Einkommens 140

5.5.2.2.2 Variation der Wahrscheinlichkeit eines Scheiterns der Steuerumgehung

5.5.2.2.3 Variation des Strafsatzes

5.5.2.2.4 Variation der Kostenfunktion 144

5.5.2.2.5 Variation des Steuertarifes 146

5.5.3 Modell der straffreien Steuerumgehung 152

$\begin{array}{lll}\text { 5.5.3.1 Statisches Modell } & 152\end{array}$

5.5.3.2 Komparativ-statische Analyse:

Die Wirkung von Parametervariationen auf das versteuerte Einkommen

5.5.3.2.1 Variation des ,wahren“ Einkommens 156

$\begin{array}{lll}\text { 5.5.3.2.2 Variation der Wahrscheinlichkeit eines Scheiterns } & \\ & \text { der Steuerumgehung } & 157\end{array}$

$\begin{array}{ll}\text { 5.5.3.2.3 Variation der Kostenfunktion } & 158\end{array}$

$\begin{array}{lll}\text { 5.5.3.2.4 Variation des Steuertarifes } & 161\end{array}$

5.6 Exkurs: Simultane Entscheidung über Steuerumgehung und Steuerhinterziehung

5.7 Interpretation der Modellergebnisse:

Welche Parameter eignen sich für eine Bekämpfung der

Steuerumgehung?

5.7.1 Einkommenshöhe

$\begin{array}{ll}\text { 5.7.2 Wahrscheinlichkeit der Nichtanerkennung } & 170\end{array}$

$\begin{array}{lll}\text { 5.7.3 Strafsatz } & 171\end{array}$

$\begin{array}{lll}\text { 5.7.4 Kosten der Steuerumgehung } & 172\end{array}$

$\begin{array}{lll}5.7 .5 & \text { Steuertarif } & 173\end{array}$

$\begin{array}{lll}\text { 5.7.5.1 Steuersatz } & 173\end{array}$

$\begin{array}{lll}\text { 5.7.5.2 Pauschaltransfer und Kopfsteuer } & 174\end{array}$

$\begin{array}{lll}\text { 5.7.5.3 Progression des Steuertarifes } & 175\end{array}$

5.8 Sonstige Bestimmungsgründe der Steuerumgehung 176

$\begin{array}{lll}\text { 5.8.1 Finanzpsychologische Erklärungsfaktoren } & 176\end{array}$

$\begin{array}{lll}\text { 5.8.1.1 Bewertung des politischen Systems } & 178\end{array}$

5.8.1.2 Beurteilung des staatlichen Budgets 179

$\begin{array}{lll}\text { 5.8.1.3 Steuerbelastungsgefühl } & 182\end{array}$

5.8.1.4 Einschätzung der Steuerdisziplin der übrigen Bevölkerung 183 
5.8.2 Gelegenheiten zu Steuerumgehung

5.9 Zwischenergebnis:

Ansatzpunkte für eine erfolgversprechende

Anti-Umgehungs-Politik

6. Bekämpfung der Steuerumgehung durch Beseitigung vorhandener Gelegenheiten zum Rechtsmißbrauch

6.1

Grundtypen der Steuerumgehung

6.2 Interpersonelle Verlagerung von Einkommen und Vermögen

Möglichkeiten für interpersonelle Einkommensverlagerungen

6.2.2 Reformvorschläge

6.2.2.1 Familiensplitting

6.2.2.2 Abschaffung der direkten Progression

6.2.2.3 Reform der Erbschaft- und Schenkungsteuer

6.4.1 Transformation zu versteuernden Einkommens in steuerbegünstigte Einkünfte

Umwandlung bestimmter Einkunfts-, Aufwands- oder

Umsatzarten in steuerbegünstigte Formen

6.4.2 Transformation steuerlich irrelevanter Ausgaben in abzugsfähige Aufwendungen

$\begin{array}{ll}\text { 6.4.3 Transformation von Umsätzen } & 213\end{array}$

$\begin{array}{lll}6.4 .4 & \text { Reformvorschläge } & 215\end{array}$

$\begin{array}{lll}6.5 & \text { Steuerarbitrage } & 218\end{array}$

$\begin{array}{ll}\text { 6.5.1 Formen der Steuerarbitrage } & 218\end{array}$

$\begin{array}{lll}\text { 6.5.2 Reformvorschläge } & 220\end{array}$

6.6 Einkommens- oder Vermögensverlagerung zwischen betrieblicher und privater Ebene

$\begin{array}{lll}\text { 6.6.1 Besonderheiten der Unternehmensbesteuerung } & 221\end{array}$

6.6.2 Möglichkeiten von Einkommens- und Vermögensverschiebungen zwischen betrieblicher und privater Ebene 222

6.6.3 Reformvorschläge

6.7 Ausnutzung von Verstößen gegen die Neutralität der Unternehmensbesteuerung

6.7.1 Verstöße gegen die Rechtsform- und Finanzierungsneutralität im deutschen Steuerrecht

6.7.1.1 Verstöße gegen die Rechtsformneutralität 228

$\begin{array}{lll}\text { 6.7.1.2 Verstöße gegen die Finanzierungsneutralität } & 228\end{array}$ 
6.7.2 Möglichkeiten der Steuerumgehung durch Ausnutzung fehlender Rechtsform- und Finanzierungsneutralität

$\begin{array}{ll}\text { 6.7.2.1 Ausnutzung fehlender Rechtsformneutralität } & 229\end{array}$

$\begin{array}{ll}\text { 6.7.2.2 Ausnutzung fehlender Finanzierungsneutralität } & 231\end{array}$

$\begin{array}{lll}6.7 .3 & \text { Reformvorschläge } & 234\end{array}$

6.8 Räumliche Verlagerung von Einkommen 235

$\begin{array}{lll}6.8 .1 & \text { Vorbemerkungen } & 235\end{array}$

6.8.2 Methoden der internationalen Steuerumgehung 236

6.8.2.1 Internationale Steuerumgehung durch unangemessene Konzernverrechnungspreise 236

6.8.2.2 Internationale Steuerumgehung durch Nutzung von Basisgesellschaften $\quad 237$

6.8.2.3 Internationale Steuerumgehung durch Mißbrauch von Doppelbesteuerungsabkommen

6.8.3 Reformvorschläge

7. Zusammenfassung und Ausblick 


\section{Abkürzungsverzeichnis}

a.A.

a.a.O.

abzgl.

All ER

AOStrafÄndG

APTIRC

art.

AStG

BAG

Begr.

Begr. RegE

BerlinFG

BewG

BFH

$\mathrm{BFH} / \mathrm{NV}$

BGB-Gesellschaft

BGH

BGHSt

BStB1.

BVerfG

BVerfGE

bzgl.

\section{CGI}

comm.

c.p.

DB

DBA

ders.

DF

Drucks.

ed.

eds.

EFG

ErbSt

ErbStG anderer Ansicht

am angegebenen $\mathrm{Ort}$

abzüglich

All England Law Reports

Gesetz zur Änderung strafrechtlicher Vorschriften der

Reichsabgabenordnung und anderer Gesetze

Asian-Pacific Tax and Investment Research Centre

article

Außensteuergesetz

Bundesarbeitsgericht

Begründung

Begründung zum Regierungsentwurf

Berlinförderungsgesetz

Bewertungsgesetz

Bundesfinanzhof

Sammlung amtlich nicht veröffentlichter Entscheidungen des Bundesfinanzhofs

Gesellschaft bürgerlichen Rechts

Bundesgerichtshof

Amtliche Sammlung von Entscheidungen des Bundesgerichtshofs in Strafsachen

Bundessteuerblatt

Bundesverfassungsgericht

Amtliche Sammlung von Entscheidungen des

Bundesverfassungsgerichts

bezüglich

Code général des Impots

commentaire

ceteris paribus

Der Betrieb (Zeitschrift)

Doppelbesteuerungsabkommen

derselbe

Droit fiscal

Drucksache

editor

editors

Entscheidungen der Finanzgerichte

Erbschaftsteuer

Erbschaftsteuergesetz 


$\begin{array}{ll}\text { Erg.-Lfg. } & \text { Ergänzungslieferung } \\ \text { ESt } & \text { Einkommensteuer } \\ \text { EStG } & \text { Einkommensteuergesetz } \\ \text { FG } & \text { Finanzgericht } \\ \text { FinBeh } & \text { Finanzbehörde } \\ \text { FN } & \text { Fußnote } \\ \text { gem. } & \text { gemäß } \\ \text { GewKapSt } & \text { Gewerbekapitalsteuer } \\ \text { GewStG } & \text { Gewerbesteuergesetz } \\ \text { GewStR } & \text { Gewerbesteuerrichtlinien } \\ \text { gl.A. } & \text { gleicher Ansicht } \\ \text { GrESt } & \text { Grunderwerbsteuer } \\ \text { GrS } & \text { Großer Senat } \\ \text { HHSp } & \text { HÜBSCHMANN/HEPP/SPITALER (AO-Kommentar) } \\ \text { h.M. } & \text { herrschende Meinung } \\ \text { i.a. } & \text { im allgemeinen } \\ \text { i.d.R. } & \text { in der Regel } \\ \text { IEA } & \text { The Institute of Economic Affairs } \\ \text { i.e.S. } & \text { im engeren Sinne } \\ \text { ifo } & \text { Institut für Wirtschaftsforschung } \\ \text { IFS } & \text { Institut „Finanzen und Steuern } \\ \text { i.H.v. } & \text { in Höhe von } \\ \text { insb. } & \text { insbesondere } \\ \text { IRC } & \text { Inland Revenue Commissioners } \\ \text { i.S. } & \text { im Sinne } \\ \text { i.S.d. } & \text { im Sinne des } \\ \text { i.S.v. } & \text { im Sinne von } \\ \text { i.V.m. } & \text { in Verbindung mit } \\ \text { JPE } & \text { Journal of Public Economics } \\ \text { KSt } & \text { Körperschaftsteuer } \\ \text { KStG } & \text { Körperschaftsteuergesetz } \\ \text { KStR } & \text { Körperschaftsteuerrichtlinien } \\ \text { LPF } & \text { Livre des Procédures fiscales } \\ \text { Ltd. } & \text { limited company } \\ \text { m.w.N. } & \text { mit weiteren Nennungen } \\ \text { N.F. } & \text { Neue Folge } \\ \text { NIT } & \text { negative income toxx } \\ \text { NJW } & \\ \text { no } & \text { Neue Juristische Wochenschrift (Zeitschrift) } \\ \text { No. } & \text { nWB } \\ \text { NWhafts-Briefe }\end{array}$


ÖPNV

o.V.

OWiG

PF

RAO

Rdnr.

RFH

RFHE

RJF

Rspr.

RStBl.

$\mathrm{Rz}$.

StAnpG

SVR

Tz.

u.a.

UK

Urt.

USt

UStG

VGR

Vol.

VSt

VStG

WLR

z.v.E.

zzgl. öffentlicher Personennahverkehr ohne Verfasserangabe Gesetz über Ordnungswidrigkeiten Public Finance (Zeitschrift)

Reichsabgabenordnung

Randnummer

Reichsfinanzhof

Sammlung der Entscheidungen des Reichsfinanzhofs

Revue de jurisprudence fiscale

Rechtsprechung

Reichssteuerblatt

Randziffer

Steueranpassungsgesetz

Sachverständigenrat zur Begutachtung der gesamtwirtschaftlichen Entwicklung

Textziffer

unter anderem

United Kingdom

Urteil

Umsatzsteuer

Umsatzsteuergesetz

Volkswirtschaftliche Gesamtrechnung

volume

Vermögensteuer

Vermögensteuergesetz

Weekly Law Reports

zu versteuerndes Einkommen

zuzüglich 
Ralf Oberheide - 978-3-631-75185-5

Downloaded from PubFactory at 01/11/2019 07:21:58AM

via free access 


\section{Symbolverzeichnis}

\begin{tabular}{|c|c|}
\hline $\begin{array}{l}E \\
E(A)\end{array}$ & $\begin{array}{l}\text { Einkommenseffekt } \\
\text { erwartetes staatliches Aufkommen an Steuern und Geldbußen }\end{array}$ \\
\hline $\mathrm{E}(\mathrm{U})$ & Erwartungsnutzen \\
\hline $\mathrm{f}$ & Strafsatz \\
\hline$f(\ldots)$ & Funktion von ... \\
\hline k & Grenzkosten \\
\hline K & Fixkosten \\
\hline $\mathrm{K}(\ldots)$ & Kostenfunktion in Abhängigkeit von ... \\
\hline $\mathrm{p}$ & Wahrscheinlichkeit der Aufdeckung / des Mißlingens \\
\hline $\mathrm{P}$ & Punkt \\
\hline$q$ & Quellensteuersatz \\
\hline r & Pauschaltransfer (bei $r>0$ ) bzw. Kopfsteuer (bei $r<0$ ) \\
\hline $\mathbf{R}_{\mathrm{A}}(\ldots)$ & absolute Risikoaversion in Abhängigkeit von ... \\
\hline $\mathrm{S}$ & Substitutionseffekt \\
\hline $\mathrm{T}$ & Steuerfunktion \\
\hline $\mathrm{T}(\ldots)$ & Steuerfunktion in Abhängigkeit von ... \\
\hline$T^{\prime}$ & Grenzsteuersatz \\
\hline $\mathrm{T}^{\prime}(\ldots)$ & Grenzsteuersatz bei einem versteuerten Einkommen i.H.v. ... \\
\hline$T^{\prime \prime}$ & 2. Ableitung der Steuerfunktion \\
\hline $\mathrm{U}(\ldots)$ & Nutzenfunktion in Abhängigkeit von ... \\
\hline $\mathrm{U}^{\prime}$ & Grenznutzen \\
\hline$U^{\prime}(\ldots)$ & Grenznutzen von ... \\
\hline U', & 2. Ableitung der Nutzenfunktion \\
\hline $\mathrm{X}$ & deklariertes Einkommen \\
\hline $\mathrm{X}_{\min }$ & nicht umgehbares Einkommen \\
\hline $\mathrm{x}_{\mathbf{\delta} \mathrm{ff}}$ & öffentliches Gut \\
\hline $\mathrm{x}_{\text {priv }}$ & privates Gut \\
\hline W & tatsächliches Bruttoeinkommen \\
\hline Y & $\begin{array}{l}\text { verbleibendes Einkommen bei geglückter Steuerumgehung/ } \\
\text {-hinterziehung }\end{array}$ \\
\hline$Y_{b r}$ & Bruttoeinkommen \\
\hline$Y_{m}$ & Mindest-Nettoeinkommen \\
\hline $\mathrm{Y}_{\mathrm{Tr}}$ & Transfergrenze \\
\hline$Y_{v}$ & verfügbares Einkommen \\
\hline Z & $\begin{array}{l}\text { verbleibendes Einkommen bei gescheiterter Steuerumgehung/ } \\
\text {-hinterziehung }\end{array}$ \\
\hline$\mu$ & Erwartungswert \\
\hline$\sigma$ & Standardabweichung \\
\hline$\theta$ & einheitlicher Grenzsteuersatz \\
\hline
\end{tabular}


Ralf Oberheide - 978-3-631-75185-5

Downloaded from PubFactory at 01/11/2019 07:21:58AM

via free access 


\section{Abbildungsverzeichnis}

Abb. 5.1 verfügbares Einkommen in Abhängigkeit von der

Deklarationsentscheidung

102

Abb. 5.2 Bernoulli-Nutzenfunktion

106

Abb. 5.3 graphische Ermittlung der optimalen

Einkommensdeklaration

108

Abb. 5.3.a) Variation des wahren Einkommens W

Abb. 5.3.b) Variation der Aufdeckungswahrscheinlichkeit p 112

Abb. 5.3.c) Variation des Strafsatzes $f$

$\begin{array}{lll}\text { Abb. 5.3.d) Variation des Grundsteuersatzes } \theta & 116\end{array}$

$\begin{array}{lll}\text { Abb. 5.3.e) Variation des Pauschaltransfers } \mathrm{r} & 118\end{array}$

Abb. 5.3.f) Variation des Progressionsgrades

120

Abb. 5.4. verfügbares Einkommen in Abhängigkeit von der Steuerumgehungsentscheidung

Abb. 5.5 graphische Ermittlung der optimalen Einkommensdeklaration (Steuerumgehung als Ordnungswidrigkeit)

Abb. 5.5.a) Variation des Einkommens W

Variation von $p$

Abb. 5.5.c) Variation des Strafsatzes $f$

Abb. 5.5.d) Variation der Fixkosten $K$

Variation der Grenzkosten k

Variation des Grenzsteuersatzes $\theta$

Abb. 5.5.g) Variation des Pauschaltransfers $\mathrm{r}$

Variation des Progressionsgrades

Abb. 5.6 verfïgbares Einkommen in Abhängigkeit von der Steuerumgehungsentscheidung bei Straffreiheit

Abb. 5.7 graphische Ermittlung der optimalen Einkommensdeklaration (straffreie Steuerumgehung)

Variation des Einkommens W

Abb. 5.7.b) Variation von $p$

Abb. 5.7.c) Variation der Fixkosten $\mathrm{K}$

Abb. 5.7.d) Variation der Grenzkosten k

$\begin{array}{lll}\text { Abb. 5.7.e) Variation des Grenzsteuersatzes } \theta & 162\end{array}$

Abb. 5.7.f) Variation des Pauschaltransfers $r$

Abb. 5.7.g) Variation des Progressionsgrades 
Abb. 5.9 optimale Steuerumgehungsentscheidung bei

eingeschränkten Umgehungsmöglichkeiten

Abb. 6.1 Entwicklung der Steuerschuld in Abhängigkeit vom verfügbaren Einkommen (NIT i.V.m. flat-rate tax)

Abb. 6.2 Entwicklung des Nettoeinkommens bei einer NIT

i.V.m. einer flat-rate tax

202 


\section{Einleitung}

Die finanzwissenschaftliche Literatur hat sich seit jeher mit den Ausweichreaktionen der Steuerpflichtigen auf bestehende oder neu einzuführende Steuern befaßt. Die Möglichkeit, solche Steuern legal zu vermeiden, indem die besteuerte Aktivität durch eine andere ersetzt (z.B. Arbeit durch Freizeit, Ersparnis durch Konsum) oder ein höher besteuertes Gut durch ein niedriger besteuertes substituiert wird (z.B. Bier durch Wein, Ratensparverträge durch Kapitallebensversicherungen), ist Gegenstand nahezu jeder Untersuchung, die sich mit den Steuerwirkungen beschäftigt. In den letzten 25 Jahren hat sich die finanzwissenschaftliche Steuerlehre auch verstärkt mit dem Phänomen „Steuerhinterziehung“ auseinandergesetzt und dieses sowohl in theoretischen Modellen als auch in empirischen Arbeiten qualitativ und quantitativ umfassend zu erforschen versucht. Der Steuerumgehung, jener "Grauzone zwischen legaler Steuervermeidung und illegaler Steuerhinterziehung", hat die Finanzwissenschaft bislang jedoch erstaunlich wenig Aufmerksamkeit gezollt und dieses Untersuchungsfeld weitgehend den Juristen überlassen.

Grundsätzlich kann sich eine ökonomische Analyse der Steuerumgehung sowohl mit deren Bestimmungsgründen (und den sich daraus ergebenden Ansatzpunkten für ihre Bekämpfung) als auch mit den gesamtwirtschaftlichen Auswirkungen befassen. Da die ökonomischen Auswirkungen der Steuerumgehung mit denen der Steuerhinterziehung praktisch identisch sein dürften (es macht im Ergebnis kaum einen Unterschied, ob eine bestimmte Aktivität vom Gesetzeswortlaut gedeckt ist oder nicht $)^{2}$ und diesbezüglich eine Vielzahl von Veröffentlichungen zur Steuerhinterziehung bereits existiert, werden die mit der Steuerumgehung verbundenen volkswirtschaftlichen Konsequenzen in Abschnitt 3 dieser Arbeit nur skizziert und ansonsten aus der Betrachtung ausgeklammert. Die vorliegende Dissertation befaßt sich vielmehr mit den Möglichkeiten, die dem Gesetzgeber und den Gesetzesanwendern zur Verfugung stehen, um das Ausma $ß$ an Steuerumgehung zu reduzieren. Dieser Untersuchungsgegenstand ist dem Grenzgebiet zwischen Rechtsund Wirtschaftswissenschaft zuzuordnen; hieraus ergibt sich die diese Arbeit prägende interdisziplinäre Herangehensweise.

Die Rechtswissenschaft befaßt sich in Deutschland schon seit den 20er-Jahren recht ausgiebig mit der Bekämpfung der Steuerumgehung. Die juristischen Methoden, ihre jeweilige Wirksamkeit und die Frage nach ihrer verfassungsrechtlichen Zulässigkeit sind Gegenstand von Abschnitt 4. Dabei steht der in Deutschland vorliegende rechtliche Rahmen im Vordergrund; doch enthält dieser Abschnitt auch einen internationalen Rechtsvergleich, um allgemeiner gültige Aussagen zu ermög-

\footnotetext{
${ }^{1}$ Eine genauere Definition liefert Abschnitt 2.

${ }^{2}$ Vgl. BRACEWELL-MIINES (1979) S. 24; SELDON in IEA (1979) S. 4.
} 
lichen und die Analyse der Steuerumgehung nicht auf diejenigen Gegebenheiten zu reduzieren, die man derzeit im Inland vorfindet.

Dem existierenden rechtswissenschaftlichen Ansatz fügt Abschnitt 5 einen ökonomischen Ansatz hinzu.

Da die Ursachen der Steuerumgehung im wesentlichen dieselben sein dürften wie die der Steuerhinterziehung, ${ }^{1}$ dient das bekannte entscheidungstheoretische Modell der Steuerhinterziehung als Grundlage für das in diesem Abschnitt entwickelte Modell der Steuerumgehung. Bevor das Steuerhinterziehungsmodell in ein Umgehungsmodell überfürt wird, werden die Ergebnisse des theoretischen Hinterziehungsmodells anhand der hierzu in großer Anzahl existierenden empirischen Arbeiten überprüft. Diese Überprüfung ist notwendig, um die Ursachen eventueller Abweichungen der empirischen von den theoretischen Ergebnissen erklären zu können. Diesbezügliche Divergenzen weisen möglicherweise auf Unvollkommenheiten des entscheidungstheoretischen Hinterziehungsmodells hin, welche auch auf das hieraus entwickelte Steuerumgehungsmodell zutreffen könnten. ${ }^{2}$

Ein besonderes Anliegen dieser Arbeit ist es, bei der Präsentation der theoretischen Modelle nicht nur - wie sonst in der Literatur üblich - die Modellannahmen, den Ansatz und die Ergebnisse vorzulegen, sondern letztere jeweils nachvollziehbar (und damit auch nachprüfbar) algebraisch und graphisch herzuleiten.

$\mathrm{Da}$ das ökonomische Modell unvollständig ist, solange es die Steuerumgehung als reine Abwägung monetärer Kosten und Nutzen betrachtet, finden auch die Erkenntnisse der Finanzpsychologie Eingang in die vorliegende Untersuchung. Damit wird versucht, in Abschnitt 5 die Motive der Steuerumgehung möglichst vollständig zu erfassen. Der Frage, inwieweit diese Motive staatlicherseits beeinflußbar sind und damit Basis einer Bekämpfung der Steuerumgehung sein können, wird am Ende des Abschnitts nachgegangen.

Damit es zu Steuerumgehung kommt, muß aber neben einem Motiv auch eine Gelegenheit vorliegen. Hier unterscheidet sich die Steuerumgehung fundamental von der Steuerhinterziehung: Zwar mag die Feststellung, ,ovoidance is a function of the tax base, evasion is a function of collecting procedures ${ }^{\text {s. }}$ eine den Sachverhalt etwas zu stark vereinfachende Aussage darstellen; doch trifft es sicherlich zu, daß die Gelegenheiten zur Steuerhinterziehung von der Art der Steuererhebung

${ }^{1}$ Das Ausmaß beider Formen des Steuerentzuges dürfte abhängig sein vom Steuertarif, vom Bruttoeinkommen, von der Wahrscheinlichkeit des Scheiterns, von einer eventuellen Bestrafung, von den mit dem Steuerentzug verbundenen Kosten, von der allgemeinen Steuermoral und dem Vorhandensein von Gelegenheiten, Steuern zu hinterziehen bzw. zu umgehen.

${ }^{2}$ Noch nützlicher für eine gesicherte Interpretation der theoretischen Modellergebnisse wären natürlich die Resultate empirischer Untersuchungen zur Steuerumgehung. Leider ist dieses Gebiet bislang empirisch nahezu unerforscht geblieben.

${ }^{3}$ FELDMAN/KAY (1981) S. 332 
(direkte vs. indirekte Steuern, Quellensteuern vs. Veranlagungsteuern) abhängen, während sich eine Möglichkeit, Steuern zu umgehen oder zu vermeiden, nur dort ergeben kann, wo nicht entscheidungsneutrale Steuerbemessungsgrundlagen oder -tarife den Steuerpflichtigen einen Ansatz bieten, sich legal oder halblegal der Besteuerung zu entziehen. Dabei ist zu beachten, daß zwar jede Abweichung von der Besteuerungsneutralität Möglichkeiten zur Steuervermeidung hervorruft, sich aber nur ein Teil dieser Abweichungen zur mißbräuchlichen Umgehung von Steuern nutzen läßt. Insofern ist es zur Bekämpfung der Steuerumgehung nicht notwendig, das gegenwärtige Steuersystem durch eine als Alleinsteuer fungierende Kopfsteuer zu ersetzen, welche zwar entscheidungsneutral, aber weder sozial verträglich noch irgendwelche volkswirtschaftliche Lenkungsfunktionen wahrzunehmen in der Lage ist. Abschnitt 6 befaßt sich vielmehr mit Steuerreformmöglichkeiten, welche die vorhandenen Gelegenheiten zur Steuerumgehung möglichst umfassend beseitigen können, ohne schädliche Nebenwirkungen aufzuweisen, die die Umgehungsbekämpfung zu einem in hohem Maße fragwürdigen politischen Vorhaben werden ließen.

Indem die vorgeschlagenen Steuerreformen nicht allein auf ihr (für den vorliegenden Untersuchungsgegenstand primäres) Ziel ihrer Wirksamkeit gegen die Steuerumgehung, sondern gleichzeitig (sekundär) auf ihre sonstigen positiven und negativen Auswirkungen untersucht werden, zeigt diese Arbeit nicht nur Wege für eine finanzwissenschaftliche Lösung der Steuerumgehungsproblematik auf, sondern bietet darüber hinaus - quasi als Nebenprodukt - Vorschläge für eine soziale, wachstums- und beschäftigungsfreundliche sowie ökologische Steuerreform. 
Ralf Oberheide - 978-3-631-75185-5

Downloaded from PubFactory at 01/11/2019 07:21:58AM

via free access 


\subsection{Der Begriff der Gesetzesumgehung}

Die Steuerumgehung stellt einen Unterfall der Gesetzesumgehung dar. ${ }^{1}$

Unter Gesetzesumgehung versteht man ein Verhalten, das zwar nicht gegen den Wortlaut einer gesetzlichen Bestimmung verstößt, aber einen Verstoß gegen Sinn und Zweck des Gesetzes bedeutet. ${ }^{2}$ Als Gesetzesumgeher wird bezeichnet, wer versucht, die Tatbestandsmerkmale begünstigender Rechtsnormen formal zu erfüllen (Tatbestandserschleichung) bzw. die Tatbestandsmerkmale belastender Rechtsnormen der Form nach zu vermeiden (Tatbestandsumgehung). ${ }^{3}$ Hierbei liegt regelmäßig ein Mißbrauch (an und für sich zulässiger) rechtlicher Gestaltungsmöglichkeiten vor. ${ }^{4}$ Die Begriffe "Gesetzesumgehung“ und „Rechtsmißbrauch" stehen somit in einem engen Zusammenhang.

Nach h.M. beginnt eine Gesetzesumgehung erst dort, wo die Umgehungshandlung nicht mehr vom ausgelegten Gesetz erfaßt wird. ${ }^{6}$

Im Falle der Tatbestandserschleichung bedeutet das, daß auch eine enge Auslegung des Gesetzeswortlauts die Anwendung einer begünstigenden Vorschrift auf den ihr zugeordneten Sachverhalt nicht verhindern kann. In solchen Fällen begegnen Verwaltung und Rechtsprechung der Gesetzesumgehung mit dem Mittel der teleologischen Reduktion. Hierunter wird die „einschränkende Korrektur des Wortsinns durch den Normsinn ${ }^{\text {“7 }}$ verstanden.

Analog zur Tatbestandserschleichung beginnt fur den Fall der Tatbestandsumgehung die Gesetzesumgehung dort, wo die Erfassung von Sachverhalten, welche nach dem Zweck des Gesetzes eigentlich zu erfassen wären, im Wege der Gesetzesauslegung nicht mehr möglich ist. ${ }^{8}$ Somit beginnt die Umgehung erst jenseits des ausgelegten Gesetzes, im Bereich der Gesetzeslücken. Eine - vom Gesetzgeber nicht gewollte - Gesetzeslücke liegt vor, wenn der Gesetzgeber bei Erstellung

${ }^{1}$ Vgl. HENSEL (1923) S. 233, 226 ff.; vgl. auch BFH-Urteil vom 14.5.1986 II R 22/84 BStBl. 1986 II S. 620 [621].

${ }^{2}$ Vgl. RIEDEL (1968) S. 3.

${ }^{3}$ Vgl. DANZER (1981) S. 12. Statt „Tatbestandsumgehung“" verwendet DANZER allerdings den mißverständlichen Begriff „Tatbestandsvermeidung“. Vgl. in diesem Zusammenhang jedoch auch WESTERHOFF (1966) S. 7.

${ }^{4}$ Vgl. ROMER (1955) S. 41.

${ }^{5} \mathrm{Vgl}$. auch TEICHMANN (1962) S. $71 \mathrm{f}$.

${ }^{6}$ Vgl. TIPKE (1993) S. 1326.

${ }^{7}$ DANZER (1981) S. 79; vgl. auch LARENZ (1991) S. 391.

${ }^{8} \mathrm{Vgl}$. HOFFMANN in KOCH/SCHOLTZ (1993) Rz. 3.

(Soweit nicht anders angegeben, beziehen sich in dieser Arbeit alle Rz.-, Rdnr.-, Anm.- und Tz.-Angaben aus juristischen Kommentaren auf $\S 42$ AO.) 
des Gesetzestextes nicht alle denkbaren Sachverhalte bedacht hat oder der Gesetzeszweck aufgrund mangelhafter sprachlicher Umsetzung nicht ausreichend durch den Wortlaut der Rechtsvorschrift zum Ausdruck kommt. ${ }^{1}$ Gesetzeslücken lassen sich schließen durch Anwendung der Analogie. Analogie bedeutet, die Rechtsfolgen des in der Norm umschriebenen Sachverhalts analog auf den - im Hinblick auf Sinn und Zweck der Norm für gleichwertig erachteten - zu beurteilenden Sachverhalt anzuwenden. ${ }^{2}$

Die Verfahren der Analogie und der teleologischen Reduktion gelten im Privatrecht nach heute vorherrschender Auffassung als ohne weiteres zulässig. ${ }^{3}$ Einer aktiven Bekämpfung der Gesetzesumgehung von Seiten des Gesetzgebers durch Schaffung spezieller oder allgemeiner „Anti-Umgehungsvorschriften “ bedarf es hier daher nicht, wenngleich solche „Mißbrauchsparagraphen“ im deutschen Privatrecht durchaus existieren.

\subsection{Die Gesetzesumgehung im Steuerrecht}

Die Existenz von Gesetzesumgehungen beschränkt sich nicht auf bestimmte Rechtsgebiete. Auch das Steuerrecht sieht sich häufig mit Fällen mißbräuchlicher Rechtsgestaltungen konfrontiert.

Als Unterfall der Gesetzesumgehung läßt sich die Steuerumgehung analog definieren:

Unter Steuerumgehung versteht man ein Verhalten, durch das die handelnde Person einen Steuervorteil zu erlangen sucht, der dem Sinn und Zweck der betreffenden Gesetzesbestimmung zuwiderläuft, ohne daß der ausgelegte Wortlaut des Steuergesetzes diesem Steuervorteil entgegenstünde. ${ }^{4}$

Die Steuerumgehung kann sowohl darin bestehen, daß ein steuerpflichtiger Tatbestand zu umgehen versucht wird, als auch in dem Bestreben, den Tatbestand einer Steuervergünstigung oder -befreiung gegen den Gesetzeszweck seinem Wortlaut nach zu erfullen. ${ }^{5}$ Kennzeichen der Steuerumgehung ist dabei ein Mißbrauch der individuellen Gestaltungsfreiheit zum Zwecke der Steuerersparnis. ${ }^{6}$

${ }^{1} \mathrm{Vgl}$. TIPKE/LANG (1994) S. 105.

${ }^{2}$ Vgl. Fischer in HHSp (1996) Rz. 55; BYDLINSKI (1991) S. 475.

${ }^{3} \mathrm{Vgl}$. DANZER (1981) S. $16 \mathrm{ff}$; anders sieht es hingegen im Strafrecht aus, wo strafverschärfende Analogie aufgrund von Art. 103 Abs. 2 GG als unzulässig angesehen wird, hierzu s.u. Kap. 4.1.2.2.1.

${ }^{4}$ Vgl. WACKERNAGEL (1949) S. 29.

${ }^{5}$ Vgl. KRUSE (1991) S. 144.

${ }^{6} \mathrm{Vgl.} \mathrm{KUHN/KUTTER/HOFMANN} \mathrm{(1990)} \mathrm{S.} 119$. 
Die fehlende Strafbarkeit ist hingegen kein notwendiges Merkmal der Steuerumgehung. ${ }^{1} \mathrm{Ob}$ und ggf. wie der Staat die Umgehung der Steuergesetze ahndet, steht in keinem Zusammenhang mit der Frage, wann eine Steuerumgehung vorliegt, sondern lediglich mit den im Gesetz hierfür vorgesehenen Rechtsfolgen.

Begrifflich abzugrenzen ist die Steuerumgehung von der Steuervermeidung und der Steuerhinterziehung.

Unter Steuervermeidung versteht man die rechtlich zulässige Einschränkung der steuerlichen Belastung durch den Steuerträger. Im einzelnen kann dieser der belastenden Aktivität in sachlicher, räumlicher oder zeitlicher Hinsicht ausweichen. ${ }^{2}$ Von der Steuerumgehung unterscheidet sich die Steuervermeidung dadurch, daß der Steuervermeider nicht nur (wie der Steuerumgeher) den Wortlaut des Gesetzes auf seiner Seite hat, sondern die von ihm erreichte Steuerminderung auch dem Sinn der betreffenden gesetzlichen Bestimmungen nicht entgegensteht.

Als Steuerhinterziehung wird der Versuch bezeichnet, die steuerliche Belastung zu vermindern, indem der FinBeh steuerlich relevante Tatsachen unrichtig, unvollständig oder überhaupt nicht mitgeteilt werden. ${ }^{3}$ Steuerhinterziehung bedeutet einen Verstoß auch gegen den Gesetzeswortlaut und ist als solcher strafbar. ${ }^{4}$

Als Oberbegriff für Steuervermeidung, Steuerumgehung und Steuerhinterziehung läßt sich das Wort Steuerentzug verwenden. ${ }^{5}$

Die vergleichsweise hohe Bedeutung, die der Steuerumgehung in der englischsprachigen Literatur beigemessen wird, legt nahe, an dieser Stelle auch auf die im angloamerikanischen Sprachraum gebräuchliche Terminologie einzugehen:

Die englische Sprache unterschied ursprünglich nur zwischen legaler „tax avoidan$c e^{\text {“ }}$ und illegaler „tax evasion". ${ }^{6}$ Während sich der Ausdruck „tox evasion" mit „Steuerhinterziehung“ ohne weiteres exakt übersetzen läßt, hat das vermehrte Auftreten von Steuerumgehungsaktivitäten auch im englischen Sprachraum dazu geführt, daß der Begriff ,tcox avoidance " nicht mehr einheitlich verwendet wird. Im allgemeinen umfaßt der Ausdruck "tax avoidance" sowohl die Steuervermei-

${ }^{1}$ so aber DIEBOLD (1984) S. 14, WREDE (1993) S. 18

${ }^{2}$ Vgl. ZIMMERMANN/HENKE (1994) S. $222 \mathrm{ff}$.

${ }^{3} \mathrm{Vgl}$. $\$ 370 \mathrm{AO}$.

${ }^{4}$ Für den Fall, daß die Steuer nicht vorsätzlich, sondern nur fahrlässig hinterzogen wurde, spricht das deutsche Steuerrecht von „leichtfertiger Steuerverkürzung“ ( $378 \mathrm{AO}$ ). Diese wird nicht als Straftat, sondern nur als Ordnungswidrigkeit geahndet.

${ }^{5} \mathrm{Vgl}$. WREDE (1993) S. 10.

${ }^{6} \mathrm{Vgl}$. BRACEWELL-MILNES (1979) S. 9.

${ }^{7}$ Man vergleiche ROSEN (1992) S. 353, der tax avoidance entsprechend dem deutschen Wort „Steuervermeidung“ umschreibt, auf der einen Seite und KAY in COLLARD/LECOMBER/SLATER (1980) S. 136 auf der anderen, der Steuervermeidungsfalle aus dem Begriff ,tax avoidance“ ausdrücklich ausklammert und ihm nur Steuerumgehungshandlungen zurechnet. 
dung als auch die Steuerumgehung, ${ }^{1}$ wobei manche Autoren zur Abgrenzung zwischen ,proper" und ,improper" tax avoidance, zwischen „morally unobjectionable" tax avoidance und tox avoidance "of questionable character" oder zwischen ,respectable "tax avoidance und ,devices" unterscheiden. ${ }^{2}$ SELDON führt aus, daß als tax avoidance "legale" und ,moralische" Steuerausweichhandlungen bezeichnet würden, tax evasion stehe hingegen für ,illegal“ und „unmoralisch“. Legale, aber als unmoralisch angesehene Handlungen, die nicht den Buchstaben, aber den Geist des Gesetzes verletzen, bezeichnet SELDON mit dem Kunstwort ,tax avoision", welches der oben definierten Steuerumgehung gleichgesetzt werden kann. ${ }^{3}$ Als gemeinsamen Oberbegriff für tox avoidance und tox evasion haben CROSS und SHAW den Ausdruck, tax aversion" geschaffen. ${ }^{4}$

In den obigen Definitionen verwendete Begriffe wie ,improper", "questionable character", „device“ bzw. „Mißbrauch“, „Sinn und Zweck der Gesetzesbestimmung" oder "ausgelegter Wortlaut des Gesetzes" machen deutlich, daß die Grenzen zwischen Steuervermeidung und Steuerumgehung fließend sind; denn wie sollte exakt festgelegt werden, ab wann von einem ,Mißbrauch“ gesprochen werden muß oder wann ein Verhalten beginnt, dem "Sinn und Zweck“ einer gesetzlichen Bestimmung zuwiderzulaufen? Es ist unmittelbar einsichtig, daß es immer wieder zu gerichtlichen Auseinandersetzungen zwischen Steuerpflichtigen und Finanzbehörde kommen muß, wenn es um die Frage geht, ob nun im Einzelfall eine Steuerumgehung vorliegt oder nicht. ${ }^{5}$ Weil die Beweislast bzgl. des Vorliegens einer Steuerumgehung im Regelfall bei der Finanzbehörde liegt ${ }^{6}$ und dieser Beweis nicht immer ohne weiteres zu erbringen ist, liegt es auf der Hand, daß es häufig zu Steuerumgehungshandlungen im oben definierten Sinne kommt, die von der Rechtsprechung nicht als solche bewertet werden. Da zudem die Beurteilung durch die Gerichte im Zeitablauf Wandlungen unterliegt ${ }^{7}$ und im übrigen die Einstellung des Gesetzgebers, der Finanzverwaltung und der Rechtsprechung von Staat zu Staat variiert, diese Arbeit jedoch auch allgemeingültige Aussagen über die Gesetzesumgehung im Steuerrecht ermöglichen soll, wird im folgenden die oben angefürte Definition der Steuerumgehung nicht auf diejenigen Fälle beschränkt, die Gesetzgebung und Finanzverwaltung in Verbindung mit der Recht-

${ }^{1}$ Vgl. NEVERMANN (1994) S. 49.

${ }^{2}$ Vgl. hierzu im einzelnen die Literaturhinweise bei JUNKER (1982) S. 18.

${ }^{3}$ Vgl. SELDON in IEA (1979) S. 4, DAVIES in IEA (1979) S. 62 und SPICER (1986) S. 13. Demgegenüber benutzen MYDDELTON in IEA (1979) S. 43 und GEEROMS/WILMOTS (1985) S. 203 den Ausdruck „tax avoision" als Oberbegriff für Steuervermeidung, Steuerumgehung und Steuerhinterziehung.

${ }^{4} \mathrm{Vgl}$. CROSS/SHAW (1982).

${ }^{5} \mathrm{Vgl}$. RAAB (1992) S. $417 \mathrm{f}$.

${ }^{6}$ Vgl. KLEIN/ORLOPP (1995) Anm. 8, GAMBIER/MERCIER (1990) S. 607 f. Siehe auch Kapitel 4.3.4.

${ }^{7} \mathrm{Vgl}$. THOMA (1950) S. $60 \mathrm{f}$. 
sprechung zu einer solchen erklären. Vielmehr ist die Entscheidung für eine Steuerumgehungshandlung als eine Entscheidung unter Unsicherheit ${ }^{1}$ anzusehen, bei der der Steuerpflichtige nicht im vorhinein weiß, ob die Finanzbehörde bzw. die Gerichte seine Vorgehensweise steuerlich anerkennen oder aber ihr als mißbäuchliche Steuerumgehung die Anerkennung versagen werden.

${ }^{1}$ Zum Begriff der Unsicherheit und seiner Abgrenzung zum Risikobegriff vgl. z.B. LƯCKE (1975) S. $64 \mathrm{f}$. 
Ralf Oberheide - 978-3-631-75185-5

Downloaded from PubFactory at 01/11/2019 07:21:58AM

via free access 


\section{Soll die Steuerumgehung bekämpft werden?}

\section{$3.1 \quad$ Vorbemerkungen}

Der Untersuchungsgegenstand dieser Arbeit liegt nicht in einer umfassenden Analyse der gesamtwirtschaftlichen positiven und negativen Auswirkungen der Steuerumgehung entsprechend der zahlreichen derartigen Literatur zur Steuerhinterziehung. Dennoch soll im folgenden nicht darauf verzichtet werden, diejenigen Argumente, die für eine Bekämpfung der Steuerumgehung sprechen könnten, zu analysieren, aber auch auf mögliche Wohlfahrtsgewinne durch Steuerumgehungshandlungen einzugehen. Sofern die Analyse den Schluß nahelegt, daß die negativen Effekte der Steuerumgehung überwiegen, ergibt sich daraus die Rechtfertigung erstens für den Staat, Maßnahmen zu ihrer Bekämpfung einzuleiten, und zweitens für diese Arbeit, diese Maßnahmen nur noch auf ihre Effektivität, Effizienz und Verfassungsmäßigkeit hin zu untersuchen, nicht jedoch ihre Zielsetzung, die Bekämpfung der Steuerumgehung, weiter zu hinterfragen.

Die ökonomischen Konsequenzen der Steuerumgehung sind im wesentlichen dieselben wie die der Steuerhinterziehung: Die Steuerumgehung beeinflußt das Volumen der ökonomischen Aktivitäten in einer Volkswirtschaft, die Einkommensverteilung, die Verteilung der Produktionsfaktoren auf Aktivitäten, die der Steuerumgehung leichter oder schwieriger zugänglich sind, und nimmt sowohl beim Staat als auch in der freien Wirtschaft die Arbeitskraft und die Fähigkeiten vieler Menschen in Anspruch, die andernfalls direkter zum Sozialprodukt beitragen könnten. ${ }^{1}$ Zudem wird in der mißbräuchlichen Umgehung von Steuergesetzen ein unmoralischer Verstoß gegen die Bürgerpflicht gegenüber dem demokratischen Gemeinwesen gesehen: Greift fehlendes Respektieren des Willens des demokratisch gewählten Gesetzgebers um sich, ergebe sich letztlich eine Gefahr für die Demokratie selbst. $^{2}$

Im folgenden sollen die politischen, fiskalischen, allokativen und distributiven Auswirkungen der Steuerumgehung beschrieben und kommentiert werden.

\subsection{Steuerumgehung als Gefahr für die Demokratie?}

Da jede zivilisierte Gesellschaft nach allgemeiner Auffassung von Gesetzen abhängig ist, die zu befolgen sind, unabhängig davon, ob man sie für angemessen hält oder nicht, wird die Steuerhinterziehung häufig als Gefahr für den demokratischen Staat angesehen, der sich hier zur Wehr setzen müsse, um einem Verfall der

\footnotetext{
${ }^{1} \mathrm{Vgl}$. SELDON in IEA (1979) S. 6, 12.

${ }^{2} \mathrm{Vgl}$. CHRISTOPHER in IEA (1979) S. 88.
} 
Rechtsordnung zu begegnen. Aufgrund der Tatsache, daß die Steuerumgehung genau wie die Steuerhinterziehung dem Ziel dient, entgegen der Absicht des Gesetzgebers einen Steuervorteil zu erlangen, der dem Geist des demokratisch zustande gekommenen Steuergesetzes widerspricht, könnte man auch die Steuerumgehung als mögliche Gefahr für die Demokratie auffassen, zumal der dem Rechtsmißbrauch innewohnende laxe Umgang mit dem Gesetz zu einer nachlassenden Autorität der Rechtsordnung beitragen könnte. Eine solche Argumentation läßt sich $\mathrm{m}$.E. keinesfalls völlig verwerfen; ${ }^{1}$ jedoch darf trotz allem nicht übersehen werden, daß die beschriebene Gefahr im Falle der Steuerumgehung nicht dieselbe Intensität aufweist wie im Falle der Steuerhinterziehung: Während die Steuerhinterziehung eine kriminelle Handlung darstellt, verstößt die Steuerumgehung nicht gegen den Wortlaut, den die Legislative dem Gesetz gegeben hat, und darf als solche auch nicht kriminalisiert werden. Kann die Steuerhinterziehung u.U. einen Einstieg in die Wirtschafts- oder andere Formen der Kriminalität darstellen oder andere Wirtschaftssubjekte zu einem solchen Einstieg veranlassen, so ist von der Steuerumgehung ein solcher Einfluß auf Verstöße gegen außersteuerliche Gesetze wohl weniger $\mathrm{zu}$ erwarten. Allerdings ist nicht auszuschließen, daß das Volumen an Steuerumgehungen das gesamtwirtschaftliche Ausmaß an Steuerhinterziehungen beeinflussen kann und somit indirekt die von der Steuerhinterziehung ausgehende Gefahr für die demokratische Rechtsordnung tangiert. Dieser letzte Aspekt (der Einfluß der Steuerumgehung auf das Hinterziehungsverhalten) soll im folgenden Kapitel mit behandelt werden.

\subsection{Fiskalische Auswirkungen der Steuerumgehung}

Ceteris paribus führt die Steuerumgehung zu Steuerausfällen beim Staat in Höhe der von den Steuerpflichtigen erzielten Steuerersparnis. Jedoch gilt für die Steuerumgehung dasselbe, was von der Literatur für die Schattenwirtschaft ${ }^{2}$ festgestellt wurde: Die Aufkommensverluste treten nur dann in voller Höhe ein, sofern die Steuerumgehung normal besteuerte Aktivitäten verdrängt, d.h. sofern sie ausschließlich dort praktiziert wird, wo die betreffenden Geschäfte auch dann stattfänden, wenn sie in vollem Umfang der Besteuerung unterlägen. ${ }^{3}$ Falls sie jedoch bestimmte Aktivitäten erst lohnend machen und damit zu zusätzlicher

${ }^{1}$ so aber - zumindest in der Tendenz - SHENFIELD (1968) S. $19 \mathrm{ff}$.

${ }^{2}$ Der Begriff der Schattenwirtschaft wird nicht einheitlich definiert. Hier soll er umfassend für die Gesamtheit aller ökonomischen Aktivităten, die nicht in der offiziellen VGR erfaßt werden, verwendet werden. Zur Schattenwirtschaft gehören damit (neben illegalen Aktivităten wie z.B. Drogenhandel oder Hehlerei) sowohl legale, offene Aktivitäten wie z.B. Haus- und Heimarbeit oder unentgeltliche Nachbarschaftshilfe als auch legale, aber verheimlichte Tătigkeiten wie Schwarzarbeit oder Schwarzmarkthandel. Vgl. hierzu beispielsweise MEYER (1989) S. 72-74.

${ }^{3} \mathrm{Vgl}$. GRETSCHMANN (1984) S. 124. 
Wirtschaftstätigkeit führen sollte, welche wiederum zusätzliche steuerwirksame Ausgaben hervorriefe, wäre ihre aufkommensmindernde Wirkung nicht mehr gewiß. ${ }^{1} \mathrm{Ob}$ es nun tatsächlich zu Aufkommensverlusten kommt, könnte dann nicht eindeutig gesagt werden. Falls dem nicht so sein sollte, verlören natürlich die meisten ökonomischen und moralischen Argumente für eine Bekämpfung der Steuerumgehung stark an Gewicht. ${ }^{2}$ Selbst ein Staat, der mit seiner Steuerpolitik ausschließlich eine Maximierung seines Steueraufkommens anstrebt, hätte kein Interesse mehr, der Steuerumgehung entgegenzutreten.

Die These, Steuerumgehung könne zu Mehrarbeit und Mehrinvestitionen führen und damit eventuelle Aufkommensverluste kompensieren oder gar überkompensieren, ist allerdings zu hinterfragen. Mag sie für die Schattenwirtschaft teilweise zutreffen, so ist im Falle der Steuerumgehung zu berücksichtigen, daß es sich dort um den Finanzbehörden offen dargelegte Transaktionen handelt, deren steuerliche Anerkennung meist ausgesprochen ungewiß ist. Während legale Steuervermeidung ohne Risiko bleibt und illegale Steuerhinterziehung i.d.R. nur dort praktiziert wird, wo ihre Ahndung als ausgesprochen unwahrscheinlich angesehen wird, besteht für die Steuerumgehung ein beträchtliches Element der Unsicherheit. $\mathrm{Ob}$ die Steuerumgehung tatsächlich in nennenswertem Umfang Aktivitäten hervorruft, die andernfalls unterblieben, muß m.E. unter diesen Umständen erheblich bezweifelt werden. Unter Berücksichtigung der bis hierher genannten Aspekte ist folglich eine Aufkommensminderung durch Steuerumgehung zwar nicht zu beweisen, aber wohl doch anzunehmen. Hinzu kommt als weiterer, in Kap. 3.2 bereits angedeuteter Gesichtspunkt, daß das Ausmaß an Steuerumgehung nicht ohne Einfluß auf das Ausmaß an Steuerhinterziehung bleiben muß. Wenn man davon ausgeht, daß Steuerhinterzieher nicht als reine homines oeconomici agieren, die ihr Volumen an hinterzogenem Einkommen allein vom Steuersatz, der Aufdeckungswahrscheinlichkeit, der möglichen Bestrafung und ihrer Einkommenssituation abhängig machen, wie in den ökonomischen Standardmodellen zur Steuerhinterziehung unterstellt, sondern darüber hinaus auch psychologische Faktoren wie die Steuerehrlichkeit der Mitmenschen und die angenommene Fairneß des Steuersystems als Ursachen der Steuerhinterziehung ansieht, ${ }^{3}$ ist eine Korrelation zwischen Steuerumgehung und Steuerhinterziehung durchaus anzunehmen. Die Versuchung, Steuern zu hinterziehen, dürfte steigen, wenn die Allgemeinheit das Gefühl bekommt, daß die Steuerpflicht faktisch nicht für die Gesamtheit der Steuerpflichtigen gilt, sondern bestimmte Gruppen oder Sektoren der Volkswirtschaft in der Lage sind, durch Steuerumgehung ihrem Anteil an der Steuerlast ganz oder teilweise zu entgehen. ${ }^{4}$ Eine wirksame Bekämpfung der Steuerumgehung

\footnotetext{
${ }^{1} \mathrm{Vgl}$. MYDDELTON in IEA (1979) S. 54.

${ }^{2} \mathrm{Vgl}$. BRACEWELL-MIILNES in IEA (1979) S. 108.

${ }^{3}$ s.u. Kapitel 5.8.1

${ }^{4}$ Vgl. PETTERSON (1978) S. 254; EUROPEAN COMMISSION (1985) S. 52.
} 
würde in diesem Fall nicht nur die aus ihr unmittelbar resultierenden Aufkommensverluste senken, sondern darüber hinaus auch eine Abnahme der Mindereinnahmen als Folge von Steuerhinterziehung bewirken. ${ }^{1}$

Im Ergebnis kann folglich mit sehr hoher Wahrscheinlichkeit davon ausgegangen werden, daß Steuerumgehung zu Aufkommensverlusten beim Staat führt. Dieser wird auf der Einnahmen- oder Ausgabenseite seines Haushalts darauf reagieren müssen. Die daraus resultierenden allokativen und distributiven Auswirkungen sind Gegenstand der folgenden Kapitel.

\subsection{Allokative Auswirkungen der Steuerumgehung}

\subsubsection{Direkte Wohlfahrtsverluste aus Steuererhöhungen oder Kür- zungen von Staatsausgaben}

$\mathrm{Ob}$ die aus der Steuerumgehung resultierenden Wohlfahrtsgewinne für die Steuerumgeher höher oder niedriger sind als die unmittelbar aus den notwendigen Steuererhöhungen oder staatlichen Ausgabenkürzungen sich ergebenden Wohlfahrtsverluste für den Rest der Gesellschaft, läßt sich nicht eindeutig feststellen:

Soweit der Fiskus die Aufkommensverluste durch Steuererhöhungen ${ }^{2}$ ausgleicht, liegt die Befürchtung nahe, daß höhere nominale Steuersätze zu einem Rückgang der volkswirtschaftlichen Aktivitäten führen könnten. ${ }^{3}$ Jedoch ist zu berücksichtigen, daß die durchschnittlichen effektiven Steuersätze in der Volkswirtschaft durch die Steuerumgehung unberührt blieben und der Betrag an Steuern, den der Fiskus der Privatwirtschaft entzieht, keinerlei Änderung erfüre. Da sich zudem theoretisch nicht eindeutig sagen läßt, ob höhere Steuersätze tatsächlich das Investitionsvolumen und das Arbeitsangebot negativ beeinflussen, ${ }^{4}$ sind gesamtwirtschaftliche Wohlfahrtsverluste als direkte Folge der steuerumgehungsbedingten Steuererhöhungen recht ungewiß.

${ }^{1}$ Dies setzt natürlich voraus, daß Steuerhinterziehung tatsächlich zu Steuermindereinnahmen führt, was in dieser Arbeit nicht näher untersucht werden soll, nach h.M. jedoch, auch unter Berücksichtigung von Sekundärwirkungen, zutrifft. Vgl. hierzu z.B. GRETSCHMANN (1984) S. 127.

2 Die Wirkung einer dritten Möglichkeit staatlicher Reaktion auf Steuerumgehungen, nämlich einer entsprechenden Erhöhung der öfentlichen Neuverschuldung, soll wegen der Ähnlichkeit der Verschuldungswirkungen im Vergleich zu den Steuerwirkungen hier nicht gesondert behandelt werden.

${ }^{3}$ Diese Befürchtung findet sich bei KAY in COLLARD/LECOMBER/SLATER (1980) S. 137.

${ }^{4}$ Vgl. hierzu beispielsweise WAGNER/DIRRIGL (1980) S. 33-42 und ROSEN (1992) S. 413-417. (Die Auswirkung einer Steuersatzerhöhung auf das Arbeitsangebot ist allerdings dann eindeutig negativ, wenn die gängige einzelwirtschaftliche Betrachtung aufgegeben und das gesamtwirtschaftliche Arbeitsangebot untersucht wird. Vgl. hierzu HANSSON/STUART (1983) S. 587.) 
Soweit die Aufkommenseinbußen des Fiskus durch Kürzungen von Staatsausgaben ausgeglichen werden, hängt die unmittelbare Wohlfahrtswirkung davon ab, ob die privaten Wohlfahrtsgewinne aus Steuerumgehung höher oder niedriger sind als der Nutzenrückgang aufgrund sinkender Staatsleistungen. Sofern der aktuelle Staatsanteil gleich hoch oder niedriger liegt, als er optimalerweise sein müßte, wiese die Steuerumgehung tendenziell eine wohlfahrtsmindernde Wirkung auf. Ist der Staatsanteil hingegen zu hoch oder entsprechen die Staatsausgaben in ihrer Struktur nicht den Wählerpräferenzen, könnten Wohlfahrtsgewinne aus der Steuerumgehung resultieren. Dasselbe gilt, soweit die Kürzung staatlicher Ausgaben zu einer Verminderung von Ressourcenverschwendung im öffentlichen Sektor führt. ${ }^{1}$ Unter den Bedingungen des Haavelmo-Theorems ${ }^{2}$ ist andererseits ein Rückgang der Steuereinnahmen stets wachstumsschädlich, da der Steuermultiplikator niedriger liegt als der Staatsausgabenmultiplikator. ${ }^{3}$ Insgesamt kann auch furr den Fall staatlicher Ausgabenkürzungen nicht eindeutig gesagt werden, ob Steuerumgehung wohlfahrtserhöhend oder -senkend wirkt.

\subsubsection{Wettbewerbsgesichtspunkte}

Es ist nicht davon auszugehen, daß die Möglichkeiten zur Steuerumgehung unter den verschiedenen Sektoren und Branchen einer Volkswirtschaft gleichmäßig verteilt sind. Aus diesem Grund führt die Steuerumgehung zu Verzerrungen auf dem Arbeits- und Kapitalmarkt; sie beeinflußt die Anlageentscheidungen der Haushalte, die Finanzierung der Unternehmen, die Gleichgewichtspreise auf dem Gütermarkt und die Struktur von Arbeitsplatzangebot und -nachfrage. ${ }^{4}$ Die sich aus der Steuerumgehung ergebenden Verzerrungen des Wettbewerbs zwischen den Unternehmen können u.a. dazu führen, daß eventuelle Grenzanbieter überleben, die unter strengen Marktbedingungen als ineffizient ausscheiden müßten. Ferner verschaffen sich Unternehmen durch Steuerumgehung Wettbewerbsvorteile, die nicht aus effizienter Produktion resultieren, sondern im Gegenteil mit Ineffizienz einhergehen können, wenn nämlich die mißbräuchliche Rechtsgestaltung mit schädlichen $\mathrm{Ne}$ benwirkungen auf Beschaffung, Lagerung, Produktion, Absatz oder Finanzierung verbunden ist und damit ohne die angestrebte Steuerersparnis betriebswirtschaftlich nachteilig wäre. ${ }^{5}$ Verfolgt der Staat mit seiner Steuerpolitik auch außerfiskalische Ziele und versucht, diejenigen Unternehmen (oder Haushalte) mit einer steuerlichen Sonderbelastung zu versehen, die bestimmte Aktivitäten ausüben bzw.

${ }^{1}$ Vgl. SHENFIELD (1968) S. 24.

${ }^{2}$ Vgl. HAAVELMO (1945) S. $311 \mathrm{ff}$.

${ }^{3}$ Vgl. GRETSCHMANN (1984) S. 129.

${ }^{4}$ Vgl. GROENEWEGEN in COLLINS (1984) S. 28 f. und S. 33; FULLERTON/KARAYANNIS (1994) S. 275.

${ }^{5}$ s.u. S. 81; vgl. auch JAHRMARKT (1981) S. 32. 
unterlassen, so mindern Möglichkeiten zur Steuerumgehung die Effektivität derartiger wirtschaftspolitischer Maßnahmen. ${ }^{1}$ Die internationale Steuerumgehung schließlich führt zu Verzerrungen internationaler Kapitalbewegungen und Wettbewerbsbedingungen. ${ }^{2}$

Insgesamt läßt sich sagen, daß eine steigende quantitative Bedeutung der Steuerumgehung wettbewerbspolitisch ausgesprochen bedenklich erscheint.

\subsubsection{Bindung von Ressourcen durch Steuerumgehung}

Die Steuerumgehung bindet Ressourcen von Beratern und Fachpersonal in den Unternehmen, aber auch von Finanzbeamten und Gerichtspersonal beim Staat. Volkswirtschaftlich gesehen wäre es vorteilhafter, wenn dieser Personenkreis seine Fähigkeiten und Arbeitskraft für den eigenen Nutzen und den der Gesellschaft einsetzen würde, statt sich mit gesamtwirtschaftlich nutzlosen, allein der Steuerminderung dienenden Rechtsgeschäften auseinanderzusetzen. ${ }^{3}$ Der Einwand, auch legale Steuervermeidung binde Ressourcen von Beratern, die andernfalls direkter zur Steigerung der volkswirtschaftlichen Wohlfahrt beitragen könnten, ohne daß es hier üblich sei, von Ressourcenverschwendung zu sprechen, ${ }^{4}$ kann nicht überzeugen. Die gesamtwirtschaftlichen Kosten der Steuerumgehung werden dadurch nicht geringer, daß auch andere, nicht mißbräuchliche Aktivitäten derartige Kosten verursachen. Im übrigen ist Steuervermeidung oft staatlicherseits erwünscht und volkswirtschaftlich vorteilhaft, ${ }^{5}$ während Steuerumgehung dem Willen des Gesetzgebers widerspricht und allenfalls in Sonderfallen, wenn nämlich eine bestimmte, gesamtwirtschaftlich besonders schädliche Abgabe umgangen wird, volkswirtschaftlichen Nutzen stiften kann.

Man kann also festhalten, daß die Steuerumgehung auch unter dem Gesichtspunkt der Verschwendung von Ressourcen i.d.R. allokativ schädlich ist. Unter diesem Aspekt wäre eine Bekämpfung der Steuerumgehung so lange angezeigt, wie der mit der Bekämpfung verbundene Verwaltungsaufwand niedriger liegt als die eingesparten Ressourcen in der Privatwirtschaft.

${ }^{1} \mathrm{Vgl}$. COLLINS in COLLINS (1984) $\mathrm{S}$. vii.

${ }^{2}$ Vgl. hierzu ausführlich SCHMID (1961) S. 245-248.

${ }^{3} \mathrm{Vgl}$. ILERSIC in IEA (1979) S. 37 f.; WAGNER (1986) S. 45.

${ }^{4} \mathrm{Vgl}$. SHENFIELD (1968) S. 26.

${ }^{5}$ Man denke beispielsweise an Umweltabgaben in Gestalt einer Pigou-Steuer. Jeder betriebswirtschaftlich sinnvolle Einsatz von Ressourcen, um eine solche Abgabe ganz oder teilweise zu vermeiden, ist auch volkswirtschaftlich von Vorteil. Man mag dagegen einwenden, daß es in der Praxis keine echten Pigou-Steuern gibt; doch gilt obige Aussage auch dann uneingeschränkt, wenn die Abgabe geringer ist, als sie es nach dem Pigou-Konzept sein müßte. 


\subsection{Distributive Auswirkungen der Steuerumgehung}

Wie bereits festgestellt wurde, führt das Auftreten von Steuerumgehung im Regelfall zur Kürzung von Staatsausgaben oder zur Erhöhung von Steuern. Im Ergebnis bedeutet Steuerumgehung deshalb eine Bereicherung der Steuerumgeher auf Kosten derjenigen Personen, die keine Steuerumgehung betreiben können oder wollen.

\subsubsection{Horizontale Verteilungswirkungen}

Steuerumgehung führt zu einer horizontalen Ungleichbehandlung der Steuerpflichtigen. Selbst wenn die verschiedenen Berufsgruppen und die verschiedenen Einkunftsarten nominell gleich behandelt werden, kommt es zu Ungleichheiten, da die Möglichkeiten, Steuerumgehung zu praktizieren, weder unter den Individuen noch zwischen den verschiedenen Aktivitäten gleich verteilt sind. ${ }^{1}$ Wenn beispielsweise Steuern auf Kapitalgewinne oder Unternehmereinkommen leichter umgangen werden können als Steuern auf Einkünfte aus nichtselbständiger Arbeit, sind Arbeitnehmer gegenüber einkommensgleichen Berufsspekulanten oder Selbständigen tendenziell steuerlich benachteiligt. Es kommt dann zu Situationen, in denen Personen mit gleicher wirtschaftlicher Leistungsfähigkeit unterschiedlich hohe Steuerbeträge abzuführen haben, ohne daß sich dieser Zustand durch andere finanzwissenschaftliche Begründungen außerhalb des Leistungsfähigkeitsprinzips rechtfertigen ließe.

Der Hinweis, auch ohne Steuerumgehung gäbe es im Wirtschaftsleben viele Situationen, in denen eine Person gegenüber einer anderen im Nachteil ist, kann kein Argument dafür sein, die mit der Steuerumgehung verbundenen horizontalen Ungleichbehandlungen hinzunehmen: ${ }^{2}$ Die Existenz von Ungerechtigkeiten, die im Steuersystem selbst oder im gesamten Wirtschaftssystem ihre Ursache haben, darf nicht davon ablenken, daß Steuerumgehung zu zusätzlichen Ungerechtigkeiten führen kann, deren Bekämpfung in Deutschland auch aus verfassungsrechtlicher Sicht (Gleichheitsgrundsatz des Art. 3 GG) geboten ist. ${ }^{3}$

${ }^{1} \mathrm{Vgl} . \mathrm{KAY}$ in COLLARD/LECOMBER/SLATER (1980) S. 137; SANDFORD in COLLARD/ LECOMBER/SLATER (1980) S. 160.

${ }^{2}$ so aber die Argumentation von SHENFIELD (1968) S. 25

${ }^{3}$ Ein Ableiten der Forderung nach einer wirksamen Verhinderung von Steuerumgehungen aus dem verfassungsrechtlichen Gebot der prinzipiell gleichen Rechtsanwendung nach Art. 3 GG findet sich beispielsweise bei DANZER (1981) S. $24 \mathrm{f}$. 


\subsubsection{Vertikale Verteilungswirkungen}

Die vertikalen Verteilungswirkungen hängen naturgemäß davon $a b$, in welcher Weise der Staat mit Steuererhöhungen reagiert bzw. welche Staatsausgaben er kürzt. Da hierüber keine allgemeingültigen Aussagen möglich sind, sollen hier nur die Verteilungswirkungen der Steuerumgehung selbst, nicht jedoch die der staatlichen Reaktion auf die Einnahmenausfälle untersucht werden.

Es wird nirgends bestritten, daß der Steuerumgehung bei den Besserverdienenden eine absolut und relativ höhere Bedeutung zukommt als bei Geringverdienern. Zwar mögen einige mißbräuchliche Steuertricks auch für letztere gelegentlich möglich und lohnend sein, doch, real avoidance is only for the wealthy". ${ }^{1}$ Beispielsweise gestalten sich Möglichkeiten der Steuerarbitrage ${ }^{2}$ am einfachsten für buchführungspflichtige Selbständige und Freiberufler, da hier die steuerliche Absetzbarkeit von Schuldzinsen leicht erreicht werden kann. ${ }^{3}$ Geht man davon aus, $\mathrm{da}$ dieser Personenkreis meist zu den Besserverdienenden gehört und auch sonst tendenziell mehr Gelegenheiten besitzt, Steuerumgehung zu betreiben, als die im Durchschnitt einkommensschwächeren Personen, denen fast ausschließlich Einkünfte aus nichtselbständiger Tätigkeit zufließen, dann ergibt sich bereits aus den unterschiedlichen Möglichkeiten zur Steuerumgehung je nach Einkunftsart eine regressive Verteilungswirkung. Diese wird dadurch verstärkt, daß viele der Steuerumgehung dienenden Rechtskonstruktionen so aufwendig sind, daß sie nur bei hohen Grenzsteuersätzen, d.h. bei hohen Einkommen, lohnend sind. Damit sorgt die Steuerumgehung für eine faktische Begrenzung staatlicher Umverteilung.

$\mathrm{Ob}$ ein derartiger Eingriff in die vom Gesetzgeber vorgesehene Steuerlastverteilung als verteilungspolitisch bedenklich einzustufen oder aber eher zu begrüßen ist, wird naturgemäß unterschiedlich gesehen: Während BRACEWELL-MINES darauf hinweist, daß aus Gründen des Staatsversagens nicht gewährleistet ist, daß der von den Steuerumgehern verletzte „Geist des Gesetzes“ und „Wille des Gesetzgebers“ mit den Wählerpräferenzen übereinstimmt, ${ }^{4}$ läßt sich in Anlehnung an KAY $Y^{5}$ dagegen argumentieren, daß als Folge von Steuerumgehung eher zufallsverteilte effektive Steuersätze wohl erst recht nicht den Wählerpräferenzen entsprechen. Die Beurteilung der Regressionswirkung wird selbstverständlich auch davon abhängen, ob man die gesetzlich vorgesehene Einkommensumverteilung für gerecht bzw. für

${ }^{1}$ ILERSIC in IEA (1979) S. 31; vgl. auch GROENEWEGEN in COLLINS (1984) S. 34 und SANDFORD in COLLARD/LECOMBER/SLATER (1980) S. 160.

${ }^{2}$ Als Steuerarbitrage wird u.a. die Verwendung von Krediten für steuerbegünstigte Finanzanlagen bezeichnet, sofern die zugehörigen Kreditzinsen steuerlich absetzbar sind. Vgl. hierzu und zu anderen Formen der Steuerarbitrage Kap. 6.5.1 dieser Arbeit.

${ }^{3}$ Vgl. RAAB (1992) S. 420.

${ }^{4} \mathrm{Vgl}$. BRACEWELL-MILNES in IEA (1979) S. 111.

${ }^{5} \mathrm{Vgl}$. KAY in COLLARD/LECOMBER/SLATER (1980) S. 137. 
zu gering ausgeprägt hält oder ob man sie als überzogenen, nicht mehr leistungsgerechten ,Raub an den Besserverdienenden“" ansieht.

Die distributiven Wirkungen der Steuerumgehung können wiederum allokative Rückwirkungen aufweisen: So weist MYDDELTON darauf hin, daß eine Begrenzung staatlicher Umverteilung durch Steuerumgehung die wachstumsfeindlichen Folgen überzogener Redistribution wirksam mindern könne, ${ }^{1}$ während NEVILE es für wahrscheinlich hält, daß die Mehrzahl der Arbeitnehmer ein Steuersystem, das vor allem Gewerbetreibenden und Freiberuflern Möglichkeiten zur Steuerumgehung läßt, als ungerecht ansehen und deshalb weniger Lohnzurückhaltung üben wird, was wiederum Inflation und Arbeitslosigkeit anwachsen ließe. ${ }^{2}$

\subsection{Ergebnis}

Während von der Steuerumgehung im Gegensatz zur Steuerhinterziehung keine wesentliche Gefahr für den demokratischen Rechtsstaat ausgeht, führt auch erstere zu fiskalisch unerwünschten Aufkommenseinbußen und damit i.d.R. zu Steuererhöhungen oder Staatsausgabenkürzungen. Ob die aus solcher staatlicher Reaktion unmittelbar resultierenden Wohlfahrtsverluste höher liegen als die Wohlfahrtsgewinne bei den Steuerumgehern, läßt sich nicht eindeutig feststellen. Jedoch wurde gezeigt, daß das Auftreten mißbräuchlicher Steuerumgehungen wettbewerbspolitisch bedenkliche Folgen auslöst und durch die Bindung von Personal in den Unternehmen und beim Staat volkswirtschaftliche Ressourcenverschwendung bedeutet. Bezüglich der distributiven Konsequenzen der Steuerumgehung ist in vertikaler Hinsicht eine regressive Wirkung festzustellen, deren Positiv- oder Negativbewertung in erster Linie von der jeweiligen politischen Einstellung abhängig ist. Die aus der Steuerumgehung resultierenden horizontalen Ungleichbehandlungen sind jedoch sowohl aus finanzwissenschaftlicher Sicht als auch unter rechtlichen Gesichtspunkten eindeutig unerwünscht.

Insgesamt legen die Ausführungen dieses Abschnitts den Schluß nahe, daß die Steuerumgehung in erster Linie nachteilige gesamtwirtschaftliche Auswirkungen aufweist. Auch wenn die vorliegende Arbeit keinen umfassenden Beweis furr diese These liefern kann, so unterstützen die hier angeführten Argumente doch die Auffassung, daß der Staat bemüht sein sollte, das Ausmaß an Steuerumgehungen in Grenzen zu halten. Die Möglichkeiten, die ihm dafür offenstehen, sind im folgenden Gegenstand der Arbeit.

\footnotetext{
${ }^{1} \mathrm{Vgl}$. MYDDELTON in IEA (1979) S. $55 \mathrm{ff}$.

${ }^{2} \mathrm{Vgl}$. NEVILE in COLLINS (1984) S. $39 \mathrm{ff}$.
} 
Ralf Oberheide - 978-3-631-75185-5

Downloaded from PubFactory at 01/11/2019 07:21:58AM

via free access 


\section{Die Bekämpfung der Steuerumgehung aus rechts- wissenschaftlicher Sicht}

\subsection{Die Diskussion um die Notwendigkeit einer Generalklau- sel gegen die Steuerumgehung - Alternativen zur Gene- ralklausel}

In der rechtswissenschaftlichen Diskussion tauchen im wesentlichen vier Alternativen auf, die u.U. geeignet sind, der Steuerumgehung entgegenzuwirken:

- Zum einen kann versucht werden, durch laufende Anpassungen der Gesetzestexte sowie durch Erlaß spezieller Vorschriften gegen bestimmte auftretende Steuerumgehungshandlungen die Umgehung der Gesetze zu erschweren.

- Eine andere Möglichkeit ist die Schaffung einer allgemein gehaltenen Bestimmung im Steuerrecht, die Steuerumgehungen generell für steuerlich unwirksam erklärt („Generalklausel"). Eine solche Vorschrift findet sich im deutschen Steuerrecht seit 1919.

- Generalklausel und Spezialvorschriften wären jedoch verzichtbar, sofern die Rechtsanwender (Finanzbehörden, Steuergerichtsbarkeit) die Möglichkeit hätten, vom Gesetzeswortlaut gedeckte, aber dem Sinn des Gesetzes widersprechende Steuervorteile im Rahmen der juristischen Methodenlehre zu verhindern, ohne daß hierfür eine ausdrückliche gesetzliche Ermächtigung erforderlich wäre.

- Eine vierte Möglichkeit bestünde darin, Steuerumgehungsversuchen durch Schaffung gesetzlicher Bestimmungen mit rückwirkender Kraft zu begegnen, wie es britischer Praxis entspricht (s.u. S. 67 f.). Sofern eine solche Rückwirkung belastender Rechtsvorschriften nicht als verfassungswidrig eingestuft wird, kann auch diese Methode bei konsequenter Anwendung den Verzicht auf eine Generalklausel durchaus kompensieren.

\subsubsection{Die Verhinderung der Steuerumgehung durch Gesetzestext- anpassungen und Spezialklauseln}

Nach Möglichkeit ist der Gesetzestext so zu fassen, daß er sich in allen Fällen mit dem Sinn und Zweck des Gesetzes deckt und Steuerumgehungen somit ausgeschlossen bleiben. Jedoch kann bei der Formulierung der Steuergesetze trotz aller Sorgfalt nicht ausgeschlossen werden, daß es raffinierten Steuerpflichtigen gelingt, noch Unvollkommenheiten im Wortlaut aufzuspüren und für Umgehungsgestaltungen zu nutzen. 
$\mathrm{Da}$ nachträgliche Wortlautverbesserungen zwangsläufig dem Erfindungsreichtum der Steuerumgeher hinterherhinken, können sie keinen umfassenden Schutz vor Steuerumgehungshandlungen bieten.

Auch die Schaffung von Spezialvorschriften zur Beseitigung einzelner Umgehungsmöglichkeiten wird notwendig der Entwicklung nachhinken und im übrigen bei lückenloser Anwendung zu einer unerwünschten Ausuferung und Verkomplizierung der Gesetzestexte führen, ohne daß es in Anbetracht der Vielfalt an Gestaltungsmöglichkeiten, die das Rechtssystem den Wirtschaftssubjekten zur Verfügung stellt, denkbar wäre, durch Spezialklauseln tatsächlich alle Umgehungshandlungen $\mathrm{zu}$ verhindern. ${ }^{1}$

Somit können Gesetzestextanpassungen und Spezialvorschriften zwar im Einzelfall durchaus sinnvoll sein, um bestimmte publik gewordene oder von vornherein naheliegende Umgehungsversuche zu vereiteln; für eine wirkungsvolle allgemeine Bekämpfung der Steuerumgehung sind sie jedoch nicht geeignet. ${ }^{2}$

\subsubsection{Die Bekämpfung der Steuerumgehung im Wege der Geset- zesanwendung ohne Zuhilfenahme einer Generalklausel}

„Die echte Steuerumgehung fängt genau dort an, wo die Auslegungskunst zu versagen beginnt. ${ }^{33}$ Diese vielzitierte Aussage ALBERT HENSELs macht deutlich, daß dem Problem der Steuerumgehung nicht mit Auslegung beizukommen ist. Es liegt deshalb nahe, zunächst eine Grenzziehung zwischen erweiternder Auslegung und Analogie bzw. zwischen einschränkender Auslegung und teleologischer Reduktion vorzunehmen, um damit zu klären, wo die Auslegung einer Vorschrift endet und der Anwendungsbereich von Analogie und teleologischer Reduktion einsetzt. $\mathrm{Ob}$ die Gesetzesanwender (Finanzbehörden, Gerichtsbarkeit) befugt sind, Steuerumgehungen mit den Mitteln der Analogie und teleologischen Reduktion zu begegnen, soll anschließend eingehend untersucht werden. Schließlich wird als eine weitere, früher in Deutschland sogar gesetzlich fixierte juristische Interpretationsmethode die wirtschaftliche Betrachtungsweise einer näheren Untersuchung unterzogen, da auch diese in der Vergangenheit zur Steuerumgehungsbekämpfung herangezogen worden ist.

${ }^{1}$ Vgl. Begr. RegE $\S 45$ ( $\triangleq \S 42 \mathrm{AO}$ ) in MTTTELSTEINER/SCHAUMBURG (1977) S. $79 \mathrm{f}$.

${ }^{2}$ KAY in COLLARD/LECOMBER/SLATER (1980) S. 140 weist auch auf die Gefahr hin, daß Spezialklauseln gegen die Steuerumgehung sogar zu Ideenlieferanten der Konstrukteure von Steuerumgehungsgestaltungen werden können: „Roy Tucker, a leading inventor of avoidance schemes, has commented that his principal source of ideas is existing anti-avoidance legislation."

${ }^{3}$ HENSEL (1923) S. 244 


\subsubsection{Zur Abgrenzung zwischen Auslegung und Analogie sowie zwischen Auslegung und teleologischer Reduktion}

Nach herrschender Auffassung endet die Möglichkeit der Auslegung einer gesetzlichen Norm bei ihrem ,weitesten nach dem Sprachgebrauch noch möglichen Wortsinn. "'l Wo die Auslegung endet, beginnt die Gesetzeslücke und damit der Anwendungsbereich der Analogie. ${ }^{2}$ Bei der Auslegung ist zunächst vom Gesetzeswortlaut auszugehen (,grammatische Auslegung"). Von Bedeutung für die Frage der Grenze zwischen Auslegung und Analogie ist jedoch erst die sog. teleologische Auslegung. Hierunter versteht man eine den Sinn und Zweck einer Rechtsnorm berücksichtigende Auslegung. ${ }^{3}$

Teilweise wird der Begriff der teleologischen Auslegung jedoch noch weiter gefaßt. Einige Autoren definieren die teleologische Auslegung als eine den Sinn und Zweck des gesamten Gesetzes berücksichtigende, über den möglichen Wortsinn der auszulegenden Norm hinausgehende Interpretation. ${ }^{4}$ Erst jenseits der teleologischen Auslegung, „wo die Entscheidung des Rechtsanwenders nicht mehr von der ratio legis, sondern von durch die ratio legis nicht gedeckten Werturteilen determiniert ist ${ }^{\text {cs }}$, beginne die Analogie. ${ }^{6}$

Diese weite Auffassung vom Begriff der Auslegung (auch über den möglichen Wortsinn hinaus) erscheint jedoch nicht sinnvoll, wenn man sich den Zweck einer Abgrenzung der Auslegung von der Analogie vor Augen hält. Die Abgrenzung ist dort von Bedeutung, wo ein Analogieverbot besteht. Unzweifelhaft ist dies der Fall im Strafrecht (s.u. Kap. 4.1.2.2.1). Sinn des strafrechtlichen Analogieverbotes ist die kaum bestrittene Auffassung, daß in einem Rechtsstaat ein Verhalten nicht strafbar sein darf, das der sorgfältige Leser der in Frage kommenden strafgesetzli-

${ }^{1}$ BYDLINSKI (1991) S. $467 \mathrm{f}$.

${ }^{2}$ s.o. Abschnitt 2.1

${ }^{3}$ Vgl. TILCH (1987) S. 589.

Zwischen grammatischer und teleologischer Auslegung werden noch die „systematische" und die „historische“ Auslegung angesiedelt; vgl. hierzu ausführlich BYDLINSKI (1991) S. 437 ff. An dieser Stelle sei nur darauf hingewiesen, daß es sich hier nicht um vier verschiedene, miteinander konkurrierende Auslegungsmethoden handelt, sondern um vier Elemente der Auslegung, die alle zu berücksichtigen sind; vgl. LARENZ (1991) S. 319. Vgl. auch BVerfGBeschluß vom 17.5.1960 - 2 BvL 11/59, 11/60 - BVerfGE 11, 126 [130].

${ }^{4}$ Vgl. beispielsweise KIRCHHOF (1983) S. 174.

${ }^{5}$ DANZER (1981) S. $82 \mathrm{f}$.

${ }^{6}$ HESS (1974) S. 4 f. m.w.N. sieht überhaupt keine Grenze zwischen Auslegung und Analogie. Analogie umfasse sämtliche mögliche Rechtsfindung und könne somit auch Hilfsmittel der Auslegung sein. Eine Erörterung dieser These brächte jedoch im Hinblick auf die hier zu untersuchenden Möglichkeiten der Steuerumgehungsbekämpfung im Rahmen der Gesetzesanwendung keinen Nutzen und soll deshalb an dieser Stelle unterbleiben. Von der herrschenden Auffassung, daß die Analogie erst jenseits der Auslegung beginnt, wird im folgenden nicht abgewichen. 
chen Norm ohne juristische Vorbildung nicht als möglicherweise strafbar erkennen kann. Eine Auslegung strafrechtlicher Normen über ihren möglichen Wortsinn hinaus würde dieser Auffassung zuwiderlaufen und damit das im Strafrecht besonders hoch zu bewertende Gebot der Rechtssicherheit verletzen. ${ }^{1}$

Im folgenden soll daher die oben angeführte, übliche Abgrenzung übernommen werden:

Die Auslegung endet an der Grenze des möglichen Wortsinns, erst jenseits dieser Grenze beginnt die Gesetzesumgehung und gleichzeitig der Anwendungsbereich der Analogie. ${ }^{2}$

Ähnlich wie die Analogie zu einer erweiternden Auslegung verhält sich die teleologische Reduktion zu einer einschränkenden Auslegung. Auch die einschränkende Auslegung endet an der Grenze des möglichen Wortsinns einer Norm; wird der Anwendungsbereich einer Vorschrift über die durch den möglichen Wortsinn gezogene Grenze hinaus eingeengt, so liegt teleologische Reduktion vor. ${ }^{3}$

\subsubsection{Zur Zulässigkeit von Analogie und teleologischer Reduktion}

Die Diskussion darüber, ob für das Steuerrecht ein Analogieverbot gilt, wird in der Literatur äußerst intensiv und konträr geführt. Für die Thematik dieser Arbeit allein von Interesse ist dabei die Frage nach Zulässigkeit belastender, d.h. steuerlastenschaffender oder steuerverschärfender Analogie. Wenn im folgenden vom steuerrechtlichen Analogieverbot die Rede ist, geht es demnach nicht um die RechtmäBigkeit begünstigender Analogieschlüsse. Dafür beinhaltet die Diskussion um das Analogieverbot gleichzeitig die Frage nach einem Verbot der teleologischen Reduktion im belastenden Steuerrecht. Denn wo die am möglichen Wortsinn einer belastenden - Norm liegende Grenze der erweiternden Auslegung nicht per Analogie überschritten werden darf, kann die Überschreitung der ebenfalls am möglichen Wortsinn einer - begünstigenden - Norm liegenden Grenze der einschränkenden Auslegung per teleologischer Reduktion ebenso wenig statthaft sein. Genau wie im Strafrecht aus dem Analogieverbot ein Verbot teleologischer Reduktion abgeleitet wird, ${ }^{4}$ wäre also aus einem steuerrechtlichen Analogieverbot ebenfalls auf ein Ver-

${ }^{1}$ Vgl. BYDLINSKI (1991) S. $470 \mathrm{f}$.

2 Vgl. DAUMKE (1988) S. 42; INSTTTUT "FINANZEN UND STEUERN" (1985) S. 7 f;; TIPKE (1993) S. 1329. Daß die Grenze des möglichen Wortsinns nicht immer exakt bestimmt werden kann und damit Auslegung und Analogie in der Praxis fließend ineinander übergehen, darf natürlich hierbei nicht übersehen werden, ist aber kein spezifischer Nachteil der hier vorgenommenen Abgrenzung, sondern eine unvermeidbare Eigenschaft aller diesbezüglichen $\mathrm{Ab}$ grenzungsversuche, vgl. BYDLINSKI (1991) S. 470.

${ }^{3}$ Vgl. LARENZ (1991) S. 391.

${ }^{4} \mathrm{Vgl}$. CANARIS (1964) S. 193. 
bot der Rechtsfortbildung durch teleologische Reduktion zu schließen. Es reicht demnach aus, im folgenden zu untersuchen, ob für das Steuerrecht von einem Analogieverbot auszugehen ist, und das Ergebnis dann auf die teleologische Reduktion zu übertragen. ${ }^{1}$

\subsection{Die Nähe von Steuer und Strafe}

„Eine Tat kann nur bestraft werden, wenn die Strafbarkeit gesetzlich bestimmt war, bevor die Tat begangen wurde" (Art. 103 Abs. 2 GG).

Diese Vorschrift wird in der juristischen Literatur praktisch ausnahmslos als Analogieverbot für das Strafrecht ausgelegt. ${ }^{2}$ Eine entsprechende Vorschrift für das Steuerrecht existiert zwar nicht; da aber Steuern den Staatsbürger u.U. weit stärker belasten können als beispielsweise eine Geldstrafe, könnte man versuchen, aus Art. 103 Abs. 2 GG auch für das Steuerrecht ein Verbot belastender Analogie herzuleiten. ${ }^{3}$ Voraussetzung dafür wäre, daß Steuer und Strafe einander so wesensähnlich sind, daß sie im Hinblick auf das Analogieverbot des Art. 103 Abs. 2 GG gleichzusetzen sind. ${ }^{4}$

Dies wird jedoch in der Literatur zu Recht einhellig ${ }^{5}$ bestritten: Der steuerliche Zugriff gründet sich allein auf die Verwirklichung wertfreier Tatbestände, demge-

${ }^{1}$ im Ergebnis gl.A.: INSTITUT „FINANZEN UND STEUERN““ (1985) S. 17

${ }^{2}$ Vgl. HESS (1974) S. 137 m.w.N.

${ }^{3}$ Die Behauptung HERZOGs, das strafrechtliche Analogieverbot analog auch auf das Steuerrecht zu übertragen, sei als Analogieverbot aufgrund Analogie „-- zumindest logisch - ein Monstrum“, erscheint als Einwand wenig überzeugend, da es bei der Frage eines Verbotes belastender Analogie im Steuerrecht nicht um die Zulässigkeit von Analogieschlüssen vom Strafrecht auf das Steuerrecht geht.

Ebenso wenig einleuchtend ist HERZOGs These, aus der Tatsache, daß das Grundgesetz nur für das Strafrecht ein Analogieverbot ausspreche, könne man im Umkehrschluß folgern, daß ein solches für das Steuerrecht nicht existiere (vgl. HERZOG (85/86) S. 43 f.). Tatsache ist, daß das Grundgesetz ein steuerrechtliches Analogieverbot weder ausdrücklich ausspricht noch explizit verneint.

${ }^{4} \mathrm{Vgl}$. PFLUGFELDER (1984) S. 291.

${ }^{5}$ Die oftmals zu lesende Behauptung, einige Befürworter eines steuerrechtlichen Analogieverbotes stützten ihre Auffassung auf Art. 103 Abs. 2 GG, entspricht nicht den Tatsachen. Vgl. hierzu z.B. TIPKE (1981) S. 124: „Gelegentlich wird das Steuerrecht mit dem Strafrecht verglichen und angenommen, daß Art. 103 II GG Ausdruck einer umfassenden rechtsstaatlichen Regel sei, die für den gesamten Bereich belastender, freiheitsbeschränkender Hoheitsakte von erheblicher Schwere gelten.“ Vgl. auch PFLUGFELDER (1984) S. 291: „... Frage, ob Steuertatbestände den Straftatbeständen so ähnlich sind, daß sie hinsichtlich der Rechtsfolge Verneinung der Analogiefähigkeit - gleichzustellen sind. Dies wird oft mit dem Hinweis begründet, daß die Steuergesetze den einzelnen stärker und häufiger (regelmäßiger) treffen als Strafgesetze." 
genüber basieren strafrechtliche Sanktionen auf rechtswidrigem Verhalten und damit auf einem persönlichen Vorwurf. ${ }^{1}$ Sinn einer strafrechtlichen Norm ist es, die Bürger darüber zu informieren, was strafbar ist, und sie damit von der entsprechenden Handlung abzuhalten. Ziel einer steuerlastenschaffenden Norm ist es jedoch i.d.R. nicht, daß die steuerbare Handlung unterlassen wird; denn andernfalls würde die Steuer ohne Aufkommen bleiben. ${ }^{2}$ Somit besteht ein substantieller Unterschied zwischen Steuer und Strafe, so daß dem Art. 103 Abs. 2 GG kein steuerrechtliches Analogieverbot entnommen werden kann.

\subsection{Demokratieprinzip und Gewaltenteilung}

Das Demokratieprinzip wird aus Art. 20 Abs. 1 GG und Art. 28 Abs. 1 GG abgeleitet. Es besagt, daß Maßnahmen der Exekutive und Judikative auf eine Willensentschließung der demokratisch legitimierten Gesetzgebungsorgane zurückführbar sein müssen. ${ }^{3}$ Weil die Spielräume des Rechtsanwenders im Falle der Lückenausfüllung ohne Zweifel größer sind, als wenn die Rechtsfortbildung auf den möglichen Wortsinn beschränkt ist, wird in der Analogie von einigen Autoren eine Gefahr für das Demokratieprinzip gesehen. ${ }^{4} \mathrm{Da}$ jedoch die Lückenausfüllung darin besteht, den Sinn und Zweck der gegebenenfalls anzuwendenden Normen bei der Rechtsfindung zu berücksichtigen, ist hierin kein Handeln gegen den Willen des vom Volk bestellten Gesetzgebers, sondern vielmehr eine Entscheidung in dessen Sinne zu sehen. Somit kann in der Analogie m.E. kein Verstoß gegen das Demokratieprinzip gesehen werden.

Aus dem gleichen Grund liegt in der Anwendung der Analogie auch kein Verstoß gegen den Grundsatz der Gewaltenteilung vor. ${ }^{6}$ Zwar beruht die Methode der Analogie selbst nicht auf parlamentarischen Mehrheitsentscheidungen; ${ }^{7}$ aber da durch den Analogieschluß vom Rechtsanwender nur vollzogen wird, was aus dem Willen des Gesetzgebers resultiert, wird der Grundsatz der Gewaltenteilung durch die Rechtsfortbildung per Analogie nicht verletzt. ${ }^{8}$ Wäre die Analogie ein Verstoß gegen die Gewaltenteilung, so müßte dies konsequenterweise auch für das Zivil-

Bezeichnenderweise finden sich weder bei TIPKE noch bei PFLUGFELDER irgendwelche diesbezüglichen Quellenhinweise. Lediglich TIPKE selbst scheint früher eine solche Auffassung vertreten zu haben; vgl. TIPKE (1978) S. 35.

${ }^{1} \mathrm{Vgl}$. WALZ (1980) S. 144.

${ }^{2}$ Vgl. TIPKE (1981) S. $124 \mathrm{f}$.

${ }^{3}$ Vgl. BVerfG-Beschluß vom 14.6.1983 - 2 BvR 488/80 - BVerfGE 64, 208 [214 f.].

${ }^{4}$ Vgl. INSTTTUT „FINANZEN UND STEUERN“ (1985) S. 75.

${ }^{5}$ gl.A.: TIPKE/LANG (1994) S. 106 f.

${ }^{6}$ so aber OFFERHAUS (1984) S. 996

${ }^{7}$ Vgl. FRIEDRICH (1985) S. 154.

${ }^{8}$ gl.A.: HESS (1974) S. 154 
recht gelten. Ein zivilrechtliches Analogieverbot wird aber, soweit ersichtlich, von niemandem behauptet.

\subsection{Sachgesetzlichkeiten im Steuerrecht}

KRUSE sieht das von ihm behauptete Fehlen von Sachgesetzlichkeiten im Steuerrecht als Begründung für das Analogieverbot an. ${ }^{1}$ Dieses Argument wird von DANZER ausgeführt: $\mathrm{Da}$ es im Steuerrecht keinen Sachverhalt gebe, der seiner Natur nach zu besteuern sei, fehle die ,innere Verbindung von Tatbestand und Rechtsfolge", die Grundvoraussetzung der Analogie ist. Ein Analogieschluß könne im Steuerrecht lediglich auf allgemeinen Gerechtigkeitsüberlegungen basieren, die aber aufgrund des Gesetzesvorbehalts (Art. 20 Abs. 3 GG) ${ }^{2}$ nicht zur Lückenausfüllung durch Verwaltung und Justiz berechtigen könnten. ${ }^{3}$

Dagegen ist einzuwenden, daß das Steuerrecht (wie jedes andere Rechtsgebiet auch) durchaus Sachgesetzlichkeiten unterliegt: Die Gesamtheit der Tatbestände eines jeden Steuergesetzes läßt Wertungen des Gesetzgebers erkennen, was er als steuerwürdig erachtet und was nicht, wobei diese Wertungen keinesfalls allein auf Gerechtigkeitsüberlegungen basieren. ${ }^{4}$ Auch wenn einige Steuergesetze in Teilbereichen eine durchgehende Systematik vermissen lassen, so wird man doch innerhalb bestimmter Gruppen zusammenhängender Vorschriften einen Gesetzesplan feststellen können, ${ }^{5}$ so daß sich eine generelle Analogieunfähigkeit des Steuerrechts mit dem Argument fehlender Sachgesetzlichkeiten nicht begründen läßt.

\subsection{Bindung an Recht und Gesetz}

Nicht allein die These vom Fehlen analogiefähiger Sachgesetzlichkeiten im Steuerrecht wird als Argument für ein Verbot steuerbelastender Analogie aufgrund der Lehre vom Gesetzesvorbehalt angefuihrt.

Der Gesetzesvorbehalt ergibt sich in Deutschland aus Art. 20 Abs. 3 GG (,... die vollziehende Gewalt und die Rechtsprechung sind an Gesetz und Recht gebunden."). Entscheidend für die Frage, ob hieraus ein Analogieverbot abzuleiten ist, ist die Auffassung über die Bedeutung des Begriffs „,Recht“ in diesem Zusammenhang. ${ }^{6}$ Der Umstand, daß der Parlamentarische Rat sich bei der Formulierung des Art. 20 Abs. 3 GG nicht auf die Bindung an die Gesetze beschränkt hat, läßt

\footnotetext{
${ }^{1}$ Vgl. KRUSE (1991) S. 144 f.; TIPKE/KRUSE (1996) Tz. 7.

${ }^{2}$ zum Gesetzesvorbehalt s.u.

${ }^{3} \mathrm{Vgl}$. DANZER (1981) S. $76 \mathrm{f}$.

${ }^{4}$ Vgl. HESS (1974) S. 96 f.; TIPKE (1993) S. 223 f;; WAGNER (1992) S. 4.

${ }^{5} \mathrm{Vgl}$. VÖLKER (1989) S. 239.

${ }^{6} \mathrm{Vgl}$. TANZER (1981) S. 202.
} 
schließen, daß unter ,Recht" hier mehr zu verstehen ist als nur die Summe der Gesetze. ${ }^{1}$ Ohne Zweifel sind auch die anerkannten Rechtsfortbildungsverfahren der juristischen Methodenlehre zum „Recht“ zu zählen, so daß allein die „Bindung an Gesetz und Recht" dem Analogieschluß nicht entgegenstehen kann, zumal auch eine auf einem Analogieschluß basierende Rechtsfindung sich letztlich auf ein Gesetz zurückführen läßt. ${ }^{2}$ Ein Hinwegsetzen über das Gesetz unter Berufung auf das Recht $^{3}$ ist somit in der Analogie nicht zu sehen.

\subsection{Grundsätze der Tatbestandsmäßigkeit und Rechtssicherheit}

Ein steuerrechtliches Analogieverbot ergibt sich vielmehr aus den Grundsätzen der Tatbestandsmäßigkeit und der Rechtssicherheit.

Auch der Grundsatz der Tatbestandsmäßigkeit ist Ausdruck des Vorbehaltsprinzips und wurde in $\S 38$ AO kodifiziert (,Die Ansprüche aus dem Steuerschuldverhältnis entstehen, sobald der Tatbestand verwirklicht ist, an den das Gesetz die Leistungspflicht knüpft."). Daraus wird im Umkehrschluß abgeleitet, daß keine Steuerschuld entsteht, wenn der gesetzliche Tatbestand nicht verwirklicht wird. ${ }^{4}$ Somit ist allein der Gesetzgeber berechtigt, Steuertatbestände zu schaffen oder zu verschärfen. ${ }^{5}$ Auch wenn $\S 38$ AO kein unmittelbarer Verfassungsrang zukommt, so kann das Prinzip der Tatbestandsmäßigkeit dennoch als verfassungsmäßiges Argument gegen die belastende Analogie angefuhrt werden, da es laut BVerfG Ausdruck des Rechtsstaatsprinzips (Art. 28 Abs. $1 \mathrm{GG}$ ) ist und im übrigen auch die Vorausberechenbarkeit der Steuerlast durch den Steuerpflichtigen erfordert. ${ }^{6}$ Eng hiermit im Zusammenhang steht das rechtsstaatliche Postulat der Rechtssicherheit, aus dem sich die Forderung nach Meßbarkeit und Verläßlichkeit staatlichen Handelns ergibt. ${ }^{7}$

Das Bedürfnis nach Vorausberechenbarkeit des Rechts ist im Steuerrecht als hoch belastendem Eingriffsrecht naturgemäß besonders ausgeprägt. Bei der Lückenausfüllung durch Analogie werden neue Steuertatbestände begründet (hierzu s.u.), so daß ohne Zweifel die Vorausberechenbarkeit des Steuerrechts vermindert wird. ${ }^{8}$ Zwar sind diese neuen Steuertatbestände aus dem Gesetz abgeleitet; aber dabei

\footnotetext{
${ }^{1}$ Vgl. HESS (1974) S. 60.

2 Vgl. ebenda S. 101.

3 so die Bedenken des INSTTTUTs „FINANZEN UND STEUERN“ (1985) S. 39

${ }^{4}$ Vgl. RIEDEL (1968) S. 43.

${ }^{5} \mathrm{Vgl}$. PFLUGFELDER (1984) S. 292.

${ }^{6} \mathrm{Vgl}$. BVerfG-Urteil vom 14.12.1965 - 1 BvR 571/60 - BVerfGE 19, 253 [267].

${ }^{7} \mathrm{Vgl}$. INSTTTUT „FINANZEN UND STEUERN“ (1985) S. 43 sowie HESS (1974) S. 158 f.; vgl. auch BVerfG-Urteil vom 19.12.1961 - 2 BvL 6/59 - BVerfGE 13, 261 [271]; BVerfG-Beschluß vom 22.6.1971 - 2 BvL 6/70 - BVerfGE 31, 222 [225].

${ }^{8} \mathrm{Vgl}$. FRIEDRICH (1985) S. 154.
} 
sollte berücksichtigt werden, daß die Analogie nicht allein auf logischen Schlüssen beruht, sondern einem Analogieschluß der ermittelte Sinn und Zweck des Gesetzes und somit eine Wertung zugrunde liegen. ${ }^{1}$

Nicht überzeugen kann in diesem Zusammenhang TPREs Einwand, der Steuerpflichtige verstehe das Gesetz in der Regel ohnehin nicht, kenne es of nicht einmal, und im übrigen habe das Steuerrecht zum Inhalt, was der BFH zu seinem Inhalt erkläre, dies wüßten alle Steuersparer und -berater. ${ }^{2}$ Das verfassungsmäßig gebotene Postulat der Rechtssicherheit und Vorausberechenbarkeit gilt für alle Steuerpflichtigen und nicht nur für die Mehrheit, die „das Gesetz ohnehin nicht

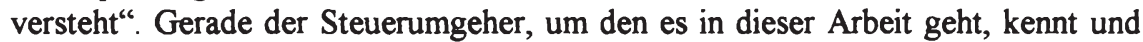
versteht das Gesetz im Regelfall sehr gut, andernfalls wäre er gar nicht in der Lage, durch mißbräuchliche Rechtsgestaltungen Minderungen seiner Steuerlast zu erzielen. Im übrigen darf auch der BFH nur innerhalb der ihm vorgegebenen Grenzen der Rechtsfortbildung erklären, was zum Inhalt der Steuergesetze gehört. Keinesfalls darf der BFH diese Grenzen nach seinem Belieben überschreiten und sein Vorgehen dann damit rechtfertigen, daß ohnehin jeder wisse, daß das Steuerrecht beinhalte, was der BFH zu seinem Inhalt erklärt. Bislang hat der BFH auch noch nie versucht, das Postulat der Rechtssicherheit auf diese Weise außer Kraft zu setzen.

Auch TANZERs Einwand, es sei „Willkür gegenüber dem allein verpflichtenden Gesetz", wenn der erkennbare und nachweisliche Wille des Gesetzgebers einem Lückenausfüllungsverbot geopfert werde, das Ziel der Rechtsrichtigkeit werde damit dem ohnehin vielfach nicht erfullten Rechtssicherheitspostulat geopfert, ${ }^{3}$ erweist sich im Falle näherer Prüfung als wenig stichhaltig.

Erstens kann davon ausgegangen werden, daß auch das Ziel der „Rechtsrichtigkeit" (was auch immer TANZER konkret darunter verstehen mag) ebenfalls „ohnehin vielfach nicht erfüllt" ist. Zweitens läßt sich kaum bestreiten, daß die Rechtssicherheit, mag sie schon ohne Zulässigkeit der Analogie nicht immer vollständig gegeben sein, durch die Analogie weiter vermindert wird. Ferner ist der einem Analogieschluß zugrunde liegende „nachweisliche Wille des Gesetzgebers“ für den Steuerpflichtigen eben nicht aus den ihm relevant erscheinenden Bestimmungen des Steuergesetzes erkennbar; das gilt selbst für steuerrechtlich überdurchschnittlich vorgebildete Steuerpflichtige.

Somit kann festgestellt werden, daß die Analogie eindeutig einen Verstoß gegen das Postulat der Rechtssicherheit bedeutet.

\footnotetext{
${ }^{1}$ Vgl. HESS (1974) S. 163 f.

${ }^{2} \mathrm{Vgl}$. TIPKE (1985) S. 147 sowie TIPKE/LANG (1994) S. 107.

${ }^{3} \mathrm{Vgl}$. TANZER (1981) S. 216.
} 
Dem kann auch nicht entgegengehalten werden, daß die Analogie eine „ebenso stringente teleologische Methode wie die Auslegung“ und keine Neuschöpfung oder Erweiterung des Steuertatbestandes sei. ${ }^{1}$ Wenn selbst die Befurworter der Analogie im Steuerrecht die Ansicht vertreten, Art. 103 Abs. 2 GG (,Eine Tat kann nur bestraft werden, wenn die Strafbarkeit gesetzlich bestimmt war, bevor die Tat begangen wurde. ") schreibe ein strafrechtliches Analogieverbot vor, ${ }^{2}$ dann bestreiten sie offensichtlich nicht, daß aus der Analogie resultierende Tatbestände eben nicht gesetzlich bestimmt sind. Daraus folgt aber zwangsläufig, daß jeder Analogieschluß einen neuen Tatbestand schafft oder einen vorhandenen erweitert. ${ }^{3}$

\subsection{Abwägen zwischen Rechtssicherheitspostulat und Gleichheits- grundsatz?}

BARTH vertritt ebenfalls die Auffassung, daß das Rechtssicherheitspostulat gegen eine steuerbegründende Analogie spreche. ${ }^{4}$ Seines Erachtens ist aber jeweils abzuwägen, ob der Verlust an Rechtssicherheit im Einzelfall stärker wiegt als der ansonsten drohende Verstoß gegen den ebenfalls verfassungsmäßig gebotenen Gleichheitsgrundsatz. ${ }^{5}$

Richtig ist, daß die Steuerrechtswissenschaft die Notwendigkeit einer Verhinderung der Steuerumgehung aus dem Gleichheitsgrundsatz des Art. 3 GG ableitet. ${ }^{6}$ Es ist jedoch Aufgabe der Legislative, die Gesetze so auszugestalten, daß das Gebot prinzipiell gleicher Rechtsanwendung erfült ist. Wo die Gesetze gegen dieses Gebot verstoßen, ist es das Recht jedes Betroffenen, gegen die entsprechende gesetzliche Bestimmung zu klagen. Die Abwägung zwischen Gleichheitsgrundsatz und eventuell gegenläufiger anderer Verfassungsgrundsätze ist dann Aufgabe des angerufenen Gerichtes. Ist jedoch eine bestimmte steuergesetzliche Regelung bislang von keinem Staatsbürger gerichtlich angefochten worden, so haben Finanzverwaltung und Finanzgerichtsbarkeit nach dem Grundsatz der Gewaltenteilung diese Bestimmung anzuwenden, ohne irgendwelche - miteinander in Konflikt stehenden - verfassungsmäßigen Grundsätze wie Rechtssicherheit und Gleichheitsgrundsatz gegeneinander abzuwägen. Die Bekämpfung der Steuerumgehung ist eine vom Gleichheitsgrundsatz des Art. 3 GG gestützte Aufgabe des Gesetzgebers, nicht jedoch der Finanzgerichte. Die Postulate der Tatbestandsmäßigkeit und der Rechtssicherheit i.V.m. dem Gewaltenteilungsgrundsatz verbieten der Finanzge-

'so aber TIPKE/LANG (1994) S. 107

${ }^{2}$ Vgl. TANZER (1981) S. 215, HERZOG (85/86) S. 43, TIPKE/LANG (1994) S. 106, KLEIN/ ORLOPP (1995) § 4 Anm. 9.

3 im Ergebnis gl.A.: RIEDEL (1968) S. 44, HESS (1974) S. 6 und S. 163.

${ }^{4} \mathrm{Vgl}$. BARTH (1996) S. 548.

${ }^{5}$ Vgl. ebenda S. 559.

${ }^{6}$ Vgl. auch Kap. 3.5.1 dieser Arbeit. 
richtsbarkeit, unter Berufung auf den Gleichheitsgrundsatz steuerbegründende analoge Rechtsanwendung zu betreiben. Damit wird der Grundsatz der Rechtssicherheit nicht über den Gleichheitsgrundsatz gestellt. ${ }^{1}$ Wo die Gesetze zu Verstößen gegen den Gleichheitsgrundsatz führen, sind - wie erwähnt - gerichtliche Klagen zulässig. Gleichheitsgrundsatz und Rechtssicherheitspostulat bestehen damit nebeneinander. Aufgabe von Finanzbehörden und Finanzgerichten ist die Auslegung der bestehenden Gesetze unter Beachtung des Grundsatzes der Rechtssicherheit. Analoge Rechtsanwendung zu Lasten der Steuerpflichtigen ist ihnen nicht gestattet. Die Verwirklichung des Gleichheitsgrundsatzes obliegt dem Gesetzgeber. Wo er diese Aufgabe vernachlässigt, kann das Bundesverfassungsgericht korrigierend eingreifen. Dies hat es in der jüngeren Vergangenheit (z.B. in seiner Rechtsprechung zur Zinsbesteuerung) durchaus getan. Die Finanzgerichtsbarkeit ist hierzu ebenso wenig befugt wie die Finanzverwaltung. Ihre Aufgabe ist die Anwendung der Steuergesetze, nicht ihre Ausdehnung auf vom Gesetz nicht geregelte Fälle.

\subsection{Die Rechtsprechung zur steuerverschärfenden Analogie}

Die bisher zur Frage der Zulässigkeit steuerverschärfender Analogie ergangene Rechtsprechung des BFH ist uneinheitlich.

In diversen Entscheidungen hat sich der $\mathrm{BFH}$ ausdrücklich für ein Analogieverbot ausgesprochen; ${ }^{2}$ in seinem Urteil vom 20.10.1983 hat der IV. Senat jedoch die Feststellung getroffen, ein Analogieverbot bestehe im Steuerrecht nicht, Lückenausfullung sei auch zu Lasten des Steuerpflichtigen möglich. ${ }^{3}$

TANZER $^{4}$ und TIPKE ${ }^{5}$ nennen noch weitere BFH-Entscheidungen, die als Indiz dafür gelten können, daß der BFH auch in anderen Urteilen von der sonst vorherrschenden Annahme eines Analogieverbotes abgewichen ist; jedoch hat der BFH in keinem dieser Urteile die Zulässigkeit belastender Analogie offen bekannt.

${ }^{1}$ Dies scheinen die Bedenken BARTHs zu sein; vgl. ebenda S. 559.

${ }^{2}$ so z.B. in BFH-Urteil vom 28.11.1967 II 110/62 BStBl. 1968 II S. 216 [217];

BFH-Urteil vom 18.2.1977 VI R 177/75 BStBl. 1977 II S. 524 [525];

BFH-Urteil vom 8.12.1981 VIII R 125/79 BStBl. 1982 II S. 618 [619];

BFH-Beschluß vom 28.4.1982 I R 89/77 BStBl. 1982 II S. 556 [559].

${ }^{3}$ Vgl. BFH-Urteil vom 20.10.1983 IV R 175/79 BStBl. 1984 II S. 221 [224]. Ob der BFH im vorliegenden Fall tatsächlich zum Mittel analoger Rechtsanwendung gegriffen hat, wird allerdings von SEUFFERT bestritten. Nach seiner Auffassung stellt das, was der Senat als Analogieschluß bezeichnet hat, lediglich einen Fall systematischer Auslegung dar (vgl. SEUFFERT (1985) S. 9).

${ }^{4}$ Vgl. TANZER (1981) S. 206.

${ }^{5} \mathrm{Vgl}$. TIPKE (1993) S. 206 f. 
So bleibt in der bisherigen Rechtsprechung des BFH ein Übergewicht derjenigen Entscheidungen, die ein Lückenausfuillungsverbot bejahen; endgültige Klarheit über die diesbezügliche Auffassung des BFH wird jedoch erst dann bestehen, sobald sich der Große Senat des BFH mit dieser Frage befaßt hat. ${ }^{1}$ Dessen Entscheidung wird möglicherweise vom Bundesverfassungsgericht, welches sich bislang noch nicht eindeutig zu dieser Frage geäußert hat, einer Prüfung unterzogen werden müssen.

Anders, als von TANZER ${ }^{2}$ behauptet, bedeutet der BVerfG-Beschluß vom 13.12.1966 (1. Senat) nicht, daß eine Rechtsanwendung über den Wortsinn einer Vorschrift hinaus im Steuerrecht zulässig sei; im Gegenteil spricht der 1. Senat ausdrücklich von der Zulässigkeit einer einschränkenden Auslegung, nicht von teleologischer Reduktion, wobei der Wortsinn die Grenze der Auslegung bildet. ${ }^{3}$ Die richterliche Neuschaffung oder Ausweitung von Steuertatbeständen sei unzulässig. ${ }^{4} \mathrm{Da}$ im Falle der Analogie der besteuerte Tatbestand nicht im Gesetz bestimmt ist, ist die Analogie als eine solche Neuschaffung oder Ausweitung steuerlicher Tatbestände anzusehen, ${ }^{5}$ so daß die Annahme eines Analogieverbotes durch die Entscheidungen vom 24.1.1962 und vom 13.12.1966 naheliegt. Hinzu kommt der hohe Stellenwert, den das BVerfG in diversen Entscheidungen ${ }^{6}$ der Forderung nach Voraussehbarkeit der steuerlichen Belastung beigemessen hat. $\mathrm{Da}$ Analogie und teleologische Reduktion der Voraussehbarkeit der Steuerlast in erheblichem Maße entgegenstehen, ${ }^{7}$ erscheint es in Anbetracht der bisher ergangenen Entscheidungen schwer vorstellbar, daß das Bundesverfassungsgericht, wenn es zur Frage der Zulässigkeit belastender Analogie eindeutig Stellung zu nehmen hätte, diese bejahen würde.

\subsection{Zwischenergebnis}

Die Verfahren der Analogie und der teleologischen Reduktion sind grundsätzlich geeignete Mittel, die der Verwaltung und Rechtsprechung zur Verfügung stehen, um der Gesetzesumgehung wirkungsvoll entgegenzutreten. Die vorangegangene

${ }^{1}$ Vgl. v. WALLIS (1986) S. $4681 \mathrm{f}$.

${ }^{2} \mathrm{Vgl}$. TANZER (1981) S. 208.

${ }^{3}$ Vgl. BVerfG-Beschluß vom 13.12.1966 - 1 BvR 512/65 - BVerfGE 21, 1 [4] i.V.m. BVerfGUrteil vom 21.5.1952 - 2 BvH 2/52 - BVerfGE 1, 299 [312].

${ }^{4}$ Im Beschluß vom 13.12.1966 wird dabei auf das BVerfG-Urteil vom 24.1.1962 - 1 BvR 232/60 - BVerfGE 13, 318 [328] verwiesen.

${ }^{5}$ s.o. S. 53

${ }^{6}$ Vgl. BVerfG-Beschluß vom 10.10.1961 - 2 BvL 1/59 - BVerfGE 13, 153 [160]; BVerfG-Urteil vom 14.12.1965, a.a.O., S. 267; BVerfG-Beschluß vom 8.1.1981 - 2 BvL 3, 9/77 - BVerfGE 56, 1 [12].

${ }^{7}$ s.o. S. 52 f. 
Analyse hat jedoch gezeigt, daß sich nach deutscher Verfassungslage im Steuerrecht aus den rechtsstaatlichen Grundsätzen der Tatbestandsmäßigkeit und der Rechtssicherheit ein Verbot belastender Analogie bzw. teleologischer Reduktion ergibt. Die hiergegen vorgebrachten Argumente (im wesentlichen von HERZOG, KLEIN/ORLOPP, TANZER und TIPKE) halten, wie sich zeigen ließ, einer näheren Prüfung nicht stand.

Auch die Rechtsprechung des BFH teilt im Ergebnis überwiegend die Auffassung vom steuerrechtlichen Analogieverbot. Das Bundesverfassungsgericht hat sich mit dieser Frage bislang noch nicht direkt befassen müssen. Doch sowohl die in dieser Arbeit angeführten Fakten und Begründungen für ein Analogieverbot als auch die bislang vom Verfassungsgericht abgegebenen, für diese Problematik relevanten Stellungnahmen legen den Schluß nahe, daß Analogie und teleologische Reduktion auch aus der Sicht des BVerfG keine in Deutschland verfassungsrechtlich zulässigen Mittel zur Bekämpfung der Steuerumgehung sein können.

\subsubsection{Die wirtschaftliche Betrachtungsweise}

Die wirtschaftliche Betrachtungsweise ist eine juristische Interpretationsmethode für die Beurteilung von Sachverhalten einerseits sowie der gesetzlichen Bestimmungen, die u.U. auf die vorliegenden Sachverhalte anzuwenden sind, andererseits. ${ }^{1}$ Da steuerliche Tatbestände ihrer Natur nach i.d.R. auf wirtschaftliche Vorgänge abstellen, ist es zunächst Aufgabe der wirtschaftlichen Betrachtungsweise, steuerrechtliche Normen und die in ihnen enthaltenen Begriffe nach ihrem wirtschaftlichen Zweck zu interpretieren. ${ }^{2}$ Bei der Sachverhaltsbeurteilung besteht die wirtschaftliche Betrachtungsweise darin, statt auf die äußere Erscheinungsform auf den wahren wirtschaftlichen Gehalt abzustellen. ${ }^{3}$ Dies bedeutet jedoch nicht zwangsläufig, daß damit für das Steuerrecht allein wirtschaftliche Erkenntnisse maßgeblich wären; wirtschaftliche Erkenntnisse sollen aber bei der Rechtsfindung als Kriterium Berücksichtigung finden. ${ }^{4}$

Die wirtschaftliche Betrachtungsweise war früher in Deutschland in $\S 4$ RAO 1919, später in § 9 RAO 1931 und bis 1976 in § 1 StAnpG 1934 kodifiziert. Im US-amerikanischen Steuerrecht findet sich eine der wirtschaftlichen Betrachtungsweise vergleichbare Methode in dem Grundsatz, ,substance over form “ .

${ }^{1}$ Vgl. RIEDEL (1968) S. 51.

${ }^{2}$ Vgl. DANZER (1981) S. 64.

${ }^{3}$ Vgl. FRIEMEL/SCHIML 12/81 S. 356.

${ }^{4}$ Vgl. URBAS (1987) S. 50.

${ }^{5}$ Vgl. S. 70 der vorliegenden Arbeit sowie TIPKE/LANG (1994) S. 136 und BOIDMAN (1981) S. 445. 
Die Auffassungen über den Anwendungsbereich der wirtschaftlichen Betrachtungsweise haben sich in Deutschland im Zeitablauf gewandelt. Während nach dem 1. Weltkrieg die Rechtsprechung zunächst dahin tendierte, im Interesse der Gleichmäßigkeit der Besteuerung die steuerrechtliche Beurteilung von Sachverhalten vollkommen von der jeweiligen zivilrechtlichen Gestaltung zu trennen, kam es nach dem 2. Weltkrieg zu einer gegenläufigen Tendenz: Das Postulat der Gleichmäßigkeit der Besteuerung wurde zugunsten der Forderungen nach Rechtssicherheit und Einheit der Rechtsordnung zurückgestellt; statt Anwendung der wirtschaftliche Betrachtungsweise stand nun das „Primat des Zivilrechts“ im Vordergrund. ${ }^{1}$ Der Gegensatz zwischen beiden Auffassungen hat sich mittlerweile weitgehend aufgelöst. Literatur und Rechtsprechung pflegen heute die wirtschaftliche Betrachtungsweise als „Element der teleologischen Auslegungsmethode ${ }^{\mathrm{c} 2} \mathrm{zu}$ betrachten. Danach kommt bei der Beurteilung eines steuerlichen Sachverhalts eine Abweichung von der gewählten zivilrechtlichen Gestaltung genau dann in Betracht, wenn diese Abweichung dem erkennbaren Zweck der anzuwendenden Rechtsnorm entspricht. Die wirtschaftliche Betrachtungsweise dürfe, um nicht Willkür und Rechtsunsicherheit Vorschub zu leisten, nicht zu einer vollkommenen Loslösung vom Gesetz führen (sog. freischwebende wirtschaftiche Betrachtungsweise), sondern nur nach den allgemeinen Regeln der Auslegungslehre dort zum Zuge kommen, wo es die Gebote der steuerlichen Gerechtigkeit und Gleichbehandlung erfordern. ${ }^{3}$

$\mathrm{Da}$ die wirtschaftliche Betrachtungsweise nach dieser Auffassung eine Anwendungsform der teleologischen Auslegung im Rahmen der allgemeinen juristischen Methodenlehre darstellt, ist ihre gesetzliche Fixierung heute (anders als zum Zeitpunkt des Inkraftretens der RAO 1919) als überflüssig anzusehen und deshalb vom Gesetzgeber nicht in die AO 1977 übernommen worden. ${ }^{4}$

Als Auslegungsprinzip endet die wirtschaftliche Betrachtungsweise am möglichen Wortsinn einer Norm und ist somit zur Bekämpfung der Steuerumgehung im in Abschnitt 2 definierten Sinne nicht geeignet.

Demgegenüber könnte eine „freischwebende“ wirtschaftliche Betrachtungsweise prinzipiell durchaus in der Lage sein, der Steuerumgehung wirksam entgegenzutreten; nur hängt ihre Zulässigkeit - wie dargestellt - von der jeweils herrschenden

${ }^{1}$ Vgl. THOMA (1950) S. 68 f. sowie BEISSE (1981), S. 4 f.

${ }^{2}$ GRIMM (1978) S. 284

${ }^{3}$ Vgl. RIEDEL (1968) S. 54; TIPKE/LANG (1994) S. 141; zu den genauen Grundsătzen des BFH für die Anwendung der wirtschaftliche Betrachtungsweise vgl. im einzelnen BEISSE (1981) S. 8.

${ }^{4} \mathrm{Vgl}$. DORNBACH (1977) S. 12. Vgl. auch Ausschußbericht zu § 3 Abs. 2 RegE in MTTTELSTEINER/SCHAUMBURG (1977) S. $27 \mathrm{f}$.

Gleichzeitig hat der Gesetzgeber damit einer freischwebenden, über die juristische Auslegungslehre hinausgehenden wirtschaftlichen Betrachtungsweise eine endgültige Absage erteilt. 
Rechtsauffassung ab und ist im deutschen Rechtskreis (Deutschland, Österreich, Schweiz) derzeit nicht gegeben.

\subsubsection{Die Verhinderung der Steuerumgehung durch rückwirkende Steuergesetze}

In Kap. 4.1.1 wurde das Instrument der Spezialklauseln und Wortlautverbesserungen für ungeeignet erachtet, das Ausmaß der Steuerumgehungstätigkeit entscheidend zu reduzieren. Anders sähe es hingegen aus, wenn derlei Gesetzestextanpassungen mit rückwirkender Kraft erlassen werden könnten. Ebenso wie bei der belastenden Analogie stellt sich jedoch auch bei der steuerlastenschaffenden Rückwirkung die Frage ihrer verfassungsrechtlichen Zulässigkeit.

Genau wie das Analogieverbot ergibt sich das Rückwirkungsverbot im Strafrecht aus Art. 103 Abs. 2 GG, wonach eine Tat nicht strafbar sein kann, wenn ihre Strafbarkeit zum Tatzeitpunkt nicht gesetzlich bestimmt war. ${ }^{1}$ Außerhalb des Bereiches rechtswidrigen Verhaltens ist die Frage nach Zulässigkeit rückwirkend belastender Rechtsnormen nicht ausdrücklich in der Verfassung geregelt.

Das Bundesverfassungsgericht leitet jedoch aus den rechtsstaatlichen Prinzipien des Vertrauensschutzes und der Rechtssicherheit ein grundsätzliches Verbot der Rückwirkung belastender Gesetze ab. ${ }^{2}$ Allerdings steht dem Rechtsstaatsprinzip auf der anderen Seite die ebenfalls verfassungsmäßig gebotene Erhaltung der Handlungsfähigkeit des Staates gegenüber, der in der Lage sein muß, die Rechtsordnung wirksam zu verändern, sofern die Wandlung der Verhältnisse solche Neuregelungen im Interesse des Gemeinwohls erforderlich macht. ${ }^{3}$ Bezüglich der Entscheidung, welchen der genannten verfassungsmäßigen Prinzipien der Vorrang einzuräumen ist, unterscheidet das Bundesverfassungsgericht zwischen „echter" und „unechter" Rückwirkung. ${ }^{4}$ Unechte Rückwirkung liegt vor, „wenn ein Gesetz auf gegenwärtige, noch nicht abgeschlossene Rechtsbeziehungen für die Zukunft

\footnotetext{
${ }^{1}$ Wer, wie HERZOG (85/86) S. 43 f. und KLEIN/ORLOPP (1995) Anm. 9, aus der Tatsache, daß das Grundgesetz nur für das Strafrecht ein Analogieverbot statuiert hat, im Umkehrschluß folgert, daß außerhalb des Strafrechts ein solches Verbot nicht bestehe, müßte rückwirkende Steuergesetze mit der gleichen Argumentation ebenfalls für ohne weiteres zulässig halten. Vgl. jedoch HERZOG in MAUNZIDÚRIG (1994), Art. 20 (VII) Rdnr. 65 und 69!

2 Vgl. BVerfG-Beschluß vom 10.4.1984 - 2 BvL 19/82 - BVerfGE 67, 1 [14 f.].

Vgl. auch BFH-Urteil vom 10.7.1986 IV R 12/81 BStBl. 1986 II S. 811 [812].

${ }^{3}$ Vgl. BVerfG-Beschluß vom 22.3.1983 - 2 BvR 475/78 - BVerfGE 63, 343 [357].

${ }^{4}$ Statt des Ausdrucks „unechte Rückwirkung“ findet sich in der neueren Rechtsprechung des BVerfG gelegentlich die Bezeichnung "tatbestandliche Rückanknüpfung“, ohne daß ein qualitativer Unterschied vorliegt. Dasselbe gilt für die in jüngerer Zeit bisweilen verwendete Formulierung „Rückbewirkung von Rechtsfolgen“ als Ersatz für den Begriff der „echten Rückwirkung“. Vgl. hierzu SNELTING (1996) S. 55 f. m.w.N.
} 
einwirkt und damit zugleich die betroffenen Rechtspositionen nachträglich entwertet. “l Unechte Rückwirkung ist grundsätzlich zulässig, aber selbst hier ist vom Gesetzgeber der Grundsatz der Verhältnismäßigkeit zu beachten, der ein sorgfältiges Abwägen zwischen Vertrauensschutz des einzelnen und gesetzgeberischem Anliegen des Allgemeinwohls erforderlich macht und die Legislative gegebenenfalls $\mathrm{zu}$ einer angemessenen Übergangsregelung verpflichtet. ${ }^{2}$

Geht es um die Frage, inwieweit Steuerumgehungen durch rückwirkende Gesetzesänderungen begegnet werden darf, so haben wir es regelmäßig mit dem Problem zu tun, ob der Gesetzgeber befugt ist, in abgewickelte, der Vergangenheit angehörende Tatbestände einzugreifen (echte Rückwirkung). ${ }^{3}$ Diesbezüglich hat das Bundesverfassungsgericht in diversen Entscheidungen den Grundsatz entwickelt, daß allein zwingende Gründe des Gemeinwohls oder aber Umstände, die den Betroffenen zum Zeitpunkt der Tatbestandsverwirklichung mit der rückwirkenden Gesetzesänderung rechnen lassen mußten, eine Durchbrechung des rechtsstaatlichen Rückwirkungsverbotes rechtfertigen könnten. ${ }^{4}$

Zwingende Gründe des Gemeinwohls liegen dann vor, wenn rückwirkende Gesetzesänderungen unabdingbar notwendig sind, um dem Staat die Fähigkeit zu belassen, Konjunkturpolitik, Sozialpolitik, Gesellschaftspolitik usw. betreiben zu können. ${ }^{5}$ Eine solche unabdingbare Notwendigkeit ist sicherlich nicht anzunehmen, wenn das Anliegen des Gesetzgebers einzig darin besteht, bestimmte vorgekommene Steuerumgehungen nachträglich unwirksam zu machen.

Wenn die Betroffenen mit dem rückwirkenden Gesetz rechnen mußten, war ein etwaiges Vertrauen des Steuerpflichtigen auf die Rechtslage sachlich nicht gerechtfertigt, so daß das Prinzip des Vertrauensschutzes in einem solchen Fall nicht anwendbar ist. ${ }^{6}$ Dieser Grundsatz bedeutet jedoch nicht, daß es für seine Anwendung genügen würde, wenn der Gesetzgeber bekanntgäbe, daß er sich im Falle von Steuerumgehungen allgemein vorbehalte, Rechtsnormen mit Rückwirkung zu erlassen. Selbst die Bekanntgabe einer konkreten Gesetzesinitiative oder des Planes einer Neuregelung reicht keineswegs aus, um die Schutzwürdigkeit des Vertrauens

${ }^{1}$ BVerfG-Urteil vom 8.2.1977 - 1 BvR 79, 278, 282/70 - BVerfGE 43, 242 [286]

${ }^{2}$ Vgl. BVerfG-Beschluß vom 10.4.1984, a.a.O., S. 15; BVerfG-Urteil vom 8.2.1977, a.a.O., S. 286.

${ }^{3}$ Diese Definition der echten Rückwirkung findet sich z.B. im BVerfG-Beschluß vom 13.5.1986 1 BvR 99, 461/85 - BVerfGE 72, 175 [196].

${ }^{4}$ Vgl. BVerfG-Beschluß vom 14.5.1986 - 2 BvL 2/83 - BVerfGE 72, 200 [258];

vgl. ferner INSTTTUT „FINANZEN UND STEUERN“ (1987) S. 68-70 mit diversen Hinweisen auf Entscheidungen des BVerfG aus den 50er- und 60er- Jahren.

${ }^{5}$ Vgl. BVerfG-Beschluß vom 22.3.1983, a.a.O., S. 357.

${ }^{6}$ Vgl. LARENZ (1991) S. 424 unter Berufung auf BVerfG-Urteil vom 19.12.1961 - 2 BvL 6/59 BVerfGE 13, 261 [272]. 
in die geltende Rechtslage aufzuheben. ${ }^{1}$ Das Vertrauen in die derzeitige Rechtsposition gilt erst dann als nicht oder nicht mehr sachlich gerechtfertigt, wenn die Gesetzesänderung lediglich vorhandene Widersprüche im Gesetz rückwirkend beseitigen oder nichtige Bestimmungen aufheben oder ändern würde. ${ }^{2}$ Auch in Fällen, in denen eine Rechtsnorm vom Bundesverfassungsgericht für nichtig erklärt worden ist und dadurch eine andere, noch nicht angefochtene Norm systemwidrig wurde, ist mit der Aufhebung der nunmehr systemwidrigen Bestimmung zu rechnen und das Vertrauen in ihre Gültigkeit nicht mehr gerechtfertigt. ${ }^{3}$

Hält man sich diese wenigen Ausnahmen vom Grundsatz des Rückwirkungsverbotes im belastenden Recht vor Augen, so wird klar, daß bei gegenwärtiger Verfassungslage das Mittel rückwirkender Gesetze in Deutschland nicht zur Beseitigung oder nennenswerten Einschränkung des Umfanges an Steuerumgehungsaktivitäten einsetzbar ist. In anderen Staaten kann bei entsprechender Verfassung und Verfassungsrechtsprechung die Rückwirkung durchaus geeignet sein, um die Steuerumgehung zu bekämpfen. In keinem Rechtsstaat allerdings darf dieses Instrument in beliebigem Umfang von staatlicher Seite eingesetzt werden, selbst wenn es von der dortigen Gerichtsbarkeit nicht für prinzipiell unzulässig erachtet wird (vgl. dazu auch unten Kap. 4.2.1.2). Bei nicht lückenloser Anwendung bleibt die Steuerumgehungsproblematik dann jedoch grundsätzlich bestehen, zumal der Gesetzgeber sich auch über die Gefahr ausufernder Gesetzestexte und komplizierter werdenden Steuerrechts im klaren sein muß, wenn den Gesetzen immer neue Spezialvorschriften gegen die Steuerumgehung hinzugefügt werden. Die Steuerumgeher würden ihre Aktivitäten zwar zurückschrauben, weil sie stets die Möglichkeit rückwirkender Rechtsnormen bei ihrer Entscheidungsfindung berücksichtigen müßten. Wenn sie sich aber darüber im klaren sind, daß der Staat nur einem Teil der Steuerumgehungen mit dem Mittel der Rückwirkung begegnen wird, so können Versuche, das Steuerrecht zu umgehen, nach wie vor rational sein.

\subsubsection{Zwischenergebnis}

Die zu Beginn von Abschnitt 4.1 aufgezählten denkbaren Alternativen zur Generalklausel gegen die Steuerumgehung sind in Deutschland nicht geeignet, die Umgehungsproblematik zu beseitigen.

Laufende Gesetzestextanpassungen und Spezialklauseln sind zwar rechtlich zulässig, in der Praxis aber wenig wirkungsvoll. Erst wenn sie mit rückwirkender Kraft erlassen werden könnten, wäre der Gesetzgeber - je nach Intensität der Anwendung dieses Instruments - in der Lage, Steuerumgehungen ggf. vollständig auszu-

\footnotetext{
${ }^{1}$ Vgl. BVerfG-Beschluß vom 10.3.1971 - 2 BvL 3/68 - BVerfGE 30, 272 [287].

${ }^{2}$ Vgl. TIPKE/LANG (1994) S. 102 mit Hinweisen auf eine Vielzahl von BVerfG-Entscheidungen.

${ }^{3} \mathrm{Vgl}$. BVerfG-Beschluß vom 16.11.1965 - 2 BvL 8/64 - BVerfGE 19, 187 [196 f.].
} 
schließen. Rückwirkend belastende Steuergesetze hat das Bundesverfassungsgericht jedoch für grundsätzlich unzulässig erklärt.

Die Gesetzesanwender hätten ohne die Existenz einer Generalklausel in Deutschland keinerlei Möglichkeit, gegen Steuerumgehungshandlungen vorzugehen. Die Mittel der Analogie und der teleologischen Reduktion wären zwar diesbezüglich wirksam, sind jedoch rechtlich nicht zulässig. Die wirtschaftliche Betrachtungsweise ist in ihrem heutigen Verständnis ein reines Auslegungsprinzip und als solches zwar rechtlich unbedenklich, aber definitionsgemäß nicht auf Steuerumgehungsfalle anwendbar.

Eine gesetzliche Generalklausel gegen die Steuerumgehung erscheint notwendig, um ihr wirksam entgegentreten zu können. Bevor untersucht wird, inwieweit eine solche Generalklausel auch hinreichend ist, soll im folgenden die Situation in zwei Staaten analysiert werden, die keine solche Generalklausel im Steuerrecht kennen, in denen Finanzverwaltung und Rechtsprechung aber möglicherweise aufgrund einer von der deutschen differierenden Verfassungslage oder Rechtsauffassung in der Lage sind, durch Rechtsfortbildung, d.h. durch über den Wortlaut hinausgehende Auslegung, durch Analogie und teleologische Reduktion oder durch eine weitreichende Anwendung der wirtschaftlichen Betrachtungsweise, Steuerumgehungen zu verhindern.

\subsection{Die Bekämpfung von Steuerumgehungsaktivitäten ohne Zuhilfenahme einer Generalklausel im Ausland}

Viele Staaten haben keine Generalklausel gegen die Steuerumgehung in ihre Gesetzgebung aufgenommen. Dazu gehören Belgien, Dänemark, Großbritannien, Japan, Portugal und die USA. ${ }^{1}$

Im folgenden wird exemplarisch die Situation in Großbritannien und in den Vereinigten Staaten einer Analyse unterzogen - Länder, die bei der Bekämpfung der Steuerumgehung traditionell auf vollkommen unterschiedliche Art und Weise den Verzicht auf eine Generalklausel zu kompensieren versuchen, auch wenn es in jüngerer Zeit - jedenfalls vorübergehend - zu einer gewissen Annäherung gekommen ist.

${ }^{1}$ Vgl. TIPKE (1993) S. 1350-1352 m.w.N. sowie v. HOORN in APTIRC (1984) S. 73. 


\subsubsection{Großbritannien}

\subsubsection{Die Rechtsprechung zur Steuerumgehung}

Eine von Rechtswissenschaftlern entwickelte juristische Methodenlehre, an die sich die Rechtsprechung bindet, gibt es in Großbritannien nicht. Gerichtsurteile beziehen sich fast nie auf steuerrechtliche Literatur, dafür aber in ausgeprägt hohem $\mathrm{Maße}$ auf frühere Entscheidungen. ${ }^{1}$ Die Aussagen früherer Urteile werden nur sehr selten umgestoßen; britische Rechtsprechungsgrundsätze haben deshalb i.d.R. eine äußerst lange Lebensdauer. ${ }^{2}$ Geschriebenes Gesetz wird - gerade im Steuerrecht traditionell streng wortwörtlich ausgelegt (Vorrang der, „literal interpretation rule $)^{3}{ }^{3}$ Dieses Prinzip enger Wortlautauslegung ohne Rücksicht auf den „Geist des Gesetzes" oder auf Gerechtigkeitsüberlegungen wurde bereits im Urteil Partington vs. Attorney-General von 1869 geprägt. $^{4}$

Das Recht der Steuerzahler, ihre Geschäfte nach Belieben steuersparend zu gestalten, solange eine solche Gestaltung nicht ausdrücklich gesetzlich verboten ist, wurde erstmals in der Entscheidung A.-G. vs. Duke of Richmond, Gordon and Lennox (No. 1) von 1908 gerichtlich festgestellt. ${ }^{5}$

Wegweisend für rund 45 Jahre (und noch heute die Rechtsprechung beeinflussend) wurde dann der Fall IRC vs. Duke of Westminster von 1936 mit der berühmt gewordenen Erklärung des Richters Lord TOMLIN: „Every man is entitled if he can to order his affairs so that the tax attaching under the appropiate Acts is less than

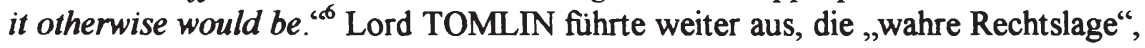
d.h. die rechtliche Einkleidung einer Transaktion, sei relevant fur die steuerliche Beurteilung eines Falles. Diese dürfe nicht zugunsten der wirtschaftlichen Substanz des Rechtsgeschäftes außer acht gelassen werden. ${ }^{7}$ Der Westminster-Fall diente jahrzehntelang als Beleg für die Vorstellung, im englischen Steuerrecht sei allein die rechtliche Form einer Gestaltung von Bedeutung, ihre wirtschaftliche Substanz hingegen völlig irrelevant (,form over substance"). Diese einseitige Interpretation der Westminster-Entscheidung machte den Fall zum Symbol einer steuerzahlerfreundlichen Grundhaltung britischer Gerichte, zur "tax avoidance charter" des britischen Steuerrechts. ${ }^{8}$ Obwohl Lord TOMLIN mit seiner Urteilsbegründung

${ }^{1}$ Vgl. NEVERMANN (1994) S. $37 \mathrm{f}$.

${ }^{2}$ Vgl. ebenda S. 28.

${ }^{3}$ Von dieser Regel wird i.a. nur dann abgewichen, wenn ein doppeldeutiger Wortlaut im Gesetzestext eine Auslegung allein nach dem Wortlaut unmöglich macht oder wenn die wortgetreue Auslegung zu Widersprüchen innerhalb des Gesetzes führen würde. Vgl. JUNKER (1982) S. 68.

${ }^{4}$ Vgl. BOIDMAN (1981) S. 439.

${ }^{5} \mathrm{Vgl}$. JUNKER (1982) S. 45.

${ }^{6} \mathrm{Vgl}$. FISCHER (1995) S. 91.

${ }^{7}$ Vgl. MILLETT (1986) S. 333.

${ }^{8} \mathrm{Vgl}$. NEVERMANN (1994) S. 121, 127. 
wohl lediglich einer freischwebenden wirtschaftlichen Betrachtungsweise eine Absage erteilen wollte und keinesfalls die Substanz eines Rechtsgeschäftes für bedeutungslos erklärt hat, wurde Westminster zur Grundlage einer von praktischen oder wirtschaftlichen Erwägungen vollkommen losgelösten Gesetzesanwendung und damit zu einer wesentlichen Ursache für das - auch im internationalen Vergleich - gewaltige Ausmaß, das die Steuerumgehung dann vor allem in den siebziger Jahren in Großbritannien annahm. ,I feel that the citizens of UK are ... far more inclined to tax avoidance, than most citizens of any country", stellte A. G. DAVIES noch 1983 fest. ${ }^{1}$

Die Rechtsprechung in der Zeit zwischen Westminster (1936) und dem 1981 einsetzenden ,new approach" (s.u.) blieb im Verlauf relativ konstant. Zwar gab es Zeiten stärkerer moralischer Mißbilligung der Steuerumgehung durch die Gerichte (speziell während des Zweiten Weltkrieges), freilich ohne daß dies deren Entscheidungen materiell beeinflußt hätte, ${ }^{2}$ und es gab einerseits Perioden extrem enger Wortlautauslegung, von der selbst bei unsinnigen Ergebnissen nicht abgewichen wurde (speziell in den funfziger Jahren), und andererseits Zeiträume, in denen in vereinzelten Urteilen vorsichtig versucht wurde, den wirtschaftlichen Hintergrund einer Gestaltung bei der Urteilsfindung mit zu berücksichtigen, ohne dabei den Grundsatz vom Vorrang wortwörtlicher Gesetzesauslegung in Frage zu stellen. ${ }^{3}$ Doch insgesamt blieben die in Westminster zum Ausdruck gekommenen bzw. hineininterpretierten Grundprinzipien über viereinhalb Jahrzehnte weitgehend unverändert erhalten. Die Rechtsprechung sah es nicht als ihre Aufgabe an, die Steuerumgehung zu bekämpfen; dies sei allein Sache des Gesetzgebers. ${ }^{4}$

Erst das in den siebziger Jahren massive Auftreten einer regelrechten ,tax avoidance industry", einer Unternehmensbranche, deren Tätigkeit darin bestand, Steuerumgehungsprojekte (,tox avoidance schemes") zu entwickeln und zu vermarkten, führte 1981 zu einem Umdenken der Gerichte (,new approach“). Während sich die Rechtsprechung nach Westminster angewöhnt hatte, bei Gestaltungen, die aus steuerlichen Gründen aus einer Vielzahl von Einzelschritten zusammengesetzt waren, jeden Schritt bei der steuerlichen Sachverhaltswürdigung isoliert zu betrachten, wurde im Fall W. T. Ramsay Ltd. vs. IRC (1981) erstmals einer Gestaltungskette, die ohne jeden wirtschaftlichen Zweck und ohne jede rechtlichen Konsequenzen allein zum Zweck einer Steuerersparnis errichtet worden war, die steuerliche Anerkennung versagt. ${ }^{5}$

${ }^{1} \mathrm{Vgl}$. DAVIES in APTIRC (1984) S. 2 (Abdruck eines 1983 in Singapore gehaltenen Vortrages).

${ }^{2} \mathrm{Vgl}$. JUNKER (1982) S. 49.

${ }^{3}$ Vgl. NEVERMANN (1994) S. 169.

${ }^{4}$ Vgl. ebenda S. 155 f., 178.

${ }^{5} \mathrm{Vgl}$. ebenda S. 63 f., $179 \mathrm{ff}$. 
In den Fällen IRC vs. Burmah Oil Co Ltd. (1982) und Furniss (Inspector of Toxes) vs. Dawson (1984) wurde das Prinzip der Gesamtbetrachtung auch auf Transaktionsketten ausgedehnt, die zwar einen wirtschaftlichen Hintergrund hatten, jedoch Schritte enthielten, die rein steuerlich motiviert und ohne Einfluß auf das wirtschaftliche Endergebnis waren. ${ }^{1}$

Die Entscheidung Craven (Inspector of Taxes) vs. White (1988) stoppte jedoch mit einer 3:2-Mehrheitsentscheidung der urteilenden Richter zugunsten des Steuerpflichtigen die Weiterentwicklung des new approach: Voraussetzung, um in einer Kette von Transaktionen einzelne rechtlich wirksame Teilschritte steuerlich ignorieren zu können, sei, daß diese einzig aus Gründen der Steuerersparnis eingebaut worden seien und daß es sich um eine von vornherein in dieser Form geplante Gestaltung handle, deren Ablauf von Beginn an Schritt für Schritt praktisch feststand. ${ }^{2}$

Zwei jüngere höchstrichterliche Entscheidungen zeigen deutlich den Einfluß, den der new approach auf die derzeitige Rechtsprechung ausübt bzw. nicht ausübt.

Zum einen ist hier die Entscheidung im Fall Moodie vs. IRC (1993) zu nennen, in der von den urteilenden Richtern eine Gestaltung einstimmig verworfen wurde, die praktisch identisch war mit einem tax avoidance scheme, welches 1979 von der gleichen Instanz noch anerkannt worden war. Richter Lord KEITH OF KINKEL, der an beiden Entscheidungen beteiligt war, rechtfertigte seinen Gesinnungswandel damit, daß der Fiskus im Fall Moodie diejenigen Argumente vorlegte, die bereits 1981 in Ramsay erfolgreich waren, während dem Gericht 1979 keine entsprechende Argumentation präsentiert worden war. ${ }^{3}$

Bei der anderen Entscheidung handelt es sich um den Fall Fitzwilliam vs. IRC (1993), in dem mit einer 4:1-Mehrheitsentscheidung eine füfstufige Kettenschenkung steuerlich anerkannt wurde. Die Richter räumten zwar ein, daß es sich bei den Stufen 2 bis 5 der Transaktionskette um eine von vornherein in ihrem genauen Ablauf Schritt für Schritt vorausgeplante Gestaltung handle, doch treffe dies fur die erste Stufe der Kettenschenkung nicht zu. Da diese Stufe für den Gesamtablauf entscheidend gewesen sei, dürfe - wie im Fall Craven (1988) - nicht von einer preordained single composite transaction gesprochen werden. ${ }^{4} \mathrm{Da}$ die Schritte 2 und 4 der Gestaltungskette einzig der Steuerminderung gedient hatten, ${ }^{5}$ reichte nach mehrheitlicher Auffassung der Richter nicht aus, um die von der Steuerpflichtigen erschlichenen Steuerbefreiungen zu verweigern, da beide Schritte vorüber-

${ }^{1}$ Vgl. ebenda S. 187-201.

${ }^{2} \mathrm{Vgl}$. ebenda S. 204 und 208 sowie POPKIN (1991) S. 299.

${ }^{3}$ Vgl. Moodie vs. IRC [1993] 2 All ER S. 49 [51] $\hat{=}$ WLR v. 26.2.93 S. 266 [269].

${ }^{4}$ so die Auffassung von Lord BROWNE-WILKINSON; vgl. Fitzwilliam vs. IRC [1993] 3 All ER S. 184 [220 f.].

${ }^{5}$ Aus diesem Grund seien sie steuerlich zu ignorieren, so die Forderung von Lord TEMPLEMAN in seinem Minderheitsvotum; vgl. ebenda S. 213. 
gehende reale Konsequenzen aufgewiesen hätten. ${ }^{1}$ Damit sei der vorliegende Fall anders gelagert als Ramsay (1981), Burmah Oil (1982), Dawson (1984) und Moodie (1993), ${ }^{2}$ das durch Dawson ausgeweitete Ramsay principle sei hier nicht anwendbar. ${ }^{3}$ Der Einwand, Gerechtigkeitserwägungen und die Einbeziehung der Intentionen des Gesetzgebers müßten ebenfalls bei der Urteilsfindung berücksichtigt werden, ${ }^{4}$ fand bei der Mehrheit der Richter keine Zustimmung.

Die Entscheidung Moodie (1993) hat gezeigt, daß die Steuerpflichtigen nunmehr etwas raffinierter vorgehen müssen, als es vor Ramsay der Fall gewesen war; extrem „plumpe“ Steuerumgehungsversuche, wie sie in den Fällen Ramsay und Moodie vorlagen, werden heute nicht mehr anerkannt. Auf der anderen Seite hat Fitzwilliam (1993) deutlich gemacht, wie der new approach relativ einfach ausgehebelt und die Anerkennung selbst rein steuerlich motivierter Zwischenschritte in einer Gestaltung erreicht werden kann.

Zusammenfassend läßt sich sagen, daß der new approach durch die in Ramsay, Burmah und Dawson aufgestellten Grundsätze die tax avoidance industry zwar in erhebliche Schwierigkeiten gebracht, durch die Entscheidung Craven jedoch bereits wieder die Basis für ihr Wiedererstarken gelegt hat: Durch das Aufstellen von Kriterien, welche festlegen, wann einer Gestaltung die steuerliche Anerkennung versagt werden kann, wird den Steuerpflichtigen deutlich gemacht, wie sie vorzugehen haben, um ein Scheitern ihrer Steuerumgehungsprojekte zu vermeiden. ${ }^{5}$

Zumindest vorübergehend hat sich die traditionelle britische Auffassung wieder durchgesetzt, die besagt, daß die Bekämpfung der Steuerumgehung in erster Linie Aufgabe des Gesetzgebers sei. ${ }^{6}$ Teleologische Auslegung sowie die Einbeziehung von Gerechtigkeitsüberlegungen scheinen nach wie vor nicht mehrheitsfähig zu sein; die literal interpretation rule ist immer noch dominierendes Auslegungsprinzip.

\subsubsection{Die Gesetzgebung gegen die Steuerumgehung}

Die erste gezielt gegen die Steuerumgehung gerichtete Gesetzgebung enthielt der Finance Act $1922 .^{7}$ Die Finance Acts der dreißiger Jahre dehnten die antiavoidance legislation anhand einer Fülle weiterer Einzelvorschriften erheblich aus. ${ }^{8}$

\footnotetext{
${ }^{1}$ Vgl. ebenda S. 186 (Lord BROWNE-WILKINSON).

${ }^{2}$ Vgl. ders., ebenda S. 193-195.

${ }^{3}$ Vgl. ebenda S. 199 (Lord KEITH OF KINKEL).

${ }^{4} \mathrm{Vgl}$. ebenda S. 219 f. (Lord TEMPLEMAN).

${ }^{5}$ Vgl. NEVERMANN (1994) S. 329.

${ }^{6} \mathrm{Vgl}$. ebenda S. 216.

${ }^{7} \mathrm{Vgl}$. JUNKER (1982) S. $30 \mathrm{f}$.

${ }^{8}$ Vgl. NEVERMANN (1994) S. 56.
} 
Seit 1941 hat der Gesetzgeber bisweilen allgemeiner formulierten und damit breiter wirkenden Anti-Umgehungs-Bestimmungen (,shotgun approach") den Vorzug vor Vorschriften gegeben, die nur ein ganz bestimmtes, exakt beschriebenes tax avoidance scheme erfassen (,sniper approach" $\left.{ }^{\prime}\right){ }^{1}$ Die Diskussion shotgun approach versus sniper approach hält bis heute an. Während generalklauselartige Formulierungen eine noch stärkere Verkomplizierung und Ausweitung der Steuergesetze verhindern sollen und in gewissen Grenzen auch bislang noch nicht praktizierten Steuerumgehungsaktivitäten vorbeugen können, wird der Vorteil von ganz eng auf eine bestimmte Aktivität ausgerichteten Spezialklauseln in der erhöhten Rechtssicherheit gesehen. ${ }^{2}$ Traditionell herrscht in Großbritannien der regelmäßige Erlaß spezieller Anti-Umgehungs-Bestimmungen nach dem sniper approach vor; der in der Literatur z.T. als rechtsstaatlich bedenklich ${ }^{3}$ bezeichnete shotgun approach kommt in einzelnen Steuergesetzen gelegentlich zum Einsatz, während die immer wieder diskutierte Einführung einer allgemeinen, fur das gesamte Steuerrecht geltenden Generalklausel gegen die Steuerumgehung bislang stets verworfen wurde. Mehr noch als in dem shotgun approach wird in einer allgemeinen Generalklausel eine Verletzung der Rechtsklarheit und Rechtssicherheit und damit ein Verstoß gegen das Rechtsstaatsprinzip gesehen. Ferner würde eine Generalklausel der Bürokratie und den Gerichten erlauben, das geschriebene Gesetz eigenmächtig zu ergänzen, und damit auch gegen das Prinzip der Gewaltenteilung verstoßen. ${ }^{4}$ Auch wenn solche Auffassungen keineswegs unumstritten sind, so haben sie doch den Gesetzgeber bis jetzt erfolgreich von der Einführung einer dem deutschen $§ 42 \mathrm{AO}$ vergleichbaren Bestimmung abgehalten.

Das nach kontinentaleuropäischer Rechtsauffassung rechtsstaatlich weitaus bedenklichere Mittel rückwirkender Gesetzgebung gegen die Steuerumgehung ist hingegen in Großbritannien mehrfach zur Anwendung gekommen. Ein Beispiel ist der gegen sog. commodity future schemes gerichtete $\S 31$ Finance Act 1978, der rückwirkend zum 6.4.1976 in Kraft trat; erste Vorschriften dieser Art enthielt bereits der Finance Act 1936. Das Recht des britischen Gesetzgebers, rückwirkend belastende steuerliche Regelungen zu erlassen, ergibt sich aus der herrschenden Auffassung von der Souveränität des Parlaments bzgl. der Gesetzgebung und wurde in der Entscheidung James vs. IRC (1977) gerichtlich bestätigt. ${ }^{5}$ Dennoch ist diese gegen die Steuerumgehung gerichtete Waffe auch in Großbritannien nicht unumstritten. Auf der einen Seite wird darauf hingewiesen, daß aufgrund des Feh-

${ }^{1}$ Vgl. JUNKER (1982) S. $31 \mathrm{f}$.

${ }^{2} \mathrm{Vgl}$. ebenda S. $36 \mathrm{f}$.

${ }^{3}$ Diese Auffassung findet sich z.B. bei SHENFIELD (1968) S. 30.

${ }^{4} \mathrm{Vgl}$. HOUGHTON in IEA (1979) S. 89 [93]; HOUGHTON in IEA (1979) S. 99 [102]; MASTERS (1994) S. $672 \mathrm{f}$. Keine wirtschaftlichen oder selbst Gerechtigkeitsüberlegungen „could possibly justify removing one of the foundations of our liberty" (Lord HOUGHTON).

${ }^{5} \mathrm{Vgl}$. JUNKER (1982) S. $38 \mathrm{f}$. 
lens einer Generalklausel und in Anbetracht der hohen, durch die Steuerumgehung verursachten jährlichen Steuerausfalle das Instrument der Rückwirkung unbedingt benötigt werde, ${ }^{1}$ auf der anderen Seite werden vielfach moralische Bedenken dagegen vorgebracht, daß etwas nachträglich für steuerpflichtig erklärt wird, was zum Zeitpunkt des Geschehens steuerfrei war. ${ }^{2}$ Aus diesem Grund hält die herrschende Auffassung in Literatur und Politik die Rückwirkung nur unter ganz besonderen Umständen, bei extremem Handlungsbedarf, für angebracht. ${ }^{3}$ Um der Forderung nach Rechtssicherheit besser gerecht zu werden, ist es üblich geworden, rückwirkende Vorschriften nur nach vorhergehender ministerieller Warnung zu erlassen und ihren Geltungszeitraum nicht über den Zeitpunkt der Warnung hinaus zu erstrecken. ${ }^{4}$

\subsubsection{USA}

Anders als in Großbritannien sieht in den USA die Rechtsprechung die Bekämpfung der Steuerumgehung nicht nur als Aufgabe des Gesetzgebers, sondern auch als eigenen Auftrag an. Aus diesem Grund existiert in den Vereinigten Staaten keine derart umfangreiche Ansammlung von Anti-Umgehungsvorschriften wie in der britischen Steuergesetzgebung, auch wenn mittlerweile einige Bestimmungen in das US-amerikanische Steuergesetz aufgenommen worden sind, die dazu dienen, bestimmten Steuerumgehungstechniken $\mathrm{zu}$ begegnen. ${ }^{5}$ Im wesentlichen wird die Steuerumgehung nicht im Wege der Gesetzgebung, sondern im Rahmen der Gesetzesanwendung bekämpft.

Dabei ist zu berücksichtigen, daß eine herrschende geschlossene Methodenlehre in den USA ebensowenig existiert wie in Großbritannien; ${ }^{6}$ entsprechend gibt es keine genaue Grenzziehung zwischen Auslegung und Analogie. Die Rechtsprechung in den USA wird auch eher von übergeordneten Prinzipien als von speziellen Regeln beherrscht; ${ }^{7}$ praktische Erwägungen haben Vorrang gegenüber der strikten Ein-

\footnotetext{
${ }^{1} \mathrm{Vgl}$. CHRISTOPHER in IEA (1979) S. 87.

${ }^{2} \mathrm{Vgl}$. MYDDELTON in IEA (1979) S. 44.

${ }^{3}$ Vgl. JUNKER (1982) S. 40.

${ }^{4}$ Kritisch über den Wert einer solchen Selbstbeschränkung der Politik für die Rechtssicherheit äußern sich u.a. SHENFIELD (1968) S. 32 f. und MYDDELTON in IEA (1979) S. 45: Absichtserklärungen von Ministern seien unverbindlich, könnten im Parlament scheitern und seien auch meist zu unpräzise formuliert, als daß die Steuerpflichtigen sicher sein könnten, welche Handlungen im einzelnen unter das rückwirkende Gesetz fallen würden. Würden die Steuerpflichtigen derartige Ministerankündigungen ignorieren, liefen sie Gefahr, später rückwirkend belastet zu werden; andernfalls gäbe es jedoch keinen Schadenersatz, falls die Ankündigung nicht umgesetzt werde.

${ }^{5} \mathrm{Vgl}$. BOIDMAN (1981) S. 445.

${ }^{6} \mathrm{Vgl}$. WALZ (1982) S. 1.

${ }^{7}$ Vgl. POPKIN (1991) S. 286.
} 
haltung juristischer Prinzipien, wenn diese zu unsinnigen, ungerechten oder aus anderen Gründen bedenklichen Ergebnissen führt. Es kann deshalb nicht verwundern, daß die amerikanischen Gerichte der britischen Praxis streng wortwörtlicher Auslegung nicht gefolgt sind: Wenige Monate vor der britischen Entscheidung IRC vs. Duke of Westminster (1935) wurde in den USA der vergleichbare und ebenfalls wegweisende Fall Gregory vs. Helvering (1935) höchstrichterlich entschieden. Zwar räumten auch hier die Gerichte ausdrücklich den Steuerpflichtigen das Recht ein, ihre Geschäfte steuerminimierend zu gestalten (,Any one may so arrange his affairs that his taxes shall be as low as possible" (Circuit Court of Appeals 1934)), doch bedeute der Grundsatz, daß das Motiv der Steuerersparnis legitim sei, nicht, daß der Zweck einer Vorschrift bei ihrer Auslegung außer Betracht gelassen werden dürfe (Supreme Court 1935). ${ }^{1}$ Eine solche den Gesetzeszweck berücksichtigende (teleologische) Auslegung muß dabei keineswegs am möglichen Wortsinn einer Vorschrift enden: Schon im besagten Fall Gregory vs. Helvering wurde (nach deutscher Terminologie) eine teleologische Reduktion der relevanten Befreiungsvorschrift vorgenommen; ${ }^{2}$ viele weitere gerichtliche Entscheidungen nach 1935 zeigen, daß auch belastende Analogieschlüsse im amerikanischen Steuerrecht durchaus möglich sind und praktiziert werden. ${ }^{3}$ Ausgehend von der Gregory-Entscheidung, haben die US-Gerichte dabei eine Reihe bis heute angewendeter Prinzipien zur Bekämpfung der Steuerumgehung entwickelt: Im wesentlichen sind dies der business purpose test, die step transaction doctrine und die substance over form doctrine. ${ }^{4}$

Der business purpose test besteht in der Prüfung, ob mit einem Rechtsgeschäft irgendein wirtschaftlicher Zweck verfolgt wird oder ob es ausschließlich der Steuerminderung dient. Gestaltungen ohne reale ökonomische Wirkung, die nichts weiter bezwecken, als Steuern zu sparen, werden von amerikanischen Gerichten aufgrund ihres fehlenden business purpose steuerlich ignoriert. ${ }^{5}$

Neben Gestaltungen, denen keinerlei eigenständige ökonomische Bedeutung zukommt, gibt es aber auch solche, die zwar einem wirtschaftlichen Zweck dienen, aber einzelne Schritte enthalten, die ausschließlich aus steuerlichen Gründen eingefügt wurden. Nach der step transaction doctrine kann ein Gericht derartigen Schritten (steps) die steuerliche Anerkennung versagen. ${ }^{6}$

${ }^{1}$ Vgl. NEVERMANN (1994) S. 130-132. Die Pflicht der Gerichte, bei der Gesetzesanwendung den Gesetzeszweck mit zu berücksichtigen, hat in den Vereinigten Staaten sogar Verfassungsrang; vgl. POPKN (1991) S. 285.

${ }^{2}$ Vgl. NEVERMANN (1994) S. 131.

${ }^{3} \mathrm{Vgl}$. WALZ (1982) S. 7 und 9.

${ }^{4}$ Vgl. MASTERS (1994) S. 647.

${ }^{5}$ Vgl. MILLETT (1986) S. $331 \mathrm{f}$.

${ }^{6}$ Vgl. BOIDMAN (1981) S. 446. 
Die US-amerikanische Rechtsprechungspraxis ist nicht ohne Einfluß auf die britische Rechtsprechung geblieben: Nach amerikanischer Terminologie gesprochen, ließe sich sagen, daß Ramsay (1981) und Moodie (1993) am fehlenden business purpose gescheitert sind, während in den Fällen Burmah Oil (1982) und Dawson (1984) die Gerichte die step transaction doctrine anwandten. Daß der ,new approach" in seiner langfristigen Wirkung dennoch hinter den amerikanischen Methoden zurückbleibt, liegt neben der sehr viel engeren Auslegungspraxis britischer Gerichte auch daran, daß die substance over form doctrine der USA von der britischen Rechtsprechung nie übernommen worden ist.

Das Prinzip substance over form bedeutet, daß bei stark ,gekünstelt“ (artificial) erscheinenden Rechtsgeschäften die Gerichte sich vorbehalten, statt der gewählten rechtlichen Einkleidung den tatsächlichen wirtschaftlichen Gehalt der Besteuerung zugrunde zu legen. ${ }^{1}$ Auch wenn das früher in Großbritannien vorherrschende entgegengesetzte Prinzip form over substance durch den new approach an Bedeutung verloren hat, zeigen die Fälle Craven (1988) und Fitzwilliam (1993), daß die britische Rechtsprechung von einem Vorrang der wirtschaftichen Substanz einer Gestaltung vor ihrer äußeren Form immer noch weit entfernt ist.

Es kann demnach nicht verwundern, daß die Steuerumgehung in den USA nie einen solchen Umfang erlangt hat wie in Großbritannien. Die intensive Anwendung der Doktrinen vom business purpose, von den step transactions und der substance over form legen i.V.m. einer weiten, nicht auf den möglichen Wortsinn begrenzten Auslegung steuerrechtlicher Vorschriften den Schluß nahe, daß in den Vereinigten Staaten auf eine dem deutschen $\S 42 \mathrm{AO}$ vergleichbare Generalklausel ohne weiteres verzichtet werden kann.

\subsubsection{Zwischenergebnis}

Nach aktuellem Stand von Recht und Rechtswissenschaft ist in Deutschland eine Generalklausel gegen die Steuerumgehung unentbehrlich, da eine über den möglichen Wortsinn einer steuerlichen Norm hinausgehende Auslegung nicht zulässig ist (auch nicht im Rahmen einer „wirtschaftlichen Betrachtungsweise") und nach geltendem Verfassungsrecht die Bekämpfung des Rechtsmißbrauchs durch analoge Rechtsanwendung bzw. teleologische Reduktion ebenso wenig statthaft ist wie der Erlaß rückwirkend belastender Rechtsnormen durch die Legislative.

Dieses Ergebnis ist jedoch nicht ohne weiteres auf andere Staaten übertragbar.

So herrscht in den USA ein weitaus geringerer Formalismus in der Rechtsanwendung als in Deutschland. Steuerrechtliche Bestimmungen pflegen ggf. sehr weit ausgelegt zu werden, wobei dabei keineswegs am möglichen Wortsinn der Vor-

${ }^{1}$ Vgl. ebenda S. 445. 
schrift haltgemacht wird. Daher kann auch eine weitreichende Anwendung der Regel ,substance over form" zur Bekämpfung der Steuerumgehung Anwendung finden; ebenso ist es den Gerichten nicht verwehrt, Gestaltungen, die keinen anderen Zweck als eine Steuerersparnis erkennen lassen, die steuerliche Anerkennung zu versagen (business purpose test), ohne daß es hierfür einer ausdrücklichen gesetzlichen Grundlage bedürfte.

Demgegenüber gilt in Großbritannien traditionell eher der Grundsatz ,form over substance “; die vorherrschende streng wörtliche Auslegung steuerlicher Rechtsnormen erleichtert potentiellen Steuerumgehern ihre Steuerminimierungsstrategie. Dafür wird allerdings das Fehlen einer Generalklausel durch die dem Gesetzgeber eingeräumte Möglichkeit, Gesetzeslücken rückwirkend zu schließen und damit ihren Mißbrauch zu verhindern, teilweise kompensiert.

Insofern erscheint sowohl in den USA als auch in Großbritannien eine Generalklausel verzichtbar; soweit der Steuerumgehung überhaupt mit den traditionellen Methoden der Rechtswissenschaft begegnet werden kann, sind die dort zulässigen Mittel ausreichend, eine dem deutschen $\S 42$ AO vergleichbare Vorschrift mithin entbehrlich. Inwieweit die u.a. in Deutschland gegebene Unzulässigkeit der britischen und US-amerikanischen Methoden durch die Existenz einer Generalklausel aufgewogen werden kann, soll im folgenden eingehend untersucht werden.

\subsection{Die Generalklausel gegen die Steuerumgehung in Deutschland: § 42 AO}

In welchem Umfang eine Generalklausel Steuerumgehungen wirksam verhindern kann, hängt $a b$ von den enthaltenen Tatbestandsmerkmalen, von der Intensität ihrer Anwendung durch die Finanzbehörden und der diesbezüglichen Haltung der zuständigen Gerichte sowie von den aus einer Anwendung der Klausel resultierenden Rechtsfolgen. Diese die Effektivität der allgemeinen Umgehungsvorschrift bestimmenden Faktoren müssen weder im Zeitablauf konstant bleiben, noch sind sie international identisch.

Um die grundsätzliche Wirksamkeit von Generalklauseln nicht zu einseitig und verallgemeinernd an der aktuell in Deutschland gegebenen Situation festzumachen, sollen einer ausführlichen Analyse der derzeitigen Ausgestaltung und Anwendung des $\S 42 \mathrm{AO}$ seine Entstehungsgeschichte und die mit seinen Vorgängervorschriften gesammelten historischen Erfahrungen vorangestellt und im Anschluß an diesen Abschnitt die französische Generalklausel vergleichend untersucht werden. Damit soll es ermöglicht werden, am Ende von Kapitel 4 neben einer zusammenfassenden kritischen Würdigung der deutschen Generalklausel auch allgemeingültige Aussagen zu derartigen Vorschriften machen zu können. 


\subsubsection{Zur Geschichte der Generalklausel}

Aufgrund der praktischen Unmöglichkeit, Steuerumgehungen durch Spezialklauseln zu verhindern, hat der Gesetzgeber der RAO 1919 mit dem $\S 5$ erstmals eine Generalklausel gegen die Steuerumgehung in die Steuergesetzgebung aufgenommen. Hinzu kam, daß sich die Auffassung des Verfassers der Reichsabgabenordnung, ENNO BECKER, das Umgehungsproblem sei ein Problem der Gesetzesauslegung und der Sachverhaltsbeurteilung in wirtschaftlicher Betrachtungsweise, nicht durchsetzen konnte. Die Generalklausel wurde für unentbehrlich angesehen, um zu verhindern, daß Handlungen, die nach dem Zweck des Gesetzes besteuert werden sollten, durch mißbräuchliche Rechtsgestaltungen (bei gleichem wirtschaftlichen Erfolg) auf Kosten der Allgemeinheit steuerfrei blieben. $^{1}$

\section{$\S 5$ Abs. 1 RAO 1919 hatte folgenden Wortlaut:}

„Durch Mißbrauch von Formen und Gestaltungsmöglichkeiten des bürgerlichen Rechts kann die Steuerpflicht nicht umgangen oder gemindert werden."

Um eine zu weite Auslegung des Tatbestandes der Generalklausel zu Lasten der Steuerpflichtigen zu verhindern, sah sich der Gesetzgeber genötigt, in Absatz 2 die Voraussetzungen eines Mißbrauchs durch Aufzählung dreier erschöpfender Tatbestandsmerkmale zu konkretisieren:

„Ein Mißbrauch im Sinne des Abs. 1 liegt vor

1. in Fällen, wo das Gesetz wirtschaftliche Vorgänge, Tatsachen und Verhältnisse in der ihnen entsprechenden rechtlichen Gestaltung einer Steuer unterwirft, zur Umgehung der Steuer ihnen nicht entsprechende, ungewöhnliche Rechtsformen gewählt oder Rechtsgeschäfte vorgenommen werden, und

2. nach Lage der Verhältnisse und nach der Art, wie verfahren wird oder verfahren werden soll, wirtschaftlich für die Beteiligten im wesentlichen derselbe Erfolg erzielt wird, der erzielt wäre, wenn eine den wirtschaftlichen Vorgängen, Tatsachen und Verhältnissen entsprechende rechtliche Gestaltung gewählt wäre, und ferner

3. etwaige Rechtsnachteile, die der gewählte Weg mit sich bringt, tatsächlich keine oder nur geringe Bedeutung haben."

Absatz 3 bestimmte schließlich die Rechtsfolgen der Steuerumgehung:

„Liegt ein Mißbrauch vor, so sind die getroffenen Maßnahmen für die Besteuerung ohne Bedeutung. Die Steuern sind so zu erheben, wie sie bei einer den wirtschaftlichen Vorgängen, Tatsachen und Verhältnissen angemessenen Gestaltung zu erheben wăren. Steuern, die auf

${ }^{1}$ Vgl. Begr. zum Entwurf einer RAO, Nationalversammlung 1919, Drucks. Nr. 759, 94; zitiert bei: FISCHER in HHSp (1996) Rz. 2. 
Grund der für unwirksam zu erachtenden Maßnahmen etwa entrichtet sind, werden auf Antrag erstattet, wenn die Entscheidung, die diese Maßnahmen als unwirksam behandelt, rechtskräftig geworden ist.“

§ 5 RAO 1919 hat zum ersten Mal im April 1921 Eingang in die Rechtsprechung des Reichsfinanzhofes gefunden. ${ }^{1}$ Dennoch blieb die praktische Bedeutung der Vorschrift gering. Dies hatte insbesondere in den Umschreibungsversuchen für den Begriff ,Rechtsmißbrauch" in $§ 5$ Abs. 2 RAO 1919 seine Ursache: Es brauchte nur eines der dort aufgezählten Merkmale vermieden zu werden, um die Anwendbarkeit der Mißbrauchsvorschrift auszuschließen. Die Generalklausel gegen die Steuerumgehung war damit ihrerseits relativ leicht zu umgehen. ${ }^{2}$ Trotzdem wurde bei der Reform der Reichsabgabenordnung 1931 der § 5 RAO 1919 ohne Veränderung als $\S 10$ RAO 1931 übernommen.

Erst mit dem Steueranpassungsgesetz von 1934 hat der Gesetzgeber auf die mangelnde Wirksamkeit der Umgehungsnorm reagiert. Zwar stimmte $\S 6$ Abs. 1 StAnpG wortwörtlich mit $\S 10$ Abs. 1 RAO 1934 überein; jedoch wurde Absatz 2 des $§ 10$ RAO 1931 ersatzlos gestrichen. Damit sollte verhindert werden, daß die wegen ihrer bis dahin zu stark einengenden Tatbestandsmerkmale selten anwendbare Generalklausel vollkommen bedeutungslos würde, zumal die Rechtsprechung mehr und mehr dazu neigte, Steuerumgehungen mit Hilfe einer auf $§ 9$ RAO 1931 gestützten „freischwebenden" wirtschaftlichen Betrachtungsweise entgegenzutreten. $^{3}$

$\S 6$ StAnpG lautete wie folgt:

„(1) Durch Mißbrauch von Formen und Gestaltungsmöglichkeiten des bürgerlichen Rechts kann die Steuerpflicht nicht umgangen oder gemindert werden.

(2) Liegt ein Mißbrauch vor, so sind die Steuern so zu erheben, wie sie bei einer den wirtschaftlichen Vorgängen, Tatsachen und Verhältnissen angemessenen rechtlichen Gestaltung zu erheben wären.

(3) Steuern, die aufgrund der für unwirksam zu erachtenden Maßnahmen etwa entrichtet worden sind, werden auf den Betrag, der nach Absatz 2 zu entrichten ist, auf andere Rückstände des Steuerpflichtigen angerechnet und, soweit eine solche Anrechnung nicht möglich ist, erstattet. Nach Ablauf des Jahres, das auf die endgültige Feststellung der Unwirksamkeit folgt, kann der Steuerpflichtige die Anrechnung oder Erstattung nicht mehr verlangen.

(4) Werden einem Steuerpflichtigen von einer mit ihm zusammen veranlagten Person in oder nach dem Veranlagungszeitraum, für den noch Steuerrückstände bestehen, unentgeltlich

\footnotetext{
${ }^{1}$ Vgl. RFH-Urteil vom 26.4.1921 II A 412/20 RFHE 5, 247 [250 ff.].

${ }^{2}$ Vgl. RIEDEL (1968) S. 75.

${ }^{3}$ Vgl. Begründung zum Steueranpassungsgesetz, RStBl. 1934 II, S. 1398 [1401 f.]; RIEDEL (1968) S. 76.
} 
Vermögensgegenstände zugewendet, so kann der Empfänger über den sich nach $\S 7$ Abs. 3 Sazz 4 ergebenden Steuerbetrag hinaus bis zur Höhe des gemeinen Werts dieser Zuwendung für die Steuerschuld in Anspruch genommen werden."

Ein grundsätzlicher Bruch mit der früheren Rechtsprechung war mit § 6 StAnpG nicht vorgesehen; der Anwendungsbereich der Mißbrauchsvorschrift sollte lediglich erweitert werden. ${ }^{1}$

Trotz der erhofften verbesserten Wirksamkeit der Generalklausel wurde auf die Kodifizierung der wirtschaftlichen Betrachtungsweise nicht verzichtet; vielmehr stellte der den $\S 9$ RAO 1931 ersetzende $\S 1$ StAnpG sogar eine Erweiterung der Anwendungsmöglichkeiten für eine (über eine reine Auslegungsmethode hinausgehende) wirtschaftliche Betrachtungsweise dar.

Tatsächlich ist auch der $\S 6$ StAnpG von den Gerichten nur relativ selten bemüht worden; durchaus im Sinne eines Teils der Literatur hat sich die Rechtsprechung im allgemeinen gescheut, Steuerumgehungsfälle mit dem „schweren Geschütz des $\S 6$ StAnpG“ zu lösen. ${ }^{2}$ Weniger die mit Inkraftreten der Abgabenordnung 1977 erfolgte Neufassung der Umgehungsnorm, sondern eher ein verändertes Methodenbewußtsein der Gerichte (Verständnis der wirtschaftlichen Betrachtungsweise nur noch als Auslegungsregel, nicht mehr als Methode zur Bekämpfung von Steuerumgehungen) sowie eine Zunahme betriebswirtschaftlicher Steuerminimierungsplanung und (z.T. mißbräuchlicher) Steuersparmodelle haben dazu geführt, daß die Generalklausel mittlerweile erheblich häufiger Gegenstand der Rechtsprechung in Steuersachen geworden ist. ${ }^{3}$

$\S 42$ AO hat die Absätze 1 und 2 des $\S 6$ StAnpG im wesentlichen übernommen. Er lautet in der noch heute gültigen Fassung von 1977:

„Durch Mißbrauch von Gestaltungsmöglichkeiten des Rechts kann das Steuergesetz nicht umgangen werden. Liegt ein Mißbrauch vor, so entsteht der Steueranspruch so, wie er bei einer den wirtschaftlichen Vorgängen angemessenen rechtlichen Gestaltung entsteht."

Fälle, die dem $\S 6$ Abs. 3 StAnpG unterlagen, sind nunmehr nach $\S 174$ Abs. 1 AO zu erledigen; $\S 6$ Abs. 4 StAnpG ist in $\S 278$ Abs. 2 AO aufgegangen.

Außer einer Aufhebung der Beschränkung des Anwendungsbereiches der Umgehungsnorm lediglich auf Gestaltungsmöglichkeiten des bürgerlichen Rechts sollte ihre Neufassung keine wesentliche Änderung gegenüber dem bis dahin geltenden

${ }^{1} \mathrm{Vgl}$. THOMA (1950) S. 60.

${ }^{2} \mathrm{Vgl}$. KRUSE (78/79) S. $445 \mathrm{f}$.

${ }^{3}$ In dem Jahrzehnt von 1986-1995 hat die Anzahl derjenigen (in den EFG veröffentlichten) Urteile, in denen die Finanzgerichte die Generalklausel des $\S 6$ StAnpG bzw. § 42 AO angewendet haben, um genau $60 \%$ gegenüber den vorangegangenen zehn Jahren (1976-1985) zugenommen (von 85 auf 136 Fälle). Vgl. ferner TIPKE/KRUSE (1996) Tz. 1 sowie KRUSE (78/79) S. 460. 
Recht herbeiführen. Weitere inhaltliche Veränderungen gegenüber $\S 6$ Abs. 1 und 2 StAnpG hat der Gesetzgeber der AO 1977 bewußt unterlassen, so daß die bestehende Rechtsprechung zur Mißbrauchsvorschrift uneingeschränkt gültig blieb. Ebenfalls verzichtet wurde aufgrund der Erfahrungen mit § 5 Abs. 2 RAO 1919 / $\S 10$ Abs. 2 RAO 1931 auf eine gesetzliche Konkretisierung des Mißbrauchstatbestandes. Diese Konkretisierung sollte der Rechtsprechung überlassen werden. ${ }^{1}$

Inwieweit die Generalklausel in ihrer heutigen Fassung i.V.m. der dazu ergangenen Rechtsprechung als Instrument zur Bekämpfung der Steuerumgehung geeignet ist, soll im folgenden anhand ihrer Tatbestandsmerkmale, ihren Rechtsfolgen und den Rechtsprechungsgrundsätzen geprüft werden.

\subsubsection{Der Anwendungsbereich der Generalklausel: Abgrenzung der Steuerumgehung (§ 42 AO) vom Scheingeschäft ( 411 AO)}

$\S 42 \mathrm{AO}$ ist lediglich dann auf eine Rechtsgestaltung anwendbar, wenn diese nicht als Scheingeschäft im Sinne von $\S 41 \mathrm{AO}$ anzusehen ist. ${ }^{2}$

Von einem Scheingeschäft wird dann gesprochen, wenn die einem Rechtsgeschäft zugrunde liegenden Willenserklärungen nur zum Schein abgegeben wurden. ${ }^{3}$ Scheingeschäfte sind steuerlich unerheblich. Dient ein Scheingeschäft dem Zweck, ein anderes Rechtsgeschäft zu verdecken, so ist für die Besteuerung das verdeckte Rechtsgeschäft maßgeblich ( $\$ 41$ Abs. 2 AO).

Im Unterschied zur Umgehungshandlung ist das Scheingeschäft von den Beteiligten nicht ernstlich gewollt; es besteht nicht die Absicht, es tatsächlich durchzuführen. ${ }^{4}$ Diese theoretisch klare Abgrenzung des Umgehungsgeschäftes vom Scheingeschäft ist in der Praxis allerdings oftmals problematisch, da der Rechtsanwender den einem Rechtsgeschäft zugehörigen Fakten nicht immer eindeutig entnehmen kann, ob das Geschäft tatsächlich gewollt ist oder nicht. Anders als bei der Steuerumgehung liegt jedoch einem zwecks Steuerersparnis abgeschlossenen Scheingeschäft die Absicht zugrunde, die zuständige Finanzbehörde bzgl. des wahren Sachverhalts zu täuschen, während ihr bei einer reinen Steuerumgehung alle relevanten Sachverhaltsmerkmale offenbart werden. Hieraus resultieren auch die unterschiedlichen Rechtsfolgen beider hier betrachteten Steuerminderungsversuche: Zwar wird in beiden Fällen nicht der äußerliche Sachverhalt, sondern der tatsächliche wirtschaftliche Gehalt des betreffenden Rechtsgeschäfts der Besteuerung zugrunde gelegt, jedoch ist ein Scheingeschäft regelmäßig Teil

\footnotetext{
${ }^{1}$ Vgl. Begr. RegE $\S 45(\hat{=} \S 42 \mathrm{AO})$ in MTTTELSTEINER/SCHAUMBURG (1977) S. 80.

${ }^{2} \mathrm{Vgl}$. SCHWARZ (1996) Anm. 4.

${ }^{3}$ Vgl. BOPP (1958) S. 133.

${ }^{4} \mathrm{Vgl}$. AX/GROSSE/CÄMMERER (1995) S. 117.
} 
einer Steuerhinterziehung, während eine Steuerumgehung lediglich dann den Tatbestand einer Steuerhinterziehung erfüllt, wenn der Ausnahmefall vorliegt, daß der Steuerpflichtige das Vorliegen einer Steuerumgehung durch Abgabe falscher oder unvollständiger Angaben zu verschleiern versucht hat. ${ }^{1}$

\subsubsection{Die Tatbestandsmerkmale des $§ 42 \mathrm{AO}$ im einzelnen}

\subsubsection{Umgehung des Gesetzes}

Die in $\S 42$ Satz 1 AO enthaltene Formulierung ,... kann das Steuergesetz nicht umgangen werden" wird von FISCHER als zentrale Aussage der Vorschrift angesehen: $\S 42$ hat zum Ziel, die Steuerumgehung zu bekämpfen. ${ }^{2}$ Das Wort "Steuergesetz" bezeichnet dabei nicht nur das Gesetz als Ganzes, sondern insbesondere auch die einzelne gesetzliche Vorschrift. ${ }^{3}$

Da eine Umgehung nur dann vorliegen kann, wenn der Zweck des Gesetzes durch seinen Wortlaut nicht voll zum Ausdruck kommt, ist zunächst zu prüfen, ob nach dem Gesetzeszweck eine steuerliche Belastung tatsächlich eintreten soll. ${ }^{4}$ Voraussetzung der Anwendung der Umgehungsvorschrift ist also, daß ansonsten der Steuerpflichtige einen steuerlichen Erfolg erzielen würde, der - im Hinblick auf Zweck und Ziel der steuerlichen Rechtsordnung - vom Gesetz mißbilligt wird. ${ }^{5}$

Dabei ist es unerheblich, ob der steuerliche Erfolg durch Tatbestandsumgehung oder durch Tatbestandserschleichung herbeizuführen versucht wurde. ${ }^{6}$

${ }^{1}$ Vgl. KOTTKE (1994) S. 287 sowie unten Kap. 4.3.6.

${ }^{2} \mathrm{Vgl}$. FISCHER in HHSp (1996) Rz. 86.

${ }^{3}$ Vgl. $\$ 4$ AO: „Gesetz ist jede Rechtsnorm.“

${ }^{4}$ Vgl. TIPKE (1993) S. 1342.

5 Vgl. BFH-Urteil vom 8.1.1958 I 131/57 U BStBl. 1958 III S. 97 [99]; BFH-Urteil vom 25.10.1979 VIII R 46/76 BStB1. 1980 II S. 247 [248] m.w.N.;

die von KOTTKE (1983) S. 1148 f. und TIPKE (1993) S. 1340 an dieser Formulierung geübte Kritik, es ginge hier nicht um den Zweck der Rechtsordnung, sondern lediglich der umgangenen Norm, übersieht, daß sich der Zweck einer Norm i.d.R nicht aus ihrer isolierten Betrachtung ergibt, sondern erst unter Berücksichtigung des Bedeutungszusammenhanges, „welcher alle Rechtsinstitute und Rechtsregeln zu einer großen Einheit verknüpft" (so bereits SAVIGNY (1840) S. 214, vgl. auch ders., a.a.O., S. 10, sowie LARENZ (1991) S. 324 ff.).

${ }^{6} \mathrm{Vgl}$. BFH-Urteil vom 31.7.1984 IX R 3/79 BStBl. 1985 II S. 33 [35] unter Berufung auf KRUSE (78/79) S. 454; BFH-Urteil vom 13.8.1985 VII R 172/83 BStBl. 1985 II S. 636 [641]; BFHUrteil vom 28.4.1987 IX R 7/83 BStBl. 1987 II S. 814 [815];

a.A.: BFH-Urteil vom 10.2.1988 II R 145/85 BStBl. 1988 II S. 547 [548 f.], ohne Begründung. 


\subsubsection{Gestaltungsmöglichkeiten des Rechts}

Während § 6 StAnpG nur Gestaltungsmöglichkeiten des bürgerlichen Rechts erfaßte, trägt $\S 42 \mathrm{AO}$ der Tatsache Rechnung, daß (in selteneren Fällen ${ }^{1}$ ) auch Gestaltungsmöglichkeiten des öffentlichen Rechts steuerlich mißbraucht werden können. ${ }^{2} \mathrm{Da}$ auch das Steuerrecht zum öffentlichen Recht gehört, kann somit im Einzelfall sogar die Ausübung steuerlicher Wahlrechte einen Mißbrauch nach $\S$ 42 darstellen. ${ }^{3}$

Voraussetzung für die Anwendung des Mißbrauchsparagraphen ist in jedem Fall, daß die Rechtsordnung dem Steuerpflichtigen mehrere Gestaltungsmöglichkeiten eröffnet und dieser sich dabei einer Gestaltung bedient, die eigentlich für andere Zwecke vorgesehen ist. ${ }^{4}$ Erfaßt werden dabei nur solche Gestaltungen, die einer vom Zivilrecht abweichenden steuerrechtlichen Beurteilung zugänglich sind, nicht jedoch solche, wo das Steuerrecht unmittelbar an das Zivilrecht anknüpft, wie es z.B. bzgl. der Körperschaftsteuersubjektfähigkeit (vgl. § 1 Abs. $1 \mathrm{KStG}$ ), aber auch bei einer Eheschließung oder Adoption der Fall ist. ${ }^{5} \S 42$ kann also nur dort eingreifen, wo steuergesetzliche Bestimmungen nicht die angegebenen Rechtsgestaltungen als solche meinen, sondern vielmehr die mit ihnen verbundenen wirtschaftlichen Vorgänge oder Zustände erfassen wollen. ${ }^{6}$

\subsubsection{Mißbrauch}

4.3.3.3.1 Die von der Rechtsprechung entwickelten Merkmale eines Mißbrauchs

Das Kriterium des „Mißbrauchs“ fand bereits in § 5 RAO 1919 Verwendung. Wenn FISCHER diese Tatbestandsvoraussetzung des $\S 42$ AO für „sachlich mißglückt“" hält und den Begriff, „Nichtgebrauch“" an seine Stelle setzt, ${ }^{7}$ so übersieht er, daß sich der Rechtsanwender zunächst am Gesetzeswortlaut zu orientieren hat und

${ }^{1}$ Vgl. BFH-Urteil vom 12.8.1986 VII R 169/83 BStBl. 1986 II S. 821: In dieser Entscheidung ging es um die Kraftfahrzeugsteuerfreiheit von Mietanhängern mit „Berlin-Zulassung“.

2 Vgl. Begr. RegE $\S 45$ in MTTELSTEINER/SCHAUMBURG (1977) S. 80; vgl. auch BFHBescheid vom 10.9.1959 (Urteil vom 22.1.1960) V 52/56 S BStB1. 1960 III S. 111 [112].

${ }^{3}$ Vgl. KRUSE (1991) S. 146; FG Baden-Württemberg Urt. v. 11.3.1987 VII-K 396/84 EFG 1987 S. 429; FG Baden-Württemberg Urt. vom 13.4.1989 II K 55/87 EFG 1989 S. 540 [541]; FG Rheinland-Pfalz Urt. vom 14.3.1989 2 K 316/88 EFG 1989 S. 598; BFH v. 7.4.1987 IX R 41/86 BFH/NV 1987 S. 714; a.A.: FISCHER in HHSp (1996) Rz. 98; TIPKE/KRUSE (1996) Tz. 13.

${ }^{4}$ Vgl. GUNTHER (1987) S. 198.

${ }^{5}$ Vgl. BFH-Urteil vom 29.10.1986 I R 202/82 BStBl. 1987 II S. 308 [310]; DANZER (1981) S. 39.

${ }^{6}$ Vgl. TIPKE/LANG (1994) S. 147.

${ }^{7}$ Vgl. FISCHER in HHSp (1996) Rz. 91, 93. 
diesen keinesfalls nach Belieben durch eine für sinnvoller erachtete Formulierung ersetzen kann. Auch die Auslegung des $\S 42$ und der in ihm enthaltenen Rechtsbegriffe endet an der Grenze ihres möglichen Wortsinns; die Ersetzung von „Mißbrauch" durch „Nichtgebrauch" würde zweifellos diese Grenze überschreiten.

Zur Klärung der Frage, wann im Einzelfall vom Vorliegen eines Mißbrauchs auszugehen sei, hat die Rechtsprechung folgenden Leitsatz entwickelt:

„Ein Rechtsmißbrauch [...] liegt dann vor, wenn eine Gestaltung gewählt wird, die gemessen an dem erstrebten Ziel unangemessen ist, der Steuerminderung dienen soll und durch wirtschaftliche oder sonst beachtliche Gründe nicht zu rechtfertigen ist."

Demnach gehören drei Merkmale zum Mißbrauchsbegriff, die gemeinsam erfüllt sein müssen, damit $\S 42$ greifen kann:

die Unangemessenheit der Rechtsgestaltung, die Steuerminderungsabsicht sowie das Fehlen beachtlicher nichtsteuerlicher Gründe für die gewählte Gestaltung. ${ }^{2}$

\subsection{Unangemessenheit}

Der Begriff der Unangemessenheit ergibt sich im Umkehrschluß aus $§ 42$ Satz 2 $\mathrm{AO}^{3}$

Als unangemessen anzusehen ist laut Bundesfinanzhof eine Gestaltung, „die vernünftige Beteiligte bei Würdigung aller Umstände des Falles, insbesondere des mit der Regelung erstrebten wirtschaftlichen Zieles, nicht wählen würden ${ }^{c 4}$, sofern der Gesichtspunkt der Steuerersparnis unberücksichtigt bliebe. Als unangemessen und somit steuerlich unbeachtlich sind auch Gestaltungen anzusehen, die „den tatsächlichen wirtschaftlichen Gegebenheiten nicht gerecht" werden (z.B. der Abschluß zweier sich gegenseitig aufhebender Verträge). ${ }^{5}$

Darüber hinaus fehlt es in der Literatur nicht an Versuchen, den unbestimmten Rechtsbegriff „unangemessen“ durch eine möglichst große Anzahl z.T. untereinan-

${ }^{1}$ BFH-Urteil vom 19.6.1985 I R 115/82 BStBl. 1985 II S. 680 [681]; vgl. auch BFH-Urteil vom 1.2.1989 I R 2/85 BStB1. 1989 II S. 473 [474] m.w.N.

${ }^{2}$ Eine andere Auffassung vertreten TIPKE/LANG (1994) S. 148: Mißbrauch sei identisch mit Unangemessenheit, weiterer Voraussetzungen für den Tatbestand des Mißbrauchs bedürfe es nicht. Diese These stellt jedoch lediglich eine Privatmeinung der Autoren dar; eine Grundlage in der Rechtsprechung und damit praktische Relevanz für Steuerpflichtige und Finanzbehörden besitzt sie indes nicht.

${ }^{3}$ Vgl. KRUSE (1991) S. 146.

${ }^{4}$ BFH-Urteil vom 11.2.1972 III R 5/70 BStBl. 1972 II S. 480 [482]; vgl. auch BFH-Urteil vom 3.2.1987 IX R 85/85 BStBl. 1987 II S. 492 [493 f.]; kritisch FISCHER in HHSp (1996) Rz. 40 sowie PAULICK (1977) S. 159.

${ }^{5}$ Vgl. BFH-Urteil vom 16.3.1988 X R 27/86 BStBl. 1988 II S. 629 [631]. 
der austauschbarer, nicht weniger unbestimmter Begriffe zu umschreiben. ${ }^{1}$ Danach pflegten angemessene Rechtsgestaltungen das Ziel auf einem mehr oder weniger geraden Weg zu verfolgen, einfach, zweckmäßig und übersichtlich zu sein, während unangemessene Rechtsgestaltungen nicht selten Umwege benutzten und oft umständlich, kompliziert, schwerfällig, unökonomisch, gekünstelt, unnatürlich, undurchsichtig, widersinnig, wenig effektiv oder gar überflüssig seien. ${ }^{2}$ Argumente dafür, daß derartige Umschreibungen mehr Klarheit bzgl. der Begriffe „angemessen" und „unangemessen" herbeifuhren könnten, dürften sich jedoch schwer finden lassen. Die fehlende Justitiabilität einer solchen Ansammlung von Synonymen hat dazu gefuhrt, daß sie kaum Eingang in die Rechtsprechung gefunden haben. Lediglich der Begriff, ,gekünstelt" läßt sich in einigen wenigen BFHEntscheidungen wiederfinden. ${ }^{3}$

Laut BFH kann eine Rechtsgestaltung nur dann als unangemessen verworfen werden, wenn „sie entweder im wirtschaftlichen Ergebnis auf das gleiche hinausläuft wie der unmittelbar der Besteuerung unterworfene Sachverhalt oder sich zumindest in der allgemeinen Umgebung des Komplexes bewegt, auf den sich die Besteuerung bezieht. ${ }^{\text {(4 }}$ Die Beteiligten müssen also einen wirtschaftichen Effekt herbeigeführt haben, der bei der vom Gesetzgeber dafür vorausgesetzten rechtlichen Einkleidung steuerpflichtig wäre, aber durch eine abweichende Rechtsgestaltung - bei in etwa identischem wirtschaftlichen Ergebnis - vom Gesetz nicht mehr erfaßt wird. ${ }^{5}$

In vielen BFH-Entscheidungen findet sich ferner die Formulierung ,unangemessen, also ungewöhnlich“. 6 Diese zugegebenermaßen wenig glückliche Formulierung wird in der Literatur meist dahingehend fehlinterpretiert, daß unterstellt wird, der BFH setze die Wörter „unangemessen“ und „ungewöhnlich“ gleich, jede unübliche Gestaltung sei unangemessen, jede gebräuchliche Gestaltung automatisch angemessen. ${ }^{7}$

Das Kriterium der Ungewöhnlichkeit stammt aus $§ 5$ Abs. 2 Nr. 1 RAO 1919, nach dem ein Gestaltungsmißbrauch allenfalls dann vorliegen konnte, wenn den wirtschaftlichen Vorgängen nicht entsprechende, ungewöhnliche Rechtsgeschäfte

${ }^{1}$ Vgl. BÖHMER (1958) S. 98; in der neueren Literatur vor allem TIPKE/KRUSE (1996) Tz. 15 sowie TIPKE/LANG (1994) S. 147.

2 so TIPKE/LANG (1994) S. 147

${ }^{3}$ Vgl. z.B. BFH-Urteil vom 18.1.1972 VIII R 125/69 BStBl. 1972 II S. 344 [345].

${ }^{4}$ BFH-Urteil vom 27.1.1977 IV R 46/76 BStBI. 1977 II S. 754 [756]; vgl. auch BFH-Urteil vom 5.5.1970 II R 98/69 BStBl. 1970 II S. 757 [758].

${ }^{5} \mathrm{Vgl}$. TIPKE/KRUSE (1996) Tz. 10; vgl. auch § 5 Abs. 2 Nr. 1 bis 3 RAO 1919.

${ }^{6} \mathrm{Vgl}$. z.B. BFH-Urteil vom 16.3.1988 X R 27/86 BStBl. 1988 II S. 629 [631]; BFH-Urteil vom 11.8.1987 IX R 163/83 BStBl. 1989 II S. 702 [705]; BFH-Urteil vom 20.11.1980 IV R 81/77 BStBl. 1981 II S. 223 [225] m.w.N.

${ }^{7}$ Vgl. z.B. KOTTKE (1983) S. 1148; FISCHER in HHSp (1996) Rz. 33 f. 
vorgenommen wurden. Jedoch hat bereits 1922 der Reichsfinanzhof die Feststellung getroffen, daß der Tatbestand der Ungewöhnlichkeit keinesfalls dadurch ausgeschlossen werden könne, daß eine bestimmte Rechtskonstruktion nicht vereinzelt geblieben sei. Ungewöhnlichkeit sei vielmehr „nur vom Standpunkt der natürlichen Befriedigung des wirtschaftlichen Bedürfnisses aus zu beurteilen“, was den Schluß nahelegt, daß ungewöhnlich eher im Sinne von „unnatürlich“" verstanden werden müsse. ${ }^{1}$ Auch der Bundesfinanzhof hat in seiner Rechtsprechung zu $\S 42 \mathrm{AO}$ deutlich werden lassen, daß eine Rechtsgestaltung auch dann unangemessen sein könne, wenn sie „weitgehend geübt" sei. ${ }^{2}$ Umgekehrt sei eine noch nicht allgemein übliche Gestaltung nicht zwangsläufig als ungewöhnlich (im Sinne von unangemessen) zu bewerten. ${ }^{3}$ Die Rechtsprechung setzt also die Unüblichkeit einer Gestaltung keineswegs gleich mit ihrer Unangemessenheit. Allerdings müsse in Zweifelsfällen für vom Normalbild abweichende Rechtsgestaltungen dargelegt werden, daß ihnen „vernünftige Erwägungen“ zugrunde lägen. ${ }^{4}$ Insofern kann die Unüblichkeit einer Gestaltung durchaus ein Indiz für ihre Unangemessenheit sein, aber eben auch nicht mehr. ${ }^{5}$

Die Kritik vieler Autoren an der in diversen BFH-Entscheidungen enthaltenen Formulierung „unangemessen, also ungewöhnlich“ ist somit nur berechtigt, was die Wortwahl betriff; bzgl. der steuerlichen Konsequenzen unüblicher Gestaltungen besteht zwischen Rechtsprechung und Literatur jedoch Einigkeit dahingehend, daß § 42 AO keinesfalls der Benutzung neuartiger rechtlicher Wege entgegensteht (jede Innovation ist zunächst ungewöhnlich), genau wie andererseits ein unangemessener Weg nicht dadurch angemessen wird, daß er immer wieder praktiziert wird.

\subsection{Steuerminderungsabsicht}

Ein Mißbrauch kann nur dann vorliegen, wenn der Steuerpflichtige mit der von ihm gewählten Gestaltung eine Steuerminderung gegenüber der „angemessenen“ Gestaltung anstrebt. ${ }^{6}$ Ohne die Absicht der Steuerersparnis als Leitmotiv kann demnach der Tatbestand des $\S 42 \mathrm{AO}$ nicht erfüllt sein.

Andererseits ist grundsätzlich jedermann befugt, seine Rechtsverhältnisse so zu gestalten, daß die Steuerlast möglichst gering gehalten wird. ${ }^{7}$ Das Ziel der Steuer-

${ }^{1}$ Vgl. RFH-Urteil vom 30.6.1922 II A 132/22 RFHE 10, 65 [67].

${ }^{2}$ Vgl. BFH-Urteil vom 12.8.1986, a.a.O., S. 823.

${ }^{3}$ Vgl. BFH-Urteil vom 16.3.1988, a.a.O., S. 631.

${ }^{4}$ Vgl. BFH-Urteil vom 29.10.1985 IX R 107/82 BStB1. 1986 II S. 217 [220]; BFH-Urteil vom 29.11.1984 V R 38/78 BStBl. 1985 II S. 269 [270].

${ }^{5} \mathrm{Vgl}$. FISCHER in HHSp (1996) Rz. 34.

${ }^{6} \mathrm{Vgl}$. BFH-Urteil vom 1.12.1982 I R 43/79 BStBl. 1985 II S. 2 [3].

${ }^{7} \mathrm{Vgl}$. Begr. RegE $\S 45$ in MTTTELSTEINER/SCHAUMBURG (1977) S. 80. 
minimierung allein begründet folglich noch keinen Mißbrauch. ${ }^{1}$ Das gilt selbst dann, wenn die betreffende Rechtsgestaltung entscheidend aus Gründen der Steuerersparnis gewählt wurde. ${ }^{2}$ Erst wenn die Milderung der steuerlichen Belastung das einzig beachtliche Motiv darstellt (s.u.) und der gewählte Weg unangemessen im Sinne obiger Ausfuihrungen ist, liegt der Tatbestand eines Rechtsmißbrauchs nach $\S 42$ vor.

\subsection{Nichtexistenz beachtlicher außersteuerlicher Gründe}

Nach ständiger höchstrichterlicher Rechtsprechung scheidet ein Rechtsmißbrauch aus, wenn sich für die gewählte Gestaltung ein einleuchtendes wirtschaftliches Motiv - außer der Absicht, Steuern zu sparen - anführen läßt. ${ }^{3}$ Sofern sich für eine Gestaltung jedoch überhaupt keine wirtschaftlichen Argumente finden lassen, sie sich möglicherweise ohne die mit ihr verbundene Steuerersparnis sogar wirtschaftlich negativ auswirken würde, liegt der Verdacht eines Rechtsmißbrauchs nahe. ${ }^{4}$ Es sind allerdings nicht allein wirtschaftliche Gründe, die dem Mißbrauchstatbestand entgegenstehen: Wenn berechtigte außersteuerliche Interessen, gleich welcher Art, für die gewählte Gestaltung mit ausschlaggebend waren, so scheidet die Anwendung des $\S 42$ auf jeden Fall aus. ${ }^{5}$ Dabei ist es unerheblich, ob neben den außersteuerlichen Gründen auch die angestrebte Steuerersparnis die Wahl der Rechtsgestaltung beeinflußt hat. ${ }^{6}$

${ }^{1}$ Vgl. BFH-Beschluß vom 29.11.1982 GrS 1/81 BStBl. 1983 II S. 272 [277].

2 Vgl. BFH-Urteil vom 14.10.1964 II 175/61 U BStBl. 1964 III S. 667 [669]; vgl. auch KUHN/ KUTTER/HOFMANN (1990) S. 121.

${ }^{3}$ Vgl. bereits RFH-Urteil vom 30.6.1922, a.a.O., S. 67; vgl. auch BFH-Urteil vom 13.12.1983 VIII R 173/83 BStBl. 1984 II S. 428 [431];

a.A. TIPKE/LANG (1994) S. 148. Die dort zu findende Behauptung, das wirtschaftliche oder sonstige Motiv für die Wahl der Rechtsgestaltung sei unerheblich, es komme allein auf ihre Unangemessenheit an, hat keine Grundlage in der BFH-Rechtsprechung. Im übrigen sind die Umschreibungsversuche der Autoren für den Begriff der Unangemessenheit (s.o. S. 78 f.) viel zu unkonkret, als daß sie - bei Beachtung des Postulats der Rechtssicherheit - alleinige Grundlage für eine dem Rechtsstaatsprinzip genügende Anwendung des $\S 42$ sein könnten.

${ }^{4} \mathrm{Vgl}$. HOFFMANN in KOCH/SCHOLTZ (1993) Rz. 6.

Die Ähnlichkeit dieses Kriteriums mit der vom BFH zur Kennzeichnung der Unangemessenheit oftmals verwendeten Formulierung: „Gestaltung, die vernünftige Beteiligte [...] nicht wählen würden“ (s.o. S. 78) ist nicht zu übersehen; insofern gehen die beiden Merkmale „Unangemessenheit" und „fehlende beachtliche nichtsteuerliche Gründe" ineinander über. Dennoch pflegen sie vom BFH nebeneinander genannt zu werden (s.o. Kap. 4.3.3.3.1).

5 Vgl. BFH-Urteil vom 30.11.1960 II 154/59 U BStBl. 1961 III S. 21 [22]; BFH-Urteil vom 14.3.1962 II 218/59 U BStBl. 1962 III S. 206 [207]; vgl. auch BFH-Urteil vom 16.3.1988, a.a.O., S. 631 sowie BFH-Urteil vom 13.7.1989 V R 8/86 BStBl. 1990 II S. 100 [101].

${ }^{6} \mathrm{Vgl}$. BFH-Urteil vom 29.11.1966 I 216/64 BStBl. 1967 III S. 392 [395]; BFH-Urteil vom 15.11.1967 IV R 139/67 BStB1. 1968 II S. 152 [155]. 
Wenn die zuständige Finanzbehörde bzw. die Gerichtsbarkeit bei der Sachverhaltsermittlung keine Anhaltspunkte dafür finden kann, daß wirtschaftliche oder sonst beachtliche nichtsteuerliche Gründe mit zu der gewählten Gestaltung geführt haben, so hat der Steuerpflichtige die Möglichkeit, solche Motive vorzubringen und zu erläutern. Sofern die vorgebrachten Gründe nicht als unbeachtlich angesehen werden, scheidet ein Rechtsmißbrauch i.S. von $\S 42 \mathrm{AO}$ aus. ${ }^{1}$

Diese Rechtsprechungspraxis nimmt dem $\S 42$ viel von seiner Wirksamkeit und wird aus diesem Grunde erheblich kritisiert. ${ }^{2}$ Sie hat zu der Empfehlung an die Steuerpflichtigen geführt, ursprünglich rein aus Steuersparmotiven gewählte Sachverhaltsgestaltungen derart umzufunktionieren, daß nichtsteuerliche Gründe in den Vordergrund treten. ${ }^{3}$ Den Beweis zu führen, daß diese Gründe in Wahrheit nur vorgeschoben sind und somit fur die Wahl der Rechtsgestaltung unbeachtlich waren, dürfte den Finanzbehörden im allgemeinen äußerst schwer fallen.

Prominentes Beispiel hierfür sind die vor allem vor der Körperschaftsteuerreform von 1977 meist aufgrund rein steuerlicher Gesichtspunkte durchgeführten zahlreichen Umwandlungen von Gesellschaften mit beschränkter Haftung in die Rechtsform der $\mathrm{GmbH} \& \mathrm{Co}$. KG: Wurde dieser Rechtsform ursprünglich noch häufig die steuerliche Anerkennung versagt, ${ }^{4}$ so gelang es später den Steuerpflichtigen fast immer, durch Vorbringen angeblicher nichtsteuerlicher Gründe den alleinigen Zweck der Steuerersparnis in den Hintergrund zu drängen und die Anerkennung zu erwirken. ${ }^{5}$ Ähnlich verhält es sich mit Betriebsaufspaltungen, die meist zwecks Ersparnis von Gewerbesteuer und Vermögensteuer errichtet werden, für die sich aber i.d.R. ohne weiteres organisatorische Gründe anführen lassen, so daß die Betriebsaufspaltung heutzutage von den Finanzbehörden genauso wenig hinterfragt wird wie die $\mathrm{GmbH} \& \mathrm{Co} . \mathrm{KG}^{6}$

\subsubsection{Steuerumgehungsabsicht}

$\mathrm{Zu}$ dem Tatbestandsmerkmal der Steuerminderungsabsicht (s.o. Kap. 4.3.3.3.3) muß die Absicht der Steuerumgehung hinzukommen. ${ }^{7} \S 42$ ist demnach nicht an-

${ }^{1} \mathrm{Vgl}$. TIPKE/KRUSE (1996) Tz. 21.

${ }^{2}$ Vgl. FISCHER in HHSp (1996) Rz. 40.

${ }^{3}$ Siehe KOTTKE (1994) S. 251.

${ }^{4}$ Vgl. RFH-Urteil vom 30.6.1922, a.a.O., S. 65 ff.; RFH-Urteil vom 15.7.1925 I A 18/25 RFHE 17,91 [93 f.].

5 Vgl. BFH-Urteil vom 16.9.1958 I 351/56 U BStBl. 1958 III S. 462 [463]; BFH-Urteil vom 15.11.1967 IV R 139/67 BStBl. 1968 II S. 152 [155].

${ }^{6} \mathrm{Vgl}$. BFH-Beschluß vom 8.11.1971 GrS 2/71 BStBl. 1972 II S. 63 [65].

7 Vgl. BFH-Urteil vom 5.2.1992 I R 127/90 BStBl. 1992 II S. 532 [536]; BFH-Urteil vom 6.3.1990 II R 88/87 BStBI. 1990 II S. 446 [447]; BFH-Urteil vom 23.2.1988 IX R 157/84 BStB1. 1988 II S. 604 [606] m.w.N.; BFH-Urteil vom 22.1.1960, a.a.O., S. 112 m.w.N.; 
wendbar, wenn seine übrigen Tatbestandsvoraussetzungen lediglich aus Ungeschicklichkeit oder Unerfahrenheit, nicht jedoch aus der Absicht eines Rechtsmißbrauchs heraus erfullt worden sind. Die Konsequenz, daß damit zwei ansonsten identische Fälle u.U. steuerlich unterschiedlich behandelt werden, wenn in einem Fall die Umgehung unbeabsichtigt war, in dem anderen jedoch Umgehungsabsicht vorlag, mag zwar im Hinblick auf die gebotene Gleichmäßigkeit der Besteuerung unbefriedigend erscheinen. ${ }^{1}$ Das Erfordernis der Steuerumgehungsabsicht ergibt sich jedoch eindeutig aus dem in $\S 42$ enthaltenen Begriff "Mißbrauch", der eine zweckgerichtete (finale) Handlung beinhaltet, ${ }^{2}$ ein "unbeabsichtigter Mißbrauch“ erscheint nicht vorstellbar, wäre ein Widerspruch in sich. Man mag (wie DANZER) den $\S 42$ für terminologisch mißglückt halten; ${ }^{3}$ der Rechtsanwender ist dennoch nicht befugt, den in $\S 42$ nun einmal enthaltenen subjektiven Mißbrauchsbegriff gedanklich durch den objektiven Begriff des Fehlgebrauchs nach eigenem Ermessen zu ersetzen. ${ }^{4}$

Urteile von BAG und BGH, die besagen, daß für das Vorliegen einer Gesetzesumgehung keine Umgehungsabsicht erforderlich sei, sind nicht, wie von FISCHER ${ }^{5}$ irrtümlich angenommen, auf die Steuerumgehung nach $\S 42$ übertragbar. FISCHERs Ansicht beruht auf seiner Vorstellung, jede Umgehung eines Steuergesetzes werde durch $\S 42$ erfaßt, die in der Vorschrift enthaltene Formulierung ,Mißbrauch von Gestaltungsmöglichkeiten des Rechts" sei irrelevant. Doch selbst, wenn man - entgegen den in Abschnitt 2 dieser Arbeit zugrunde gelegten Definitionen - das Mißbrauchsmerkmal nicht als notwendigen Bestandteil jeder Umgehungshandlung ansähe und von der mißbräuchlichen Steuerumgehung eine nicht mißbräuchliche Steuerumgehung unterschiede, wäre diese Auffassung nicht haltbar. $\mathrm{Da}$ in diesem Fall $\S 42$ seinem in dieser Hinsicht eindeutigen Wortlaut nach lediglich einem Sonderfall der Steuerumgehung entgegenträte, nämlich dem des Mißbrauchs rechtlicher Gestaltungsmöglichkeiten ${ }^{6}$, also nur der mißbräuchlichen Steuerumgehung, ist eine Übertragung von Gerichtsurteilen zur allgemeinen Gesetzesumgehung auf den Tatbestand des $\S 42$ keinesfalls gerechtfertigt.

a.A.: BFH-Beschluß vom 23.2.1989 V B 60/88 BStBl. 1989 II S. 396 [399]; die hier erfolgte Stellungnahme des BFH ist allerdings insofern wenig eindeutig, als zwar zunächst die Voraussetzung einer Umgehungsabsicht ausdrücklich verneint wird, jedoch bereits im folgenden Satz festgestellt wird, es könne offenbleiben, ob $\S 42$ eine Umgehungsabsicht voraussetzt.

${ }^{1}$ Entsprechende Bedenken finden sich bei PAULICK (1977) S. 160 sowie bei WACKERNAGEL (1949) S. 52.

${ }^{2}$ Vgl. TIPKE/KRUSE (1996) Tz. 18; gl.A. mittlerweile auch KRUSE (1991) S. 146.

${ }^{3}$ Vgl. DANZER (1981) S. 102.

${ }^{4}$ Vgl. oben Kap. 4.3.3.3.1.

${ }^{5} \mathrm{Vgl}$. FISCHER in HHSp (1996) Rz. 107.

${ }^{6} \mathrm{Vgl}$. auch TIPKE/KRUSE (1996) Tz. 9. 
Auch FISCHERs Hinweis auf $\S 38 \mathrm{AO}$, wonach der Steueranspruch unabhängig davon entstehe, ob der Steuerpflichtige die Absicht hatte, den Steuertatbestand zu erfüllen, ${ }^{1}$ kann hier nicht überzeugen: Ohne das Vorliegen einer Steuerumgehungsabsicht ist der in $\S 42$ formulierte Tatbestand eben nicht erfullt, weder absichtlich noch unabsichtlich.

Erst recht muß die These verwundern, weder der Gesetzeswortlaut ${ }^{2}$ noch die Entstehungsgeschichte des $\S 42$ stützten die Erfordernis einer Mißbrauchsabsicht, ${ }^{3}$ heißt es doch in demselben Kommentar, der Gesetzgeber der RAO 1919 sei davon ausgegangen, daß für die Umgehung des Steuergesetzes eine Mißbrauchsabsicht erforderlich sei. ${ }^{4}$ Auch ist bei den Beratungen zu $§ 42$ der AO 1977 vom Bundesrat eine objektive Fassung der Generalklausel gefordert und diese Forderung explizit damit begründet worden, daß der subjektive Mißbrauchsbegriff nach ständiger Rechtsprechung die Erfordernis für den Nachweis einer Steuerumgehungsabsicht mit sich bringt. Die Bundesregierung hat jedoch ausdrücklich auf dem Tatbestandsmerkmal des Mißbrauchs bestanden und den Vorschlag des Bundesrates verworfen. ${ }^{5}$

Indes ist das Tatbestandsmerkmal der Steuerumgehungsabsicht von relativ geringer praktischer Bedeutung:

Als subjektives Tatbestandsmerkmal ist die Umgehungsabsicht nicht unmittelbar feststellbar; es muß vielmehr aus objektiv feststellbaren Fakten auf sie zurückgeschlossen werden können. Dabei ist jedoch dieses Merkmal keineswegs mit höheren Nachweisanforderungen zu konfrontieren, als es für die übrigen Tatbestandsmerkmale des $\S 42$ der Fall ist. ${ }^{6}$ Wenn der Tatbestand des $\S 42$ im übrigen erfullt ist, sich insbesondere keine wirtschaftlichen oder sonstigen außersteuerlichen Gründe für die gewählte Gestaltung anführen lassen, dann sprechen die für die Beweisfuihrung relevanten Indizien regelmäßig für das Vorliegen einer Umgehungsabsicht. ${ }^{7}$ Insofern erlangt die Steuerumgehungsabsicht erst dann als eigenes Tatbestandsmerkmal Bedeutung, wenn es dem Steuerpflichtigen gelingt, seinerseits

${ }^{1} \mathrm{Vgl}$. FISCHER in HHSp (1996) Rz. 107.

${ }^{2}$ FISCHERs Auffassung zur fehlenden Notwendigkeit einer Mißbrauchsabsicht beruht ja gerade auf einem Hinwegsetzen über den Gesetzeswortlaut, indem der für „sachlich mißglückt“ erachtete Begriff „Mißbrauch“ gedanklich durch das Wort „Nichtgebrauch“ ersetzt wird; vgl. FISCHER in HHSp (1996) Rz. 91, 93; vgl. auch oben S. 77 f.

${ }^{3} \mathrm{Vgl}$. FISCHER in HHSp (1996) Rz. 107.

${ }^{4} \mathrm{Vgl}$. FISCHER in HHSp (1996) Rz. 103.

${ }^{5}$ Vgl. Stellungnahme des Bundesrates zu § 45 RegE sowie Gegenăußerung der Bundesregierung in MITTELSTEINER/SCHAUMBURG (1977) S. $80 \mathrm{f}$; vgl. in diesem Zusammenhang auch den Alternativvorschlag TIPKEs zum Regierungsentwurf (TIPKE (1971) S. 101).

${ }^{6} \mathrm{Vgl}$. BFH-Urteil vom 5.3.1986 I R 201/82 BStBl. 1986 II S. 496 [497].

${ }^{7}$ Vgl. neben BFH-Unteil vom 5.3.1986 a.a.O. S. 497 auch TIPKE/KRUSE (1996) Tz. 18 sowie KOTTKE (1994) S. 231. 
Indizien dafür aufzuzeigen, daß die gewählte unangemessene Rechtsgestaltung auf Gutgläubigkeit, Rechtsunkenntnis, Unerfahrenheit oder Ungeschicklichkeit zurückzufuhren ist. ${ }^{1}$

Es läßt sich also festhalten, daß zwar sowohl nach üblicher BFH-Rechtsprechung als auch nach der in der Literatur herrschenden Auffassung der Tatbestand des $\S 42$ ohne den Nachweis einer Steuerumgehungsabsicht nicht erfullt ist; da jedoch dieser Nachweis in aller Regel ohne Schwierigkeiten aus dem Vorliegen der anderen Tatbestandsmerkmale erbracht werden kann, nimmt die Erfordernis einer Umgehungsabsicht der Generalklausel nur wenig von ihrer Wirkung.

\subsubsection{Minderung der Steuer}

$\S 42$ ist nur dann anwendbar, wenn die gewählte unangemessene Gestaltung zu einem steuerlichen Vorteil gegenüber dem angemessenen Weg führen würde. ${ }^{2}$

Der steuerliche Vorteil besteht im allgemeinen in einer Minderung der Steuerpflicht; er kann aber auch in einer zeitlichen Verzögerung der Steuerzahlung liegen. Da $\S 42$ AO anders als $\S 6$ StAnpG nicht mehr von Umgehung der Steuerpflicht, sondern des Steuergesetzes spricht, greift er auch dann, wenn der aus dem Rechtsmißbrauch resultierende steuerliche Vorteil in einem höheren oder früheren Erstattungs- oder Vergütungsanspruch besteht. ${ }^{3}$

Falls die mißbräuchliche Gestaltung eine gleiche oder höhere steuerliche Belastung herbeifürt, greift $\S 42$ hingegen nicht ein. Das ergibt sich aus dem Sinn der Vorschrift, die dazu dient, vom Gesetzgeber mißbilligte steuerliche Erfolge zu verhindern. ${ }^{4}$ Würde der Zweck des $\S 42$ (entgegen seinem Wortlaut und seiner Entstehungsgeschichte) darin liegen, generell die Besteuerung nach dem gesetzge-

${ }^{1} \mathrm{Da}$ der Steuerpflichtige hierbei wohl selten Erfolg haben wird (man denke an die oftmals in starkem Ausmaß gekünstelten, vielfach äußerst raffinierten rechtlichen Konstruktionen der Steuerumgeher, welche kaum auf Rechtsunkenntnis oder Ungeschicklichkeit beruhen können), ist die schon bei BOHMER (1958) S. 106 f. zu findende Kritik nicht ganz unberechtigt, daß dann, wenn auf die Umgehungsabsicht ohnehin aus dem Vorliegen der übrigen Tatbestandsmerkmale geschlossen werden könne, ihr ,die dem Tatbestandsmerkmal eigene, unterscheidende Kraft" fehle.

${ }^{2}$ Vgl. BFH-Urteil vom 3.3.1988 V R 183/83 BStBl. 1989 II S. 205 [206 f.]; BFH-Urteil vom 1.12.1982, a.a.O., S. 3.

${ }^{3}$ Vgl. SCHWARZ (1996) Anm. 11; TIPKE/KRUSE (1996) Tz. 19.

${ }^{4}$ Vgl. Begr. RegE $\S 45$ (MTTTELSTEINER/SCHAUMBURG (1977) S. 80), wonach die Vorschrift „der Verhinderung der Steuerumgehung, der mißbräuchlichen Steuervermeidung“ dienen soll. Steuervermeidung liegt aber nur dann vor, wenn tatsächlich Steuer vermieden, und nicht, wenn zu viel Steuer gezahlt wird; vgl. auch BFH-Urteil vom 12.7.1989 I R 46/85 BStBl. 1990 II S. 113 [115]. 
berischen Plan sicherzustellen, wie von DANZER ${ }^{1}$ und FISCHER ${ }^{2}$ unzutreffenderweise angenommen (vgl. voriger Abschnitt), müßte die Generalklausel allerdings auch dann anwendbar sein, wenn aus der unangemessenen Rechtsgestaltung eine höhere Steuerlast resultiert. ${ }^{3}$

Da dies vom Bundesfinanzhof zu Recht bestritten wird, ist der Tatbestand des $\S 42$ ohne das Merkmal „Minderung der Steuer“ nicht erfullt. In seiner Wirksamkeit gegen die Steuerumgehung wird der Mißbrauchsparagraph dadurch naturgemäß nicht eingeschränkt. Lediglich wer den Sinn der Vorschrift nicht in der Verhinderung von Einnahmenausfällen für den Fiskus, sondern primär in einer besseren Verwirklichung des Postulats der Gleichmäßigkeit der Besteuerung sieht, wird das Tatbestandsmerkmal der Steuerminderung als Einschränkung der Effektivität der Generalklausel betrachten.

\subsubsection{Beweislastverteilung}

Die Anwendung des $\S 42$ liegt nicht im Ermessen der Finanzbehörde, sondern ist von dieser als zwingendes Recht überall dort anzuwenden, wo sein Tatbestand erfullt ist. ${ }^{4}$ Für die Sachverhaltsermittlung gelten dabei die allgemeinen Verfahrensvorschriften der Abgabenordnung, wonach die Finanzbehörde den Sachverhalt von Amts wegen zu ermitteln hat ( $\S 88$ Abs. 1), der Steuerpflichtige dabei jedoch „nach den Umständen des Einzelfalles" zur Mitwirkung verpflichtet ist ( $\S 90$ Abs. 1). ${ }^{5}$ Eine gesteigerte Mitwirkungspflicht für den Steuerpflichtigen gilt insbesondere beim Vorliegen von Auslandsbeziehungen, da hier eine Sachaufklärung allein durch die Finanzbehörde allenfalls unter unvertretbar hohem Aufwand durchführbar wäre. $^{6}$ Ist der Steuerpflichtige seinen Mitwirkungspflichten in vollem Umfang nachgekommen, so liegt die Beweislast über das Vorliegen einer Steuerumgehung i.S.v. $\S 42$ vollständig bei der Finanzbehörde; eventuelle Zweifel wirken sich zugunsten des Steuerpflichtigen aus. ${ }^{7}$

${ }^{1}$ Vgl. DANZER (1981) S. 102.

${ }^{2} \mathrm{Vgl}$. FISCHER in HHSp (1996) Rz. 107, wonach $§ 42$ der „Bewahrung der objektiven Rechtsordnung" dienen soll.

${ }^{3}$ insofern inkonsequent FISCHER in HHSp (1996) Rz. 101 (gl.A: TIPKE (1993) S. 1342; von FISCHER (HHSp (1996) Rz. 106) ohne überzeugende Begründung bestritten), konsequent hingegen PAULICK (1977) S. 160

${ }^{4}$ Vgl. FELIX (1981) S. 647.

${ }^{5}$ Vgl. BFH-Urteil vom 19.5.1988 V R 115/83 BStBl. 1988 II S. 916 [918]; KÜHN/KUTTER/ HOFMANN (1990) S. 126.

${ }^{6}$ Vgl. BFH-Urteil vom 21.1.1976 I R 234/73 BStBl. 1976 II S. 513 [515]; § 90 Abs. 2 AO.

${ }^{7} \mathrm{Vgl}$. BFH-Urteil vom 29.1.1975 I R 135/70 BStBl. 1975 II S. 553 [554]; BVerfG-Beschluß vom 10.6.1963 - 1 BvR 345/61 - BVerfGE 16, 203 [210]. 
Wenn der Beweis für einen Rechtsmißbrauch nicht geführt werden kann, so sind die Rechtsfolgen der Mißbrauchsvorschrift nicht anwendbar; eine Vermutung für eine Steuerumgehung besteht grundsätzlich nicht. Allerdings hat der BFH für bestimmte häufig wiederkehrende steuermindernde Rechtsgestaltungen Vermutungen für eine Steuerumgehung aufgestellt, sofern für die gewählte Gestaltung wirtschaftliche oder sonst beachtliche Gründe fehlen. Eine solche Vermutung gilt beispielsweise für die Zwischenschaltung sog. Basisgesellschaften im niedrig besteuerten Ausland zur Umgehung inländischer Steuer, aber auch für die Einschaltung von Zwischenvermietern zwecks Umsatzsteuerersparnis bei sog. Bauherrenmodellen. ${ }^{1}$

Dennoch bleibt festzuhalten, daß die (hier keinesfalls beanstandete) Rechtsprechung zur Beweislastverteilung die Anwendung des $\S 42$ in hohem Maße erschwert. Da das Vorhandensein gewisser Anhaltspunkte für eine Steuerumgehung nicht ausreicht, sondern vielmehr grundsätzlich der eindeutige Nachweis für das Vorliegen aller Tatbestandsmerkmale der Generalklausel für ihr Wirksamwerden erforderlich ist, kann $\S 42$ nicht gewährleisten, daß aufgrund seiner Existenz tatsächlich alle oder auch nur die Mehrzahl aller Steuerumgehungsversuche unterbleiben bzw. unwirksam gemacht werden. ${ }^{2}$

Hinzu kommt die in Kap. 4.3.3.3.4 bereits angesprochene Möglichkeit der Steuerpflichtigen, durch Darlegung außersteuerlicher Gründe für die gewählte Gestaltung möglichen Indizien für einen Rechtsmißbrauch entgegenzutreten. Solange die Finanzbehörde nicht nachweisen kann, daß diese Gründe in Wahrheit unbeachtlich oder nur vorgeschoben sind, bleibt für die Anwendung des $\S 42$ kein Raum.

\subsubsection{Rechtsfolgen des $§ 42$ AO}

„Liegt ein Mißbrauch vor, so entsteht der Steueranspruch so, wie er bei einer den wirtschaftlichen Vorgängen angemessenen rechtlichen Gestaltung entsteht" ( $\$ 42$ Satz 2).

Es wird also nicht die tatsächlich gewählte (mißbräuchliche) Rechtsgestaltung der Besteuerung zugrunde gelegt, sondern es wird der einer angemessenen Gestaltung entsprechende Sachverhalt als verwirklicht unterstellt („Sachverhaltsfiktion des $\left.\S 42 \mathrm{AO}^{\prime \prime}\right){ }^{3}$ Somit ist die Technik des $\S 42 \mathrm{AO}$ eine andere als die der Analogie: Während bei der Analogie der tatsächliche Sachverhalt unter einen fingierten, dem gesetzlichen Tatbestand ähnelnden Tatbestand subsumiert wird, wird durch $\S 42$

\footnotetext{
${ }^{1}$ Vgl. BFH-Beschluß vom 4.8.1987 V B 16/87 BStBI. 1987 II S. 756 [758].

${ }^{2} \mathrm{Vgl}$. auch BFH-Urteil vom 2.3.1966 II 113/61 BStBI. 1966 III S. 509 [511].

${ }^{3} \mathrm{Vgl}$. KÜHN/KUTTER/HOFMANN (1990) S. 120 und 124; vgl. auch BFH-Urteil vom 31.7.1984, a.a.O., S. 36 .
} 
ein vom Steuerpflichtigen nicht verwirklichter, also fingierter Sachverhalt unter den tatsächlichen gesetzlichen Tatbestand subsumiert. ${ }^{1}$

$\S 42 \mathrm{AO}$ ist also keine Vorschrift, die das ansonsten geltende Verbot von Analogie und teleologischer Reduktion im Steuerrecht durchbricht; ${ }^{2}$ vielmehr wird die für unangemessen erachtete Gestaltung gedanklich durch die - bzgl. ihres wirtschaftlichen Inhalts identische - angemessene Gestaltung ersetzt. ${ }^{3}$

Das Ergebnis der Sachverhaltsfiktion ist freilich das gleiche wie das der Analogie: In beiden Fällen wird ein vom ausgelegten Gesetz nicht erfaßter Sachverhalt besteuert, wo ansonsten durch mißbräuchliche Gestaltung ein Steuervorteil entstünde, der dem Sinn und Zweck des Gesetzes zuwiderliefe. ${ }^{4}$

Sind mehrere Rechtsgestaltungen denkbar, die als angemessen anzusehen wären, so hat nach dem Gebot der Verhältnismäßigkeit und dem Übermaßverbot die zuständige Finanzbehörde die für den Steuerpflichtigen günstigste Gestaltung zu unterstellen. ${ }^{5} \mathrm{Da}$ es niemandem verwehrt ist, von mehreren angemessenen Gestaltungen die steuergünstigste auszuwählen, würde eine andere Entscheidung der Finanzbehörde gleichbedeutend mit einer Bestrafung sein, für welche aber keine gesetzliche Grundlage existiert. ${ }^{6}$

Eine unzulässige Bestrafung des Steuerumgehers läge ebenfalls dann vor, wenn etwaige aufgrund der unangemessenen Gestaltung zu viel gezahlte Steuern nicht auf den nach Anwendung des $\S 42$ Abs. 2 zu entrichtenden Steuerbetrag anrechenbar wären. Aus diesem Grund hatte der Gesetzgeber die Anrechenbarkeit zu viel entrichteter Steuern in $\S 6$ Abs. 3 StAnpG ausdrücklich festgeschrieben. Diese Vorschrift wurde nicht in $\S 42$ AO 1977 übernommen, da sich ihr Inhalt nunmehr aus dem neu geschaffenen $\S 174$ Abs. 1 AO 1977 („Widerstreitende Steuerfestsetzungen") ergibt. ${ }^{7}$

Nach h.M. muß die Sachverhaltsfiktion des $\S 42$ auf alle relevanten Steuerarten angewendet werden; die Anrechnung zu viel gezahlter Steuern ist damit nicht auf diejenige Steuerart begrenzt, die der Steuerumgeher durch seine mißbräuchliche Rechtsgestaltung mindern wollte. ${ }^{8}$ Der Zweite Senat des BFH hat jedoch in seinem

${ }^{1}$ Vgl. KRUSE (1991) S. 145.

${ }^{2}$ so aber FISCHER in HHSp (1996) Rz. 76

${ }^{3} \mathrm{Vgl}$. TIPKE/KRUSE (1996) Tz. 8.

${ }^{4}$ Vgl. WESTERHOFF (1966) S. 94 f. sowie SCHWARZ (1996) Anm. 3.

${ }^{5}$ Vgl. FELIX (1981) S. 649.

${ }^{6}$ Vgl. RIEDEL (1968) S. 100.

${ }^{7}$ Vgl. Begr. RegE $\S 45$ in MITTELSTEINER/SCHAUMBURG (1977) S. 80.

${ }^{8} \mathrm{Vgl}$. FELIX (1981) S. 649; KLEIN/ORLOPP (1995) Anm. 5; KUHN/KUTTER/HOFMANN (1990) S. 124 f.; KOTTKE (1994) S. 246 f. 
Urteil vom 5.10.1983 die entgegengesetzte Auffassung vertreten. ${ }^{1}$ Eine solche Entscheidung, durch die ein und derselbe Sachverhalt für die verschiedenen Steuerarten eine unterschiedliche wirtschaftliche Interpretation erfährt (jeweils zum Nachteil des Steuerpflichtigen), steht allerdings im Widerspruch zu der sonst stets beschworenen "Einheit der Steuerrechtsordnung" und erscheint rechtsstaatlich bedenklich. Der h.M. ist somit m.E. zuzustimmen; für den Steuerumgeher bleibt freilich das Risiko, daß Finanzbehörde und Rechtsprechung im Einzelfall anders urteilen können und sich somit (ausnahmsweise) eine Steuerlast ergeben kann, die insgesamt höher ist, als sie es ohne den Rechtsmißbrauch gewesen wäre.

\subsubsection{Strafbarkeit der Steuerumgehung}

\subsubsection{Derzeitige Rechtslage}

Die Steuerumgehung ist keine strafbare Handlung, $\S 42$ AO kein Straftatbestand. ${ }^{2}$ Strafbar (und zwar als Steuerhinterziehung gem. § 370 AO) wird die Umgehung des Steuergesetzes lediglich dann, wenn der Steuerpflichtige zur Verschleierung der Steuerumgehung der Finanzbehörde fehlerhafte oder unvollständige Angaben gemacht hat. (Dies war in $\S 396$ Abs. 4 RAO 1931 ausdrücklich geregelt; die Streichung dieser Bestimmung durch das 2. AOStrafÄndG vom $12.8 .1968^{3}$ hat an der Rechtslage nichts geändert, da der Tatbestand der Steuerhinterziehung in $\S 396$ Abs. 1-3 und $\S 397$ Abs. 1 RAO 1931, mittlerweile in $\S 370$ Abs. 1 und 2 AO 1977 hinreichend geregelt war bzw. ist. $)^{4}$

Der Auffassung von SCHUZE-OSTERLOH, eine mißbräuchliche Rechtsgestaltung i.S.d. § 42 AO könne selbst dann keine strafbare Steuerhinterziehung darstellen, wenn die in $\S 370$ Abs. 1 AO genannten Voraussetzungen für eine Steuerhinterziehung vorliegen, kann hier nicht gefolgt werden. SCHULZE-OSTERLOH stützt seine Ansicht darauf, daß $\S 42$ AO eine Vorschrift sei, die eine steuerverschärfende Analogie zulasse, und sich demzufolge jede Bestrafung einer Steuerumgehung letztlich auf einen Analogieschluß zurückführen lasse und damit am strafrechtlichen Analogieverbot scheitere. Selbst wenn man $\S 42$ für überflüssig erachte und den Analogieschluß im Steuerrecht für ohnehin zulässig halte, würde die Strafbarkeit einer Steuerumgehung immer noch auf Analogie beruhen und wäre somit unzulässig. ${ }^{5}$

\footnotetext{
${ }^{1}$ Vgl. BFH-Urteil vom 5.10.1983 II R 92/79 BStBl. 1984 II S. 147 [149]; vgl. auch BFH-Urteil vom 10.2.1988, a.a.O., S. 549.

${ }^{2}$ Vgl. BFH-Urteil vom 22.1.1960, a.a.O., S. 113.

${ }^{3}$ BGBI. 1968 I S. 953 [955]

${ }^{4}$ Vgl. TIPKE (1993) S. 1345; KRUSE (78/79) S. 451.

${ }^{5}$ Vgl. SCHULZE-OSTERLOH (1983) S. $62 \mathrm{ff}$.
} 
Dem ist entgegenzuhalten, daß die Strafbarkeit einer Steuerhinterziehung gesetzlich in $\S 370$ Abs. 1 und $2 \mathrm{AO}$ hinreichend genau umschrieben ist. Ist eines der dort enthaltenen Tatbestandsmerkmale erfültt, so liegt Steuerhinterziehung vor, ohne $\mathrm{da} ß$ es hierfür von Belang ist, ob die Voraussetzungen des $\S 42$ gegeben sind. ${ }^{1} \mathrm{Im}$ übrigen ist, wie in Kap. 4.1.2.2.5 und 4.3.5 dieser Arbeit festgestellt wurde, $\S 42$ weder überflüssig, noch gestattet er eine Durchbrechung des steuerrechtlichen Analogieverbotes, so daß die Bestrafung einer Steuerumgehung als Steuerhinterziehung gem. § 370 AO keinesfalls auf - im Strafrecht unzulässiger - Analogie basiert.

Sofern der Steuerpflichtige seine Erklärung hingegen vorschriftsmäßig ausgefullt hat und sich eventuellen Rückfragen der Finanzbehörde nicht verweigert, setzt er sie in die Lage, den Rechtsmißbrauch zu erkennen und die richtige Steuer gemäß $\S 42$ Satz 2 festzusetzen. ${ }^{2}$ In diesem Fall ist der Straftatbestand des $\S 370$ AO nicht erfullt; der Rechtsmißbrauch als solcher ist straffrei.

Die fehlende Strafbarkeit der Steuerumgehung führt dazu, daß die abschreckende Wirkung des $\S 42$ auf potentielle Steuerumgeher gering ist. Im ungünstigsten Fall wird der Rechtsmißbrauch von der Finanzbehörde als solcher erkannt und der unangemessenen Gestaltung die steuerliche Anerkennung verweigert. Kosten entstehen dem Steuerpflichtigen lediglich in Form eventueller wirtschaftlicher Nachteile, die die möglicherweise unter außersteuerlichen Gesichtspunkten eher unvorteilhafte Rechtsgestaltung mit sich bringt, sowie, falls die Entscheidung der Finanzbehörde gerichtlich angefochten wird, in Form von Prozeßkosten, sofern der Steuerpflichtige unterliegt.

\subsubsection{Verfassungsrechtliche Grenzen einer Verschärfung der Rechtsfol- gen}

Es stellt sich an dieser Stelle die Frage, ob sich die Abschreckungswirkung des §. 42 AO nicht durch eine dem französischen art. 1729 CGI entsprechende Vorschrift erhöhen ließe, die die Steuerumgehung als Ordnungswidrigkeit mit einer Geldbuße belegen würde. ${ }^{3}$ Während die Wirksamkeit einer solchen Bestimmung kaum bestritten werden kann, ${ }^{4}$ ist die Frage nach ihrer verfassungsrechtlichen $\mathrm{Zu}-$ lässigkeit schwieriger zu beantworten. Obwohl sich angesichts der Existenz einer derartigen Norm in Frankreich der Gedanke einer Übernahme ins deutsche Recht geradezu aufdrängt, hat sich bislang, soweit ersichtlich, weder die Literatur zur

\footnotetext{
${ }^{1}$ Vgl. dazu auch BGH-Urteil vom 27.1.1982 - 3 StR 217/81 - DB 1982 S. 2676 [2676].

${ }^{2}$ Vgl. BFH-Beschluß vom 1.2.1983 VIII R 30/80 BStBl. 1983 II S. 534 [536]; THOMA in NIEMANN (72/73) S. $537 \mathrm{f}$.

${ }^{3}$ Vgl. Kap. 4.4 dieser Arbeit.

${ }^{4}$ Hierzu s.u. Kap. 5.5.2.2.3.
} 
Steuerumgehung noch das vorliegende Schrifttum zur allgemeinen Gesetzesumgehung mit dieser Problematik auseinandergesetzt. ${ }^{1}$

$\mathrm{Ob}$ die Ahndung von Steuerumgehungshandlungen mit einer Geldbuße verfassungskonform wäre, ist vor dem Hintergrund des Art. 103 Abs. 2 GG zu prüfen, wonach lediglich solche Aktivitäten unter Strafe gestellt werden dürfen, deren Strafbarkeit gesetzlich bestimmt ist. Zwar wäre durch die Aufnahme einer art. 1729 CGI gleichenden Bestimmung in die Abgabenordnung die Bestrafung mißbräuchlicher steuerlicher Gestaltungen gesetzlich fixiert und damit dem Grundsatz ,mulla poena sine lege" genüge getan. Doch ist unter Verfassungsrechtlern unbestritten, daß Art. 103 mit der Formulierung, gesetzlich bestimmt" nicht nur die Festlegung als solche, sondern auch die inhaltliche Präzisierung des Straftatbestandes fordert. ${ }^{2}$ Wenn eine Strafnorm nicht selbst ihre Tatbestandsmerkmale abschließend aufzählt, sondern auf andere, nicht strafrechtliche Vorschriften verweist, so ist das Bestimmtheitspostulat nur dann erfüllt, wenn auch die zugehörige ausfullende Norm (hier $\S 42 \mathrm{AO}$ ) den strengen Anforderungen des Art. 103 standhält. ${ }^{3}$ Das aus Art. 103 Abs. 2 abgeleitete strafrechtliche Bestimmtheitsgebot geht über das allgemeine, für sämtliche Rechtsnormen geltende Bestimmtheitsgebot des Art. 80 Abs. 1 GG hinaus; die ,freiheitsgewährleistende Funktion“ des Art. 103 Abs. 2 stellt besondere Anforderungen an die Vorhersehbarkeit, Erkennbarkeit und Verständlichkeit von Strafnormen. ${ }^{4}$ Strafrechtliche Bestimmungen müssen ihre Tatbestandsvoraussetzungen so konkret umschreiben, daß die Adressaten in die Lage versetzt werden, das Erlaubte und das Verbotene klar voneinander abzugrenzen. ${ }^{5}$ Zwar ist die Verwendung auslegungsbedürftiger Begriffe hierbei nicht unzulässig, doch muß sich der Anwendungsbereich der Straftatbestände durch Auslegung von im Gesetz selbst formulierten Kriterien ergeben. ${ }^{6}$ Wo die Auslegung nicht $\mathrm{zu}$ eindeutigen Ergebnissen führt, sondern unterschiedliche Interpretationen ermöglicht, ist eine Bestrafung im Zweifel unstatthaft. ${ }^{7}$

Somit wird deutlich, daß die Generalklausel des $\S 42 \mathrm{AO}$ als Grundlage furr eine strafrechtliche Vorschrift kaum verfassungskonform sein kann. Während die Vor-

${ }^{1}$ WESTERHOFF (1966) S. 150 spricht die mögliche Ahndung von Gesetzesumgehungen zwar an, verzichtet jedoch auf eine nähere Untersuchung dieser Frage.

${ }^{2}$ Vgl. BVerfG-Beschluß vom 26.2.1969 - 2 BvL 15, 23/68 - BVerfGE 25, 269 [285].

${ }^{3}$ Vgl. BVerfG-Beschluß vom 11.2.1976 - 2 BvL 2/73 + BVerfGE 41, 314 [319].

${ }^{4} \mathrm{Vgl}$. SCHMIDT-ASSMANN in MAUNZ/DÜRIG (1994) Art. 103 Rdnr. 179 und 185 (unter Berufung auf BVerfG-Beschluß vom 6.5.1987 - 2 BvL 11/85 - BVerfGE 75, 329 [340 f.]).

${ }^{5}$ Vgl. LEIBHOLZ/RINCK/HESSELBERGER (1995), Art. 103, Rz. 1286-1288, mit diversen Nachweisen aus der Rspr. des BVerfG.

${ }^{6} \mathrm{Vgl}$. RUPING in DOLZER/VOGEL (1995), Art. 103 Abs. 2, Rdnr. 26 und 80; vgl. dazu auch BVerfG-Beschluß vom 17.11.1992 - 1 BvR 168, 1509/89 und 638, 639/90 BVerfGE 87, 363 [391].

${ }^{7}$ Vgl. RUPING in DOLZER/VOGEL (1995), Art. 103 Abs. 2, Rdnr. 30. 
gängervorschriften $\S 5$ Abs. 2 RAO $1919 \hat{=} \S 10$ Abs. 2 RAO 1931 noch recht konkret den Mißbrauchstatbestand umschrieben, kann hiervon bei § 42 AO 1977 nicht mehr die Rede sein. Die in der Begründung des $\S 45$ des Regierungsentwurfes zur AO $1977 \mathrm{zu}$ findende Formulierung, die Tatbestandskonkretisierung werde die Rechtsprechung klären müssen, verdeutlicht, daß das o.g. Postulat, der Anwendungsbereich einer Strafnorm müsse sich ,durch Auslegung von im Gesetz selbst formulierten Kriterien" ermitteln lassen, hier nicht erfüllt ist. Eine Bestrafung auf der Grundlage von $\S 42$ AO stünde im Widerspruch zur aus Art. 103 Abs. 2 GG abgeleiteten Forderung nach Vorhersehbarkeit strafrechtlicher Konsequenzen und zur vom BGH entwickelten Lehre vom Unrechtsbewußtsein, wonach die $\mathrm{Zu}$ lässigkeit einer Bestrafung davon abhängt, ob sich die betroffene Person bewußt sein konnte, durch ihr Verhalten „einen vom Recht anerkannten Wert zu verletzen“. 1

Das Bestimmtheitsgebot des Art. 103 Abs. 2 bezieht sich nicht nur auf Kriminalstrafen. Da die Ausgliederung der Ordnungswidrigkeiten aus dem Strafrecht erst nach Inkraftreten des Grundgesetzes erfolgt ist, steht außer Zweifel, daß auch nach dem OWiG erhobene Geldbußen dem Art. 103 unterliegen. ${ }^{2}$ Zwar sind die Anforderungen an die Präzisionspflicht des Gesetzgebers um so niedriger, je leichter die angedrohte Strafe ist. ${ }^{3}$ Doch kann eine derart allgemein formulierte Generalklausel wie $\S 42 \mathrm{AO}$ nicht die Grundlage selbst einer verhältnismäßig niedrig angesetzten Geldbuße nach dem Ordnungswidrigkeitenrecht sein.

Demgegenüber würde eine den Mißbrauchstatbestand genauer umschreibende, mit § 5 RAO 1919 vergleichbare Generalklausel, gekoppelt mit einer Bußgeldvorschrift, einer verfassungsrechtlichen Prüfung m.E. durchaus standhalten. ${ }^{4}$ Jedoch haben die historischen Erfahrungen mit § 5 RAO 1919 gezeigt, daß eine im Gesetz formulierte Präzisierung des Mißbrauchstatbestandes die Anwendungsmöglichkeiten der Generalklausel derart einengt, daß auch die Belegung der Steuerumgehung

${ }^{1}$ RÚPING in DOLZER/VOGEL (1995), Art. 103 Abs. 2, Rdnr. 30 f., mit Hinweis auf BGHBeschluß vom 18.3.1952 - GSSt 2/51 - BGHSt 2, 194 [196 ff. (insb. 197 f., 200 f., 209)]

${ }^{2}$ Vgl. KUNIG in v. MƯNCH (1983) Rn. 18 zu Art. 103; vgl. ferner BVerfG-Beschluß vom 23.10.1985 - 1 BvR 1053/82 - BVerfGE 71, 108 [114].

${ }^{3}$ Vgl. z.B. BVerfG-Beschluß vom 27.11.1990 - 1 BvR 402/87 - BVerfGE 83, 130 [145].

${ }^{4}$ Vgl. BVerfG-Beschluß vom 21.6.1977 - 2 BvR 308/77 - BVerfGE 45, 363 [371 f.]: „Generalklauseln ... im Strafrecht sind .. nicht von vornherein verfassungsrechtlich zu beanstanden. Gegen die Verwendung derartiger Klauseln ... bestehen jedenfalls dann keine Bedenken, wenn sich mit Hilfe der üblichen Auslegungsmethoden, insbesondere durch Heranziehung anderer Vorschriften desselben Gesetzes, durch Berücksichtigung des Normzusammenhangs oder aufgrund einer gefestigten Rechtsprechung eine zuverlässige Grundlage für die Auslegung und Anwendung der Norm gewinnen läßt, so daß der Einzelne die Möglichkeit hat, den durch die Strafnorm geschützten Wert sowie das Verbot bestimmter Verhaltensweisen zu erkennen und die staatliche Reaktion vorauszusehen."

Vgl. in diesem Zusammenhang auch TIEDEMANN (1969) S. 7 f. 
mit einer Geldbuße aufgrund ihrer geringen Anwendungswahrscheinlichkeit kaum eine nennenswerte Abschreckungswirkung auf potentielle Steuerumgeher ausüben könnte. ${ }^{1}$

\subsubsection{VerfassungsmäBigkeit des $§ 42 \mathrm{AO}$}

$\S 42$ wäre naturgemäß ein bezüglich seiner Wirksamkeit äußerst unsicheres Instrument der Steuerumgehungsbekämpfung, wenn zu befürchten wäre, daß ihn das Bundesverfassungsgericht auch ohne Verknüpfung mit einer Bußgeldvorschrift für verfassungswidrig und damit für unwirksam erklären könnte. Jedoch wird die Vorschrift zu Recht von der h.M. fur verfassungskonform erachtet. ${ }^{2}$

Während sich das Verbot belastender Analogie im Steuerrecht aus den Grundsätzen der Tatbestandsmäßigkeit und der Rechtssicherheit und damit aus dem in Art. 28 Abs. 1 GG normierten Rechtsstaatsprinzip ableitet, ist die Sachverhaltsfiktion des $\S 42$ gesetzlich fixiert und steht somit nicht im Widerspruch zum Tatbestandsmäßigkeitspostulat. Die Mißbrauchsvorschrift bedeutet auch keinen Verstoß gegen den Grundsatz der Rechtssicherheit, da sie nicht - wie der Analogieschluß - allein auf dem (für den Steuerpflichtigen selten klar erkennbaren) Sinn und Zweck des Gesetzes basiert, sondern vielmehr die Sachverhaltsfiktion nur für einen engen, im Gesetz benannten Anwendungsbereich gestattet, nämlich für Gestaltungsmöglichkeiten des Rechts im Falle eines Mißbrauchs. ${ }^{3}$ Zwar verwendet $\S 42$ dabei notwendigerweise unbestimmte Rechtsbegriffe; jedoch kann $\mathrm{KIRCHHOF}^{4}$, der die Vorschrift unter Hinweis auf Art. 80 Abs. $1 \mathrm{GG}$ als Verstoß gegen die rechtsstaatlich gebotene Bestimmtheit ansieht, nicht zugestimmt werden. Die Verwendung unbestimmter Rechtsbegriffe ist dem Gesetzgeber auch im Hinblick auf den Bestimmtheitsgrundsatz nicht untersagt. Generalklauseln und unbestimmte Rechtsbegriffe sind gerade im Steuerrecht unverzichtbar, wenn die Finanzbehörden in der Lage sein sollen, den besonderen Gegebenheiten des Einzelfalles Rechnung zu tragen. ${ }^{5}$ Der Gesetzgeber hat zwar bei der Verwendung unbestimmter Rechtsbegriffe den Grundsätzen der Normenklarheit und Justitiabilität gerecht zu werden; er darf aber bei der tatbestandlichen Fixierung nicht mit von vornherein unerfullbaren Anforderungen konfrontiert werden. ${ }^{6}$ Einen Verstoß ge-

${ }^{1}$ Vgl. Kap. 4.3.1 dieser Arbeit.

${ }^{2}$ Vgl. TIPKE/LANG (1994) S. 146; TIPKE (1993) S. 1332 f.; DANZER (1981) S. 95 f.; FISCHER in HHSp (1996) Rz. 22; PAPIER (1973) S. 188 ff.; HENSEL (1974) S. 137 ff.

${ }^{3} \mathrm{Vgl}$. PAPIER (1973) S. $188 \mathrm{f}$.

${ }^{4}$ Vgl. KIRCHHOF (1983) S. 176; KIRCHHOF (79/80) S. 259.

${ }^{5}$ Vgl. BVerfG-Beschluß vom 19.4.1978 - 2 BvL 2/75 - BVerfGE 48, 210 [222]; HENSEL (1974) S. $121 \mathrm{f}$

${ }^{6} \mathrm{Vgl}$. BVerfG-Beschluß vom 31.5.1988 - 1 BvR 520/83 - BVerfGE 78, 214 [226]; BVerfGBeschluß vom 8.1.1981, a.a.O., S. 12 f. 
gen Art. 80 Abs. 1 GG würde die Generalklausel gegen die Steuerumgehung erst dann darstellen, wenn ihr unnötige Unbestimmtheit anzulasten wäre. Davon kann jedoch keine Rede sein. „Immerhin ist $\S 42$ AO bestimmter gefaßt als der Gleichheitssatz, dem er dienen will.“1

Rechtsstaatlich unbedenklich ist auch die mit $\S 42$ verbundene Fiktion eines tatsächlich nicht gegebenen Sachverhaltes, da nur die angemessene Rechtsgestaltung in ihrer äußeren Aufmachung, nicht aber ihr tatsächlicher wirtschaftlicher Inhalt fingiert wird. ${ }^{2}$

\subsection{Die Bekämpfung der Steuerumgehung in Frankreich}

Ähnlich wie Deutschland versucht beispielsweise auch Frankreich, der Steuerumgehung anhand einer Generalklausel Herr zu werden. ${ }^{3}$ Dennoch bestehen in der konkreten Ausgestaltung und Anwendung der Umgehungsvorschrift signifikante Unterschiede zum deutschen Recht, so daß sich an dieser Stelle ein vergleichender Überblick über die französische Praxis der Steuerumgehungsbekämpfung anbietet.

Wie in Deutschland, Großbritannien und den USA ist es den Steuerpflichtigen auch in Frankreich unbenommen, unter mehreren möglichen Rechtsgestaltungen die steuerlich günstigste auszuwählen. ${ }^{4}$ Mißbräuchlichen Gestaltungen begegnet die Finanzverwaltung jedoch mit Hilfe der Generalklausel des art. L. 64 Livre des Procédures fiscales (LPF). Diese Vorschrift ermächtigt die FinBeh, diejenigen Bestandteile einer Rechtsgestaltung steuerlich außer acht zu lassen, die nicht dem realen Charakter der Transaktion entsprechen, und statt dessen die ,wirklich effektiven Aktionen“ zur Besteuerungsgrundlage zu machen (,„Realismus« des Steuerrechts"s). ${ }^{5}$ Führt die mißbräuchliche Gestaltung allerdings im Einzelfall zu einer höheren als der normalerweise entstehenden Steuerlast, so ist die FinBeh gemäß art. 1321 Code civil berechtigt, zu Lasten des Steuerpflichtigen auf die Anwendung von art. L. 64 LPF zu verzichten. ${ }^{6}$ Die Beweislast für einen Rechtsmißbrauch (abus de droit) trägt grundsätzlich die Finanzverwaltung. ${ }^{7}$ Doch sieht art. L. 64 vor, daß die Behörde im Streitfall berechtigt ist, den Fall einem speziellen

${ }^{1}$ TIPKE (1993) S. 1332.

${ }^{2}$ Vgl. dazu ULMER (1986) S. 294.

${ }^{3}$ Ferner existieren vergleichbare Generalklauseln u.a. in Israel, Schweden, Finnland, Österreich, den Niederlanden, Australien, Neuseeland und seit 1988 auch in Kanada. Vgl. TIPKE (1993) S. 1348-1352; TIPKE/LANG (1994) S. 145.

${ }^{4} \mathrm{Vgl}$. DAVID/LATOURNERIE/FOUQUET (1991) S. 110 unter Hinweis auf die ständige Rechtsprechung.

${ }^{5}$ Vgl. ebenda S. 106.

${ }^{6}$ Vgl. COZIAN (1986) S. 38.

${ }^{7}$ Urt. des Conseil d'État (oberste Instanz der Verwaltungsgerichte) vom 10.6.1981; vgl. dazu ausfuihrlich GAMBIER/MERCIER (1990) S. 607 f. 
unabhängigen Beirat (comité consultatif spécial) zur Entscheidung vorzulegen. Seit der Gesetzesänderung vom 8. Juli 1987 darf auch der Steuerpflichtige den beratenden Sonderausschuß anrufen. Will eine der Parteien die Entscheidung des comité consultatif nicht akzeptieren, so trägt sie für das nachfolgende gerichtliche Verfahren die Beweislast.

Die Zusammensetzung des beratenden Ausschusses bestimmt art. $1653 \mathrm{C}$ Code général des Impots (CGI):

Danach besteht der vierköpfige Ausschuß aus einem Vertreter des Staates, einem Vertreter der Gerichtsbarkeit (des „,Kassationshofes“), einem Professor der Rechtsfakultät und dem für Steuern zuständigen Ministerialdirektor.

Falls der beratende Sonderausschuß bzw. das zuständige Verwaltungsgericht in seiner Entscheidung das Vorliegen eines Rechtsmißbrauchs bestätigt, so wird gemäß art. 1729 CGI von den am Mißbrauch beteiligten Parteien eine Geldbuße i.H.v. $80 \%$ der zusätzlich fälligen Steuer erhoben.

Ein Rechtsmißbrauch liegt nach französischer Rechtsprechung dann vor, wenn es sich bei einem Rechtsgeschäft oder Vertrag nur um ein Scheingeschäft ohne reale Existenz handelt, wenn eine Transaktion, obgleich nicht fingiert, nur dazu dient, die tatsächlichen wirtschaftlichen Vorgänge zu verschleiern, oder wenn eine Verringerung der persönlichen Steuerlast durch die Einschaltung von Strohmännern zu erreichen versucht wird. ${ }^{1}$ Voraussetzung furr die steuerliche Nichtanerkennung einer nicht fingierten Transaktion ist jedoch (wie in Deutschland), daß die gewählte Gestaltung rein fiskalisch motiviert war, also keine außersteuerlichen Gründe für ihre Wahl ausschlaggebend waren. ${ }^{2}$ Bei Anwendung der gesetzlichen Vorschriften zum Rechtsmißbrauch ist die FinBeh verpflichtet, die Steuerpflichtigen darüber zu informieren, daß sich die vorgenommene Korrektur der für mißbräuchlich erachteten Gestaltung auf art. L. 64 LPF stützt. ${ }^{3}$ Dadurch soll gewährleistet werden, daß es die Steuerpflichtigen nicht aus Unkenntnis unterlassen, ihr Recht auf Anrufung des comité consultatif in Anspruch zu nehmen. ${ }^{4}$ Die Korrektur einer Steuerumgehungshandlung ohne Berufung auf art. L. 64 ist der FinBeh nur dann gestattet, wenn ihr der Nachweis gelingt, daß die Gestaltung real etwas anderes darstellt als das, was vertraglich geregelt wurde. In diesem Fall kann die Behörde infolge einer

\footnotetext{
${ }^{\mathrm{l}}$ Vgl. COZIAN (1986) S. 29 f., S. 30 ff., S. 38 f., jeweils mit diversen Nachweisen aus der Rechtsprechung.

${ }^{2} \mathrm{Vgl}$. Urteil des Cour administrative d'appel de Nantes vom 19.4.1989, Revue de jurisprudence fiscale (RJF) 1989, S. 518, ${ }^{\circ} 1000$; Urteil des Conseil d'État vom 15.1.1992, Droit fiscal (DF) 1992 , S. $1923, \mathrm{n}^{\circ} 48-49$, comm. 2288.

${ }^{3}$ Vgl. Urteil des Conseil d'État vom 23.2.1979, RJF 1979, S. 143, n 4.

${ }^{4}$ Vgl. GAMBIER/MERCIER (1990) S. 606.
} 
einfachen Tatbestandsermittlung eine von den Steuerpflichtigen angestrebte Steuerbefreiung oder -minderung verweigern. ${ }^{1}$

Während die französischen Rechtsanwender die gesetzlichen Bestimmungen zum Rechtsmißbrauch ursprünglich recht zurückhaltend angewendet haben, neigen die Gerichte seit einiger Zeit vermehrt dazu, im Zweifel einen Mißbrauch anzunehmen und damit zugunsten des Fiskus zu entscheiden. ${ }^{2}$ In Verbindung mit der Ahndung mißbräuchlicher Gestaltungen durch eine Geldbuße ergibt sich somit eine vergleichsweise hohe Wirksamkeit der französischen Generalklausel gegen die Steuerumgehung.

\subsection{Zwischenergebnis}

Die bisherigen Ausführungen haben gezeigt, daß in Deutschland auf eine Generalklausel gegen die Steuerumgehung nicht verzichtet werden kann. Daß ein solcher Verzicht in anderen Staaten wie Großbritannien und den USA möglich ist, liegt an abweichenden Rechtsauffassungen in diesen Ländern. Während in den Vereinigten Staaten die Zulässigkeit belastender Analogie die Steuerumgehungsaktivitäten erschwert, hat in Großbritannien der vereinzelte Einsatz rückwirkender Steuergesetzgebung ein noch höheres Ausmaß an Steuerumgehung verhindert. Da beide Methoden in Deutschland verfassungsrechtlich untersagt sind, ist $\S 42 \mathrm{AO}$ hier ein unverzichtbarer Bestandteil des dem Gesetzgeber zur Verfügung stehenden Instrumentariums gegen mißbräuchliche steuerliche Gestaltungen. Die bisherige Rechtsprechung des Bundesfinanzhofs zu $\S 42$ AO zeigt aber auch deutlich die Grenzen seiner Wirksamkeit auf. Insbesondere die vom BFH zum Tatbestandsmerkmal erhobene Nichtexistenz beachtlicher außersteuerlicher Gründe i.V.m. einer bei der Finanzverwaltung liegenden Beweislast schmälern die Möglichkeiten einer Anwendung der Mißbrauchsklausel erheblich. Durch die fehlende Strafbarkeit der Steuerumgehung ist die Abschreckungswirkung des $\S 42$ ohnehin gering. Wie auch in den USA und Großbritannien liegt das einzige Risiko fur den Steuerumgeher in der Möglichkeit der behördlichen bzw. gerichtlichen Nichtanerkennung der mißbräuchlichen Rechtsgestaltung. Es kann daher nicht verwundern, daß das Phänomen „Steuerumgehung“ bislang in keinem der drei Länder, selbst nicht in den von vergleichsweise steuerzahlerfeindlicher Rechtsprechung geprägten Vereinigten

${ }^{1}$ In zwei Entscheidungen des Conseil d'État vom 21.7.1989 ging es um derartige Fälle, wo die FinBeh sich nicht auf einen Rechtsmißbrauch nach art. L. 64 berufen hatte. Indem einmal für und einmal gegen den Steuerpflichtigen entschieden wurde, setzte das Gericht sowohl die Möglichkeit einer Korrektur ohne Inanspruchnahme von art. L. 64 als auch ihre Grenzen fest. Vgl. DAVID/LATOURNERIE/FOUQUET (1991) S. 100 f. sowie GAMBIER/MERCIER (1990) S. $608 \mathrm{f}$.

${ }^{2}$ Vgl. VOGEL (1996) S. 225 mit Hinweis auf mehrere Entscheidungen des Conseil d'État. 
Staaten, zu einem Schattendasein gelangt ist. Weitaus wirksamer sind die in Frankreich existierenden gesetzlichen Regelungen, die die Beweislastverteilung von der Entscheidung eines unabhängigen Ausschusses abhängig machen und als mißbräuchlich erkannte Gestaltungen mit einer Geldbuße belegen. In Verbindung mit einer, ,in dubio pro fisco"-Grundhaltung der Gerichte ergibt sich eine hohe Effektivität der französischen Generalklausel. Eine Anpassung an das französische Recht ist dem deutschen Gesetzgeber aus verfassungsrechtlichen Gründen jedoch kaum möglich. Im übrigen zeigt der Umstand, daß auch der Conseil d'État immer wieder mit Fällen befaßt wird, in denen es um das Vorliegen eines Rechtsmißbrauchs geht, $\mathrm{da} ß$ es selbst in Frankreich an Versuchen, die Steuer zu umgehen, keinesfalls fehlt.

Man kann deshalb zusammenfassend festhalten, daß die in Kapitel 4.1 vorgestellten Alternativen der Steuerumgehungsbekämpfung je nach den verfassungsrechtlichen Gegebenheiten und der Haltung der Dritten Gewalt zwar durchaus geeignet und derzeit z.T. unentbehrlich sind, um das Ausmaß an Steuerumgehung in Grenzen zu halten, daß jedoch weder in Deutschland noch in den anderen hier behandelten Staaten diese Mittel bislang ausgereicht haben, um die Steuerumgehung und die mit ihr verbundenen gesamtwirtschaftlichen Nachteile auf ein tolerierbares Restvolumen abzusenken oder gar ganz zu beseitigen.

Fast zwangsläufig stellt sich hier die Frage, ob sich nicht weitere, außerhalb der in der Rechtswissenschaft diskutierten Maßnahmen liegende Ansätze finden lassen, die eine wirksamere Eindämmung des Rechtsmißbrauchs im Steuerrecht ermöglichen. Eine Chance, diesbezüglich zu hilfreichen Erkenntnissen zu gelangen, bietet eine ökonomische Analyse der Steuerumgehung. 
Ralf Oberheide - 978-3-631-75185-5

Downloaded from PubFactory at 01/11/2019 07:21:58AM

via free access 


\section{5. Ökonomische Theorie der Steuerumgehung}

\subsection{Vorbemerkungen}

Bislang existiert äußerst wenig ökonomische Literatur zur Steuerumgehung. Demgegenüber geht die moderne Theorie der Steuerhinterziehung bereits auf das Jahr 1972 zurück, und seither ist eine vergleichsweise große Anzahl an wirtschaftswissenschaftlichen Publikationen zu diesem Gebiet erschienen. Da Steuerhinterziehung und -umgehung primär dem gleichen Ziel dienen (Erhöhung des verfügbaren Einkommens nach Steuern) und das erwartete verfügbare Einkommen in jedem Fall bestimmt sein dürfte vom Bruttoeinkommen, dem Steuertarif, den Kosten des Steuerentzuges, der Wahrscheinlichkeit seines Mißlingens und der ggf. hierauf erhobenen Strafe, kann davon ausgegangen werden, daß diejenigen Faktoren, die das Ausma $ß$ an individueller Steuerumgehung beeinflussen, weitgehend identisch sind mit den Bestimmungsgründen der Steuerhinterziehung. ${ }^{1}$ Es liegt daher nahe, ein theoretisches Modell der Steuerumgehung aus den bereits vorhandenen Modellen der Steuerhinterziehung abzuleiten. In Abschnitt 5 wird deshalb zunächst ein auf der grundlegenden Arbeit von ALLINHAM und SANDMO (1972) basierendes entscheidungstheoretisches Modell der Einkommensteuerhinterziehung ${ }^{2}$ vorgestellt, wobei die seitdem erschienenen Variationen und Erweiterungen des Grundmodells in den Ansatz integriert werden, sofern sie für ein Modell der Steuerumgehung relevant erscheinen. ${ }^{3}$

Die Ergebnisse des theoretischen Modells werden anhand der vorhandenen empirischen Arbeiten zur Steuerhinterziehung (empirische Untersuchungen zu den Bestimmungsgründen der Steuerumgehung existieren kaum $^{4}$ ) überprüft, und den sich ergebenden Abweichungen wird auf den Grund gegangen. Die gewonnenen Erkenntnisse zur Steuerhinterziehung bilden eine wichtige Grundlage für eine erfolgversprechende gegen die Steuerumgehung gerichtete Politik. Zunächst muß dafür das Steuerhinterziehungsmodell in ein Modell der Steuerumgehung überführt werden; die Modellergebnisse zeigen auf, welche Faktoren für die Umgehungsent-

${ }^{1}$ gl.A.: SELDON in IEA (1979) S. 4; CHRISTOPHER in IEA (1979) S. 80; WREDE (1993) S. 21-24.

2 Die ökonomische Literatur zum Steuerentzug konzentriert sich bislang fast ausschließlich auf die Einkommensteuer. Da die für den Einkommensteuerentzug maßgeblichen Parameter wie Bemessungsgrundlage, Ahndungswahrscheinlichkeit, Strafmaß und Steuertarif für andere Steuerarten dieselben sein dürften, lassen sich die in diesem Abschnitt gewonnenen Erkenntnisse jedoch relativ unproblematisch verallgemeinern. Vgl. hierzu auch HAGEDORN (1991) S. $49 \mathrm{f}$. sowie die Literaturhinweise bei WREDE (1993) S. 4.

${ }^{3}$ Das in Kap. 5.2 vorgestellte Modell der Steuerhinterziehung kann gleichzeitig als (spezielles) Modell der Steuerumgehung für den Fall angesehen werden, daß letztere mit einer Geldbuße belegt werden kann, ansonsten jedoch keine Kosten verursacht.

${ }^{4}$ Eine Ausnahme bildet die Arbeit von GEEROMS/WILMOTS (1985), welche Steuerumgehung und -hinterziehung gemeinsam behandelt. 
scheidung maßgeblich sind und wo sich hier mögliche Ansatzpunkte für die Politik ergeben. Am Ende von Abschnitt 5 werden weitere, im Modell nicht enthaltene Erklärungsfaktoren angesprochen und die Möglichkeiten ihrer staatlichen Beeinflussung diskutiert.

\subsection{Das entscheidungstheoretische Modell der Einkommen- steuerhinterziehung}

\subsubsection{Modellprämissen ${ }^{1}$}

1) Beim einfachen Grundmodell handelt es sich um ein statisches Modell, in dem die Steuerpflichtigen allein über den aktuellen Umfang ihrer Einkommensteuerhinterziehung entscheiden, ohne dabei ihr Deklarationsverhalten vergangener Perioden oder ihre zukünttig geplante Steuerhinterziehung mit in die Entscheidung einzubeziehen.

2) Einzige Entscheidungsvariable ist das deklarierte Einkommen $X$. Mögliche Interdependenzen mit anderen ökonomischen Wahlmöglichkeiten bleiben unberücksichtigt; insbesondere wird von einem gegebenen Bruttoeinkommen W (mit $\mathrm{W}>0$ und $0 \leq \mathrm{X} \leq \mathrm{W}$ ) ausgegangen, eine Verknüpfung der Hinterziehungsentscheidung mit der Arbeit-Freizeit-Entscheidung also nicht vorgenommen.

3) Die Steuerpflichtigen handeln streng nutzenmaximierend. Dabei wird der Nutzen allein durch das verbleibende Nettoeinkommen bestimmt. Eventuelle Gewissensbelastungen oder die Rufschädigung durch aufgedeckte Steuerhinterziehung gehen nicht in die Nutzenfunktion ein. $^{2}$

4) Das Einkommen stiftet einen positiven, aber abnehmenden Grenznutzen (U'>0, U' < 0), d.h. die Zensiten sind risikoscheu eingestellt.

5) Mit einer bestimmten, von der Deklarationsentscheidung unabhängigen und den Steuerpflichtigen bekannten Wahrscheinlichkeit $p$ (mit $0<p<1$ ) findet eine Überprüfung der Steuererklärung statt; in diesem Fall wird die Steuerhinterziehung vollständig aufgedeckt und neben der fälligen Steuernachzahlung eine rein monetäre, proportionale Strafe auf den hinterzogenen Steuerbetrag erhoben, wobei der Strafsatz $f(m i t f>0)$ fest und im vorhinein bekannt ist. ${ }^{3}$

${ }^{1}$ Soweit nicht anders angegeben, finden sich die hier genannten Prămissen bei ALLINGHAM/ SANDMO (1972) S. $323 \mathrm{f}$.

${ }^{2}$ Vgl. hierzu auch ALLINGHAM/SANDMO (1972) S. 326 f.; RADECK (1988) S. $11 \mathrm{f}$.

${ }^{3}$ Vgl. ALLINGHAM/SANDMO (1972) S. 324 f.; HAGEDORN (1991) S. 8. Abweichend von ALLINGHAM und SANDMO, in deren Modell die Geldstrafe auf die Minderdeklaration erhoben wird, wird hier im Hinblick auf den Untersuchungsgegenstand dieser 
6) Ohne Überprüfung der Steuererklärung ist der Finanzbehörde das tatsächliche Einkommen der Zensiten vollständig unbekannt.

7) Eine Quellensteuer existiert nicht; die Steuer wird als reine Veranlagungsteuer erhoben. ${ }^{1}$

8) Die Steuerfunktion $T=T(X)$ ist über den ganzen Wertebereich differenzierbar. Für den Grenzsteuersatz T' gilt $0<\mathrm{T}^{\prime}<1$. $^{2}$

9) Außer einer möglichen Bestrafung entstehen den Steuerhinterziehern keine Kosten. Eventuell anfallende Aufwendungen zur Verschleierung der wahren Einkommenslage werden im Modell vernachlässigt. ${ }^{3}$

\subsubsection{Das Modell ${ }^{4}$}

Die Hinterziehungsentscheidung ist eine Entscheidung unter Risiko: ${ }^{5}$

Mit der Wahrscheinlichkeit $\mathrm{p}$ wird die Minderdeklaration aufgedeckt und neben der Steuer auf das tatsächliche Einkommen eine Geldstrafe auf die hinterzogene Steuer erhoben.

Mit einer Wahrscheinlichkeit von (1-p) bleibt die Steuerhinterziehung unentdeckt; in diesem Fall verbleibt dem Steuerpflichtigen sein gesamtes Bruttoeinkommen abzüglich der Steuer auf das deklarierte Einkommen.

Arbeit von einer Geldbuße ausgegangen, die wie die in Frankreich gesetzlich festgesetzte Ahndung von Steuerumgehungen auf den dem Fiskus vorenthaltenen Geldbetrag bezogen ist. Eine derartige Variation des Grundmodells von ALLINGHAM/SANDMO wurde erstmals von YITZHAKI (1974) S. $201 \mathrm{f}$. vorgenommen.

${ }^{1}$ Vgl. HAGEDORN (1991) S. 6.

${ }^{2}$ Vgl. KOSKELA (PF 1983) S. 71.

${ }^{3}$ Vgl. WREDE (1993) S. 41.

${ }^{4}$ Vgl. ALLINGHAM/SANDMO (1972) S. 324-326 sowie YTTZHAKI (1974) S. 201.

${ }^{5}$ Durch die Prämisse einer den Steuerpflichtigen bekannten Aufdeckungswahrscheinlichkeit wird die in Kap. 2.2 als Entscheidung unter Unsicherheit bezeichnete Deklarationsentscheidung nach wirtschaftswissenschaftlicher Terminologie im Steuerhinterziehungs- bzw. Steuerumgehungsmodell zu einer Entscheidung unter Risiko. Vgl. LUCCKE (1975) S. 64 f. 
Abb. 5.1 stellt die Entscheidungssituation für den Fall eines direkt-progressiven Steuertarifes graphisch dar: ${ }^{1}$

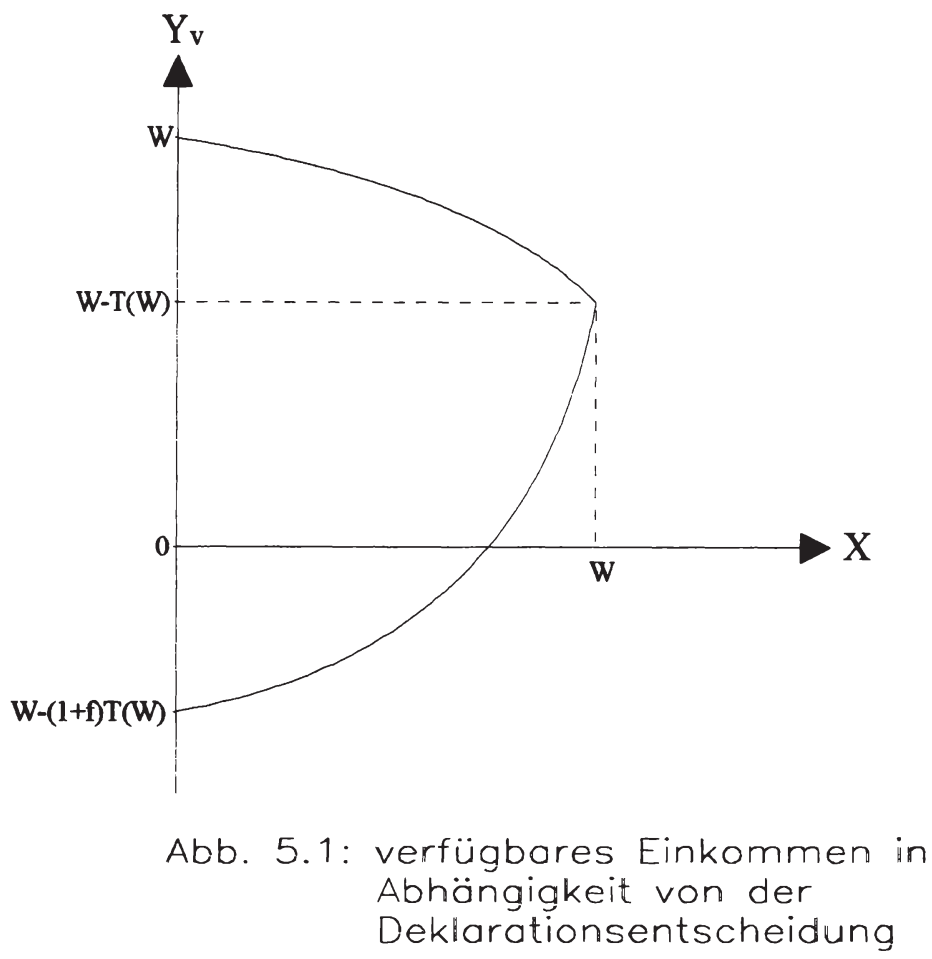

Falls keine Überprüfung ihrer Einkommensdeklaration stattfindet, stehen sich diejenigen Steuerpflichtigen am besten, die überhaupt kein Einkommen deklariert haben; ihnen verbleibt ein verfügbares Einkommen in Höhe von W. Je mehr Einkommen deklariert wurde, desto niedriger wird das verfügbare Einkommen; im Falle $X=W$ beträgt es $W-T(W)$. Wird die Einkommensteuererklärung hingegen überprüf, so ist eine Deklaration von $\mathrm{X}=\mathrm{W}$ mit dem Ergebnis $\mathrm{Y}_{\mathrm{v}}=\mathrm{W}-\mathrm{T}(\mathrm{W})$ die

${ }^{1}$ In der vorliegenden Arbeit wird für alle in Abschnitt 5 enthaltenen Abbildungen (soweit nicht anders gekennzeichnet) von einem Steuertarif ausgegangen, für den (wie international üblich) $T(0)=0$ gilt .

Die hier präsentierte Abb. 5.1 basiert auf einer entsprechenden Graphik in COWELL (1990) S. 52, der allerdings ein proportionaler Steuertarif und ein Strafsatz von genau 1 zugrunde gelegt wurden. 
vorteilhafteste Alternative. Mit sinkender Deklaration vermindert sich das verfügbare Einkommen bis hin $z u \mathrm{Y}_{\mathrm{v}}=\mathrm{W}-(1+\mathrm{f}) * \mathrm{~T}(\mathrm{~W})$ bei $\mathrm{X}=0$.

In dieser Entscheidungssituation unter Unsicherheit werden rational handelnde Steuerpflichtige ihr $\mathrm{X}$ so wählen, daß der Erwartungsnutzen $\mathrm{E}(\mathrm{U})$ maximiert wird. Der Erwartungsnutzen des Einkommens errechnet sich dabei wie folgt:$$
\mathrm{E}(\mathrm{U})=(1-\mathrm{p}) * \mathrm{U}(\mathrm{W}-\mathrm{T}(\mathrm{X}))+\mathrm{p} * \mathrm{U}(\mathrm{W}-\mathrm{T}(\mathrm{W})-\mathrm{f} *(\mathrm{~T}(\mathrm{~W})-\mathrm{T}(\mathrm{X})))
$$$$
(1) \Leftrightarrow E(U)=(1-p) * U(W-T(X))+p * U(W-(1+f) * T(W)+f * T(X)) \text {. }
$$

Zur Ermittlung des Maximums ist es notwendig, die erste und zweite Ableitung der Erwartungsnutzenfunktion zu bestimmen:

Mit Hilfe der Kettenregel ergibt sich für die 1. Ableitung:

$$
\begin{aligned}
\frac{\partial \mathrm{E}(\mathrm{U})}{\partial \mathrm{X}}= & (1-\mathrm{p}) *\left(-\mathrm{T}^{\prime}(\mathrm{X})\right) * \mathrm{U}^{\prime}(\mathrm{W}-\mathrm{T}(\mathrm{X}))+ \\
& +\mathrm{pf} * \mathrm{~T}^{\prime}(\mathrm{X}) * \mathrm{U}^{\prime}(\mathrm{W}-(1+\mathrm{f}) * \mathrm{~T}(\mathrm{~W})+\mathrm{f} * \mathrm{~T}(\mathrm{X}))
\end{aligned}
$$

Setzt man $Y:=W-T(X)$ und $Z:=W-(1+f) * T(W)+f * T(X)$, so ergibt sich nach Umformung

$$
\frac{\partial E(U)}{\partial X}=T^{\prime}(X) *\left[p f * U^{\prime}(Z)-(1-p) * U^{\prime}(Y)\right]
$$

Die Gleichung pf*U'(Z) $=(1-p) * U^{\prime}(Y)$ ist folglich notwendige Bedingung für ein inneres Maximum. Ein inneres Maximum liegt an der Stelle $\frac{\partial \mathrm{E}(\mathrm{U})}{\partial \mathrm{X}}=0$ genau dann vor, wenn an dieser Stelle die 2. Ableitung der Erwartungsnutzenfunktion negativ ist.

Die 2. Ableitung lautet:

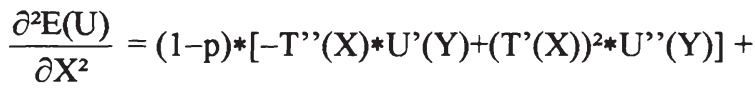

$$
\begin{aligned}
& +p f^{*}\left[T^{\prime \prime}(X) * U^{\prime}(Z)+f *\left(T^{\prime}(X)\right)^{2} * U^{\prime \prime}(Z)\right]
\end{aligned}
$$


Da an der Stelle $\frac{\partial \mathrm{E}(\mathrm{U})}{\partial \mathrm{X}}=0$

$\mathrm{pf} * \mathrm{U}^{\prime}(\mathrm{Z})=(1-\mathrm{p}) * \mathrm{U}^{\prime}(\mathrm{Y})$ gilt, vereinfacht sich an dieser Stelle die 2. Ableitung zu

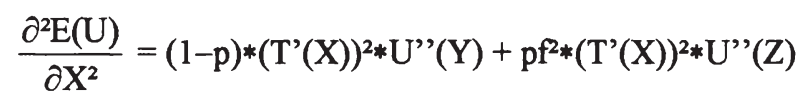

(3) $\Leftrightarrow \frac{\partial^{2} E(U)}{\partial X^{2}}=\left(T^{\prime}(X)\right)^{2} *\left[(1-p) * U^{\prime \prime}(Y)+p f^{2} * U^{\prime \prime}(Z)\right]$

Wegen $\left(\mathrm{T}^{\prime}(\mathrm{X})\right)^{2}>0,1-\mathrm{p}>0, \mathrm{p} * \mathrm{f}^{2}>0$ und $\mathrm{U}^{\prime \prime}<0$ ist die 2 . Ableitung negativ.

Damit existiert für die Erwartungsnutzenfunktion genau dann ein inneres Maximum, wenn es einen Wert für $\mathrm{X}$ gibt, bei dem die 1 . Ableitung null wird. Andernfalls liegt die optimale Strategie bei $X=0$ (vollständige Hinterziehung) oder bei $\mathrm{X}=\mathrm{W}$ (vollständige Steuerehrlichkeit).

Die Alternative „vollständige Hinterziehung“ ist immer dann vorteilhaft, wenn die Erwartungsnutzenfunktion bereits an der Stelle $X=0$ eine negative Steigung aufweist, d.h. wenn

$$
\begin{aligned}
& \left.\frac{\partial E(U)}{\partial X}\right|_{X=0}=T^{\prime}(0) *\left[p f * U^{\prime}(W-(1+f) * T(W)+f * T(0))-(1-p) * U^{\prime}(W-T(0))\right]<0 \\
& \Leftrightarrow p f^{\prime} * U^{\prime}(W-(1+f) * T(W)+f * T(0))<(1-p) * U^{\prime}(W-T(0)) \\
& (4) \Leftrightarrow \frac{U^{\prime}(W-(1+f) * T(W)+f * T(0))}{U^{\prime}(W-T(0))}<\frac{1-p}{p * f}
\end{aligned}
$$

Vollständige Steuerehrlichkeit ist hingegen dann die optimale Strategie, wenn die Steigung von $\mathrm{E}(\mathrm{U})$ an der Stelle $\mathrm{X}=\mathrm{W}$ noch positiv ist, wenn also

$$
\begin{aligned}
& \left.\frac{\partial E(U)}{\partial X}\right|_{X=W}=T^{\prime}(W) *\left[p f^{\prime}(W-(1+f) * T(W)+f * T(W))-(1-p) * U^{\prime}(W-T(W))\right]>0 \\
& \Leftrightarrow p f * U^{\prime}(W-T(W))>(1-p) * U^{\prime}(W-T(W)) \\
& \Leftrightarrow p * f>1-p \\
& (5) \Leftrightarrow 1>\frac{1-p}{p^{*} f} \\
& \Leftrightarrow p *(f+1)>1
\end{aligned}
$$


Gilt jedoch

(6) $1<\frac{1-\mathrm{p}}{\mathrm{p} * \mathrm{f}}<\frac{\mathrm{U}^{\prime}(\mathrm{W}-(1+\mathrm{f}) * \mathrm{~T}(\mathrm{~W})+\mathrm{f} * \mathrm{~T}(0))}{\mathrm{U}^{\prime}(\mathrm{W}-\mathrm{T}(0))}$,

so existiert ein Wert für $\mathrm{X}$ (mit $0<\mathrm{X}<\mathrm{W}$ ), der die Bedingung 1. Ordnung für ein inneres Maximum $\left(\frac{\partial \mathrm{E}(\mathrm{U})}{\partial \mathrm{X}}=0\right)$ erfüllt.

Wegen $\mathrm{W}-(1+\mathrm{f}) * \mathrm{~T}(\mathrm{~W})+\mathrm{f} * \mathrm{~T}(0)<\mathrm{W}-\mathrm{T}(0)$ und $\mathrm{U}$ " $<0$ gilt

$\mathrm{U}^{\prime}(\mathrm{W}-(1+\mathrm{f}) * \mathrm{~T}(\mathrm{~W})+\mathrm{f} * \mathrm{~T}(0))>\mathrm{U}^{\prime}(\mathrm{W}-\mathrm{T}(0))$

bzw. $\frac{\mathrm{U}^{\prime}(\mathrm{W}-(1+\mathrm{f}) * \mathrm{~T}(\mathrm{~W})+\mathrm{f} * \mathrm{~T}(0))}{\mathrm{U}^{\prime}(\mathrm{W}-\mathrm{T}(0))}>1$.

Damit ist gewährleistet, daß es Kombinationen der Parameter W, $p, f$ und der die Steuerfunktion $\mathrm{T}$ bestimmenden Parameter gibt, für die Ungleichung (6) erfullt ist, d.h. für die ein inneres Maximum existiert. Für diesen Fall einer inneren Lösung wird im folgenden der Einfluß von Variationen der genannten Parameter auf die Höhe des deklarierten Einkommens untersucht.

\subsubsection{Der EinfluB von Bruttoeinkommen, Aufdeckungswahrschein- lichkeit, Strafsatz und Steuertarif auf die Höhe des deklarier- ten Einkommens ${ }^{1}$}

\subsubsection{Vorüberlegungen}

In Kap. 5.2.1 wurde unterstellt, daß der Nutzen der Steuerpflichtigen eine Funktion allein des verfugbaren Einkommens $Y_{v}$ ist, wobei von positivem, aber abnehmendem Grenznutzen des Einkommens ausgegangen wird.

Die Prämisse „U”' $\left(\mathrm{Y}_{\mathrm{v}}\right)<0$ “ bedeutet, daß die Nutzenfunktion des Einkommens rechtsgekrümmt ist; hieraus ergibt sich, daß die Wirtschaftssubjekte risikoscheu eingestellt sind. Abb. 5.2 zeigt derartige Bernoulli-Nutzenfunktionen in Abhängigkeit vom Einkommen. ${ }^{2}$

\footnotetext{
${ }^{1} \mathrm{Vgl}$. ALLINGHAM/SANDMO (1972) S. 327-330; YTTZHAKI (1974) S. 201 f.; KOSKELA (PF 1983) S. 74-77.

Zur graphischen Analyse vgl. COWELL (1987) S. 177-182; COWELL (1990) S. 53-65; HAGEDORN (1991) S. 12-19.

${ }^{2}$ Vgl. COWELL (1990) S. 57.
} 


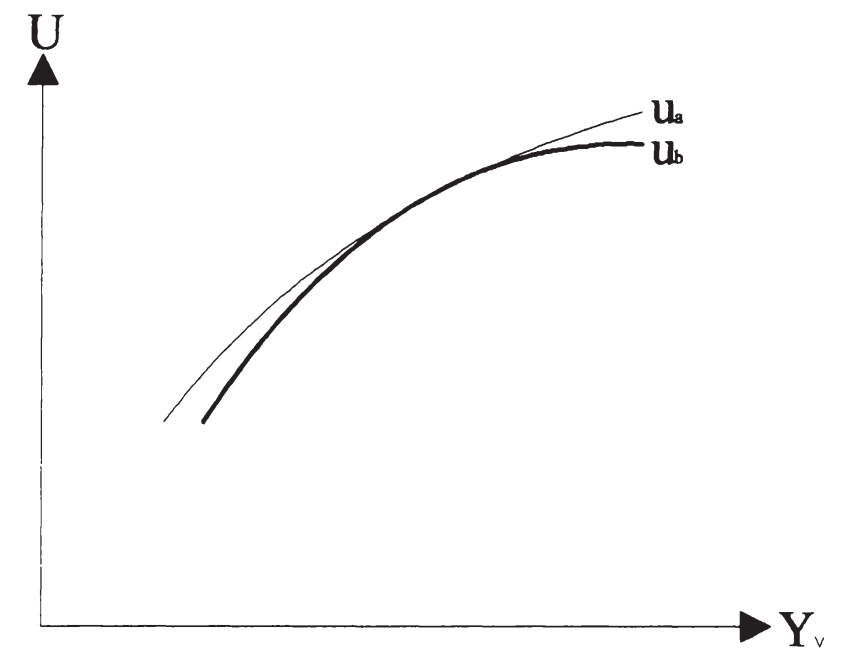

Abb. 5.2: Bernoulli-Nutzenfunktionen

Sie sind wenig rechtsgekrümmt bei geringer Risikoaversion, stark rechtsgekrümmt bei hoher Risikoaversion. Als Maß furr die Krümmung der Nutzenfunktion dient

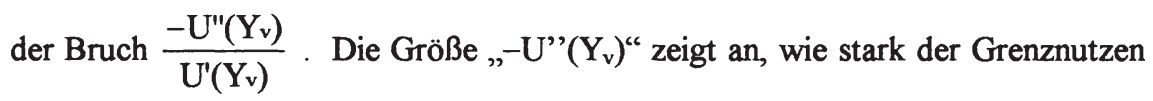
des Einkommens absolut abnimmt; der Bruch $\frac{-U^{\prime \prime}\left(Y_{v}\right)}{U^{\prime}\left(Y_{v}\right)}$ bezeichnet die relative Abnahme von U'( $\left.Y_{v}\right)$ (der Steigung der Nutzenfunktion). Dieses Krümmungsmaß $R_{A}\left(Y_{v}\right)=-\frac{U^{\prime \prime}\left(Y_{v}\right)}{U^{\prime}\left(Y_{v}\right)}$ wird ,absolute Risikoaversion“ genannt.

Man nimmt allgemein an, daß die absolute Risikoaversion mit steigendem Einkommen abnimmt, daß also ein Steuerpflichtiger mit zunehmendem Einkommen eher bereit ist, für eine bestimmte Gewinnaussicht einen bestimmten Geldbetrag zu riskieren. Diese Annahme abnehmender absoluter Risikoaversion wird für die Untersuchung des Einflusses des Steuertarifes sowie des tatsächlichen Einkommens auf das deklarierte Einkommen $\mathrm{X}$ benötigt. Des weiteren wird im folgenden auch 
der Einfluß der Parameter $\mathrm{p}$ und $\mathrm{f}$ auf das Deklarationsverhalten analysiert. Für jeden Parameter wird dabei wie folgt vorgegangen:

$\mathrm{Da}$ im Falle einer inneren Lösung das nutzenmaximierende $\mathrm{X}$ stets bei demjenigen Wert liegt, bei welchem die 1. Ableitung der Erwartungsnutzenfunktion (s.o. Gleichung (2)) den Wert null annimmt, wird zunächst die implizite Funktion gebildet, die die Kombinationen von $\mathrm{X}$ und dem jeweils untersuchten Parameter beschreibt, für die Gleichung (2) gleich null wird. Diese implizite Funktion wird nach dem jeweiligen Parameter partiell abgeleitet. Die Wirkungsrichtung des betreffenden Parameters ergibt sich dann aus dem Vorzeichen der Ableitung.

Kap. 5.2.3 beschränkt sich auf die Herleitung und Darstellung der mathematischen Ergebnisse des entscheidungstheoretischen Modells. Eine Kommentierung und empirische Überprüfung der gewonnenen Resultate findet sich im Anschluß in Kap. 5.3.

Die den Erwartungsnutzen maximierende Einkommensdeklaration läßt sich auch graphisch darstellen. In Abb. 5.3 sind die möglichen Kombinationen des verfuggbaren Einkommens bei Nichtaufdeckung der Steuerhinterziehung $\left(\mathrm{Y}_{\mathrm{v}}=\mathrm{Y}\right)$ und im Aufdeckungsfalle $\left(Y_{v}=Z\right)$ als Gerade $P_{1} P_{2}$ eingezeichnet. $P_{1}$ bezeichnet die optimale Strategie, wenn Ungleichung (5) erfült ist, $P_{2}$ wird gewählt, wenn Ungleichung (4) gilt. Gilt hingegen Ungleichung (6), so existiert eine innere Lösung, d.h. ein Punkt auf $\overline{\mathrm{P}_{1} \mathrm{P}_{2}}$, in dem eine Indifferenzkurve die Gerade tangiert.

Die Steigung der Indifferenzkurven zeigt an, auf wie viele Geldeinheiten der Steuerpflichtige im Aufdeckungsfall zu verzichten bereit ist, wenn dafur das verfugbare Einkommen im Falle der Nichtaufdeckung um eine Einheit steigt. Dieses Substitutionsverhältnis hängt $a b$ von dem Verhältnis der Grenznutzen von $Y$ und $Z$ und den Wahrscheinlichkeiten, mit denen es zu einem verfügbaren Einkommen von $\mathrm{Y}$ bzw. von $\mathrm{Z}$ kommt.

Da $Y_{v}=Y$ mit einer Wahrscheinlichkeit von $(1-p)$ und $Y_{v}=Z$ mit einer Wahrscheinlichkeit von $p$ eintritt, beträgt die Steigung jeder Indifferenzkurve $-\frac{(1-p) * U^{\prime}(Y)}{p^{*} U^{\prime}(Z)}$.

Bei abnehmendem Grenznutzen des Einkommens sind die Indifferenzkurven an jeder Stelle linksgekrümmt.

Die Steigung von $\overline{\mathrm{P}_{1} \mathrm{P}_{2}}$ wird allein vom Strafsatz bestimmt und beträgt $-\mathrm{f}$. 


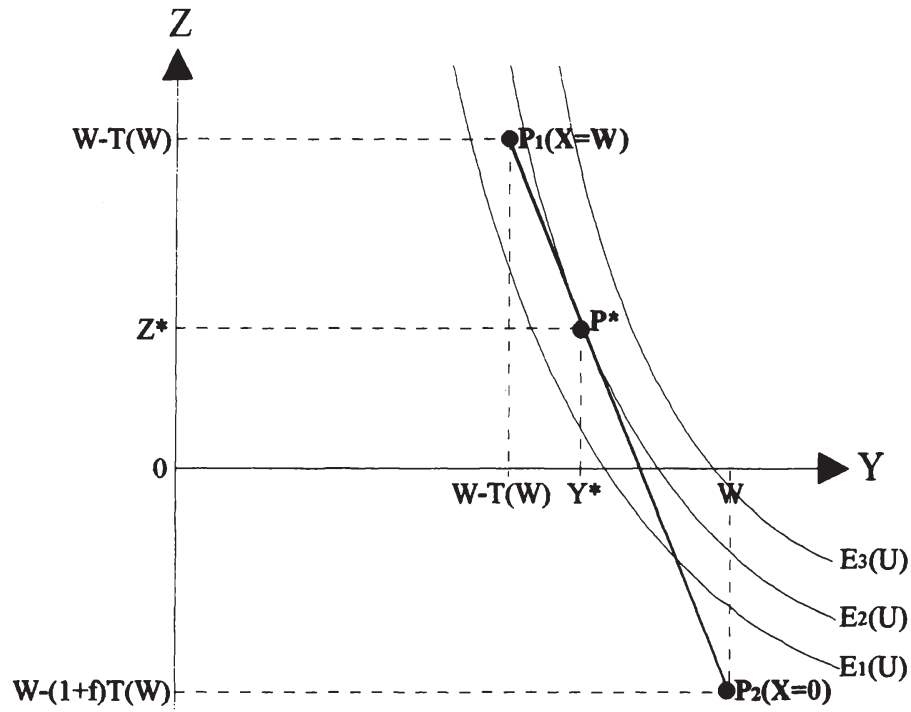

Abb. 5.3: graphische Ermittlung der optimalen Einkommensdeklaration im Steuerhinterziehungsmodell

Im Tangentialpunkt $P^{*}$ gilt dann $f=\frac{(1-p) * U^{\prime}(Y)}{p^{*} U^{\prime}(Z)} \Leftrightarrow p f * U^{\prime}(Z)=(1-p) * U^{\prime}(Y)$, was der Optimalitätsbedingung gemäß Gleichung (2) entspricht.

Der den Erwartungsnutzen des Steuerpflichtigen maximierende Betrag an hinterzogener Steuer ist gleich dem horizontalen Abstand zwischen $\mathbf{P}_{1}$ und $\mathrm{P}^{*}$.

\subsubsection{Der Einfluß des tatsächlichen Einkommens auf die Höhe des dekla- rierten Einkommens}

Diejenigen Parameterkombinationen von $\mathrm{X}$ und $\mathrm{W}$, für die $\frac{\partial \mathrm{E}(\mathrm{U})}{\partial \mathrm{X}}=\mathrm{T}^{\prime}(\mathrm{X}) * \mathrm{pf} * \mathrm{U}^{\prime}(\mathrm{W}-(1+\mathrm{f}) * \mathrm{~T}(\mathrm{~W})+\mathrm{f} * \mathrm{~T}(\mathrm{X}))-\mathrm{T}^{\prime}(\mathrm{X}) *(1-\mathrm{p}) * \mathrm{U}^{\prime}(\mathrm{W}-\mathrm{T}(\mathrm{X}))=0$ 
gilt, werden durch die implizite Funktion $\mathrm{f}(\mathrm{W}, \mathrm{X})=0$ beschrieben. Abgeleitet nach $\mathrm{W}$, ergibt sich nach der Regel zur Ableitung impliziter Funktionen ${ }^{1}$

$$
\frac{\partial \mathrm{X}}{\partial \mathrm{W}}=-\frac{\mathrm{f}_{\mathrm{w}}(\mathrm{W}, \mathrm{X})}{\mathrm{f}_{\mathrm{x}}(\mathrm{W}, \mathrm{X})}=\frac{\mathrm{f}_{\mathrm{w}}(\mathrm{W}, \mathrm{X})}{-\frac{\partial^{2} \mathrm{E}(\mathrm{U})}{\partial \mathrm{X}^{2}}}
$$

mit $\mathrm{f}_{\mathrm{w}}(\mathrm{W}, \mathrm{X})=\mathrm{T}^{\prime}(\mathrm{X}) * \mathrm{pf} * \mathrm{U}^{\prime \prime}(\mathrm{Z}) *\left(1-(1+\mathrm{f}) * \mathrm{~T}^{\prime}(\mathrm{W})\right)-\left(\mathrm{T}^{\prime}(\mathrm{X}) *(1-\mathrm{p}) * \mathrm{U}^{\prime \prime}(\mathrm{Y})\right)$

$$
\begin{aligned}
= & (1-\mathrm{p}) * \mathrm{~T}^{\prime}(\mathrm{X}) * \mathrm{U}^{\prime}(\mathrm{Y}) *\left(-\frac{\mathrm{U}^{\prime \prime}(\mathrm{Y})}{\mathrm{U}^{\prime}(\mathrm{Y})}\right)- \\
& -\mathrm{pf} * \mathrm{~T}^{\prime}(\mathrm{X}) * \mathrm{U}^{\prime}(\mathrm{Z}) *\left(-\frac{\mathrm{U}^{\prime \prime}(\mathrm{Z})}{\mathrm{U}^{\prime}(\mathrm{Z})}\right) *\left(1-(1+\mathrm{f}) * \mathrm{~T}^{\prime}(\mathrm{W})\right) \\
= & (1-\mathrm{p}) * \mathrm{~T}^{\prime}(\mathrm{X}) * \mathrm{U}^{\prime}(\mathrm{Y}) * \mathrm{R}_{\mathrm{A}}(\mathrm{Y})-\mathrm{pf} * \mathrm{~T}^{\prime}(\mathrm{X}) * \mathrm{U}^{\prime}(\mathrm{Z}) * \mathrm{R}_{\mathrm{A}}(\mathrm{Z}) *\left(1-(1+\mathrm{f}) * \mathrm{~T}^{\prime}(\mathrm{W})\right) .
\end{aligned}
$$

$\mathrm{Da}$ die 1. Ableitung der Erwartungsnutzenfunktion gleich null ist, gilt $\mathrm{pf} * \mathrm{U}^{\prime}(\mathrm{Z})=(1-\mathrm{p}) * \mathrm{U}^{\prime}(\mathrm{Y})$ und folglich

$$
\begin{aligned}
f_{w}(W, X)= & (1-p) * T^{\prime}(X) * U^{\prime}(Y) * R_{A}(Y)- \\
& -(1-p) * T^{\prime}(X) * U^{\prime}(Y) * R_{A}(Z) *\left(1-(1+f) * T^{\prime}(W)\right) \\
= & (1-p) * T^{\prime}(X) * U^{\prime}(Y) *\left[R_{A}(Y)-R_{A}(Z)+(1+f) * T^{\prime}(W) * R_{A}(Z)\right] \\
= & (1-p) * T^{\prime}(X) * U^{\prime}(Y) *\left[(1+f) * T^{\prime}(W) * R_{A}(Z)-\left(R_{A}(Z)-R_{A}(Y)\right)\right]
\end{aligned}
$$

Für den Nenner $f_{x}(W, X)=\frac{\partial^{2} E(U)}{\partial X^{2}}$ ergibt sich

$$
\begin{aligned}
& \mathrm{f}_{\mathrm{x}}(\mathrm{W}, \mathrm{X})=\left(\mathrm{T}^{\prime}(\mathrm{X})\right)^{2} *\left[(1-\mathrm{p}) * \mathrm{U}^{\prime \prime}(\mathrm{Y})+\mathrm{pf}^{2} * \mathrm{U}^{\prime \prime}(\mathrm{Z})\right] \quad \text { (s.o. Gleichung (3)) } \\
& =\left(\mathrm{T}^{\prime}(\mathrm{X})\right)^{2} *(1-\mathrm{p}) *\left(-\mathrm{U}^{\prime}(\mathrm{Y})\right) *\left(-\frac{\mathrm{U}^{\prime \prime}(\mathrm{Y})}{\mathrm{U}^{\prime}(\mathrm{Y})}\right)+\left(\mathrm{T}^{\prime}(\mathrm{X})\right)^{2} \mathrm{pf}^{2} *\left(-\mathrm{U}^{\prime}(\mathrm{Z})\right)^{*}\left(-\frac{\mathrm{U}^{\prime \prime}(\mathrm{Z})}{\mathrm{U}^{\prime}(\mathrm{Z})}\right) \\
& =-\left(\mathrm{T}^{\prime}(\mathrm{X})\right)^{2} * \mathrm{pf}^{2} * \mathrm{U}^{\prime}(\mathrm{Z}) * \mathrm{R}_{\mathrm{A}}(\mathrm{Z})-\left(\mathrm{T}^{\prime}(\mathrm{X})\right)^{2} *(1-\mathrm{p}) * \mathrm{U}^{\prime}(\mathrm{Y}) * \mathrm{R}_{\mathrm{A}}(\mathrm{Y}) \\
& =-\left(T^{\prime}(X)\right)^{2} * f^{*} *(1-p) * U^{\prime}(Y) * R_{A}(Z)-\left(T^{\prime}(X)\right)^{2 *}(1-p) * U^{\prime}(Y) * R_{A}(Y) \\
& =-\mathrm{T}^{\prime}(\mathrm{X}) *(1-\mathrm{p}) * \mathrm{U}^{\prime}(\mathrm{Y}) *\left[\mathrm{~T}^{\prime}(\mathrm{X}) * \mathrm{f}^{*} * \mathrm{R}_{\mathrm{A}}(\mathrm{Z})+\mathrm{T}^{\prime}(\mathrm{X}) * \mathrm{R}_{\mathrm{A}}(\mathrm{Y})\right] \\
& =-\mathrm{T}^{\prime}(\mathrm{X}) *(1-\mathrm{p}) * \mathrm{U}^{\prime}(\mathrm{Y}) *\left[(1+\mathrm{f}) * \mathrm{~T}^{\prime}(\mathrm{X}) * \mathrm{R}_{\mathrm{A}}(\mathrm{Z})-\mathrm{T}^{\prime}(\mathrm{X}) *\left(\mathrm{R}_{\mathrm{A}}(\mathrm{Z})-\mathrm{R}_{\mathrm{A}}(\mathrm{Y})\right)\right] \text {. }
\end{aligned}
$$

${ }^{1}$ Eine einfache, in diesem Zusammenhang völlig ausreichende Darstellung dieser Regel findet sich bei BOSCH/JENSEN (1994) S. 207. 
$\Rightarrow \frac{\partial \mathrm{X}}{\partial \mathrm{W}}=-\frac{\mathrm{f}_{\mathrm{W}}(\mathrm{W}, \mathrm{X})}{\mathrm{f}_{\mathrm{X}}(\mathrm{W}, \mathrm{X})}=\frac{(1+\mathrm{f}) * \mathrm{~T}^{\prime}(\mathrm{W}) * \mathrm{R}_{\mathrm{A}}(\mathrm{Z})-\left(\mathrm{R}_{\mathrm{A}}(\mathrm{Z})-\mathrm{R}_{\mathrm{A}}(\mathrm{Y})\right)}{(1+\mathrm{f}) * \mathrm{~T}^{\prime}(\mathrm{X}) * \mathrm{R}_{\mathrm{A}}(\mathrm{Z})-\mathrm{T}^{\prime}(\mathrm{X}) *\left(\mathrm{R}_{\mathrm{A}}(\mathrm{Z})-\mathrm{R}_{\mathrm{A}}(\mathrm{Y})\right)}$

Wegen $\mathrm{Z}<\mathrm{Y}$ gilt aufgrund der Annahme sinkender absoluter Risikoaversion $\mathbf{R}_{\mathbf{A}}(\mathrm{Z})-\mathbf{R}_{\mathbf{A}}(\mathrm{Y})>0$. Damit ist der Subtrahend im Nenner kleiner als im Zähler; im Falle eines direkt-progressiven Tarifs gilt entsprechendes jedoch auch für die Minuenden. Daher ist ungewiß, ob $\frac{\partial \mathrm{X}}{\partial \mathrm{W}}$ größer oder kleiner als 1 ist. Lediglich für den Fall eines konstanten (oder abnehmenden) Grenzsteuersatzes läßt sich eine eindeutige Aussage machen: In diesem Fall gilt $\frac{\partial \mathrm{X}}{\partial \mathrm{W}}<1$; ein Anstieg des wahren Einkommens W führt dann zu einer unterproportionalen Veränderung des deklarierten Einkommens X, d.h. mit steigendem Einkommen steigt der hinterzogene Anteil. Bei direkter Progression ist eine solche Beziehung jedoch nicht gesichert.

$\mathrm{Ob}$ es zu einem absoluten Anstieg des deklarierten Einkommens kommt, ist ebenfalls ungewiß, da nur der Nenner eindeutig positiv ist, während das Vorzeichen des Zählers davon abhängig ist, ob die Ungleichung $\left((1+f) * T^{\prime}(W)-1\right) * R_{A}(Z)+R_{A}(Y)>0$ erfullt ist.

Nur für den Fall $(1+f) * T^{\prime}(W) \geq 1$ ist gesichert, daß $\frac{\partial X}{\partial W}$ positiv ist und folglich mit steigendem tatsächlichen Einkommen die Höhe des deklarierten Einkommens absolut zunimmt; andernfalls hängt dies vom konkreten Verlauf der Risikoaversionsfunktion $\mathrm{ab}$.

In Abb. 5.3 würde ein Anstieg von $W$ den Punkt $P_{1}$ nach rechts oben verschieben. $\mathrm{Ob} \mathrm{P}_{2}$ unter- oder oberhalb seiner Ausgangsposition liegen würde, hinge von der konkreten Gestalt der Steuerfunktion und dem Strafsatz ab. Auf jeden Fall käme es zu einer Rechtsverschiebung von $\mathrm{P}_{2}$, wobei die Neigung von $\overline{\mathrm{P}_{1} \mathrm{P}_{2}}$ unverändert bei 
-f bliebe. Der Abstand zwischen $P_{1}$ und $P^{*}$ würde steigen, die Steuerhinterziehung demnach absolut zunehmen.

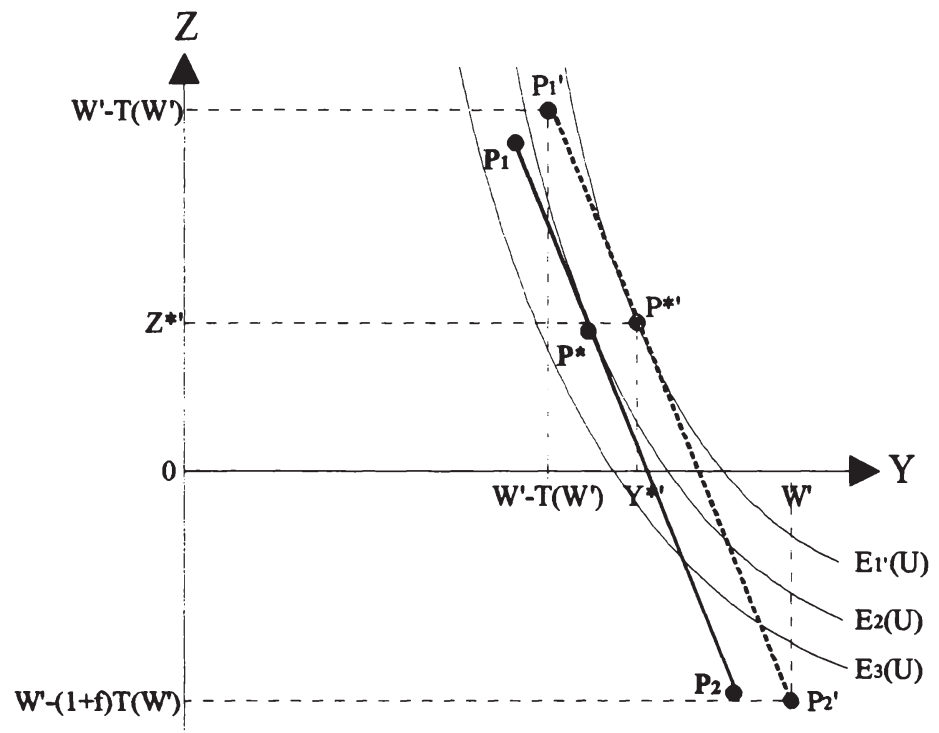

Abb. 5.3.a) Variation der Aufdeckungswahr-
scheinlichkeit $W$

\subsubsection{Der Einfluß der Überprüfungswahrscheinlichkeit auf die Höhe des deklarierten Einkommens}

Diejenigen Parameterkombinationen von $X$ und $p$, fur die $\frac{\partial E(U)}{\partial X}=0$ gilt, werden durch die implizite Funktion $f(p, X)=0$ beschrieben. Abgeleitet nach $p$, ergibt sich $\frac{\partial \mathrm{X}}{\partial \mathrm{p}}=-\frac{\mathrm{f}_{\mathrm{p}}(\mathrm{p}, \mathrm{X})}{\mathrm{f}_{\mathrm{x}}(\mathrm{p}, \mathrm{X})}=-\frac{\mathrm{f} * \mathrm{~T}^{\prime}(\mathrm{X}) * \mathrm{U}^{\prime}(\mathrm{Z})+\mathrm{T}^{\prime}(\mathrm{X}) * \mathrm{U}^{\prime}(\mathrm{Y})}{\frac{\partial^{2} \mathrm{E}(\mathrm{U})}{\partial \mathrm{X}^{2}}}$

$$
=\frac{T^{\prime}(X) *\left(f * U^{\prime}(Z)+U^{\prime}(Y)\right)}{-\frac{\partial^{2} E(U)}{\partial X^{2}}}
$$


Da Zähler und Nenner stets positiv sind, ist $\frac{\partial X}{\partial p}$ eindeutig größer als null. Folglich führt im Modell eine Erhöhung der Überprüfungswahrscheinlichkeit c.p. zu einer Zunahme des deklarierten Einkommens und zu einer Abnahme der Steuerhinterziehung.

Graphisch bedeutet eine Erhöhung von $\mathrm{p}$, daß die Steigung der Indifferenzkurven in Abb. $5.3\left(-\frac{(1-p) * U^{\prime}(Y)}{p * U^{\prime}(Z)}\right)$ betragsmäßig an jeder Stelle abnimmt, d.h., daß die Indifferenzkurven flacher verlaufen. Der Rückgang der Steuerhinterziehung zeigt sich in der Verminderung des Abstandes zwischen den Punkten $\mathrm{P}_{1}$ und $\mathrm{P}^{*}$.

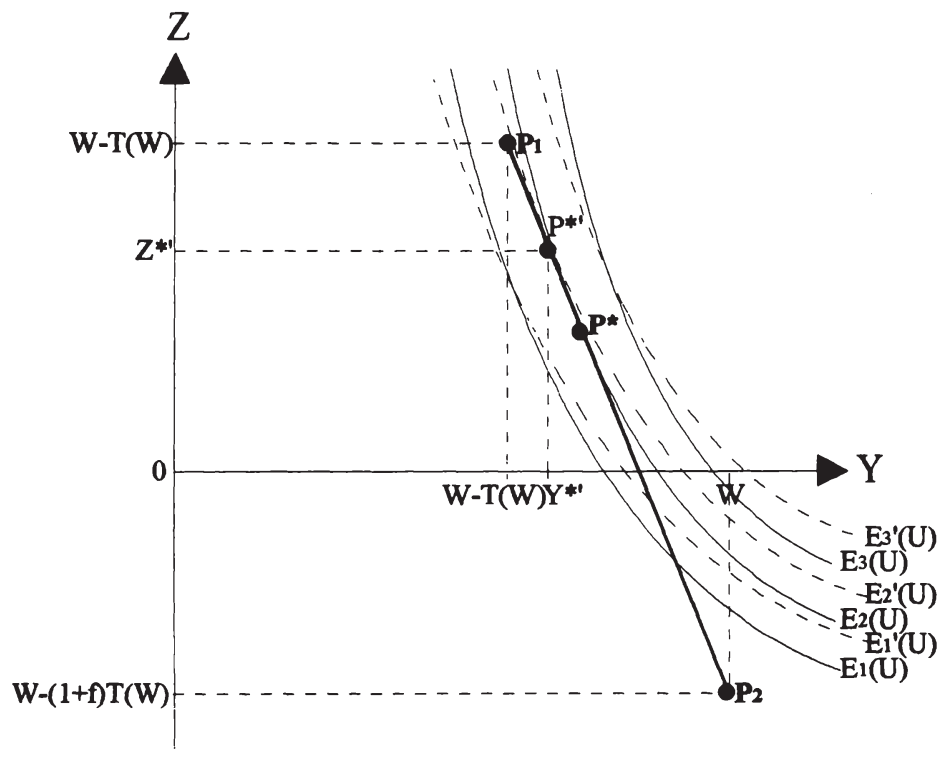

\footnotetext{
Abb. 5.3.b) Variation der Aufdeckungswahrscheinlichkeit $p$
} 


\subsubsection{Der Einfluß des Strafsatzes auf die Höhe des deklarierten Ein- kommens}

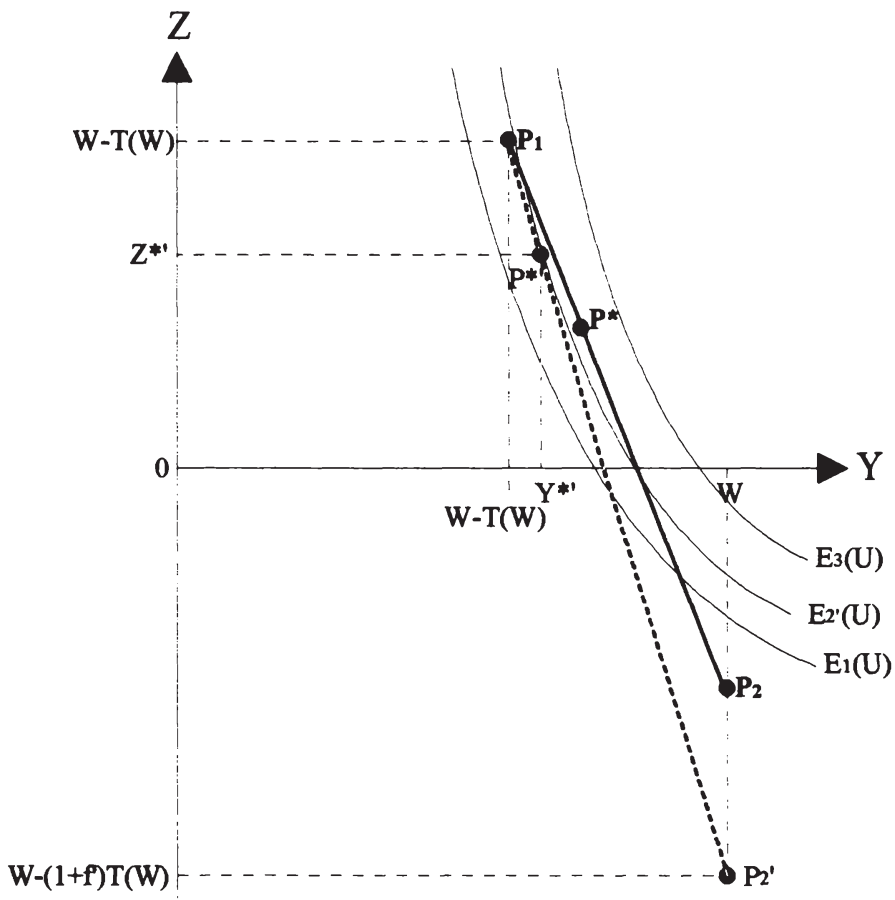

Abb. 5.3.c) Variation des Strafsatzes $f$

Leitet man die implizite Funktion $f(f, X)=0$ nach $f a b$, so ergibt sich

$$
\begin{aligned}
\frac{\partial X}{\partial f} & =-\frac{f(f, X)}{f_{x}(f, X)} \\
& =\frac{p * T(X) * U^{\prime}(Z)+p f * T(X) * U^{\prime \prime}(Z) *(-T(W)+T(X))}{-\frac{\partial^{2} E(U)}{\partial X^{2}}} .
\end{aligned}
$$


Zähler und Nenner des Bruches sind eindeutig positiv, folglich ist $\frac{\partial \mathrm{X}}{\partial \mathrm{f}}$ stets größer als null, so daß eine Erhöhung des Strafsatzes c.p. einen Anstieg des deklarierten Einkommens und damit einen Rückgang der Steuerhinterziehung bewirkt.

In Abb. 5.3 würde ein höherer Strafsatz den Punkt $P_{2}$ (bei unverändert bleibendem $P_{1}$ ) nach unten verschieben. Der Berührungspunkt der damit steiler werdenden Gerade $\overline{\mathbf{P}_{1} \mathbf{P}_{2}}$ mit einer der Indifferenzkurven läge dann weiter links als in der Ausgangsposition, wodurch das Ergebnis einer zurückgehenden Steuerhinterziehung bestätigt wird.

\subsubsection{Der Einfluß des Steuertarifes auf die Höhe des deklarierten Ein- kommens}

Um den Einfluß einer Steuersatzänderung auf das Deklarationsverhalten analog der Vorgehensweise in den vorigen Abschnitten untersuchen zu können, sind bestimmte Annahmen bzgl. des Steuertarifes vonnöten. Im folgenden sei zur Vereinfachung von einem konstanten Grenzsteuersatz $\theta$ ausgegangen, wobei der Steuertarif $T(X)=\theta X-r$ progressiv, proportional oder regressiv sein kann, je nachdem, ob r größer, gleich oder kleiner als null ist. ${ }^{1}$ Ist $r$ positiv, so läßt sich dieser Parameter als Pauschaltransfer vom Staat an den Steuerpflichtigen deuten (z.B. im Rahmen einer negativen Einkommensteuer). Ein negatives $r$ ließe sich als zusätzlich zur allgemeinen Einkommensteuer erhobene Kopfsteuer ähnlich der 1990 vorübergehend in Großbritannien eingefuihrten poll tox interpretieren.

\subsection{Der Einfluß des Steuersatzes auf die Einkommensdeklaration}

Setzt man die Steuertariffunktion $T(X)=\theta X-r$ in Gleichung (1) ein, so ergibt sich für die Erwartungsnutzenfunktion

$E(U)=(1-p) * U(W-\theta X+r)+p * U(W-\theta W+r-f \theta *(W-X))$.

Für die 1. Ableitung wird Gleichung (2) zu $\frac{\partial E(U)}{\partial X}=\theta p f * U^{\prime}(Z)-\theta *(1-p) * U^{\prime}(Y)$

mit $\mathrm{Y}=\mathrm{W}-\theta \mathrm{X}+\mathrm{r}$

und $\mathrm{Z}=\mathrm{W}-\theta \mathrm{W}+\mathrm{r}-\mathrm{f} \theta *(\mathrm{~W}-\mathrm{X})$.

Für die Ableitung der impliziten Funktion $\mathrm{f}(\theta, X)=0$ nach $\theta$ ergibt sich

${ }^{1}$ Einen indirekt-progressiven Steuertarif dieser Form verwendet beispielsweise KOSKELA (JPE 1983) S. $127 \mathrm{ff}$. 


$$
\begin{aligned}
& \frac{\partial \mathrm{X}}{\partial \theta}=-\frac{\mathrm{f}_{\theta}(\theta, \mathrm{X})}{\mathrm{f}_{\mathrm{x}}(\theta, \mathrm{X})} \\
& =-\frac{\mathrm{pf} * \mathrm{U}^{\prime}(\mathrm{Z})+\theta \mathrm{pf} *(-\mathrm{W}-\mathrm{fW}+\mathrm{fX}) * \mathrm{U}^{\prime \prime}(\mathrm{Z})-(1-\mathrm{p}) * \mathrm{U}^{\prime}(\mathrm{Y})+\theta *(1-\mathrm{p}) * \mathrm{X} * \mathrm{U}^{\prime \prime}(\mathrm{Y})}{\frac{\partial^{2} \mathrm{E}(\mathrm{U})}{\partial \mathrm{X}^{2}}} \\
& =\mathrm{S}-\frac{-\theta \mathrm{pf} *(\mathrm{~W}+\mathrm{fW}-\mathrm{fX}) * \mathrm{U}^{\prime \prime}(\mathrm{Z})+\theta *(1-\mathrm{p}) * \mathrm{X}^{*} \mathrm{U}^{\prime \prime}(\mathrm{Y})}{\frac{\partial^{2} \mathrm{E}(\mathrm{U})}{\partial \mathrm{X}^{2}}} \quad\left(\text { mit } \mathrm{S}:=\frac{\mathrm{pf} * \mathrm{U}^{\prime}(\mathrm{Z})-(1-\mathrm{p}) * \mathrm{U}^{\prime}(\mathrm{Y})}{-\frac{\partial^{2} \mathrm{E}(\mathrm{U})}{\partial \mathrm{X}^{2}}}\right)
\end{aligned}
$$

Wegen $p{ }^{*} U^{\prime}(Z)=(1-p) * U^{\prime}(Y)$ gilt $S=0$ und folglich

$$
\begin{aligned}
& \frac{\partial X}{\partial \theta}=-\frac{\theta p f *(W+f *(W-X)) * U^{\prime}(Z) *\left(-\frac{U^{\prime \prime}(Z)}{U^{\prime}(Z)}\right)}{\frac{\partial^{2} E(U)}{\partial X^{2}}}- \\
& -\frac{\theta *(1-\mathrm{p}) * \mathrm{X}^{*} \mathrm{U}^{\prime}(\mathrm{Y}) *\left(-\frac{\mathrm{U}^{\prime \prime}(\mathrm{Y})}{\mathrm{U}^{\prime}(\mathrm{Y})}\right)}{\frac{\partial^{2} \mathrm{E}(\mathrm{U})}{\partial \mathrm{X}^{2}}} \\
& =-\frac{\theta p f * U^{\prime}(\mathrm{Z}) *(\mathrm{~W}+\mathrm{f} *(\mathrm{~W}-\mathrm{X})) * \mathrm{RA}_{\mathrm{A}}(\mathrm{Z})-\theta *(1-\mathrm{p}) * \mathrm{X}^{\prime} * \mathrm{U}^{\prime}(\mathrm{Y}) * \mathrm{R}_{\mathrm{A}}(\mathrm{Y})}{\frac{\partial^{2} \mathrm{E}(\mathrm{U})}{\partial \mathrm{X}^{2}}} \\
& =-\frac{\theta *(1-\mathrm{p}) * \mathrm{U}^{\prime}(\mathrm{Y}) *(\mathrm{~W}+\mathrm{f} *(\mathrm{~W}-\mathrm{X})) * \mathrm{R}_{\mathrm{A}}(\mathrm{Z})-\theta *(1-\mathrm{p}) * \mathrm{U}^{\prime}(\mathrm{Y}) * \mathrm{X} * \mathrm{R}_{A}(\mathrm{Y})}{\frac{\partial^{2} \mathrm{E}(\mathrm{U})}{\partial \mathrm{X}^{2}}} \\
& =-\frac{\theta *(1-\mathrm{p}) * \mathrm{U}^{\prime}(\mathrm{Y}) *\left[(\mathrm{~W}+\mathrm{f} *(\mathrm{~W}-\mathrm{X})) * \mathrm{R}_{\mathrm{A}}(\mathrm{Z})-\mathrm{X} * \mathrm{R}_{\mathrm{A}}(\mathrm{Y})\right]}{\frac{\partial^{2} \mathrm{E}(\mathrm{U})}{\partial \mathrm{X}^{2}}} \\
& =-\frac{\theta *(1-\mathrm{p}) * \mathrm{U}^{\prime}(\mathrm{Y}) *\left[(\mathrm{X}+(\mathrm{f}+1) *(\mathrm{~W}-\mathrm{X})) * \mathrm{R}_{\mathrm{A}}(\mathrm{Z})-\mathrm{X} * \mathrm{R}_{\mathrm{A}}(\mathrm{Y})\right]}{\frac{\partial^{2} \mathrm{E}(\mathrm{U})}{\partial \mathrm{X}^{2}}}
\end{aligned}
$$




$$
=\frac{\theta *(1-\mathrm{p}) * \mathrm{U}^{\prime}(\mathrm{Y}) *\left[\mathrm{X} *\left(\mathrm{R}_{\mathrm{A}}(\mathrm{Z})-\mathrm{R}_{\mathrm{A}}(\mathrm{Y})\right)+(\mathrm{f}+1) *(\mathrm{~W}-\mathrm{X}) * \mathrm{R}_{\mathrm{A}}(\mathrm{Z})\right]}{-\frac{\partial^{2} \mathrm{E}(\mathrm{U})}{\partial \mathrm{X}^{2}}}
$$

Dieser Ausdruck ist bei abnehmender absoluter Risikoaversion stets positiv; ein Anstieg des Steuersatzes führt demnach zu einem Anstieg der Einkommensdeklaration.

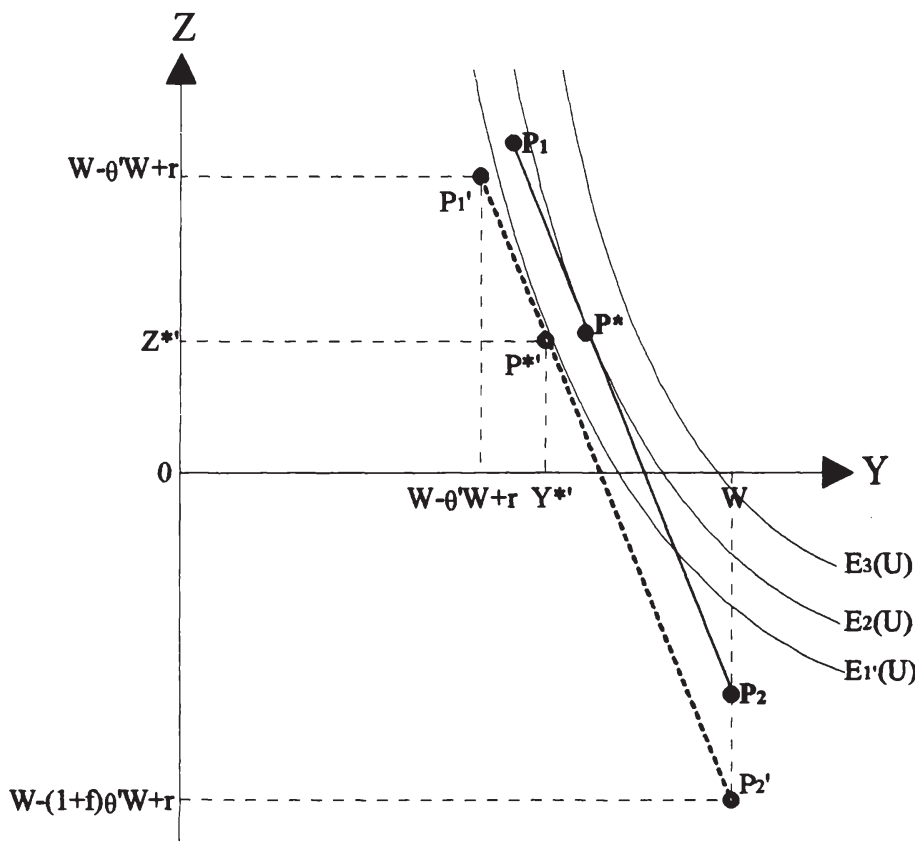

Abb. 5.3.d) Variation des Grenzsteuersatzes $\theta$

Graphisch ist eine Erhöhung des Steuersatzes gleichbedeutend mit einer Verschiebung von $P_{1}$ in Abb. 5.3 nach links unten in Richtung auf den Ursprung i.V.m. einer Verschiebung von $P_{2}$ nach unten, wobei die Steigung von $\overline{P_{1} P_{2}}$ unverändert 
bei $-\mathrm{f}$ bleibt. Der horizontale Abstand zwischen $\mathrm{P}_{1}$ und $\mathrm{P}^{*}$ sinkt, was gleichbedeutend ist mit einem Rückgang der Steuerhinterziehung. ${ }^{1}$

5.2.3.5.2 Der Einfluß des Pauschaltransfers bzw. der Kopfsteuer auf die Einkommensdeklaration

$$
\begin{aligned}
\frac{\partial \mathrm{X}}{\partial \mathrm{r}} & =-\frac{\mathrm{f}_{\mathrm{r}}(\mathrm{r}, \mathrm{X})}{\mathrm{f}_{\mathrm{x}}(\mathrm{r}, \mathrm{X})} \\
& =\frac{\theta p f * \mathrm{U}^{\prime \prime}(\mathrm{Z})-\theta *(1-\mathrm{p}) * \mathrm{U}^{\prime \prime}(\mathrm{Y})}{-\frac{\partial^{2} \mathrm{E}(\mathrm{U})}{\partial \mathrm{X}^{2}}} \\
& =\frac{-\theta p f * \mathrm{U}^{\prime}(\mathrm{Z}) * \mathrm{R}_{\mathrm{A}}(\mathrm{Z})+\theta *(1-\mathrm{p}) * \mathrm{U}^{\prime}(\mathrm{Y}) * \mathrm{R}_{\mathrm{A}}(\mathrm{Y})}{-\frac{\partial^{2} \mathrm{E}(\mathrm{U})}{\partial \mathrm{X}^{2}}} \\
& =\frac{\theta *(1-\mathrm{p}) * \mathrm{U}^{\prime}(\mathrm{Y}) * \mathrm{R}_{\mathrm{A}}(\mathrm{Z})-\theta *(1-\mathrm{p}) * \mathrm{U}^{\prime}(\mathrm{Y}) * \mathrm{R}_{\mathrm{A}}(\mathrm{Y})}{\frac{\partial^{2} \mathrm{E}(\mathrm{U})}{\partial \mathrm{X}^{2}}} \\
& =\frac{\theta *(1-\mathrm{p}) * \mathrm{U}^{\prime}(\mathrm{Y}) *\left[\mathrm{R}_{\mathrm{A}}(\mathrm{Z})-\mathrm{R}_{\mathrm{A}}(\mathrm{Y})\right]}{\frac{\partial^{2} \mathrm{E}(\mathrm{U})}{\partial \mathrm{X}^{2}}}
\end{aligned}
$$

Bei abnehmender absoluter Risikoaversion ist dieser Ausdruck stets negativ, d.h. eine Erhöhung des Pauschaltransfers bzw. eine Senkung der Kopfsteuer führt c.p. zu sinkender Einkommensdeklaration und damit zu steigender Steuerhinterziehung.

In Abb. 5.3 (S. 108) galt in der Ausgangssituation $r=0$. Die Einführung eines Pauschaltransfers würde $\overline{\mathrm{P}_{1} \mathrm{P}_{2}}$ parallel nach rechts oben verschieben. Dabei steigt der Abstand zwischen $\mathrm{P}_{1}$ und $\mathrm{P}^{*}$; das algebraisch ermittelte Ergebnis zunehmender Steuerhinterziehung wird demnach durch die zeichnerische Analyse bestätigt.

\footnotetext{
${ }^{1}$ Vgl. hierzu auch CHRISTIANSEN (1980) S. $392 \mathrm{f}$.
} 


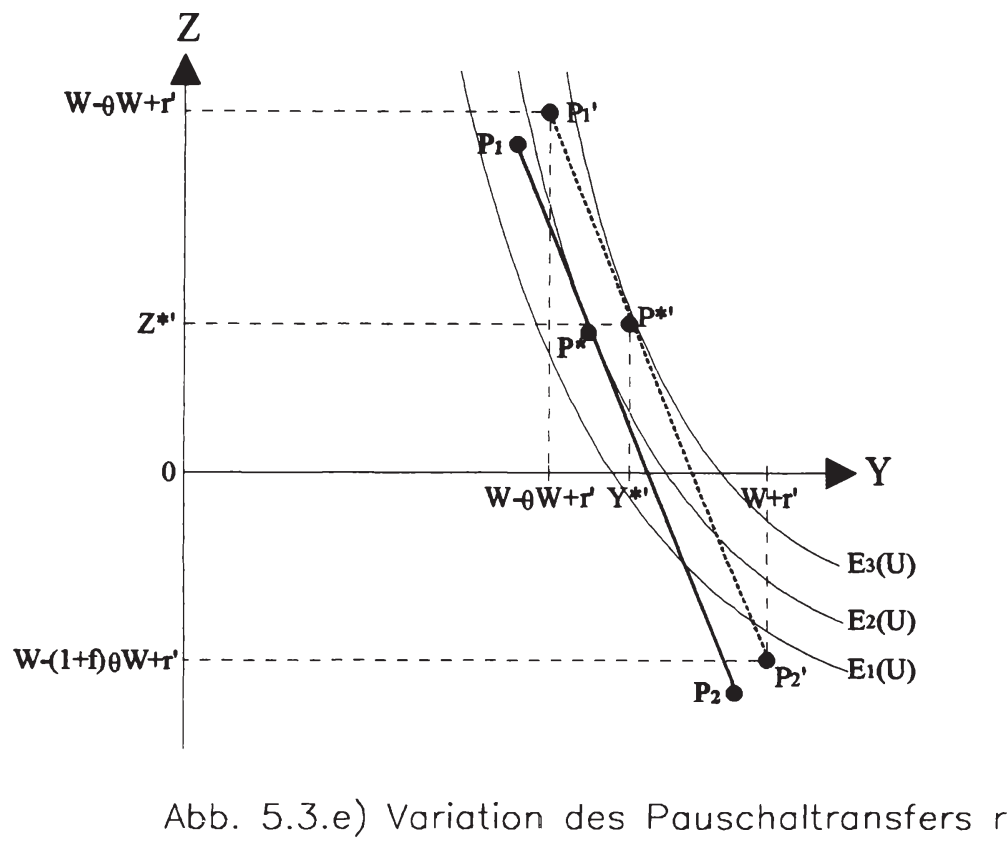

\subsection{Der Einfluß einer Veränderung der Progressivität des Steuertarifes auf die Einkommensdeklaration}

In den Kapiteln 5.2.3.5.1 und 5.2.3.5.2 war untersucht worden, wie sich im Falle eines Steuertarifes der Form $T(X)=\theta X-r$ eine isolierte Veränderung des Steuersatzes $\theta$ bzw. des Pauschaltransfers $r$ auf das Deklarationsverhalten auswirkt. In diesem Kapitel sollen beide Maßnahmen derart miteinander kombiniert werden, daß die erwarteten Einnahmen des Staates aus Steuern und Geldstrafen konstant bleiben. Im Falle einer Progressionsverschärfung ${ }^{1}$ hieße dies, daß Steuersatz und Pauschaltransfer gleichzeitig und insgesamt aufkommensneutral angehoben würden.

${ }^{1}$ Als Progressionsmaß diene die Veränderung des Durchschnittssteuersatzes mit steigender Bemessungsgrundlage $\frac{d\left(\frac{T(X)}{X}\right)}{d X}$. Dieser Ausdruck ist im Falle eines regressiven Tarifs negativ, im Falle eines progressiven Tarifs positiv. Der Steuertarif wird als um so progressiver (bzw. als um so weniger regressiv) bezeichnet, je höher der Wert ist, den das Progressionsmaß annimmt. 
Das erwartete Aufkommen des Staates beträgt $E(A)=\theta X-r+p *(f+1) * \theta *(W-X)$. $\mathrm{Zu}$ untersuchen ist der Einfluß einer Steuersatzvariation auf das deklarierte Einkommen unter der Nebenbedingung, daß die Veränderung von $\theta$ so durch eine Veränderung von $r$ kompensiert wird, daß E(A) konstant bleibt. Die gesamte Auswirkung einer solche Maßnahme auf die Höhe der Einkommensdeklaration setzt sich zusammen aus dem direkten Einfluß der Steuersatzveränderung auf X zuzüglich des Einflusses der Steuersatzvariation, der indirekt (über den veränderten Pauschaltransfer) auf das deklarierte Einkommen ausgeht, d.h.

$$
\left.\frac{\mathrm{dX}}{\mathrm{d} \theta}\right|_{\mathrm{dE}(\mathrm{A})=0}=\frac{\partial \mathrm{X}}{\partial \theta}+\frac{\partial \mathrm{X}}{\partial \mathrm{r}} * \frac{\mathrm{dr}}{\mathrm{d} \theta} \text {. }
$$

Aus $E(A)=\theta X-r+p *(f+1) * \theta *(W-X)$ ergibt sich

$\mathrm{r}=(\mathrm{X}+\mathrm{p} *(\mathrm{f}+1) *(\mathrm{~W}-\mathrm{X})) * \theta-\mathrm{E}(\mathrm{A})$ und folglich (bei Konstanz von $\mathrm{E}(\mathrm{A}))$

$\frac{\mathrm{dr}}{\mathrm{d} \theta}=\mathrm{X}+\mathrm{p} *(\mathrm{f}+1) *(\mathrm{~W}-\mathrm{X})$.

Bei Einbeziehung der Ergebnisse aus 5.2.3.5.1 und 5.2.3.5.2 erhält man dann

$$
\begin{aligned}
& \left.\frac{\mathrm{dX}}{\mathrm{d} \theta}\right|_{\mathrm{dE}(\mathrm{A})=0}=\frac{\partial \mathrm{X}}{\partial \theta}+\frac{\partial \mathrm{X}}{\partial \mathrm{r}} * \frac{\mathrm{dr}}{\mathrm{d} \theta} \\
& =\theta *(1-p) * \mathrm{U}^{\prime}(\mathrm{Y}) * \frac{\mathrm{X} *\left[\mathrm{RA}_{\mathrm{A}}(\mathrm{Z})-\mathrm{RA}_{\mathrm{A}}(\mathrm{Y})\right]+(\mathrm{f}+1) *(\mathrm{~W}-\mathrm{X}) * \mathrm{R}_{\mathrm{A}}(\mathrm{Z})}{-\frac{\partial^{2} \mathrm{E}(\mathrm{U})}{\partial \mathrm{X}^{2}}}- \\
& -\theta *(1-\mathrm{p}) * \mathrm{U}^{\prime}(\mathrm{Y}) * \frac{[\mathrm{X}+\mathrm{p} *(\mathrm{f}+1) *(\mathrm{~W}-\mathrm{X})] *\left[\mathrm{R}_{A}(\mathrm{Z})-\mathrm{R}_{A}(\mathrm{Y})\right]}{-\frac{\partial^{2} \mathrm{E}(\mathrm{U})}{\partial \mathrm{X}^{2}}} \\
& =\theta *(1-p) * U^{\prime}(Y) \frac{(f+1) *(W-X) * R_{A}(Z)-p *(f+1) *(W-X) *\left[R_{A}(Z)-R_{A}(Y)\right]}{-\frac{\partial^{2} E(U)}{\partial X^{2}}} \\
& =\theta *(1-p) * U^{\prime}(Y) *(f+1) *(W-X) * \frac{(1-p) * R_{A}(Z)+p * R_{A}(Y)}{-\frac{\partial^{2} E(U)}{\partial X^{2}}} .
\end{aligned}
$$

Dieser Ausdruck ist stets positiv, d.h. eine Progressionsverschärfung führt im Modell zu einer Erhöhung des deklarierten Einkommens. ${ }^{1}$

${ }^{1}$ Zum gleichen Ergebnis gelangt (auf anderem Wege) KOSKELA (JPE 1983) S. 130, 133. 
Zeichnerisch hat COWELL die Folgen einer derartigen Progressionsverschärfung analysiert. ${ }^{1}$ Die Erhöhung des Steuersatzes bedeutet in der graphischen Darstellung eine Parallelverschiebung von $\overline{\mathrm{P}_{1} \mathrm{P}_{2}}$ nach links unten, die Einführung (oder Erhöhung) eines Pauschaltransfers eine Parallelverschiebung nach rechts oben. Werden beide Teilmaßnahme so bemessen, daß der Erwartungsnutzen des Steuerpflichtigen konstant bleibt, d.h. daß die gleiche Indifferenzkurve durch $\overline{\mathrm{P}_{1} \mathrm{P}_{2}}$ tangiert wird wie in der Ausgangsposition, dann bleibt das Gleichgewicht in $\mathrm{P}^{*}$ (bei ebenfalls unveränderter Lage von $\left.P_{1}\right)$. Das Ausmaß an Steuerhinterziehung $(\theta *(W-X))$ bleibt damit unverändert; da $\theta$ gestiegen ist, muß sich das deklarierte Einkommen $\mathrm{X}$ erhöht haben.

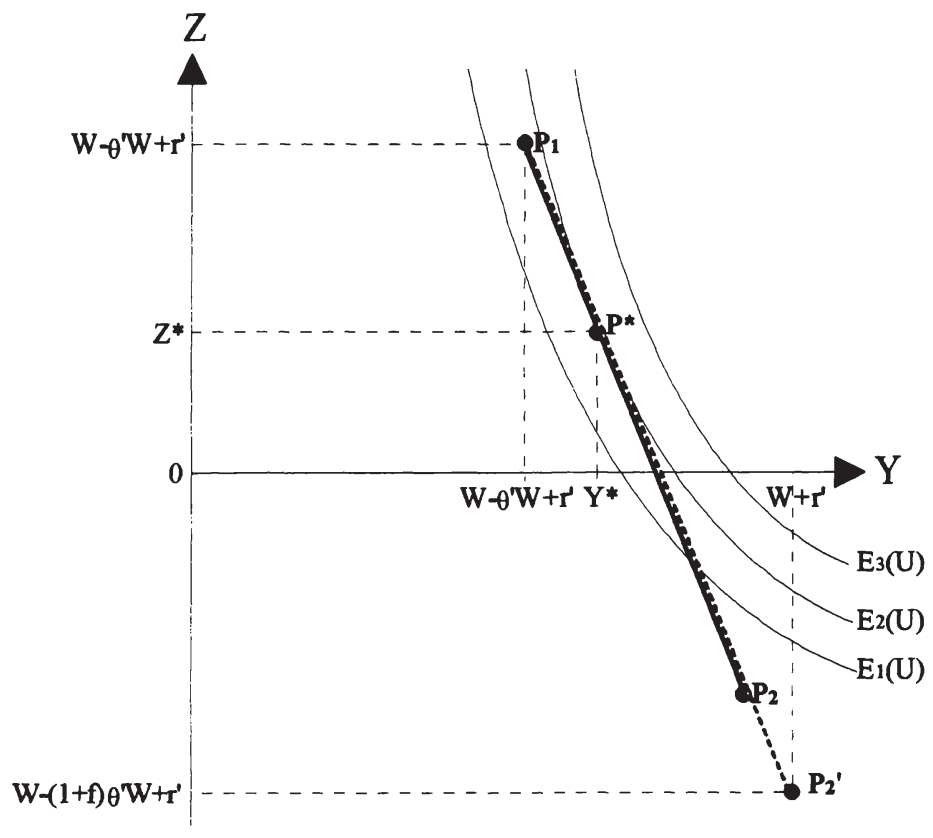

Abb. 5.3.f) Variation des Progressionsgrades

\footnotetext{
${ }^{1} \mathrm{Vgl}$. COWELL (1990) S. 64 f. COWELL hălt dabei allerdings nicht die erwarteten Staatseinnahmen, sondern den erwarteten Einkommensnutzen des Steuerpflichtigen konstant.
} 


\subsection{Empirische Fundierung der Ergebnisse des theoretischen Modells der Hinterziehung}

\subsubsection{Vorbemerkungen}

Mittlerweile existiert eine große Anzahl empirischer Untersuchungen zu den Bestimmungsgründen der Steuerhinterziehung, die sich je nach verwendetem Ansatz in drei Gruppen einteilen lassen: indirekte Erhebungen, Interview-Analysen und experimentelle Simulationsstudien. ${ }^{1}$

In experimentellen Studien wird versucht, die Hinterziehungsentscheidung der Steuerpflichtigen unter Laborbedingungen zu simulieren und auf ihre Einflußfaktoren zu testen. Die Stichprobengröße pflegt sich im zweistelligen Bereich zu bewegen.

Untersuchungen, deren Daten auf Umfragen oder Interviews basieren, liegt meist eine dreistellige Stichprobengröße zugrunde.

Diejenigen Arbeiten, die das Verhalten der Steuerpflichtigen nicht direkt auf dem Wege der Befragung oder der individuellen Beobachtung, sondern indirekt anhand des beobachteten Verhaltens einer aggregierten Gruppe ermitteln, greifen meist auf anonymisierte Daten der nationalen Steuerbehörden zurück. Die Stichprobengröße liegt dann im vier- bis fünfstelligen Bereich.

Für die vorliegende Arbeit wurden zahlreiche Veröffentlichungen aus jeder dieser drei Gruppen herangezogen. Die Ergebnisse der empirischen Forschung werden mit denen des theoretischen Modells sowie den intuitiv erwarteten Resultaten verglichen und eventuelle Abweichungen zu erklären versucht. Zusätzlich zu den in Kap. 5.2.3 verwendeten Variablen W, p, f und $\theta$ werden auch solche Faktoren berücksichtigt, welche die Gelegenheit bzw. die innere Einstellung zur Steuerhinterziehung widerspiegeln. Weitere in einigen Studien verwendete Parameter, welche für den Untersuchungsgegenstand dieser Arbeit keine Rolle spielen (z.B. Alter, Geschlecht und Hautfarbe), werden hingegen nicht behandelt.

\subsubsection{Einkommenshöhe}

Für den Einfluß des tatsächlichen auf das deklarierte Einkommen hatte sich im Modell kein eindeutiges Resultat ergeben. Eine negative Korrelation wäre jedoch lediglich für den Fall $(1+f) * T^{\prime}(W) * R_{A}(Z)<R_{A}(Z)-R_{A}(Y)$ gegeben, was tendenziell nur bei äußerst stark abnehmender Risikoaversion möglich wäre. Andernfalls wird das deklarierte Einkommen mit steigendem W absolut zunehmen; jedoch blieb

\footnotetext{
${ }^{1}$ Vgl. POMMEREHNE (1984) S. 10-17.
} 
unklar, in welche Richtung sich der Anteil des deklarierten am gesamten Einkommen verändern würde.

Auch intuitiv wird man über diesen Zusammenhang kaum eine Aussage machen können; jedoch legt die Intuition nahe, daß ein Einkommensanstieg teilweise dem deklarierten und z.T. dem nicht deklarierten Einkommen zugeführt werden dürfte.

Die bisher durchgeführten empirischen Untersuchungen führten zu ähnlichen Resultaten wie Theorie und Intuition. Sowohl die deklarierten Einkünfte ${ }^{1}$ als auch die hinterzogenen Steuern ${ }^{2}$ nehmen danach mit steigendem Einkommen absolut $\mathrm{zu} . \mathrm{Ob}$ der Anteil des deklarierten Einkommens positiv oder negativ mit dem tatsächlichen Einkommen korreliert ist, war nicht eindeutig festzustellen. ${ }^{3}$ Hingegen fanden zwei der untersuchenden Teams heraus, daß die (stets positive) Korrelation von $\mathrm{W}$ und $\mathrm{X}$ mit steigendem $\mathrm{W}$ abnimmt. ${ }^{4}$

\subsection{3 Überprüfungswahrscheinlichkeit}

$\mathrm{Da}$ im theoretischen Modell eine Erhöhung der Wahrscheinlichkeit einer Überprüfung zu sinkender Hinterziehungstätigkeit führt, entspricht dem gemeinhin erwarteten Ergebnis und ist durch zahlreiche empirische Untersuchungen statistisch gut abgesichert. ${ }^{5}$ Zwar existieren auch empirische Studien, die keinen signifikanten Einfluß der Aufdeckungswahrscheinlichkeit ermitteln konnten, ${ }^{6}$ doch sind dort mit

${ }^{1} \mathrm{Vgl}$. BENJAMINI/MAITAL in GÄRTNER/WENIG (1985) S. 259, WITTE/WOODBURY (1985) S. 9, CRANE/NOURZAD (1986) S. 222, DUBIN/GRAETZ/WILDE (1987) S. 244, BÜCHNER (1988) S. 40, CRANE/NOURZAD (1990) S. 195, 197.

${ }^{2}$ Vgl. MORK (1975) S. 71, CLOTFELTER (1983) S. 368, SLEMROD (1985) S. 238, BENJAMINI/ MAITAL in GÄRTNER/WENIG (1985) S. 257, POMMEREHNE/WECK-HANNEMANN (1992) S. 454. Dabei läßt SLEMROD offen, ob eine Einkommenserhöhung unmittelbar oder nur indirekt über den mit ihr verbundenen Anstieg des Grenzsteuersatzes die Steuerhinterziehung fordert (vgl. auch MORK S. 74).

(Bei SPICER/LUNDSTEDT (1976) S. 298 f., 303 ergab sich kein Einfluß der Einkommenshöhe auf den von den Verfassern konstruierten, nicht näher präzisierten tax evasion index.)

${ }^{3}$ Bei MORK (1975) S. 71 und BENJAMINI/MATTAL in GÄRTNER/WENIG (1985) S. 259 ergab sich ein negativer, bei CLOTFELTER (1983) S. 368, CRANE/NOURZAD (1986) S. 222 und CRANE/NOURZAD (1990) S. 195 ff. ein positiver und bei BÜCHNER (1988) S. 40 f. kein signifikanter Zusammenhang.

${ }^{4}$ Vgl. WITTE/WOODBURY (1985) S.9, DUBIN/GRAETZ/WILDE (1987) S. 244.

${ }^{5} \mathrm{Vgl}$. FRIEDLAND/MAITAL/RUTENBERG (1978) S. $113 \mathrm{f}$., ISACHSEN/SAMUELSON/STRØM in GÄRTNER/WENIG (1985) S. 240, CRANE/NOURZAD (1986) S. 221, DUBIN/GRAETZ/WILDE (1987) S. 243 f., POTERBA (1987) S. 236, BÜCHNER (1988) S. 40 f., DUBIN/WILDE (1988) S. 70 f., KLEPPER/NAGIN (1989) S. $22 \mathrm{f}$.

${ }^{6} \mathrm{Vgl}$. SPICER/LUNDSTEDT (1976) S. 303, WITTE/WOODBURY (1985) S. 7 (vgl. hierzu auch die Anmerkungen bei DUBIN/GRAETZ/WILDE (1987) S. 242), BENJAMINI/MAITAL in GÄRTNER/ WENIG (1985) S. 256, POMMEREHNE/WECK-HANNEMANN (1992) S. 454. 
Ausnahme der Untersuchung von POMMEREHNE und WECK-HANNEMANN die zugrunde liegenden Regressionsgleichungen dahingehend fehlspezifiziert, als - wie im theoretischen Grundmodell der Steuerhinterziehung - die Variable p als exogen gegeben angenommen wird. ${ }^{1}$ Wenn jedoch die Finanzbehörde ungefähre Vorstellungen vom wahren Einkommen der Steuerpflichtigen besitzt und die Überprüfungswahrscheinlichkeit deshalb von der Höhe des deklarierten Einkommens abhängig macht, also schwerpunktmäßig dort prüft, wo eine Hinterziehung vermutet wird, ${ }^{2}$ dann kann in den Schätzungen ein positiver Einfluß von $\mathrm{p}$ auf $\mathrm{X}$ durch einen negativen Einfluß von $X$ auf $p$ überdeckt werden, so daß sich insgesamt keine oder gar eine negative Korrelation zwischen beiden Variablen ergibt. ${ }^{3}$ Wird jedoch die Endogenität von $\mathrm{p}$ im empirischen Modell berücksichtigt, so stellt sich in fast allen Untersuchungen der erwartete positive Einfluß der Aufdeckungswahrscheinlichkeit auf das Deklarationsverhalten ein. ${ }^{4}$

\subsubsection{Strafsatz}

Der im theoretischen Modell ermittelte positive Einfluß einer Strafverschärfung auf das Deklarationsverhalten entspricht den Erwartungen bzgl. des Verhaltens rational handelnder Wirtschaftssubjekte. Diverse empirische Arbeiten haben diesen $\mathrm{Zu}$ sammenhang zwischen Geldbuße und Steuerehrlichkeit bestätigen können. ${ }^{5}$ Während HANSSON nur eine schwache abschreckende Wirkung feststellen konnte, ${ }^{6}$ kamen sowohl die Simulationsstudie von FRIEDLAND, MAITAL und RUTENBERG als auch die indirekte Erhebung von CRANE und NOURZAD (US-Daten von 19471981) zu dem Ergebnis, daß eine Anhebung der Geldstrafen ein wirksameres Instrument zur Eindämmung der Steuerhinterziehung sei als eine Erhöhung der

${ }^{1}$ Vgl. hierzu auch die Anmerkungen in Kap. 5.4 zu Prämisse 5.

${ }^{2}$ Ein solcher Einfluß von $X$ auf $p$ findet bei DUBIN/WILDE (1988) empirische Bestătigung (S. 70).

${ }^{3} \mathrm{Vgl}$. DUBIN/GRAETZ/WILDE (1987) S. 241.

${ }^{4}$ Die Aufdeckungswahrscheinlichkeit - wie CLOTFELTER (1983) - als erklärende Variable einfach fortzulassen und damit das Problem ihrer Endogenität zu umgehen ist unangemessen und fuihrt zu verzerrten Ergebnissen. Zwar mag für viele Steuerpflichtige, die kaum Gelegenheit zur Hinterziehung haben, die Variable $\mathrm{p}$ weitgehend irrelevant sein; daraus eine vernachlässigbare Bedeutung der Aufdeckungswahrscheinlichkeit für die Steuerhinterziehung herzuleiten ist jedoch ein Fehlschluß, solange bei denjenigen Steuerpflichtigen, welche Hinterziehungsmöglichkeiten besitzen und auf die es hier entscheidend ankommt, die vermutete Wahrscheinlichkeit einer Überprüfung die Entscheidungsfindung eben doch beeinflußt. Vgl. hierzu GRAETZ/WILDE (1985) S. 362 (Endnote 16).

${ }^{5} \mathrm{Vgl}$. FRIEDLAND/MAITAL/RUTENBERG (1978) S. 113 f., GEEROMS/WLMOTS (1985) S. 205, HANSSON in GÄRTNER/WENIG (1985) S. 296 f., CRANE/NOURZAD (1986) S. 221, KLEPPER NAGIN (1989) S. 22.

${ }^{6}$ Vgl. auch KINSEY (1986) S. 409. 
Aufdeckungswahrscheinlichkeit. Für GEEROMS und WLMOTS stellt das Instrument der Geldbuße sogar "the only effective way" zur Bekämpfung der Steuerhinterziehung dar.

Demgegenüber kamen andere empirische Studien zu keinem signifikanten Ergebnis bzgl. der Auswirkung einer Sanktionsverschärfung auf das allgemeine Hinterziehungsverhalten. ${ }^{1}$

Die Effektivität von Variationen des Parameters f bleibt daher insgesamt ungewiß. Bildet man einen „Durchschnitt“ aus den Ergebnissen der vorhandenen Untersuchungen, so kann man davon ausgehen, daß die Strafhöhe einen gewissen Einfluß auf das Deklarationsverhalten ausübt, ein Teil der abschreckenden Wirkung jedoch möglicherweise durch eine Art „Trotzreaktion“ kompensiert wird. ${ }^{2}$

\subsubsection{Grenzsteuersatz}

In aller Regel wird davon ausgegangen, daß höhere Steuersätze zu vermehrter Steuerhinterziehung führen. ${ }^{3}$

Die Steuerhinterziehungstheorie kommt jedoch zu einem gegenteiligen Ergebnis. Zwar erhöht ein Steuersatzanstieg den Grenzertrag des nicht deklarierten Einkommens (Substitutionseffekt); doch wenn die Geldbuße auf die hinterzogene Steuer bemessen wird, so steigen gleichzeitig mit dem Grenzertrag im Nichtaufdeckungsfall die Grenzkosten im Falle der Aufdeckung. Im Modell beträgt der erwartete marginale Nutzenverlust durch die aufgedeckte Minderdeklaration pf $\theta * U^{\prime}(Z)$, der erwartete marginale Nutzenzuwachs durch eine erfolgreiche Minderdeklaration $(1-p) * \theta * U^{\prime}(Y)$. Welcher der beiden Effekte überwiegt, hängt (neben dem Verlauf des Grenznutzens des verfügbaren Einkommens) insb. von der Höhe der Parameter $\mathrm{p}$ und $\mathrm{f} a \mathrm{~b}$. Bei hohem Strafsatz und hoher Aufdeckungswahrscheinlichkeit wird die Wirkung einer aufgrund eines gestiegenen Grenzsteuersatzes höheren Geldbuße stärker sein als die Wirkung des höheren möglichen Ertrages der Steuerhinterziehung. Im umgekehrten Fall (niedrige Werte für $p$ und $f$ ) wäre die abschreckende Wirkung der ggf. höheren Geldbuße geringer als der Anreiz, aufgrund des gestiegenen Grenzertrages des nicht deklarierten Einkommens dieses auszuweiten.

${ }^{1}$ Vgl. SPICER/LUNDSTEDT (1976) S. 303, WITTE/WOODBURY (1985) S. 7, POMMEREHNE/ WECK-HANNEMANN (1992) S. 454, 457.

2 So können Strafverschärfungen die Einstellung zum Staat insgesamt verschlechtern und der verstärkte staatliche Druck eine Gegenreaktion der Steuerzahler hervorrufen, welche eine stärkere Bereitschaft zum Steuerwiderstand beinhaltet. Vgl. hierzu auch Kap. 5.3.6 dieser Arbeit sowie HOUGHTON in IEA (1979) S. 89 [98 f.].

${ }^{3} \mathrm{Vgl}$. beispielsweise MYDDELTON in IEA (1979) S. 46 f., DAVIES in IEA (1979) S. 72, SWAN in COLLINS (1984) S. $48 \mathrm{f}$. 
Unter den Bedingungen des theoretischen Modells sind jedoch im Falle eines inneren Maximums der Erwartungsnutzenfunktion die Parameter $p$ und $f$ so bemessen, daß die Gleichung $p f \theta * U^{\prime}(Z)=(1-p) * \theta * U^{\prime}(Y) \Leftrightarrow p f * U^{\prime}(Z)=(1-p) * U^{\prime}(Y)$ gilt.

Der gesamte Substitutionseffekt $S=\frac{p f * U^{\prime}(Z)-(1-p) * U^{\prime}(Y)}{-\frac{\partial^{2} E(U)}{\partial X^{2}}}$

ist in diesem Fall unabhängig von $\theta$ stets gleich null; ein Anstieg von $\theta$ erhöht „beide Teile“ des Substitutionseffektes um den gleichen Faktor, Anreiz- und Abschreckungswirkung einer Steuersatzerhöhung gleichen sich damit exakt aus.

Somit verbleibt als Effekt einer Steuersatzerhöhung nur noch der Einkommenseffekt, welcher darin besteht, daß eine höhere Steuerlast das Einkommen der Steuerpflichtigen und damit deren Risikobereitschaft senkt. Als Entscheidung unter Risiko wird die Steuerhinterziehung infolge eines Anstiegs des Grenzsteuersatzes unter den Modellbedingungen zurückgehen.

Dieses eher unerwartete Ergebnis wird durch die Empirie nicht bestätigt. Soweit ersichtlich ermittelte bislang keine einzige Studie einen signifikant positiven $\mathrm{Zu}$ sammenhang zwischen Grenzsteuersatz und Einkommensdeklaration. Im Gegenteil gelangen fast alle empirischen Untersuchungen zu dem Schluß, daß höhere Grenzsteuersätze die Hinterziehung fördern. ${ }^{1}$

Der hier bestehende strenge Gegensatz zwischen den Ergebnissen von Theorie und Empirie legt nahe, den der Steuerhinterziehungstheorie zugrunde liegenden Rahmen zu hinterfragen. Zunächst einmal stellt sich die Frage, ob der partialanalytische Ansatz dem Untersuchungsgegenstand angemessen ist. Im Modell ist der Einkommenseffekt negativ, da die individuelle Steuerzahlung den Konsum öffentlicher Güter nicht signifikant erhöht und deshalb vernachlässigt werden kann. ${ }^{2}$ Gesamtwirtschaftlich betrachtet bleibt jedoch die staatliche Verwendung der Steuereinnahmen nicht ohne Einfluß auf die Nutzenposition der Steuerpflichtigen. Werden die Steuersätze erhöht, so sinkt zwar der Nutzen, den die Steuerpflichtigen aus dem Konsum privater Güter ziehen, jedoch steigt auf der anderen Seite auch der Nutzen aus dem Konsum öffentlicher Güter. Liegt eine Unterversorgung mit öf-

${ }^{1}$ Vgl. FRIEDLAND/MATTAL/RUTENBERG (1978) S. 113 f., CLOTFELTER (1983) S. 368, SLEMROD (1985) S. 236 (bei SLEMROD wird nur die gemeinsame Wirkung eines Einkommens- und Steuersatzanstieges ermittelt, vgl. ebenda, S. 238), ISACHSEN/SAMUELSON/STRØM in GÄRTNER/WENIG (1985) S. 240, BENJAMINI/MAITAL in GÄRTNER/WENIG (1985) S. 256, 259, CRANE/NOURZAD (1986) S. 221, POTERBA (1987) S. 237, RICE (1990) S. 83, CRANE/ NOURZAD (1990) S. 195, POMMEREHNE/WECK-HANNEMANN (1992) S. 454. Lediglich bei GEEROMS/WILMOTS (1985) S. 199, 205 ergibt sich ergibt sich ein schwach negativer Zusammenhang zwischen der Höhe der Steuersätze und dem Ausmaß an Steuerhinterziehung.

${ }^{2}$ Vgl. hierzu FALKINGER (1988) S. 392. 
fentlichen Gütern vor, dann wirkt eine Steuererhöhung für das durchschnittliche Wirtschaftssubjekt wohlfahrtserhöhend; dessen Risikoaversion nimmt ab, die Steuerhinterziehung nimmt c.p. zu. Umgekehrt führt eine Steuererhöhung c.p. zu einem Rückgang der Steuerhinterziehung, falls eine Überversorgung mit öffentlichen Gütern vorliegt. Im Falle eines optimalen Angebotes an öffentlichen Gütern sind der Grenznutzen aus dem Konsum privater Güter und der Grenznutzen aus dem Konsum öffentlicher Güter für das repräsentative Wirtschaftssubjekt gleich hoch, so daß der Einkommenseffekt gleich null ist. ${ }^{1}$

Somit ist ein positiver Einkommenseffekt nicht mehr gewährleistet, während auf der anderen Seite der ermittelte Substitutionseffekt i.H.v. null von den speziellen Prämissen des Grundmodells abhängt. So wird der Substitutionseffekt eindeutig negativ, wenn die Prämisse nicht vorhandener Grenzkosten der Steuerhinterziehung fallengelassen wird (s.u. Kap. 5.5.2).

Das empirisch ermittelte Ergebnis eines negativen Zusammenhanges zwischen Grenzsteuersatz und Einkommensdeklarationen steht somit durchaus mit der Theorie im Einklang, wenn man bzgl. des Einkommenseffektes die einzelwirtschaftliche Betrachtungsweise verläßt und ferner die Prämisse „kostenfreier“ Steuerhinterziehung aufgibt.

\subsubsection{Sonstige Einflubfaktoren}

Neben den im Grundmodell der Steuerhinterziehung enthaltenen Bestimmungsfaktoren haben in den vorhandenen empirischen Arbeiten verschiedene weitere Parameter Berücksichtigung gefunden. Hier seien diejenigen Einflußfaktoren aufgefürt, deren Analyse auch für eine Bekämpfung der Steuerumgehung hilfreiche Erkenntnisse liefert.

Diverse Untersuchungen haben sich mit dem Einfluß von Quellensteuern auf das Ausmaß an Steuerhinterziehung befaßt. ${ }^{2}$ Hierbei ergab sich ausnahmslos ein signifikant negativer Zusammenhang zwischen Quellenbesteuerung und der Hinterziehung von Einkommensteuern. ${ }^{3}$

Die empirischen Resultate zeigen, daß eine Beschneidung der Möglichkeiten zur Steuerhinterziehung zu den effektivsten Methoden ihrer Bekämpfung gehört.

${ }^{1}$ Vgl. COWELL (1990) S. 67 f.; HANSSON in GÄRTNER/WENIG (1985) S. 292; PETERSEN in SCHÄFER (1984) S. 81.

${ }^{2} \mathrm{Zu}$ der Bedeutung von Quellensteuern im theoretischen Modell s.u. Kap. 5.4 (Anmerkungen zu Prämisse 7).

${ }^{3} \mathrm{Vgl}$. CLOTFELTER (1983) S. 368, WTTTE/WOODBURY (1985) S. 8, CRANE/NOURZAD (1986)

S. 221, DUBIN/WILDE (1988) S. 68, POMMEREHNE/WECK-HANNEMANN (1992) S. 454. 
Als weiterer im Grundmodell nicht enthaltener Bestimmungsfaktor fur die Steuerhinterziehung sei ferner die Einstellung zum Staat, vor allem zum Staatshaushalt, genannt. Der Einbeziehung einer solchen Variablen liegt die Beobachtung zugrunde, daß viele Steuerpflichtige mehr Einkommen deklarieren, als sie es unter der alleinigen Zielsetzung einer Maximierung des Erwartungsnutzens aus dem verfügbaren Einkommen tun würden. Sinkt jedoch die Akzeptanz des politischen Systems, insbesondere des Steuersystems, so ist eine zunehmende Anzahl von Bürgern bereit, dem Staat die ihm zustehenden Abgaben vorzuenthalten, ohne sich dabei von ihrem Gewissen leiten zu lassen bzw. ohne dabei überhaupt Gewissenskonflikte zu empfinden.

Diejenigen empirischen Untersuchungen, die die Einstellung zu Steuer und Staat in ihren Schätzungen als Bestimmungsfaktor furr die Hinterziehungsentscheidung berücksichtigt haben, kamen einhellig zu dem Ergebnis, daß ein signifikant positiver Einfluß auf das Deklarationsverhalten besteht. ${ }^{1}$ Während WITTE und WOODBURY nur allgemein einen Einfluß der Einstellung zum Staat auf die Höhe der hinterzogenen Steuern feststellen und über die Bestimmungsgründe für jene Einstellung lediglich spekulieren, heben GEEROMS und WLMOTS die Bedeutung des Äquivalenzprinzips hervor: Steuerwiderstand entstünde vor allem dort, wo die vom Staat empfangenen Leistungen niedriger eingeschätzt werden als die persönliche Steuerlast. SPICER und LUNDSTEDT sehen eher Verstöße gegen das Leistungsfähigkeitsprinzip als Ursache für eine negative Einstellung zum Steuersystem. Gewinnt die Masse der Steuerzahler den Eindruck, daß gerade der wohlhabendere Teil der Bevölkerung sowie die großen Unternehmen nicht genügend zur Finanzierung der Staatsausgaben beitragen, so steige der Steuerwiderstand. Eine statistisch signifikante Rolle spielt nach den Untersuchungsergebnissen von SPICER/LUNDSTEDT auch die Anzahl der persönlich bekannten Steuerhinterzieher: Je mehr die Steuerzahler annehmen, daß (auch) die anderen Steuerpflichtigen einen Teil ihrer Abgaben hinterziehen, desto mehr neigen sie selbst zur Steuerhinterziehung. ${ }^{2}$ Dies mag auch ein Grund für die von POMMEREHNE und WECK-HANNEMANN angesprochene geringe Wirksamkeit moralischer Appelle sein. ${ }^{3}$ Moralische Appelle an die Steuerehrlichkeit machen den Steuerpflichtigen deutlich bewußt, daß in der Gesellschaft eine größere Anzahl von Steuerhinterziehern existiert; ansonsten würden

${ }^{1}$ Vgl. SPICER/LUNDSTEDT (1976) S. 302 f., GEEROMS/WLMOTS (1985) S. 203/205, WITTE/ WOODBURY (1985) S. 8-10, POMMEREHNE/WECK-HANNEMANN (1992) S. 455/460 f.; vgl. ferner KINSEY (1986) S. 410 m.w.N.

${ }^{2}$ Dieses Ergebnis wird durch eine Studie von MILLER in IEA (1979) S. $117 \mathrm{f}$. (Befragung von 712 Steuerpflichtigen) bestätigt. Demgegenüber konnten SPICER/HERO (1985) in einem Laborexperiment mit 36 Studenten keinen derartigen Zusammenhang feststellen (S. 265 f.). Die Verfasser sahen als Ursache für ihr abweichendes Ergebnis die in Laboruntersuchungen im Gegensatz zur „realen“ Steuerhinterziehung fehlende Rufschädigung durch aufgedeckte Steuervergehen. Diese Rufschädigung ist um so geringer, je mehr Menschen derartige Vergehen betreiben.

${ }^{3}$ Vgl. POMMEREHNE/WECK-HANNEMANN (1992) S. 437 f., 440. 
solche Aufrufe unterbleiben. Eine eventuelle positive Beeinflussung des Gewissens einiger Steuerpflichtiger kann dadurch sogar überkompensiert werden, wenn - wie von SPICER und LUNDSTEDT festgestellt - der Glaube an das Deklarationsverhalten der übrigen Steuerzahler einen Bestimmungsfaktor für die persönliche Hinterziehungsentscheidung darstellt.

Ausfuihrlich befassen sich POMMEREHNE und WECK-HANNEMANN mit den Bestimmungsgründen für die Steuermoral. So führen sie den von CRANE und NOURZAD für die USA festgestellten negativen Einfluß der Inflationsrate auf die Steuerehrlichkeit zurück auf die Ausgestaltung der Einkommensteuer als Nominalsteuer und die damit verbundene, von den Steuerpflichtigen als unfair angesehene kalte Progression. ${ }^{1}$ Die von POMMEREHNE/WECK-HANNEMANN selbst durchgeführte Untersuchung für die Schweiz stützt diese These. Die empirischen Daten ergaben, daß in jenen Kantonen, in denen Indexierungen die kalte Progression verhindern, die Steuerhinterziehung geringer ausfallt als in dem übrigen Teil der Schweiz. Ferner zeigen die Verfasser die hohe Bedeutung der Akzeptanz des Staatshaushalts im ganzen für die Steuermoral auf: In jenen Kantonen nämlich, in denen die Bürger aufgrund der dort herrschenden direkten Demokratie an der Festlegung der Höhe und der Struktur der öffentlichen Ausgaben sowie der Einnahmen beteiligt sind, wurden im Untersuchungszeitraum deutlich weniger Steuern hinterzogen als dort, wo aufgrund indirekter Demokratie keine entsprechende Mitwirkungsmöglichkeit besteht. $^{2}$

Die Untersuchungsergebnisse zur Bedeutung der Einstellung zu Staat und Staatshaushalt haben deutlich gemacht, daß ein signifikanter Einfluß auf das Steuerhinterziehungsniveau vorliegt. Während die Untersuchung von SPICER und LUNDSTEDT zu dem Ergebnis kommt, daß Verstöße gegen das Leistungsfähigkeitsprinzip in Form einer zu geringen Belastung der Besserverdienenden den Steuerwiderstand der übrigen Bevölkerung erhöhen, hebt die Studie von GEEROMS und WLMOTS hervor, daß eine konsequente Umsetzung des Leistungsfähigkeitsprinzips dazu führt, daß für den wohlhabenderen Teil der Steuerzahler das Äquivalenzprinzip nicht mehr erfüllt ist und infolgedessen dieser Teil der Bevölkerung verstärkt zur Steuerhinterziehung neigt. Einen möglichen Ausweg aus diesem Dilemma deuten die Ausführungen von POMMEREHNE und WECK-HANNEMANN an: Durch Beseitigung steuerrechtlicher Regelungen, die jeder Teil der Bevölkerung als unfair empfinden muß, wie z.B. fehlender Indexierung gegen die kalte Progression, sowie durch die Beteiligung der Steuerpflichtigen an der Aufstellung

${ }^{1}$ Vgl. CRANE/NOURZAD (1986) S. 222, POMMEREHNE/WECK-HANNEMANN (1992) S. 459.

2 Dies bestätigt die Bedenken HOUGHTONs gegen eine rigorose Steuereintreibungspolitik, der, den Ruf ,No taxation without representation!" aufgreifend, darauf hinweist, daß die Steuergesetze oft nur eine knappe Mehrheit im Parlament und häufig eine Minderheit der Wählerstimmen hinter sich haben. Vgl. HOUGHTON in IEA (1979) S. 89 [98 f.]; vgl. ferner POMMEREHNE/WECK-HANNEMANN (1992) S. $460 \mathrm{f}$. 
des staatlichen Budgets kann es gelingen, ein in wesentlichen Zügen am Leistungsfähigkeitsprinzip orientiertes Steuersystem zu schaffen, das auch bei denjenigen Steuerpflichtigen Akzeptanz findet, welche mehr Steuern zu entrichten als Staatsleistungen zu empfangen haben, solange diese der Überzeugung sind, daß ihr Steuergeld sinnvoll und effizient verwendet wird. ${ }^{1}$

\subsection{Mögliche Erweiterungen des Grundmodells der Ein- kommensteuerhinterziehung und ihre Relevanz für ein Modell der Steuerumgehung}

In der Literatur sind mittlerweile zahlreiche Variationen und Erweiterungen des Grundmodells der Einkommensteuerhinterziehung vorgenommen worden, welche sich im wesentlichen auf Veränderungen bzw. auf den Fortfall einiger der eingangs aufgezählten Modellprämissen gründen. Über diese möglichen Modellerweiterungen wird im folgenden ein Überblick geliefert, wobei jeweils überprüft wird, ob ein näheres Eingehen auf derartige Varianten auch dann noch lohnend erscheint, wenn - wie ab Kapitel 5.5 - der Untersuchungsgegenstand dieser Arbeit nicht mehr in der Steuerhinterziehung, sondern allein in der Steuerumgehung liegt.

Der Fortfall von Prämisse 1 (statische Betrachtung) wurde bereits von ALLINGHAM und SANDMO selbst in ihr Modell aufgenommen. ${ }^{2}$ Die Autoren haben das Grundmodell variiert, indem sie berücksichtigten, daß die Steuerfahnder im Falle einer aufgedeckten Steuerhinterziehung in der Realität auch die Korrektheit der Deklarationen vergangener Veranlagungszeiträume überprüfen werden. Rational handelnde Steuerpflichtige werden dann den Umstand in ihre Deklarationsentscheidung einbeziehen, daß die Aufdeckung ihrer Minderdeklaration der abgelaufenen Periode neben der dafür fälligen Bestrafung auch erhebliche Nachzahlungen und Strafen für frühere Hinterziehungen mit sich bringen kann. Gegenüber dem statischen Modell geht die optimale Steuerhinterziehung im sog. dynamischen Modell erwartungsgemäß zurück.

Für die Steuerumgehung ist eine solche Modellerweiterung nicht von Belang. Da der Gestaltungsmißbrauch offen durchgefürt worden ist, ist die FinBeh im Falle einer für den abgelaufenen Veranlagungszeitraum erkannten Steuerumgehung nicht

${ }^{1}$ Den Einfluß, den Äquivalenzprinzip, öffentliche Umverteilung, Effizienz der Mittelverwendung und Bürgerbeteiligung am Staatshaushalt auf den Steuerwiderstand ausüben, behandelt ausführlich DIEBOLD (1984). Vgl. vor allem S. 149 f. und S. 181-191.

${ }^{2}$ Vgl. ALLINGHAM/SANDMO (1972) S. 332-337. 
berechtigt, bereits abgeschlossene Veranlagungen für frühere Perioden nachträglich erneut auf Rechtsmißbrauch zu untersuchen und gegebenenfalls zu ändern. ${ }^{1}$

Prämisse 2 (Einkommensdeklaration als einzige Entscheidungsvariable) wurde erstmals im Modell von ANDERSEN fallengelassen. ${ }^{2}$ In diesem erweiterten Modell nehmen die Steuerpflichtigen ihre Deklarationsentscheidung und ihre ArbeitFreizeit-Entscheidung simultan vor, wobei berücksichtigt wird, daß das Hinterziehungsverhalten nicht nur direkt von Variationen der im Grundmodell betrachteten Parameter abhängt, sondern auch indirekt über die ebenfalls von den Parametervariationen beeinflußte Wahl des Arbeitsangebotes berührt wird.

Die Endogenisierung des wahren Einkommens W durch Einbeziehung der ArbeitFreizeit-Entscheidung in das Steuerhinterziehungsmodell führt zu einer erheblichen Verkomplizierung der Analyse, ${ }^{3}$ ändert jedoch nichts an den von ALLINGHAM/ SANDMO gewonnenen Ergebnissen des Grundmodells. Obwohl die von ANDERSEN vorgenommene Modellerweiterung auch ein Modell der Steuerumgehung realitätsnäher werden ließe, soll deshalb an der Prämisse 2 im folgenden festgehalten werden. Hinzu kommt, daß die Berücksichtigung einer variablen Arbeitszeit nur unter neuen der Realität nicht entsprechenden Prämissen praktikabel erscheint: So geht ANDERSEN, um überhaupt $\mathrm{zu}$,interesting and reasonably simple results ${ }^{\text {s4 }}$ gelangen zu können, davon aus, daß sich der Gesamtnutzen eines Individuums additiv aus dem Nutzen des verfügbaren Einkommens und dem (negativen) Nutzen der Arbeitszeit zusammensetze. Hierbei bleibt unberücksichtigt, daß eine Erhöhung der Anzahl der Arbeitsstunden den Grenznutzen des Einkommens aufgrund der aus Zeitgründen verringerten Konsummöglichkeiten vermindern dürfte, während als Folge eines Einkommensanstieges eine Erhöhung des Grenznutzens der Freizeit aufgrund vermehrter Möglichkeiten der Freizeitgestaltung plausibel erscheint. ${ }^{5}$

${ }^{1}$ Eine Änderung bestandskräftiger Steuerbescheide ist, sofern sie nicht vom Steuerpflichtigen selbst betrieben wird, nur unter den engen Voraussetzungen der $\S \S 172-177$ AO statthaft. Vgl. hierzu DAUMKE (1988) S. 136-165 oder ausführlich MIHATSCH (1988), insb. Kap. VIII-XI (S. 105-156).

${ }^{2} \mathrm{Vgl}$. ANDERSEN (1977) S. $375 \mathrm{ff}$.

${ }^{3}$ Einfacher, aber formal nicht mehr korrekt wird die Analyse, wenn - wie bei BUCHNER (1985) S. 6-9 - die Deklarationsentscheidung und die Wahl der Arbeitszeit zwar in einem Modell untersucht, die bestehenden Interdependenzen jedoch vernachlässigt werden. (Bei BÜCHNER (1988) tritt dieser Fehler nicht mehr auf; dort beschränkt sich der Verfasser auf eine simple Wiedergabe des Aufsatzes von ANDERSEN (1977).)

${ }^{4}$ ANDERSEN (1977) S. 376

${ }^{5}$ Ein anderer Ansatz zur Einbeziehung der Arbeitsangebotsentscheidung geht auf ISACHSEN/ STRøM (1980) zurück. Die Verfasser unterteilen den Arbeitsmarkt in einen regulären und einen irregulären Sektor, wobei die gesamte Arbeitszeit des Wirtschaftssubjektes konstant gehalten wird. Das Modell ist später von einigen Autoren u.a. dahingehend erweitert worden, daß die Prämisse einer konstanten Arbeitszeit aufgegeben wurde. Ein solches erweitertes Modell findet sich beispielsweise bei WIEGARD in SCHÄFER (1984) S. 122-142. Die dort 
Prämisse 3 (streng nutzenmaximierende Steuerpflichtige "ohne Gewissen") erscheint für jede ökonomische Analyse krimineller Handlungen äußerst problematisch. ${ }^{1}$ Dies gilt auch für die Steuerhinterziehung, wo die Hemmschwelle bei den meisten Individuen zwar niedriger liegt als bei anderen Straftaten vergleichbaren Umfanges, ${ }^{2}$ die aber dennoch für viele Menschen eine aus ethischen oder religiösen Gründen nicht in Frage kommende Handlung darstellt. ${ }^{3}$ Von daher müßten eventuelle Gewissensbelastungen als Kosten der Steuerhinterziehung im Modell berücksichtigt werden. In abgeschwächter Form gilt dies auch für den Problemkreis der Steuerumgehung. Auch wenn die Hemmschwelle hier abermals niedriger liegen dürfte, so werden mißbräuchliche Gestaltungen zum Zwecke einer Reduzierung der vom Gesetz vorgesehenen Steuerlast der inneren Einstellung mancher ,guter Staatsbürger" zuwiderlaufen. ${ }^{4}$ Insofern könnte man es für sinnvoll erachten, die (auch von der Einstellung zum Staat abhängenden) eventuellen Gewissenskonflikte als mögliche Kosten des Steuerentzuges in das Modell zu integrieren. ${ }^{5} \mathrm{Um}$ eine übertriebene Ausuferung des Modells zu verhindern, soll allerdings im folgenden auf die Einfürung einer spezifischen „Gewissensvariablen“ verzichtet werden. ${ }^{6}$ Vgl. jedoch die Anmerkungen zu Prämisse 9.

gewonnenen Erkenntnisse über die Auswirkungen von Variationen der Parameter $f, r, \theta$ und $p$ entsprechen den in Kap. 5.2.3 dieser Arbeit ermittelten Ergebnissen. Die Annahme additiv separabler Nutzenfunktionen findet sich jedoch auch bei WIEGARD (S. 127).

Demgegenüber kommt COWELL (1985), der auf eine solche Annahme verzichtet, nicht einmal für Variationen von Aufdeckungswahrscheinlichkeit, Strafsatz und dem für Schwarzarbeit gezahlten Lohnsatz zu eindeutigen Ergebnissen bzgl. des Angebotes an Schwarzarbeit.

${ }^{1}$ So werden die meisten Menschen einen Raubmord auch dann nicht begehen, wenn der Erwartungsnutzen aus der hieraus resultierenden Bereicherung höher liegt als der erwartete Nutzenverlust für den Fall einer (für unwahrscheinlich erachteten) Aufdeckung der Tat.

${ }^{2}$ Dieser Umstand wird durch eine 1976 in Großbritannien anhand von Interviews durchgefuihrte Untersuchung empirisch bestătigt. Vgl. MILLER in IEA (1979) S. 118.

${ }^{3} \mathrm{Vgl}$. hierzu auch die Ausfiuhrungen in Kap. 5.3.6.

${ }^{4} \mathrm{Da}$ die Steuerumgehung im Gegensatz zur Steuerhinterziehung stets frei von moralischen Bedenken sei (vgl. DIEBOLD (1984) S. 14), ist eine unbewiesene und m.E. unzutreffende Behauptung. Wenn es wohlhabenden Steuerzahlern gelingt, ihre Steuerlast mit Hilfe rechtsmißbräuchlicher Gestaltungen nahe null zu halten, während materiell weitaus schlechter gestellte Personen einer relativ oder gar absolut höheren steuerlichen Belastung ausgesetzt sind, so handelt es sich hier durchaus auch um eine Gewissensfrage. Vgl. in diesem Zusammenhang auch WESTERHOFF (1966) S. 7.

${ }^{5}$ Die Kosten der Steuerumgehung können natürlich auch negativ sein, wenn Steuerpflichtige als Folge ihrer Tat keine Gewissensbelastung, sondern im Gegenteil eine Bedürfnisbefriedigung aus dem Versuch empfinden, den Leviathan-Staat ,überlistet zu haben“.

${ }^{6}$ BENJAMINIMAITAL in GÄRTNER/WENIG (1985) S. $247 \mathrm{f}$. haben das Modell von YTTZHAKI (1974) um eine Variable erweitert, welche die mit der Steuerhinterziehung verbundene Rufschädigung verkörpern soll. Diese Variable entspricht in etwa der am Ende von Kap. 5.4 der vorliegenden Arbeit eingefuihrten Variablen $\mathrm{K}$, so daß ein năheres Eingehen auf diese Modellerweiterung hier nicht lohnend erscheint. Auch BENJAMINI und MAITAL kommen in ihrer 
An Prämisse 4 (risikoscheue Wirtschaftssubjekte) wird weiterhin festgehalten. ${ }^{1}$ Dies gilt auch für die Annahme einer mit steigendem Einkommen abnehmenden absoluten Risikoaversion.

Prämisse 5 (von der Deklarationsentscheidung unabhängige Aufdeckungswahrscheinlichkeit und proportionale Geldstrafe auf den hinterzogenen Steuerbetrag) ist in der Literatur zur Steuerhinterziehung vielfach abgewandelt worden.

So erscheint es - entgegen Prämisse 6 - durchaus plausibel, daß die Finanzbehörden eine ungefähre Vorstellung vom wahren Einkommen der Steuerpflichtigen besitzen und um so eher eine Überprüfung der Einkommensdeklaration vornehmen werden, je höher das tatsächliche ${ }^{2}$, das nicht deklarierte ${ }^{3}$ oder je niedriger das deklarierte ${ }^{4}$ Einkommen liegt (s.o. Kap. 5.3.3). Derartige Modellvariationen sind im Hinblick auf die Steuerumgehung nicht relevant. Die Finanzbehörden und -gerichte haben die geltenden Vorschriften zur Steuerumgehung unabhängig davon anzuwenden, wie hoch der Bruttoverdienst oder das „umgangene" Einkommen des Zensiten liegt. Der Parameter „Überprüfungswahrscheinlichkeit“ muß für die Steuerumgehung lediglich umgedeutet werden. $p$ bezeichnet im folgenden die (von den Steuerpflichtigen vermutete) Wahrscheinlichkeit, mit der einer der Umgehung von Steuern dienenden Rechtsgestaltung die steuerliche Anerkennung versagt wird.

Viele Modelle zur Steuerhinterziehung verwenden Straffunktionen, die von der hier verwendeten, auf den Betrag an hinterzogener Steuer bezogenen proportionalen und einkommensunabhängigen Geldstrafe abweichen. So berücksichtigt PENCAVEL, daß die Geldstrafe bzgl. der hinterzogenen Steuer progressiv ausgestaltet oder in schweren Fällen durch eine Gefängnisstrafe ergänzt werden kann. ${ }^{5}$ HAGEDORN führt seine Berechnungen anhand dreier verschiedener Straffunktionen durch, wobei es sich jeweils um Geldstrafen handelt, die proportional zur hinterzogenen Steuer, zum nicht deklarierten Einkommen oder zum Produkt von hinterzogener Steuer und regulärem Nettoeinkommen bemessen sind. ${ }^{6}$ Im folgenden wird im Hinblick auf art. 1729 des französischen Code général des Impots an

(stark simplifizierenden) Modellvariante zu dem Ergebnis, daß der von YTTZHAKI ermittelte positive Zusammenhang von Steuersatz und Einkommensdeklaration nicht mehr eindeutig ist, sobald die Variable „social stigma“ ins Modell aufgenommen wird. (Vgl. an dieser Stelle auch den Hinweis auf GORDON (1989) auf S. 135 (Fußnote 1) dieser Arbeit.)

${ }^{1}$ Ein Modell der Steuerhinterziehung ohne diese Prämisse findet sich bei SRINIVASAN (1973). Indem in SRINIVASANs Modell die Steuerpflichtigen nicht den erwarteten Nutzen aus ihrem Nettoeinkommen, sondern den Betrag des Nettoeinkommens selbst maximieren, geht der Verfasser implizit von risikoneutral eingestellten Zensiten aus.

${ }^{2} \mathrm{Vgl}$. SRINIVASAN (1973) S. $341 \mathrm{f}$.

${ }^{3}$ Vgl. YTTZHAKI (1987) S. $127 \mathrm{f}$.

${ }^{4} \mathrm{Vgl}$. REINGANUM/WILDE (1985) S. 9.

${ }^{5}$ Vgl. PENCAVEL (1979) insb. S. 117.

${ }^{6} \mathrm{Vgl}$. HAGEDORN (1991) S. $28 \mathrm{ff}$. 
der proportional auf den Betrag an hinterzogener/umgangener Steuer bemessenen Geldbuße festgehalten. Andere Straffunktionen besitzen - soweit ersichtlich - für die Steuerumgehung keine praktische Relevanz.

Prämisse 6 (keine Kenntnis der Finanzbehörde vom tatsächlichen Einkommen) wird nicht mehr benötigt, sobald anstelle der Steuerhinterziehung die Steuerumgehung zum Untersuchungsgegenstand wird. Im Gegenteil besitzt das zuständige Finanzamt in Fällen reiner Steuerumgehung vollständige Kenntnis über die wahren Einkommensverhältnisse der Steuerpflichtigen. Da die Höhe des tatsächlichen Einkommens für die etwaige Einstufung einer Gestaltung als Steuerumgehung keine Rolle spielen darf, ist ein Einfluß dieser Kenntnis auf den Parameter $p$ nicht gegeben, so daß der Fortfall von Prämisse 6 keine Änderungen im Modell der Steuerumgehung herbeiführt.

Mit den Auswirkungen eines Fortfalls von Prämisse 7 (keine Quellensteuern) auf die Modellergebnisse hat sich HAGEDORN befaßt. ${ }^{1}$ Er kommt zu dem Ergebnis, daß die Einführung einer Quellensteuer in das Modell die Höhe der hinterzogenen Steuer nicht beeinflußt, solange der Steuerpflichtige in der Lage ist, durch Senkung seiner Einkommensdeklaration seine abschließende Einkommensteuerzahlung um den Betrag der Quellensteuer zu vermindern. Erst wenn die Untergrenze der Einkommensdeklaration $\mathrm{X}=0$ erreicht wird, ist es nicht mehr möglich, die zusätzliche Quellensteuerbelastung durch eine entsprechende Minderdeklaration auszugleichen. Wenn q den (konstanten) Quellensteuersatz bezeichnet, so senkt die Quellensteuer den maximal hinterziehbaren Steuerbetrag von $T(W)$ auf $T(W)-q * W$. Die Aufnahme einer Quellensteuer in das Steuerhinterziehungsmodell hat demnach nur insofern eine Auswirkung auf die Höhe der hinterzogenen Steuer, als sie zu einer Senkung der möglichen Obergrenze der Steuerhinterziehung führt.

Für die Steuerumgehung gilt zwar ebenso wie für die Steuerhinterziehung, daß ihr Volumen entscheidend davon abhängt, inwieweit überhaupt Gelegenheit zu derartigem Steuerentzug besteht. Doch während eine Quellensteuer die Möglichkeiten, Steuern zu hinterziehen, einschränkt, ist ein solcher Zusammenhang zwischen Quellenbesteuerung und Steuerumgehung nicht gegeben. Eine entsprechend HAGEDORNs Modell ermittelte Obergrenze des Steuerentzuges existiert für die Steuerumgehung in dieser Form nicht. Eine wirkungsvolle Beschneidung der Möglichkeiten zur Steuerumgehung wäre im Modell gleichbedeutend mit einer Erhöhung der Untergrenze für X. Gelänge es dem Fiskus, sämtliche Gelegenheiten zu beseitigen, so läge diese Untergrenze bei $\mathrm{X}=\mathrm{W}$.

Prämisse 8 (differenzierbare Steuerfunktion mit $0<T^{\prime}<1$ ) wird für das Modell der Steuerumgehung beibehalten und im folgenden um T" $\geq 0$ erweitert; ein direkt-regressiver Steuertarif, d.h. fallende Grenzsteuersätze, werden also ausge-

${ }^{1}$ Vgl. HAGEDORN (1989) S. $30 \mathrm{f}$. 
schlossen. Diese Erweiterung von Prämisse 8 ist notwendig, um in den folgenden Abschnitten zu gewährleisten, daß die Bedingung 2. Ordnung für ein inneres Maximum der Erwartungsnutzenfunktion erfullt ist.

Prämisse 9 (keine Kosten des Steuerentzuges) erscheint bereits bzgl. der Steuerhinterziehung nicht immer realistisch. Zwar kann eine Steuerhinterziehung im einfachsten Fall darin bestehen, bestimmte Angaben in der Einkommensteuererklärung zu unterlassen oder zu verändern, und verursacht in diesem Fall keine monetären Kosten; doch ist nicht zu verkennen, daß viele Steuerpflichtige mittlerweile einen erheblichen Aufwand betreiben, um ihre Steuerlast auf illegale Art und Weise zu senken (beispielsweise durch Herstellung gefälschter Belege oder durch persönlich vorgenommenen Transport von Bargeld ins quellensteuerfreie Ausland zwecks Hinterziehung von Steuern auf Zinserträge). Die Annahme „kostenfreien“ Steuerentzuges wird daher im folgenden aufgegeben.

Für ein Modell der Steuerumgehung wäre eine solche Annahme erst recht inadäquat. „Unangemessene Rechtsgestaltungen ... sind oft umständlich, kompliziert, schwerfällig, unökonomisch, ... widersinnig, wenig effektiv ... . " Diese von TIPKE stammende Auflistung von Begriffen, die den Ausdruck „unangemessen“ umschreiben sollen, wird zwar des öfteren aufgrund ihres Mangels an Justitiabilität zu Recht kritisiert, veranschaulicht jedoch recht gut den kaum bestreitbaren Umstand, daß Steuerumgehung häufig von ökonomischen Nachteilen begleitet wird, die einzig aufgrund der angestrebten Steuerersparnis in Kauf genommen werden. In das Modell der Steuerumgehung wird deshalb eine Kostenfunktion der Gestalt $\mathrm{K}(\mathrm{W}-\mathrm{X})=\mathrm{K}+\mathrm{k} *(\mathrm{~W}-\mathrm{X})$ mit $\mathrm{K}, \mathrm{k} \geq 0$ aufgenommen. Die Variable $\mathrm{K}$ bezeichnet Fixkosten, die auftreten, sobald eine mißbräuchliche Rechtskonstruktion geschaffen (oder ein entsprechendes Modell käuflich erworben) wird oder zur Anwendung kommt (für $\mathrm{X}=\mathrm{W}$ gilt $\mathrm{K}=0$ ). Die variablen Kosten des Steuerentzuges seien abhängig von der Höhe des Einkommens, das der Steuerpflichtige der Besteuerung zu entziehen versucht. Dabei seien die Grenzkosten $\mathrm{k}$ konstant.

Wie bereits in den Anmerkungen zu Prämisse 3 bemerkt wurde, können auch mit dem Steuerentzug verbundene Gewissenskonflikte als Kosten i.w.S. angesehen werden. Eine eventuelle Gewissensbelastung wäre im einfachsten Fall gleichbedeutend mit einer Erhöhung von $\mathrm{K}$ oder $\mathrm{k}$; eine aus dem Steuerentzug resultierende etwaige Bedürfnisbefriedigung ließe sich im Modell als Minderung der Grenz- oder Fixkosten darstellen. Die Fälle $\mathrm{K}<0$ und $\mathrm{k}<0$ werden im folgenden jedoch nicht betrachtet. Auch wird zur Vereinfachung davon abgesehen, daß Gewissenskonflikte in ihrer Intensität statt von $\mathrm{W}-\mathrm{X}$ auch von der Höhe der umgangenen Steuer

${ }^{1}$ TIPKE/LANG (1994) S. 147 
abhängen können ${ }^{1}$ und im Falle einer erfolgreichen Steuerumgehung gegenüber einem gescheiterten Umgehungsversuch möglicherweise verstärkt auftreten.

\subsection{Entscheidungstheoretisches Modell der Steuerumgehung}

\subsubsection{Vorbemerkungen}

Im folgenden wird das in Kap. 5.2 beschriebene Modell der Steuerhinterziehung um eine (lineare) Kostenfunktion erweitert und damit für den Untersuchungsgegenstand „Steuerumgehung“ realitätsnäher gestaltet. Die mögliche Ahndung einer gescheiterten Steuerumgehung mit einer Geldbuße wird dabei zunächst nicht ausgeschlossen, so daß das in Kap. 5.5.2 präsentierte allgemeine Modell der Steuerumgehung gleichzeitig als umfassenderes Modell der Steuerhinterziehung verstanden werden kann.

In Kap. 5.5.3 wird das Modell an die Realitäten in denjenigen Staaten angepaßt, die auf eine Bestrafung der Steuerumgehung generell verzichten, und durch Fortfall der Bußgeldvariablen $f$ vereinfacht.

Die Vorgehensweise in den Kapiteln 5.5.2 und 5.5.3 entspricht grundsätzlich derjenigen in Kap. 5.2. Es werden also erneut (algebraisch und graphisch) die Bedingungen für ein inneres Maximum ermittelt und für den Fall einer inneren Lösung die Wirkungsrichtung von Parametervariationen durch partielle Ableitung nach dem jeweiligen Parameter ermittelt.

\subsubsection{Allgemeines Modell der Steuerumgehung}

\subsubsection{Statisches Modell}

Ebenso wie die Hinterziehungsentscheidung ist die Umgehungsentscheidung eine Entscheidung unter Risiko: Mit einer Wahrscheinlichkeit von $\mathrm{p}$ wird der mißbräuchlichen Rechtsgestaltung die steuerliche Anerkennung versagt und ggf. eine Geldbuße auf die umgangene Steuer erhoben. Mit einer Wahrscheinlichkeit von $(1-p)$ ist die Steuerumgehung hingegen erfolgreich; der Einfachheit halber sei angenommen, daß der Rechtsmißbrauch zur Steuerfreiheit des umgangenen Einkommens und nicht lediglich zu einer niedrigeren Grenzbelastung fuihrt.

${ }^{1}$ GORDON hat das Modell der Steuerhinterziehung um eine Funktion der psychischen Kosten in Abhängigkeit von der hinterzogenen Steuer erweitert (ohne Berücksichtigung der monetären Kosten des Steuerentzuges und eventueller fixer psychischer Kosten). GORDON gelangt dabei zu der Erkenntnis, daß der von YTTZHAKI (1974) und CHRISTIANSEN (1980) festgestellte negative Zusammenhang zwischen Steuersatz und Steuerhinterziehung mit wachsenden psychischen Grenzkosten der Steuerhinterziehung positiv wird. Vgl. GORDON (1989) S. 799 f. 
Wird das in Kap. 5.2 dargestellte Modell um eine Kostenfunktion der Form $\mathrm{K}(\mathrm{W}-\mathrm{X})=\mathrm{K}+\mathrm{k} *(\mathrm{~W}-\mathrm{X})$ erweitert, so stellt sich die Entscheidungssituation eines Steuerpflichtigen in Anlehnung an Abb. 5.1 graphisch nun wie folgt dar: ${ }^{1}$

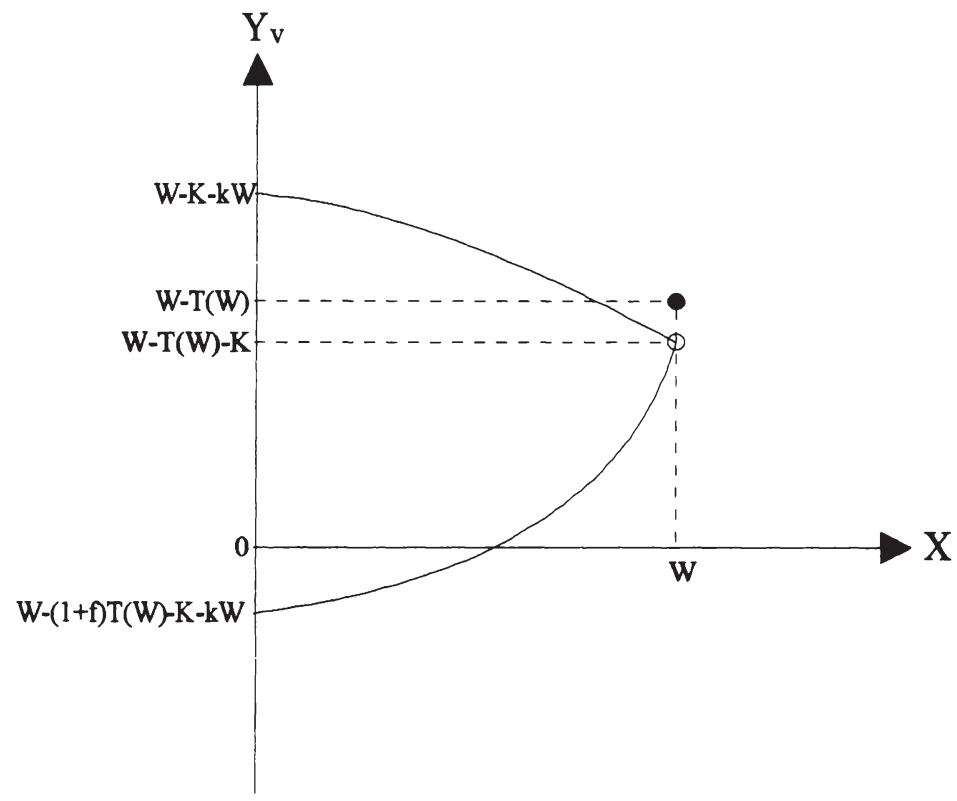

Abb. 5.4: verfügbares Einkommen in
Abhängigkeit von der
Steuerumgehungsentscheidung

Wird das gesamte Einkommen auf normale Weise deklariert, so fallen keine Kosten der Steuerumgehung an, und es verbleibt in jedem Falle ein verfugbares Einkommen i.H.v. W-T(W). Im Falle $\mathrm{K}>0$ führt eine marginale Minderdeklaration zu einem sprunghaften Rückgang des Einkommens um die Fixkosten. Wird die Steuerumgehung ausgeweitet, so bewirkt sie im Falle des Gelingens unter der Voraussetzung $T^{\prime}(X)>k$ einen stetigen Anstieg des verfügbaren Einkommens bis auf maximal $\mathrm{W}-\mathrm{K}-\mathrm{k} * \mathrm{~W}$. Wird hingegen die gewählte Rechtsgestaltung von der Finanzbehörde bzw. den Gerichten steuerlich nicht anerkannt, so verschlechtert sich

${ }^{1}$ Es wird erneut ein progressiver Steuertarif mit $T(0)=0$ zugrunde gelegt. 
die Einkommenssituation um so mehr, je mehr Steuerumgehung betrieben wurde. Wurde die gesamte Steuer zu umgehen versucht, so verbleibt ein Einkommen von $\mathrm{W}-(1+\mathrm{f}) * \mathrm{~T}(\mathrm{~W})-\mathrm{K}-\mathrm{k} * \mathrm{~W}$.

Im Modell lösen die Steuerpflichtigen ihre Entscheidungssituation erneut durch Maximierung ihres Erwartungsnutzens. Die Bestimmungsgleichung für den erwarteten Nutzen (Gleichung (1) aus Kap. 5.2.2) wird durch die Einführung einer Kostenfunktion zu

(1') $\mathrm{E}(\mathrm{U})=(1-\mathrm{p}) * \mathrm{U}(\mathrm{Y})+\mathrm{p} * \mathrm{U}(\mathrm{Z})$

$$
\begin{aligned}
& \text { mit } \mathrm{Y}:=\mathrm{W}-\mathrm{T}(\mathrm{X})-\mathrm{K}-\mathrm{k} *(\mathrm{~W}-\mathrm{X}) \\
& \text { und } \mathrm{Z}:=\mathrm{W}-\mathrm{T}(\mathrm{W})-\mathrm{f} *(\mathrm{~T}(\mathrm{~W})-\mathrm{T}(\mathrm{X}))-\mathrm{K}-\mathrm{k} *(\mathrm{~W}-\mathrm{X})) \\
& \Leftrightarrow \mathrm{Z}=\mathrm{W}-(1+\mathrm{f}) * \mathrm{~T}(\mathrm{~W})+\mathrm{f} * \mathrm{~T}(\mathrm{X})-\mathrm{K}-\mathrm{k} *(\mathrm{~W}-\mathrm{X}) \text {. }
\end{aligned}
$$

Für die erste Ableitung ergibt sich

$$
\text { (2') } \frac{\partial \mathrm{E}(\mathrm{U})}{\partial \mathrm{X}}=(1-\mathrm{p}) *\left(\mathrm{k}-\mathrm{T}^{\prime}(\mathrm{X})\right) * \mathrm{U}^{\prime}(\mathrm{Y})+\mathrm{p} *\left(\mathrm{f}^{*} \mathrm{~T}^{\prime}(\mathrm{X})+\mathrm{k}\right) * \mathrm{U}^{\prime}(\mathrm{Z}) \text {, }
$$

so daß die Gleichung $(1-\mathrm{p}) *\left(\mathrm{~T}^{\prime}(\mathrm{X})-\mathrm{k}\right) * \mathrm{U}^{\prime}(\mathrm{Y})=\mathrm{p} *\left(\mathrm{f} * \mathrm{~T}^{\prime}(\mathrm{X})+\mathrm{k}\right) * \mathrm{U}^{\prime}(\mathrm{Z})$ die Bedingung 1. Ordnung für ein inneres Maximum darstellt.

Diese Bedingung kann nur erfullt sein, wenn $k<T^{\prime}(X)$ gilt, d.h. daß Steuerumgehung lediglich dann lohnend sein kann, wenn die Grenzkosten der (erfolgreichen) Steuerumgehung $\mathrm{k}$ niedriger liegen als ihr angestrebter Grenzertrag T'(X).

Die zweite Ableitung der Erwartungsnutzenfunktion lautet

$$
\text { (3') } \begin{aligned}
\frac{\partial^{2} \mathrm{E}(\mathrm{U})}{\partial \mathrm{X}^{2}}= & -(1-\mathrm{p}) * \mathrm{~T}^{\prime \prime}(\mathrm{X}) * \mathrm{U}^{\prime}(\mathrm{Y})+(1-\mathrm{p}) *\left(\mathrm{k}-\mathrm{T}^{\prime}(\mathrm{X})\right)^{2} * \mathrm{U}^{\prime \prime}(\mathrm{Y})+ \\
& +\mathrm{pf} * \mathrm{~T}^{\prime \prime}(\mathrm{X}) * \mathrm{U}^{\prime}(\mathrm{Z})+\mathrm{p} *\left(\mathrm{f} * \mathrm{~T}^{\prime}(\mathrm{X})+\mathrm{k}\right)^{2} * \mathrm{U}^{\prime \prime}(\mathrm{Z}) .
\end{aligned}
$$

$\mathrm{Da}$ der zweite und der vierte Summand eindeutig negativ sind, ist die 2. Ableitung der Erwartungsnutzenfunktion an der Stelle $\frac{\partial E(U)}{\partial X}=0$ in jedem Fall negativ; denn es gilt:

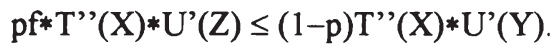

\section{Beweis:}

Für T'”(X) = 0 gilt: pf*T"' $(X) * U^{\prime}(Z)=(1-p) T^{\prime \prime}(X) * U^{\prime}(Y)$.

Im Falle T' $(X)>0$ wird die Behauptung zu pf*U'(Z) $\leq(1-p) * U^{\prime}(Y)$. Bleibt die Steuerumgehung straffrei, so ist die linke Seite der Ungleichung gleich null, während die rechte Seite in jedem Fall ein positives Vorzeichen aufweist. 
Für $f>0$ leitet sich der Beweis aus der Bedingung 1. Ordnung für eine innere Lösung $a b$ :

$$
\begin{aligned}
& (1-p) *\left(T^{\prime}(X)-k\right) * U^{\prime}(Y)=p *\left(f * T^{\prime}(X)+k\right) * U^{\prime}(Z) \\
\Leftrightarrow & \frac{U^{\prime}(Y)}{U^{\prime}(Z)}=\frac{p f * T^{\prime}(X)+p k}{(1-p) *\left(T^{\prime}(X)-k\right)} \\
\Rightarrow & \frac{U^{\prime}(Y)}{U^{\prime}(Z)}>\frac{p f * T^{\prime}(X)-p f k}{(1-p) *\left(T^{\prime}(X)-k\right)} \text { für den Fall k }>0, \\
& \text { bzw. } \frac{U^{\prime}(Y)}{U^{\prime}(Z)}=\frac{p f * T^{\prime}(X)}{(1-p) * T^{\prime}(X)} \text { für } k=0 \\
\Leftrightarrow & \frac{U^{\prime}(Y)}{U^{\prime}(Z)}>\frac{p f}{1-p} \text { für } k>0 ; \frac{U^{\prime}(Y)}{U^{\prime}(Z)}=\frac{p f}{1-p} \text { für } k=0 \\
\Leftrightarrow & p f * U^{\prime}(Z)<(1-p) * U^{\prime}(Y), \text { falls } k>0 ; p f * U^{\prime}(Z)=(1-p) * U^{\prime}(Y), \text { falls } k=0
\end{aligned}
$$

q.e.d.

Hieraus folgt, daß die Bedingung 1. Ordnung hinreichend ist für ein lokales Maximum.

An den Rändern des für X vorgegebenen Definitionsbereiches ergibt sich für die 1 . Ableitung:

$$
\begin{aligned}
\begin{aligned}
\text { (4') }\left.\frac{\partial \mathrm{E}(\mathrm{U})}{\partial \mathrm{X}}\right|_{\mathrm{X}=0}= & (1-\mathrm{p}) *\left(\mathrm{k}-\mathrm{T}^{\prime}(0)\right) * \mathrm{U}^{\prime}(\mathrm{W}-\mathrm{T}(0)-\mathrm{K}-\mathrm{k} * \mathrm{~W})+ \\
& +\mathrm{p} *\left(\mathrm{f}^{\prime} \mathrm{T}^{\prime}(0)+\mathrm{k}\right) * \mathrm{U}^{\prime}(\mathrm{W}-(1+\mathrm{f}) * \mathrm{~T}(\mathrm{~W})+\mathrm{f} * \mathrm{~T}(0)-\mathrm{K}-\mathrm{k} * \mathrm{~W}) \\
\text { (5') }\left.\frac{\partial \mathrm{E}(\mathrm{U})}{\partial \mathrm{X}}\right|_{\mathrm{X}=\mathrm{W}}= & (1-\mathrm{p}) *\left(\mathrm{k}-\mathrm{T}^{\prime}(\mathrm{W})\right) * \mathrm{U}^{\prime}(\mathrm{W}-\mathrm{T}(\mathrm{W}))+ \\
& +\mathrm{p} *\left(\mathrm{f}^{\prime} \mathrm{T}^{\prime}(\mathrm{W})+\mathrm{k}\right) * \mathrm{U}^{\prime}(\mathrm{W}-\mathrm{T}(\mathrm{W}))
\end{aligned}
\end{aligned}
$$

Als Bedingungen für die Existenz eines inneren Maximums erhält man hieraus nach einigen analog zu Kap. 5.2.2 vorgenommenen Umformungen:

$$
\begin{aligned}
& \text { (6a') } \frac{(1-\mathrm{p}) *\left(\mathrm{~T}^{\prime}(0)-\mathrm{k}\right)}{\mathrm{p} *\left(\mathrm{f}^{*} \mathrm{~T}^{\prime}(0)+\mathrm{k}\right)}<\frac{\mathrm{U}^{\prime}((\mathrm{W}-(1+\mathrm{f}) * \mathrm{~T}(\mathrm{~W})+\mathrm{f} * \mathrm{~T}(0)-\mathrm{K}-\mathrm{k} * \mathrm{~W})}{\mathrm{U}^{\prime}(\mathrm{W}-\mathrm{T}(0)-\mathrm{K}-\mathrm{k} * \mathrm{~W})} \\
& \text { (6b') } 1<\frac{(1-p) *\left(T^{\prime}(W)-k\right)}{p *\left(f^{*} T^{\prime}(W)+k\right)}
\end{aligned}
$$


Wenn die Ungleichungen (6a') und (6b') erfüllt sind, so existiert ein Wert für X (mit $0<\mathrm{X}<\mathrm{W}$ ), der der Bedingung 1. Ordnung für ein inneres Maximum genügt.

Wegen $\mathrm{K}=0$ für $\mathrm{X}=\mathrm{W}$ ist Ungleichung (6b') allerdings noch nicht hinreichend für eine Lösung $\mathrm{X}^{*}<\mathrm{W}$. Für eine solche Lösung muß ferner gelten:

$$
\begin{aligned}
&\left.\mathrm{E}(\mathrm{U})\right|_{\mathrm{X}=\mathrm{X}^{*}}>\left.\mathrm{E}(\mathrm{U})\right|_{\mathrm{X}=\mathrm{W}} \\
&\left.\mathbf{( 7}^{\prime}\right) \Leftrightarrow(1-\mathrm{p}) * \mathrm{U}(\mathrm{W}-\mathrm{T}(\mathrm{X})-\mathrm{K}-\mathrm{k} *(\mathrm{~W}-\mathrm{X}))+ \\
&+\mathrm{p} * \mathrm{U}(\mathrm{W}-(1+\mathrm{f}) * \mathrm{~T}(\mathrm{~W})+\mathrm{f} * \mathrm{~T}(\mathrm{X})-\mathrm{K}-\mathrm{k} *(\mathrm{~W}-\mathrm{X}))>\mathrm{U}(\mathrm{W}-\mathrm{T}(\mathrm{W}))
\end{aligned}
$$

Wenn einer der Parameter $\mathrm{p}, \mathrm{f}, \mathrm{K}$ oder $\mathrm{k}$ steigt, so bleibt die rechte Seite von Ungleichung (7') unberührt, während die linke Seite im Wert abnimmt. In einem solchen Fall wird eine Randlösung der Gestalt X=W wahrscheinlicher. ${ }^{1}$ Von Änderungen in der Steuerfunktion oder des Parameters $W$ werden hingegen beide Seiten der Ungleichung berührt, wobei sich nicht ohne weiteres sagen läßt, ob eine Randlösung jeweils wahrscheinlicher oder unwahrscheinlicher wird.

Analog zu Abb. 5.3 wird in Abb. 5.5 die den Erwartungsnutzen maximierende Einkommensdeklaration für das allgemeine Steuerumgehungsmodell graphisch ermittelt. Die möglichen Kombinationen des verfügbaren Einkommens bei geglückter Steuerumgehung $\left(Y_{v}=Y\right)$ und im Falle des Scheiterns $\left(Y_{v}=Z\right)$ werden durch den Punkt $P_{0}$ sowie durch die Verbindung zwischen den Punkten $P_{1}$ und $P_{2}$ dargestellt. $P_{0}$ wird gewählt, wenn Ungleichung $\left(7^{\prime}\right), P_{2}$, wenn Ungleichung (6a') nicht erfüllt ist. Im Falle der Gültigkeit der in (6a'), (6b') und ( $\left.7^{\prime}\right)$ formulierten Bedingungen existiert hingegen eine innere Lösung, d.h. es gibt einen Berührungspunkt zwischen $\mathrm{P}_{1} \mathrm{P}_{2}$ und einer der Indifferenzkurven.

Die Steigung der Indifferenzkurven beträgt (gegenüber Abb. 5.3 unverändert) $-\frac{(1-p) * U^{\prime}(Y)}{p * U^{\prime}(Z)}$. Die Steigung von $P_{1} P_{2}$ bemißt sich nunmehr auf $-\frac{f^{*} T^{\prime}(X)+k}{T^{\prime}(X)-k}$.

$\mathbf{P}_{1} \mathbf{P}_{2}$ ist damit furr $\mathbf{k}>0$ keine Gerade mehr, sondern an jeder Stelle rechtsgekrümmt. Im Tangentialpunkt $P^{*}$ ist die Steigung der berührten Indifferenzkurve gleich der Steigung der Budgetlinie $\mathrm{P}_{1} \mathrm{P}_{2}$, d.h. $(1-p) *\left(T^{\prime}(X)-k\right) * U^{\prime}(Y)=p *\left(f * T^{\prime}(X)+k\right) * U^{\prime}(Z)$. Dies entspricht der oben algebraisch ermittelten Bedingung 1. Ordnung für ein inneres Maximum.

${ }^{1}$ Dies läßt einen negativen Zusammenhang zwischen den genannten Parametern und der individuell nutzenmaximierenden Steuerumgehung vermuten. Ob ein solcher Zusammenhang auch im Falle einer inneren Lösung mit Sicherheit gegeben ist, kann jedoch erst die komparativstatische Analyse in Kap. 5.5.2.2 zeigen. 

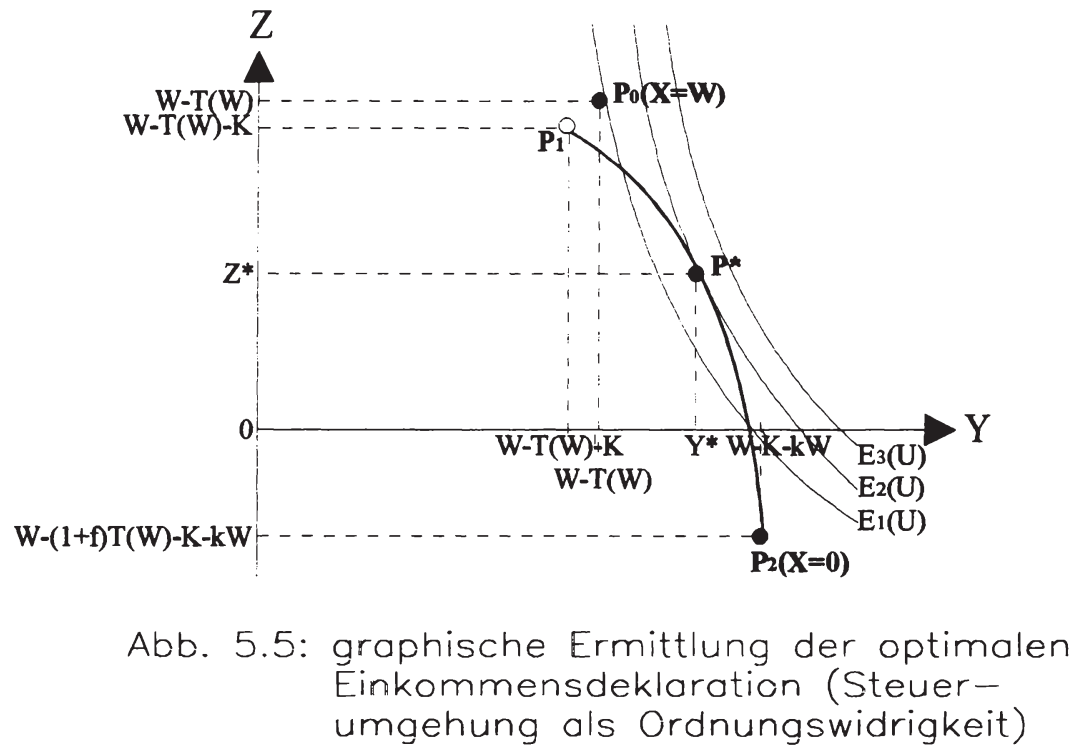

Der den erwarteten Nutzen maximierende Betrag an umgangener Steuer läßt sich aus Abb. 5.5 nicht mehr direkt ablesen. $\mathrm{Da}$ die Steuerumgehung nun gleich dem horizontalen Abstand zwischen $P_{1}$ und $\mathrm{P}^{*}$ zzgl. der variablen Kosten ist, kann man aber nach wie vor von einer Veränderung des horizontalen Abstandes auf eine gleichgerichtete Veränderung des umgangenen Steuerbetrages schließen.

Die folgende komparativ-statische Analyse untersucht - analog zur Vorgehensweise in Kap. 5.2.3 - die Wirkung von Parameteränderungen für den Fall einer inneren Lösung $(0<\mathrm{X}<\mathrm{W})$.

\subsubsection{Komparativ-statische Analyse: Die Wirkung von Parameter- variationen auf das versteuerte Einkommen}

5.5.2.2.1 Variation des „wahren“ Einkommens

Die nach $\mathrm{W}$ abgeleitete implizite Funktion $\mathrm{f}(\mathrm{W}, \mathrm{X})=0$ lautet:

$$
\frac{\partial X}{\partial W}=-\frac{f_{w}(W, X)}{f_{x}(W, X)}=\frac{f_{w}(W, X)}{-\frac{\partial^{2} E(U)}{\partial X^{2}}}
$$


mit $\mathrm{f}_{\mathrm{w}}(\mathrm{W}, \mathrm{X})=(\mathrm{l}-\mathrm{p}) *\left(\mathrm{k}-\mathrm{T}^{\prime}(\mathrm{X})\right) *(1-\mathrm{k}) * \mathrm{U}^{\prime \prime}(\mathrm{Y})+$

$+\mathrm{p} *\left(\mathrm{f} * \mathrm{~T}^{\prime}(\mathrm{X})+\mathrm{k}\right) *\left(1-(1+\mathrm{f}) * \mathrm{~T}^{\prime}(\mathrm{W})-\mathrm{k}\right) * \mathrm{U}^{\prime \prime}(\mathrm{Z})$

$=(1-\mathrm{p}) *\left(\mathrm{~T}^{\prime}(\mathrm{X})-\mathrm{k}\right) *(1-\mathrm{k}) * \mathrm{U}^{\prime}(\mathrm{Y}) * \mathrm{R}_{\mathrm{A}}(\mathrm{Y})-$

$-\mathrm{p} *\left(\mathrm{f} * \mathrm{~T}^{\prime}(\mathrm{X})+\mathrm{k}\right) *\left(1-(1+\mathrm{f}) * \mathrm{~T}^{\prime}(\mathrm{W})-\mathrm{k}\right) * \mathrm{U}^{\prime}(\mathrm{Z}) * \mathrm{R}_{\mathrm{A}}(\mathrm{Z})$

$=(1-\mathrm{p}) *\left(\mathrm{~T}^{\prime}(\mathrm{X})-\mathrm{k}\right) * \mathrm{U}^{\prime}(\mathrm{Y}) *\left[(1-\mathrm{k}) * \mathrm{R}_{\mathrm{A}}(\mathrm{Y})-\left(1-(1+\mathrm{f}) * \mathrm{~T}^{\prime}(\mathrm{W})-\mathrm{k}\right) * \mathrm{R}_{\mathrm{A}}(\mathrm{Z})\right]$

$=(1-\mathrm{p}) *\left(\mathrm{~T}^{\prime}(\mathrm{X})-\mathrm{k}\right) * \mathrm{U}^{\prime}(\mathrm{Y}) *\left[(1+\mathrm{f}) * \mathrm{~T}^{\prime}(\mathrm{W}) * \mathrm{R}_{\mathrm{A}}(\mathrm{Z})-(1-\mathrm{k}) *\left(\mathrm{R}_{\mathrm{A}}(\mathrm{Z})-\mathrm{R}_{\mathrm{A}}(\mathrm{Y})\right)\right]$

$$
\begin{aligned}
\text { und }-\frac{\partial^{2} E(U)}{\partial X^{2}}= & (1-p) *\left(T^{\prime}(X)-k\right)^{2} * U^{\prime}(Y) * R_{A}(Y)+ \\
& +p *\left(f * T^{\prime}(X)+k\right)^{2} * U^{\prime}(Z) * R_{A}(Z)+ \\
& +(1-p) * T^{\prime \prime}(X) * U^{\prime}(Y)-p f^{\prime} T^{\prime \prime}(X) * U^{\prime}(Z)
\end{aligned}
$$$$
\Rightarrow-\frac{\partial^{2} \mathrm{E}(\mathrm{U})}{\partial \mathrm{X}^{2}} \geq(1-\mathrm{p})^{*}\left(\mathrm{~T}^{\prime}(\mathrm{X})-\mathrm{k}\right)^{2} * \mathrm{U}^{\prime}(\mathrm{Y}) * \mathrm{R}_{\mathrm{A}}(\mathrm{Y})+\mathrm{p} *\left(\mathrm{f}^{\prime} \mathrm{T}^{\prime}(\mathrm{X})+\mathrm{k}\right)^{2} * \mathrm{U}^{\prime}(\mathrm{Z}) * \mathrm{R}_{\mathrm{A}}(\mathrm{Z})
$$$$
\Leftrightarrow-\frac{\partial^{2} \mathrm{E}(\mathrm{U})}{\partial \mathrm{X}^{2}} \geq(1-\mathrm{p}) *\left(\mathrm{~T}^{\prime}(\mathrm{X})-\mathrm{k}\right) * \mathrm{U}^{\prime}(\mathrm{Y}) *\left[\left(\mathrm{~T}^{\prime}(\mathrm{X})-\mathrm{k}\right) * \mathrm{R}_{\mathrm{A}}(\mathrm{Y})+\left(\mathrm{f}^{\prime} \mathrm{T}^{\prime}(\mathrm{X})+\mathrm{k}\right) * \mathrm{R}_{\mathrm{A}}(\mathrm{Z})\right]
$$

$$
\begin{aligned}
\Leftrightarrow-\frac{\partial^{2} E(U)}{\partial X^{2}} \geq & (1-p) *\left(T^{\prime}(X)-k\right) * U^{\prime}(Y) * \\
& *\left[(1+f) * T^{\prime}(X) * R_{A}(Z)-\left(T^{\prime}(X)-k\right) *\left(R_{A}(Z)-R_{A}(Y)\right)\right]
\end{aligned}
$$

$\Rightarrow \frac{\partial \mathrm{X}}{\partial \mathrm{W}} \leq \frac{(1+\mathrm{f}) * \mathrm{~T}^{\prime}(\mathrm{W}) * \mathrm{R}_{\mathrm{A}}(\mathrm{Z})-(1-\mathrm{k}) *\left(\mathrm{R}_{\mathrm{A}}(\mathrm{Z})-\mathrm{R}_{\mathrm{A}}(\mathrm{Y})\right)}{(1+\mathrm{f}) * \mathrm{~T}^{\prime}(\mathrm{X}) * \mathrm{R}_{\mathrm{A}}(\mathrm{Z})-\left(\mathrm{T}^{\prime}(\mathrm{X})-\mathrm{k}\right) *\left(\mathrm{R}_{\mathrm{A}}(\mathrm{Z})-\mathrm{R}_{\mathrm{A}}(\mathrm{Y})\right)}$

Gilt ein einheitlicher Grenzsteuersatz, so ist $T^{\prime}(W)=T^{\prime}(X)$ und folglich $\frac{\partial X}{\partial W}<1$. In diesem Fall steigt mit zunehmendem Einkommen der umgangene Anteil. Andernfalls ist sowohl der Minuend als auch der Subtrahend im Zähler größer als im Nenner, so daß nicht eindeutig gesagt werden kann, ob ein Anstieg von W zu einer nur unterproportionalen Veränderung von $\mathrm{X}$ führt.

Auf der anderen Seite ist auch ungewiß, ob ein Anstieg des Einkommens überhaupt eine Erhöhung von $\mathrm{X}$ mit sich bringt. Während der Nenner des Bruches stets positiv ist, hängt das Vorzeichen des Zählers davon ab, ob $\left((1+f) * T^{\prime}(W)+k-1\right) * R_{A}(Z)+(1-k) * R_{A}(Y)$ größer oder kleiner als null ist. Im Falle $(1+f) * T^{\prime}(W)+k \geq 1$ ist $\frac{\partial X}{\partial W}$ auf jeden Fall positiv; andernfalls ist das Vorzeichen vom konkreten Verlauf der Risikoaversionsfunktion abhängig.

In Abb. 5.5 verschiebt eine Einkommenserhöhung die Punkte $P_{0}$ und $P_{1}$ nach rechts oben. $P_{2}$ wandert nach rechts und - je nachdem, welche Werte $f, T$ ' und $k$ aufwei- 
sen - nach oben oder unten. Die Steigung von $P_{1} P_{2}$ bleibt unverändert, d.h. es liegt eine Parallelverschiebung vor. Der horizontale Abstand zwischen $\mathrm{P}_{1}$ und $\mathrm{P}^{*}$ steigt in der Abbildung; demnach nimmt die Steuerumgehung absolut zu.

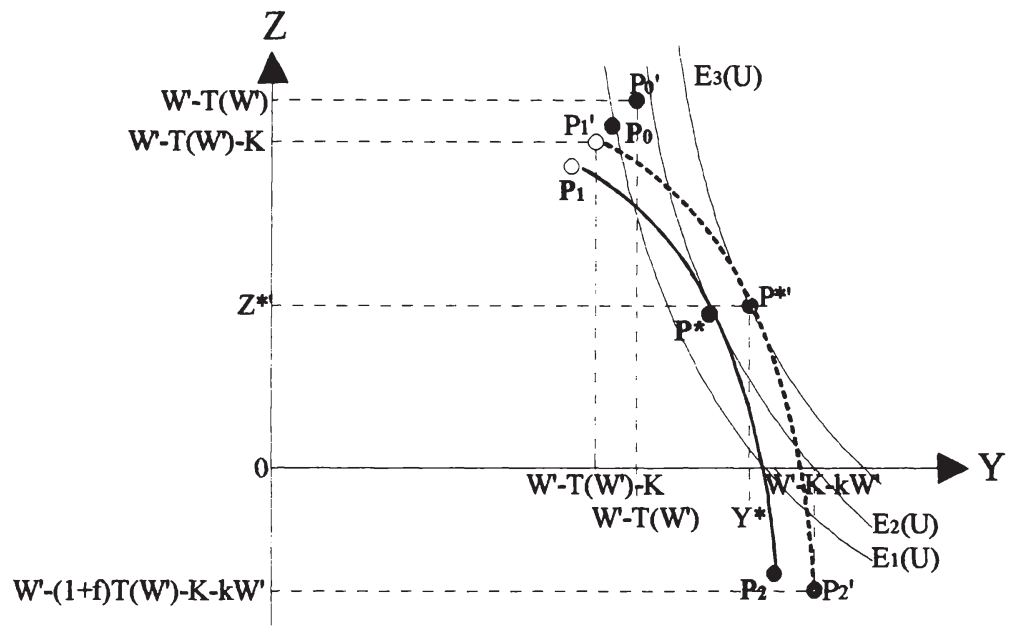

Abb. 5.5.a) Variation des Einkommens W

5.5.2.2.2 Variation der Wahrscheinlichkeit eines Scheiterns der Steuerumgehung

Für die Ableitung der impliziten Funktion $\mathrm{f}(\mathrm{p}, \mathrm{X})=0$ nach $\mathrm{p}$ ergibt sich

$$
\frac{\partial \mathrm{X}}{\partial \mathrm{p}}=\frac{(\mathrm{T}(\mathrm{X})-\mathrm{k}) * \mathrm{U}^{\prime}(\mathrm{Y})+(\mathrm{f} * \mathrm{~T}(\mathrm{X})+\mathrm{k}) * \mathrm{U}^{\prime}(\mathrm{Z})}{-\frac{\partial^{2} \mathrm{E}(\mathrm{U})}{\partial \mathrm{X}^{2}}}>0 .
$$

Wenn sich die Wahrscheinlichkeit eines Scheiterns der mißbräuchlichen steuerlichen Gestaltung erhöht, kommt es demnach c.p. zu einem Rückgang der Steuerumgehung.

Dieses Ergebnis wird durch die graphische Analyse bestätigt: In Abb. 5.5 nähmen die Indifferenzkurven einen flacheren Verlauf an; damit sänke der horizontale Abstand zwischen $P_{1}$ und $P^{*}$, die Steuerumgehung ginge zurück: 


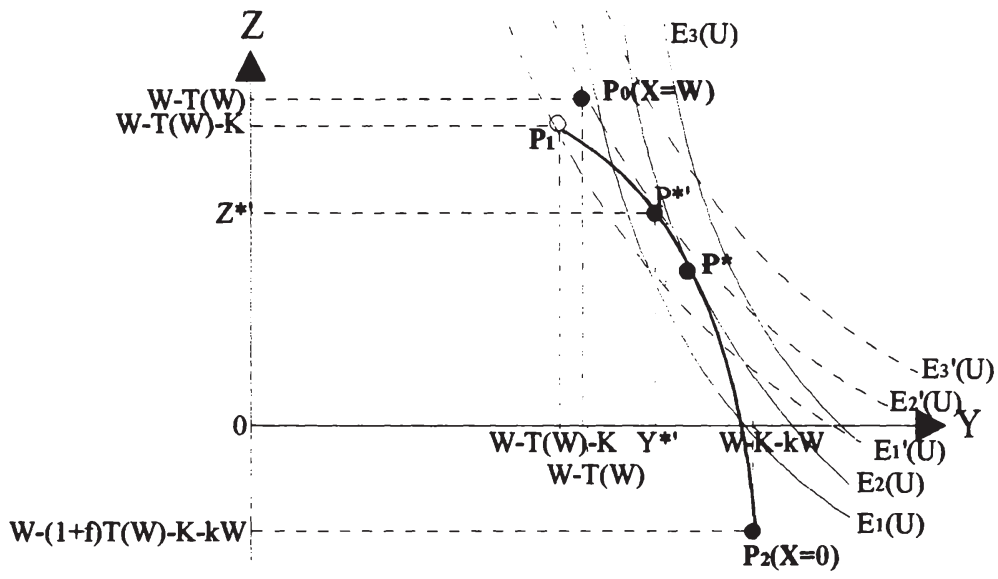

Abb. 5.5.b) Variation von $p$

5.5.2.2.3 Variation des Strafsatzes

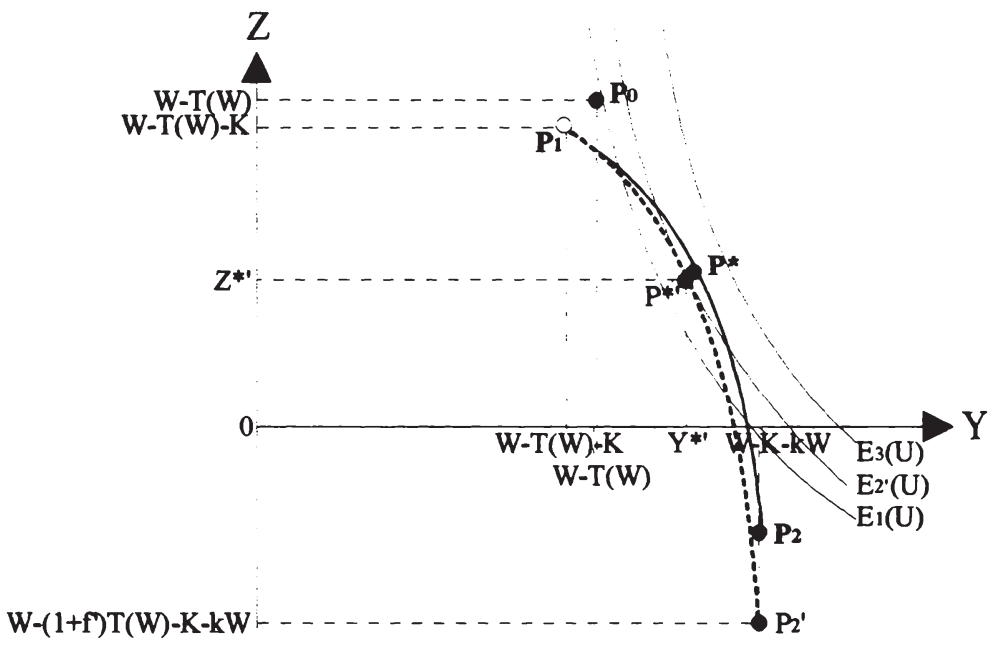

Abb. 5.5.c) Variation des Strafsatzes f 
Ebenfalls eindeutig ist die Auswirkung einer Erhöhung des Strafsatzes, wenn die gescheiterte Steuerumgehung mit einer Geldbuße belegt wird:

$$
\frac{\partial X}{\partial f}=\frac{p * T^{\prime}(X) * U^{\prime}(Z)+p *\left(f * T^{\prime}(X)+k\right) *(T(X)-T(W)) * U^{\prime \prime}(Z)}{-\frac{\partial^{2} E(U)}{\partial X^{2}}}>0
$$

Auch hier geht unter den Modellbedingungen die Steuerumgehung zurück.

In Abb. 5.5 verschöbe ein Anstieg von $f$ den Punkt $P_{2}$ nach unten; dadurch würde $\mathrm{P}_{1} \mathrm{P}_{2}$ steiler, $\mathrm{P}^{*}$ läge nun weiter links, was gleichbedeutend ist mit abnehmender Steuerumgehung.

\subsection{Variation der Kostenfunktion}

a) Variation der fixen Kosten der Steuerumgehung

Untersucht man die Auswirkungen einer Veränderung der mit einer mißbräuchlichen Rechtsgestaltung verbundenen Fixkosten, so erhält man

$$
\begin{aligned}
\frac{\partial \mathrm{X}}{\partial \mathrm{K}} & =\frac{(1-\mathrm{p}) *\left(\mathrm{~T}^{\prime}(\mathrm{X})-\mathrm{k}\right) * \mathrm{U}^{\prime \prime}(\mathrm{Y})-\mathrm{p} *(\mathrm{f} * \mathrm{~T}(\mathrm{X})+\mathrm{k}) * \mathrm{U}^{\prime \prime}(\mathrm{Z})}{-\frac{\partial^{2} \mathrm{E}(\mathrm{U})}{\partial \mathrm{X}^{2}}} \\
& =\frac{-(1-\mathrm{p}) *\left(\mathrm{~T}^{\prime}(\mathrm{X})-\mathrm{k}\right) * \mathrm{U}^{\prime}(\mathrm{Y}) * \mathrm{R}_{\mathrm{A}}(\mathrm{Y})+\mathrm{p} *\left(\mathrm{f} * \mathrm{~T}^{\prime}(\mathrm{X})+\mathrm{k}\right) * \mathrm{U}^{\prime}(\mathrm{Z}) * \mathrm{R}_{\mathrm{A}}(\mathrm{Z})}{-\frac{\partial^{2} \mathrm{E}(\mathrm{U})}{\partial \mathrm{X}^{2}}} \\
& =\frac{(1-\mathrm{p}) *\left(\mathrm{~T}^{\prime}(\mathrm{X})-\mathrm{k}\right) * \mathrm{U}^{\prime}(\mathrm{Y}) *\left[\mathrm{R}_{\mathrm{A}}(\mathrm{Z})-\mathrm{R}_{\mathrm{A}}(\mathrm{Y})\right]}{-\frac{\partial^{2} \mathrm{E}(\mathrm{U})}{\partial \mathrm{X}^{2}}}>0 .
\end{aligned}
$$

Eine Erhöhung der fixen Kosten führt demzufolge zu einem Rückgang der Steuerumgehung.

Graphisch bedeutet eine Erhöhung der fixen Kosten bei unveränderter Lage von $\mathbf{P}_{0}$ eine Parallelverschiebung von $\mathrm{P}_{1} \mathrm{P}_{2}$ nach links unten. In $\mathrm{Abb}$. 5.5 würde sich der horizontale Abstand zwischen $\mathrm{P}_{1}$ und $\mathrm{P}^{*}$ verringern, das algebraisch ermittelte Ergebnis sich damit bestätigen. 


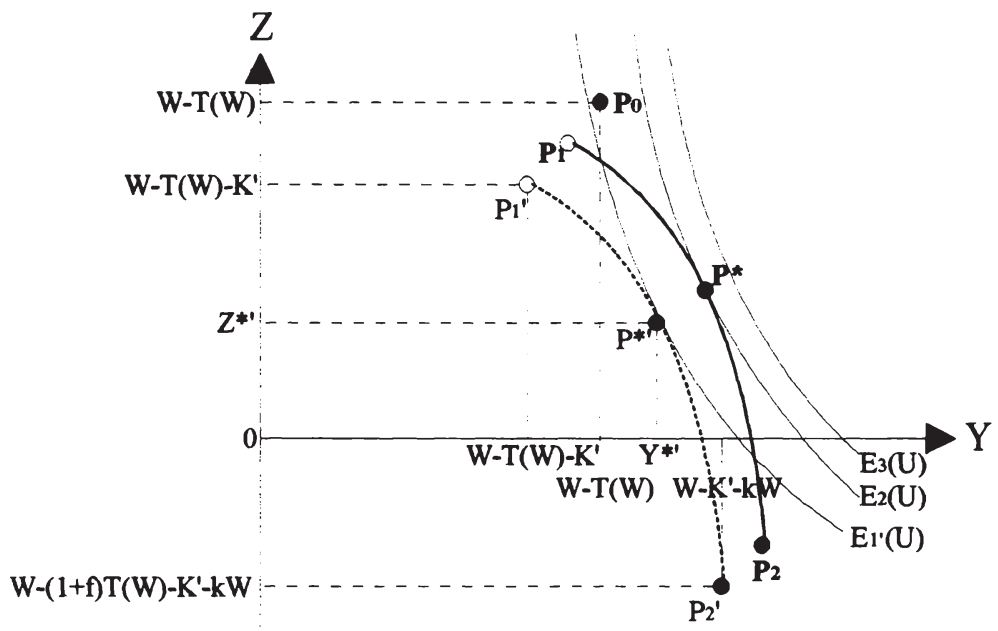

Abb. 5.5.d) Variation der Fixkosten $\mathrm{K}$

b) Variation der Grenzkosten der Steuerumgehung

Für den Fall einer Veränderung der marginalen Kosten ergibt sich

$$
\begin{aligned}
\frac{\partial \mathrm{X}}{\partial \mathrm{k}}= & \frac{(1-\mathrm{p}) * \mathrm{U}^{\prime}(\mathrm{Y})+\mathrm{p} * \mathrm{U}^{\prime}(\mathrm{Z})}{-\frac{\partial^{2} \mathrm{E}(\mathrm{U})}{\partial \mathrm{X}^{2}}}+ \\
& +\frac{(1-\mathrm{p}) *\left(\mathrm{k}-\mathrm{T}^{\prime}(\mathrm{X})\right) *(\mathrm{X}-\mathrm{W}) * \mathrm{U}^{\prime \prime}(\mathrm{Y})+\mathrm{p} *\left(\mathrm{f} * \mathrm{~T}^{\prime}(\mathrm{X})+\mathrm{k}\right) *(\mathrm{X}-\mathrm{W}) * \mathrm{U}^{\prime \prime}(\mathrm{Z})}{-\frac{\partial^{2} \mathrm{E}(\mathrm{U})}{\partial \mathrm{X}^{2}}} \\
= & \frac{(1-\mathrm{p}) * \mathrm{U}^{\prime}(\mathrm{Y})+\mathrm{p}^{*} \mathrm{U}^{\prime}(\mathrm{Z})+\mathrm{p}^{*}\left(\mathrm{f} * \mathrm{~T}^{\prime}(\mathrm{X})+\mathrm{k}\right) *(\mathrm{~W}-\mathrm{X}) * \mathrm{U}^{\prime}(\mathrm{Z}) * \mathrm{R}_{\mathrm{A}}(\mathrm{Z})}{-\frac{\partial^{2} \mathrm{E}(\mathrm{U})}{\partial \mathrm{X}^{2}}}+ \\
& +\frac{-(1-\mathrm{p}) *\left(\mathrm{~T}^{\prime}(\mathrm{X})-\mathrm{k}\right) *(\mathrm{~W}-\mathrm{X}) * \mathrm{U}^{\prime}(\mathrm{Y}) * \mathrm{R}_{\mathrm{A}}(\mathrm{Y})}{-\frac{\partial^{2} \mathrm{E}(\mathrm{U})}{\partial \mathrm{X}^{2}}}
\end{aligned}
$$




$$
\begin{aligned}
= & \frac{(1-p) * U^{\prime}(Y)+p * U^{\prime}(Z)}{-\frac{\partial^{2} E(U)}{\partial X^{2}}}+ \\
& +\frac{(1-p) *\left(T^{\prime}(X)-k\right) *(W-X) * U^{\prime}(Y) *\left[R_{A}(\mathrm{Z})-R_{A}(Y)\right]}{-\frac{\partial^{2} E(U)}{\partial X^{2}}}>0
\end{aligned}
$$

Eine Steigerung der Grenzkosten einer mißbräuchlichen steuerlichen Gestaltung führt also ebenfalls zu einer Abnahme der Steuerumgehung.

In $A b b$. 5.5 ließe ein Grenzkostenanstieg die Punkte $P_{0}$ und $P_{1}$ unverändert, während $P_{2}$ nach links unten wandern würde. $P_{1} P_{2}$ würde damit steiler, d.h. auch graphisch ergäbe sich ein Rückgang der Steuerumgehung.

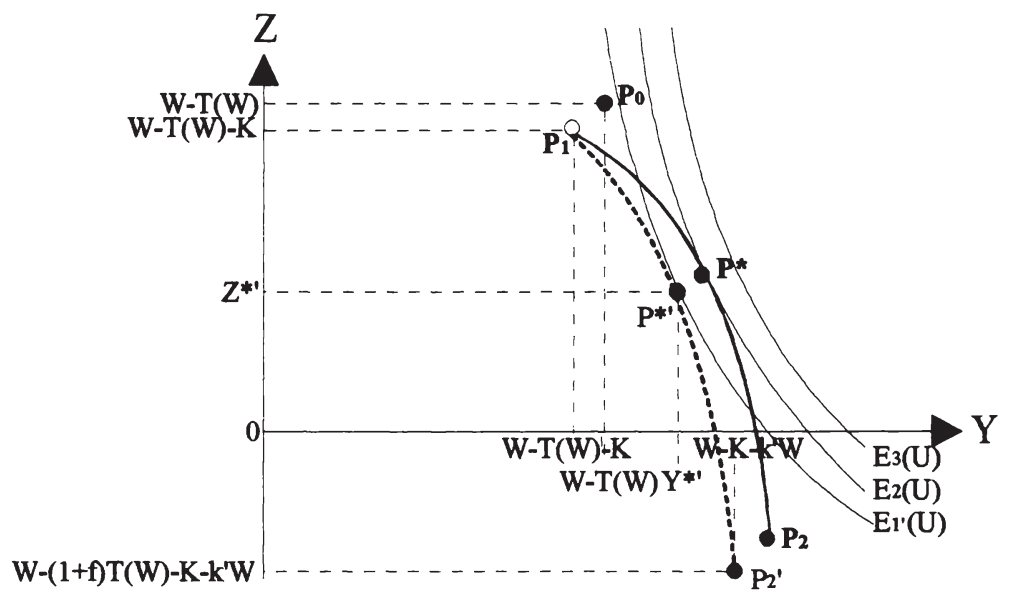

Abb. 5.5.e) Variation der Grenzkosten k

\subsection{Variation des Steuertarifes}

Analog zu Kap. 5.2.3.5 sei erneut von einem Steuertarif der Form $T(X)=\theta X-r$ ausgegangen.

Die Erwartungsnutzenfunktion wird dann zu 
$\mathrm{E}(\mathrm{U})=(1-\mathrm{p}) * \mathrm{U}(\mathrm{W}-\theta \mathrm{X}+\mathrm{r}-\mathrm{K}-\mathrm{k} *(\mathrm{~W}-\mathrm{X}))+$ $+p * U(W-\theta W+r-f \theta *(W-X)-K-k *(W-X))$

und deren 1. Ableitung $z \mathrm{zu} \frac{\partial \mathrm{E}(\mathrm{U})}{\partial \mathrm{X}}=(1-\mathrm{p}) *(\mathrm{k}-\theta) * \mathrm{U}^{\prime}(\mathrm{Y})+\mathrm{p} *(\mathrm{f} \theta+\mathrm{k}) * \mathrm{U}^{\prime}(\mathrm{Z})$.

a) Variation des Steuersatzes

Leitet man die implizite Funktion $f(\theta, X)=0$ nach $\theta$ ab, so erhält man

$$
\frac{\partial \mathrm{X}}{\partial \theta}=\mathrm{S}+\mathrm{E}
$$

mit $S:=\frac{p f * U^{\prime}(Z)-(1-p) * U^{\prime}(Y)}{-\frac{\partial^{2} E(U)}{\partial X^{2}}}$

und $E:=\frac{(1-p) *(\theta-k) * X * U^{\prime \prime}(Y)-p *(f \theta+k) *(W+f *(W-X)) * U^{\prime \prime}(Z)}{-\frac{\partial^{2} E(U)}{\partial X^{2}}}$

$$
\begin{aligned}
& =\frac{-(1-\mathrm{p}) *(\theta-\mathrm{k}) * \mathrm{X} * \mathrm{U}^{\prime}(\mathrm{Y}) * \mathrm{R}_{\mathrm{A}}(\mathrm{Y})}{-\frac{\partial^{2} \mathrm{E}(\mathrm{U})}{\partial \mathrm{X}^{2}}}+ \\
& +\frac{\mathrm{p} *(\mathrm{f} \theta+\mathrm{k}) *((1+\mathrm{f}) * \mathrm{~W}-\mathrm{fX}) * \mathrm{U}^{\prime}(\mathrm{Z}) * \mathrm{R}_{\mathrm{A}}(\mathrm{Z})}{-\frac{\partial^{2} \mathrm{E}(\mathrm{U})}{\partial \mathrm{X}^{2}}} \\
& =\frac{(1-\mathrm{p}) *(\theta-\mathrm{k}) * \mathrm{U}^{\prime}(\mathrm{Y}) *\left[-\mathrm{X} * \mathrm{R}_{\mathrm{A}}(\mathrm{Y})+((1+\mathrm{f}) * \mathrm{~W}-\mathrm{fX}) * \mathrm{R}_{\mathrm{A}}(\mathrm{Z})\right]}{-\frac{\partial^{2} \mathrm{E}(\mathrm{U})}{\partial \mathrm{X}^{2}}} \\
& =\frac{(1-p) *(\theta-k) * U^{\prime}(Y) *\left[X *\left(R_{A}(Z)-R_{A}(Y)\right)+(f+1) *(W-X) * R_{A}(Z)\right]}{-\frac{\partial^{2} E(U)}{\partial X^{2}}}>0 .
\end{aligned}
$$

Wie dem Beweis auf S. $137 \mathrm{f}$. entnommen werden kann, gilt $\mathrm{S}<0$, falls $\mathrm{k}>0$, und $\mathrm{S}=0$ für $\mathrm{k}=0$. Im Falle positiver Grenzkosten der Steuerumgehung ist also der Substitutionseffekt $\mathrm{S}$ einer Steuersatzerhöhung in jedem Falle negativ. Da der Einkommenseffekt $\mathrm{E}$ ein positives Vorzeichen aufweist, kann insgesamt nicht eindeutig gesagt werden, in welche Richtung eine Steuersatzvariation auf die Höhe des deklarierten Einkommens wirkt. Lediglich in Fällen, in denen der Steuerentzug 
ohne Grenzkosten möglich ist, ist die Wirkung einer Erhöhung von $\theta$ auf das Deklarationsverhalten entsprechend dem in Kap. 5.2.3.5.1 ermittelten Ergebnis eindeutig positiv.

In Abb. 5.5 ließe ein Anstieg des Grenzsteuersatzes die Punkte $P_{0}$ und $P_{1}$ nach links unten wandern, $P_{2}$ verschöbe sich nach unten. Im Falle positiver Grenzkosten der Steuerumgehung wird die Linksverschiebung der Budgetlinie von einer dem Betrage nach verringerten Steigung begleitet. Insgesamt läßt deshalb auch die graphische Analyse offen, ob ein höherer Steuersatz die Steuerumgehung zurückgehen läßt oder einen Anstieg bewirkt.

In Abb. 5.5.f) dominiert der Effekt der flacheren Budgetlinie. Das Ergebnis einer insgesamt steigenden Steuerumgehung läßt sich jedoch nicht verallgemeinern, sondern hängt von den konkreten Verläufen der Budgetlinie und der Indifferenzkurven ab.

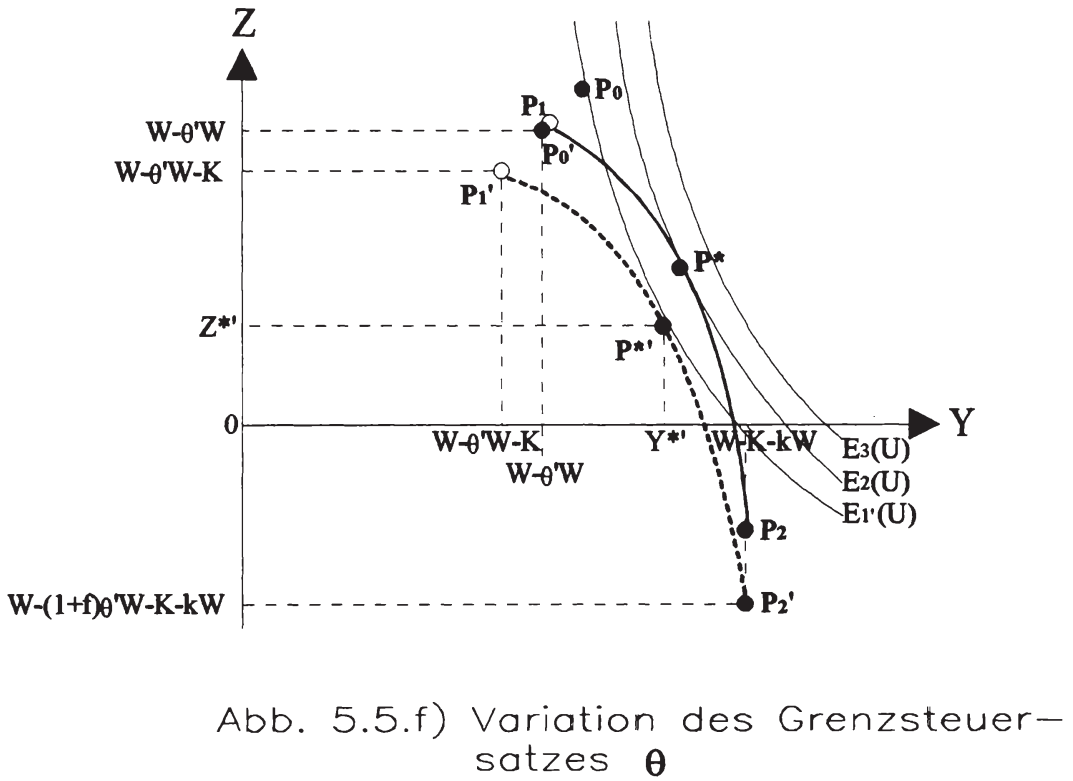

b) Variation des Pauschaltransfers bzw. der Kopfsteuer

$$
\frac{\partial \mathrm{X}}{\partial \mathrm{T}}=\frac{(1-\mathrm{p}) *(\mathrm{k}-\theta) * \mathrm{U}^{\prime \prime}(\mathrm{Y})+\mathrm{p} *(\mathrm{f \theta}+\mathrm{k}) * \mathrm{U}^{\prime \prime}(\mathrm{Z})}{-\frac{\partial^{2} \mathrm{E}(\mathrm{U})}{\partial \mathrm{X}^{2}}}
$$




$$
\begin{aligned}
& =\frac{(1-p) *(\theta-k) * U^{\prime}(Y) * R_{A}(Y)-p *(f \theta+k) * U^{\prime}(Z) * R_{A}(Z)}{-\frac{\partial^{2} E(U)}{\partial X^{2}}} \\
& =\frac{(1-p) *(\theta-k) * U^{\prime}(Y) *\left[R_{A}(Y)-R_{A}(Z)\right]}{-\frac{\partial^{2} E(U)}{\partial X^{2}}}<0
\end{aligned}
$$

Eine Erhöhung des Pauschaltransfers bzw. Senkung der Kopfsteuer bringt also einen Rückgang des deklarierten Einkommens mit sich.

Graphisch bedeutet eine Erhöhung von $r$ eine Parallelverschiebung von $P_{0}$ und $P_{1} P_{2}$ nach rechts oben. In Abb. 5.5 stiege damit die Steuerumgehung, wodurch das algebraisch ermittelte Ergebnis bestätigt wird.

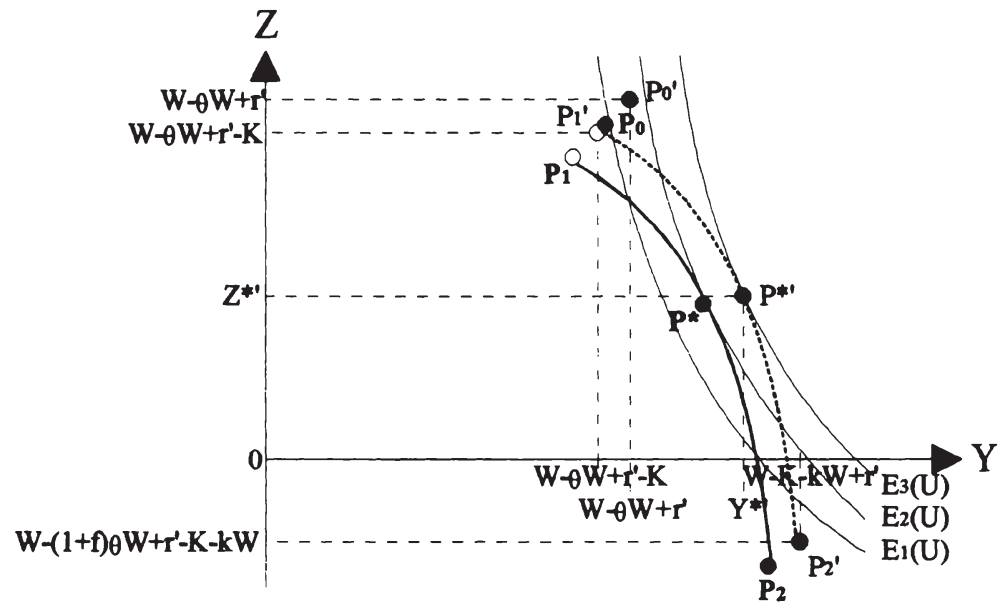

Abb. 5.5.g) Erhöhung des Pauschaltransfers $r$

c) Variation des Progressionsgrades

Entsprechend dem Vorgehen in Kap. 5.2.3.5.3 wird auch hier eine Progressionsveränderung bei konstanten erwarteten Einnahmen des Staates (Steuern + Geldbußen) untersucht.

Dieses erwartete Aufkommen des Fiskus beträgt für das einzelne Wirtschaftssubjekt

$$
E(A)=\theta X-r+p *(f+1) * \theta *(W-X)
$$


$\Leftrightarrow \mathrm{r}=\theta \mathrm{X}+\mathrm{p} *(\mathrm{f}+1) * \theta *(\mathrm{~W}-\mathrm{X})-\mathrm{E}(\mathrm{A})$.

Für die eine Steuersatzvariation kompensierende Veränderung des Pauschaltransfers ergibt sich dann $\frac{d r}{d \theta}=X+p *(f+1) *(W-X)$.

Die gesamte Auswirkung einer Progressionsveränderung läßt sich analog zu Kap. 5.2.3.5.3 ermitteln:

$$
\begin{aligned}
&\left.\frac{\mathrm{dX}}{\mathrm{d} \theta}\right|_{\mathrm{dE}(\mathrm{A})=0}=\frac{\partial \mathrm{X}}{\partial \theta}+\frac{\partial \mathrm{X}}{\partial \mathrm{r}} * \frac{\mathrm{dr}}{\mathrm{d} \theta} \\
&=\mathrm{S}+\frac{(1-\mathrm{p}) *(\theta-\mathrm{k}) * \mathrm{U}^{\prime}(\mathrm{Y}) *\left[\mathrm{X}^{*}\left(\mathrm{R}_{\mathrm{A}}(\mathrm{Z})-\mathrm{R}_{\mathrm{A}}(\mathrm{Y})\right)+(\mathrm{f}+1) *(\mathrm{~W}-\mathrm{X}) * \mathrm{R}_{\mathrm{A}}(\mathrm{Z})\right]}{-\frac{\partial^{2} \mathrm{E}(\mathrm{U})}{\partial \mathrm{X}^{2}}}+ \\
& \quad+\frac{\left.(1-\mathrm{p}) *(\theta-\mathrm{k}) * \mathrm{U}^{\prime}(\mathrm{Y}) *\left[\mathrm{R}_{\mathrm{A}}(\mathrm{Y})-\mathrm{R}_{\mathrm{A}}(\mathrm{Z})\right] * \mathrm{X}+\mathrm{p} *(\mathrm{f}+1) *(\mathrm{~W}-\mathrm{X})\right]}{-\frac{\partial^{2} \mathrm{E}(\mathrm{U})}{\partial \mathrm{X}^{2}}} \\
&=\mathrm{S}+\frac{(1-\mathrm{p})(\theta-\mathrm{k}) \mathrm{U}^{\prime}(\mathrm{Y})\left[(\mathrm{f}+1)(\mathrm{W}-\mathrm{X}) \mathrm{R}_{\mathrm{A}}(\mathrm{Z})+\mathrm{p}(\mathrm{f}+1)(\mathrm{W}-\mathrm{X})\left(\mathrm{R}_{\mathrm{A}}(\mathrm{Y})-\mathrm{R}_{\mathrm{A}}(\mathrm{Z})\right)\right]}{-\frac{\partial^{2} \mathrm{E}(\mathrm{U})}{\partial \mathrm{X}^{2}}} \\
&=\mathrm{S}+\frac{(1-\mathrm{p}) *(\theta-\mathrm{k}) * \mathrm{U}^{\prime}(\mathrm{Y}) *(\mathrm{f}+1) *(\mathrm{~W}-\mathrm{X}) *\left[(1-\mathrm{p}) * \mathrm{R}_{\mathrm{A}}(\mathrm{Z})+\mathrm{p}^{2} \mathrm{R}_{\mathrm{A}}(\mathrm{Y})\right]}{-\frac{\partial^{2} \mathrm{E}(\mathrm{U})}{\partial \mathrm{X}^{2}}}
\end{aligned}
$$

mit $S:=\frac{p f * U^{\prime}(Z)-(1-p) * U^{\prime}(Y)}{-\frac{\partial^{2} E(U)}{\partial X^{2}}}$

Das Vorzeichen von $S$ ist (s.o. Kap. 5.5.2.2.5.a)) negativ für $\mathrm{k}>0$, während der zweite Summand in jedem Falle positiv ist. Insgesamt läßt sich nicht mit Sicherheit sagen, ob eine Progressionsverschärfung unter den Bedingungen des vorliegenden Modells zu einer Erhöhung oder zu einer Abnahme des deklarierten Einkommens führt.

In jedem Fall gilt aber: ${ }^{1}$

$$
\left.\frac{\mathrm{dX}}{\mathrm{d} \theta}\right|_{\mathrm{dE}(\mathrm{A})=0}<\frac{\partial \mathrm{X}}{\partial \theta}
$$

\footnotetext{
${ }^{1}$ zur Bedeutung der nachfolgenden Aussage s.u. Kap. 5.7.5.3
} 


$$
\begin{aligned}
& \Leftrightarrow \mathrm{S}+\frac{(1-\mathrm{p}) *(\theta-\mathrm{k}) * \mathrm{U}^{\prime}(\mathrm{Y}) *(\mathrm{f}+1) *(\mathrm{~W}-\mathrm{X}) *\left[(1-\mathrm{p}) * \mathrm{R}_{\mathrm{A}}(\mathrm{Z})+\mathrm{p} * \mathrm{R}_{\mathrm{A}}(\mathrm{Y})\right]}{-\frac{\partial^{2} \mathrm{E}(\mathrm{U})}{\partial \mathrm{X}^{2}}}<\mathrm{S}+\mathrm{E} \\
& \Leftrightarrow(1-\mathrm{p}) *(\theta-\mathrm{k}) * \mathrm{U}^{\prime}(\mathrm{Y}) *(\mathrm{f}+1) *(\mathrm{~W}-\mathrm{X}) *\left[(1-\mathrm{p}) * \mathrm{R}_{\mathrm{A}}(\mathrm{Z})+\mathrm{p} * \mathrm{R}_{\mathrm{A}}(\mathrm{Y})\right]< \\
& \quad<(1-\mathrm{p}) *(\theta-\mathrm{k}) * \mathrm{U}^{\prime}(\mathrm{Y}) *\left[\mathrm{X} *\left(\mathrm{R}_{\mathrm{A}}(\mathrm{Z})-\mathrm{R}_{\mathrm{A}}(\mathrm{Y})\right)+(\mathrm{f}+1) *(\mathrm{~W}-\mathrm{X}) * \mathrm{R}_{\mathrm{A}}(\mathrm{Z})\right]
\end{aligned}
$$

\section{Beweis:}

Unter der Voraussetzung abnehmender absoluter Risikoaversion gilt

$$
\begin{aligned}
& \mathbf{R}_{\mathrm{A}}(\mathrm{Y})<\mathbf{R}_{\mathrm{A}}(\mathrm{Z}) \\
& \text { und folglich }[(\mathrm{f}+1) *(\mathrm{~W}-\mathrm{X}) * \mathrm{p}+\mathrm{X}] * \mathrm{R}_{\mathrm{A}}(\mathrm{Y})<[(\mathrm{f}+1) *(\mathrm{~W}-\mathrm{X}) * \mathrm{p}+\mathrm{X}] * \mathrm{R}_{\mathrm{A}}(\mathrm{Z}) \\
& \Leftrightarrow[(\mathrm{f}+1) *(\mathrm{~W}-\mathrm{X}) * \mathrm{p}+\mathrm{X}] * \mathrm{R}_{\mathrm{A}}(\mathrm{Y})< \\
& <[\mathrm{p} *(\mathrm{f}+1) *(\mathrm{~W}-\mathrm{X})-(\mathrm{f}+1) *(\mathrm{~W}-\mathrm{X})+(\mathrm{f}+1) * \mathrm{~W}-\mathrm{f} * \mathrm{X}] * \mathrm{R}_{\mathrm{A}}(\mathrm{Z}) \\
& \Leftrightarrow(f+1) *(W-X) * p * R_{A}(Y)+X * R_{A}(Y)< \\
& <(\mathrm{f}+1) * \mathrm{~W} * \mathrm{R}_{\mathrm{A}}(\mathrm{Z})-\mathrm{f} * \mathrm{X} * \mathrm{R}_{\mathrm{A}}(\mathrm{Z})-(\mathrm{f}+1) *(\mathrm{~W}-\mathrm{X}) *(1-\mathrm{p}) * \mathrm{R}_{\mathrm{A}}(\mathrm{Z}) \\
& \Leftrightarrow(\mathrm{f}+1) *(\mathrm{~W}-\mathrm{X}) *(1-\mathrm{p}) * \mathrm{R}_{\mathrm{A}}(\mathrm{Z})+(\mathrm{f}+1) *(\mathrm{~W}-\mathrm{X}) * \mathrm{p} * \mathrm{R}_{\mathrm{A}}(\mathrm{Y})< \\
& <(\mathrm{f}+1) * \mathrm{~W} * \mathrm{R}_{\mathrm{A}}(\mathrm{Z})-\mathrm{X} * \mathrm{R}_{\mathrm{A}}(\mathrm{Y})-(\mathrm{f}+1) * \mathrm{X} * \mathrm{R}_{\mathrm{A}}(\mathrm{Z})+\mathrm{X} * \mathrm{R}_{\mathrm{A}}(\mathrm{Z}) \\
& \Leftrightarrow(1-p) *(\theta-k) * U^{\prime}(Y) *(f+1) *(W-X) *\left[(1-p) * R_{A}(Z)+p * R_{A}(Y)\right]< \\
& <(1-\mathrm{p}) *(\theta-\mathrm{k}) * \mathrm{U}^{\prime}(\mathrm{Y}) *\left[\mathrm{X} *\left(\mathrm{R}_{\mathrm{A}}(\mathrm{Z})-\mathrm{R}_{\mathrm{A}}(\mathrm{Y})\right)+(\mathrm{f}+1) *(\mathrm{~W}-\mathrm{X}) * \mathrm{R}_{\mathrm{A}}(\mathrm{Z})\right]
\end{aligned}
$$

q.e.d.

$\mathrm{Ob}$ und ggf. in welche Richtung eine Progressionsverschärfung das Ausmaß an Steuerumgehung beeinflußt, zeigt Abb. 5.5.h). Wird die durch den Anstieg des Steuersatzes bewirkte Linksverschiebung von $\mathrm{P}_{1} \mathrm{P}_{2}$ durch den Pauschaltransfer und die mit ihm verbundene Rechtsverschiebung so ausgeglichen, daß die gleiche Indifferenzkurve wie in der Ausgangssituation berührt wird, so verringert sich im Falle $k \neq 0$ die Steigung von $P_{1} P_{2}$ dem Betrage nach. Damit bewegt sich der Tangentialpunkt $\mathrm{P}^{*}$ nach rechts, der horizontale Abstand zum Punkt $\mathbf{P}_{1}$ wird größer, die Steuerumgehung nimmt zu. Wegen des gestiegenen Steuersatzes kann daraus jedoch nicht gefolgert werden, daß das versteuerte Einkommen zurückgeht. Das graphisch ermittelte Ergebnis für eine Progressionsveränderung bei konstantem Erwartungsnutzen steht also nicht im Widerspruch zum rechnerisch ermittelten Resultat bei konstant gehaltenen Steuereinnahmen. 


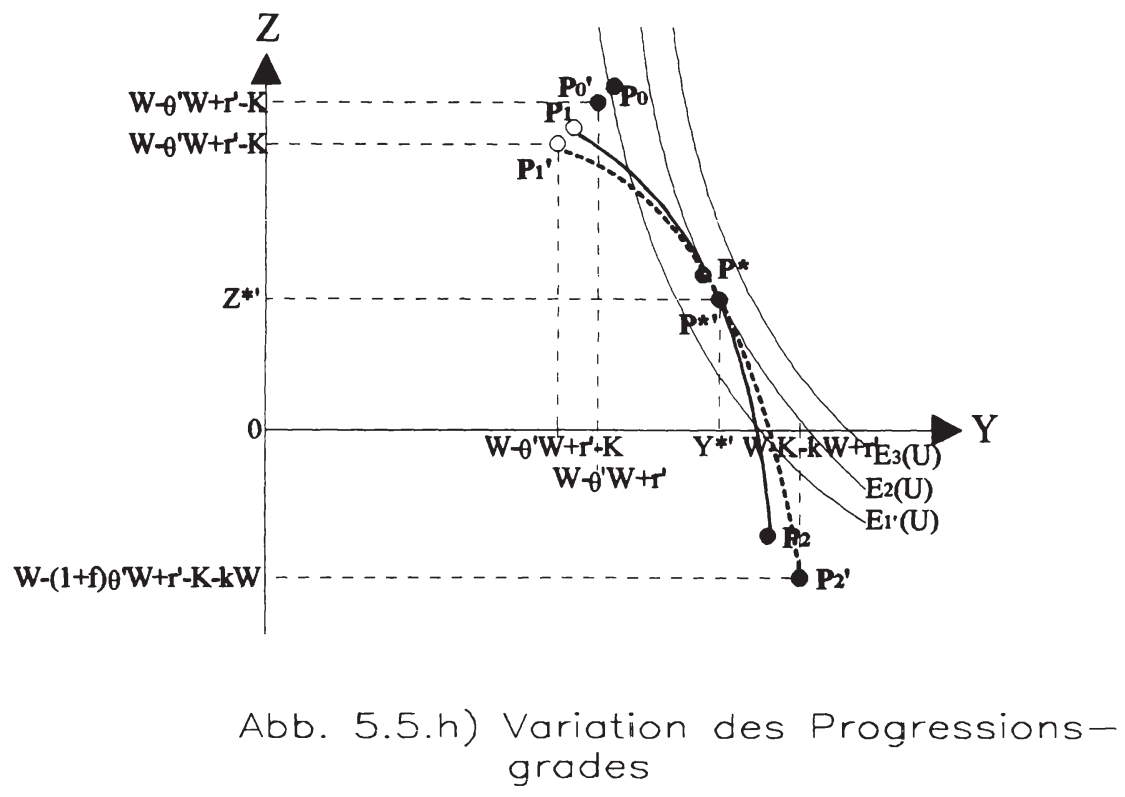

\subsubsection{Modell der straffreien Steuerumgehung}

\subsubsection{Statisches Modell}

Das in Kap. 5.5.2 behandelte allgemeine Modell der Steuerumgehung wird nun durch Fortfall des Bußgeldparameters vereinfacht und damit an die in der Bundesrepublik Deutschland bestehende Rechtslage angepaßt.

Analog zu Abb. 5.4 stellt Abb. 5.6 die Entscheidungssituation eines Steuerpflichtigen für den Fall eines direkt-progressiven Steuertarifes graphisch dar:

Mit einer Wahrscheinlichkeit von $p$ wird der rechtsmißbräuchlichen Gestaltung die steuerliche Anerkennung versagt, und dem Steuerpflichtigen verbleibt sein Nachsteuereinkommen abzgl. der Kosten der Steuerumgehung, welche im Falle k $>0$ um so niedriger ausfallen, je weniger Einkommen zu umgehen versucht wurde. Für den Fall, daß keine Steuerumgehung betrieben wurde, beträgt das verfügbare Einkommen W-T(W).

Mit einer Wahrscheinlichkeit von 1-p wird die steuerliche Gestaltung von den Rechtsanwendern anerkannt. Sofern die Steuerersparnis höher liegt als die Kosten der Steuerumgehung, so steht sich der Steuerpflichtige um so besser, je mehr 
Steuerumgehung betrieben wurde. Falls es gelingt, jedwede Einkommensteuerzahlung zu umgehen, so verbleibt ein verfügbares Einkommen i.H.v. W-K-k*W.

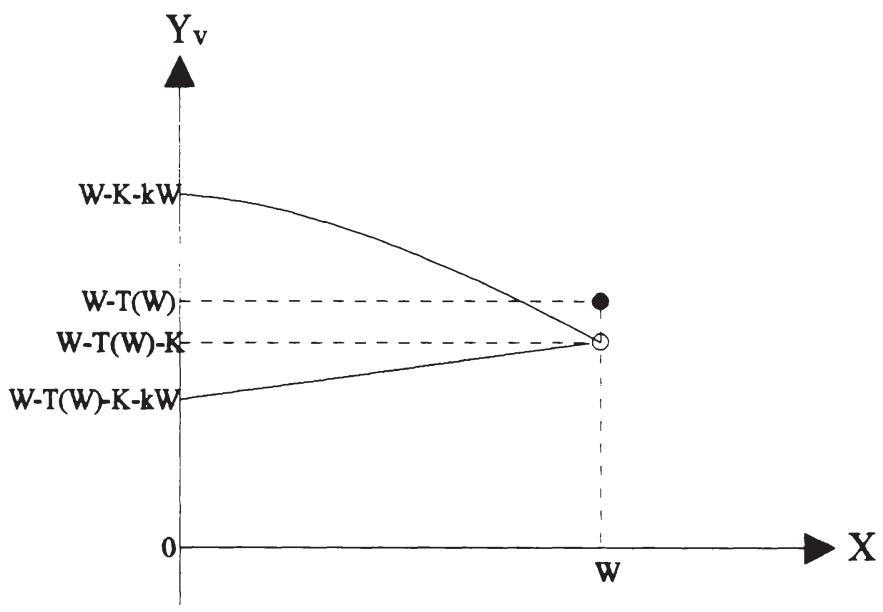
Abb. 5.6: verfügbares Einkommen in Abhängigkeit von der Steuerumgehungsentscheidung bei Straffreiheit

Die Steuerpflichtigen werden in dem Umfang Steuerumgehung betreiben, durch welchen sie ihren erwarteten Nutzen aus dem verfuggaren Einkommen maximieren können. Der Erwartungsnutzen beträgt für den Fall einer stets straffrei bleibenden Steuerumgehung

(1') $\mathrm{E}(\mathrm{U})=(1-\mathrm{p}) * \mathrm{U}(\mathrm{W}-\mathrm{T}(\mathrm{X})-\mathrm{K}-\mathrm{k} *(\mathrm{~W}-\mathrm{X}))+\mathrm{p} * \mathrm{U}(\mathrm{W}-\mathrm{T}(\mathrm{W})-\mathrm{K}-\mathrm{k} *(\mathrm{~W}-\mathrm{X}))$.

Setzt man das verfügbare Einkommen im Falle der steuerlichen Anerkennung der gewählten Rechtsgestaltung erneut gleich $\mathrm{Y}$ und das verbleibende Einkommen im Falle der Nichtanerkennung gleich $Z$, so lautet die 1. Ableitung

$\left(2^{\prime \prime}\right) \frac{\partial E(U)}{\partial X}=(1-p) *\left(k-T^{\prime}(X)\right) * U^{\prime}(Y)+p * k * U^{\prime}(Z)$.

Als notwendige Bedingung für ein inneres Maximum ergibt sich

$$
(1-\mathrm{p}) *\left(\mathrm{~T}^{\prime}(\mathrm{X})-\mathrm{k}\right) * \mathrm{U}^{\prime}(\mathrm{Y})=\mathrm{p} * \mathrm{k} * \mathrm{U}^{\prime}(\mathrm{Z}) \text { mit } \mathrm{k}<\mathrm{T}^{\prime}(\mathrm{X}) \text {. }
$$

Für die 2. Ableitung der Erwartungsnutzenfunktion gilt: 
(3') $\frac{\partial^{2} \mathrm{E}(\mathrm{U})}{\partial \mathrm{X}^{2}}=(1-\mathrm{p}) *\left(\mathrm{k}-\mathrm{T}^{\prime}(\mathrm{X})\right)^{2} * \mathrm{U}^{\prime \prime}(\mathrm{Y})-(1-\mathrm{p}) * \mathrm{~T}^{\prime \prime}(\mathrm{X}) * \mathrm{U}^{\prime}(\mathrm{Y})+\mathrm{p} * \mathrm{k}^{2} * \mathrm{U}^{\prime \prime}(\mathrm{Z})<0$

Die Bedingung 1. Ordnung ist somit hinreichend ist für ein lokales Maximum.

An den Rändern des für $\mathrm{X}$ vorgegebenen Definitionsbereiches ergibt sich für die 1 . Ableitung:

$$
\begin{aligned}
\left.\left(4^{\prime \prime}\right) \frac{\partial \mathrm{E}(\mathrm{U})}{\partial \mathrm{X}}\right|_{\mathrm{X}=0}= & (1-\mathrm{p}) *\left(\mathrm{k}-\mathrm{T}^{\prime}(0)\right) * \mathrm{U}^{\prime}(\mathrm{W}-\mathrm{T}(0)-\mathrm{K}-\mathrm{k} * \mathrm{~W})+ \\
& +\mathrm{pk} * \mathrm{U}^{\prime}(\mathrm{W}-\mathrm{T}(\mathrm{W})-\mathrm{K}-\mathrm{k} * \mathrm{~W}) \\
\left.\left(5^{\prime \prime}\right) \frac{\partial \mathrm{E}(\mathrm{U})}{\partial \mathrm{X}}\right|_{\mathrm{X}=\mathrm{W}}= & (1-\mathrm{p}) *\left(\mathrm{k}-\mathrm{T}^{\prime}(\mathrm{W})\right) * \mathrm{U}^{\prime}(\mathrm{W}-\mathrm{T}(\mathrm{W}))+\mathrm{pk} * \mathrm{U}^{\prime}(\mathrm{W}-\mathrm{T}(\mathrm{W}))
\end{aligned}
$$

Hieraus erhält man als notwendige Bedingungen für die Existenz eines inneren Maximums:

$$
\begin{aligned}
& \left(6 a^{\prime \prime}\right) \frac{(1-p) *\left(T^{\prime}(0)-k\right)}{p * k}<\frac{U^{\prime}(W-T(W)-K-k * W)}{U^{\prime}(W-T(0)-K-k * W)} \text { für } k>0 \text { sowie } \\
& \left(6 b^{\prime \prime}\right) 1<\frac{(1-p) *\left(T^{\prime}(W)-k\right)}{p^{* k}} \text { für } k>0
\end{aligned}
$$

(Im Falle $\mathrm{k}=0$ wäre die 1. Ableitung der Erwartungsnutzenfunktion immer negativ, d.h. $\left.E(U)\right|_{X=X_{1}}<\left.E(U)\right|_{X=X_{2}}$ für $X_{1}>X_{2}$ mit $X_{1}, X_{2}>0$.)

Wegen $\mathrm{K}=0$ für $\mathrm{X}=\mathrm{W}$ muß zusätzlich gelten:

$$
\left.\mathrm{E}(\mathrm{U})\right|_{\mathrm{X}=\mathrm{X}^{*}}>\left.\mathrm{E}(\mathrm{U})\right|_{\mathrm{X}=\mathrm{W}} \text {, }
$$

d.h. $(1-p) * U(W-T(X)-K)+p * U(W-T(W)-K)>U(W-T(W))$ für $k=0$ und

$(1-\mathrm{p}) * \mathrm{U}(\mathrm{W}-\mathrm{T}(\mathrm{X})-\mathrm{K}-\mathrm{k} *(\mathrm{~W}-\mathrm{X}))+\mathrm{p} * \mathrm{U}(\mathrm{W}-\mathrm{T}(\mathrm{W})-\mathrm{K}-\mathrm{k} *(\mathrm{~W}-\mathrm{X}))>\mathrm{U}(\mathrm{W}-\mathrm{T}(\mathrm{W}))$ für $\mathrm{k} \geq 0$.

Wenn einer der Parameter $\mathrm{p}, \mathrm{K}$ oder $\mathrm{k}$ steigt, so nimmt die linke Seite der Ungleichung bei konstant bleibender rechter Seite ab. In einem solchen Fall wird eine Randlösung der Gestalt $\mathrm{X}=\mathrm{W}$ wahrscheinlicher. Von Änderungen des Parameters W sowie der Steuerfunktion $T(X)$ werden hingegen beide Seiten der Ungleichung berührt, wobei sich nicht ohne weiteres sagen läßt, ob die Wahrscheinlichkeit einer Randlösung jeweils zu- oder abnimmt.

Graphisch stellt sich die optimale Einkommensdeklaration gemäß Abb. 5.7 dar:

Im Falle einer Randlösung wird die nutzenmaximale Indifferenzkurve in einem der Punkte $P_{0}$ und $P_{2}$ erreicht. Für den Fall einer inneren Lösung existiert hingegen ein Berührungspunkt zwischen $P_{1} P_{2}$ und einer Indifferenzkurve, welcher die den Erwartungsnutzen maximierende Entscheidung des Steuerpflichtigen verkörpert. 

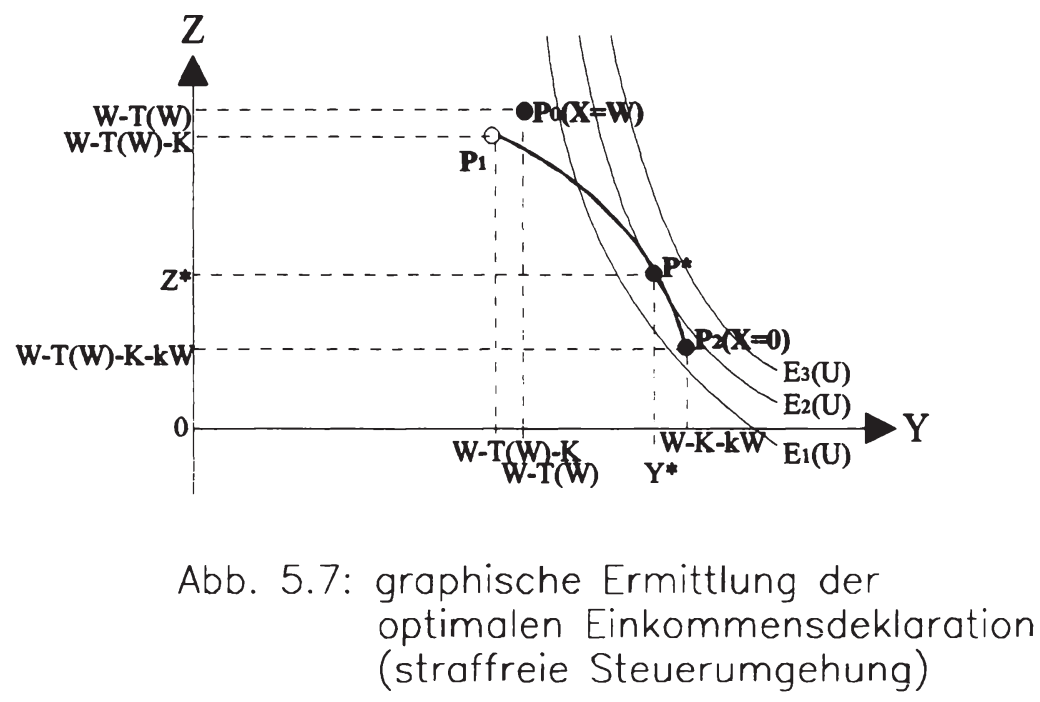

Die Steigung von $P_{1} P_{2}$ beträgt $-\frac{k}{T(X)-k}$, diejenige der Indifferenzkurven $-\frac{(1-p) * U^{\prime}(Y)}{p * U^{\prime}(Z)}$. Im Tangentialpunkt weisen beide Brüche den gleichen Wert auf, d.h. $(1-p) *\left(T^{\prime}(X)-k\right) * U^{\prime}(Y)=p * k * U^{\prime}(Z)$. Diese Gleichung ist identisch mit der aus (2") abgeleiteten notwendigen Bedingung für ein inneres Maximum.

Der Betrag an umgangener Steuer ist auch hier gleich dem horizontalen Abstand zwischen $\mathrm{P}_{1}$ und $\mathrm{P}^{*}$ zuzüglich der variablen Kosten der Steuerumgehung.

Für den Fall $k=0$ verläuft die Budgetlinie waagerecht. In diesem Fall liegt das Optimum stets bei $\mathrm{X}=0$.

Die Wirkung von Parametervariationen für den Fall einer inneren Lösung wird im folgenden analog zu den Kapiteln 5.2.3 und 5.5.2 untersucht. 


\subsubsection{Komparativ-statische Analyse:}

Die Wirkung von Parametervariationen auf das versteuerte Einkommen

5.5.3.2.1 Variation des „wahren“ Einkommens

Für die Ableitung der impliziten Funktion $\mathrm{f}(\mathrm{W}, \mathrm{X})=0$ nach $\mathrm{W}$ ergibt sich:

$$
\frac{\partial \mathrm{X}}{\partial \mathrm{W}}=\frac{\mathrm{f}_{\mathrm{w}}(\mathrm{W}, \mathrm{X})}{-\frac{\partial^{2} \mathrm{E}(\mathrm{U})}{\partial \mathrm{X}^{2}}}
$$

mit $\mathrm{f}_{\mathrm{w}}(\mathrm{W}, \mathrm{X})=(1-\mathrm{p}) *\left(\mathrm{k}-\mathrm{T}^{\prime}(\mathrm{X})\right) *(1-\mathrm{k}) * \mathrm{U}^{\prime \prime}(\mathrm{Y})+\mathrm{pk} *\left(1-\mathrm{k}-\mathrm{T}^{\prime}(\mathrm{W})\right) * \mathrm{U}^{\prime \prime}(\mathrm{Z})$

$$
\begin{aligned}
= & (1-\mathrm{p}) *\left(\mathrm{~T}^{\prime}(\mathrm{X})-\mathrm{k}\right) *(1-\mathrm{k}) * \mathrm{U}^{\prime}(\mathrm{Y}) * \mathrm{R}_{\mathrm{A}}(\mathrm{Y})- \\
& -\mathrm{pk} *\left(1-\mathrm{k}-\mathrm{T}^{\prime}(\mathrm{W})\right) * \mathrm{U}^{\prime}(\mathrm{Z}) * \mathrm{R}_{\mathrm{A}}(\mathrm{Z}) \\
= & (1-\mathrm{p}) *\left(\mathrm{~T}^{\prime}(\mathrm{X})-\mathrm{k}\right) * \mathrm{U}^{\prime}(\mathrm{Y}) *\left[(1-\mathrm{k}) * \mathrm{R}_{\mathrm{A}}(\mathrm{Y})-\left(1-\mathrm{k}-\mathrm{T}^{\prime}(\mathrm{W})\right) * \mathrm{R}_{\mathrm{A}}(\mathrm{Z})\right] \\
= & (1-\mathrm{p}) *\left(\mathrm{~T}^{\prime}(\mathrm{X})-\mathrm{k}\right) * \mathrm{U}^{\prime}(\mathrm{Y}) *\left[\mathrm{~T}^{\prime}(\mathrm{W}) * \mathrm{R}_{\mathrm{A}}(\mathrm{Z})-(1-\mathrm{k}) *\left(\mathrm{R}_{\mathrm{A}}(\mathrm{Z})-\mathrm{R}_{\mathrm{A}}(\mathrm{Y})\right)\right]
\end{aligned}
$$

und $-\frac{\partial^{2} E(U)}{\partial X^{2}}=(1-p) * T^{\prime \prime}(X) * U^{\prime}(Y)+(1-p) *\left(T^{\prime}(X)-k\right)^{2} * U^{\prime}(Y) * R_{A}(Y)+$

$$
+\mathrm{pk}^{2} * \mathrm{U}^{\prime}(\mathrm{Z}) * \mathrm{R}_{\mathrm{A}}(\mathrm{Z})
$$

$\Rightarrow-\frac{\partial^{2} \mathrm{E}(\mathrm{U})}{\partial \mathrm{X}^{2}} \geq(1-\mathrm{p}) *\left(\mathrm{~T}^{\prime}(\mathrm{X})-\mathrm{k}\right) * \mathrm{U}^{\prime}(\mathrm{Y}) *\left[\left(\mathrm{~T}^{\prime}(\mathrm{X})-\mathrm{k}\right) * \mathrm{R}_{\mathrm{A}}(\mathrm{Y})+\mathrm{k}^{\prime} \mathrm{R}_{\mathrm{A}}(\mathrm{Z})\right]$

$\Leftrightarrow-\frac{\partial^{2} \mathrm{E}(\mathrm{U})}{\partial \mathrm{X}^{2}} \geq(1-\mathrm{p}) *\left(\mathrm{~T}^{\prime}(\mathrm{X})-\mathrm{k}\right) * \mathrm{U}^{\prime}(\mathrm{Y}) *$

$$
*\left[\mathrm{~T}^{\prime}(\mathrm{X}) * \mathrm{R}_{\mathrm{A}}(\mathrm{Z})-\left(\mathrm{T}^{\prime}(\mathrm{X})-\mathrm{k}\right) *\left(\mathrm{R}_{\mathrm{A}}(\mathrm{Z})-\mathrm{R}_{\mathrm{A}}(\mathrm{Y})\right)\right]
$$

$\Rightarrow \frac{\partial \mathrm{X}}{\partial \mathrm{W}} \leq \frac{\mathrm{T}^{\prime}(\mathrm{W}) * \mathrm{R}_{\mathrm{A}}(\mathrm{Z})-(1-\mathrm{k}) *\left(\mathrm{R}_{\mathrm{A}}(\mathrm{Z})-\mathrm{R}_{\mathrm{A}}(\mathrm{Y})\right)}{\mathrm{T}^{\prime}(\mathrm{X}) * \mathrm{R}_{\mathrm{A}}(\mathrm{Z})-\left(\mathrm{T}^{\prime}(\mathrm{X})-\mathrm{k}\right) *\left(\mathrm{R}_{\mathrm{A}}(\mathrm{Z})-\mathrm{R}_{\mathrm{A}}(\mathrm{Y})\right)}$

Im Falle eines direkt-progressiven Steuertarifes mit $T^{\prime}(W)>T^{\prime}(X)$ ist im Zähler sowohl der Minuend als auch der Subtrahend größer als im Nenner. Es ist daher ungewiß, ob $\frac{\partial X}{\partial W}$ größer oder kleiner als 1 ist. Für den Fall $T^{\prime}(W)=T^{\prime}(X)$ gilt hingegen eindeutig $\frac{\partial X}{\partial W}<1$, d.h. eine Zunahme von $W$ führt - wenn überhaupt nur zu einem unterproportionalen Anstieg von X. 
Der Nenner des Bruches ist stets größer als null. Demgegenüber ist das Vorzeichen des Zählers davon abhängig, ob $\left(T^{\prime}(W)+k-1\right) * R_{A}(Z)+(1-k) * R_{A}(Y)$ positiv oder negativ ist.

Im Falle $T^{\prime}(W)+k \geq 1$ ist $\frac{\partial X}{\partial W}$ auf jeden Fall positiv; andernfalls hängt das Vorzeichen vom konkreten Verlauf der Risikoaversionsfunktion ab.

$\mathrm{Ob}$ ein Anstieg von $\mathrm{W}$ zu einer Zunahme von $\mathrm{X}$ führt, ist demnach nicht eindeutig gesichert.

In Abb. 5.7 käme es durch eine Einkommenserhöhung zu einer Verschiebung von $P_{0}$ und $P_{1}$ nach rechts oben sowie von $P_{2}$ nach rechts und - je nach Gestalt der Steuerfunktion und in Abhängigkeit von $\mathrm{k}$ - nach unten oder oben. Die Steigung von $P_{1} P_{2}$ bliebe unverändert. Der horizontale Abstand zwischen $P_{1}$ und $P^{*}$ stiege in der Abbildung, d.h. es käme zu einer absoluten Zunahme der Steuerumgehung.

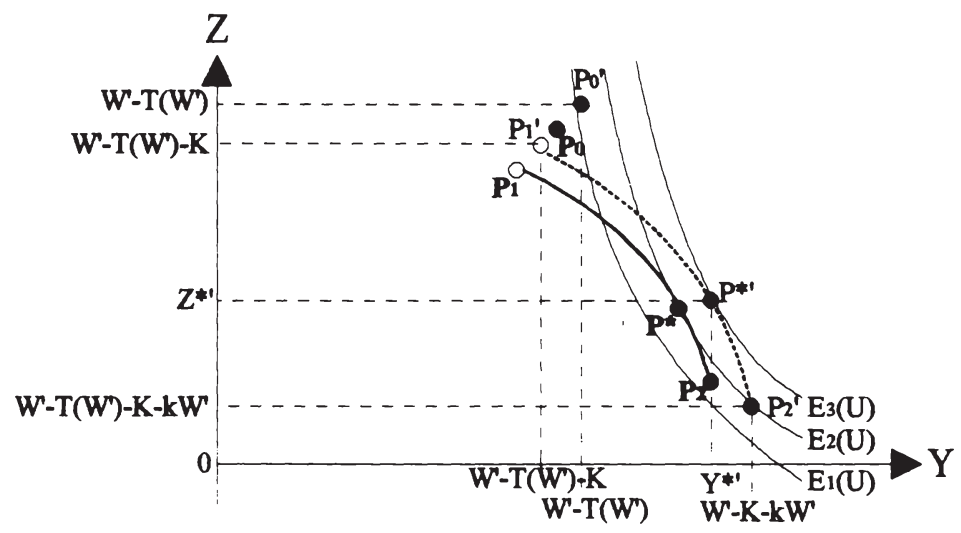

Abb. 5.7.a) Variation des Einkommens W

5.5.3.2.2 Variation der Wahrscheinlichkeit eines Scheiterns der Steuerumgehung

Leitet man die implizite Funktion $f(p, X)=0$ nach $p a b$, so ergibt sich - analog $z u$ dem Ergebnis aus Kap. 5.5.2.2.2 - folgendes Resultat: 


$$
\frac{\partial \mathrm{X}}{\partial \mathrm{p}}=\frac{\left(\mathrm{T}^{\prime}(\mathrm{X})-\mathrm{k}\right) * \mathrm{U}^{\prime}(\mathrm{Y})+\mathrm{k} * \mathrm{U}^{\prime}(\mathrm{Z})}{-\frac{\partial^{2} \mathrm{E}(\mathrm{U})}{\partial \mathrm{X}^{2}}}>0 .
$$

Dies bedeutet, daß die Steuerumgehung um so geringer ausfält, je höher die Wahrscheinlichkeit liegt, daß die gewählte Rechtsgestaltung steuerlich nicht anerkannt wird.

Graphisch wäre ein steigendes $p$ gleichbedeutend mit flacher verlaufenden Indifferenzkurven, wodurch der horizontale Abstand zwischen $\mathrm{P}_{1}$ und $\mathrm{P}^{*}$ geringer würde. Die zeichnerische Analyse bestätigt demnach das rechnerisch ermittelte Ergebnis sinkender Steuerumgehung.

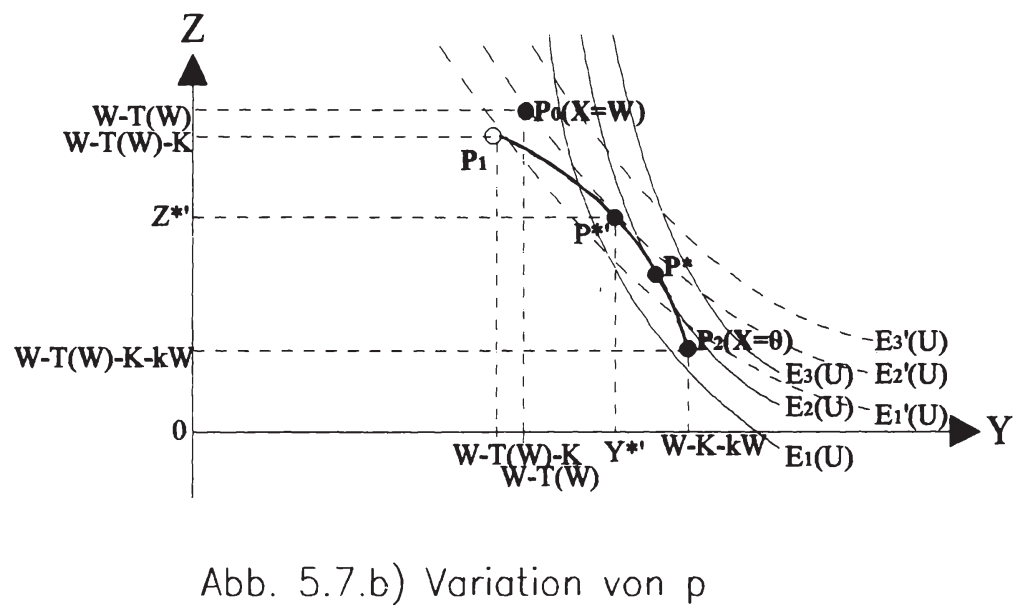

5.5.3.2.3 Variation der Kostenfunktion

a) Variation der fixen Kosten der Steuerumgehung

Abgeleitet nach den Fixkosten der mißbräuchlichen Rechtsgestaltung, ergibt sich

$$
\frac{\partial \mathrm{X}}{\partial \mathrm{K}}=\frac{(1-\mathrm{p}) *\left(\mathrm{~T}^{\prime}(\mathrm{X})-\mathrm{k}\right) * \mathrm{U}^{\prime \prime}(\mathrm{Y})-\mathrm{p} * \mathrm{k} * \mathrm{U}^{\prime \prime}(\mathrm{Z})}{-\frac{\partial^{2} \mathrm{E}(\mathrm{U})}{\partial \mathrm{X}^{2}}}
$$




$$
\begin{aligned}
& =\frac{-(1-p) *\left(\mathrm{~T}^{\prime}(\mathrm{X})-\mathrm{k}\right) * \mathrm{U}^{\prime}(\mathrm{Y}) * \mathrm{R}_{\mathrm{A}}(\mathrm{Y})+\mathrm{p} * \mathrm{k}^{*} \mathrm{U}^{\prime}(\mathrm{Z}) * \mathrm{R}_{\mathrm{A}}(\mathrm{Z})}{-\frac{\partial^{2} \mathrm{E}(\mathrm{U})}{\partial \mathrm{X}^{2}}} \\
& =\frac{(1-\mathrm{p}) *\left(\mathrm{~T}^{\prime}(\mathrm{X})-\mathrm{k}\right) * \mathrm{U}^{\prime}(\mathrm{Y}) *\left[\mathrm{R}_{\mathrm{A}}(\mathrm{Z})-\mathrm{R}_{\mathrm{A}}(\mathrm{Y})\right]}{-\frac{\partial^{2} \mathrm{E}(\mathrm{U})}{\partial \mathrm{X}^{2}}}>0
\end{aligned}
$$

Das hieraus abzuleitende Ergebnis sinkender Steuerumgehungstätigkeit bei steigenden Fixkosten wird zeichnerisch bestätigt: In Abb. 5.7 wäre ein Anstieg von $\mathrm{K}$ gleichbedeutend mit einer Parallelverschiebung von $P_{1} P_{2}$ nach unten links, der horizontale Abstand zwischen $P_{1}$ und $P^{*}$ ginge zurück, d.h. die Steuerumgehung nähme ab.

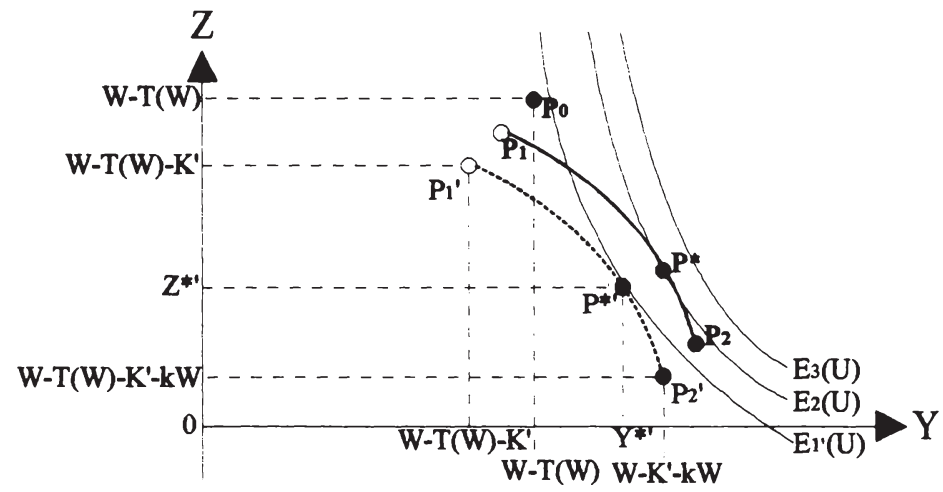

Abb. 5.7.c) Variation der Fixkosten $K$

b) Variation der Grenzkosten der Steuerumgehung

$$
\begin{aligned}
\frac{\partial \mathrm{X}}{\partial \mathrm{k}}= & \frac{(1-p) * U^{\prime}(\mathrm{Y})+\mathrm{p}^{*} \mathrm{U}^{\prime}(\mathrm{Z})}{-\frac{\partial^{2} \mathrm{E}(\mathrm{U})}{\partial \mathrm{X}^{2}}}+ \\
& +\frac{(1-\mathrm{p}) *\left(\mathrm{~T}^{\prime}(\mathrm{X})-\mathrm{k}\right) *(\mathrm{~W}-\mathrm{X}) * \mathrm{U}^{\prime \prime}(\mathrm{Y})-\mathrm{p} * \mathrm{k} *(\mathrm{~W}-\mathrm{X}) * \mathrm{U}^{\prime \prime}(\mathrm{Z})}{-\frac{\partial^{2} \mathrm{E}(\mathrm{U})}{\partial \mathrm{X}^{2}}}
\end{aligned}
$$




$$
\begin{aligned}
= & \frac{(1-p) * U^{\prime}(\mathrm{Y})+\mathrm{p}^{*} \mathrm{U}^{\prime}(\mathrm{Z})}{-\frac{\partial^{2} \mathrm{E}(\mathrm{U})}{\partial \mathrm{X}^{2}}}+ \\
& +\frac{-(1-\mathrm{p}) *\left(\mathrm{~T}^{\prime}(\mathrm{X})-\mathrm{k}\right) *(\mathrm{~W}-\mathrm{X}) * \mathrm{U}^{\prime}(\mathrm{Y}) * \mathrm{R}_{\mathrm{A}}(\mathrm{Y})+\mathrm{pk} *(\mathrm{~W}-\mathrm{X}) * \mathrm{U}^{\prime}(\mathrm{Z}) * \mathrm{R}_{\mathrm{A}}(\mathrm{Z})}{-\frac{\partial^{2} \mathrm{E}(\mathrm{U})}{\partial \mathrm{X}^{2}}} \\
= & \frac{(1-\mathrm{p}) * \mathrm{U}^{\prime}(\mathrm{Y})+\mathrm{p} * \mathrm{U}^{\prime}(\mathrm{Z})}{-\frac{\partial^{2} \mathrm{E}(\mathrm{U})}{\partial \mathrm{X}^{2}}}+ \\
& +\frac{(1-\mathrm{p}) *\left(\mathrm{~T}^{\prime}(\mathrm{X})-\mathrm{k}\right) *(\mathrm{~W}-\mathrm{X}) * \mathrm{U}^{\prime}(\mathrm{Y}) *\left[\mathrm{R}_{\mathrm{A}}(\mathrm{Z})-\mathrm{R}_{\mathrm{A}}(\mathrm{Y})\right]}{\partial^{2} \mathrm{E}(\mathrm{U})} \\
& \quad-0
\end{aligned}
$$

Je höher also die Grenzkosten der Steuerumgehung liegen, desto weniger Steuerumgehung wird betrieben.

Graphisch käme es - bei Konstanz der Punkte $P_{0}$ und $P_{1}$ - zu einer Verschiebung von $P_{2}$ nach links unten und damit zu einer steiler werdenden Linie $P_{1} P_{2}$. Damit sänke der horizontale Abstand zwischen $\mathrm{P}_{1}$ und $\mathrm{P}^{*}$; das Ergebnis zurückgehender Steuerumgehung wird demnach bestätigt.

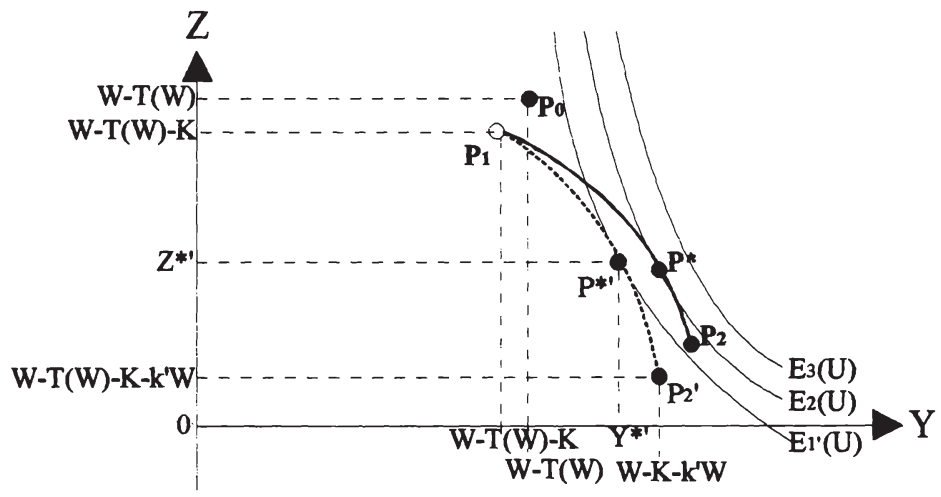

Abb. 5.7.d) Variation der Grenzkosten k 


\subsection{Variation des Steuertarifes}

Zugrunde gelegt werden soll wiederum ein Steuertarif der Form $T(X)=\theta X-r$. Es gelten dann

$$
\begin{aligned}
& \mathrm{E}(\mathrm{U})=(1-\mathrm{p}) * \mathrm{U}(\mathrm{W}-\theta \mathrm{X}+\mathrm{r}-\mathrm{K}-\mathrm{k} *(\mathrm{~W}-\mathrm{X}))+\mathrm{p} * \mathrm{U}(\mathrm{W}-\theta \mathrm{W}+\mathrm{r}-\mathrm{K}-\mathrm{k} *(\mathrm{~W}-\mathrm{X})) \text { und } \\
& \frac{\partial \mathrm{E}(\mathrm{U})}{\partial \mathrm{X}}=(1-\mathrm{p}) *(\mathrm{k}-\theta) * \mathrm{U}^{\prime}(\mathrm{Y})+\mathrm{p} * \mathrm{k}^{*} \mathrm{U}^{\prime}(\mathrm{Z})
\end{aligned}
$$

a) Variation des Steuersatzes

$$
\begin{aligned}
\frac{\partial X}{\partial \theta} & =S+E \\
\text { mit } S: & =\frac{(1-p) * U^{\prime}(Y)}{\frac{\partial^{2} E(U)}{\partial X^{2}}} \\
\text { und } E & :=\frac{(1-p) *(\theta-k) * X^{*} U^{\prime \prime}(Y)-p k * W^{*} U^{\prime \prime}(Z)}{-\frac{\partial^{2} E(U)}{\partial X^{2}}} \\
& =\frac{-(1-p) *(\theta-k) * X^{*} U^{\prime}(Y) * R_{A}(Y)+p k * W^{\prime} * U^{\prime}(Z) * R_{A}(Z)}{-\frac{\partial^{2} E(U)}{\partial X^{2}}} \\
& =\frac{(1-p) *(\theta-k) * U^{\prime}(Y) *\left[-X^{*} R_{A}(Y)+W^{\prime} * R_{A}(Z)\right]}{-\frac{\partial^{2} E(U)}{\partial X^{2}}}
\end{aligned}
$$

Wegen $\mathrm{S}<0$ und $\mathrm{E}>0$ kann insgesamt nicht eindeutig gesagt werden, in welche Richtung eine Steuersatzvariation auf die Höhe des deklarierten Einkommens wirkt.

In Abb. 5.7 würde eine Steuersatzvariation $P_{2}$ vertikal nach unten, $P_{0}$ und $P_{1}$ um den gleichen Betrag nach unten und nach links wandern lassen. $P_{1} P_{2}$ würde dabei flacher werden. Letzteres würde isoliert betrachtet einen Anstieg der Steuerumgehung bedeuten, die Linksverschiebung hingegen einen Rückgang bewirken. Die Gesamtwirkung einer Erhöhung des Steuersatzes muß damit auch nach der graphischen Analyse offen bleiben. In Abb. 5.7.e) dominiert der Effekt der flacheren Budgetlinie, doch könnte sich bei anderem Verlauf der Budgetlinie und Indifferenzkurven theoretisch etwas anderes ergeben. 


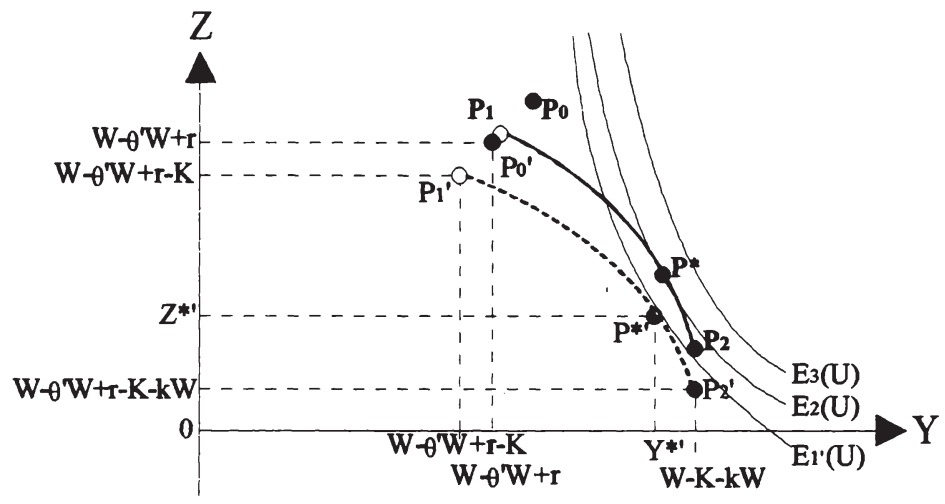

Abb. 5.7.e) Variation des Grenzsteuer-
satzes $\boldsymbol{\theta}$

b) Variation des Pauschaltransfers bzw. der Kopfsteuer

$$
\begin{aligned}
\frac{\partial \mathrm{X}}{\partial \mathrm{r}} & =\frac{(1-\mathrm{p}) *(\mathrm{k}-\theta) * \mathrm{U}^{\prime \prime}(\mathrm{Y})+\mathrm{p} * \mathrm{k} * \mathrm{U}^{\prime \prime}(\mathrm{Z})}{-\frac{\partial^{2} \mathrm{E}(\mathrm{U})}{\partial \mathrm{X}^{2}}} \\
& =\frac{(1-\mathrm{p}) *(\theta-\mathrm{k}) * \mathrm{U}^{\prime}(\mathrm{Y}) * \mathrm{R}_{\mathrm{A}}(\mathrm{Y})-\mathrm{pk} * \mathrm{U}^{\prime}(\mathrm{Z}) * \mathrm{R}_{\mathrm{A}}(\mathrm{Z})}{-\frac{\partial^{2} \mathrm{E}(\mathrm{U})}{\partial \mathrm{X}^{2}}} \\
& =\frac{(1-\mathrm{p}) *(\theta-\mathrm{k}) * \mathrm{U}^{\prime}(\mathrm{Y}) *\left[\mathrm{R}_{\mathrm{A}}(\mathrm{Y})-\mathrm{R}_{\mathrm{A}}(\mathrm{Z})\right]}{-\frac{\partial^{2} \mathrm{E}(\mathrm{U})}{\partial \mathrm{X}^{2}}}<0
\end{aligned}
$$

Eine Erhöhung des Pauschaltransfers (bzw. Senkung der Kopfsteuer) führt also zu einem Absinken des deklarierten Einkommens und damit zu steigender Steuerumgehung.

In Abb. 5.7 ist der Anstieg von $\mathrm{r}$ gleichbedeutend mit einer Parallelverschiebung von $\mathbf{P}_{1} \mathbf{P}_{2}$ nach rechts oben. Damit bestätigt sich das Ergebnis wachsender Steuerumgehung auch graphisch. 


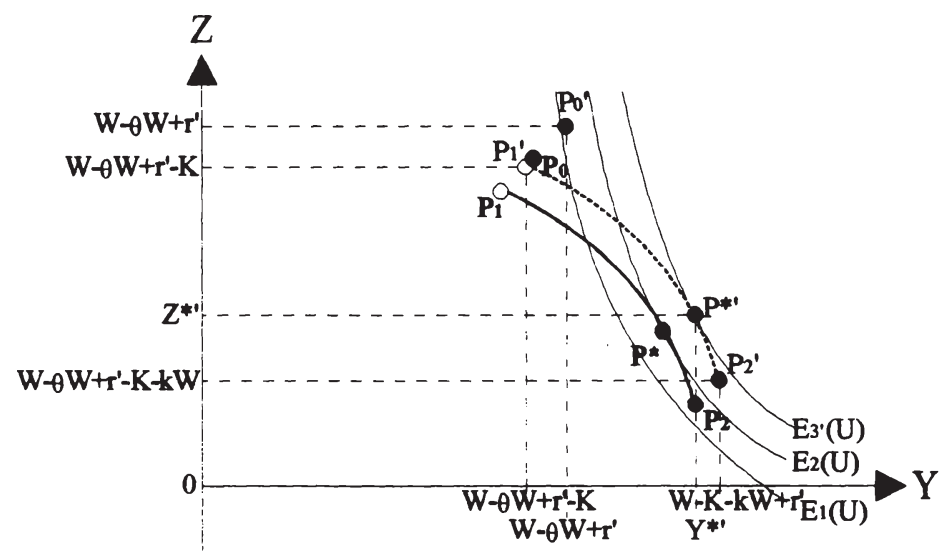

Abb. 5.7.f) Variation des Pauschaltransfers $r$

c) Variation des Progressionsgrades

Wird von einer Bestrafung der Steuerumgehung abgesehen, so entspricht das erwartete Aufkommen des Staates der erwarteten Steuerzahlung, d.h.

$\begin{aligned} & E(A)=\theta X-r+p \theta *(W-X) \\ \Leftrightarrow & r=\theta X+p \theta *(W-X)-E(A) .\end{aligned}$

Abgeleitet nach $\theta$, ergibt sich:

$$
\frac{\mathrm{dr}}{\mathrm{d} \theta}=\mathrm{X}+\mathrm{p} *(\mathrm{~W}-\mathrm{X})
$$

Die gesamte Wirkung einer Progressionsveränderung beträgt dann

$$
\begin{aligned}
& \left.\frac{\mathrm{dX}}{\mathrm{d} \theta}\right|_{\mathrm{dE}(\mathrm{A})=0}=\frac{\partial \mathrm{X}}{\partial \theta}+\frac{\partial \mathrm{X}}{\partial \mathrm{r}} * \frac{\mathrm{dr}}{\mathrm{d} \theta} \\
& =\mathrm{S}+\frac{(1-\mathrm{p}) *(\theta-\mathrm{k}) * \mathrm{U}^{\prime}(\mathrm{Y}) *\left[\mathrm{~W} * \mathrm{R}_{A}(\mathrm{Z})-\mathrm{X} * \mathrm{R}_{\mathrm{A}}(\mathrm{Y})\right]}{-\frac{\partial^{2} \mathrm{E}(\mathrm{U})}{\partial \mathrm{X}^{2}}}+ \\
& +\frac{(1-\mathrm{p}) *(\theta-\mathrm{k}) * \mathrm{U}^{\prime}(\mathrm{Y}) *\left[\mathrm{RA}_{A}(\mathrm{Y})-\mathrm{R}_{\mathrm{A}}(\mathrm{Z})\right] *[\mathrm{X}+\mathrm{p} *(\mathrm{~W}-\mathrm{X})]}{-\frac{\partial^{2} \mathrm{E}(\mathrm{U})}{\partial \mathrm{X}^{2}}}
\end{aligned}
$$




$$
\begin{aligned}
& =\mathrm{S}+\frac{(1-\mathrm{p}) *(\theta-\mathrm{k}) * \mathrm{U}^{\prime}(\mathrm{Y}) *\left[\mathrm{~W} * \mathrm{R}_{\mathrm{A}}(\mathrm{Z})-\mathrm{X}^{*} \mathrm{R}_{\mathrm{A}}(\mathrm{Y})\right]}{-\frac{\partial^{2} \mathrm{E}(\mathrm{U})}{\partial \mathrm{X}^{2}}}+ \\
& +\frac{(1-\mathrm{p}) *(\theta-\mathrm{k}) * \mathrm{U}^{\prime}(\mathrm{Y}) *\left[\mathrm{X} *\left(\mathrm{R}_{\mathrm{A}}(\mathrm{Y})-\mathrm{R}_{\mathrm{A}}(\mathrm{Z})\right)+\mathrm{p} *(\mathrm{~W}-\mathrm{X}) *\left(\mathrm{R}_{\mathrm{A}}(\mathrm{Y})-\mathrm{R}_{\mathrm{A}}(\mathrm{Z})\right)\right]}{-\frac{\partial^{2} \mathrm{E}(\mathrm{U})}{\partial \mathrm{X}^{2}}} \\
& =\mathrm{S}+\frac{(\mathrm{l}-\mathrm{p}) *(\theta-\mathrm{k}) * \mathrm{U}^{\prime}(\mathrm{Y}) *\left[(\mathrm{~W}-\mathrm{X}) * \mathrm{R}_{\mathrm{A}}(\mathrm{Z})+\mathrm{p} *(\mathrm{~W}-\mathrm{X}) *\left(\mathrm{R}_{\mathrm{A}}(\mathrm{Y})-\mathrm{R}_{\mathrm{A}}(\mathrm{Z})\right)\right]}{-\frac{\partial^{2} \mathrm{E}(\mathrm{U})}{\partial \mathrm{X}^{2}}} \\
& =\mathrm{S}+\frac{(1-\mathrm{p}) *(\theta-\mathrm{k}) * \mathrm{U}^{\prime}(\mathrm{Y}) *(\mathrm{~W}-\mathrm{X}) *\left[(1-\mathrm{p}) * \mathrm{R}_{\mathrm{A}}(\mathrm{Z})+\mathrm{p} * \mathrm{R}_{\mathrm{A}}(\mathrm{Y})\right]}{-\frac{\partial^{2} \mathrm{E}(\mathrm{U})}{\partial \mathrm{X}^{2}}}
\end{aligned}
$$

mit $S:=\frac{(1-p) * U^{\prime}(Y)}{\frac{\partial^{2} E(U)}{\partial X^{2}}}$

Während S negativ ist, ist der zweite Summand in jedem Falle positiv. Insgesamt läßt sich daher keine klare Aussage darüber machen, ob eine Progressionsverschärfung unter den Bedingungen des vorliegenden Modells zu einer Erhöhung oder zu einer Abnahme des deklarierten Einkommens führt.

Es gilt jedoch auch für die straffreie Steuerumgehung unter der Voraussetzung sinkender absoluter Risikoaversion eindeutig

$$
\left.\frac{\mathrm{dX}}{\mathrm{d} \theta}\right|_{\mathrm{dE}(\mathrm{A})=0}<\frac{\partial \mathrm{X}}{\partial \theta} \text {. }
$$

Beweis:

$$
\begin{aligned}
& \mathrm{R}_{\mathrm{A}}(\mathrm{Y})<\mathrm{R}_{\mathrm{A}}(\mathrm{Z}) \\
\Leftrightarrow & {[(\mathrm{W}-\mathrm{X}) * \mathrm{p}+\mathrm{X}] * \mathrm{R}_{\mathrm{A}}(\mathrm{Y})<[(\mathrm{W}-\mathrm{X}) * \mathrm{p}+\mathrm{X}] * \mathrm{R}_{\mathrm{A}}(\mathrm{Z}) } \\
\Leftrightarrow & (\mathrm{W}-\mathrm{X}) * \mathrm{p} * \mathrm{R}_{\mathrm{A}}(\mathrm{Y})+\mathrm{X} * \mathrm{R}_{\mathrm{A}}(\mathrm{Y})<(\mathrm{W}-\mathrm{X}) * \mathrm{p} * \mathrm{R}_{\mathrm{A}}(\mathrm{Z})-(\mathrm{W}-\mathrm{X}) * \mathrm{R}_{\mathrm{A}}(\mathrm{Z})+\mathrm{W} * \mathrm{R}_{\mathrm{A}}(\mathrm{Z}) \\
\Leftrightarrow & (\mathrm{W}-\mathrm{X}) *(1-\mathrm{p}) * \mathrm{R}_{\mathrm{A}}(\mathrm{Z})+(\mathrm{W}-\mathrm{X}) * \mathrm{p} * \mathrm{R}_{\mathrm{A}}(\mathrm{Y})<-\mathrm{X} * \mathrm{R}_{\mathrm{A}}(\mathrm{Y})+\mathrm{W} * \mathrm{R}_{\mathrm{A}}(\mathrm{Z}) \\
\Leftrightarrow & (1-\mathrm{p}) *(\theta-\mathrm{k}) * \mathrm{U}^{\prime}(\mathrm{Y}) *(\mathrm{~W}-\mathrm{X}) *\left[(1-\mathrm{p}) * \mathrm{R}_{\mathrm{A}}(\mathrm{Z})+\mathrm{p} * \mathrm{R}_{\mathrm{A}}(\mathrm{Y})\right]< \\
& <(1-\mathrm{p}) *(\theta-\mathrm{k}) * \mathrm{U}^{\prime}(\mathrm{Y}) *\left[-\mathrm{X} * \mathrm{R}_{\mathrm{A}}(\mathrm{Y})+\mathrm{W} * \mathrm{R}_{\mathrm{A}}(\mathrm{Z})\right]
\end{aligned}
$$




$$
\begin{aligned}
\Leftrightarrow & S+\frac{(1-p) *(\theta-k) * U^{\prime}(Y) *(\mathrm{~W}-\mathrm{X}) *\left[(1-\mathrm{p}) * \mathrm{RA}_{\mathrm{A}}(\mathrm{Z})+\mathrm{p} * \mathrm{R}_{\mathrm{A}}(\mathrm{Y})\right]}{-\frac{\partial^{2} \mathrm{E}(\mathrm{U})}{\partial \mathrm{X}^{2}}}< \\
& <\mathrm{S}+\frac{(1-\mathrm{p}) *(\theta-\mathrm{k}) * \mathrm{U}^{\prime}(\mathrm{Y}) *\left[-\mathrm{X}^{*} \mathrm{R}_{\mathrm{A}}(\mathrm{Y})+\mathrm{W} * \mathrm{R}_{\mathrm{A}}(\mathrm{Z})\right]}{-\frac{\partial^{2} \mathrm{E}(\mathrm{U})}{\partial \mathrm{X}^{2}}} \\
\Leftrightarrow & \left.\frac{\mathrm{dX}}{\mathrm{d} \theta}\right|_{\mathrm{dE}(\mathrm{A})=0}<\frac{\partial \mathrm{X}}{\partial \theta}
\end{aligned}
$$

q.e.d.

Auch in Abb. 5.7 läßt sich eine Progressionsverschärfung als kombinierte Steuersatzerhöhung (Verschiebung von $\mathrm{P}_{1} \mathrm{P}_{2}$ nach links unten bei flacher werdendem Verlauf) und Einführung eines Pauschaltransfers (Parallelverschiebung der Budgetlinie nach rechts oben) verstehen. Werden beide Maßnahmen so bemessen, daß der Erwartungsnutzen konstant bleibt, d.h. die gleiche Indifferenzkurve wie in der Ausgangssituation berührt wird, dann wäre der nun flachere Verlauf von $\mathbf{P}_{1} \mathbf{P}_{2}$ gleichbedeutend mit einer Erhöhung des horizontalen Abstandes zwischen $P_{1}$ und $\mathrm{P}^{*}$. Dies bedeutet, daß durch eine Progressionsverschärfung die Steuerumgehung zunimmt.

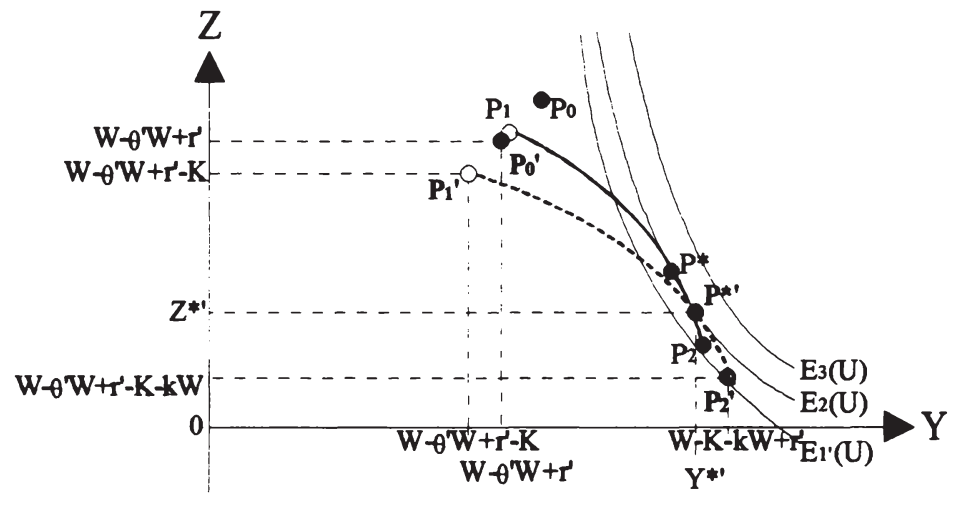

Abb. 5.7.g) Variation des Progressionsgrades 


\subsection{Exkurs: Simultane Entscheidung über Steuerumgehung und Steuerhinterziehung}

In Kap. 5.5 war die Steuerumgehung unter der Prämisse analysiert worden, daß die Steuerpflichtigen ausschließlich über ihre Steuerumgehungsaktivitäten entscheiden, ohne daß dabei andere Entscheidungen, etwa die Arbeit-Freizeit-Entscheidung oder die Steuerhinterziehungsentscheidung, gleichzeitige Berücksichtigung fanden. Nach der jeweils getrennten Behandlung von Steuerhinterziehung und -umgehung in den vorangegangenen Abschnitten soll in diesem Exkurs nun ein Überblick über die Möglichkeiten gegeben werden, das Verhalten von Steuerzahlern zu untersuchen, welche gleichzeitig das Ausmaß ihrer Steuerumgehung und ihrer Steuerhinterziehung festlegen.

In der englischsprachigen Literatur haben bereits einige theoretische Abhandlungen eine gemeinsame Untersuchung von tox evasion und tax avoidance zum Gegenstand gehabt, wobei jedoch die tax avoidance meist im Sinne reiner Steuervermeidung (als Entscheidung unter Sicherheit) in die Analyse eingeht.

Eine modelltheoretische simultane Analyse von Steuerhinterziehung und -umgehung findet sich erstmals bei ALM/McCALLIN (1990).

Innerhalb des deutschsprachigen Schriftums hat sich WREDE mit der Entscheidungssituation eines Steuerpflichtigen befaßt, welcher gleichzeitig sein Ausmaß an Steuerhinterziehung, Steuerumgehung und Steuervermeidung festlegt. WREDE behandelt dabei lediglich zwei wenig realistische Spezialfälle:

Zunächst wird eine gemeinsame Kostenfunktion des Steuerentzuges angenommen, deren Verlauf unabhängig von der Art des Steuerentzuges ist. Es liegt auf der Hand, daß bei identischem Kostenverlauf die Steuerpflichtigen nur dann Steuern umgehen werden, solange die Obergrenze der (risikofreien) Steuervermeidung noch nicht erreicht ist, und nur dann Steuerhinterziehung betreiben, wenn die Möglichkeiten der (als straffrei angenommenen) Steuerumgehung voll ausgeschöpft sind. Dies bedeutet, daß im Falle einer inneren Lösung für die Steuerumgehung weder die (bereits maximal betriebene) Steuervermeidung noch die (unvorteilhaftere) Steuerhinterziehung eine Handlungsalternative darstellt. Die oben ermittelten Ergebnisse der Steuerumgehungstheorie bleiben dann uneingeschränkt gültig. ${ }^{1}$

WREDE befaßt sich anschließend mit dem Fall additiv separabler Kostenfunktionen unter der Prämisse, daß jede Überprüfung einer Einkommensdeklaration nicht nur zu einer Aufdeckung der Steuerhinterziehung, sondern gleichzeitig auch zu einem Scheitern der Steuerumgehung führt. Dies würde bedeuten, daß die Finanzbehörden bzw. -gerichte eine steuerumgehende Gestaltung immer dann als rechts-

\footnotetext{
${ }^{1}$ Vgl. WREDE (1993) S. $90 \mathrm{f}$.
} 
mißbräuchlich qualifizieren würden, wenn die betreffende steuerpflichtige Person nachweislich auch Steuerhinterziehung betreiben hat. Wird auf solche Weise die aufgedeckte Steuerhinterziehung zum Tatbestandsmerkmal einer (offen durchgeführten) Steuerumgehung, so kommt es laut WREDE auch für den Fall, daß alle drei Alternativen des Steuerentzuges eine innere Lösung aufweisen, zu keinen wesentlichen Änderungen in den Modellergebnissen, die sich bei isolierter Untersuchung jeder der Alternativen ergeben hatten (Begründung fehlt). ${ }^{1}$

Der Aufsatz von ALM und McCALLIN aus dem Jahre 1990 ist furr die gemeinsame Untersuchung von Steuerumgehung und -hinterziehung weitaus ergiebiger, weicht jedoch in der Vorgehensweise grundlegend von dem seit ALLINGHAM und SANDMO in der ökonomischen Theorie des Steuerentzuges üblichen Ansatz ab, so daß eine Integration in die moderne Steuerhinterziehungstheorie oder in die in Kap. 5.5 entwickelte Steuerumgehungstheorie nicht möglich erscheint. An dieser Stelle seien im wesentlichen nur die Ergebnisse des Simultanmodells dargestellt.

ALM und McCALLIN betrachten ein Individuum, das seinen erwarteten Nutzen zu maximieren versucht, wobei der Nutzen eine Funktion des erwarteten verfugbaren Einkommens und dessen Varianz ist, d.h. die auch hier angenommene Risikoaversion wird nicht mehr allein nach dem Bernoulli-Prinzip, sondern nach dem $\mu-\sigma-$ Prinzip im Modell berücksichtigt. Untersucht wird der Einfluß von Variationen von insgesamt vierzehn Parametern auf die Aufteilung der gesamten Einkünte in deklariertes Einkommen, umgangenes Einkommen und hinterzogenes Einkommen. Von den in Kap. 5.2 und 5.5 verwendeten Parametern sind der Steuersatz, die Wahrscheinlichkeit einer Aufdeckung der Steuerhinterziehung, die Geldstrafe auf die aufgedeckte Steuerhinterziehung (hier bemessen auf das hinterzogene Einkommen), die Wahrscheinlichkeit eines Scheiterns der Steuerumgehung und die Grenzkosten der Steuerumgehung enthalten.

Ein Anstieg des Steuersatzes führt im Modell in jedem Fall zu einem Rückgang des versteuerten Einkommens; sowohl das hinterzogene als auch das umgangene Einkommen nehmen $\mathrm{zu}^{2}$

Steigt die Aufdeckungswahrscheinlichkeit der Steuerhinterziehung, so geht letztere zurück; der Anteil der Steuerumgehung am gesamten Steuerentzug steigt, es steigt aber auch das deklarierte Einkommen. ${ }^{3}$

Eine Erhöhung der furr Steuerhinterziehung fälligen Geldstrafe führt ebenfalls zu einem Rückgang der Hinterziehung und zu einem Anstieg des Anteils, den die

\footnotetext{
${ }^{1}$ Vgl. ebenda S. 92.

${ }^{2}$ Vgl. ALM/McCALLIN (1990) S. 197.

${ }^{3} \mathrm{Vgl}$. ebenda.
} 
(straffreie) Steuerumgehung am gesamten Steuerentzug einnimmt. Das versteuerte Einkommen nimmt zu. ${ }^{1}$

Erhöht sich die Wahrscheinlichkeit eines Scheiterns der Steuerumgehung, so werden weniger Steuern umgangen. Zwar kommt es zu einem Anstieg der Steuerhinterziehung, doch geht der Steuerentzug insgesamt zurück. ${ }^{2}$

Die gleiche Wirkung hat ein Zuwachs der Grenzkosten der Steuerumgehung: Das versteuerte Einkommen steigt, die Steuerhinterziehung nimmt ebenfalls zu, während die Steuerumgehung abnimmt. ${ }^{3}$

Insgesamt entsprechen die Ergebnisse des Alm-McCallin-Modells sowohl den intuitiven Erwartungen als auch weitgehend den Resultaten, die sich bei jeweils isolierter Betrachtung von Steuerumgehung und Steuerhinterziehung ergeben hatten. Bemerkenswert ist allerdings, daß die Berücksichtigung risikoscheu eingestellter Wirtschaftssubjekte mittels des $\mu-\sigma$-Prinzips und der Verzicht auf die Annahme abnehmender Risikoaversion dazu führen, daß eine Steuersatzvariation keinen Einkommenseffekt hervorruft und daher ein eindeutig positiver Zusammenhang zum Ausmaß an Steuerumgehung und -hinterziehung besteht. Festzuhalten ist ferner, daß eine Bekämpfung der Steuerumgehung über die Parameter „Grenzkosten“ und „Wahrscheinlichkeit des Scheiterns“ nicht zu einer vollständigen Substitution des umgangenen Einkommens durch hinterzogenes Einkommen führt, sondern auch die Steuerzahlung ansteigen läßt. Eine fiskalische Wirkungslosigkeit von gegen die Steuerumgehung gerichteten Maßnahmen aufgrund eines Ausweichens der Wirtschaftssubjekte in die Steuerhinterziehung ist demnach nicht zu erwarten, auch wenn es im Modell teilweise zu derartigen Ausweichreaktionen kommt.

\subsection{Interpretation der Modellergebnisse: Welche Parameter eignen sich für eine Bekämpfung der Steuerumgehung?}

In den Abschnitten 5.5 und 5.6 wurde die Wirkungsrichtung von Änderungen der im Modell enthaltenen Parameter ermittelt. Hieraus ergibt sich, in welche Richtung die untersuchten Bestimmungsfaktoren variiert werden müssen, um (theoretisch) die gewünschte Reduzierung der Steuerumgehungsaktivitäten zu erreichen. Eine entsprechende Eignung derartiger Parametervariationen für eine gegen die Steuerumgehung gerichtete Politik setzt jedoch voraus, daß erstens das verwendete partialanalytische Modell mit seinen Prämissen dem Untersuchungsgegenstand

${ }^{1}$ Vgl. ebenda S. 198.

${ }^{2}$ Vgl. ebenda S. 197.

${ }^{3} \mathrm{Vgl}$. ebenda. 
angemessen ist ${ }^{1}$ und zweitens der Staat in der Lage ist, die Höhe der betreffenden Parameter festzulegen oder zumindest zu beeinflussen. Unter Berücksichtigung dieser Voraussetzungen wird im vorliegenden Abschnitt 5.7 der Frage nachgegangen, inwieweit sich aus dem komparativ-statischen Modell Implikationen für eine Politik ergeben, die zum Ziel hat, das gesamtwirtschaftliche Steuerumgehungsvolumen zurückzuführen.

\subsubsection{Einkommenshöhe}

Ein positiver Einfluß der Höhe des „wahren“ Einkommens auf die Höhe des versteuerten Einkommens ist nach den Ergebnissen des theoretischen Modells nicht zweifelsfrei gesichert.

Jedoch käme es nur im Falle $(1+f) * T^{\prime}(W) * R_{A}(Z)<(1-k) *\left(R_{A}(Z)-R_{A}(Y)\right)$ zum gegenteiligen Ergebnis. Für eine derart ausgeprägte Abnahme der Risikoaversion gibt es aber empirisch keine Anhaltspunkte; im Gegenteil widersprechen die empirischen Ergebnisse zur Steuerhinterziehung eindeutig einem solchen Verlauf der Risikoaversionsfunktion (s.o. Kap. 5.3.2).

Ungewiß bleibt hingegen die Entwicklung des Anteils des versteuerten am gesamten Einkommen, sofern der Steuertarif steigende Grenzsteuersätze enthält. Immerhin ergab die graphische Analyse, daß das absolute Ausmaß der Steuerumgehung positiv mit der Einkommenshöhe korreliert ist. Die intuitiv naheliegende Annahme, zusätzliches Einkommen werde c.p. sowohl zu einer Erhöhung des deklarierten als auch des umgangenen Einkommens führen, wird also durch die Untersuchungsergebnisse durchaus gestützt.

Der Anstieg der Steuerumgehung ist für den Fiskus unproblematisch, solange er von steigenden Steuerzahlungen begleitet wird. Es gibt demnach für den einnahmemaximierenden Staat keinen Grund $\mathrm{zu}$ versuchen, durch eine negative Beeinflussung der Einkommensentwicklung das Ausmaß an Steuerumgehung zu drosseln. Ohnehin stellt das Einkommen nur sehr begrenzt einen Handlungsparameter des Staates dar. Die Einkommensentwicklung unterliegt lediglich indirekt dem Einfluß der Regierungspolitik (z.B. über die Wachstumspolitik oder die Zinsentwicklung), wird jedoch unmittelbar im wesentlichen von den Verhandlungsergebnissen der Tarifpartner bestimmt. Zwar ist auch der Staat Arbeitgeber und beeinflußt dadurch in gewissen Grenzen die Lohnentwicklung. Doch dürfte bei den Tarifverhandlungen im öffentlichen Dienst der mögliche Einfluß der Einkommensentwicklung auf die Steuerumgehung von anderen gesamtwirtschaftlichen und

${ }^{1}$ Dies wird bzgl. der Variation des Steuertarifes bestritten, da das verwendete Modell die gesamtwirtschaftlich relevante staatliche Verausgabung des veränderten Steueraufkommens unberücksichtigt läßt. Vgl. hierzu die entsprechenden Ausführungen in Kap. 5.7.5. 
fiskalischen Erwägungen dominiert werden, so daß sich insgesamt festhalten läßt, daß die Einkommensentwicklung weder einen gebräuchlichen noch einen geeigneten Parameter zur Bekämpfung der Steuerumgehung darstellt.

\subsubsection{Wahrscheinlichkeit der Nichtanerkennung}

Die Wahrscheinlichkeit, daß eine der Steuerumgehung dienende Gestaltung steuerlich nicht anerkannt wird, hat im Modell die erwartete positive Wirkung auf das Deklarationsverhalten - unabhängig davon, ob der Rechtsmißbrauch unter Strafe steht oder nicht. Damit stellt eine Steigerung dieser Wahrscheinlichkeit grundsätzlich ein effektives Mittel der Umgehungsbekämpfung dar.

Anders als bei der Steuerhinterziehung, wo der Staat einen Anstieg der Aufdekkungswahrscheinlichkeit ohne weiteres durch eine Erhöhung der Mittelzuweisung an die Steuerfahndung bewirken kann, ${ }^{1}$ unterliegt der Parameter $p$ des Steuerumgehungsmodells nur bedingt dem Einfluß des Gesetzgebers. Solange das Prinzip der Gewaltenteilung gilt, kann die Exekutive den Gerichten nicht vorschreiben, mit welcher Strenge sie die gegen die Steuerumgehung gerichteten geltenden Normen anwenden. Die Finanzverwaltung ist bei ihren Entscheidungen wiederum an die Rechtsprechung gebunden. Dem Gesetzgeber bleibt die Möglichkeit, innerhalb der verfassungsmäßig vorgegebenen Grenzen Gesetze gegen die Steuerumgehung zu erlassen und auf diese Weise den Parameter $\mathrm{p}$ zu beeinflussen. Insbesondere kann dabei die Einführung einer Generalklausel von Bedeutung sein, sofern sie nicht wie in den USA - aufgrund einer entsprechenden Rechtsprechungspraxis überflüssig ist. Eine Erhöhung von $p$ durch Ausweitung des Anwendungsbereiches einer bereits bestehenden Generalklausel ist nicht ohne weiteres möglich. In Deutschland führen vor allem die bei den Finanzbehörden liegende Beweislastverteilung und das Tatbestandsmerkmal der Nichtexistenz beachtlicher außersteuerlicher Gründe für die gewählte Rechtsgestaltung zu einer eingeschränkten Wirksamkeit des $\S 42 \mathrm{AO}$; entsprechendes gilt im Grundsatz auch in Frankreich. Eine Umkehrung der Beweislastverteilung ist in einem Rechtsstaat nicht ohne weiteres zulässig; allenfalls könnte die Einführung einer außergerichtlichen Vorinstanz, entsprechend dem französischen comité consultatif spécial, auch in Deutschland die Wahrscheinlichkeit des Scheiterns einer mißbräuchlichen Gestaltung positiv beeinflussen, sofern dieser Ausschuß weniger steuerzahlerfreundlich eingestellt ist als die Finanzgerichtsbarkeit und eine Entscheidung des Ausschusses gegen den Steuerpflichtigen

${ }^{1}$ Der Umstand, daß in der Praxis nicht jede Steuerhinterziehung im Falle einer Steuerfahndung aufgedeckt wird, setzt der staatlichen Einflußnahme auf die Aufdeckungswahrscheinlichkeit allerdings technische Grenzen. Eine weitere Grenze stellt die Belastungsfahigkeit der offentlichen Haushalte dar, sobald der Grenzertrag aus aufgedeckter Steuerhinterziehung die Grenzkosten der Steuerfahndung unterschreitet. 
die Beweislast umkehrt. Es fiele jedoch schwer, den $\S 42$ AO derart umzuformulieren, daß das von der Rechtsprechung entwickelte Tatbestandsmerkmal der Nichtexistenz beachtlicher außersteuerlicher Gründe von den Gerichten weiter ausgelegt oder ganz aufgegeben wird. Eine engere Auslegung des Wortes „beachtlich“ kann der Gesetzgeber kaum durchsetzen. Eine völlige Aufgabe dieses Tatbestandsmerkmales wäre gleichbedeutend mit einer „Besteuerung nach dem wirtschaftlichen Ergebnis“, d.h. mit einer ,freischwebenden“ wirtschaftlichen Betrachtungsweise. Die gesetzliche Verankerung einer solchen Besteuerung stieße jedoch auf verfassungsrechtliche Bedenken (Grundsatz der Rechtssicherheit). Da der Grundsatz der Besteuerung nach dem wirtschaftlichen Ergebnis nicht über das Prinzip der Neutralität der Besteuerung hinausgeht, stellt sich ohnehin die Frage, warum der Gesetzgeber dann nicht gleich dort, wo das wirtschaftiche Ergebnis Grundlage der Besteuerung sein soll, Besteuerungsneutralität verwirklicht (hierzu s.u. Abschnitt 6).

An dieser Stelle bleibt festzuhalten, daß die Wahrscheinlichkeit des Scheiterns einer rechtsmißbräuchlichen Gestaltung zwar einen negativen Zusammenhang mit dem Ausmaß an Steuerumgehung aufweist, die Möglichkeiten des Staates, diese Wahrscheinlichkeit zu beeinflussen, jedoch beschränkt sind. Sofern nötig und noch nicht geschehen, empfiehlt sich allerdings die Einführung einer Generalklausel, welche je nach Anwendungsintensität durch die Gerichte den Parameter $p$ signifikant erhöhen kann. Eine Verschärfung der bestehenden Generalklausel oder ihre Ergänzung durch eine gesetzlich verankerte freischwebende wirtschaftliche Betrachtungsweise stößt jedoch zumindest in Deutschland auf verfassungsmäßige Grenzen.

\subsubsection{Strafsatz}

Wenn die Steuerumgehung als Ordnungswidrigkeit mit einer Geldbuße belegt wird, so werden nach den Ergebnissen des Modells um so weniger Steuern umgangen, je höher der Strafsatz bemessen ist. Diese erwartete abschreckende Wirkung macht das Bußgeld zu einem theoretisch geeigneten Instrument der Steuerumgehungsbekämpfung.

In der Praxis trifft jedoch die Bestrafung einer steuerlichen Gestaltung, welche nach dem Wortlaut des Gesetzes zulässig ist, auf rechtsstaatliche Bedenken (s.o. Kap. 4.3.6.2). Selbst dort, wo (wie in Frankreich) die Ahndung der Steuerumgehung als Ordnungswidrigkeit statthaft ist, setzt der Grundsatz der Verhältnismäßigkeit einer Strafverschärfung Grenzen. So wäre es widersinnig, wenn die Strafe für Steuerumgehung gleich hoch oder höher ausfiele als für eine Steuerhinterziehung gleichen Ausmaßes. Die Strafe für Steuerhinterziehung muß sich in einem Rechtsstaat wiederum an der Bestrafung vergleichbarer Delikte (z.B. Betrug, Diebstahl, Subventionserschleichung) orientieren und kann keineswegs willkürlich und beliebig angehoben werden. Damit ist die Anhebung des Strafsatzes 
ein Instrument der Steuerumgehungsbekämpfung, das sich nur in engen Grenzen einsetzen läßt. Wo die Steuerumgehung noch gar nicht unter Strafe steht, sollte allerdings über die Einführung einer Geldbuße nachgedacht werden. Für Deutschland gilt jedoch, daß eine solche Maßnahme wohl vor dem Bundesverfassungsgericht scheitern würde. Würde der $\S 42 \mathrm{AO}$ hingegen nach dem Vorbild des $\S 5$ RAO 1919 bestimmter gefaßt, so sänken zwar die verfassungsrechtlichen Bedenken gegen eine Bußgelderhebung, doch zeigen die historischen Erfahrungen, daß eine solcherart reformierte Generalklausel noch seltener anwendbar wäre als die derzeitige. Die Abschreckungswirkung des Parameters $f$ würde dann durch ein Sinken von p erkauft; die Gesamtwirkung einer derartigen Reform wäre ungewiß.

\subsubsection{Kosten der Steuerumgehung}

$\mathrm{Da} ß$ im Modell sowohl die fixen als auch die variablen Kosten der Steuerumgehung deren Ausmaß negativ beeinflussen, entspricht dem, was man diesbezüglich gemeinhin erwarten dürfte. Es stellt sich die Frage, inwieweit der Staat in der Lage ist, die Höhe der Kosten in nennenswertem Maße zu beeinflussen. Nur wenn dies möglich ist, stellen die Parameter $\mathrm{K}$ und $\mathrm{k}$ einsetzbare Instrumente der Steuerumgehungsbekämpfung dar.

Fixe Kosten entstehen einem Steuerpflichtigen z.B., wenn ein tax avoidance scheme gegen einen festen Betrag käuflich erworben wird. Variable Kosten treten beispielsweise dann auf, wenn eine Kettenschenkung ${ }^{1}$ durchgeführt wird und die zwischengeschaltete Person mit einem bestimmten Prozentsatz an der Transaktion beteiligt wird. In beiden genannten Beispielen hat der Staat keine Möglichkeit der Einflußnahme auf die Kosten. Die Kosten der Steuerumgehung können aber beispielshalber auch in Informationskosten liegen, welche um so höher ausfallen dürften, je komplizierter die Steuergesetzgebung ist. Die Empfehlung von ALM und MCCALLIN $^{2}$, ein einnahmemaximierender Staat sollte mittels einer hohen Komplexität des Steuerrechts eine Erhöhung der Kosten der Steuerumgehung bewirken und auf diese Weise den Rechtsmißbrauch bekämpfen, ist jedoch nicht unproblematisch. Die im Gesetz enthaltenen zahlreichen Ausnahmetatbestände, Abzugsmöglichkeiten und Sonderregelungen, welche die schwierige Durchschaubarkeit der Steuergesetze ausmachen, mögen zwar die Informationskosten erhöhen, schaffen aber häufig gerade erst die Möglichkeit, Steuern zu umgehen, und führen

${ }^{1}$ Eine Kettenschenkung kann insbesondere durch Ausnutzung höherer Freibeträge je nach Verwandtschaftsgrad zur Umgehung von Schenkungsteuer führen. Beispielsweise könnte jemand seinem Enkelkind einen Geldbetrag indirekt über Vater oder Mutter des Kindes zukommen lassen, wenn eine direkte Schenkung den geltenden Freibetrag übersteigt und somit zur Steuerpflicht führt, während der Freibetrag für eine Eltern-Kind-Schenkung nicht überschritten wird. Vgl. hierzu unten Kap. 6.2.1.

${ }^{2}$ Vgl. ALM/McCALLIN (1990) S. 197. 
auch leicht dazu, daß der Gesetzgeber bei der Schaffung neuer gesetzlicher Regelungen derartige Gelegenheiten zum Mißbrauch übersieht.

An dieser Stelle läßt sich festhalten, daß ein Teil der Kosten der Steuerumgehung vom Gesetzgeber nicht beeinflußbar ist, während bei den beeinflußbaren Kosten darauf zu achten ist, ob ein Kostenanstieg nicht möglicherweise durch eine gleichzeitige Zunahme der Gelegenheiten zur Umgehung des Steuergesetzes erkauft wird (vgl. hierzu auch unten Kap. 5.8.2). Die Einsetzbarkeit der Parameter K und k als Instrumente erfolgversprechender staatlicher Anti-Umgehungs-Politik erscheint letzten Endes äußerst begrenzt.

Etwas anders sieht es aus, wenn der Kostenbegriff erweitert und auch nichtmonetäre Kosten in Form von Gewissenskonflikten einbezogen werden. ${ }^{1}$ Inwieweit rechtsmißbräuchlicher Steuerentzug mit einer Gewissensbelastung oder umgekehrt mit besonderer, über den monetären Ertrag hinausgehender Genugtuung verbunden ist, hängt von Faktoren ab, die in Kapitel 5.8.1 behandelt werden und zu einem nicht unerheblichen Teil durchaus vom Staat beeinflußbar sind.

\subsubsection{Steuertarif}

\subsubsection{Steuersatz}

Wie im Steuerhinterziehungsmodell setzt sich auch im Modell der Steuerumgehung die Gesamtwirkung einer Steuersatzvariation aus einem Einkommens- und einem Substitutionseffekt zusammen. Dabei ist der Einkommenseffekt auf das nicht umgangene Einkommen unter der Prämisse risikoscheu eingestellter Steuerpflichtiger stets positiv. Bleibt die gescheiterte Steuerumgehung straffrei, so ist der Substitutionseffekt hingegen in jedem Falle negativ. Dasselbe gilt auch, wenn die Steuerumgehung mit einem Bußgeld belegt wird, sofern die rechtsmißbräuchliche Gestaltung mit Grenzkosten verbunden ist. Dem Einkommenseffekt steht somit (außer für den Fall $\mathrm{f}>0 \mathrm{i}$. V.m. $\mathrm{k}=0$ ) ein gegenläufiger Substitutionseffekt gegenüber, so daß das Ergebnis einer Steuersatzveränderung im Modell uneindeutig bleibt.

Entsprechend den Ausführungen in Kap. 5.3.5 läßt sich jedoch auch hier feststellen, daß die Existenz des Einkommenseffektes nur im Falle einer einzelwirtschaftlichen Betrachtung mit Sicherheit gegeben ist. Berücksichtigt man die staatliche Verwendung der Steuermittel, so liegt ein positiver Einkommenseffekt nur noch dann vor, wenn aufgrund einer Überversorgung mit öffentlichen Gütern der zusätzliche Nutzen aus deren Konsum niedriger liegt als der aus der Steuererhöhung

${ }^{1}$ s.o. S. 131 und $134 \mathrm{f}$. 
unmittelbar resultierende Nutzenverlust. ${ }^{1}$ Geht man davon aus, daß der Grenznutzen aus öffentlichen Gütern gleich dem Grenznutzen aus privaten Gütern ist, so verschwindet bei gesamtwirtschaftlicher Betrachtung der Einkommenseffekt. In diesem Fall verbleibt allein der Substitutionseffekt ( mit $S \leq 0$ ), so daß ein Anstieg des Steuersatzes i.d.R. ein Sinken des versteuerten Einkommens und in jedem Fall eine Zunahme der Steuerumgehung bewirkt. Da die empirischen Untersuchungen zur Steuerhinterziehung fast ausschließlich einen positiven Zusammenhang zwischen Steuersatz und Steuerhinterziehung herausfanden und der Substitutionseffekt im Steuerumgehungsmodell dem Betrage nach höher liegt als im Steuerhinterziehungsmodell, ${ }^{2}$ ist zu erwarten, daß hohe Steuersätze in der Praxis auch die Steuerumgehung fördern. ${ }^{3}$

Es bleibt die Empfehlung an die Politik, die relevanten Steuersätze möglichst niedrig zu halten, will man die Steuerumgehung wirksam eindämmen. Es liegt allerdings auf der Hand, daß Steuersatzreduzierungen in Zeiten wachsender Staatsverschuldung und hoher Ansprüche an den Staat nur begrenzt durchführbar sind. Auf jeden Fall sollte jedoch eine weitere Ausweitung der Staatstätigkeit im Hinblick auf dafür notwendige Steuererhöhungen vermieden werden.

\subsubsection{Pauschaltransfer und Kopfsteuer}

Im partialanalytischen Modell ergibt sich für eine Variation des (positiven oder negativen) Pauschaltransfers ein negativer Einkommenseffekt auf das korrekt versteuerte Einkommen. Auch dieses Ergebnis hängt jedoch von der Annahme eines unveränderten Angebotes an öffentlichen Gütern ab. Sobald der partialanalytische Rahmen verlassen und der Zusammenhang zwischen Steuereinnahmen und staatlicher Mittelverwendung berücksichtigt wird, ist das Vorzeichen des Einkommenseffektes davon abhängig, ob im Ausgangspunkt ein Über- oder ein Unterangebot an öffentlichen Gütern vorliegt. Es läßt sich demnach nicht eindeutig sagen, in welche Richtung eine Anhebung des Pauschaltransfers wirkt. Im Falle einer optimalen

${ }^{1} \mathrm{Zu}$ dem Ergebnis eines positiven Einkommenseffektes im Falle einer Überversorgung mit öffentlichen Gütern und eines negativen Einkommenseffektes im Falle einer Unterversorgung gelangen auch COWELL und GORDON für ihr „gesamtwirtschaftliches“ Modell der Steuerhinterziehung, in welchem sie die Ausgabenseite des Staates berücksichtigen. Da die Verfasser von einer kostenfreien Hinterziehung ausgehen, existiert kein Substitutionseffekt, und die Gesamtwirkung einer Steuersatzerhöhung auf das deklarierte Einkommen entspricht dem Einkommenseffekt. Vgl. COWELL/GORDON (1988) S. 312.

${ }^{2}$ mit Ausnahme des bereits angesprochenen Sonderfalles mit $\mathrm{f}>0$ und $\mathrm{k}=0$, wo der Substitutionseffekt auch im Modell der Steuerumgehung bei null liegt

${ }^{3} \mathrm{Zu}$ letzterem Ergebnis gelangt auch die empirische Untersuchung von GEEROMS/WILMOTS (1985) S. 199.

Vgl. ferner S. 167 der vorliegenden Arbeit. 
Versorgung mit öffentlichen Gütern wäre die Wirkung auf das versteuerte Einkommen gleich null; die Steuerumgehung bliebe konstant.

Die aus den Modellergebnissen unmittelbar ableitbare Folgerung, der Staat solle von Pauschaltransfers Abstand nehmen und vielmehr eine Kopfsteuer in den Einkommensteuertarif einbauen, hält demnach einer näheren Überprüfung nicht stand. Abgesehen von der damit verbundenen sozialpolitischen Problematik, ist das Ergebnis der Einführung einer Kopfsteuer in bezug auf den Problemkreis der Steuerumgehung ungewiß; Pauschaltransfer bzw. Kopfsteuer erscheinen als staatliche Parameter für die Steuerumgehungsbekämpfung eher ungeeignet.

\subsubsection{Progression des Steuertarifes}

Wird der Steuertarif - aufkommensneutral - progressiver gestaltet, so ergibt sich zunächst einmal durch den erhöhten Grenzsteuersatz der bekannte Substitutionseffekt, der bei isolierter Betrachtung ein Absinken der Einkommensdeklaration bewirkt (sofern $k>0$ oder $f=0$ ).

Dem positiven Einkommenseffekt einer Steuersatzerhöhung auf das versteuerte Einkommen steht jedoch der gegenläufige Einkommenseffekt der simultanen Erhöhung des Pauschaltransfers gegenüber. Der gesamte Einkommenseffekt vermindert sich dadurch auf einem im Vergleich zu einem reinen Steuersatzanstieg niedrigeren, aber immer noch positiven Wert.

Somit bleibt in dem verwendeten partialanalytischen Rahmen die Gesamtwirkung einer Progressionsverschärfung auf das deklarierte Einkommen unter den Modellbedingungen ungewiß. Die graphische Analyse zeigte jedoch, daß die Summe der umgangenen Steuern im Falle einer Progressionsverschärfung auch im partialanalytischen Modell eindeutig zunimmt.

Wird eine gesamtwirtschaftiche Betrachtung vorgenommen und berücksichtigt, daß zwar nicht die individuelle Steuerzahlung, wohl aber die Gesamtheit der gezahlten Steuern das staatliche Angebot an öffentlichen Gütern maßgeblich beeinflußt, so hängt die Existenz eines positiven Einkommenseffektes erneut von der Voraussetzung ab, daß der marginale Nutzenverlust durch die gezahlte Steuer den marginalen Nutzengewinn durch zusätzliche Staatsleistungen übersteigt. Ist dies beim repräsentativen Wirtschaftssubjekt nicht der Fall, so ist die Gesamtwirkung einer aufkommensneutralen Progressionsverschärfung auf das nicht umgangene Einkommen eindeutig negativ. ${ }^{1}$

Wird also der (gesamtwirtschaftlich zweifelhafte) Einkommenseffekt vernachlässigt, so gelangt man zu dem Schluß, daß sich unter dem Gesichtspunkt der

' unter der Bedingung $k>0 \vee f=0 \vee U^{\prime}\left(x_{\Delta f f}\right)>U^{\prime}\left(x_{\text {priv }}\right)$ 
Steuerumgehung die Progression des Steuertarifes in Grenzen halten sollte. Die naheliegende Empfehlung, die Progression der Einkommensteuer nachhaltig zu senken oder gar den Tarif regressiv zu gestalten, dürfte allerdings an der hiermit verbundenen verteilungspolitischen Problematik scheitern. Jedoch sollte umgekehrt, wenn der Gesetzgeber mit dem Ziel einer verbesserten Verteilungsgerechtigkeit eine Progressionsverschärfung anstrebt, ein möglicher Anstieg der Steuerumgehung (mit den hiermit verbundenen, in Kapitel 3.5 angesprochenen distributiven Konsequenzen) bei der Entscheidungsfindung berücksichtigt werden.

\subsection{Sonstige Bestimmungsgründe der Steuerumgehung}

\subsubsection{Finanzpsychologische Erklärungsfaktoren}

Neben der Rechtswissenschaft und der Wirtschaftswissenschaft liefern auch andere Wissenschaften Erkenntnisse, die sich auf den Untersuchungsgegenstand „Steuerumgehung“ anwenden lassen. Das ökonomische Modell ist insofern unvollständig, als es stets rational verhaltende homines oeconomici voraussetzt, deren Verhalten allein von logischen Zusammenhängen bestimmt wird. Tatsächlich gehen jedoch nicht nur monetäre Faktoren in die Nutzenfunktion der Steuerpflichtigen ein. ${ }^{1}$ Für eine vollständige Erklärung ökonomischer Phänomene sind auch nichtmonetäre Kosten und Nutzen sowie arationale Verhaltensweisen in die jeweilige Untersuchung einzubeziehen. Die Berücksichtigung derartiger Abweichungen vom rein monetär bestimmten Rationalverhalten in der finanzwissenschaftlichen Forschung ist Gegenstand der Finanzpsychologie. Bezogen auf die Frage der Steuerumgehung, geht es um die Suche nach ihren Bestimmungsgründen mittels „psychologischer, soziologischer und politologischer Erklärungshypothesen“. ${ }^{2}$

Neben den im ökonomischen Modell enthaltenen Erklärungsfaktoren für die Steuerumgehung (Einkommen, Wahrscheinlichkeit der Nichtanerkennung, Strafsatz, Steuertarif, Kostenfunktion) wird die Steuerdisziplin ${ }^{3}$ von den Gelegenheiten zum illegalen Steuerwiderstand ${ }^{4}$ und von der Steuermoral bestimmt. Der Begriff „Steuermoral“ bezeichnet „die Einstellung der Staatsbürger zur Frage der Erfüllung oder Vernachlässigung der steuerlichen Pflichten“. ${ }^{5}$ Eine „gute Steuermoral“ be-

${ }^{1} \mathrm{Vgl}$. hierzu auch die Anmerkungen am Ende von Kap. 5.7.4 sowie in Kap. $5.4 \mathrm{zu}$ den Prämissen 3 und 9.

${ }^{2}$ GNAHS/JANNECK (1978) S. 27. Eine grundlegende Beschreibung der finanzpsychologischen Forschung findet sich ausfuihrlich bei SCHMÖLDERS (1951/52) S. 1-9.

${ }^{3}$ Unter Steuerdisziplin versteht man ,das Verhalten hinsichtlich der Befolgung oder Nichtbefolgung der steuerlichen Pflichten" (TRETTER (1974) S. 19 in Anlehnung an SCHMÖLDERS).

4 Der Ausdruck „illegaler Steuerwiderstand“ dient als Oberbegriff für Steuerumgehung und -hinterziehung; vgl. ENGELHARDT (1968) S. 47 f.

${ }^{5}$ TRETTER (1974) S. 19 
deutet, daß die Steuerpflichtigen sich bietende Möglichkeiten selbst dann nicht zum illegalen Steuerwiderstand nutzen, wenn dieser nach dem ökonomischen Modell rational wäre. Die Steuermoral unterliegt ihrerseits wiederum verschiedenen $\mathrm{Be}$ stimmungsfaktoren. Neben persönlichen Merkmalen (Alter, Bildung, Religiosität, Erfolgsorientierung, Beruf usw.), auf welche der Staat keinen oder nur geringen Einfluß ausüben kann, der Qualität der Finanzverwaltung und dem sozioökonomischen Entwicklungsstand ${ }^{1}$ des Landes (Faktoren, die sich erfahrungsgemäß nur in sehr langen Zeiträumen ändern bzw. ändern lassen) sind hier folgende Bestimmungsgründe zu nennen: die grundsätzliche Einstellung zum Staat, die Beurteilung des staatlichen Einnahmen- und Ausgabensystems, die Einschätzung der Steuerdisziplin der übrigen Bevölkerung und das individuelle Steuerbelastungsgefühl. ${ }^{2}$ Diese Faktoren werden im folgenden näher erläutert und auf Möglichkeiten der staatlichen Beeinflussung untersucht.

Allerdings sollte an dieser Stelle nicht unerwähnt bleiben, daß zwar der Einfluß der finanzpsychologischen Erklärungsfaktoren auf Steuermoral und Steuerhinterziehung durch zahlreiche Untersuchungen empirisch bestätigt werden konnte (s.o. Kap. 5.3.6), ${ }^{3}$ ein gleichgerichteter Einfluß der Steuermoral auch auf die Steuerumgehung jedoch nur aufgrund von Plausibilitätsüberlegungen vermutet wird. Entsprechende empirische Untersuchungen existieren bislang nicht. ${ }^{4}$ Ökonometrische Forschung in dieser Richtung ist deshalb für die Zukunt zweifellos als wünschenswert anzusehen, um gesicherte Aussagen über den Einfluß der Steuermoral bzw. der sie bestimmenden Faktoren auf die Steuerumgehung machen zu können.

${ }^{1}$ Der soziökonomische Entwicklungsstand umfaßt die gesellschaftliche Bedeutung, die der Staat für seine Bürger einnimmt. Ist die Abhängigkeit der Bürger vom Staat gering und herrscht eher eigenverantwortliches Denken vor, so ist die Steuermoral tendenziell schlechter, als wenn der Staat überall präsent ist und wohlfahrtsstaatliches Denken ihn unverzichtbar erscheinen laßt. Vgl. hierzu TRETTER (1974) S. $43 \mathrm{f}$.

${ }^{2}$ Vgl. TRETTER (1974) S. 40-46, GNAHS/JANNECK (1978) S. 36.

${ }^{3}$ Die Steuermoral wird dabei anhand von Umfragen, z.T. auch anhand objektiver Daten (z.B. Anteil der Steuerpflichtigen mit überfalligen Verbindlichkeiten gegenüber den Finanzămtern (WTTTE/ WOODBURY (1985))) zu „messen“ versucht. Vgl. ausfuihrlicher LEWIS (1979) S. 245 ff.

${ }^{4}$ Auch die Studie von GEEROMS/WILMOTS (1985), die Steuerhinterziehung und Steuerumgehung zum Gegenstand hat, mißt nur den Einfluß der Einstellung zum Staat und zum Staatshaushalt auf die Hinterziehung, nicht aber auf die Umgehung von Steuern. 


\subsubsection{Bewertung des politischen Systems}

„Die Steuerdisziplin ist ... ein Spiegel der Staatsgesinnung, an deren Demontage viele mitstricken."

Ein wesentlicher Bestimmungsfaktor für die Steuermoral ist die emotionelle Bindung an das Staatswesen. Diese wird maßgeblich von der Bewertung des politischen Systems geprägt. $^{2}$

So ist in Staaten mit einer traditionell gewachsenen und gemeinhin akzeptierten Demokratie eine positive Staatseinstellung eher zu erwarten als in Diktaturen oder in solchen Demokratien, in denen es an einer allgemein vorhandenen demokratischen Gesinnung der Staatsbürger mangelt. ${ }^{3}$ Die in den USA in der ersten Nachkriegszeit zu beobachtende hohe Steuerdisziplin mag angesichts des erfolgreich beendeten Kampfes gegen die im „Antikominternpakt" vereinigten Diktaturen sowie der zunehmenden Feindschaft zur Sowjetunion in dem festen Willen der Bürger begründet sein, einem gewünschten politischen System die Unterstützung nicht zu versagen. ${ }^{4}$ Doch ist eine solche Gesinnung eine im Zeitablauf instabile Größe. Sie hängt von einer aus Sicht der Staatsbürger erfolgreichen Politik ab und damit sowohl von der Qualität der beschlossenen politischen Maßnahmen als auch von deren Bewertung durch die Bevölkerung, welche wiederum starkem Medieneinfluß unterliegt.

Für eine verbesserte emotionelle Bindung an das Staatswesen bedarf es daher einerseits ,guter Politik“, andererseits aber auch einer positiven Darstellung des von der Politik Erreichten. Es wäre deshalb wünschenswert, wenn die derzeit in Deutschland vorherrschende Negativberichterstattung in Presse, Funk und Fernsehen durch eine ausgewogenere Nachrichtenauswahl und -bewertung ersetzt würde. ${ }^{5}$ Ohne die Pressefreiheit anzutasten müßte es staatlicherseits möglich sein,

${ }^{1}$ WILL-FELD (1985) S. 9

${ }^{2}$ Vgl. TRETTER (1974) S. $40 \mathrm{f}$.

${ }^{3}$ Für die Bundesrepublik Deutschland ist jedenfalls ein solcher statistischer Zusammenhang zwischen mangelndem Demokratiebewußtsein und sinkender Steuermoral unverkennbar. Während die Steuermoral abnimmt (vgl. NIESSEN (1995) S. 20 (Umfragevergleich 1987 und 1995)), steigt bei Parlamentswahlen der Anteil der Nichtwähler sowie der Wähler politischer Parteien, die selbst oder deren Anhängerschaft immer wieder mit legalen und illegalen Mitteln gewaltfreien oder gewalttätigen Widerstand gegen die Umsetzung demokratisch zustande gekommener Mehrheitsbeschlüsse leisten oder unterstützen.

${ }^{4}$ Vgl. POMMEREHNE/WECK-HANNEMANN (1992) S. 445, 458.

${ }^{5}$ So könnten neben Meldungen über ökonomische und gesellschaftspolitische Schwierigkeiten in den neuen Bundesländern auch Berichte über die in den letzten Jahren dort erreichten Fortschritte in bezug auf persönliche Freiheit, materielle Versorgung und Umweltqualităt in den Medien erscheinen. Ein weiteres Beispiel ist in der Bundesrepublik die intensive Berichterstattung über jede negative ökologische Entwicklung, während Erfolge im Gewässerschutz oder bzgl. der Schadstoffreduzierung bei Großfeuerungsanlagen oder Autoabgasen einen geringen 
jedenfalls in den öffentlich-rechtlichen Rundfunk- und Fernsehanstalten neben $\mathrm{Ne}$ gativmeldungen verstärkt auch positive Entwicklungen in den Mittelpunkt der Berichterstattung zu stellen und damit der eingangs zitierten „Demontage der Staatsgesinnung" entgegenzuwirken.

\subsubsection{Beurteilung des staatlichen Budgets}

Der Tausch „Steuern gegen Staatsleistungen" wird den Steuerpflichtigen grundsätzlich aufgezwungen. $\mathrm{Ob}$ aus diesem Zwang Steuerwiderstand erwächst, hängt zunächst - wie geschildert - von der grundsätzlichen Haltung zum Staat ab, aber insbesondere auch von der Beurteilung der Höhe der staatlichen Steuereinnahmen, ihrer Zusammensetzung, der Wirtschaftlichkeit bei der Mittelverwendung sowie der Struktur der Staatsausgaben. ${ }^{1}$

Die heute in vielen Industrieländern vorherrschende Einstellung zum Staat, an dessen Leistungen maximale Anforderungen gestellt werden, während Beiträge zur Finanzierung dieser Leistungen auf Ablehnung und Widerstand stoßen, ${ }^{2}$ kann ihre Ursache in öffentlichen Haushalten haben, auf deren Umfang und Struktur die Steuerpflichtigen zu wenig Einfluß haben. Als Ergebnis entsprechen die Budgets nicht den Präferenzen der Bürger, die zur Finanzierung herangezogen werden. Vielmehr kann das Finanzgebaren des öffentlichen Sektors von der Macht von Interessengruppen geprägt sein, denen es gelingt, Forderungen weniger Menschen auf Kosten der gesamten Gesellschaft durchzusetzen. ${ }^{3} \mathrm{Daß}$ in den meisten Staaten Westeuropas die Mehrheit der im Rahmen finanzpsychologischer Studien Befragten das staatliche Budget und damit die steuerliche Belastung für ,zu hoch“ hält, ${ }^{4}$ kann - mit oder ohne den Einfluß leistungsfordernder Interessengruppen - in der Bereitstellung öffentlicher Güter liegen, die von den Steuerpflichtigen nicht gewünscht werden, sowie in ineffizientem Einsatz von Steuermitteln aufgrund von Ressourcenverschwendung im öffentlichen Sektor. Wenn Politik und Verwaltung das Ziel verfehlen, einen gegebenen Output mit dem hierfür erforderlichen Mini-

Stellenwert einnehmen. Auch ließen sich Negativmeldungen beispielsweise über Operationspannen in Krankenhäusern, Streckenstillegungen bei der Deutschen Bahn oder Gebührenerhöhungen bei der Bundespost durch Informationen über erheblich verbesserte Heilungsmöglichkeiten bei vielen Krankheiten, verkürzte Fahrzeiten im Eisenbahnfernverkehr oder beschleunigte Briefbeförderung durch die Post ergänzen. Diese Auflistung von Beispielen wăre beliebig verlăngerbar, möge aber an dieser Stelle genügen, um den Einfluß der Medien auf die Einstellung der Bevölkerung zum öffentlichen Sektor und den ihn tragenden Organen aufzuzeigen.

${ }^{1}$ Vgl. METTELSIEFEN (1984) S. 71.

${ }^{2}$ Daß diese bei LANG (1985) S. 97 zu findende Feststellung mehr denn je aktuell ist, kann in Deutschland derzeit wohl jeder im eigenen Umfeld beobachten.

${ }^{3} \mathrm{Vgl}$. DIEBOLD (1984) S. 190.

${ }^{4}$ Vgl. METTELSIEFEN (1984) S. 71 m.w.N. 
mum an finanziellen Mitteln zu erzielen, so sind die Steuerpflichtigen gezwungen, überhöhte Kosten zu finanzieren. Der Steuerwiderstand dürtte dann höher liegen, als wenn die Steuergelder in den Augen der Steuerzahler effizient eingesetzt werden. $^{1}$

Abhilfe gegenüber einer Finanzpolitik, deren Einnahme- und Ausgabenprogramme nicht den Präferenzen der Steuerbürger entsprechen, kann am nachhaltigsten eine stärkere Bürgerbeteiligung an der Aufstellung des staatlichen Budgets gewährleisten. $^{2}$ Einem Staatshaushalt, dessen Struktur und Umfang die Steuerpflichtigen selbst mehrheitlich zugestimmt haben, werden sie tendenziell weniger Widerstand entgegensetzen als einem Haushalt, der im wesentlichen über die Köpfe der Steuerzahler hinweg "von oben“ festgesetzt wird. Für eine Verbesserung der Steuermoral empfiehlt sich deshalb die Einführung von Volksabstimmungen über die öffentlichen Haushalte oder - um den Wählern einen jährlichen Urnengang zu ersparen - zumindest über die mittelfristige Finanzplanung der Gebietskörperschaften.

Für die Bundesrepublik Deutschland sind derartige Volksentscheide in der Verfassung nicht vorgesehen; eine entsprechende Änderung des Grundgesetzes wäre also angezeigt. Es mag zunächst systemfremd erscheinen, das vorherrschende Prinzip der indirekten Demokratie allein für den Bereich der öffentlichen Einnahmen und Ausgaben durch Elemente der direkten Demokratie zu ergänzen. Hält man sich jedoch vor Augen, daß derzeit einzig für die Fusion oder Neugliederung von Bundesländern entsprechende Volksabstimmungen vorgesehen sind (Art. 29 GG), so stellt sich die Frage, ob eine solche Sonderrolle nicht weit eher auf dem Gebiet der Steuern und Steuermittelverwendung angebracht wäre, wo Volksentscheide das Volumen von Steuerumgehung und -hinterziehung über eine Verbesserung der Steuermoral vermindern und damit kaum bestreitbare gesellschaftliche Vorteile herbeiführen können.

Zur Bekämpfung der Ressourcenverschwendung im öffentlichen Sektor sei hier neben der häufig geforderten weiteren Privatisierung öffentlicher Unternehmen und Übertragung öffentlicher Tätigkeiten an Private (z.B. Geschwindigkeitskontrollen im Straßenverkehr, Müllbeseitigung, Fahrausweiskontrollen im ÖPNV) insbesondere die Forderung nach leistungsgerechterer Entlohnung im öffentlichen Dienst erhoben. Hierzu gehört die Bestrafung unwirtschaftlicher Mittelverwendung ebenso wie die Belohnung von Amtsträgern, denen Kosteneinsparungen und eine Beseitigung von Ineffizienzen im öffentlichen Sektor gelingen. ${ }^{3}$

\footnotetext{
${ }^{1}$ Vgl. DIEBOLD (1984) S. 198 f. Ein Überblick über Erklärungsmodelle für überhöhte Staatsausgaben aufgrund bürokratischer Einflußfaktoren findet sich ebenda auf S. 192 - 208.

2 s.o. Kap. 5.3 .6

${ }^{3} \mathrm{Vgl}$. ausführlicher LANG (1985) S. 98.
} 
Auf den Zusammenhang zwischen Äquivalenzprinzip und Steuerhinterziehung wurde bereits auf S. 127 hingewiesen: Die Steuermoral und damit die Bereitschaft, Steuern zu hinterziehen, kann davon beeinflußt sein, inwieweit die Steuerpflichtigen den Eindruck haben, für die ihnen auferlegte Steuerlast staatliche Leistungen in etwa gleicher Größenordnung zu empfangen. Ein entsprechender Einfluß einer solchen Äquivalenz über die Steuermoral auch auf die Steuerumgehung ist zu vermuten. ${ }^{1} \mathrm{Da}$ speziell unter den Besserverdienenden die persönliche steuerliche Belastung meist höher eingeschätzt wird als die von der öffentlichen Hand empfangenen Gegenleistungen, ${ }^{2}$ kann angesichts der Dominanz des Leistungsfähigkeitsprinzips in der Steuerpolitik nicht verwundern. Auf der anderen Seite weist DIEBOLD darauf hin, daß die staatliche Umverteilung grundsätzlich durchaus allgemein akzeptiert sei, die Steuerlastverteilung aber als gerecht empfunden werden müsse, um Steuerwiderstand zu vermeiden. ${ }^{3}$ Eine weitgehend am Äquivalenzprinzip ausgerichtete Steuerpolitik muß deshalb keineswegs eine zwingende Voraussetzung für eine hohe Steuermoral darstellen, solange die im Steuersystem enthaltenen Leistungsfähigkeitskomponenten und Umverteilungselemente als ausgewogen - sozial, aber auch für die Besserverdienenden nicht drückend ${ }^{4}$ - und fair empfunden werden. Ferner sei darauf hingewiesen, daß das Gefühl, für die gezahlte Steuer eine angemessene Gegenleistung zu erhalten, auch dadurch gesteigert werden kann und sollte, daß der Staat auf dem Wege einer verbesserten Öffentlichkeitsarbeit den Steuerzahlern seine steuerfinanzierten Leistungen stärker bewußt macht. Geschieht dies in Verbindung mit einer höheren Transparenz in der Mittelverwendung, so ergibt sich gleichzeitig eine verbesserte Kontrolle der staatlichen Ausgabenpolitik und damit eine verringerte Gefahr der oben angesprochenen Verschwendung von Steuermitteln. ${ }^{5}$

$\mathrm{Zu}$ einem als fair angesehenen Steuersystem gehören ferner Überschaubarkeit und Willkürfreiheit des Steuerrechts:

${ }^{1}$ Vgl. diesbezüglich GNAHS/JANNECK (1978) S. 36 i.V.m. S. 4 f., DIEBOLD (1984) S. 150 i.V.m. S. 18, METTELSIEFEN (1984) S. 73.

Die Ergebnisse empirischer Untersuchungen aus Deutschland, Schweden und den USA zur empfundenen Gleichheit bzw. Ungleichheit zwischen Steuerzahlung und offentlichen Leistungen und zum entsprechenden Einfluß auf den Steuerwiderstand beschreibt DIEBOLD (1984) S. 154, 158, 164, 166. Vgl. auch DÄKE (1995) S. 8: Danach empfinden 63\% der deutschen Steuerzahler die staatlichen Gegenleistungen für ihre gezahlten Steuern als ,zu gering“.

${ }^{2}$ Vgl. METTELSIEFEN (1984) S. 73 f., DIEBOLD (1984) S. 164.

${ }^{3} \mathrm{Vgl}$. DIEBOLD (1984) S. 181, 191.

${ }^{4}$ Ein Beispiel für einen überzogenen Spitzensteuersatz lieferte in den 70er-Jahren Großbritannien, wo sehr hohe Einkommen mit bis zu $98 \%$ besteuert wurden. Die Folge war wachsender Steuerwiderstand bei der betroffenen Bevölkerungsgruppe, der sich speziell in einem starken Anstieg der Steuerumgehung ăußerte.

${ }^{5} \mathrm{Vgl}$. DIEBOLD (1984) S. 233. 
Ein schwer durchschaubares Steuerrecht kann bei den Steuerpflichtigen leicht zu der Annahme führen, mögliche Steuervergünstigungen nicht ausgenutzt zu haben und daher moralisch berechtigt $\mathrm{zu}$ sein, als Ausgleich für entgangene Vorteile Steuern zu verkürzen oder zu umgehen. ${ }^{1}$

Der Zusammenhang zwischen kalter Progression und Steuerwiderstand wurde bereits in Kapitel 5.3.6 angesprochen. Ein noch gravierenderer Verstoß gegen das Postulat der Willkürfreiheit des Steuerrechts dürte im Zusammenhang mit der Inflationsproblematik in der Besteuerung geldentwertungsbedingter Scheinerträge liegen. An dieser Stelle sei insbesondere auf die Steuerpflicht von Zinserträgen hingewiesen, welche in vielen Staaten kaum mehr als einen Inflationsausgleich darstellen. Wird die Steuer auf die Nominalzinsen erhoben, so kann der reale Nettoertrag von Finanzanlagen sogar negativ werden. Es liegt auf der Hand, daß eine solche Besteuerungspraxis Steuerwiderstand hervorruft. ${ }^{2}$ Ein weiteres Beispiel für eine Ungereimtheit im Steuersystem, welche sich ungünstig auf die Steuermoral auswirken kann, stellt die in vielen Industriestaaten immer noch existierende Doppelbelastung von Dividenden dar (Besteuerung der Gewinne von Kapitalgesellschaften sowohl auf Gesellschafts- als auch auf Gesellschafterebene). Abhilfe schafft hier beispielsweise die volle Anrechenbarkeit der Körperschaftsteuer auf die persönliche Einkommensteuer, wie sie seit 1977 in Deutschland gegeben ist.

\subsubsection{Steuerbelastungsgefühl}

Einen bedeutenden Einfluß auf die Steuermoral hat ferner das Steuerbelastungsgefühl: Je höher die Steuerpflichtigen ihre persönliche Abgabenlast einschätzen, desto eher werden sie nach herrschender Auffassung zu Steuerwiderstand neigen. Das Steuerbelastungsgefühl ist seinerseits abhängig von der objektiv bestehenden Belastung durch direkte und indirekte Steuern und andere an Staat und Parafisci zu entrichtende Abgaben sowie von der subjektiven Wahrnehmung der Abgabenbelastung. ${ }^{3}$

Die unmittelbare Wirkung der Grenzsteuerbelastung auf die Steuerumgehung war in den Kapiteln 5.5.2.2.5 und 5.5.3.2.4 behandelt worden. Im vorliegenden Kapitel geht es um die indirekte Wirkung, die die objektive Steuerlast über ihren Einfluß auf Steuerbelastungsgefühl und Steuermoral auf die Steuerumgehung ausübt. $\mathrm{Da}$ ein Anstieg der tatsächlichen Abgabenbelastung c.p. ein höheres Steuerbelastungsgefühl hervorrufen wird, dürfte unstrittig sein.

\footnotetext{
${ }^{1}$ Vgl. BOCKELMANN (1969) S. 316.

${ }^{2}$ Vgl. hierzu WILL-FELD (1985) S. 9 sowie SWAN in COLLINS (1984) S. 53.

${ }^{3} \mathrm{Vgl}$. GNAHS/JANNECK (1978) S. 29, 35; METTELSIEFEN (1984) S. 72.
} 
Interessanter ist an dieser Stelle die Frage, inwieweit sich dem Staat die Möglichkeit bietet, das subjektive Belastungsgefuihl zu senken, ohne die objektive Steuerlast zu verändern. Die subjektive Wahrnehmung der Abgabenlast hängt $a b$ von der Merklichkeit der Besteuerung. Die Steuerpflichtigen werden um so eher das Gefühl haben, einer aus ihrer Sicht zu hohen Abgabenbelastung ausgesetzt zu sein, je direkter und fühlbarer der steuerliche Zugriff erfolgt. ${ }^{1}$ Hieraus ergibt sich für die Steuerpolitik die Empfehlung, direkte Steuern verstärkt durch die weniger merklichen indirekten Steuern zu substituieren. Der Einwand METTELSIEFENs, die durch indirekte Steuern ausgelösten Preissteigerungsprozesse würden den Grad der Steuerwahrnehmung eher erhöhen als senken, ${ }^{2}$ mag für den Zeitpunkt der Einführung oder Erhöhung indirekter Steuern durchaus zutreffen. Hat sich eine indirekte Steuer jedoch in einer bestimmten Höhe erst einmal etabliert, so dürfe ihre subjektive Wahrnehmung geringer sein, als es bei einer objektiv gleich stark belastenden direkten Steuer der Fall ist. Bei langfristiger Betrachtung ist deshalb wohl HIRAI zuzustimmen, der folgende Reihenfolge im Wahrnehmungsgrad der Steuern annimmt: veranlagte Einkommensteuer, im Quellenabzugsverfahren erhobene Einkommensteuer, spezielle Verbrauchsteuern, Umsatzsteuer. ${ }^{3}$

\subsubsection{Einschätzung der Steuerdisziplin der übrigen Bevölkerung}

Auf den Einfluß der (angenommenen) Steuerhinterziehung anderer Steuerpflichtiger auf die Höhe der eigenen Hinterziehung wurde in dieser Arbeit bereits hingewiesen (s.o. Kap. 5.3.6). Die Vermutung liegt nahe, daß allgemein die individuelle Steuerdisziplin davon beeinflußt wird, inwieweit man annimmt, ein Großteil der übrigen Steuerzahler entzöge sich durch Steuerumgehung oder -hinterziehung seiner steuerlichen Verpflichtungen. Übertriebene Darstellungen durch Presse und Politiker über die Anzahl der Steuerhinterzieher ${ }^{4}$ oder über den Anteil an Spitzenverdienern, denen es gelingt, der Einkommensteuer vollständig auszuweichen, ${ }^{5}$

${ }^{1}$ Vgl. METTELSIEFEN (1984) S. 72.

${ }^{2} \mathrm{Vgl}$. ebenda S. $72 \mathrm{f}$.

${ }^{3}$ Vgl. HIRAI (1988) S. 113.

Die übrigen direkten Steuern dürften aufgrund ihrer Erhebungstechnik in ihrer Merklichkeit in etwa der veranlagten Einkommensteuer entsprechen, während die Wahrnehmung der Verkehrsteuern derjenigen der speziellen Verbrauchsteuern vergleichbar erscheint.

${ }^{4}$ Vgl. IRMLER (1985) S. 10 f. unter Hinweis auf die auf dem Deutschen Steuerberatertag 1984 geăußerte und in der Frankfurter Allgemeinen Zeitung vom 31.10.1984 wiedergegebene (unbewiesene) Formulierung, die Deutschen seien „ein Volk von Steuerhinterziehern“.

${ }^{5}$ Für die unlängst aufgestellte These des Hamburger Bürgermeisters Henning Voscherau, die Hälfte der Hamburger Millionäre zahle keine Einkommensteuer, hat sich bis heute keinerlei Beweismaterial gefunden. Gemäß der letzten Einkommensteuerstatistik des Bundes von 1989 gelang es in Deutschland von über 18.000 Einkommensmillionăren nur zweien, keinerlei Einkommensteuer abzuführen. Vgl. Handelsblatt vom 19.3.1996 S. 4. 
können die Steuermoral der Bevölkerung weiter senken und damit zu einem Anstieg von Steuerhinterziehung und Steuerumgehung führen. Wenn bereits Ende der 70er-Jahre in einer Umfrage mehr als ein Drittel aller Befragten annahm, daß nahezu alle Steuerzahler eine sich bietende Gelegenheit zur Steuerumgehung ergreifen würden, und $80 \%$ meinten, über die Hälfte der Steuerpflichtigen würde, wenn möglich, Steuerhinterziehung betreiben, ${ }^{1}$ so dürtten Falschmeldungen über die allgemeine Verbreitung von Steuerumgehung und Steuerkriminalität ein weiteres Anwachsen dieser Prozentzahlen und auf diesem Wege eine negative Beeinflussung der Steuermoral bewirken.

Dem Staat obliegt in jedem Fall die Aufgabe, erstens die Steuerhinterziehung und -umgehung wirksam zu bekämpfen, um ihr tatsächliches Volumen zu senken, und zweitens die Steuerbürger über den wahren Umfang der illegalen oder rechtsmißbräuchlichen Steuerausweichung aufzuklären und damit dem vorherrschenden Eindruck einer allgemein sehr schlechten Steuerdisziplin entgegenzuwirken. Auf diese Weise könnte der Teufelskreis „schlechte Steuermoral $\Rightarrow$ Annahme schlechter Steuerdisziplin $\Rightarrow$ weiteres Absinken der Steuermoral ... (usw.) ..." durchbrochen und die tatsächliche Steuerdisziplin nicht nur auf direktem, sondern auch auf indirektem Wege verbessert werden.

\subsubsection{Gelegenheiten zur Steuerumgehung}

Die empirischen Arbeiten zur Steuerhinterziehung, die als erklärende Variable auch die Quellenbesteuerung einbezogen, waren durchweg zu dem Ergebnis gekommen, daß eine derartige Begrenzung der Hinterziehungsmöglichkeiten zu den effektivsten Maßnahmen gegen die Steuerhinterziehung gehört (s.o. Kap. 5.3.6). Entsprechend ist auch für die Steuerumgehung anzunehmen, daß ihr tatsächliches Ausmaß wesentlich davon abhängt, inwieweit die Steuergesetze den Steuerpflichtigen überhaupt Gelegenheit dazu geben, die Abgabenlast durch mißbräuchliche Rechtsgestaltungen zu senken. Unbestreitbar ist jedenfalls die triviale Aussage, daß das Volumen der Steuerumgehung bei null liegen wird, wenn die Steuern derart gestaltet sind, daß ihre Umgehung technisch unmöglich ist. Dies ist insbesondere der Fall bei einer Kopfsteuer. Kopfsteuern lassen sich weder umgehen noch vermeiden. ${ }^{2}$ Der starke Widerstand, welcher Kopfsteuern im allgemeinen entgegengebracht wird, liegt aber nicht allein in der Tatsache begründet, daß sie unvermeidlich sind, sondern vor allem an ihrer als unsozial anzusehenden Regressionswirkung. Die deshalb aus Gerechtigkeitserwägungen abzulehnenden Kopfsteuern ${ }^{3}$

\footnotetext{
${ }^{1}$ Vgl. LANG (1985) S. 97.

2 "The poll tax is the only tax that is wholly unavoidable (except by migration or suicide)“ (BRACEWELL-MILNES (1979) S. 89).

${ }^{3} \mathrm{Vgl}$. allerdings einschränkend S. $225 \mathrm{FN} 3$.
} 
sind jedoch nicht die einzig möglichen unumgehbaren Steuern: Wie WAGNER zutreffend feststellt, ist Steuerumgehung (ebenso wie Steuervermeidung) immer dann ausgeschlossen, wenn die Besteuerung entscheidungsneutral erfolgt. ${ }^{1}$ Nun erscheint allerdings ein in jeder Hinsicht entscheidungsneutrales Steuersystem ebensowenig realistisch wie eine als Alleinsteuer fungierende Kopfsteuer, da viele Möglichkeiten legaler Steuervermeidung vom Gesetzgeber beabsichtigt sind und z.T. volkswirtschaftlich unverzichtbar erscheinen. ${ }^{2}$ Doch sollte bei Abweichungen vom Postulat der Entscheidungsneutralität stets darauf geachtet werden, daß derartige Aneutralitäten lediglich zu volkswirtschaftlich erwünschter Steuervermeidung führen und möglichst keine oder allenfalls wenige Gelegenheiten zur Steuerumgehung schaffen. Eine Elimination sämtlicher Möglichkeiten mißbräuchlicher

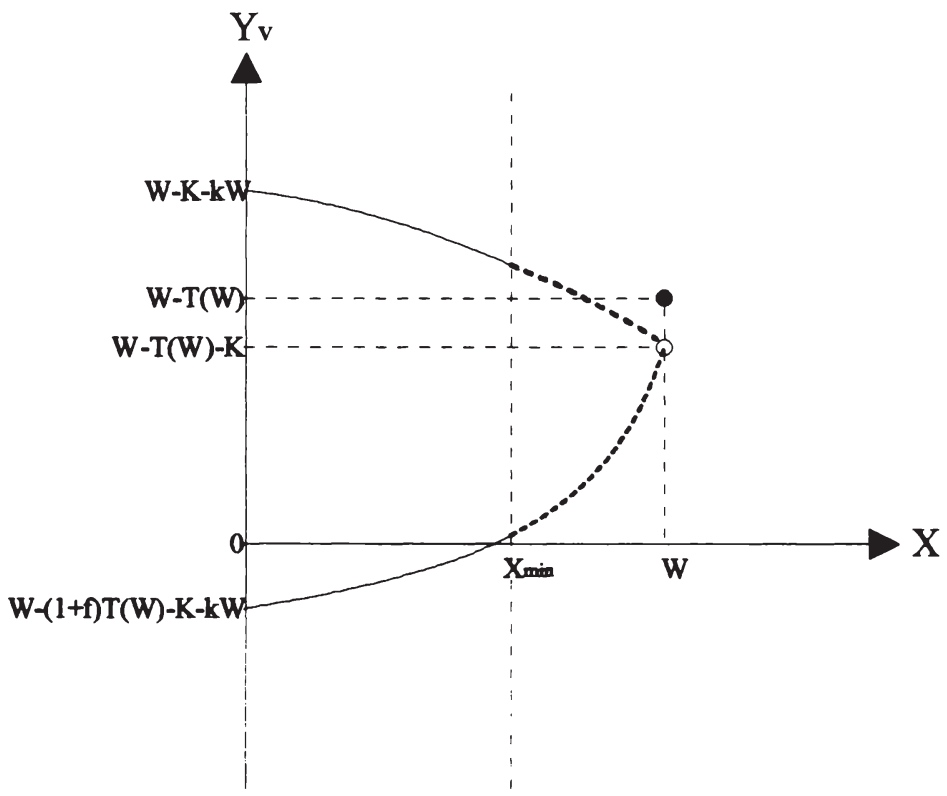

Abb. 5.8: verfügbares Einkommen in Abhängigkeit von der Steuerumgehungsentscheidung bei eingeschränkten Umgehungsmöglichkeiten

${ }^{1}$ Vgl. WAGNER (1986) S. 42, 47.

${ }^{2}$ Nicht entscheidungsneutral ist beispielsweise jede spezielle Verbrauchsteuer. Da diese aber z.T. wichtige volkswirtschaftliche Lenkungsaufgaben erfüllen (man denke z.B. an die Mineralolsteuer), wäre es äußerst problematisch, ihre Abschaffung zu fordern. 
Umgehung dürfte zwar in der Praxis nicht erreichbar sein. In den meisten entwikkelten Steuerstaaten weist jedoch das Steuersystem viele Gelegenheiten zu rechtsmißbräuchlicher Gestaltung auf, deren Beseitigung keineswegs impraktikabel wäre. Der nicht umgehbare Teil der Steuerbemessungsgrundlage stiege damit an; die Steuerumgehung könnte auf diese Weise zurückgeführt werden.

Graphisch bedeutet die Beseitigung von Gelegenheiten zur Steuerumgehung, daß die in Abb. 5.4 dargestellte Steuerumgehungsentscheidung der Beschränkung $X \geq X_{\min }$ (statt $X>0$ ) unterliegen würde. Das mögliche verfuigbare Einkommen nach Steuern beschränkt sich dann auf den in Abb. 5.8 gestrichelt eingezeichneten Bereich rechts von $\mathrm{X}_{\text {min }}$.

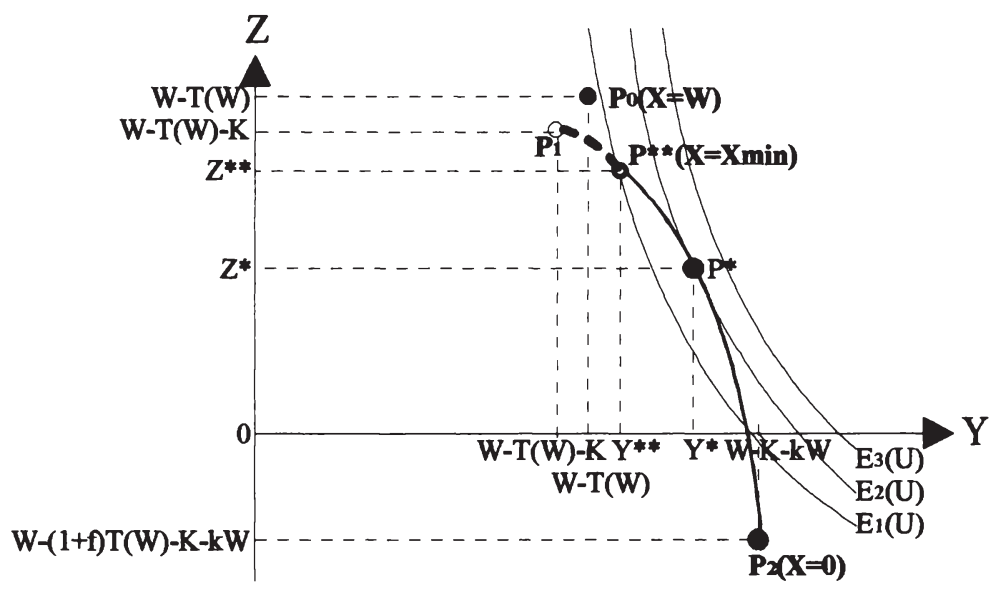

Abb. 5.9: optimale Steuerumgehungsentscheidung bei eingeschränkten Umgehungsmöglichkeiten

Auch in Abb. 5.5 war von uneingeschränkter Steuerumgehungsmöglichkeit ausgegangen worden. Existiert für einen Teil des Einkommens keine Gelegenheit zur mißbräuchlichen Umgehung, so bedeutet dies graphisch eine Verkürzung der Budgetlinie aus Abb. 5.5: Für die Festlegung des auf gewöhnlichem Wege deklarierten Einkommens steht den Steuerpflichtigen nicht mehr der gesamte Wertebereich $0 \leq \mathrm{X} \leq \mathrm{W}$ zur Verfugung. Die verbleibenden Handlungsalternativen sind in Abb. 5.9 ebenfalls gestrichelt gekennzeichnet. Der für die Steuerumgehungsent- 
scheidung eigentlich optimale Tangentialpunkt $\mathrm{P}^{*}$ ist in der Abbildung nicht mehr erreichbar; die den Erwartungsnutzen maximierende Steuerumgehung wird nun durch den Punkt $\mathrm{P}^{* *}$ bestimmt. Je geringer die Gelegenheiten zum Rechtsmißbrauch sind, desto kleiner wird der horizontale Abstand zwischen den Punkten $P_{1}$ und $\mathrm{P}^{* *}$, d.h. jede weitere Beschränkung der Möglichkeiten zur Steuerumgehung führt unmittelbar zu einem Rückgang derselben.

Welche konkreten Steuerreformen sich für den Staat anbieten, um auf diese Weise die Steuerumgehung zurückzuführen, wird ausführlich in Abschnitt 6 beschrieben.

\subsection{Zwischenergebnis:}

\section{Ansatzpunkte für eine erfolgversprechende Anti- Umgehungs-Politik}

- Das entscheidungstheoretische Modell der Steuerumgehung konnte zeigen, daß das Ausmaß an rechtsmißbräuchlichen steuerlichen Gestaltungen entscheidend davon abhängt, mit welcher Wahrscheinlichkeit derartige Rechtsgestaltungen vor der Finanzverwaltung bzw. der Finanzgerichtsbarkeit scheitern. Der Einfluß der Legislative auf die Rechtsanwendung ist jedoch gering. Für Staaten wie Großbritannien, die keine dem deutschen $\S 42$ AO vergleichbare Rechtsnorm kennen und deren Rechtsprechung eher steuerzahlerfreundlich eingestellt ist, empfiehlt sich allerdings die Einführung einer Generalklausel gegen die Steuerumgehung, wie sie in Abschnitt 4 dieser Arbeit diskutiert wurde. Auch rückwirkende Steuergesetze lassen sich, soweit sie rechtsstaatlich zulässig sind, einsetzen, um die Wahrscheinlichkeit des Mißlingens steuerumgehender Gestaltungen unmittelbar zu erhöhen.

- Die Einführung einer Geldbuße auf Versuche, das Steuergesetz mißbräuchlich zu umgehen, führt im Modell ebenfalls zu sinkender Steuerumgehung. Sofern eine Bestrafung der Gesetzesumgehung im Steuerrecht verfassungsrechtlich zulässig ist, bietet sich deshalb die Aufnahme einer dem französischen art. 1729 CGI vergleichbaren Bestimmung in die Steuergesetzgebung an.

- Die Ausfuhrungen in Kap. 5.7.5 hatten zu der Annahme eines positiven Zusammenhanges zwischen Grenzsteuersatz und Steuerumgehung gefuhrt. Soweit die Haushaltslage es zuläßt, empfehlen sich daher möglichst niedrige Grenzsteuersätze. Ferner sollte das Ziel der Verteilungsgerechtigkeit nicht durch eine übermäßige Progression in den Steuertarifen erreicht werden. Abnehmende Steuerprogression dürfte in der Regel zu abnehmender Steuerumgehung führen.

- Die monetären Kosten der Steuerumgehung sind durch den Staat kaum zweckgerecht zu beeinflussen. Anders sieht es mit den psychischen Kosten (und Nutzen) aus, welche ebenfalls für das Volumen an Steuerumgehung maßgeblich sind. Für 
eine effektive Anti-Umgehungs-Politik sollten folglich auch die finanzpsychologischen Erklärungsfaktoren für den Steuerwiderstand Berücksichtigung finden. Hierzu gehören die allgemeine Bewertung des politischen Systems, die Beurteilung des staatlichen Budgets, das Steuerbelastungsgefühl und die Einschätzung der allgemeinen Steuerdisziplin.

- Die Bewertung des politischen Systems und damit die allgemeine Einstellung zum Staat hängen sowohl von der Qualität der Politik als auch von ihrer Selbstdarstellung und der Medienberichterstattung ab. Die historischen Erfahrungen zeigen, daß untaugliche politische Systeme auf die Dauer auch durch Meinungsmonopolismus und Eigenlob nicht aufrechterhalten werden können. Umgekehrt kann jedoch die Unterstützung eines weitgehend erfolgreichen politischen Systems durch die Bevölkerung nachlassen, wenn Presse, Rundfunk und Fernsehen den Schwerpunkt ihrer Berichterstattung auf negative Entwicklungen legen.

- Eine bessere Beurteilung des staatlichen Budgets läßt sich durch eine Bekämpfung der Ressourcenverschwendung im öffentlichen Sektor herbeifüren. Darüber hinaus ist es entscheidend, ob die Steuergelder entsprechend den Präferenzen der Steuerpflichtigen verwendet werden. Um dies zu gewährleisten, empfehlen sich stärkere Mitwirkungsrechte der Steuerzahler bei der Aufstellung der öffentlichen Haushalte insbesondere mittels Volksabstimmungen nach Schweizer Vorbild. Ferner kann eine Besteuerung nach dem Äquivalenzprinzip über den Eindruck, für die geleistete Steuerzahlung einen angemessenen Gegenwert zu erhalten, die Steuermoral verbessern. Doch auch eine am Leistungsfähigkeitsprinzip orientierte, weitgehend als gerecht empfundene Steuerlastverteilung kann zu guter Steuermoral beitragen. Eine positive Beurteilung der öffentlichen Haushalte ist ferner von einem überschaubaren Steuerrecht und einer Beschränkung der Steuerpflicht auf Vorgänge, deren Besteuerung allgemein einsichtig gemacht werden kann („Willkürfreiheit des Steuerrechts"), abhängig. Schließlich kann auch eine verbesserte Aufklärung der Steuerzahler über die mit den Steuern finanzierten staatlichen Leistungen dazu beitragen, den Steuerpflichtigen den Sinn ihrer Zahlungen an das Finanzamt stärker bewußt zu machen.

- Das Steuerbelastungsgefühl läßt sich zunächst auf dem Wege einer verantwortungsvollen staatlichen Ausgabenpolitik durch eine Herabsetzung der tatsächlichen Abgabenbelastung senken. Des weiteren spielt für das Steuerbelastungsgefühl die Merklichkeit der Besteuerung eine entscheidende Rolle. Aus diesem Grund empfiehlt sich eine Rückführung der direkten Besteuerung zugunsten höherer indirekter Steuern.

- Das Simultanmodell der Steuerumgehung und -hinterziehung (Kap. 5.6) hatte ergeben, daß eine Bekämpfung der Steuerhinterziehung nur z.T. durch Ausweichen der Steuerpflichtigen auf die Steuerumgehung kompensiert wird, z.T. aber 
auch die Steuereinnahmen des Staates erhöht. Das Modellergebnis einer mit sinkender Steuerhinterziehung c.p. ansteigender Steuerumgehung muß aber in der Praxis nicht mehr zutreffen, wenn man - wie die finanzpsychologische Forschung - davon ausgeht, daß die eigene Steuerdisziplin u.a. von der angenommenen Steuerdisziplin der übrigen Bevölkerung abhängt. Eine wirksame Bekämpfung auch der Steuerhinterziehung kann dann dazu beitragen, die allgemeine Neigung zur Steuerumgehung zu senken. Neben einer Verbesserung der tatsächlichen Steuerdisziplin ist aber ferner eine ausgewogene Darstellung der bestehenden Situation durch Medien und Politiker vonnöten. In Deutschland sollte neben der notwendigen Berichterstattung über die vorhandene Problematik des illegalen Steuerwiderstandes vermehrt auch auf die im internationalen Vergleich relativ hohe Steuerehrlichkeit im Inland hingewiesen werden.

So notwendig es einerseits ist, ergänzend zu den im ökonomischen Modell der Steuerhinterziehung enthaltenen Parametern auch die finanzpsychologischen Faktoren bei der Entwicklung einer wirkungsvollen Anti-Umgehungs-Politik zu berücksichtigen, so wenig realistisch ist andererseits die Vorstellung, daß in einer Gesellschaft nahezu alle Bürger dauerhaft bereit sind, aus religiösen oder altruistischen Motiven oder aus Gründen des Ehrgefühls unabhängig von Aufdeckungswahrscheinlichkeiten, Bußgeldern und Steuertarifverläufen willig ihre Steuern zu zahlen, wenn nur die Einstellung zum Staat und zu den öffentlichen Haushalten eine positive ist. ${ }^{1}$ Es wird immer Menschen geben, die versuchen, als Trittbrettfahrer an den öffentlichen Leistungen zu partizipieren, ohne den gesetzlich vorgesehenen Beitrag zu deren Finanzierung zu leisten. Auf die Grenzen einer Variation der im entscheidungstheoretischen Modell enthaltenen Parameter wurde in Kapitel 5.7 bereits hingewiesen. Es dürfte dem Staat unmöglich sein, diese Parameter so zu beeinflussen, daß für jedes einzelne Wirtschaftssubjekt eine Steuerumgehung i.H.v. null die einzelwirtschaftlich optimale Handlungsmöglichkeit darstellt. Solange die Steuergesetze Möglichkeiten zum Mißbrauch bieten, wird es immer Steuerpflichtige geben, die derartige Möglichkeiten zu nutzen versuchen.

- Eine gegen die Steuerumgehung gerichtete Politik muß daher in besonderem Maße an dieser Stelle ansetzen: Steuern können nur dort erfolgreich umgangen werden, wo das Steuerrecht Unvollkommenheiten aufweist, welche zur Steuerumgehung Gelegenheit geben. Zwar wird es dem Gesetzgeber in der Praxis nie gelingen, die Möglichkeit, Steuern zu umgehen, völlig auszuschließen; doch sollte er bestrebt sein, durch entsprechende Steuergesetzgebung den Steuerpflichtigen möglichst wenig Ansatzpunkte für rechtsmißbräuchliche Steuerspargestaltungen zu belassen. Erfolgversprechender als kontinuierliche Veränderungen der Steuergesetze durch Wortlautverbesserungen und immer neue Spezialvorschriften (s.o. Kap. 4.1.1) erscheint dabei eine einmalige grundlegende

${ }^{1}$ Vgl. COWELL (1990) S. $195 \mathrm{f}$. 
Steuerreform, die berücksichtigt, daß sich fast alle Steuerumgehungshandlungen auf einige wenige Grundtypen zurückführen lassen, die sich ganz bestimmte Merkmale des Steuersystems zunutze machen. Diese die Steuerumgehung begünstigenden Merkmale auszumachen und Möglichkeiten ihrer Beseitigung zu prüfen muß die Grundlage einer solchen Steuerreform sein. 


\section{Bekåmpfung der Steuerumgehung durch Beseiti- gung vorhandener Gelegenheiten zum Rechtsmiß- brauch}

\subsection{Grundtypen der Steuerumgehung}

In Anlehnung an SHENFIELD, BRACEWELL-MILNES, GROENEWEGEN und STIGLITZ läßt sich feststellen, daß nahezu alle Steuerumgehungsversuche einer der sieben folgenden Methoden zuzuordnen sind: ${ }^{1}$

- interpersonelle Verlagerung von Einkünften, Ausgaben, Vermögensgegenständen oder Schulden:

Die Steuerpflichtigen machen sich den Umstand zunutze, daß das Steuersystem dahingehend nicht neutral ist, als aufgrund von Freibeträgen/Freigrenzen oder interpersonell variierender Steuersätze die Steuerlast unterschiedlich hoch ausfällt, je nachdem, wem das Einkommen oder Vermögen zugerechnet wird.

- intertemporale Verlagerung von Einkünten oder Ausgaben:

Es wird ausgenutzt, daß es im Falle intertemporal variierender Steuersätze steuerlich nicht gleichgültig ist, wann Einkünfte oder Einkommensabzüge anfallen. Selbst bei im Zeitablauf konstant bleibenden Steuersätzen ist das Hinauszögern der Steuerzahlung aufgrund möglicher Zinsgewinne immer noch lohnend.

- Umwandlung bestimmter Einkunfts-, Aufwands-, Vermögens- oder Umsatzarten in andere, steuerlich begünstigte Einkunfts-(bzw. Aufwands-, Vermögens- oder Umsatz-)arten:

In diesem Fall ergibt sich die Gelegenheit zur Steuerumgehung aus fehlender Quellenneutralität ${ }^{2}$.

- Steuerarbitrage durch Erwerb von Aktiva, die steuerbegünstigte Erträge abwerfen, bei steuerlich abzugsfähigen Finanzierungs- oder anderen Kosten:

Die Steuerpflichtigen nutzen Abweichungen der Einkommensteuer vom Reinvermögenszugangsprinzip aus.

- Verlagerung von Einkünften, Ausgaben, Vermögen oder Schulden von der betrieblichen auf die private Ebene oder umgekehrt:

1 Vgl. SHENFIELD (1968) S. 16, BRACEWELL-MILNES (1979) S. 12, GROENEWEGEN in COLLINS (1984) S. 25 ff., STIGLITZ/SCHÖNFELDER (1989) S. $631 \mathrm{ff}$.

${ }^{2}$ Unter „Quellenneutralităt" sei im Falle der ESt die steuerliche Gleichbehandlung jedweden Einkommens verstanden, unabhăngig davon, aus welcher "Quelle“ das Einkommen stammt. Für die VSt und die USt läßt sich Quellenneutralität analog definieren. 
Ursächlich für derartige Transaktionen ist die von der Besteuerung natürlicher Personen abweichende Besteuerung der Unternehmen.

- Ausnutzung fehlender Finanzierungs- oder Rechtsformneutralität der Unternehmensbesteuerung:

Obwohl von den o.g. Autoren nicht erwähnt, sind auch die hier genannten Verstöße gegen das Postulat der Steuerneutralität eine häufige Quelle für rechtsmißbräuchliche Gestaltungen.

- Ausnutzung fehlender Standortneutralität der Besteuerung:

Auch regionale und vor allem internationale Unterschiede in der Steuerbelastung lassen sich nicht nur zu legaler Steuervermeidung nutzen, sondern bieten vielfach ebenfalls Gelegenheit zu mißbräuchlicher Steuerumgehung.

\subsection{Interpersonelle Verlagerung von Einkommen und Ver- mögen}

\subsubsection{Möglichkeiten für interpersonelle Einkommensverlagerungen ${ }^{1}$}

Steuerumgehung durch interpersonelle Einkommensverlagerungen findet meist zwischen Eltern und ihren minderjährigen Kindern statt. ${ }^{2}$ Hauptzweck solcher Aktionen ist Progressionsmilderung im Falle eines direkt-progressiven Einkommensteuertarifes: Günstigstenfalls gelingt es, daß jedem Kind genau die Hälfte des elterlichen (Ehe-)Einkommens zugerechnet wird, so daß der Grenzsteuersatz für alle Beteiligten gleich hoch wird. Aufgrund der beschränkten Geschäftsfähigkeit Minderjähriger kann die freie Verfügung der Kinder über Vermögen und Vermögenserträge ausgeschlossen werden, so daß die Eltern die Verfügungsmöglichkeit über das ihren Kindern übertragene Vermögen behalten. ${ }^{3}$ Der Nachweis des Rechtsmißbrauchs ist im allgemeinen schwer $\mathrm{zu}$ führen. Die einfache Übertragung von elterlichem Vermögen auf die Kinder zwecks günstigerer Steuersätze auf die Ver-

${ }^{1}$ Für die Vermőgensteuer gilt in der Bundesrepublik Deutschland nach $\S 14$ VStG das Prinzip der Haushaltsbesteuerung, d.h. Eltern und Kinder werden gemeinsam zur VSt veranlagt. Mißbräuchliche interpersonelle Vermögensübertragungen innerhalb der Familie zwecks Umgehung der deutschen Vermögensteuer sind deshalb nicht möglich. Wegen des konstanten Steuersatzes wären Vermögensübertragungen ohnehin einzig zur besseren Ausnutzung der Freibeträge geeignet, brächten aber keine Verminderung der Grenzsteuerbelastung.

${ }^{2}$ In Ländern, in denen die Ehegatten getrennt zur Einkommensteuer veranlagt werden, lohnt sich auch die Verschiebung von Einkünften oder Ausgaben zwischen den Eheleuten.

${ }^{3}$ Lassen die Eltern die Kinder frei über das Vermögen und die daraus resultierenden Einkünfte verfügen, so muß die Einkommensverlagerung aufgrund ihrer tatsächlichen ökonomischen Wirkung als ,echt" angesehen werden; in diesem Fall liegt keine Steuerumgehung im Sinne der Definition auf S. 30, sondern lediglich völlig legale Steuervermeidung vor. 
mögenserträge unterliegt in aller Regel nicht dem Risiko eines Scheiterns vor der Finanzverwaltung. ${ }^{1}$ Ein häufigerer Gegenstand gerichtlicher Auseinandersetzungen zwischen Steuerpflichtigen und Finanzbehörde sind jedoch Verträge zwischen Eltern und Kind, die bei den Eltern zu abzugsfähigen Aufwendungen führen, wobei die Steuerersparnis bei den Eltern aufgrund der direkten Progression der Einkommensteuer höher liegt als die zusätzliche steuerliche Belastung des (geringer verdienenden) Kindes.

Beispiel:

Das Finanzgericht Münster ${ }^{2}$ hatte sich 1985 mit einem Fall zu befassen, in dem ein selbständiger Steuerberater mit den Geldmitteln seiner vier Monate alten Tochter eine für seine Praxis bestimmte EDV-Anlage anschaffe und sich diese verpachten ließ. Den Pachtzins machte er als Betriebsausgabe geltend. Das Geld des Säuglings stammte aus einem auf seinen Namen lautenden Sparguthaben sowie aus einem von den Großeltern gewährten Darlehen.

Das Finanzgericht erkannte diese Gestaltung steuerlich an. Der Vertrag halte in seiner konkreten Ausgestaltung einem Fremdvergleich durchaus stand. Die Pachtzinsen seien der Tochter tatsächlich zugeflossen, und es habe sich dabei nicht um Unterhaltsleistungen gehandelt, zu denen die Eltern ohnehin verpflichtet sind. Ein Sperrvermerk zugunsten des Kindes auf dem Sparbuch, auf welches die Pachtzinsen überwiesen wurden, sei nicht erforderlich. Für die steuerliche Anerkennung reiche es aus, wenn furr das betreffende Veranlagungsjahr nachgewiesen werde, daß die Eltern in diesem Zeitraum die auf dem Sparkonto aufgelaufenen Pachtzinsen nicht angetastet haben.

Der Bundesfinanzhof ${ }^{8}$ hob diese Entscheidung des Finanzgerichts wieder auf. Für den Fremdvergleich genüge es nicht, ob die Mietverträge zwischen Vater und Tochter bei isolierter Betrachtung einem solchen Vergleich standhielten; vielmehr sei das gesamte Vertragswerk einschließlich der die Mietverträge vorbereitenden Aktionen dem Fremdvergleich zu unterwerfen. Unabhängig davon liege im vorliegenden Fall jedoch ohnehin eine rechtsmißbräuchliche Gestaltung i.S.d. § 42 AO vor, weil fur die Vorschaltung der Tochter beim Erwerb der EDV-Anlage kein vernünftiger wirtschaftlicher Grund zu erkennen sei, zumal die vorgeschaltete Person schon allein aufgrund ihres Alters keine rechtlich oder wirtschaftlich sinnvolle Funktion erfüllen könne. Da für die gewählte Gestaltung kein vernünttiger außersteuerlicher Grund zu entdecken 'sei und verständige Parteien dieses gekünstelte Vertragswerk in Anbetracht der wirtschaftlichen Zielsetzung nicht

${ }^{1}$ Allerdings müssen die Erträge den Kindern tatsächlich zufließen und dürfen nicht für den laufenden Lebensunterhalt der Eltern verwendet werden (vgl. Urteil des FG Nürnberg vom 13.5.1977 III 176/76, EFG 1977 S. 487 [487]).

${ }^{2}$ Urteil vom 16.4.1985, VI 670/85 E, EFG 1986 S. 110 f.

${ }^{3}$ Urteil vom 17.1.1991 IV R 132/85 BStB1. 1991 II S. 607-610 
gewählt hätten, liege ein Rechtsmißbrauch vor, der zur Nichtanerkennbarkeit der Pachtzinsen als Betriebsausgabe führen müsse. ${ }^{1}$

Auch die Organisation eines Unternehmens als Familiengesellschaft dient im allgemeinen ganz oder in erster Linie einer Minderung der Steuerlast. Eine Familiengesellschaft entsteht typischerweise durch Umwandlung eines Einzelunternehmens in eine KG, wobei der bisherige Einzelunternehmer Komplementär der neuen Gesellschaft wird und seine Kinder - progressionsmildernd - als Kommanditisten beteiligt. $^{2}$ Voraussetzung für die steuerliche Anerkennung ist in Deutschland neben einem zivilrechtlich wirksamen Gesellschaftsvertrag eine „angemessene“ Gewinnverteilung. Der Große Senat des BFH hat in einem grundlegenden Beschluß von 1972 eine Rendite der (unentgeltlich erworbenen) Kommanditanteile von durchschnittlich bis zu $15 \%$ für angemessen erklärt. ${ }^{3}$

Als weiteres Beispiel für interpersonelle Einkommensverlagerungen kann die bereits auf S. 172 (Fußnote 1) angesprochene Kettenschenkung angesehen werden. In einem solchen Fall wird eine Schenkung nicht direkt der begünstigten, sondern zunächst einer dritten Person übertragen, die den Schenkungsbetrag dann an die begünstigte Person weiterleitet. Auf diese Weise wird versucht, die unterschiedlichen Steuerklassen und Freibeträge der $\S \S 16$ und 19 ErbStG auszunutzen. ${ }^{4}$ Der Bundesfinanzhof hat sich schon häufig mit Streitfällen befassen müssen, in denen es um die Frage ging, ob eine mehrstufige Schenkung rechtsmißbräuchlich i.S.d. $§ 42$ AO sei. ${ }^{5}$

\subsubsection{Reformvorschläge}

\subsubsection{Familiensplitting}

Interpersonelle Einkommensverlagerungen innerhalb von Familien haben ihre Ursache in der Individualbesteuerung der im Haushalt lebenden Kinder. ${ }^{6}$ Gilt für die

${ }^{1}$ Vgl. auch Kap. 4.3.3.3.2 und 4.3.3.3.4 dieser Arbeit.

${ }^{2}$ Vgl. CREZELIUS (1995) S. 319.

${ }^{3}$ Vgl. BFH-Beschluß vom 29.5.1972 Gr. S. 4/71 BStBl. 1973 II S. 5 [8].

${ }^{4}$ So bliebe beispielsweise eine Schenkung an das Enkelkind i.H.v. DM 90.000 steuerfrei, wenn diese indirekt über Vater oder Mutter des Kindes erfolgt (Ersparnis: DM 2.400). Eine Schenkung i.H.v. DM 500.000 an die Schwiegertochter auf direktem Wege löst eine Steuerpflicht i.H.v. DM 120.050 aus, während für eine indirekte Schenkung über den Sohn nur DM 43.905 fallig würden.

${ }^{5}$ Eine Aufzählung diesbezüglicher BFH-Entscheidungen findet sich bei TIPKE/KRUSE (1996) Tz. 32.

${ }^{6}$ Die Individualbesteuerung wäre allerdings im Falle eines einheitlichen Grenzsteuersatzes diesbezüglich nicht von Belang. Man könnte daher auch sagen, die primäre Ursache interpersoneller Einkommensverlagerungen läge in der Existenz unterschiedlicher Grenzsteuersătze je nach Einkommenshöhe. Vgl. hierzu das folgende Kapitel. 
Kinder aufgrund des direkt-progressiven Einkommensteuertarifes ein (typischerweise) niedrigerer Grenzsteuersatz als für die Eltern, so senkt die Übertragung steuerpflichtiger Einkünfte von den Eltern auf die Kinder (oder abzugsfähiger Ausgaben von den Kindern auf die Eltern) die Steuerschuld der Familie. Würden Familien (wie in Frankreich) gemeinsam zur Einkommensteuer veranlagt, so blieben innerfamiliäre Einkommensverschiebungen steuerlich ohne Wirkung. Ein solches Konzept der Zusammenveranlagung von Familien ist das als Alternative zu Kindergeld und Kinderfreibeträgen entwickelte Familiensplitting.

Wird die Familie als wirtschaftliche Einheit angesehen, in der die Einkünte unabhängig davon, wer sie erwirtschaftet hat, für alle Familienmitglieder verausgabt werden, so verkörpert das Familiensplitting eine in besonderem Maße sachgerechte Form der Familienbesteuerung. ${ }^{1}$ Hauptzweck des Familiensplittings ist ein angemessener Kinderlastenausgleich; die Verhinderung steuerumgehender Einkommensverlagerungen stellt einen positiven Nebeneffekt dar.

Das Familiensplitting kann als eine Erweiterung des Ehegattensplittings auf die gesamte Familie angesehen werden:

Beim Familienvollsplitting werden die Einkommen aller Familienmitglieder addiert und die Summe durch die Anzahl der Familienmitglieder geteilt. Auf den so ermittelten Betrag wird der Einkommensteuer-Grundtarif angewendet und das Ergebnis wieder mit der Anzahl der Familienmitglieder multipliziert. Als Resultat ergibt sich die Steuerschuld der Familie.

$\mathrm{Da}$ davon auszugehen ist, daß ein Kind in aller Regel mit einem geringeren Anteil am Familieneinkommen partizipiert als jedes Elternteil, ist ein sogenanntes Teilsplitting sachgerechter, bei dem jedem Kind ein Splittingfaktor zugeordnet wird, der kleiner als 1 ist. $^{2}$ Von einem solchen Familienteilsplitting wird im folgenden ausgegangen. ${ }^{3}$

Die Splittingfaktoren sind im einfachsten Fall für alle Kinder identisch.

Geht man davon aus, daß die Aufwendungen für Kinder von deren Alter abhängig sind, so lassen sich die Divisoren aber auch nach dem Alter der Kinder staffeln. Da

${ }^{1}$ Kinderfreibeträge berücksichtigen zwar ebenfalls die Ausgaben, die Eltern für ihre Kinder zu leisten haben; doch vernachlässigen starre Freibeträge den Umstand, daß Kindern wohlhabender Eltern in aller Regel ein höherer Lebensstandard finanziert wird als Kindern von Geringverdienern. Ferner müssen in einem solchem System die Kinder die von den Eltern erhaltenen Zuwencungen nicht versteuern.

${ }^{2}$ Geht man davon aus, daß Kinder (zum Beispiel) halb so viele Ressourcen in Anspruch nehmen wie Erwachsene, so müßten Kinder als „halbe Personen“, d.h. mit einem Splittingfaktor von 0,5, Berücksichtigung finden. Bei einer fünfköpfigen Familie würde das Familieneinkommen dann durch zwei ganze und drei „halbe“ Personen, also durch 3,5, geteilt.

${ }^{3}$ Eine Beschreibung der „Technik“ des Familienvoll- und -teilsplittings findet sich bei JANSSEN (1991) S. 21. 
in Deutschland zur Zeit weder Kindergeld noch Kinderfreibeträge nach dem Alter gestaffelt sind, kann man jedoch schließen, daß der Gesetzgeber von im Zeitablauf in etwa konstanten Kosten auszugehen scheint. ${ }^{1}$ Altersabhängige Splittingfaktoren wären dann nicht angezeigt.

Eine Differenzierung je nach Ordnungszahl des Kindes erscheint ebenfalls nicht notwendig, da konstante Splittingfaktoren der Haushaltsersparnis ${ }^{2}$ bei zunehmender Kinderzahl bereits Rechnung tragen. ${ }^{3}$

Zunächst denkbar erscheinen hingegen mit zunehmendem Einkommen abnehmende Splittingdivisoren. Damit würde berücksichtigt, daß Kinder gering verdienender Eltern zwar absolut weniger, aber im Verhältnis zum elterlichen Einkommen mehr Ausgaben verursachen dürften als die Kinder Besserverdienender. ${ }^{4}$ Um implizite Grenzsteuerbelastungen von über $100 \%$ zu vermeiden, müßten die Splittingfaktoren jedoch mit steigendem Haushaltseinkommen stetig und nicht sprunghaft abgesenkt werden, was der Transparenz des steuerlichen Konzeptes des Familiensplittings erheblich zuwiderliefe. ${ }^{5}$

Wenn die Splittingfaktoren so bemessen sind, daß sie die Aufteilung der Einkommensverwendung innerhalb der Familie angemessen widerspiegeln, dann ist der verbleibende Anstieg der absoluten Entlastungswirkung bei zunehmendem Einkommen jedoch sachgerecht. Hält der Gesetzgeber den bestehenden direktprogressiven Einkommensteuertarif für vertikal gerecht, so kann die aus diesem Tarif resultierende Verteilung der steuerlichen Entlastung durch das Familiensplitting nicht gleichzeitig für ungerecht gehalten werden. Wird allerdings durch den Kinderlastenausgleich auch eine gesicherte materielle Mindestversorgung eines jeden Kindes angestrebt, so müßte die Entlastungswirkung mindestens die Höhe

${ }^{1}$ Dies ist wohl auch nicht unrealistisch, da ältere Kinder zwar häufig mit teureren Freizeitkonsumgütern bedacht werden, mehr Nahrung und Getränke konsumieren und teuren Hobbys (wie Reiten, Instrumentalunterricht usw.) nachgehen, Kleinkinder auf der anderen Seite Betreuungskosten, extra bereitete Nahrung, häufiger neue Kleidungsstücke und spezielle Ausrüstungsgegenstände wie Kinderwagen, Auto-Kindersitze etc. benötigen.

${ }^{2}$ Unter der Haushaltsersparnis versteht man den sich aus dem gemeinsamen Konsum der Familienmitglieder ergebenden Vorteil gegenüber einer getrennten Haushaltsführung. So verursachen drei Kinder weniger als die dreifachen Kosten für ein Kind.

${ }^{3}$ Bei einem Familieneinkommen von DM 60.000 und einem Splittingfaktor von 0,5 für jedes Kind wird bei einer dreiköpfigen Familie den Eltern zusammen DM 48.000 und dem Kind DM 12.000 zugerechnet. Kommt ein weiteres Kind hinzu, so würden DM 40.000 auf die Eltern und DM 20.000 auf die beiden Kinder bezogen, d.h. nur noch DM 10.000 pro Kind.

${ }^{4}$ Einkommensunabhängige Splittingdivisoren unterstellen implizit, daß ein zehnfaches Einkommen auch zehnfache Ausgaben für die Kinder bedeutet.

5 gl.A.: TIPKE/LANG (1984) S. 132.

Ein diesbezüglich besonders abschreckendes Beispiel (mit Splittingdivisoren, die von 0,465 bei einem z.v.E. bis DM 36.000 stetig auf 0,057 ab einem z.v.E. von DM 260.000 absinken) beschreiben BRITSCHKAT/KÖRNER (1984). 
des für nötig erachteten Versorgungsminimums erreichen. Reicht das Splittingverfahren hierzu nicht aus, so müßte die Differenz den betroffenen Familien als eine Art Kindergeld ausgezahlt werden. Der bürokratische Aufwand für ein solches variables Kindergeld wäre allerdings für die Auszahlungsstelle (Arbeitgeber, Sozialamt oder Finanzbehörde) recht hoch.

Weitere Einwände, die gelegentlich gegen das Familiensplitting vorgebracht werden, erscheinen hingegen bei näherer Prüfung wenig stichhaltig:

- Der Einwand, für die Ermittlung realitätsgerechter Splittingfaktoren fehlten die notwendigen statistischen Daten über die üblichen Unterhaltskosten je nach Alter der Kinder und Einkommen der Eltern, ${ }^{1}$ ist zwar sachlich zutreffend, doch liegt hier kein spezifisches Problem des Familiensplittings vor. Die ,richtige“ Festsetzung von Kinderfreibeträgen und Kindergeld trifft auf die gleichen Probleme.

- Auch die Frage der richtigen Zuordnung eines Kindes, das z.B. teilweise von der Mutter, teilweise von Pflegeeltern unterhalten wird, ${ }^{2}$ ist ein Problem, das bei Kindergeld und -freibeträgen in ähnlicher Form auftritt. Statt einer Aufteilung des Splittingdivisors auf die am Unterhalt beteiligten Personen empfiehlt sich allerdings die volle Berücksichtigung bei demjenigen Haushalt, in dem das Kind seinen gewöhnlichen Aufenthaltsort hat, wobei von außerhalb empfangene Unterhaltsleistungen steuerpflichtig sein müßten, während die Transfergeber ihre Leistungen von ihrem zu versteuernden Einkommen abziehen könnten.

- Die Durchführung eines angemessenen Lohnsteuerabzugs, der Veranlagungsverfahren möglichst überflüssig macht, stößt m.E. durch das Familiensplitting auf keine neuen Schwierigkeiten. ${ }^{3}$ Schon jetzt werden in Deutschland Familienstand und Kinderzahl auf der Lohnsteuerkarte vermerkt und bei der Bemessung der Lohnsteuer berücksichtigt. Die Problematik des richtigen Lohnsteuerabzugs liegt in der nur groben Berücksichtigung des Einkommens des mitverdienenden Ehemannes bzw. der Ehefrau begründet, ist aber von der Art des Kinderlastenausgleichs nicht abhängig.

- Werden noch im Haushalt der Eltern lebende Volljährige in das Familiensplitting einbezogen (vgl. $\S 32$ Abs. 4 und 5 sowie $\S 67$ Abs. 2 EStG), so müßten sie im Fall eigener Einkünfte die Einkommensteuererklärung gemeinsam mit den Eltern ausfüllen und mit unterschreiben. Das Steuergeheimnis wäre dann innerhalb der Familie aufgehoben. ${ }^{4}$ Dieses Problem gegenseitiger Einsichtnahme in die Einkommensverhältnisse der Eltern bzw. der Kinder ließe sich lösen, wenn die

1 Vgl. KARL-BRÄUER-INSTTTUT (1983) S. 38.

${ }^{2}$ Vgl. STEUERREFORMKOMMISSION (1971) S. 197.

${ }^{3}$ so aber KARL-BRÄUER-INSTITUT (1983) S. 42

${ }^{4}$ Vgl. KARL-BRÄUER-INSTTTUT (1983) S. 42, JANSSEN (1991) S. 21. 
volljährigen Kinder eigene Formulare ausfüllen und diese unter Angabe der Steuernummer der Eltern getrennt beim Finanzamt einreichen könnten.

- Das Familiensplitting führt zu einer erheblichen steuerlichen Entlastung kinderreicher Steuerpflichtiger im oberen Progressionsbereich des Einkommensteuertarifes. Soll für gering verdienende Familien mit niedrigem Grenzsteuersatz eine garantierte staatliche Mindestversorgung der Kinder gewährleistet bleiben, so käme es durch Ausdehnung des Ehegattensplittings auf die Familie c.p. zu erheblichen Steuerausfallen. Diese sind eine logische Konsequenz der gewollten steuerlichen Entlastung von Familien mit Kindern und müßten sinnvollerweise durch eine steuerliche Höherbelastung Kinderloser ausgeglichen werden, z.B. über erhöhte Steuersätze bei der Einkommen- oder Umsatzsteuer oder eine Absenkung des Splittingfaktors für kinderlose Ehepaare (bei Beibehaltung des Wahlrechts auf Individualveranlagung der Ehegatten). Es geht hierbei um die Frage, ob eine steuerliche Besserstellung von Familien zu Lasten des kinderlosen Teils der erwachsenen Bevölkerung politisch gewünscht wird oder nicht; dies ist keine Frage, mit welchen Mitteln des Kinderlastenausgleichs (Kindergeld, Kinderfreibeträge oder Familiensplitting) ein solches Ziel ggf. erreicht werden sollte.

Zusammenfassend läßt sich festhalten, daß das Familiensplitting vom theoretischen Konzept her als eine positiv zu beurteilende Alternative des Kinderlastenausgleichs angesehen werden kann. Das Hauptproblem liegt bei praktischer Umsetzung in der fehlenden vertikalen Gerechtigkeit, da im Falle einer direkt-progressiven Einkommensteuer das Existenzminimum der Kinder nicht abgedeckt wird und hohe Einkommen unangemessen stark entlastet werden. Abhilfe schaffen würden Ausgleichszahlungen für gering verdienende Eltern sowie Splittingfaktoren, die mit steigendem Einkommen absinken und damit die Verteilung der Einkommensverwendung innerhalb der Familien wirklichkeitsgetreuer widerspiegeln. Während ersteres, wenn auch mit hohem Aufwand, durchaus praktikabel erscheint, würden einkommensabhängige Splittingdivisoren das System für die Mehrzahl der Bevölkerung weitgehend undurchschaubar machen.

Damit ist die Zusammenveranlagung von Familien zwar eine grundsätzlich geeignete Maßnahme zur Eindämmung der Steuerumgehung, doch stellt ihr - im gegenwärtigen Steuersystem in der Praxis kaum vermeidbares - Defizit an vertikaler Gerechtigkeit eine Nebenwirkung dar, welche die Frage aufwirf, ob die Vorteile diese Nebenwirkung aufwiegen. Dabei ist zu berücksichtigen, daß das Familiensplitting die Steuerumgehung durch Einkommensverlagerungen innerhalb eines Haushalts, nicht jedoch unter Freunden oder außerhalb des Haushalts lebenden Verwandten verhindert. Mißbräuchliche Einkommensverschiebungen würden zwar erheblich erschwert, bleiben aber nach wie vor möglich, solange unterschiedliche Steuerpflichtige mit unterschiedlichen Grenzsteuersätzen belastet werden. Die 
konsequentere Lösung wäre eine Einkommensteuer mit nur noch einem einzigen Grenzsteuersatz (ohne Nullzone), eine sog. flat-rate tox. ${ }^{1}$ Diese könnte auch die oben genannten Verstöße des Familiensplittings gegen die vertikale Gerechtigkeit beseitigen, da die Verteilung der Entlastungswirkung durch das Splittingverfahren ein Spiegelbild der Verteilung der Grenzsteuersätze darstellt. ${ }^{2} \mathrm{Ob}$ die flat-rate tox selbst einen zwingenden Verstoß gegen das Postulat vertikaler Gerechtigkeit darstellt, ist im folgenden Kapitel, welches sich der Abschaffung der direkten Progression als Maßnahme gegen die Steuerumgehung widmet, genauer zu prüfen.

\subsubsection{Abschaffung der direkten Progression}

Die Ausgestaltung der Einkommensteuer als flat-rate tax schließt Steuerumgehung durch interpersonelle Einkommensverlagerungen völlig aus. ${ }^{3}$ Aus Gründen der Verteilungsgerechtigkeit wird jedoch im allgemeinen eine progressive Einkommensteuer als unverzichtbar angesehen. Doch sind mit zunehmendem Einkommen ansteigende Grenzsteuersätze keine zwingende Voraussetzung für steigende Durchschnittssteuersätze und die hierdurch meist angestrebte Umverteilungswirkung der Einkommensteuer zu Lasten einkommensstarker Haushalte. Die derzeit dem direkt-progressiven Tarif zukommende Umverteilungsaufgabe ${ }^{4}$ läßt sich auch durch eine mit einer flat-rate tox verknüpfte, ,negative Einkommensteuer"

${ }^{1}$ Die Forderung nach einer flat-rate tax als Mittel zur Bekämpfung der Steuerumgehung findet sich auch bei SWAN in COLLINS (1984) S. 49.

${ }^{2}$ Ohne Verknüpfung der flat-rate tax mit einem Grundfreibetrag oder einer negativen Einkommensteuer (siehe folgendes Kapitel) hätte das Familiensplitting allerdings überhaupt keine Entlastungswirkung aufzuweisen.

${ }^{3}$ Von grenzüberschreitenden Einkommensverlagerungen sei an dieser Stelle abgesehen. Zur internationalen Steuerumgehung vgl. Kap. 6.8 dieser Arbeit.

${ }^{4}$ Eine progressive Steuer muß nicht in jedem Fall umverteilend wirken, sondern kann theoretisch allein dem Ziel dienen, mit der Besteuerung allen Steuerpflichtigen ein gleiches relatives Opfer abzuverlangen. Für dieses Ziel ist jedoch auch unter der Annahme eines abnehmenden Grenznutzens des Einkommens ein progressiver Tarif nicht zwingend erforderlich (unzutreffend in diesem Zusammenhang HABERSTOCK/BREITHECKER (1996) S. 13: Man denke z.B. an jede Nutzenfunktion der Gestalt $U(Y)=Y^{\mathbf{3}}$ mit $\left.0<a<1\right)$. Zwar sind auch Nutzenverlăufe denkbar, welche eine Steuerprogression implizieren (beispielsweise $U(Y)=\ln (Y+1)$ ); doch ist in den meisten Staaten die Progression des Einkommensteuertarifes derart ausgeprägt, daß die Konstruktion mathematischer Nutzenfunktionen, die diese Progression allein nach der Opfertheorie rechtfertigen würden, kaum möglich sein dürfte. So wird nach der deutschen EStGrundtabelle für 1996 auf ein z.v.E. von DM 36.000 eine Steuer von DM 6.691 erhoben. Bei der o.a. logarithmischen Nutzenfunktion müßte nach dem Prinzip des gleichen relativen Opfers ein Einkommen von DM 72.000 einer Steuer von DM 14.172,75 unterliegen. Tatsăchlich wird jedoch eine Steuer von DM 18.809 fallig. 
(negative income tax $=\mathrm{NIT}$ ) erfüllen. ${ }^{1}$ Als Voraussetzung für eine als Waffe gegen die Steuerumgehung fungierende flat-rate tox, welche mit dem Postulat der vertikalen Gerechtigkeit im Einklang stehen soll, wird im folgenden das Konzept der NIT beschrieben und auf seine Praxistauglichkeit hin untersucht. Die Abhandlung orientiert sich dabei an den in der Bundesrepublik Deutschland vorliegenden Verhältnissen; doch sind die Grundzüge des Steuer- und Transfersystems in den meisten entwickelten Volkswirtschaften vergleichbar, so daß die Einfuihrung der NIT im Ausland in etwa die gleichen Vorteile erbringen und Probleme aufwerfen dürfte wie in Deutschland.

Ziel der NIT ist nicht allein die hiermit verbundene Möglichkeit einer sozial verträglichen Beseitigung der direkten Progression im Einkommensteuertarif. Angestrebt wird mit der NIT ferner eine Vereinfachung des Systems der sozialen Sicherung und die Gewährleistung positiver finanzieller Anreize, einer Arbeit nachzugehen. $^{2}$

Die Ausgestaltung einer derart reformierten Einkommensteuer ist höchst einfach, es müssen nur zwei Parameter festgelegt werden: das garantierte Mindesteinkommen $Y_{m}$ und der einheitliche Grenzsteuersatz $\theta$.

Das garantierte Mindesteinkommen soll dem sozialkulturellen Existenzminimum entsprechen. Wer keine Einkünfte hat, erhält vom Finanzamt eine Zahlung in eben dieser Höhe als ,negative“ Einkommensteuer. Bei Einkommensbeziehern vermindert sich die negative Einkommensteuer um das mit dem Steuersatz multiplizierte z.v.E.; ab einer bestimmten Einkommenshöhe (der sog. Transfergrenze $Y_{\mathrm{Tr}_{\mathrm{r}}}$ ) wird aus der negativen eine ,positive“ Einkommensteuer, d.h. es werden Zahlungen an das Finanzamt fällig.

Es ergibt sich folgende Tariffunktion: $T=\theta * Y_{b r}-Y_{m}$.

Mit seinem Urteil von 1992 zur Nullzone des Einkommensteuertarifs ${ }^{3}$ hat das Bundesverfassungsgericht festgelegt, daß Einkommen erst dann besteuert werden darf, wenn es den Betrag übersteigt, der Bedürftigen nach dem Sozialrecht als staatliche Unterstützungsleistung zusteht. Der Umstand, daß der das Existenzminimum abdeckende Teil des Einkommens steuerfrei bleibt, gewährleistet jedoch noch nicht, daß die Aufnahme von Arbeit in jedem Fall das verfugbare Einkommen erhöht. Wenn Sozialhilfe in Höhe des Existenzminimums gewährt wird und Er-

${ }^{1}$ Die Einführung einer NIT ist nicht zwingend an eine flat-rate tax gebunden, doch ist im $\mathrm{Zu}-$ sammenhang mit dem Problem der Steuerumgehung die NIT nur dann von Interesse, wenn sie mit einer Abschaffung der direkten Progression einhergeht.

${ }^{2} \mathrm{Vgl}$. MTTSCHKE (1986) S. 315.

${ }^{3}$ Vgl. BVerfG-Beschluß vom 25.9.1992 - 2 BvL 5, 8, 14/91 - BVerfGE 87 S. 153 ff. 


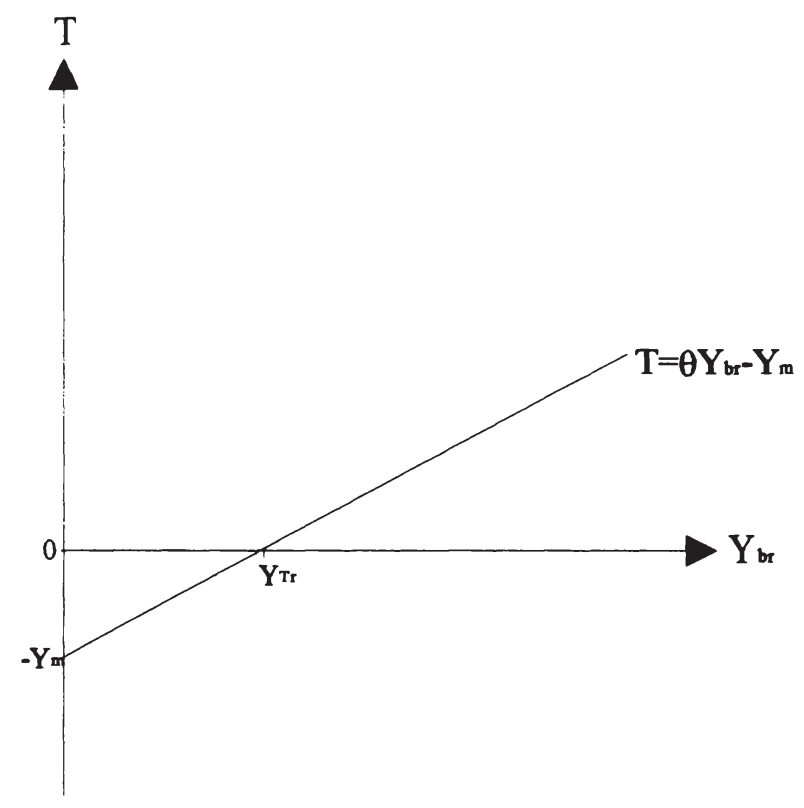

Abb. 6.1: Entwicklung der Steuerschuld in Abhöngigkeit vom verfügbaren Einkommen (NIT i.V.m.flat-rote tax)

werbseinkünfte in gleicher Höhe steuerfrei bleiben, so lohnt sich die Aufnahme einer gering bezahlten Erwerbstätigkeit nicht, sofern diese nicht durch eine negative Einkommensteuer oder andere staatliche Leistungen bezuschußt wird. Wie Abbildung 6.2 zeigt, stellt eine NIT in der oben beschriebenen Form hingegen sicher, daß im gesamten Tarifbereich für die Erzielung zusätzlicher Einkünfte stets ein finanzieller Anreiz verbleibt: Werden neben der NIT keine weiteren einkommensabhängigen Unterstützungsleistungen gewährt, so werden implizite Grenzsteuersätze von $100 \%$ oder mehr vollständig vermieden.

Als Konsequenz aus dem BVerfG-Urteil hat der Gesetzgeber die Nullzone ausgeweitet und zur Kompensation der Einnahmenausfalle den Eingangssteuersatz erhöht. Im Ergebnis wurde der Verlauf der Grenzsteuersätze flacher, die direkte Progression ging damit zurück. $\mathrm{Zu}$ einer völligen Abschaffung der direkten Progression konnte man sich jedoch nicht entschließen. Immerhin hat die Diskussion um eine negative Einkommensteuer (bzw. „Bürgergeld“) neuen Nährstoff erhalten. 


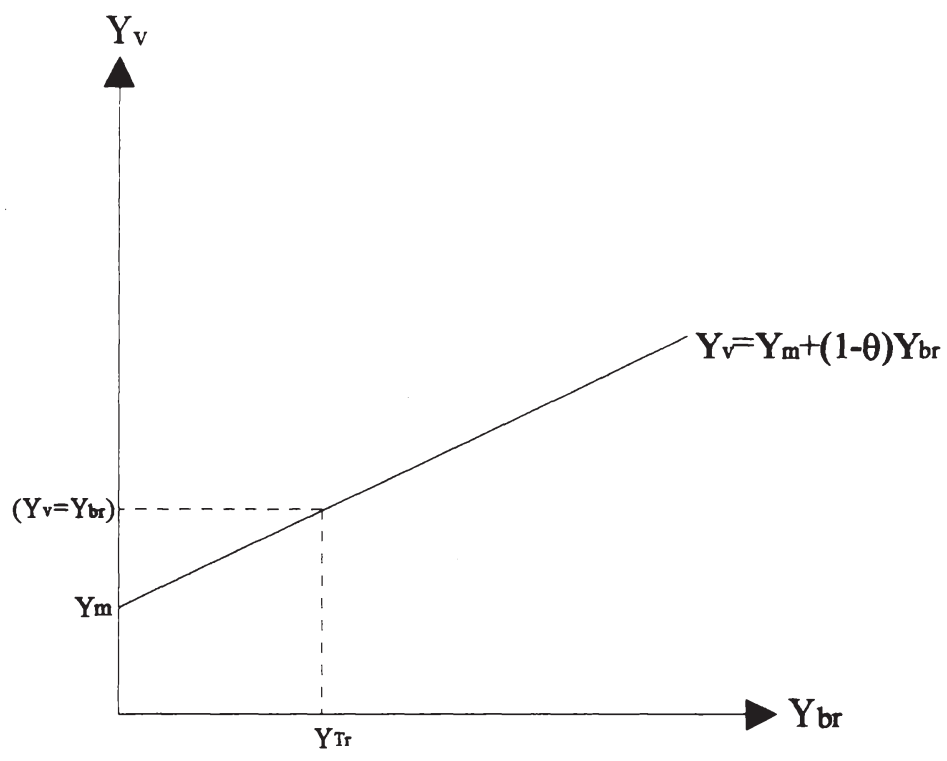

Abb. 6.2: Entwicklung des Nettoeinkommens bei einer NIT i.V.m. einer flat-rate tax

Die Einfürung der NIT würde einen Übergang vom Kausalprinzip zum Finalprinzip bedeuten, d.h. durch die NIT wird die Herbeiführung eines verteilungspolitisch erwünschten Zustands bezweckt, unabhängig von der Ursache (z.B. Bedürttigkeit, Arbeitslosigkeit, Kindererziehung, Ausbildung etc.) der zu korrigierenden Ausgangsposition. Dabei stellt sich die Frage, welche Transferleistungen (und Abgaben) des öffentlichen Sektors in das System der NIT einbezogen werden sollen. ${ }^{1}$ Nach der engsten Konzeption würden lediglich ESt und Sozialhilfe zusammengeführt; nach dem weitestgehenden Ansatz würden auch sonstige gegenleistungsfreie Transfers, Leistungen aus der gesetzlichen Sozialversicherung sowie die Erbschaft- und Schenkungsteuer integriert.

Meines Erachtens wäre es sinnvoll, (eventuell schrittweise) folgende öffentliche Transfers einzubeziehen: Neben der Sozialhilfe und der Arbeitslosenhilfe sollten auch die gesetzliche Rentenversicherung und Arbeitslosenversicherung eingegliedert werden. Um Übergangsprobleme bei Eintritt vorübergehender Arbeitslosigkeit

${ }^{1}$ Vgl. hierzu SVR (1993) S. 223. 
abzumildern (z.B. Bedienung laufender Kredite, Bezahlung der Wohnungsmiete), könnte für einen bestimmten Zeitraum weiterhin beitragsfinanziertes Arbeitslosengeld in Höhe der Differenz zwischen dem derzeitigen Anspruch und der NIT gezahlt werden. Sieht der Gesetzgeber eine über den Grundbedarf hinausgehende Alterssicherung als meritorisches Gut an, so kann eine Versicherungspflicht bei einer privaten Rentenversicherung angeordnet werden. Bisher aufgelaufene gesetzliche Rentenansprüche, welche die Höhe der NIT übersteigen, müßten aus rechtlichen Gründen (in Höhe des übersteigenden Betrages) weiter ausgezahlt werden. Ferner sollten neben der Sozialhilfe auch weitere gegenleistungsfreie Transfers wie Erziehungsgeld, Kindergeld ${ }^{1}$, Bafög-Leistungen, Wohngeld ${ }^{2}$ etc. in die NIT integriert werden. Nicht einzubeziehen sind hingegen die Leistungen der gesetzlichen Kranken-, Pflege- und Unfallversicherung, da diese Versicherungen nicht den von der NIT erfaßten üblichen Grundbedarf der Bevölkerung, sondern außerordentliche Aufwendungen abdecken, die nicht jedem Menschen unabhängig vom Eintreten des Versicherungsfalls erstattet bzw. ausbezahlt werden sollten. Die Einführung eines einheitlichen Steuersatzes ermöglicht schließlich auch die Integration der Erbschaft- und Schenkungsteuer in die ESt, ohne - wie im Fall einer direkt-progressiven Einkommensteuer - zu einer im Jahr des Erbanfalls unter Lebenseinkommensaspekten überhöhten Besteuerung zu führen. ${ }^{3}$

Das System der NIT i.V.m. einer flat-rate tax weist neben der wirksamen Reduzierung der Gelegenheiten zur Steuerumgehung eine Reihe weiterer Vorteile auf:

Indem eine Vielzahl von Umverteilungskomponenten in der Steuer- und Sozialgesetzgebung auf die NIT übertragen wird, wird das Umverteilungssystem transparenter und weniger verwaltungsaufwendig. Die einzelnen Bestandteile des

${ }^{1}$ Zum Kinderlastenausgleich s.u. S. 204 f.

${ }^{2}$ Kommunen mit überdurchschnittlich hohen Mieten könnten weiterhin durch Wohngeldzahlungen oder Sozialwohnungen bezahlbaren Wohnraum schaffen, wenn die nach dem landesüblichen Mietniveau ausgerichtete NIT dort nicht ausreicht.

${ }^{3}$ Solange das Bundesverfassungsgericht an seiner dem Leistungsfahigkeitsprinzip widersprechenden und das Prinzip der Gewaltenteilung verletzenden Rechtsprechung festhält, müßten Erbschaften als weitere Einkunftsart dem Einkommensteuerrecht hinzugefügt und mit den vom Gericht geforderten Freibeträgen versehen werden. Vgl. BVerfG-Beschluß vom 22.6.1995 - 2 BvR 552/91 - NJW 1995 S. 2624 ff. i.V.m. BVerfG-Beschluß vom 22.6.1995 - 2 BvL 37/91 NJW 1995 S. 2615 ff.

Der Widerspruch zum Leistungsfahigkeitsprinzip liegt darin begründet, daß Erbschaften und Schenkungen die persönliche Leistungsfähigkeit genauso erhöhen wie alle anderen Einkünfte auch. Das Prinzip der Gewaltenteilung wurde insbesondere dadurch verletzt, indem das Gericht, angerufen wegen der Bewertung von Grundbesitz in der VSt und ErbSt, Dinge regelte, welche nicht Gegenstand der Klage waren und damit allein der Legislative oblagen. Vgl. hierzu auch die treffenden Ausführungen von Richter BÖCKENFORDE in seinem Minderheitsvotum zum BVerfG-Beschluß vom 22.6.1995 - 2 BvL 37/91 - a.a.O. S. 2615 [2620-2624]. Vgl. ferner Art. 14 Abs. 1 Satz 2 GG! 
Systems werden einfacher aufeinander abstimmbar, Leistungskumulation auf der einen Seite verhindert, auf der anderen Seite die lückenlose Versorgung Bedürftiger gewährleistet. ${ }^{1}$ Die Wahrscheinlichkeit impliziter Grenzsteuersätze von $100 \%$ oder mehr sinkt. ${ }^{2}$ Durch Aufnahme bestimmter Teile der gesetzlichen Sozialversicherung in die NIT sinken die Lohnnebenkosten. Das Problem der ,kalten Progression" wird auf die Höhe der maximalen NIT, Freibeträge und Freigrenzen reduziert. Die Diskussion um die progressive Entlastungswirkung von Freibeträgen und anderer Abzüge von der Einkommensteuer-Bemessungsgrundlage hätte ein Ende. $^{3}$

Die mit der Einführung der NIT verbundenen Nachteile und zu lösenden Probleme sind $\mathrm{m} . \mathrm{E}$. vergleichsweise weniger gravierend:

Man könnte der mit einer NIT verknüpften flat-rate tax anlasten, daß sich der Gesetzgeber hiermit auf einen bestimmten Progressionsverlauf festlegt. Konkrete Annahmen über die Nutzenfunktionen der Steuerpflichtigen sowie exakt festgelegte Vorgaben über die mit dem Einkommensteuertarif bezweckte Umverteilung könnten Progressionsverläufe erforderlich machen, welche mit einem einheitlichen Grenzsteuersatz nicht erreichbar sind. Für die Praxis darf jedoch bezweifelt werden, daß der Steuertarifverlauf tatsächlich das Ergebnis mathematischer Nutzenfunktionen und exakt durchgeplanter Umverteilungsvorgaben ist. Es gibt keinerlei Anhaltspunkte für die Annahme, daß der aus einer NIT resultierende Progressionsverlauf die verteilungspolitischen Präferenzen der Gesellschaft schlechter widerspiegelt als der derzeitige direkt-progressive Steuertarif.

Ein weiteres Problem ergibt sich bei konsequenter Umsetzung des Finalprinzips aus dem Umstand, daß auch nicht arbeitswillige Personen und Schwarzarbeiter negative Einkommensteuer erhielten. Um dies zu verhindern, wäre es notwendig, die Zahlung der vollen Negativsteuer auf solche Personen zu beschränken, die nicht arbeitsfähig sind oder denen kein Arbeitsplatz angeboten werden kann. ${ }^{4}$ Der hiermit verbundene Verwaltungsaufwand existiert aber auch im derzeitigen System aus Arbeitslosengeld, Arbeitslosenhilfe und Sozialhilfe, so daß ein spezifischer Nachteil der NIT diesbezüglich nicht vorliegt.

$\mathrm{Zu}$ lösen ist des weiteren die Frage des Kinderlastenausgleichs: Da die NIT das sozialkulturelle Existenzminimum abdecken soll, müßte entsprechendes auch für

${ }^{1}$ Vgl. MTTSCHKE (1986) S. 314, 319.

2 Sie bleibt größer als null, da die Beibehaltung einer zeitlich befristeten Arbeitslosenhilfe schlecht bezahlte Arbeit u.U. vorübergehend finanziell nachteilig werden läßt und bestimmte Einkommensgrenzen (z.B. für die Arbeitnehmer-Sparzulage, Sozialwohnungen, staatliche Abtreibungsfinanzierung, Rückzahlungspflicht für bestehende Bafög-Schulden, Unterhaltspflicht für geschiedene Ehegatten und deren Kinder) wohl bestehen blieben.

${ }^{3}$ Vgl. MTTSCHKE (1986) S. 318.

${ }^{4}$ Vgl. METZE (1982) S. 794. 
Kinder gelten. Damit wäre auch für Kinder ein - einkommensunabhängiger - Abzug von der Einkommensteuer zu gewähren, der deren Existenzminimum entspricht. ${ }^{1}$ Im Falle einer flat-rate tox spielt es dabei keine Rolle, ob dieser Abzug als Kindergeld ausgezahlt, ein (entsprechend höherer) Kinderfreibetrag gewährt wird oder ob Kinder im Rahmen eines Familiensplittings berücksichtigt werden: Die Entlastungswirkung wäre stets unabhängig vom Einkommen die gleiche. Die hieraus resultierende erhebliche Besserstellung von Familien mit Kindern führt i.V.m. der erst bei der Transfergrenze einsetzenden Positivbesteuerung und der Erfordernis, bestehende Pensionsverpflichtungen - steuerfinanziert - weiterhin zu erfullen, zu Steuerausfällen, die anderweitig auszugleichen wären. ${ }^{2} \mathrm{Da}$ die Einsparungen bei Arbeitslosen- und Sozialhilfe und sonstigen Transfers hierfür nicht ausreichen können, müßte der einheitliche Steuersatz relativ hoch festgesetzt werden. Setzt man das Existenzminimum für Erwachsene, entsprechend dem Einkommensteuertarif für 1999, bei DM 13.000 und für Kinder bei DM 6.500 an, $^{3}$ so würde selbst ein sich nach dem derzeitigen Spitzensteuersatz bemessender einheitlicher Steuersatz von $53 \%$ die Aufkommensneutralität kaum gewährleisten. ${ }^{4}$ Die Steuerreform sollte daher begleitet werden von einer Abschaffung der steuerlichen Abzugsfähigkeit diverser Aufwendungen (wie z.B. Vorsorgeaufwendungen, deren Rückflüsse steuerfrei sind, staatliche Bauförderung, Geschäftsessen etc.) sowie einer Ausdehnung der Steuerbemessungsgrundlage (z.B. Einbeziehung von Stipendien, Krankengeld usw., capital gains, fiktiver Miete auf selbstgenutztes Wohneigentum; Abschaffung von $\S 3 \mathrm{~b} \mathrm{EStG)}$. Verbleibende Einnahmeausfalle könnten beispielsweise durch die Einfürung der geplanten $\mathrm{CO}_{2}$ - oder allgemeinen Energiesteuer kompensiert werden. Wenn ohnedies beabsichtigt ist, das Steuersystem um weitere ökologische Komponenten zu ergänzen und dies durch Mindereinnahmen bei der Lohn- und Einkommensteuer auszugleichen, so stellt die Einfuihrung der NIT i.V.m. einer Energiesteuer eine familienfreundliche und sozial ausgewogene Reformalternative dar, welche sich gut in die derzeit diskutierten Steuerreformpläne einfügt. ${ }^{5}$

${ }^{1}$ Vgl. ebenda S. $797 \mathrm{f}$.

${ }^{2}$ Mit den fiskalischen Folgen einer Einführung der NIT in Deutschland befaßt sich ausführlich HUTHER (1990) mit Hilfe von Simulationsmodellen.

${ }^{3}$ Der Betrag von DM 6.500 entspricht in etwa dem in $\S 32 \mathrm{EStG}$ als Existenzminimum angesetzten Kinderfreibetrag i.H.v. DM 6.264 p.a.

${ }^{4}$ Alleinstehende ohne Kinder hătten bei einem solchen Tarif bis zu einem jăhrlichen Einkommen von knapp 38.000 DM Steuervorteile gegenüber dem Einkommensteuertarif für 1999, bei kinderlosen Ehepaaren läge die Grenze bei knapp 76.000 DM, und eine vierköpfige Familie stünde sich bis zu einem z.v.E. von nahezu 114.000 DM nach der Reform besser als vorher.

${ }^{5}$ Die erhebliche steuerliche Besserstellung von Geringverdienern insb. mit Familie würde gleichzeitig den Tarifpartnern umfassende Arbeitszeitverkürzungen bei entsprechend geringeren Netto-, aber nur wenig veränderten Bruttolohnen ermöglichen. Insofern kann die NIT auch Bestandteil einer konzertierten Aktion zur Bekämpfung der Arbeitslosigkeit sein. 
Die abschließende Beurteilung der durch eine NIT ergänzten flat-rate tax fällt insgesamt positiv aus:

Wesentliche Nachteile sind mit einer solchen Maßnahme m.E. nicht verbunden; die zu erwartenden Steuerausfalle ließen sich z.T. innerhalb der Einkommensteuer, z.T. auf dem Gebiet der indirekten Besteuerung kompensieren. Der Vorteil einer effizienten, zielgerechten, transparenten und familienfreundlichen Sozialpolitik läßt eine solche Reform selbst dann vorteilhaft erscheinen, wenn man die wirksame Verhinderung mißbräuchlicher interpersoneller Einkommensübertragungen vernachlässigt. Gerade auf diesem Gebiet aber ist die flat-rate tox an Effektivität nicht zu überbieten, da sie direkt die Ursache des Problems (unterschiedliche Grenzsteuerbelastung je nach Person des Einkommensempfängers) völlig beseitigt. Da die Steuerrechtswissenschaft keine zuverlässigen Verfahren zu entwickeln in der Lage ist, welche eine stets korrekte individuelle Zurechnung von Einkünften gewährleisten, trifft genau das Gegenteil der Behauptung LANGs zu, interpersonelle Einkommensverlagerungen seien kein Problem des Steuertarifs, sondern ein Problem der Bestimmung des zu versteuernden Einkommens. ${ }^{1}$ In Wirklichkeit ist dieses Problem einzig durch eine Reform des Steuertarifs zu lösen.

$\mathrm{Zu}$ berücksichtigen ist, daß die hier vorgeschlagenen Maßnahmen eine radikale Veränderung des bestehenden Steuer- und Transfersystems bedeuten, weshalb sich ein behutsamer Übergang zum neuen System empfiehlt. Beispielsweise könnte in einem ersten Schritt die Nullzone des Einkommensteuertarifs bis zur geplanten Transfergrenze ausgeweitet werden und für Einkommen, die zwischen der Transfergrenze und der derzeitigen oberen Proportionalzone liegen, ein einheitlicher, in etwa Aufkommensneutralität bewirkender Grenzsteuersatz von z.B. $40 \%$ eingeführt werden. Im zweiten Schritt könnten Sozialhilfe, Arbeitslosenhilfe und andere gegenleistungsfreie Transfers durch ein einkommensunabhängiges Bürgergeld ersetzt und die Nullzone in der Einkommensteuer abgeschafft werden. Die noch fehlenden Maßnahmen (Einbeziehung von Arbeitslosen- und Rentenversicherung, Erbschaftsteuer, flat-rate tax, Ausweitung der ESt-Bemessungsgrundlage, Einführung oder Erhöhung indirekter Steuern) wären dann in einem dritten und letzten Schritt umzusetzen.

Man mag gegen die hier vorgeschlagene Steuerreform einwenden, daß sie in einem weiten Bereich des Einkommensteuertarifs eine Erhöhung der Grenzsteuerbelastung mit sich bringt und damit dort den Anreiz zur Steuerumgehung erhöht. Die völlige Beseitigung der Möglichkeiten zur Steuerumgehung durch interpersonelle Einkommensverlagerungen dürfte einen solchen Effekt jedoch mehr als kompensieren. Dabei ist auch der Umstand zu berücksichtigen, daß in den meisten Gerichtsverfahren, die sich mit Steuerumgehung befassen, die Prozeßgegner der

\footnotetext{
${ }^{1}$ Vgl. TIPKE/LANG (1984) S. 132.
} 
Finanzbehörden gut verdienende Steuerpflichtige sind, welche i.d.R. schon jetzt dem Spitzensteuersatz von $53 \%$ unterliegen. ${ }^{1}$

Insgesamt ist die Abschaffung der direkten Progression die vielleicht wichtigste $\mathrm{Maßnahme} \mathrm{gegen} \mathrm{die} \mathrm{Steuerumgehung} \mathrm{überhaupt,} \mathrm{da} \mathrm{sie} \mathrm{einen} \mathrm{bedeutenden} \mathrm{Anteil}$ mißbräuchlicher Gestaltungen erfaßt und völlig ausschließen kann. Auch die Nebenwirkungen dieser Maßnahme erscheinen eher positiv als negativ, so daß eine praktische Umsetzung der Reform für die nahe Zukunft als unbedingt erstrebenswert anzusehen ist.

\subsubsection{Reform der Erbschaft- und Schenkungsteuer}

Kettenschenkungen haben ihre Ursache in den Freibeträgen sowie den in Deutschland je nach Verwandtschaftsgrad und Zuwendungshöhe variierenden Steuersätzen des ErbStG. Unabhängig davon, ob die ErbSt als selbständige Steuer bestehen bleibt oder ob Erbschaften und Schenkungen als weitere Einkunftsart in die ESt integriert werden, liegt die Lösung des Problems in einer Abschaffung der Freibeträge und der Einführung eines einheitlichen Steuersatzes.

Eine Abschaffung oder zumindest Reduzierung der Freibeträge ist in der Bundesrepublik Deutschland durch die wenig sachgerechte, nichtsdestoweniger den Gesetzgeber bindende Rechtsprechung des Bundesverfassungsgerichts unmöglich geworden (s.o. S. 203 FN 3). Der mißbräuchlichen Ausnutzung der Freibeträge durch Kettenschenkungen ist daher nur mittels $\S 42$ AO beizukommen. Doch hat auch hier die Rechtsprechung mittlerweile eine steuerumgeherfreundliche Position eingenommen: Nur wenn eine Willensäußerung des Schenkers vorliegt, durch die sich der Erstempfänger der Schenkung ihrer Weitergabe faktisch nicht entziehen kann, sei $\S 42$ anwendbar. ${ }^{2} \mathrm{Da} ß$ Steuerpflichtige die solcherart festgelegte Voraussetzung für die Anwendung der Generalklausel relativ leicht umgehen können, liegt auf der Hand. ${ }^{3}$ Dem Gesetzgeber bleibt im wesentlichen nur die Möglichkeit, durch einen einheitlichen Schenkungsteuersatz einen Teil des Anreizes zur Steuerumgehung durch Kettenschenkungen zu beseitigen und verbleibende mißbräuchliche Gestaltungen dieser Art hinzunehmen.

1 Steuerumgehung im großen Stil ist im wesentlichen ein Privileg der „Reichen“. Vgl. hierzu oben Kap. 3.5.2.

${ }^{2}$ Vgl. MEINCKE (1994) Rz. 68 und 68a unter Berufung auf den BFH (Urteil vom 14.3.1962 II 218/59 U BStBl. 1962 III S. 206 f.) und das FG Münster (Urteil vom 7.3.1991 3 K 8178/88 Erb EFG 1991 S. 737 f.).

${ }^{3}$ Entsprechende Tips finden sich bei KOTTKE (1994) S. 223. 


\subsection{Intertemporale Verlagerung von Einkünften oder Ausga- ben}

\subsubsection{Möglichkeiten der Verminderung oder Verzögerung der Steu- erzahlung durch intertemporale Einkommensverschiebung}

Die intertemporale Verschiebung der Besteuerung von Einkommen und Erträgen kann sowohl dem Hinauszögern der Steuerzahlung dienen (Zinseffekt) als auch zu einer endgültigen Steuerersparnis führen. In beiden Fällen muß es sich nicht zwangsläufig um Steuerumgehung handeln. Vielfach stellen zeitliche Einkommensverlagerungen simple Steuervermeidung dar. So ist weder in einer steuerlich motivierten Gewinnrealisierung zu Beginn eines Jahres statt am Ende des Vorjahres noch in dem Erwerb von Aufzinsungspapieren (z.B. Bundesschatzbrief Typ B) eine Steuerumgehung zu sehen. Erst wenn die intertemporale Verschiebung der Steuerpflicht durch rechtsmißbräuchliche Gestaltung erreicht wird, liegt eine Steuerumgehung im Sinne der Definition von Abschnitt 2 dieser Arbeit vor.

Vier Typen zeitlicher Einkommensverschiebungen lassen sich unterscheiden:

Zunächst kann versucht werden, Änderungen des Steuertarifs so auszunutzen, daß im Falle einer Steuererhöhung steuerpflichtiges Einkommen möglichst vor Inkrafttreten der höheren Steuersätze anfällt, während im umgekehrten Fall die Steuerpflicht möglichst hinausgezögert wird. ${ }^{1}$

Auch bei unverändertem Steuertarif kommt es im Falle direkter Progression zu jährlichen Schwankungen der individuellen Steuersätze. Gelingt es, Einkünfte und Ausgaben so zu verschieben, daß das Jahreseinkommen im Zeitablauf in etwa konstant bleibt, so lassen sich Progressionsspitzen vermeiden und die durchschnittliche Steuerbelastung auf diese Weise senken. ${ }^{2}$

Die dritte Methode nutzt die international übliche Steuerfreiheit unrealisierter $c a$ pital gains aus. Da Wertsteigerungen von Vermögensgegenständen im Regelfall mit Unsicherheit verbunden sind, konzentrieren sich Steuervermeidungs- und Steuerumgehungsstrategien insbesondere auf Geldanlagen und Kredite nach dem Zero-Bonds-Modell. In Deutschland werden die Erträge aus Zero-Bonds zwar nicht als capital gains, sondern als Zinserträge nach $\S 20$ Abs. 1 Nr. 7 EStG, aber ebenfalls erst am Ende der Laufzeit versteuert.

Möglichkeiten, auf diese Weise eine Verzögerung der Steuerzahlung zu erreichen, welche auch bei einem einheitlichen und im Zeitablauf unveränderten Steuersatz über den Zinseffekt von Vorteil ist, beschreibt KOTTKE: ${ }^{3}$

\footnotetext{
${ }^{1}$ Vgl. JAHRMARKT (1981) S. 20, 22.

${ }^{2}$ Vgl. ebenda S. $20 \mathrm{f}$.

${ }^{3}$ Vgl. KOTTKE (1994) S. 301-305.
} 
A verleiht B für dessen Betrieb Geld nach dem Zero-Bonds-Modell. B kann die Schuldzinsen jeweils in dem Jahr geltend machen, auf das sie wirtschaftlich entfallen. A muß die Zinseinkünfte erst am Ende der Laufzeit versteuern.

Diese Steuervermeidung wird zur Steuerumgehung, wenn die Unternehmer A und B sich gegenseitig aus ihrem Privatvermögen Darlehen dieser Art gewähren. In einem solchen Fall kann davon ausgegangen werden, daß die Finanzverwaltung der Rechtsgestaltung die steuerliche Anerkennung verwehrt.

Bei geschickterer Gestaltung verbessern sich jedoch die Erfolgsaussichten der Beteiligten: KOTTKE schlägt eine „Darlehensgewährung im Kreisverkehr“ vor. Dabei sollten die einzelnen Darlehensverträge so ausgestaltet werden, daß der sachliche, betragsmäßige und zeitliche Zusammenhang nicht mehr erkennbar ist. ${ }^{1}$

Schließlich lassen sich intertemporale Einkommensverlagerungen auch durch Ausnutzung der willkürlich gesetzten Besteuerungsperiode (i.d.R. Kalenderjahr) herbeiführen. Während die Realisierung von capital gains am 2. Januar des neuen statt am 30. Dezember des Vorjahres lediglich der erlaubten Steuervermeidung zuzurechnen ist, kann über die Terminbörsen auch Steuerumgehung in größerem Stil betrieben werden: STIGLITZ ${ }^{2}$ beschreibt den Fall eines Unternehmens, das zwei fast vollkommen negativ korrelierte Wertpapierposten in gleichem Umfang erwirbt (Kauf- plus Verkaufsoption bzgl. desselben Wertpapiers bzw. derselben Ware zu gleichen Optionsbedingungen). Am Ende des Jahres wird der eine Teil der Anlage einen Gewinn aufweisen, der andere einen Verlust. Der Verlust wird unmittelbar vor Jahreswechsel realisiert, der Gewinn gleich zu Beginn des neuen Jahres. Damit fällt die Steuerersparnis noch für das alte Jahr an, der zu versteuernde Gewinn erst für das Folgejahr. Bei jährlicher Wiederholung einer solchen Transaktion läßt sich die Steuerzahlung theoretisch unendlich hinauszögern.

\subsubsection{Reformvorschläge}

Der Ausnutzung von Steuersatzänderungen kann durch eine stetige Steuerpolitik begegnet werden, welche nur seltene und möglichst behutsame Änderungen des Steuertarifs beinhaltet. Gelegentlich für notwendig erachtete Korrekturen der Steuersätze sollten unter dem Aspekt intertemporaler Einkommensverlagerungen so kurzfristig wie möglich angekündigt werden.

Bezüglich der Glättung der Progressionsspitzen durch künstliches Konstanthalten des jährlichen Einkommens erweist sich erneut die direkte Progression als eigentliche Ursache für derartige Gestaltungen. Durch Einführung der in Kapitel 6.2.2.2

\footnotetext{
${ }^{1}$ Vgl. ebenda S. 304.

${ }^{2}$ Vgl. STIGLITZ (1985) S. 328.
} 
beschriebenen flat-rate tax läßt sich auch dieses Problem ohne weiteres vollständig lösen.

Die mißbräuchliche Ausnutzung der Steuerfreiheit unrealisierter capital gains ließe sich nur dann völlig ausschalten, wenn Wertsteigerungen jeder Art der Einkommensteuer unterlägen. ${ }^{1}$

Ohnehin stellt die Steuerfreiheit unrealisierter Wertsteigerungen einen Verstoß gegen das Reinvermögenszugangsprinzip dar und widerspricht dem Postulat der horizontalen Gerechtigkeit: Wird das Einkommen, definiert nach SCHANZ-HAIGSIMONS als Konsum plus Vermögenszuwachs während des betrachteten Zeitraums, als Maßstab der steuerlichen Leistungsfähigkeit gesehen, so ist eine unterschiedliche Leistungsfähigkeit je nachdem, ob Wertsteigerungen zu Geld gemacht wurden oder nicht, nicht zu erkennen. Wer capital gains realisiert, hat andere Präferenzen bzgl. seiner Vermögenshaltung als jemand, der dies nicht tut. Ein Zusammenhang mit der Frage, ob Einkommen entstanden ist, besteht jedoch nicht. ${ }^{2}$

Gegen die Besteuerung von capital gains vor deren Realisierung werden vor allem Praktikabilitätserwägungen vorgebracht:

Die notwendige jährliche Bewertung sämtlicher Vermögensgegenstände wäre zu aufwendig, um in der Praxis durchfuhrbar zu sein. ${ }^{3}$ Als Ausweg bietet sich an, die Besteuerung unrealisierter Wertsteigerungen auf Wertpapiere ${ }^{4}$ und Edelmetalle sowie Immobilien zu beschränken (deren Kurs- bzw. Verkehrswert relativ leicht zu ermitteln ist) und sonstige Vermögensgegenstände erst ab einer relativ hoch angesetzten Grenze (beispielsweise ab DM 100.000) in die periodische Neubewertungspflicht einzubeziehen. Die Steuer wäre dann zwar immer noch nicht zu 100\% neutral in bezug auf Art und Struktur der Vermögenshaltung, doch wären die Verstöße gegen die Steuerneutralität zweifellos geringer als bei dem derzeitigen Verzicht auf die Besteuerung sämtlicher unrealisierter Wertsteigerungen.

Ein weiteres Problem der Besteuerung auch unrealisierter Wertzuwächse ergibt sich, wenn es sich um solche Güter handelt, die in der Praxis unteilbar oder nicht handelbar sind, so daß den Eigentümern häufig die für die Steuerzahlung notwendigen liquiden Mittel fehlen. ${ }^{5}$ In solchen Fällen entsteht u.U. ein Zwang zur vollen Liquidation oder zur Kreditaufnahme. Dieses Problem verliert jedoch an Bedeu-

\footnotetext{
${ }^{1}$ Zur Besteuerung realisierter capital gains s.u. Kap. 6.4.4.

${ }^{2} \mathrm{Vgl}$. MUSGRAVE/MUSGRAVE/KULLMER (1993) S. $180 \mathrm{f}$.

${ }^{3} \mathrm{Vgl}$. KAY in COLLARD/LECOMBER/SLATER (1980) S. 141.

${ }^{4}$ Um eine Doppelbesteuerung thesaurierter Unternehmensgewinne zu verhindern, müßten unrealisierte und realisierte Kursgewinne von Aktien um den anteiligen einbehaltenen Gewinn bereinigt werden.

${ }^{5} \mathrm{Vgl}$. KAY in COLLARD/LECOMBER/SLATER (1980) S. 141.
} 
tung, wenn in derartigen Situationen den Steuerpflichtigen eine angemessene Zahlungsfrist eingeräumt wird. ${ }^{1}$

Es läßt sich festhalten, daß die Besteuerung unrealisierter Wertsteigerungen aus Gründen der horizontalen Gerechtigkeit angebracht erscheint und mit den genannten Einschränkungen m.E. durchaus praktikabel ist. Die Steuerumgehung mittels Ausnutzung der Steuerfreiheit nicht realisierter capital gains ließe sich somit erheblich eindämmen. Kann der Gesetzgeber sich nicht zu einer umfassenden Wertzuwachsbesteuerung entschließen, so wäre bereits die Besteuerung der Erträge aus Auf- und Abzinsungspapieren als jährliche Zinserträge statt als einmalige Kursgewinne (oder Zinsausschüttungen) am Laufzeitende eine wirksame Maßnahme gegen derartige Steuerumgehungen. Ein Disagio bei unter pari emittierten Anleihen müßte ebenfalls auf die Laufzeit verteilt und als Zinsertrag jährlich zu versteuern sein.

Intertemporalen Einkommensverlagerungen durch Ausnutzung der periodischen Besteuerung ist nicht ohne weiteres beizukommen. Allgemein gilt, daß derartige Steuerumgehung um so weniger ergiebig ist, je kürzer der Besteuerungszeitraum gesetzt wird, doch setzt der mit kürzeren Veranlagungszeiträumen verbundene Anstieg des Verwaltungsaufwands einer diesbezüglichen Anti-Umgehungs-Politik praktische Grenzen. Hilfreich wäre ein Abbau der Veranlagungssteuern zu Gunsten von Quellensteuern und indirekter Verbrauchsbesteuerung. Die verbleibende Steuerumgehung ist $\mathrm{m} . \mathrm{E}$. hinnehmbar, zumal es sich hier nur um Zinsgewinne der Steuerpflichtigen, nicht jedoch um wiederholbare endgültige Steuereinsparungen handelt. Besonders offensichtlich betriebener Rechtsmißbrauch, wie von STIGLITZ beschrieben (s.o.), dürfte in Deutschland ohnehin an $\S 42 \mathrm{AO}$ scheitern. Je weniger perfekt die in diesem Zusammenhang erworbenen Wertpapiere miteinander korreliert sind, desto eher werden solche Gestaltungen zwar vor Gericht Bestand haben; doch kommt dann zu den unumgehbaren Transaktionskosten ein steigendes Risiko fur die Anleger hinzu, wodurch ein hohes Ausmaß an Steuerumgehung dieser Kategorie eher unwahrscheinlich wird.

${ }^{1}$ Vgl. MUSGRAVE/MUSGRAVE/KULLMER (1993) S. $181 \mathrm{f}$. 


\subsection{Umwandlung bestimmter Einkunfts-, Aufwands- oder Umsatzarten in steuerbegünstigte Formen ${ }^{1}$}

\subsubsection{Transformation zu versteuernden Einkommens in steuerbe- günstigte Einkünfte}

Ein typisches und in fast allen Staaten der Welt gültiges Beispiel für steuerlich begünstigtes Einkommen bilden - wie bereits angesprochen - die capital gains. Demzufolge stellt die Umwandlung von steuerpflichtigem Einkommen in (meist steuerfreie) capital gains eine international gebräuchliche Methode der Steuerumgehung dar. Besonders bekannte Beispiele hierfur sind das „bond-washing“ und das ,dividend-stripping".

Diese Methoden nutzen den Umstand aus, daß Zinsen und Dividenden nicht kontinuierlich, sondern in Intervallen (z.B. einmal jährlich) gezahlt werden. Werden die im Laufe der Periode aufgelaufenen Zinsen und Dividenden im Verkaufsfall steuerlich als capital gains behandelt und wird der volle Ausschüttungsbetrag derjenigen Person zugerechnet, die zum Zeitpunkt der Ausschüttung Halterin des Papiers ist, so ist es einzelwirtschaftlich vorteilhaft, wenn sich Wertpapiere zum Ausschüttungstermin vorübergehend in der Hand von Personen befinden, die einer niedrigeren oder gar keiner Grenzsteuerbelastung unterliegen. ${ }^{2}$ Das Dividendenstripping durch Verkauf von Aktien unmittelbar vor und Rückkauf direkt nach dem Ausschüttungstermin (Vereinnahmung des steuerfreien Dividendenabschlags statt der steuerpflichtigen Dividende) hat den Reichsfinanzhof bereits im Jahre 1934 beschäftigt. Im konkreten Fall verweigerte der RFH seinerzeit unter Berufung auf $\S 6$ StAnpG einer solchen Gestaltung die steuerliche Anerkennung. ${ }^{3}$

${ }^{1}$ Theoretisch denkbar ist auch die mißbräuchliche Umwandlung zu versteuernder Vermögensteile in steuerbefreite oder -begünstigte Arten der Vermögenshaltung. Das deutsche VStG bietet aber kaum Ansatzpunkte für derartige Aktivitäten. Sachliche Steuerbefreiungen und -ermäßigungen finden sich im wesentlichen in $\S 115$ BewG. Diese Vorschrift eröffnet jedoch m.E. lediglich Möglichkeiten zur Steuervermeidung und Steuerhinterziehung. Die mißbräuchliche Umgehung der VSt beschränkt sich in der Praxis weitestgehend auf die Verlagerung von Vermögen oder Schulden von der betrieblichen auf die private Ebene bzw. umgekehrt sowie auf die Ausnutzung fehlender Rechtsformneutralität der betrieblichen Substanzbesteuerung. Hierzu s.u. Kap. 6.6 und 6.7.

${ }^{2} \mathrm{Vgl}$. KAY in COLLARD/LECOMBER/SLATER (1980) S. 139.

${ }^{3}$ Vgl. KOTTKE (1994) S. 296. 


\subsubsection{Transformation steuerlich irrelevanter Ausgaben in abzugsfä- hige Aufwendungen}

Eine in Deutschland die Rechtsprechung des öfteren beschäftigende Fallgruppe stellt die Umwandlung steuerlich nicht abzugsfähiger Unterhaltsaufwendungen (§ $12 \mathrm{Nr} .2 \mathrm{EStG}$ ) in abzugsfähige Zinsaufwendungen dar. ${ }^{1}$

$\mathrm{KRUSE}^{2}$ schildert einen Fall, in dem eine Minderjährige von beiden Elternteilen jeweils 30.000 DM geschenkt bekam, die sie den Eltern wieder als Darlehen überließ. Der Vater machte die Darlehenszinsen als Betriebsausgabe seiner Firma geltend, die Mutter nutzte den damals noch möglichen Abzug von Schuldzinsen als Sonderausgaben (vgl. hierzu auch unten S. 224). Der BFH verweigerte in seiner Entscheidung vom 16. März 1977 dieser Gestaltung unter Berufung auf die wirtschaftliche Betrachtungsweise ( $§ 1$ StAnpG) die steuerliche Anerkennung und bewertete die Zinsaufwendungen als verdeckte Unterhaltszahlungen.

Im beschriebenen Fall war die Steuerumgehung besonders offensichtlich, da Schenkung und Darlehen in der Höhe völlig identisch waren, nahezu zeitgleich gewährt wurden und die Darlehensverträge in ihrer konkreten Ausgestaltung einem Fremdvergleich nicht standhielten. KOTTKE empfiehlt den Steuerpflichtigen im Hinblick auf die bislang ergangene Rechtsprechung und die enthaltenen Urteilsbegründungen, die Darlehensverträge mit einer angemessenen Kündigungsfrist und der üblichen Verzinsung zu versehen und zwischen Schenkung und Darlehensgewährung einen Zeitraum von mindestens einem Monat verstreichen zu lassen. ${ }^{3}$

\subsubsection{Transformation von Umsätzen}

Eine einheitliche Besteuerung von Umsätzen ist weder in Deutschland noch im europäischen Ausland gegeben, so daß sowohl legale als auch mißbräuchliche Ausweichreaktionen möglich sind.

In Deutschland gelten für die nach $\S 1$ UStG steuerbaren Umsätze (dies sind vor allem die von Unternehmen ${ }^{4}$ im Inland ausgeführten Lieferungen und Leistungen) unterschiedliche Steuersätze und Steuerarten:

I Vgl. BFH-Urteil vom 22.11.1963 VI 178/62 U BStBl. 1964 III S. 74 ff.; BFH-Urteil vom 16.3.1977 I R 213/74 BStBl. 1977 II S. 414 f.; BFH-Urteil vom 10.4.1984 VIII R 134/81 BStBI. 1984 II S. 705 f;; BFH-Urteil vom 20.3.1987 III R 197/83 BStBl. 1988 II S. 603 f.; BFH-Urteil vom 12.2.1992 X R 121/88 BStBl. 1992 II S. 468 ff.

${ }^{2} \mathrm{Vgl}$. KRUSE (78/79) S. $444 \mathrm{f}$.

${ }^{3}$ Vgl. KOTTKE (1994) S. 343, 345.

${ }^{4} \S 2$ Abs. 1 UStG definiert den Unternehmensbegriff sehr weit. Unternehmerische Tătigkeit ist danach jede selbstăndig ausgeübte gewerbliche oder berufliche Tătigkeit zur Erzielung von 
Im Regelfall gilt ein Umsatzsteuersatz von $15 \%$ ( $\$ 9$ Abs. 1 UStG) bei Berechtigung zum Vorsteuerabzug ( $\$ 15 \mathrm{UStG}$ ).

Für einige, in $\S 12$ Abs. 2 UStG bezeichnete Umsätze (z.B. Leistungen des ÖPNV, Druckerzeugnisse, Nahrungsmittel) gilt aus sozialen und anderen Gründen ein ermäßigter Steuersatz von 7\%, ebenfalls mit der Möglichkeit des Vorsteuerabzugs.

Eine dritte Gruppe steuerbarer Umsätze wird von der USt freigestellt, wobei das Recht zum Vorsteuerabzug verlorengeht ( $\$ 4$ i.V.m. $\S 15$ Abs. 2 Nr. 1 UStG). Hierzu gehören u.a. Umsätze aus Vermietung und Verpachtung sowie die Umsätze von Ärzten, Krankenhäusern, Schulen, Theatern und Museen. Wiegt der Vorteil der Steuerfreiheit geringer als der Nachteil durch den Ausschluß vom Vorsteuerabzug, so kann nach $\S 9$ UStG unter bestimmten Voraussetzungen auf die Steuerbefreiung verzichtet werden.

Schließlich gibt es Umsätze, auf welche die USt ebenfalls nicht erhoben wird, die aber einer speziellen Verkehrsteuer unterliegen. Hierzu gehören insbesondere Versicherungsbeiträge sowie die entgeltliche Übertragung von Grundstücken. Während der Steuersatz der Versicherungsteuer mit 15\% dem UmsatzsteuerNormalsatz entspricht, beträgt die Grunderwerbsteuer 2\% vom Kaufpreis.

Fälle der Umgehung von Umsatzsteuer betreffen häufig die mißbäuchliche Erschleichung des Vorsteuerabzugs bei Verzicht auf Umsatzsteuerbefreiungen.

Ein Beispiel, welches Gesetzgeber und Rechtsprechung über viele Jahre immer wieder beschäftigt hat, ist die Zwischenvermietung von Wohnraum, wobei das zwischenvermietende Rechtsinstitut in aller Regel dem Erstvermieter gehört und die Gewinne an diesen abführt. Der Erstvermieter verzichtet auf die USt-Befreiung und kann damit seine gesamte Vorsteuer geltend machen. Die Weitervermietung erfolgt umsatzsteuerfrei. ${ }^{1}$

An von der Rechtsprechung entwickelten Kriterien zur Frage der steuerlichen Anerkennung derartiger Zwischenvermietungen mangelt es nicht. ${ }^{2}$ Unter anderem wurde als Indiz für einen Rechtsmißbrauch ein Mietvertrag zwischen Erstvermieter und Zwischenmieter angesehen, der eine Miete deutlich unterhalb der Kostenmiete vorsieht. $^{3}$

Auch der Gesetzgeber hat wiederholt auf derartige Gestaltungen reagiert. Durch mehrfache Abänderung des den Verzicht auf USt-Befreiung regelnden $\S 9$ Abs. 2

Einnahmen, also z.B. auch die Untervermietung eines Zimmers oder das Erteilen von Klavierunterricht.

${ }^{1}$ Vgl. SCHNEIDER (1985) S. 350.

${ }^{2}$ Ein Rechtsprechungsüberblick findet sich bei GUNTHER (1987) S. 202 f.

${ }^{3} \mathrm{Vgl}$. BFH-Urteil vom 15.12.1983 V R 169/75 BStBl. 1984 II S. $388 \mathrm{ff}$. 
UStG (1981, 1984 und zuletzt 1993) wurde versucht, dem Mißbrauch auf diesem Gebiet beizukommen.

Die GrESt ist ebenfalls des öfteren Gegenstand von Steuerumgehungsversuchen. ${ }^{1}$ Ein Beispiel ist der Erwerb eines Grundstücks durch eine Personengesellschaft auf dem Wege der vorübergehenden Aufnahme des Verkäufers als Gesellschafter. Dieser bringt das Grundstück in die Gesellschaft ein (grunderwerbsteuerfreier Vorgang) und scheidet kurz darauf gegen eine Abfindung als Gesellschafter wieder aus. Ein anderes Beispiel ist die Grundstücksübertragung von einem Ehepaar auf ein anderes mittels Gründung einer BGB-Gesellschaft durch das Verkäuferehepaar, Aufnahme der Käufer in die Gesellschaft und anschließendem Ausscheiden der ursprünglichen Gesellschafter gegen eine Abfindung. In beiden Fällen ist der BFH in seinen Entscheidungen vom Mai $1978^{2}$ und Februar $1980^{3}$ von Rechtsmißbrauch ausgegangen, doch können leichte Variationen derartiger Gestaltungen durchaus zur steuerlichen Anerkennung führen. ${ }^{4}$

\subsubsection{Reformvorschläge}

Der Steuerumgehung mittels Umwandlung zu versteuernder Einkommensbestandteile in steuerbegünstigte Einkünfte ist insbesondere durch eine umfassende EStBemessungsgrundlage ohne ungerechtfertigte Aussparung oder Begünstigung bestimmter Einkommensteile beizukommen.

Gegen das oben beschriebene bond-washing hilft die in Deutschland bereits existierende Stückzinsenbesteuerung.

Entsprechend könnte gegen das Dividendenstripping durch eine „Stückdividenden"-Besteuerung, d.h. durch eine Besteuerung der anteilig bis zum Verkaufstermin aufgelaufenen Dividende vorgegangen werden. Problematisch wäre hierbei die Handhabung eines Verkaufs von Aktien weit vor dem Ausschüttungstermin, wenn die kommende Dividende weder rechtlich noch faktisch feststeht. Die Besteuerung von "Stückdividenden" wäre aber ohnehin nicht erforderlich, wenn eine lückenlose Besteuerung realisierter capital gains vorgenommen würde. Soweit die aufgelaufenen Dividenden in den Aktienkursen enthalten sind, würde ein Verkauf zur Versteuerung des Kursgewinns und damit der „Stückdividende“ führen. Auf S. 210 f. war die Besteuerung unrealisierter capital gains als vorteilhaft sowohl im Kampf gegen die Steuerumgehung als auch zur Verwirklichung horizontaler Gerechtigkeit erkannt worden. Die dort angefuihrten, m.E. lösbaren

${ }^{1}$ Für eine systematische Übersicht vgl. FISCHER in HHSp (1996) Rz. $281 \mathrm{ff}$.

${ }^{2} \mathrm{Vgl}$. BFH-Urteil vom 31.5.1978 II R 53/76 BStBl. 1978 II S. $577 \mathrm{ff}$.

${ }^{3} \mathrm{Vgl}$. BFH-Urteil vom 13.2.1980 II R 18/75 BStBI. 1980 II S. $364 \mathrm{f}$.

${ }^{4}$ Entsprechende Hinweise unter Berufung auf ergangene Entscheidungen der Gerichtsbarkeit finden sich bei KOTTKE (1994) S. $453 \mathrm{ff}$. 
Probleme treten bei einer Besteuerung realisierter Wertsteigerungen nicht auf, so $\mathrm{da} ß$ die Besteuerung letzterer erst recht erstrebenswert ist. Eine umfassende Besteuerung sowohl realisierter als auch unrealisierter capital gains wäre nicht nur wirksam gegen das Dividendenstripping, sondern würde ganz allgemein die Steuerumgehung durch Umwandlung zu versteuernder Einkünfte in capital gains verhindern. Um inflationsbedingte Scheingewinnbesteuerung zu verhindern, sollten allerdings nur reale Wertsteigerungen der Einkommensteuer unterliegen.

Bond-washing und dividend-stripping basieren darauf, daß es Steuerpflichtige gibt, die einem niedrigeren Steuersatz unterliegen als die Steuerumgehung betreibenden Wertpapierhalter. Andernfalls würden sich kurz vor Ausschüttungstermin keine Käufer finden, die bereit wären, die Papiere zu einem vorteilhaften Kurs zu übernehmen. Insofern ließe sich den geschilderten Methoden auch durch Einführung der in Kap. 6.2.2.2 beschriebenen flat-rate tox beikommen.

Insgesamt gilt für die Steuerumgehung durch Einkommensumwandlung, daß ihr durch eine synthetische Einkommensteuer mit umfassender Bemessungsgrundlage und einheitlichem Steuersatz wirksam begegnet werden kann. Unterschiedliche Steuersätze je nach Einkunftsart (Schedulensteuer) oder je nach Person der Steuerpflichtigen (direkte Progression) sollten ebenso wenig existieren wie eine Aussparung bestimmter Einkommensteile wie Schenkungen oder capital gains.

Der auf S. 213 beschriebene Fall der Umwandlung steuerlich irrelevanter Unterhaltsaufwendungen in abzugsfähige Zinsaufwendungen ist in Deutschland in dieser Form nicht mehr möglich, seit die Kreditzinsen privater Haushalte nicht mehr als Sonderausgaben von der ESt-Bemessungsgrundlage abzugsfähig sind. Da betriebliche Schuldzinsen nach wie vor steuerlich relevant sind, wäre die Umwandlung von Unterhaltsleistungen in Betriebsausgaben aber weiterhin durchfuhrbar. Der Fehler liegt in der fehlenden oder nur partiellen Versteuerungspflicht empfangener Unterhaltsleistungen und Zinsen ${ }^{1}$ in Verbindung mit einer auf Empfängerseite niedrigeren marginalen Steuerbelastung als auf der Geberseite. Es spräche nichts dagegen, die in $\S 12 \mathrm{Nr}$. 2 EStG genannten geldlichen Zuwendungen, also auch Zahlungen an Unterhaltsberechtigte, zu abzugsfähigen Aufwendungen zu erklären, wenn diese Zahlungen bei der empfangenden Person als Einkommen steuerpflichtig wären. Voraussetzung sollte erneut ein einheitlicher Grenzsteuersatz für alle Steuerpflichtigen sein. In diesem Fall würde die gekünstelte Konstruktion abzugsfähiger Aufwendungen zu einer Steuerersparnis führen, die nicht höher läge als die zusätzliche Steuerbelastung beim Tansferempfänger. $\S 12 \mathrm{Nr}$. 1 und 2 EStG könnten gestrichen werden; das Motiv für die Umwandlung von Unterhaltsleistungen in

${ }^{1}$ Der in $§ 20$ Abs. 4 EStG kodifizierte Sparer-Freibetrag von DM 6.000 stellt einen erheblichen Anteil der Zinsempfänger faktisch steuerfrei. Um eine Gleichbehandlung der Einkunftsarten zu erreichen, müßte dieser Freibetrag erheblich gesenkt werden. Im Ausgleich wäre die Umstellung auf eine Realzinsbesteuerung angebracht (vgl. hierzu auch oben S. 182). 
andere Aufwendungen entfiele damit, ohne daß dies Mindereinnahmen für den Fiskus mit sich bringen würde.

Die Transformation von Umsätzen hat ihre Ursache in unterschiedlichen Steuersätzen, Freistellungen und Einschränkungen des Vorsteuerabzugs.

Im geschilderten Beispiel der mißbräuchlichen Zwischenvermietung von Wohnraum hat der Gesetzgeber mit seinen mehrfachen Wortlautverbesserungen des den Verzicht auf Steuerbefreiung regelnden $\S 9$ UStG die Ursache derartiger Gestaltungen nicht beseitigt. Der ökonomische Fehler liegt zum einen in der Freistellung der Vermietung und Verpachtung von der Umsatzsteuer, zum anderen im Ausschluß steuerbefreiter Umsätze vom Vorsteuerabzug.

Wenn einzelne steuerbare Umsätze von der Besteuerung befreit sind, so besteht immer die Gefahr mißbräuchlicher Inanspruchnahme der Befreiung. Will der Staat eine zu hohe Belastung der Mieter verhindern, so sollte er das Ziel, daß für jedermann bezahlbarer Wohnraum zur Verfugung steht, durch sozialen Wohnungsbau, Wohngeld oder allgemeines Bürgergeld (negative Einkommensteuer) zu erreichen suchen statt durch eine systemwidrige Steuerbefreiung. ${ }^{1}$

Selbst wenn man die Steuerfreiheit bestimmter Umsätze akzeptiert, liegt derzeit ein Fehler im System vor: Wenn die Umsatzsteuer den Endverbrauch belasten und der Verbrauch bestimmter Güter und Leistungen mittels einer USt-Befreiung unbelastet bleiben soll, so wird dieses (meist sozialpolitisch motivierte) Ziel verfehlt, wenn die Steuerbefreiung mit einem Ausschluß vom Vorsteuerabzug einhergeht. ${ }^{2}$ Der Unternehmer wird die aufgelaufene Umsatzsteuer ebenso auf den Endpreis überwälzen wie sonst auch. Der Vorsteuerabzug sollte deshalb auch in solchen Fällen nicht verwehrt werden.

Zusätzlich zur Abschaffung systemwidriger Steuerfreiheit bestimmter Umsätze und der Gewährung des Vorsteuerabzugs auch dort, wo eine Umsatzsteuerbefreiung zwecks Verbilligung des Endverbrauchs unverzichtbar erscheint, sollte zur Eindämmung der mißbräuchlichen Umgehung von Umsatzsteuer auch die Existenz unterschiedlicher Steuersätze beseitigt werden. Das derzeitige Nebeneinander steuerfreier, steuerermäßigter und voll besteuerter Umsätze führt zwangsläufig zu Steuerausweichhandlungen, von denen ein Teil immer rechtsmißbräuchlich sein wird. Die durch die Verbilligung bestimmter Güter und Dienstleistungen angestrebte sozialpolitische Zielsetzung ließe sich wesentlich zielsicherer durch eine negative Einkommensteuer in angemessener Höhe erreichen.

Die Grunderwerbsteuer sollte in die Umsatzsteuer integriert werden. Da sich die GrESt ohnehin nur als Ergänzung zur USt, welche Grundstücksumsätze nicht er-

\footnotetext{
${ }^{1} \mathrm{Vgl}$. SCHNEIDER (1985) S. $350 \mathrm{f}$.

${ }^{2}$ Vgl. HABERSTOCK/BREITHECKER (1996) S. 100.
} 
faßt, rechtfertigen läßt, ${ }^{1}$ besteht kein Grund, sie als gesonderte Steuer beizubehalten. $^{2}$ Die steuerliche Belastung von Grundstücksumsätzen würde damit zwar auf derzeit $15 \%$ erhöht, doch wäre diese Steuer für Unternehmen als Vorsteuer anrechenbar. Umsätze zwischen privaten Haushalten wären steuerfrei. Die Unternehmen im Ergebnis von der Steuer freizustellen wäre systemkonform, da der Grunderwerb durch Betriebe als Investition zu sehen ist und die Umsatzsteuer den Konsum und nicht die Investitionen belasten soll. Die Freistellung des Eigentumswechsels zwischen privaten Haushalten wäre wohlfahrtssteigernd, da die Besteuerung der Übertragung dauerhafter Konsumgüter Transaktionen verhindern kann, welche für beide beteiligten Parteien zu einem Nutzenzuwachs führen würden.

Im Gegensatz zur Grunderwerbsteuer kann die Versicherungsteuer m.E. problemlos in ihrer derzeitigen Form beibehalten werden. Sie ist wenig anfällig für Steuerumgehungen, ${ }^{3}$ und ihr Steuersatz wurde mittlerweile dem Normalsatz der allgemeinen Umsatzsteuer angeglichen.

\subsection{Steuerarbitrage}

\subsubsection{Formen der Steuerarbitrage}

Steuerarbitrage i.e.S. bezeichnet die Geldanlage in steuerbefreiten oder steuerbegünstigten Anlageformen, wobei den Erträgen steuerlich abzugsfähige Finanzierungs- oder andere Kosten gegenüberstehen. ${ }^{4}$

STIGLITZ beschreibt, ohne Anspruch auf Vollständigkeit zu erheben, drei Methoden der Steuerarbitrage:

Methode 1 führt zur Realisierung von capital losses bei gleichzeitiger Erzielung von capital gains, deren Realisierung hinausgezögert oder ganz vermieden wird:

Der Kauf von Wertpapieren wird so mit dem Erwerb von Verkaufsoptionen über dasselbe oder ein eng korreliertes Wertpapier kombiniert, daß Kursgewinne bei

${ }^{1}$ Vgl. MUSGRAVE/MUSGRAVE/KULLMER (1993) S. 358; HABERSTOCK/BREITHECKER (1996) S. 103; TIPKE (1993) S. 1024.

${ }^{2}$ In ihrer derzeitigen Form ist die GrESt als Brutto-Umsatzsteuer (mit Kumulativwirkung) auf Grundstücke anzusehen, welche Investitionen belastet und Eigentumswechsel zwischen Konsumenten behindert.

${ }^{3}$ Weder im Rechtsprechungsüberblick bei GUNTHER (1987) noch in den AO-Kommentaren von HÜBSCHMANN/HEPP/SPITALER und TIPKE/KRUSE finden sich Beispiele für die Umgehung von Versicherungsteuer. Lediglich KOTTKE (1994) S. 466 f. beschreibt einen Fall aus dem Jahr 1964, der jedoch vom BFH zu Recht als legale Steuervermeidung angesehen wurde.

${ }^{4}$ Vgl. RAAB (1992) S. 417. Die bisweilen ebenfalls als Steuerarbitrage bezeichnete interpersonelle Übertragung von Einkommen fällt nicht unter diese enge Definition. 
dem einen Papier von in etwa gleich hohen Kursverlusten bei dem anderen Papier begleitet werden. Am Jahresende wird der eine Teil der Finanzinvestition im Wert gestiegen, der andere Teil entsprechend gesunken sein. Der Kursverlust wird realisiert und zum Ausgleich für andere, positive Einkünfte verwendet. Von dem dabei erzielten Verkaufserlös werden Wertpapiere erworben, die den verkauften Papieren möglichst exakt entsprechen, so daß die Nettoposition des Anlegers unverändert bleibt. Am Ende steht eine Steuerersparnis, ohne daß die Anlage ein Risiko beinhaltet. ${ }^{1}$

Voraussetzung für das Funktionieren dieser Methode ist die Möglichkeit, capital losses steuerlich geltend zu machen.

Zudem ergibt sich nur dann eine Steuerersparnis, wenn sich die Kurse der erworbenen Papiere tatsächlich verändern. Je nach Ausmaß der Kursschwankungen und je nach persönlichem Steuersatz fällt die Steuerersparnis unterschiedlich hoch aus, und es ist zu prüfen, ob die Minderung der Steuerlast tatsächlich höher liegt als der mögliche Renditevorsprung einer Alternativanlage ohne Steuertricks.

Schließlich bedeuten auch Unvollkommenheiten im Kapitalmarkt eine Einschränkung für derartige Transaktionen: In der Praxis ist nicht gewährleistet, daß zu jedem Wertpapier perfekt positiv oder negativ korrelierte Wertpapiere existieren.

Methode 2 nutzt die unterschiedliche steuerliche Behandlung kurzfristiger Spekulationsgewinne und langfristig realisierter capital gains aus:

Erneut wird der Kauf von Wertpapieren mit dem Erwerb von Verkaufsoptionen über dasselbe oder ein eng korreliertes Wertpapier kombiniert, wobei Kursgewinne bei dem einen Papier mit entsprechenden Kursverlusten bei dem anderen Papier einhergehen. Kurz vor Ende der Spekulationsfrist wird der Verlust realisiert, unmittelbar nach Ablauf der Frist dasjenige Wertpapier verkauft, welches einen Gewinn aufweist. ${ }^{2}$

Die Voraussetzungen für den tatsächlichen Erfolg dieser Methode sind im wesentlichen dieselben wie bei Methode 1.

Methode 3 besteht in dem kreditfinanzierten Erwerb von Anlagegütern, deren Erträge ganz (z.B. Edelmetalle) oder teilweise (z.B. unterhalb des Rückzahlungskurses notierte Anleihen) als capital gains anfallen. ${ }^{3}$

Diese Methode führt zu einer Steuerersparnis, sofern Kreditzinsen steuerlich abzugsfähig und capital gains steuerlich begünstigt oder ganz von der Steuer befreit sind. Sie ist nur dann frei von Risiken, wenn die Wertsteigerungen bei den erworbenen Aktiva tatsächlich gesichert sind. Dies ist bei der von STIGLITZ als Beispiel

\footnotetext{
${ }^{1} \mathrm{Vgl}$. STIGLITZ (1985) S. 327.

${ }^{2} \mathrm{Vgl}$. ebenda.

${ }^{3} \mathrm{Vgl}$. ebenda S. 328.
} 
gewählten Anlage in Gold nicht der Fall. ${ }^{1}$ Methode 3 ist ferner nur dann lohnend, wenn die (Netto-)Rendite der Anlagegüter höher liegt als der Sollzinsfuß nach Steuern. Dies wird in der Praxis erst ab einem bestimmten Grenzsteuersatz der Fall sein. STIGLITZ selbst weist ferner darauf hin, daß Methode 3 nur dann zu Aufkommensverlusten beim Staat führt, falls die Kreditgeber einem niedrigeren Grenzsteuersatz unterliegen als die Kreditnehmer. Andernfalls steht der mit den Sollzinsen verbundene Steuerersparnis eine an anderer Stelle entsprechend höhere Steuerlast gegenüber. ${ }^{2}$ (Zwar führt die Geldanlage in Güter, deren Erträge als capital gains anfallen, in jedem Fall zu Steuermindereinnahmen des Staates; doch sind letztere davon unabhängig, ob Steuerarbitrage betrieben wird oder ob simple Steuervermeidung durch Berücksichtigung der Besteuerung bei der Anlageentscheidung vorliegt.)

\subsubsection{Reformvorschläge}

Steuerarbitrage basiert immer auf der steuerlichen Begünstigung bestimmter Einkünfte i.V.m. der Abzugsfähigkeit der zugehörigen Ausgaben. Um diese Form der Steuerumgehung zu unterbinden, muß daher entweder eine lückenlose Besteuerung sämtlicher Einkünfte mit einem einheitlichen Steuersatz unabhängig von der Einkunftsart erfolgen, oder es müssen diejenigen Ausgabenarten, welche mit derartigen Arbitragegeschäften üblicherweise verbunden sind (Kreditzinsen, capital losses), steuerlich ignoriert werden.

Eine Nichtabzugsfähigkeit von Sollzinsen und Wertminderungen wirft in den international üblichen Steuersystemen erhebliche Probleme auf: Solange derartige Aufwendungen im Unternehmenssektor abzugsfähig sind, führt ihre Nichtanerkennung im privaten Sektor nahezu zwangsläufig zu Steuerumgehung durch Ausgabenverlagerungen von privaten Haushalten auf die betriebliche Ebene (vgl. hierzu den folgenden Abschnitt). Würden diese Ausgaben hingegen sowohl bei den Haushalten als auch bei den Unternehmen für steuerlich unbeachtlich erklärt, so bedeutete dies den Übergang zu einem cash-flow-Steuersystem. ${ }^{3}$ Die Aufgabe der Körperschaftsteuer zugunsten einer cash-flow-Steuer würde jedoch eine radikale Umgestaltung des Steuersystems mit sich bringen, die einer solchen Maßnahme in absehbarer Zeit kaum eine Realisierungschance läßt. ${ }^{4}$ Neben erheblichen Über-

${ }^{1}$ Sicher sind Wertsteigerungen hingegen bei Zero-Bonds. Da jedoch die im Zeitablauf garantierten Kursgewinne bei Nullkuponanleihen unter anderem in Deutschland steuerlich wie am Laufzeitende ausgeschüttete Zinsen behandelt werden, empfiehlt RAAB statt dessen niedrig verzinste Optionsanleihen ohne Schein, deren Kurs meist deutlich unter pari liegt. Vgl. RAAB (1992) S. $418 \mathrm{f}$.

${ }^{2}$ Vgl. STIGLITZ (1985) S. 330.

${ }^{3}$ Vgl. hierzu RAAB (1992) S. $428 \mathrm{f}$.

${ }^{4}$ gl.A.: CANSIER (1989) S. 54. 
gangsproblemen bei Einführung einer solchen Maßnahme käme es in Anbetracht der engen weltwirtschaftlichen Verflechtungen zu Verzerrungen insb. bei der Besteuerung multinationaler Konzerne, wenn in einigen Staaten der Jahresüberschuß, in anderen der cash flow Besteuerungsgrundlage wäre. Eine Bekämpfung der Steuerarbitrage mittels Nichtabzugsfähigkeit sämtlicher hierfür relevanter Ausgaben scheidet daher derzeit als praktisch nicht umsetzbarer Reformvorschlag aus der Diskussion aus. Da eine konsequente Ausgestaltung der Einkommensteuer nach dem Reinvermögenszugangsprinzip hier denselben Zweck erfullt, wird in dieser Arbeit auf die cash-flow-Steuer nicht näher eingegangen. ${ }^{1}$

Alle in Kap. 6.5.1 beschriebenen Methoden basieren auf der steuerlichen Begünstigung von capital gains. ${ }^{2}$ Bereits in Kap. 6.3.2 und 6.4.4 war die Wichtigkeit einer möglichst lückenlosen Besteuerung realisierter und unrealisierter Wertsteigerungen für eine effektive Bekämpfung der Steuerumgehung hervorgehoben worden. Auch bzgl. der Steuerarbitrage zeigt sich die ausschlaggebende Bedeutung, die einer umfassenden Einkommensteuer-Bemessungsgrundlage nach SCHANZ-HAIG-SIMONS zukommt. Steuerarbitrage ist dann nicht mehr möglich, wenn fur alle Einkunftsarten, insbesondere auch für alle capital gains, ein einheitlicher Steuersatz gilt. Die Verwirklichung des Reinvermögenszugangsprinzips bei der Einkommensbesteuerung dient demnach nicht nur der horizontalen Gerechtigkeit, sondern führt - bei vollständiger Umsetzung - zu einer lückenlosen Beseitigung sämtlicher Möglichkeiten zur Steuerumgehung durch Steuerarbitrage.

\subsection{Einkommens- oder Vermögensverlagerung zwischen be- trieblicher und privater Ebene}

\subsubsection{Besonderheiten der Unternehmensbesteuerung}

Eine neben der Personenbesteuerung bestehende selbständige Besteuerung der Unternehmen entspricht der Praxis sämtlicher Industrienationen. Insbesondere die Körperschaftsteuer wird im allgemeinen als unverzichtbar angesehen, da ihr eine Ergänzungsfunktion zur Einkommensteuer insofern zukommt, als andernfalls die von der Einkommensteuer nicht erfaßten thesaurierten Gewinne der Kapitalgesellschaften unbesteuert blieben. Unterscheidet sich die Unternehmensbesteuerung in Steuersatz oder Bemessungsgrundlage von der Besteuerung natürlicher Personen, so ist es für die Steuerpflichtigen nicht gleichgültig, ob bestimmte Erträge, Auf-

\footnotetext{
${ }^{1} \mathrm{Zu}$ Einzelheiten der cash-flow-Besteuerung vgl. ebenda S. $49 \mathrm{ff}$.

${ }^{2}$ RAAB (1992) S. 421 verweist ferner auf die in Deutschland bestehende Möglichkeit zur Steuerarbitrage mit Hilfe einer Kapitallebensversicherung, welche mit einem Immobiliendarlehen gekoppelt wird. Die ökonomisch ohnehin nicht zu rechtfertigende Freistellung der Ertrăge aus Lebensversicherungen (ab zwölf Jahren Laufzeit) von der Besteuenung sollte auch unter diesem Gesichtspunkt beseitigt werden.
} 
wendungen, Vermögensgegenstände oder Verbindlichkeiten der betrieblichen oder der privaten Sphäre zugeordnet werden. Der Versuch, die Steuerlast durch entsprechende Umschichtungen zu mindern, liegt nahe.

Auch in Deutschland besteht keine Identität zwischen der Besteuerung betrieblichen und privaten Einkommens (bzw. Vermögens):

Die Gewinne der Kapitalgesellschaften unterliegen der Körperschaftsteuer mit einem Steuersatz von z.Zt. $45 \%$ auf thesaurierte Gewinne.

Personengesellschaften sind von dieser Steuer nicht betroffen; die Gewinne werden den Gesellschaftern zugerechnet und unterliegen dort (wie auch die ausgeschütteten Gewinne der Kapitalgesellschaften) der persönlichen Einkommensteuer mit einem ansteigenden Grenzsteuersatz von $0-47 \%$ für gewerbliche bzw. $0-53 \%$ für sonstige Einkünfte.

Unabhängig von der Rechtsform werden Gewerbebetriebe ferner mit Gewerbeertragsteuer belastet, wobei der effektive Steuersatz wegen der Hebesatzautonomie der Gemeinden regionale Unterschiede aufweist.

Nicht aus unternehmerischer Tätigkeit stammendes Einkommen privater Haushalte wird lediglich von der progressiven Einkommensteuer (Grenzsteuersatz: 0-53\%) erfaßt.

Eine weitere Besonderheit der Unternehmensbesteuerung liegt in der Abzugsfähigkeit insb. von Schuldzinsen und capital losses, welche auf privater Ebene durch $\S 9$ Abs. 1 bzw. $§ 23$ Abs. 3 Satz 4 EStG eingeschränkt ist. Demgegenüber sind Zinserträge und realisierte Wertsteigerungen auf betrieblicher Ebene voll steuerpflichtig, während für private Haushalte der Sparer-Freibetrag des $\S 20$ Abs. 4 EStG einen Teil der Zinserträge steuerfrei stellt und Wertsteigerungen nur unter den Einschränkungen des $\S 23$ Abs. 1 und Abs. 3 Satz 3 EStG zu einer Besteuerung führen.

Das Vermögen natürlicher Personen wird mit 1\% (ermäßigter Steuersatz unter anderem für Betriebsvermögen 0,5\%) Vermögensteuer belegt. Zusätzlich unterliegt das Vermögen der Kapitalgesellschaften einer betrieblichen Vermögensteuer von $0,6 \%$. Des weiteren werden Gewerbebetriebe jeder Rechtsform mit Gewerbekapitalsteuer belastet (effektiver Steuersatz hebesatzabhängig).

\subsubsection{Möglichkeiten von Einkommens- und Vermögensverschiebun- gen zwischen betrieblicher und privater Ebene}

Resultierend aus den dargestellten Abweichungen der betrieblichen von der Haushaltsbesteuerung, betreffen rechtsmißbräuchliche Einkommens- und Vermögensverlagerungen zwischen betrieblicher und privater Ebene in Deutschland vor allem 
- das Verlagern von Einkünften von der betrieblichen auf die private Ebene zwecks Einsparung von Gewerbeertragsteuer,

- die Umwandlung privater Schulden in Betriebsschulden vor allem, um Schuldzinsen als Betriebsausgabe geltend machen zu können,

- die Verlagerung von Vermögensgegenständen von der Unternehmens- auf die private Ebene zur Einsparung von Gewerbekapitalsteuer und ggf. betrieblicher Vermögensteuer.

Ein die Rechtsprechung des öfteren beschäftigendes Beispiel für Einkunftsverlagerungen von der betrieblichen auf die private Ebene bilden die sogenannten Ehegatten-Arbeitsverträge. Stellt beispielsweise ein Gewerbetreibender seine Ehefrau als abhängig Beschäftigte in seinem Betrieb ein, so mindern die Gehaltszahlungen den steuerpflichtigen Gewerbeertrag und damit die Belastung mit $\mathrm{Ge}$ werbesteuer. Liegt das Gehalt höher, als es für die tatsächlich geleistete Arbeit üblich und angemessen wäre, so wird aus der mit der Einstellung verbundenen, an sich zulässigen Steuervermeidung eine mißbräuchliche Steuerumgehung. Entsprechend hat der Bundesfinanzhof die steuerliche Anerkennung von Arbeitsverträgen zwischen Ehegatten u.a. davon abhängig gemacht, ob die vertragliche Gestaltung und Durchführung einem Fremdvergleich standhält. ${ }^{1}$ Ferner müssen die Vertragsbedingungen klar und eindeutig festgelegt und tatsächlich durchgeführt werden. ${ }^{2}$ Die Gehaltszahlungen müssen auf ein Konto des angestellten Ehegatten (kein Gemeinschaftskonto) geleistet werden, ${ }^{3}$ wobei es unerheblich ist, was anschließend mit dem Geld geschieht ${ }^{4}$ und ob der Arbeitgeber-Ehegatte eine Vollmacht für dieses Konto besitzt. ${ }^{5}$ Stellen Ehegatten, die beide einen Gewerbebetrieb unterhalten, sich gegenseitig ein, so werden die Arbeitsverträge steuerlich nur dann anerkannt, wenn es sich um kurzfristige oder Teilzeitarbeitsplätze handelt und die Vertragsbedingungen der unter Fremden üblichen Ausgestaltung vergleichbar sind. ${ }^{6}$

Insgesamt macht die BFH-Rechtsprechung den Steuerpflichtigen die Steuerumgehung durch Ehegatten-Arbeitsverträge relativ einfach: Es müssen nur normale, ,angemessene“ Arbeitsverträge erstellt werden, deren Realisierung nicht von vornherein unglaubwürdig ist, und das Geld muß auf ein Konto fließen, das unabhängig von der geplanten Geldverwendung auf den Namen des abhängig beschäftigten

\footnotetext{
${ }^{1}$ Vgl. BFH-Urteil vom 14.10.1981 I R 34/80 BStBl. 1982 II S. 119 ff.

${ }^{2}$ Vgl. BFH-Urteil vom 26.9.1968 IV 121/64 BStB1. 1969 II S. 102.

${ }^{3} \mathrm{Vgl}$. BFH-Beschluß vom 27.11.1989 GrS 1/88 BStBl. 1990 II S. $160 \mathrm{ff}$.

${ }^{4}$ Selbst eine Schenkung an den Arbeitgeber-Ehegatten ist unschädlich; vgl. BFH-Urteil vom 4.11.1986 VIII R 82/85 BStBl. 1987 II S. 336 ff.

${ }^{5}$ Vgl. BFH-Urteil vom 16.1.1974 I R 176/72 BStBl. 1974 II S. 294 f.

${ }^{6}$ Vgl. KOTTKE (1994) S. 175 unter Berufung auf die BFH-Rechtsprechung.
} 
Ehegatten lautet. $\mathrm{Ob}$ die vertraglich festgesetzte Arbeitszeit dann tatsächlich eingehalten wird, kann von den Finanzämtern kaum nachgeprüft werden. ${ }^{1}$

Ebenso wie die Verlagerung von Einkünften von der betrieblichen auf die private Ebene zur Einsparung von Gewerbeertragsteuer führt, gilt dasselbe naturgemäß auch für die Verlagerung von Ausgaben von der privaten auf die betriebliche Ebene. Besonders lohnend sind solche Umschichtungen, wenn es sich um Ausgaben handelt, die im Unternehmen als Betriebsausgaben den steuerpflichtigen Gewinn mindern, bei privaten Haushalten hingegen steuerlich irrelevant sind. In diesem Fall kommt es neben der Gewerbesteuerersparnis auch zu einer Minderbelastung an Einkommen- bzw. Körperschaftsteuer. Ein Beispiel für Ausgaben dieser Art sind Schuldzinsen, welche bei privaten Haushalten seit 1974 nur noch als Werbungskosten mit positiven Einkünften verrechenbar sind, soweit sie mit der betreffenden Einkunftsart in einem wirtschaftlichen Zusammenhang stehen. Schuldzinsen für Konsumentenkredite sind hingegen nicht mehr abzugsfähig. Versuche einer Umqualifizierung in betriebliche Schuldzinsen werden seitdem immer wieder unternommen.

KOTTKE $^{2}$ empfiehlt Freiberuflern und Gewerbetreibenden, zur Verlagerung von Zinsaufwendungen in den betrieblichen Bereich zwei Kontokorrentkonten einzurichten, ein privates und ein betriebliches Konto. Auf letzterem werden alle Betriebsausgaben abgewickelt, während die Einnahmen, soweit für die private Lebensfuhrung benötigt, dem Privatkonto als Entnahmen aus dem Betriebsvermögen zugeführt werden. Auf diese Weise läßt sich ein Debetsaldo auf dem Privatkonto vermeiden; alle Verbindlichkeiten befinden sich auf dem betrieblichen Kontokorrentkonto, sämtliche Sollzinsen sind gewinnmindernde Betriebsausgaben. Der Große Senat des BFH hat in einer Entscheidung von 1990 derartige Gestaltungen ausdrücklich für zulässig erklärt. ${ }^{3}$ Eine betriebliche Kreditaufnahme zur direkten Finanzierung von Entnahmen wird nach neuerer BFH-Rechtsprechung hingegen nicht anerkannt. ${ }^{4}$ Steuerpflichtigen ist deshalb $\mathrm{zu}$ raten, Barentnahmen wie oben beschrieben aus betrieblichen Einnahmen zu finanzieren; die anschließende Kreditfinanzierung betrieblicher Aufwendungen wird steuerlich nicht beanstandet. ${ }^{5}$

${ }^{1}$ Hier bewegt man sich allerdings schon an der Grenze zur Steuerhinterziehung. Gerade auf dem Gebiet der Abgrenzung privaten Einkommens von geschäftlichem Einkommen ist der Grad zwischen Steuerumgehung und -hinterziehung sehr schmal. Vgl. auch SANDFORD in COLLARD/LECOMBER/SLATER (1980) S. 153.

${ }^{2}$ Vgl. KOTTKE (1994) S. $362 \mathrm{ff}$.

${ }^{3} \mathrm{Vgl}$. BFH-Beschluß vom 4.7.1990 GrS 2-3/88 BStBl. 1990 II S. 817 [829 f.].

${ }^{4} \mathrm{Vgl}$. BFH-Urteil vom 5.3.1991 VIII R 93/84 BStBl. 1991 II S. 516 ff.

${ }^{5}$ Vgl. BFH-Beschluß vom 4.7.1990, a.a.O., S. 825. 
Die Verlagerung von Vermögen von der betrieblichen auf die private Ebene dient vor allem der Ersparung von Gewerbekapitalsteuer, bei Kapitalgesellschaften auch von Vermögensteuer.

Eine gebräuchliche Form mißbräuchlicher Vermögensverlagerungen stellt die $\mathrm{Be}$ einflussung von Stichtagswerten dar: Durch Übernahme von Teilen des betrieblichen Vermögens in das Privatvermögen vor dem Bewertungsstichtag und anschließender Wiedereinlage in das Unternehmen kommt es zu einer vorübergehenden Minderung des zu versteuernden Betriebsvermögens und Gewerbekapitals. Erfolgt die Entnahme direkt am Jahresende und wird das entnommene Vermögen bereits Anfang Januar des folgenden Jahres wieder eingelegt, so erkennen Finanzbehörden und -gerichtsbarkeit regelmäßig auf Rechtsmißbrauch i.S.v. § $42 \mathrm{AO} .{ }^{1}$ Der Fall wird jedoch um so schwieriger zu beurteilen sein, je länger der Zeitraum zwischen Entnahme und Wiedereinlage wird: Ab einer gewissen, von den Steuerpflichtigen noch auszutestenden Zeitspanne dürfte der unmittelbare Zusammenhang zwischen den beiden gegenläufigen Vermögenstransfers den Finanzgerichten weniger eindeutig erscheinen und der Nachweis einer Steuerumgehung den Finanzämtern schwerer fallen.

\subsubsection{Reformvorschläge}

Die Schwierigkeit zu entscheiden, was als persönliche Ausgabe und was als Betriebsausgabe anzusehen ist, bietet ein weites Betätigungsfeld furr Steuerumgeher, solange die Besteuerung der Unternehmen wesentlich von der Besteuerung privater Haushalte abweicht. Es gibt ein kontinuierliches Spektrum von den betrieblichen zu den privaten Ausgaben, und die Grenzen sind fließend. ${ }^{2}$ Entsprechend gehen auch Steuervermeidung und Steuerumgehung gerade auf diesem Gebiet nahtlos ineinander über, so daß eine tendenziell steuerzahlerfreundliche Rechtsprechung den Steuerpflichtigen viele Möglichkeiten eröffnet, durch geschickte Rechtskonstruktionen Steuern zu umgehen. Eine Harmonisierung von Unternehmens- und Individualbesteuerung würde jedoch derartige Gelegenheiten zur Steuerumgehung erheblich reduzieren.

Für die Bundesrepublik Deutschland empfiehlt sich zunächst eine Abschaffung der Gewerbesteuer. ${ }^{3}$ Diese Steuer stellt eine sachlich nicht gerechtfertigte Sonderabga-

${ }^{1} \mathrm{Vgl}$. BFH-Urteil vom 18.12.1968 III R 71/68 BStBl. 1969 II S. 232 f.; BFH-Urteil vom 6.3.1985 II R 240/83 BStBl. 1985 II S. $494 \mathrm{ff}$.

${ }^{2} \mathrm{Vgl}$. KAY in COLLARD/LECOMBER/SLATER (1980) S. 143.

${ }^{3}$ Die damit verbundenen Einnahmenausfalle ließen sich teilweise ausgleichen, indem der ermäBigte Spitzensteuersatz der ESt sowie der Korperschaftsteuersatz auf einbehaltene Gewinne dem normalen Spitzensteuersatz wieder angeglichen würden. Verbleibenden Mindereinnahmen könnte durch eine Anhebung der USt begegnet, die Kommunen sollten je nach in der Gemeinde 
be auf eine bestimmte Art der Einkommenserzielung dar und führt nicht nur zu Steuerumgehung, sondern auch zu unerwünschter Steuervermeidung durch eine Reduzierung gewerblicher Aktivitäten oder durch Abwanderung von Kapital und Arbeitsplätzen in Staaten, welche auf eine solche Sonderbelastung verzichten. Mit Abschaffung der Gewerbeertragsteuer würde der Hauptanreiz für EhegattenArbeitsverhältnisse und andere Versuche, betriebliche Erträge in den privaten Bereich zu verschieben, verschwinden. Die Abschaffung der Gewerbekapitalsteuer würde die mißbräuchliche Verlagerung von Betriebsvermögen in das private Vermögen der Unternehmenseigner weniger rentabel machen. Der Anreiz entfiele völlig, wenn zusätzlich die betriebliche Vermögensteuer beseitigt würde, welche ohnehin zu einer ungerechtfertigten Doppelbelastung des Vermögens von Kapitalgesellschaften (Besteuerung sowohl auf Gesellschafts- als auch auf Gesellschafterebene) führt.

Neben der Abschaffung von Gewerbesteuer und betrieblicher Vermögensteuer ist ferner eine Harmonisierung der Bemessungsgrundlage der Einkommensbesteuerung bei Unternehmen und privaten Haushalten zu fordern. Insbesondere ist die Behandlung von Zinsen und Wertänderungen zu vereinheitlichen. So müßte beides sowohl bei den Unternehmen als auch bei den Haushalten möglichst umfassend von der Steuer erfaßt werden. ${ }^{1}$ Dies bedeutete auf der einen Seite eine volle Steuerpflicht von Zinserträgen und capital gains, andererseits aber auch eine uneingeschränkte Abzugsfähigkeit von Zinsaufwendungen und capital losses nicht nur auf betrieblicher, sondern nun auch auf Haushaltsebene. ${ }^{2}$ Die Nichtabzugsfähigkeit von Zinsen auf Konsumentenkredite und im privaten Bereich anfallender capital losses

befindlicher Anzahl der Arbeitsplätze, Summe der Betriebsvermögen oder Höhe der Wertschöpfung an der USt werden. Die derzeit auf dem Hebesatzrecht basierende Finanzautonomie der Gemeinden ließe sich wahren, wenn der Gemeindeanteil an der ESt durch eine von den Gemeinden innerhalb bestimmter Grenzen (z.B. monatlich 80 - 120 DM) autonom festzusetzende Kopfsteuer nach dem Vorbild der früheren britischen poll tax ersetzt würde. Diese wäre durchaus sozial verträglich, wenn eine entsprechend Kap. 6.2.2.2 in Kraft gesetzte negative Einkommensteuer bundesweit um den maximalen Kopfsteuerbetrag erhöht würde. (Die Alternative eines kommunalen Hebesatzrechts auf einen Teil der ESt würde infolge von damit zwangsläufig verbundenen Verstößen gegen die Rechtsform-, Finanzierungs- und Standortneutralität (vgl. die folgenden Kapitel dieser Arbeit) neue Möglichkeiten der Steuerumgehung auftun und ist daher trotz unbestrittener Vorzüge abzulehnen.)

${ }^{1}$ Die Alternative, beides sowohl auf betrieblicher als auch auf privater Ebene steuerlich zu ignorieren, würde zwar mißbräuchlichen Einkommensverlagerungen zwischen beiden Ebenen ebenso wirkungsvoll vorbeugen, wäre jedoch ein wesentlich einschneidenderer Eingriff in die derzeit international übliche Besteuerungspraxis. Wie auf S. $220 \mathrm{f}$. bereits erwähnt wurde, erscheint der Übergang zu einer kombinierten cash-flow- und Konsumbesteuerung z.Zt. nicht realistisch.

${ }^{2}$ Selbstverständlich sollten stets nur die inflationsbereinigten Zinsen und Wertänderungen steuerlich relevant sein, um eine Besteuerung von Scheinertrăgen bzw. eine Abzugsfähigkeit von Scheinverlusten zu vermeiden. 
kann derzeit zwar dazu beitragen, das Ausmaß an Steuerumgehung durch Steuerarbitrage (wie in Kap. 6.5.1 beschrieben) in Grenzen zu halten; doch würde die in Kap. 6.5.2 geforderte konsequente Umsetzung des Reinvermögenszugangsprinzips in der Einkommensbesteuerung die Nichtabzugsfähigkeit derartiger Ausgaben diesbezüglich überflüssig machen. Im übrigen stellt die steuerliche Nichtberücksichtigung von Schuldzinsen und Wertminderungen einen Verstoß gegen das von der Politik und der Rechtswissenschaft sonst so hochgehaltene Leistungsfähigkeitsprinzip dar: Wer Habenzinsen und Wertsteigerungen (zu Recht) als die persönliche Leistungsfähigkeit erhöhend ansieht, kann kaum bestreiten, daß Sollzinsen und Wertverluste die Leistungsfähigkeit vermindern.

Schließlich würde die Neugestaltung der Einkommensteuer als flat-rate tax (vgl. Kap. 6.2.2.2), deren Steuersatz dem Thesaurierungssatz der Körperschaftsteuer entspricht, einen weiteren Unterschied zwischen Unternehmens- und Haushaltsbesteuerung und damit möglichen Anreiz für Einkommensverlagerungen zwischen betrieblicher und privater Sphäre beseitigen.

\subsection{Ausnutzung von VerstöBen gegen die Neutralität der Un- ternehmensbesteuerung}

Verstöße gegen die Besteuerungsneutralität führen im Unternehmenssektor zu Steuervermeidungsreaktionen, welche im allgemeinen volkswirtschaftlich unerwünscht sind. Im Bereich der Unternehmensbesteuerung werden vor allem Rechtsform-, Finanzierungs-, Investitions- und Standortneutralität gefordert. Dabei führt die Nichtexistenz von Rechtsform-, Finanzierungs- und Standortneutralität über legale Steuervermeidung hinaus erfahrungsgemäß auch zu Versuchen, durch mißbräuchliche rechtliche Konstruktionen Steuern zu umgehen. ${ }^{1}$ Während der Einfluß fehlender Standortneutralität auf die Steuerumgehung in Kapitel 6.8 gesondert untersucht werden wird, beschäftigt sich der vorliegende Abschnitt mit den Auswirkungen fehlender Rechtsform- und Finanzierungsneutralität. Verletzungen dieser beiden Formen der Steuerneutralität dürften in fast jedem Staat der Welt existieren; im folgenden wird auf die Situation in Deutschland Bezug genommen, die vor allem durch die Existenz der Gewerbesteuer einige Besonderheiten aufweist.

\footnotetext{
${ }^{1}$ Aus Verstößen gegen die Investitionsneutralităt, welche nicht allein aus fehlender Finanzierungsneutralităt erwachsen, ergeben sich m.E. keine Gelegenheiten zur Steuerumgehung.
} 


\subsubsection{Verstöße gegen die Rechtsform- und Finanzierungsneutralität im deutschen Steuerrecht}

\subsubsection{Verstöße gegen die Rechtsformneutralität}

Die folgenden Ausführungen erheben keinen Anspruch auf Vollständigkeit, doch dürften die meisten in Deutschland bestehenden Aneutralitäten bzgl. der Rechtsformwahl durch sie abgedeckt werden:

Während einbehaltene Gewinne der Kapitalgesellschaften mit $45 \%$ Körperschaftsteuer belastet werden, unterliegen sie bei Personengesellschaften der individuellen Einkommensteuer-Grenzbelastung der Anteilseigner, die je nach Höhe des Gesamteinkommens zwischen 0 und 53\% (Gewerbebetriebe: 0-47\%) liegt.

Eine gesonderte betriebliche Vermögensteuer i.H.v. 0,6\% wird nur von Kapitalgesellschaften erhoben.

Die Gewerbeertragsteuer enthält sowohl Elemente, die Personengesellschaften, als auch solche, die Kapitalgesellschaften begünstigen, wobei sich diese Besteuerungsunterschiede je nach Rechtsform allenfalls zufällig genau ausgleichen:

Kapitalgesellschaften können mit ihren Gesellschaftern Miet- und Darlehensverträge abschließen, wobei der Miet- und Zinsaufwand den Gewerbeertrag mindert. Dasselbe gilt für Arbeitsverträge; insbesondere ist das Geschäftsfuihrergehalt bei Kapitalgesellschaften steuerlich abzugsfähig. Miet-, Darlehens- und Dienstverträge zwischen einer Personengesellschaft und ihren Anteilseignern sind hingegen steuerlich unbeachtlich.

Dafür wird Personengesellschaften für den Gewerbeertrag ein Freibetrag von DM 48.000 eingeräumt.

Ferner beträgt die Steuermeßzahl für den Gewerbeertrag bei Kapitalgesellschaften generell $5 \%$, bei Personengesellschaften ist sie je nach Höhe des Gewerbeertrages von $1-5 \%$ gestaffelt ( $§ 11 \mathrm{Abs}$. $2 \mathrm{GewStG})$.

\subsubsection{Verstöße gegen die Finanzierungsneutralität}

Finanzierungsneutralität bedeutet nicht nur steuerliche Gleichbehandlung von Kredit-, Beteiligungs- und Gewinnfinanzierung, sondern innerhalb der Kreditfinanzierung auch identische Handhabung kurz- und langfristiger Fremdfinanzierung unabhängig von der Person des Kreditgebers.

Wie in Kap. 6.7.1.1 erwähnt, werden jedoch Darlehensverträge zwischen Personengesellschaften und ihren Gesellschaftern steuerlich nicht anerkannt, d.h. die Darlehen der Gesellschafter werden steuerlich wie Einlagen behandelt und die Darlehenszinsen wie ausgeschüttete Gewinne. Damit kommt es zu einer uneinheit- 
lichen Besteuerung der Fremdfinanzierung der Personengesellschaften je nachdem, ob die Darlehensvergabe durch Gesellschafter oder Nicht-Gesellschafter erfolgt.

Das Gewerbesteuergesetz unterscheidet ferner zwischen kurz- und langfristiger Fremdfinanzierung, indem im zu versteuernden Gewerbeertrag 50\% der Dauerschuldzinsen und im Gewerbekapital 50\% der Dauerschulden enthalten sind, während kurzfristige Verbindlichkeiten und die mit ihnen verbundenen Schuldzinsen dem gemäß BewG ermittelten Einheitswert bzw. dem nach den Vorschriften des EStG/KStG ermittelten Gewinn nicht hinzugerechnet werden.

$\mathrm{Da}$ auch von den Dauerschulden und Dauerschuldzinsen nur die Hälfte dem Gewinn bzw. Einheitswert wieder hinzugerechnet wird, liegt wegen des Definitivcharakters der Gewerbesteuer ferner eine generelle Benachteiligung der Beteiligungsfinanzierung gegenüber der Kreditfinanzierung vor. Diese Diskriminierung der Beteiligungsfinanzierung wird bei Kapitalgesellschaften durch die Existenz der betrieblichen Vermögensteuer weiter verschärft, da Fremdkapital im Gegensatz zu Eigenkapital vom steuerpflichtigen Vermögen abgezogen werden kann.

Während die Körperschaftsteuer aufgrund ihrer Anrechenbarkeit bei der Einkommensteuer im Falle der Ausschüttung neutral ist in bezug auf die Entscheidung zwischen Kredit- und Beteiligungsfinanzierung, weist die Besteuerung der Gewinnfinanzierung Abweichungen auf: Da einbehaltene Gewinne dem Körperschaftsteuersatz von $45 \%$ unterliegen, die Belastung ausgeschütteter Gewinne sich hingegen nach dem Einkommensteuersatz richtet, wird die Finanzierung aus thesaurierten Gewinnen je nach Einkommenshöhe gegenüber der Außenfinanzierung begünstigt oder diskriminiert.

\subsubsection{Möglichkeiten der Steuerumgehung durch Ausnutzung feh- lender Rechtsform- und Finanzierungsneutralität}

\subsubsection{Ausnutzung fehlender Rechtsformneutralität}

Die bestehenden Unterschiede in der Unternehmensbesteuerung je nach Rechtsform haben bereits seit den 20er-Jahren zur Konstruktion von Mischformen zwischen Personen- und Kapitalgesellschaft geführt mit dem Ziel, die steuerlichen (z.T. auch außersteuerlichen) Vorteile beider Rechtsformen unter weitestgehender Vermeidung ihrer Nachteile zu verbinden. ${ }^{1}$

Das bekannteste Beispiel einer solchen Mischform ist die GmbH \& Co. KG, durch welche die Haftungsbeschränkung der Kapitalgesellschaft mit der Besteuerung ausgeschütteter Gewinne wie bei einer reinen Personengesellschaft verbunden wurde. Da die Besteuerung von Gewinnausschüttungen seit der KSt-Reform 1977

${ }^{1}$ Vgl. hierzu auch Kap. 4.3.3.3.4 der vorliegenden Arbeit. 
rechtsformneutral erfolgt, ist das Hauptmotiv für die Umwandlung bestehender Gesellschaften mbH in die Rechtsform der $\mathrm{GmbH} \& \mathrm{Co}$. KG bzw. für die Neugründung einer derartig organisierten Gesellschaft mittlerweile entfallen. Gleichwohl kann sich immer noch ein Steuervorteil ergeben, indem die Gewinne so zwischen $\mathrm{GmbH}$ einerseits und Kommanditisten andererseits aufgeteilt werden, daß es zu einer möglichst niedrigen Gesamt-Steuerbelastung kommt. Je nachdem, ob die individuellen Grenzsteuersätze der Einkommensteuer höher oder niedriger liegen als der einheitliche Steuersatz der Körperschaftsteuer auf einbehaltene Gewinne, kann ein hoher oder niedriger Gewinnanteil der Komplementär-GmbH von Vorteil sein. Die Belastung mit Gewerbeertragsteuer entspricht derjenigen einer reinen Personengesellschaft; ob dies gegenüber einer einfachen $\mathrm{GmbH}$ insgesamt vorteilhaft oder eher von Nachteil ist, hängt vom Einzelfall ab (s.o. S. 228).

Die steuerliche Anerkennung der $\mathrm{GmbH} \&$ Co. KG bereitet spätestens seit der diesbezüglichen Entscheidung des Vierten Senats des BFH von 1967 keine Schwierigkeiten mehr. ${ }^{1}$

Steuerlich heute meist attraktiver als die $\mathrm{GmbH} \&$ Co. KG ist die Organisation eines Unternehmens als sog. Betriebsaufspaltung. Diese erfolgt i.d.R. durch Aufteilung eines einheitlichen Unternehmens in eine Besitzpersonen- und eine Betriebskapitalgesellschaft, wobei sich das Anlagevermögen weitgehend im Eigentum der Personengesellschaft befindet und gegen Entgelt an die Kapitalgesellschaft verpachtet wird. Durch Variation des Pachtzinses läßt sich der Gewinn so zwischen beiden Gesellschaften aufteilen, wie es im Einzelfall steuerlich am günstigsten ist. Dabei läßt sich der Umstand ausnutzen, daß der Steuersatz für thesaurierte Gewinne bei der Kapitalgesellschaft mit $45 \%$ in aller Regel vom Einkommensteuersatz der Personengesellschafter abweicht.

Die Geschäftsführergehälter bei der Kapitalgesellschaft können vom zu versteuernden Gewerbeertrag abgezogen werden; gleichzeitig gilt aber für den auf die Personengesellschaft entfallenden Gewerbeertrag der Vorteil der gestaffelten Meßzahlen und des Freibetrages von DM 48.000. Da das Vermögen des Unternehmens sich weitgehend im Eigentum der Besitzpersonengesellschaft befindet, wird keine oder nur geringe betriebliche Vermögensteuer fällig. Ferner ermöglicht die Betriebsaufspaltung die doppelte Ausnutzung des GewKapSt-Freibetrages von DM 120.000 .

Die Entscheidung des Großen Senats des BFH von 1971 zur Betriebsaufspaltung ${ }^{2}$ brachte deren endgültige steuerliche Anerkennung. Danach sind nicht nur Betriebsaufspaltungen als solche, sondern auch Gewinnverlagerungen innerhalb des Unternehmens selbst dann zulässig, wenn die Miet- und Pachtzinsen in erheblichem

\footnotetext{
${ }^{1}$ Vgl. BFH-Urteil vom 15.11.1967 a.a.O.

${ }^{2} \mathrm{Vgl}$. BFH-Beschluß vom 8.11.1971 a.a.O.
} 
Maße vom üblichen Niveau abweichen. Erst wenn die innerbetriebliche Leistungsverrechnung so bemessen ist, daß bei der einen Gesellschaft laufend Verluste entstehen, während die andere zur gleichen Zeit in der Gewinnzone arbeitet, kann es zu Schwierigkeiten mit der Finanzverwaltung kommen. ${ }^{1}$

Insgesamt stellt die Betriebsaufspaltung eine Form der Unternehmensorganisation dar, durch die es mit Hilfe der diesbezüglich äußerst steuerzahlerfreundlichen Rechtsprechung möglich ist, die steuerlichen Vorteile einer Personengesellschaft mit denen einer Kapitalgesellschaft nahezu perfekt miteinander zu kombinieren.

\subsubsection{Ausnutzung fehlender Finanzierungsneutralität}

Die steuerliche Nichtanerkennung von Gesellschafterdarlehen bei Personengesellschaften bei gleichzeitiger Abzugsfahigkeit sonstiger Darlehen und Darlehenszinsen legt Versuche nahe, Darlehen von Kommanditisten und persönlich haftenden Gesellschaftern in abzugsfähige Darlehen umzuwandeln.

KOTTKE $^{2}$ befaßt sich mit einem Fall aus dem Jahr 1961, in dem Kommanditisten ihre Darlehensforderungen gegenüber der KG an ihre Ehefrauen und Kinder abgetreten und damit die Gesellschafterdarlehen formal zu Fremddarlehen gemacht hatten. Während das Finanzamt die Forderungsabtretungen als rechtsmißbräuchlich ansah, gelang es den Steuerpflichtigen, vor dem Bundesfinanzhof angebliche erbrechtliche Gründe für die gewählte Gestaltung geltend zu machen, so daß der 3. BFH-Senat als letzte Instanz außersteuerliche Motive für ausschlaggebend hielt und daher eine Steuerumgehung i.S.d. § 6 StAnpG ausschloß. ${ }^{3}$

Die Umwandlung nicht abzugsfähiger Gesellschafterdarlehen in abzugsfähige Verbindlichkeiten ist damit für verheiratete oder nicht kinderlose Gesellschafter eine relativ unproblematische und risikolose Methode zur erfolgreichen Umgehung von Gewerbesteuer.

Die im GewStG verankerte Diskriminierung von Dauerschulden gegenüber sonstigen Verbindlichkeiten (vgl. $\S 8 \mathrm{Nr} .1$ und $\S 12$ Abs. 2 Nr. 1 GewStG) fordert steuerumgehende Gestaltungen zur Umwandlung langfristiger in kurzfristige Verbindlichkeiten geradezu heraus.

Für die Steuerpflichtigen bietet sich diesbezüglich vor allem die Aufnahme von Kontokorrentkrediten statt langfristiger Darlehen an. Verbindlichkeiten auf dem laufenden Konto haben i.d.R. vorübergehenden Charakter. Allerdings werden auch Kontokorrentverbindlichkeiten zu Dauerschulden i.S.d. GewStG, soweit über den gesamten Veranlagungszeitraum ohne Unterbrechung eine bestimmte Mindest-

${ }^{1}$ Vgl. BFH-Urteil vom 8.11.1960 I 131/59 S BStBl. 1960 III S. 513 ff.

${ }^{2}$ Vgl. KOTTKE (1994) S. 429.

${ }^{3}$ Vgl. BFH-Urteil vom 28.1.1972 III R 108/70 BStBl. 1972 II S. $414 \mathrm{ff}$. 
schuld besteht. An Versuchen, Gewerbesteuer zu umgehen, indem diese Schuld vorübergehend getilgt und wenige Tage später erneut aufgenommen wird oder indem sie auf ein zweites Kontokorrentkonto übertragen wird, hat es in der Vergangenheit nicht gefehlt. ${ }^{1}$

Die Finanzverwaltung erkennt die zwischenzeitliche Tilgung von Kontokorrentschulden dann an, wenn sie fur mehr als sieben Tage Bestand hat (Abschnitt 47 Satz 4 GewStR). In einzelnen Fällen ${ }^{2}$ ist die Rechtsprechung jedoch von einem Mindestzeitraum von rund vierzehn Tagen ausgegangen, der überschritten werden müsse, um eine rechtsmißbräuchliche Umgehung von Dauerschulden auszuschlieBen.

Die vorübergehende Verlagerung einer Kontokorrentverbindlichkeit auf ein zweites Konto kann dem Kredit laut Bundesfinanzhof seinen Dauerschuldcharakter nicht nehmen. ${ }^{3}$ Auch können im Einzelfall mehrere Kreditkonten bei ein und derselben Bank zur Bestimmung der gewerbesteuerlichen Dauerschuld rechnerisch zusammengefaßt werden, so daß gegenläufige Schwankungen der einzelnen Sollsalden zu keiner Minderung der hinzurechnungspflichtigen Dauerschulden führen. ${ }^{4}$ Demgegenüber gehen die Steuerpflichtigen kein Risiko ein, wenn sie bei verschiedenen Kreditinstituten Kontokorrentkonten unterhalten und Dauerschulden nicht durch Transaktionen zwischen den Konten, sondern durch gezielte Steuerung der Ein- und Auszahlungen vermeiden. Ein Rechtsmißbrauch nach $\S 42 \mathrm{AO}$ ist dann gemäß BFH-Rechtsprechung ausgeschlossen. ${ }^{5}$

KOTTKE empfiehlt daher den Steuerpflichtigen für den Fall, daß eine Kontokorrentverbindlichkeit gegen Jahresende zur Dauerschuld zu werden droht, dem betreffenden Konto einen möglichst hohen Anteil der Zahlungseingänge zuzuleiten und Auszahlungen von einem zweiten, bei einer anderen Bank geführten Konto zu leisten. ${ }^{6}$

Die steuerliche Begünstigung der Kreditfinanzierung gegenüber der Beteiligungsfinanzierung hat bei Kapitalgesellschaften zu dem Tatbestand der verdeckten Einlage

${ }^{1}$ Vgl. hierzu KOTTKE (1994) S. $110 \mathrm{ff}$.

${ }^{2}$ Vgl. BFH-Urteil vom 4.8.1977 IV R 57/74 BStBl. 1977 II S. 843 ff.; FG Nürnberg vom 21.3.1979 V 256/77 EFG 1979 S. $460 \mathrm{f}$.

${ }^{3}$ Vgl. BFH-Urteil vom 6.6.1973 I R 257/70 BStBl. 1973 II S. 670 ff.; BFH-Urteil vom 5.11.1980 I R 132/77 BStB1. 1981 II S. 219 [220]; BFH-Urteil vom 20.11.1980 IV R 81/77 BStBl. 1981 II S. $223 \mathrm{ff}$.

${ }^{4}$ Vgl. BFH-Urteil vom 25.7.1961 I 54/60 U BStBl. 1961 III S. $422 \mathrm{f}$.

${ }^{5}$ Vgl. BFH-Urteil vom 6.2.1991 I R 101/88 BStBl. 1991 II S. 851 [852 f.]; BFH-Urteil vom 4.8.1977 IV R 57/74 BStBl. 1977 II S. 843 [844]; BFH-Urteil vom 16.1.1974 I R 254/70 BStBl. 1974 II S. 388 [390].

${ }^{6}$ Vgl. KOTTKE (1994) S. $113 \mathrm{f}$. 
bzw. verdeckten Gewinnausschüttung geführt. ${ }^{1}$ Geben die Anteilseigner ihrer Gesellschaft Darlehen, so vermindern sie, verglichen mit einer Aufstockung ihrer Beteiligungen, den zu versteuernden Gewinn und das zu versteuernde Vermögen der Gesellschaft. Als mißbräuchlich können derartige Gestaltungen insbesondere dann angesehen werden, wenn die Darlehensverzinsung die marktüblichen Konditionen übersteigt. Während die Umwandlung von Gewinnanteilen in Zinserträge auf Gesellschafterebene steuerlich ohne Wirkung bleibt und seit der 1977 erfolgten Abschaffung der Doppelbelastung der Kapitalgesellschaften mit Körperschaftsteuer verdeckte Gewinnausschüttungen bei anrechnungsberechtigten Anteilseignern keine KSt-Ersparnis mehr hervorrufen, kommt es nach wie vor zu einer Minderung der Gewerbeertragsteuer, der Gewerbekapitalsteuer und der Vermögensteuer.

Früher ist die Rechtsprechung gegen verdeckte Einlagen bzw. Ausschüttungen anhand der Generalklausel gegen die Steuerumgehung vorgegangen. ${ }^{2}$ Durch die 1934 erfolgte Aufnahme des Begriffs der verdeckten Gewinnausschüttung in den Gesetzestext ist dieses Problem zu einer Auslegung des $\S 8$ Abs. 3 Satz 2 KStG geworden. Nach Abschnitt 31 Abs. 3 Satz $3 \mathrm{KStR}$ sind Darlehensverträge zwischen Kapitalgesellschaft und Anteilseignern steuerlich wirksam, soweit sie bei vernünftiger kaufmännischer Beurteilung einem Fremdvergleich standhalten. Sind dagegen die Zinsen für das der Gesellschaft gewährte Darlehen unangemessen hoch, so wird der das übliche Maß übersteigende Teil der Zinszahlungen als verdeckte Gewinnausschüttung interpretiert und bleibt für die Bemessung der Gewerbeertragsteuer unerheblich. ${ }^{3}$

Sofern der Thesaurierungssatz der KSt höher liegt als der individuelle Grenzsteuersatz der ESt für die Anteilseigner, liegt eine Diskriminierung der direkten Gewinnfinanzierung der Kapitalgesellschaft vor. In diesem Fall lohnt es sich steuerlich für die Gesellschafter, den Steuersatz auf einbehaltene Gewinne zu umgehen, indem der Jahresüberschuß zunächst ausgeschüttet und anschließend als Einlage dem Unternehmen wieder zugefuhrt wird. Während faktisch eine Gewinnfinanzierung vorliegt, handelt es sich formell um eine (hier steuerlich begünstigte) Beteiligungsfinanzierung.

Obwohl diese als Schütt-aus-hol-zurück-Verfahren bekannte Steuersparmethode stark gekünstelt erscheint und außer der Steuerersparnis keine Vorteile aufweist, durch den erhöhten Verwaltungsaufwand sogar betriebswirtschaftlich von Nachteil ist, stellt dieses Verfahren in Deutschland lediglich einen völlig legalen Weg der Steuervermeidung dar. Da der Gesetzgeber im Zusammenhang mit dem Inkraft-

${ }^{1} \mathrm{Da}$ Gesellschafterdarlehen bei Personengesellschaften steuerlich generell nicht anerkannt werden (s.o.), sind verdeckte Gewinnausschüttungen auf Kapitalgesellschaften beschrănkt.

${ }^{2} \mathrm{Vgl}$. RFH-Urteil vom 26.7.1919 I A 82/19 RFHE 2 S. $183 \mathrm{ff}$.

${ }^{3}$ Vgl. BFH-Urteil vom 28.10.1964 I 198/62 U BStBl. 1965 III S. 119 [121] i.V.m. BFH-Urteil vom 10.6.1987 I R 149/83 BStBl. 1988 II S. 25 ff. 
treten der KSt-Reform 1977 ausdrücklich auf die Möglichkeit einer Schütt-aushol-zurück-Politik hingewiesen hatte, ${ }^{1}$ liegt kein Verstoß gegen den Willen des Gesetzgebers und damit keine Steuerumgehung i.S.d. in Kap. 2.2 vorgenommenen Definition vor. ${ }^{2}$ Fälle, in denen die Anwendung des Schütt-aus-hol-zurückVerfahrens von der Rechtsprechung als Gestaltungsmißbrauch gemäß $§ 42 \mathrm{AO}$ angesehen würde, erscheinen bei derzeitiger Rechtslage kaum denkbar. ${ }^{3}$

\subsubsection{Reformvorschläge}

Steuerumgehung, welche aus fehlender Rechtsform- oder Finanzierungsneutralität erwächst, ist naturgemäß durch Beseitigung der zugrunde liegenden Verstöße gegen die Besteuerungsneutralität am effektivsten zu begegnen. Im einzelnen handelt es sich dabei um die gleichen Maßnahmen, die schon in Kap. 6.6.3 gegen die mißbräuchliche Verlagerung von Einkommen und Vermögen zwischen betrieblicher und privater Ebene entwickelt wurden:

Neben der in Deutschland bereits erfolgten Abschaffung der Doppelbelastung ausgeschütteter Gewinne von Kapitalgesellschaften mit Körperschaftsteuer sind erneut die Abschaffung der Gewerbesteuer und der betrieblichen Vermögensteuer sowie die Umgestaltung der Einkommensteuer in eine flat-rate tox, deren Steuersatz dem Körperschaftsteuersatz auf einbehaltene Gewinne entspricht, zu fordern. Damit wären sowohl Rechtsform- als auch Finanzierungsneutralität hergestellt.

Gewinnverlagerungen innerhalb einer $\mathrm{GmbH} \& \mathrm{Co}$. KG blieben bei Vereinheitlichung der Steuersätze von KSt und ESt steuerlich ohne Wirkung; Unterschiede zur reinen $\mathrm{GmbH}$ in der Belastung des Gewerbeertrags verschwänden mit Beseitigung der Gewerbesteuer. Auch die Betriebsaufspaltung böte keinen steuerlichen Vorteil mehr, da weder eine Gewerbe- oder Vermögensteuerreduzierung erreicht werden könnte noch durch Gewinnverlagerungen unterschiedliche Steuersätze zwischen ESt und KSt ausnutzbar wären.

Der Umgehung von Dauerschulden und Dauerschuldzinsen könnte bereits innerhalb des Gewerbesteuergesetzes durch eine Gleichstellung der kurzfristigen mit der langfristigen Fremdfinanzierung begegnet werden. Als Maßnahme gegen verdeckte Einlagen bzw. Gewinnausschüttungen mittels Gesellschafterdarlehen würde die Abschaffung der Gewerbekapital- und der betrieblichen Vermögensteuer ausreichen, wenn die Schuldzinsen bei der Ermittlung des Gewerbeertrages statt zur Hälfte in voller Höhe hinzugerechnet würden. Dasselbe gilt auch bzgl. der Um-

\footnotetext{
${ }^{1}$ Vgl. TIPKE/KRUSE (1996) Tz. 30 unter Hinweis auf Bundestagsdrucksache VII/5310 S. 9.

${ }^{2}$ Im Ausland konnte hingegen eine Schütt-aus-hol-zurück-Politik als Steuerumgehung angesehen werden, sofern sie - anders als in Deutschland - vom Gesetzgeber nicht vorgesehen ist.

${ }^{3}$ Vgl. ausfuihrlicher KOTTKE (1994) S. 163; vgl. auch Abschnitt 77 Abs. 5 und 6 KStR.
} 
wandlung von Gesellschafterdarlehen in abzugsfähige Verbindlichkeiten durch Übertragung der Darlehensforderung auf Familienangehörige. Wegen ihrer Verstöße gegen die Rechtsformneutralität (s.o.) und ihrer Eigenschaft als Sonderbelastung gewerblicher Einküntte (Kap. 6.6.3) ${ }^{1}$ empfiehlt sich jedoch eine völlige Beseitigung der Gewerbesteuer. Die Einführung eines einheitlichen Einkommensteuersatzes, der dem Thesaurierungssatz der Körperschaftsteuer entspricht, würde zu einer steuerlichen Gleichstellung der Gewinnfinanzierung mit der Beteiligungsfinanzierung führen und damit den Anreiz für eine Schütt-aus-hol-zurück-Politik beseitigen. $^{2}$

\subsection{Räumliche Verlagerung von Einkommen}

\subsubsection{Vorbemerkungen}

Die räumliche Verlagerung von Einkommen zwecks Ausnutzung fehlender Standortneutralität der Besteuerung fältt in den Bereich der Steuerflucht. Unter Steuerflucht versteht man die Verlagerung vorhandener oder künftiger Steuersubstanz (Einkommen bzw. Vermögen) aus einem steuerlich ungünstigen Gebiet in niedriger besteuerte Regionen. ${ }^{3}$ Grundsätzlich können sowohl natürliche Personen als auch Unternehmen Steuerflucht betreiben. Die Steuerflucht von Privatpersonen (denkbar ist hier die Vermögensanlage im Ausland oder die Verlegung des Wohnsitzes) dürfte ausschließlich in die Bereiche der Steuervermeidung und der Steuerhinterziehung fallen; demgegenüber kann die Steuerflucht von Unternehmen mittels räumlicher Gewinnverlagerung neben legaler Steuervermeidung und illegaler Steuerhinterziehung auch mißbräuchliche Steuerumgehung darstellen.

Steuerflucht ist grundsätzlich auf nationaler Ebene wie auch grenzüberschreitend möglich. Innerhalb der Bundesrepublik Deutschland ergeben sich jedoch für Unternehmen kaum Möglichkeiten zur Steuerumgehung durch Gewinnverlagerungen. Eine mißbräuchliche Ausnutzung der Hebesatzunterschiede bei der Gewerbesteuer durch Gewinnverschiebungen zwischen verbundenen Unternehmen ist durch $\S \S 28$, 29 GewStG i.V.m. $§ 2$ Abs. 2 GewStG und $\S 14 \mathrm{KStG}$ weitgehend ausgeschlos-

${ }^{1}$ An letzterer könnte auch der Ersatz der Gewerbesteuer durch eine rechtsform- und finanzierungsneutrale Wertschöpfung- oder cash-flow-Steuer nichts ändern.

${ }^{2}$ Die oftmals geforderte Angleichung des KSt-Satzes an den Spitzensteuersatz der ESt führt weder zu Rechtsform- noch zu Finanzierungsneutralităt und macht eine Schütt-aus-hol-zurückPolitik im Vergleich zum derzeit international üblichen Zustand (KSt-Thesaurierungssatz < ESt-Spitzensteuersatz) sogar noch attraktiver. Abhilfe schafft einzig ein einheitlicher, der KSt angepaßter Grenzsteuersatz der ESt.

${ }^{3} \mathrm{Vgl}$. SCHMID (1961) S. 1. 
sen. Die früher mögliche rechtsmißbräuchliche Nutzung des BerlinFG ${ }^{1}$ ist seit Auslaufen der Berlinförderung nicht mehr praktizierbar.

Gegenstand der folgenden Ausführungen ist daher ausschließlich die betriebliche Steuerumgehung durch internationale Steuerflucht. Diese findet vor allem durch unangemessene Konzernverrechnungspreise, Nutzung von Basisgesellschaften und Mißbrauch von Doppelbesteuerungsabkommen statt.

\subsubsection{Methoden der internationalen Steuerumgehung}

\subsubsection{Internationale Steuerumgehung durch unangemessene Konzern- verrechnungspreise}

Unter Konzernverrechnungspreisen versteht man das Entgelt, das zwischen verbundenen Unternehmen für einander gelieferte Waren oder geleistete Dienste festgesetzt wird. ${ }^{2}$ Durch Manipulation der Konzernverrechnungspreise können multinationale Unternehmen versuchen, das internationale Steuergefalle zur Minimierung der Gesamtsteuerlast auszunutzen. Indem die von Tochtergesellschaften, welche in Hochsteuerländern ansässig sind, abgegebenen Leistungen möglichst niedrig bewertet und die empfangenen Leistungen möglichst hoch angesetzt werden, kann es gelingen, daß der Konzerngewinn rechnerisch ganz oder überwiegend auf den in Niedrigsteuerländern befindlichen Teil des Konzerns entfällt.

Um derartige Gewinnverlagerungen zu verhindern, versuchen die betroffenen nationalen Steuerverwaltungen in aller Regel, der Besteuerung Verrechnungspreise zugrunde zu legen, welche einem Fremdvergleich standhalten. ${ }^{3}$ Dieser als dealing at arm's length principle bezeichnete Grundsatz stößt jedoch in der praktischen Umsetzung häufig auf erhebliche Schwierigkeiten, da meist nicht exakt feststellbar ist, welcher Preis für eine bestimmte Ware oder Dienstleistung fremden Unternehmen in Rechnung gestellt worden wäre. ${ }^{4}$ Die für die Ermittlung angemessener Konzernverrechnungspreise verwendbaren Methoden (von Bedeutung sind vor allem die Preisvergleichsmethode, die Wiederverkaufspreismethode und die Kostenaufschlagsmethode) $)^{5}$ sind nicht frei von Bewertungsspielräumen. Hierdurch kann es zu volkswirtschaftlich unerwünschter Doppelbesteuerung kommen, wenn sich die beteiligten nationalen Steuerbehörden nicht auf eine einheitliche Bewer-

\footnotetext{
${ }^{1}$ Vgl. hierzu FISCHER in HHSp Rz. $301 \mathrm{f}$.

${ }^{2}$ Vgl. PETTERSSON (1978) S. 256.

${ }^{3}$ So ist das Verfahren des Fremdvergleichs in Deutschland in $\S 1 \mathrm{AStG}$, in Frankreich in art. 57 CGI gesetzlich verankert.

${ }^{4}$ Vgl. REUTER (1978) S. 229.

${ }^{5}$ Eine Beschreibung dieser Verfahren findet sich bei DANNECKER (1984) S. 18-21. Die USRichtlinien von 1994 enthalten daneben einige weitere Verfahren; zu diesen und den mit ihnen verbundenen Problemen vgl. EIMERMANN (1994).
} 
tung verständigen. Da die einzelnen Staaten nicht allein eine Bekämpfung der Steuerumgehung, sondern vor allem ein möglichst hohes Steueraufkommen anstreben dürften, scheitert eine solche Verständigung häufig an deren entgegengesetzter fiskalischer Interessenlage. ${ }^{1}$ Soll die anhand unangemessener Verrechnungspreise praktizierte Steuerumgehung durch das arm 's-length-Prinzip verhindert, gleichzeitig aber eine Doppelbelastung von Teilen des Konzerngewinns vermieden werden, so müßte eine supranationale Behörde eingerichtet werden, welche die wechselseitige Leistungsverrechnung der multinationalen Konzerne überprüft und ggf. korrigiert. In jedem Fall ist jedoch das Verfahren des Fremdvergleichs mit einer gewissen Willkür bei der Bewertung verbunden und nur bei lückenloser und damit äußerst verwaltungsaufwendiger Anwendung tatsächlich in der Lage, mißbräuchliche grenzüberschreitende Gewinnverlagerungen völlig auszuschließen.

Die Praxis einer von den Einzelstaaten unabhängig voneinander betriebenen Anwendung des arm's-length-Prinzips, verbunden mit grundsätzlich von den Konzernen festgesetzten Verrechnungspreisen, welche von den Finanzbehörden nur dann korrigiert werden, wenn sie als „unangemessen“ angesehen werden, kann - neben der Gefahr von Doppelbesteuerungen - auch leicht zur Folge haben, daß die Unternehmen ihre Leistungsverrechnung so manipulieren, daß sie von Finanzverwaltung und -gerichtsbarkeit als, gerade noch angemessen“ Bestand haben dürfte. In Deutschland setzt $\S 1$ Abs. $1 \mathrm{AStG}$ fest, daß Verrechnungspreise, die voneinander unabhängige Dritte so nicht vereinbart hätten, „so anzusetzen [sind], wie sie unter den zwischen unabhängigen Dritten vereinbarten Bedingungen angefallen wären. " $\mathrm{Da}$ eine solche Vorschrift aufgrund ihrer notwendigen Unbestimmtheit leicht Gegenstand gerichtlicher Auseinandersetzungen werden kann, ${ }^{2}$ liegt ebenso auf der Hand wie die Bemühungen deutscher Konzerntöchter und -mütter, den infolge ergangener Gerichtsentscheidungen und Verwaltungsanweisungen verbleibenden Bewertungsspielraum so weit wie möglich zur Gewinnverlagerung in niedriger besteuernde Länder auszunutzen.

\subsubsection{Internationale Steuerumgehung durch Nutzung von Basisgesell- schaften}

Unter einer Basisgesellschaft versteht man einen selbständigen Rechtsträger, „der von inländischen natürlichen oder juristischen Personen im Ausland zum Zwecke der Vereinnahmung von Erträgen unter günstigeren steuerlichen Bedingungen als im Inland gegründet wird. ${ }^{33}$ Die Bezeichnung „Basisgesellschaften“ rührt aus ihrer

${ }^{1}$ Vgl. ENGEL (1986) S. 213.

${ }^{2}$ Ein umfassender Überblick über die Rechtsprechung zu den Verrechnungspreisen zwischen verbundenen Unternehmen findet sich bei FLICK/WASSERMEYER/BECKER (1995), § 1 AStG.

${ }^{3}$ KLUGE (1977) S. 328. 
Funktion als „Basen“ für die steuergünstige Ansammlung von Einkommen und Vermögen. ${ }^{1}$ Neben den definitionsgemäß vorliegenden steuerlichen Motiven können auch organisatorische, devisenrechtliche oder politische Erwägungen mit ausschlaggebend für die Errichtung einer Basisgesellschaft sein. ${ }^{2}$ Basisgesellschaften können reine „Briefkastenfirmen“ ohne jede wirtschaftliche Betätigung sein; ${ }^{3}$ sie können aber auch eigene Geschäftstätigkeit entfalten und theoretisch jede betriebswirtschaftliche Funktion, im Extremfall bis hin zur Produktion, übernehmen. ${ }^{4}$ Typischerweise fungieren Basisgesellschaften als Holding-, Finanzierungs- oder Zwischenhandelsgesellschaften für die verbundenen Unternehmen oder üben für diese Dienstleistungen wie Lizenzerteilung, Maklergeschäfte, technische Beratung u.ä. aus. ${ }^{5}$ Mittels der für derartige Tätigkeiten von der Mutter- bzw. den Schwestergesellschaften erhobenen Entgelte lassen sich Gewinne auf die Basisgesellschaft verlagern. Die hierdurch erzielbare Steuerersparnis erreicht vor allem dann eine lohnende Größenordnung, wenn es gelingt, durch unangemessene Verrechnungspreise einen möglichst großen Anteil des Konzerngewinns auf die Basisgesellschaft entfallen zu lassen (hierzu s.o. Kap. 6.8.2.1), oder wenn deren Errichtung in einem Land mit besonders günstigen steuerlichen Bedingungen (sog. Steueroase) erfolgt. Steueroasen sind vor allem dadurch gekennzeichnet, daß sie für natürliche oder juristische Personen auf bestimmte Arten von Einkommen und Kapital keine oder nur geringe Steuern erheben und ein hohes Niveau von Bank- und Geschäftsgeheimnis aufweisen. ${ }^{6}$ Mittlerweile haben viele Industriestaaten eine spezielle Gesetzgebung gegen die Einkommens- und Vermögensverlagerung in Oasenländer erlassen; in Deutschland sind die $\S \S 7-14$ AStG gezielt gegen die Steuerflucht durch Gründung von Basisgesellschaften in Steueroasen gerichtet.

Allgemein gilt hier für Basisgesellschaften innerhalb und außerhalb von Steueroasen, daß zunächst geprüft wird, ob sie nach den allgemeinen Vorschriften der Abgabenordnung steuerlich anzuerkennen sind.

${ }^{1}$ Vgl. DEBATIN (1979) S. 181.

2 Vgl. JUNKER (1982) S. 214.

${ }^{3}$ Derartige Firmen haben weder eigene Räumlichkeiten noch eigenes Personal noch einen aktiven Geschäftsbetrieb, sondern dienen einzig der Steuerersparnis. Ihre praktische Bedeutung ist recht hoch: So gibt es Schätzungen zufolge in Liechtenstein mehr Briefkastenfirmen als Einwohner; vgl. MESSNER (1987) S. 5. Vgl. in diesem Zusammenhang auch KAY/KING (1990) S. 206: „Many major companies have financing subsidiaries based, for example, in the Netherlands Antilles. It goes without saying that nothing of substance happens in the Netherlands Antilles and that few of those who purport to do business there could locate the islands on the map."

${ }^{4}$ Vgl. DANNECKER (1984) S. 57.

${ }^{5} \mathrm{Vgl}$. SCHMID (1961) S. 55.

${ }^{6} \mathrm{Vgl}$. OECD (1987) S. $22 \mathrm{f}$.

Praktisch vollständige Auflistungen und Beschreibungen aller existierenden Steueroasen finden sich bei MESSNER (1987) S. 55-163 und MEDENBACH (1988) S. 34-47. 
So gilt die Errichtung von Briefkastenfirmen von vornherein als steuerlich irrelevantes Scheingeschäft nach § $41 \mathrm{AO} .{ }^{1}$ Entfaltet die Basisgesellschaft hingegen eine eigene Geschäftstätigkeit, welche nicht bloß fingiert ist, so gilt die Gründung der Gesellschaft als solche als real erfolgt und kann auch keinen Rechtsmißbrauch nach $\S 42 \mathrm{AO}$ darstellen. ${ }^{2}$

Bei Prüfung von Basisgesellschaften auf die Tatbestandsmerkmale des $\S 42 \mathrm{AO}$ kann deshalb die Errichtung der Gesellschaft nicht in Frage gestellt werden; vielmehr gilt es festzustellen, ob ihre konkrete Nutzung als rechtsmißbräuchlich einzustufen ist. Nach der Rechtsprechung des Bundesfinanzhofs ist ein Rechtsmißbrauch vor allem dann anzunehmen, wenn wirtschaftliche oder sonst beachtliche außersteuerliche Gründe für die Zwischenschaltung der Basisgesellschaft fehlen und diese keine eigene wirtschaftliche Tätigkeit entfaltet. Die reine Vermögensverwaltung gilt dabei nicht als eigene wirtschaftliche Tätigkeit. ${ }^{3}$

Erst wenn sowohl ein Scheingeschäft nach $\S 41 \mathrm{AO}$ als auch ein Rechtsmißbrauch nach $\S 42 \mathrm{AO}$ ausgeschlossen worden ist, sind die Voraussetzungen der $\S \S 7-14$ AStG zu prüfen. ${ }^{4}$ Ziel dieses Teils des Außensteuergesetzes ist es, Gewinnverlagerungen auf in Steueroasen ansässige Basisgesellschaften entgegenzuwirken, indem die von der Basisgesellschaft erzielten Einkünfte bei den inländischen Gesellschaftern entsprechend ihrer Beteiligung steuerlich hinzugerechnet werden $(\S 7$ Abs. 1 AStG). Voraussetzung für die Hinzurechnung ist, daß die Ertragsteuerbelastung in der „Steueroase“ unter $30 \%$ liegt ( $\$ 8 \mathrm{Abs}$. $3 \mathrm{AStG}$ ), an der Basisgesellschaft Inländer mit mehr als $50 \%$ beteiligt sind $(\S 7 \mathrm{Abs} .1 \mathrm{AStG})$ und die Einkünfte nicht aus aktiver Geschäftstätigkeit (im Gegensatz zu „passiver“ Verwaltungstätigkeit, Grundstücksvermietung u.ä.) im Sinne von $\S 8$ Abs. 1 AStG stammen.

Die Vorschriften der AO und des AStG legen den Steuerpflichtigen nahe, furr die Errichtung von Basisgesellschaften außersteuerliche Begründungen ${ }^{5}$ zu finden, ihnen einen wirtschaftlichen Handlungsspielraum einzuräumen, der auch tatsächlich genutzt wird, ${ }^{6}$ und entweder die inländische Beteiligung auf 50\% zu beschränken oder die Gesellschaft in einem Staat zu errichten, dessen Ertragsteuersatz bei genau $30 \%$ oder knapp darüber liegt.

${ }^{1} \mathrm{Vgl}$. DANNECKER (1984) S. $60 \mathrm{f}$.

${ }^{2}$ Vgl. hierzu DEBATIN (1979) S. 229.

${ }^{3}$ Vgl. BFH-Urteil vom 29.7.1976 VIII R 142/73 BStBl. 1977 II S. 263 [264]; BFH-Urteil vom 5.3.1986 I R 201/82 BStBl. 1986 II S. 496 ff.; BEISSE (1978) S. 7 m.w.N.

${ }^{4} \mathrm{Vgl}$. KLUGE (1977) S. 328; BFH-Urteil vom 23.10.1991 I R 40/89 BStBI. 1992 II S. 1026 [1028]; BFH-Urteil vom 10.6.1992 I R 105/89 BStB1. 1992 II S. 1029 [1031].

${ }^{5}$ Hierbei ist die bisherige Rechtsprechung zu anerkannten bzw. nicht anerkannten nichtsteuerlichen Motiven zu beachten. Ein Überblick findet sich bei RAUER (1983) S. 2278; vgl. ferner KLEIN/ ORLOPP (1995) Anm. 9.c); FISCHER in HHSp (1996) Rz. 243 und 244; SCHWARZ (1996) Anm. 15-17.

${ }^{6}$ Vgl. KOTTKE (1994) S. 191. 
Die gesetzlichen Bestimmungen sind damit relativ leicht zu umfahren und zur Eindämmung anhand von Basisgesellschaften betriebener Steuerumgehung nur bedingt geeignet. Der verbleibenden abschreckenden Wirkung des AStG steht ein sehr hoher Verwaltungsaufwand gegenüber, der auf Seiten der Wirtschaft vor allem in der komplizierten Ermittlung und Aufstellung des Hinzurechnungsbetrages ( $\S \S 9-14$ AStG), auf Seiten der Finanzverwaltung in den notwendigen Betriebsprüfungen und Kontrollen besteht. ${ }^{1}$

\subsubsection{Internationale Steuerumgehung durch Mißbrauch von Doppelbesteuerungsabkommen}

Dem Mißbrauch von Doppelbesteuerungsabkommen sind im wesentlichen drei Fallgruppen zuzurechnen: ${ }^{2}$

Die größte Bedeutung kommt dem sog. treaty-shopping zu. Hierunter versteht man das "Sich-Einkaufen" in fremde DBA und deren Nutzung. Meist geht es dabei um Fälle, in denen zwei Geschäftspartner, die in unterschiedlichen Staaten, welche kein DBA miteinander abgeschlossen haben, ansässig sind, eine Gesellschaft in einem Drittland, welches zu beiden Staaten ein DBA unterhält, zwischenschalten und damit zu den gewünschten Abkommensvorteilen gelangen, die ihnen normalerweise nicht zustünden. ${ }^{3}$ Denkbar ist jedoch auch der Fall, daß zwischen den beiden Staaten der Akteure zwar ein DBA besteht, durch Einbeziehung des Drittlandes aber andere, für die Beteiligten günstigere Abkommen nutzbar werden.

Ob treaty-shopping einen Rechtsmißbrauch nach $\S 42 \mathrm{AO}$ darstellt oder nicht, hängt von den Umständen des Einzelfalls ab. Ist die zwischengeschaltete Gesellschaft allein zwecks Inanspruchnahme von Abkommensvorteilen errichtet worden und entfaltet sie keine eigene wirtschaftliche Tätigkeit, so liegt nach den allgemeinen Grundsätzen der Rechtsprechung zur Nutzung von Basisgesellschaften eine Steuerumgehung i.S. von $\S 42 \mathrm{AO}$ vor. ${ }^{4}$ Diese Grundsätze sind allerdings nur dann anwendbar, wenn die Gründung der zwischengeschalteten Gesellschaft durch Steuerinländer erfolgte. „Die Gründung einer Kapitalgesellschaft im Ausland durch einen Ausländer ist ein das inländische Steuerrecht nicht berührender Vorgang und entzieht sich grundsätzlich der Beurteilung, ob ein Mißbrauch von [...] Gestaltungsmöglichkeiten des Rechts ( $\$ 42$ AO 1977) vorliegt. “S Ist die zwischengeschaltete Gesellschaft (auch) aus anderen Gründen als der besseren Ausnutzung von DBA-Vorteilen errichtet worden oder entfaltet sie eine eigene wirtschaftliche

\footnotetext{
${ }^{1}$ Vgl. WASSERMEYER (1983) S. 576.

2 Vgl. PILTZ (1987) S. 2.

${ }^{3} \mathrm{Vgl}$. TIPKE/KRUSE (1996) Tz. 42.

${ }^{4}$ gl.A.: VOGEL (1985) S. 279

${ }^{5}$ BFH-Urteil vom 29.10.1981 I R 89/80 BStBl. 1982 II S. 150 [153].
} 
Tätigkeit, so stellt die Erlangung von Abkommensvorteilen durch die Zwischengesellschaft ebenfalls keinen Gestaltungsmißbrauch i.S.d. Abgabenordnung dar.

Eine zweite Fallgruppe möglichen Abkommensmißbrauchs stellt das sog. ruleshopping dar. Hierunter versteht man Fälle, in denen Steuerpflichtige Sachverhalte so gestalten, daß ihre Einkünfte unter eine Einkuntsart fallen, die durch ein DBA gegenüber sonstigen Einkünften begünstigt ist. PILTZ nennt als ein Beispiel die Umwandlung einer. Kapitalgesellschaft in eine Betriebsstätte zur Erzielung von Betriebsstättengewinnen statt der im Doppelbesteuerungsabkommen (hier: DBA Deutschland - Schweiz) schlechter gestellten Schachteldividenden. ${ }^{1}$ Ein weiteres Beispiel ist die das Eigenkapital weit übersteigende Ausstattung einer inländischen Kapitalgesellschaft mit Gesellschafterdarlehen durch einen gebietsfremden Anteilseigner, um der beschränkten Steuerpflicht auf Dividenden zu entgehen. ${ }^{2}$

$\mathrm{Ob}$ es sich bei derartigen Sachverhaltsgestaltungen tatsächlich um einen Mißbrauch von Gestaltungsmöglichkeiten des Rechts i.S.v. $\S 42 \mathrm{AO}$ handelt oder ob einfach ein aufgrund bestimmter DBA-Regelungen ungünstiger Sachverhalt legal vermieden wird, kann im Einzelfall strittig sein. Im allgemeinen dürfte der Nachweis schwer zu führen sein, daß die Ausnutzung einer im DBA nun einmal ausdrücklich vorgesehenen Begünstigung bestimmter Einkunfts- oder Finanzierungsarten im konkreten Fall tatsächlich „unangemessen“ im Sinne der Generalklausel ist. Auch PLTZ, der das rule-shopping ausdrücklich als Unterfall des AbkommensmiBbrauchs bezeichnet, beschreibt hierzu ausschließlich Beispiele, in denen er selbst einen Rechtsmißbrauch verneint. ${ }^{3}$

Die dritte Fallgruppe bilden Gestaltungen, die zur Folge haben, daß aufgrund eines DBA keinem der beiden Staaten das Besteuerungsrecht zukommt (sog. negativer Qualifikationskonflikt). Gelingt eine Sachverhaltsgestaltung, die dazu führt, daß beide Staaten von einer ausschließlichen Besteuerungsbefugnis des jeweils anderen Staates ausgehen, so können bestimmte Einkünfte völlig steuerfrei bleiben.

Auch der Ausnutzung derartiger Unstimmigkeiten zwischen den Finanzverwaltungen der Abkommensstaaten in der DBA-Auslegung dürfte für gewöhnlich mit $\S 42$ AO nicht beizukommen sein. Da fur das Profitieren von einer nicht aufeinander abgestimmten und wechselseitig nicht bekannten Verwaltungs- und Rechtsprechungspraxis in aller Regel keine gekünstelten Gestaltungen erforderlich sind, die „vernünftige Beteiligte“ normalerweise nicht wählen würden oder die den wirtschaftlichen Gegebenheiten nicht gerecht werden, wird im allgemeinen keine Unangemessenheit im Sinne der deutschen Rechtsprechungsgrundsätze zu § $42 \mathrm{AO}$ vorliegen.

${ }^{1} \mathrm{Vgl}$. PILTZ (1987) S. 14.

${ }^{2}$ Vgl. ebenda S. 4.

${ }^{3} \mathrm{Vgl}$. ebenda S. $14 \mathrm{f}$. 


\subsubsection{Reformvorschläge}

Das Problem der internationalen Steuerumgehung wäre vollständig gelöst, wenn überall auf der Welt das gleiche Steuerrecht gälte (insb. die Steuersätze angeglichen würden) und sämtliche Staaten miteinander einheitliche Doppelbesteuerungsabkommen abschlössen.

Die Abschaffung des internationalen Steuergefalles würde sowohl die Steuerumgehung durch unangemessene Verrechnungspreise als auch die mißbräuchliche Nutzung von Basisgesellschaften beseitigen. Eine solche Vereinheitlichung der Steuerarten und -sätze würde jedoch der unterschiedlichen Finanzkraft und dem unterschiedlichen Finanzbedarf der einzelnen Staaten nicht gerecht, so daß ein umfassender Finanzausgleich einzurichten wäre. ${ }^{1}$ Wie schwer selbst unter ökonomisch in etwa gleich entwickelten Ländern wie denjenigen der Europäischen Union eine Einigung über Steuerharmonisierung und innergemeinschaftichen Finanzausgleich zu erzielen ist, hat sich in der Vergangenheit bei den Bemühungen, die Steuersysteme der Mitgliedstaaten der Gemeinschaft einander anzugleichen, deutlich gezeigt. Solange unabhängige Staaten souverän über ihre Steuerpolitik entscheiden können, ist eine Abschaffung der internationalen Steuerbelastungsunterschiede kaum realistisch; Annäherungen zumindest zwischen den wichtigsten Industriestaaten sind allerdings durchaus möglich und in gewissen Grenzen auch zu beobachten.

Das Problem unangemessener Konzernverrechnungspreise wäre auch ohne vereinheitlichte Steuersätze zu lösen, wenn das derzeit vorherrschende dealing at arm's length principle durch eine sich nach objektiven Bezugsgrößen bemessende Aufteilung des Gesamtkonzernergebnisses ähnlich wie bei der deutschen Gewerbesteuer ersetzt würde (sog. unitary tax concept). ${ }^{2}$ Nach diesem Konzept bildet nicht mehr der in den einzelnen Staaten, in denen der Konzern ansässig ist, anfallende Gewinn die dortige Steuerbemessungsgrundlage. Vielmehr wird der gesamte Konzerngewinn ermittelt und nach einem bestimmten Schlüssel (z.B. nach der auf die einzelnen Staaten entfallenden Lohnsumme, den Umsatzerlösen oder dem betrieblichen Vermögen) den betreffenden Ländern zugerechnet. Auf diesen anteiligen Gewinn kann jeder Staat seine eigenen Steuern erheben, ohne daß es hierfür weiterer Steuerharmonisierung bedürfte. Eine Einigung der OECD-Länder auf das unitary tox concept dürfte weit eher erzielbar sein als eine Abschaffung sämtlicher Steuerbelastungsunterschiede. Zwischen den Staaten, die sich diesem Konzept anschließen, wäre das Problem der Steuerumgehung durch unangemessene Konzernverrechnungspreise gelöst.

${ }^{1} \mathrm{Vgl.} \mathrm{SCHMID} \mathrm{(1961)} \mathrm{S.} 256$.

${ }^{2}$ Vgl. KAY/KING (1990) S. 206 f. 
Ein Hindernis für ein weltweites Vorgehen gegen den Gebrauch von Basisgesellschaften stellen die Steueroasen dar, welche sich aufgrund ihrer speziellen Interessenlage im allgemeinen jeder Beteiligung an unilateralen Vereinbarungen zur Steuerharmonisierung widersetzen. Versuche, zur Bekämpfung der internationalen Steuerflucht Abkommen mit Steueroasen zur Konzernbesteuerung, zur Annäherung der Steuersätze und zum gegenseitigen Informationsaustausch der Finanzverwaltungen zu schließen, haben im allgemeinen selbst dann wenig Erfolgsaussichten, wenn die Industriestaaten zu teilkompensierenden Gegenleistungen bereit sind. ${ }^{1}$ Ob die Ausübung politischen, wirtschaftlichen oder im Extremfall militärischen Drucks auf die meist als Zwergstaaten zu bezeichnenden Steueroasenländer ein angemessenes Mittel der Beseitigung der Oasenproblematik darstellt, soll an dieser Stelle dahingestellt bleiben. Werden derartige Methoden abgelehnt und sind freiwillige Übereinkünfte nicht zu erzielen, so ist die Errichtung und Nutzung von Basisgesellschaften in Steueroasen in dem Ausmaß hinzunehmen, wie die bestehende und bei Bedarf zu ergänzende Gesetzgebung sie nicht zu verhindern vermag.

Der Mißbrauch von Doppelbesteuerungsabkommen durch das treaty-shopping würde durch ein lückenloses Netz gleichartiger DBA gegenstandslos. Mag ein solches Ziel auch in letzter Konsequenz nicht erreicht werden, so müßte es immerhin realisierbar sein, daß sich eine große Mehrheit der Staatengemeinschaft auf ein einheitliches Abkommen, z.B. auf das OECD-Musterabkommen, einigen könnte. Schließen sich einzelne Staaten aus, so könnten die übrigen Länder durch Aufnahme entsprechender Bestimmungen in ihre Steuergesetzgebung oder in die untereinander abgeschlossenen DBA die mißbräuchliche Einschaltung von Drittländern zu verhindern suchen. So hat das oben zitierte Urteil des Ersten BFH-Senats vom 29.10.1981 den deutschen Gesetzgeber dazu veranlaßt, durch Schaffung des neuen $\S 50 \mathrm{~d}$ Abs. la EStG Gebietsfremden die Möglichkeit zu nehmen, durch Gründung und Zwischenschaltung einer im DBA-Partnerstaat befindlichen Gesellschaft Abkommensvorteile zu erschleichen, welche ohne die Zwischengesellschaft nicht zur Anwendung kämen. Die gleiche Wirkung hat die Ergänzung bestehender DBA um entsprechende Bestimmungen; vergleichbare Vereinbarungen haben beispielsweise die USA und Kanada in ihr Doppelbesteuerungsabkommen aufgenommen. ${ }^{2}$

Zur Vermeidung negativer Qualifikationskonflikte sind eine besondere Umsicht der Finanzverwaltungen bei der gemeinsamen Abkommensinterpretation und ein hoher Umfang an gegenseitigem Informationsaustausch vonnöten. ${ }^{3}$ Wenn die Steuerbehörden in Zweifelsfällen (d.h. bei nicht sicherer Annahme, der jeweils andere Staat

\footnotetext{
${ }^{1}$ Zu derartigen Versuchen der Vereinigten Staaten vgl. OECD (Intertax 1987) S. 123 f.

${ }^{2} \mathrm{Vgl}$. BOIDMAN (1981) S. $446 \mathrm{f}$.

${ }^{3} \mathrm{Vgl}$. ebenda S. 447.
} 
besteuere den betr. Sachverhalt) einander konsultieren, so dürfte es den Steuerpflichtigen kaum gelingen, derartige Besteuerungslücken ausfindig zu machen. ${ }^{1}$

Das rule-shopping hat seine Ursache in fehlender Quellen- bzw. Finanzierungsneutralität grenzüberschreitender Vorgänge. Was in den vorigen Abschnitten bzgl. der Implikationen der (nationalen) Steuerumgehung auf die Gestaltung der Steuergesetze festgestellt wurde, gilt entsprechend auch für die internationale Steuerumgehung und die DBA: Um rule-shopping zu verhindern, sind die Doppelbesteuerungsabkommen so umzugestalten, daß die zugrunde liegenden Aneutralitäten beseitigt werden.

Allgemein ist für die Steuerumgehung durch Einkommensverlagerungen festzuhalten, daß der Schlüssel für ihre Beseitigung im wesentlichen in der Schaffung von Standortneutralität durch Harmonisierung der Steuersysteme und der Doppelbesteuerungsabkommen liegt. Die Umstellung der Konzernbesteuerung auf das unitary tax concept, die Verwirklichung von Finanzierungs- und Quellenneutralität auch bei grenzüberschreitenden Vorgängen und ein verbesserter gegenseitiger Informationsaustausch der nationalen Steuerverwaltungen könnten verbleibende Ungleichmäßigkeiten in der internationalen Besteuerung teilweise kompensieren. Schließlich kann auch eine Verlagerung des Schwergewichts der Besteuerung auf Steuerarten, welche unanfälliger gegenüber internationaler Steuerumgehung sind, eine gewisse Abhilfe bringen. So würde eine stärkere Konzentration auf indirekte Steuern nicht nur über ein auf Dauer verringertes Steuerbelastungsgefühl die Steuermoral und damit die Neigung zu nationaler und internationaler Steuerumgehung verringern, ${ }^{2}$ sondern auch aufgrund der kaum vorhandenen Gelegenheiten, grenzüberschreitende Umgehung indirekter Steuern zu betreiben, das Ausmaß möglicher internationaler Steuerumgehung entscheidend senken. ${ }^{3}$

${ }^{1}$ Am effektivsten wäre die Einrichtung einer zentralen Informationsstelle, die alle relevanten Daten speichert und für die internationale Zusammenarbeit zur Verfügung stellt. Wenn die gespeicherten Informationen von den Finanzverwaltungen aller beteiligten Staaten abrufbar sind, so lassen sich nicht nur negative Qualifikationskonflikte weitgehend ausschließen; es könnte auch ein klares Bild über alle grenzüberschreitenden Verbindungen zwischen den Unternehmen geschaffen werden, so daß Gewinnverlagerungen in Niedrigsteuerländer besser beobachtbar würden. Vgl. hierzu EUROPEAN COMMISSION (1985) S. 53 f.

${ }^{2}$ s.o. Kap. 5.8.1.3

${ }^{3}$ KAY/KING (1990) S. 206 weisen auf die Robustheit speziell der Mehrwertsteuer gegenüber grenzüberschreitender Umgehung hin. Vergleichbar unanfällig sind aber m.E. auch die speziellen Verbrauchsteuern. Vgl. auch SWAN in COLLINS (1984) S. $51 \mathrm{f}$. 


\section{Zusammenfassung und Ausblick}

Die Steuerumgehung führt zu Wettbewerbsverzerrungen, Ressourcenverschwendung, ungleichmäßigerer Einkommensverteilung und Verstößen gegen die horizontale Gerechtigkeit. Maßnahmen zu ihrer Bekämpfung erscheinen daher sowohl aus allokativen als auch aus distributiven Gründen angezeigt.

Die (insbesondere in Großbritannien gesammelten) historischen Erfahrungen zeigen, daß gezielt gegen die einzelnen aufgetretenen Methoden der Steuerumgehung gerichtete spezielle Gesetzgebung zwar die Steuergesetze erheblich verkompliziert, aber nur dann nennenswerte Erfolge herbeiführen kann, wenn die Bestimmungen rückwirkend in Kraft gesetzt werden. Rückwirkend belastende Gesetze erscheinen jedoch rechtsstaatlich bedenklich und sind in Großbritannien, wenn auch grundsätzlich einsetzbar, äußerst umstritten und in Deutschland in aller Regel verfassungswidrig.

Rechtswissenschaft und Rechtsprechung haben deshalb sowohl im angelsächsischen als auch im kontinentaleuropäischen Rechtskreis Methoden und Maßnahmen entwickelt, welche einen generellen Schutz vor Steuerumgehung bieten sollen.

In den USA dienen vor allem das Prinzip substance over form, der business purpose test und die step transaction doctrine der Ausdehnung des Wirkungskreises der Steuergesetze auf vom Gesetzeszweck, nicht jedoch vom Gesetzeswortlaut gedeckte Fälle. Auch die britischen Gerichte wenden mittlerweile (implizit) den business purpose test und die step transaction doctrine an; im Konflikt wirtschaftliche Substanz versus äußere Form von Rechtsgestaltungen dominiert jedoch immer noch die Form als Grundlage der Besteuerung.

In Deutschland hat die Rechtswissenschaft die Verfahren der Analogie bzw. der teleologischen Reduktion entwickelt, welche grundsätzlich in der Lage sind, dem Gesetzeszweck auch dort Geltung zu verleihen, wo der ausgelegte Gesetzeswortlaut hierfür nicht mehr ausreicht. Die Zulässigkeit dieser Verfahren im Steuerrecht ist in der juristischen Literatur äußerst umstritten. Diese Arbeit konnte zeigen, daß zwar viele der im Schriftum für ein Analogieverbot vorgebrachten Argumente (Verstoß der Analogie gegen Demokratieprinzip, Gewaltenteilung oder Gesetzesvorbehalt, Analogieunfähigkeit des Steuerrechts wegen fehlender Sachgesetzlichkeiten) nicht haltbar sind, die verfassungsmäßigen Grundsätze der TatbestandsmäBigkeit und der Rechtssicherheit aber gleichwohl ein Verbot analoger Rechtsanwendung erfordern. Um dennoch eine rechtliche Handhabe gegen die Umgehung von Steuern zu haben, ist eine allgemeine Rechtsnorm, welche die Finanzbehörden ermächtigt, mißbräuchliche Rechtsgestaltungen generell steuerlich zu ignorieren und statt dessen eine fingierte ,angemessene" Gestaltung der Besteuerung zugrunde zu legen, unverzichtbar. Auch das französische Steuerrecht enthält eine derartige Generalklausel. 
Der in dieser Arbeit enthaltene internationale Vergleich konnte zeigen, daß die Wirksamkeit der rechtswissenschaftlichen Methoden weniger von der im jeweiligen Rechtskreis vorherrschenden Dogmatik („Mißbrauch“ als Tatbestandsmerkmal einer Generalklausel oder „Substanz vs. Form“ als abzuwägende Grundsatzfrage), sondern weit eher von der rechtlichen Tradition eines Landes und der Einstellung der jeweiligen Gerichte abhängt. ${ }^{1}$ In Deutschland genügt den Steuerpflichtigen im Regelfall, für steuerumgehende Gestaltungen auch außersteuerliche Gründe geltend zu machen, um eine Anwendung des $\S 42 \mathrm{AO}$ zu verhindern. Noch steuerzahlerfreundlicher gibt sich traditionell die britische Rechtsprechung, während die USamerikanischen und die französischen Gerichte durch ihre eher von praktischen bzw. fiskalischen Erwägungen geprägte Grundhaltung Steuerumgehern die Arbeit tendenziell schwieriger machen. Allen betrachteten Ländern ist gemeinsam, daß die gegen die Steuerumgehung eingesetzten juristischen Methoden das Auftreten des Symptoms „Steuerumgehung" mehr oder weniger erfolgreich einzugrenzen in der Lage sind, ohne es ganz verhindern zu können. Die Erfolge ließen sich zweifellos vergrößern, wenn die Umgehungsbekämpfung stärker von der Erkenntnis geleitet wäre, daß Steuerumgehung nur dann auftreten kann, wenn erstens ein Motiv und zweitens eine Gelegenheit hierfur vorliegen.

Mit den Bestimmungsgründen mißbräuchlicher Gestaltungen befaßt sich die Ökonomische Theorie der Steuerumgehung, die den rechtswissenschaftlichen Ansatz nicht ersetzen, ihn aber sinnvoll ergänzen soll. Die Ergebnisse des aus dem bekannten entscheidungstheoretischen Modell der Steuerhinterziehung abgeleiteten Steuerumgehungsmodells zeigen den Einfluß der Parameter Einkommen, Bußgeld, Wahrscheinlichkeit der steuerlichen Nichtanerkennung, Steuersatz, Pauschaltransfer, Progressionsgrad, Fixkosten und Grenzkosten auf die individuelle Umgehungsentscheidung auf. In nennenswertem Maße von der Politik beeinflußbar sind hiervon - zumindest in Deutschland - aus rechtlichen bzw. tatsächlichen Gründen nur die den Steuertarif bestimmenden Parameter. ${ }^{2}$ Insbesondere dürften hohe Grenzsteuersätze ein entscheidendes Motiv für mißbräuchliche Gestaltungen darstellen. Zwar kommt das entscheidungstheoretische Modell hier zu keinem eindeutigen Ergebnis, doch hängt dies mit der dem Modell zugrunde liegenden einzelwirtschaftlichen Betrachtung zusammen: Wird die staatliche Wiederverausgabung der Steuermittel berücksichtigt und davon ausgegangen, daß der Grenznutzen aus öffentlichen Gütern nicht kleiner ist als derjenige aus privaten Gütern, so ist ein positiver Zusammenhang zwischen Grenzsteuersatz und Steuerumgehung auch in der Theorie eindeutig gegeben, sofern die Umgehung keine strafbare Handlung darstellt oder sie mit Grenzkosten verbunden ist. Senkungen der Grenzsteuersätze

${ }^{1}$ Vgl. auch VOGEL (1996) S. 226.

${ }^{2}$ Bezieht man die psychischen Kosten und Nutzen aus der Steuerumgehung in die Kostenparameter des Modells ein, so unterliegen auch letztere signifikantem staatlichem Einfluß (hierzu s.u.). 
erscheinen also durchaus dazu geeignet, ein Absinken der Steuerumgehung zu bewirken (zweifellos gäbe es bei einem einheitlichen Grenzsteuersatz i.H.v. null keine Steuerumgehung mehr), doch sind Steuersenkungen aus fiskalischen und verteilungspolitischen Gründen in der Praxis nur eingeschränkt durchführbar.

Motive für die Konstruktion mißbräuchlicher Rechtsgestaltungen können auch psychologischer Art sein. Es ist weitgehend unstrittig, daß die generelle Einstellung zum Staat, die Akzeptanz des öffentlichen Einnahme- und Ausgabensystems, das subjektive Steuerbelastungsgefühl und das Vertrauen in die Steuerehrlichkeit der Mitmenschen neben den im ökonomischen Modell enthaltenen Parametern ${ }^{1}$ ebenfalls eine wichtige Rolle fur das Ausmaß an gesamtwirtschaftlicher Steuerumgehung spielen können. Auf der anderen Seite wird es in jeder Gesellschaft Steuerpflichtige geben, die, sobald sie einen persönlichen finanziellen Vorteil erwarten, versuchen werden, jede sich bietende Gelegenheit zur mißbräuchlichen Steuerersparnis zu nutzen. Den Steuerumgehern diese Gelegenheiten so weit wie möglich zu nehmen dürfte der wirksamste unter den gangbaren Wegen einer Bekämpfung der Steuerumgehung sein.

Die meisten Methoden der Umgehung von Einkommensteuer basieren darauf, $\mathrm{da}$ es aufgrund intertemporal, interpersonell oder je nach Einkunftsart variierender Steuersätze steuerlich nicht gleichgültig ist, wann wem welches Einkommen zufließt. Abhilfe schaff hier eine synthetische Einkommensteuer mit einem einzigen Steuersatz, welche auch realisierte und unrealisierte capital gains und capital losses sowie Zinserträge und -aufwendungen, ferner auch Erbschaften und Schenkungen erfaßt. Wird die flat-rate tax mit einer negativen Einkommensteuer kombiniert, so ist eine derartige Maßnahme nicht nur effektiver, sondern auch sozialpolitisch verträglicher als das ebenfalls der Verhinderung mißbräuchlicher interpersoneller Einkommensübertragungen dienende Konzept des Familiensplittings, welches bei Beibehaltung der direkten Progression entweder (bei einkommensunabhängigen Splittingdivisoren) vertikal ungerecht oder (bei je nach Einkommenshöhe variierenden Divisoren) technisch nahezu undurchschaubar ist.

Für den Bereich der Unternehmensteuern sind für Deutschland eine Abschaffung der Gewerbesteuer und die (ohnehin bevorstehende) Beseitigung der betrieblichen Vermögensteuer zu fordern. Ferner sollte der KSt-Satz auf einbehaltene Gewinne dem (einheitlichen) Grenzsteuersatz der ESt entsprechen. Die Anrechenbarkeit der Körperschaftsteuer bei der Einkommensteuer der Anteilseigner muß in jedem Fall gewährleistet sein. Diese Maßnahmen würden Rechtsform- und Finanzierungsneutralität der Unternehmensbesteuerung bewirken und Einkommens- und Vermögensverlagerungen zwischen betrieblicher und privater Ebene steuerlich weitgehend irrelevant werden lassen.

\footnotetext{
${ }^{1}$ bzw. als nicht-monetärer Teil der im Modell enthaltenen Kostenparameter
} 
Die Umsatzsteuer sollte mit nur einem einzigen Steuersatz ausgestattet sein; die systemwidrige Steuerfreiheit bestimmter Umsätze ist abzuschaffen. Ausnahmen vom Vorsteuerabzug sollte es nicht geben. Als weitere Maßnahme empfiehlt sich in Deutschland die Integration der Grunderwerbsteuer in die Umsatzsteuer. Eine derartige umfassende Reform der Umsatzbesteuerung würde die mißbräuchliche Transformation von Umsätzen für die Zukunft ausschließen.

In der Praxis am schwierigsten gestaltet sich die Beseitigung der internationalen Steuerumgehung, da sie in erheblichem Umfang von multinationaler Kooperation abhängt. Eine weltweite Harmonisierung der Steuersätze, -bemessungsgrundlagen und Doppelbesteuerungsabkommen wäre effektiv, dürfte aber nur in sehr eingeschränktem Maße erzielbar sein. Gegen das verstärkt auftretende transfer pricing sollte daher durch eine Besteuerung international tätiger Konzerne nach dem unitary tax concept vorgegangen werden. Die mißbräuchliche Nutzung von Steueroasen ließe sich nur dann wirkungsvoll verhindern, wenn die Oasenländer durch Zwang oder durch positive Anreize zu kooperativem Handeln bewegt werden könnten. Nützlich gegen jede Art von grenzüberschreitender Steuerumgehung wäre allerdings die verstärkte Konzentration der Steuersysteme auf die diesbezüglich weit weniger anfälligen indirekten Steuern.

Zusammenfassend läßt sich festhalten, daß es drei grundlegende Ansatzpunkte für eine Bekämpfung der Steuerumgehung gibt:

Erstens sollte versucht werden, die Motive für rechtsmißbräuchliche Gestaltungen (insbesondere hohe Grenzsteuersätze sowie finanzpsychologische Faktoren) zu erkennen und - soweit möglich - in gewünschter Richtung zu beeinflussen (Abschnitt 5).

Zweitens sollte das Steuerrecht möglichst weitgehend von Gelegenheiten zur Steuerumgehung befreit werden. Jede Abweichung vom Postulat der Steuerneutralität ist auf daraus potentiell resultierende Umgehungsmöglichkeiten zu prüfen. Vor allem müssen die relevanten bestehenden Steuern (insb. Steuern auf das Einkommen privater Haushalte, Unternehmensteuern, Umsatzbesteuerung) möglichst umfassende Bemessungsgrundlagen und einheitliche Steuersätze aufweisen und harmonisch aufeinander abgestimmt sein (Abschnitt 6).

Drittens sind als Abhilfe, soweit trotz aller Bemühungen um Reduktion der Gelegenheiten und Motive noch Steuerumgehung auftritt, die rechtswissenschaftlichen Methoden der Ausdehnung des Gesetzeszwecks über den Gesetzeswortlaut hinaus auf mißbräuchliche rechtliche Konstruktionen anzuwenden (Abschnitt 4).

Die rechtswissenschaftlichen Methoden dienen im wesentlichen der Heilung von Unvollkommenheiten bei der Beseitigung der Motive und Gelegenheiten. Sie sind deshalb hier bewußt an letzter Stelle genannt, obwohl sie meist im Zentrum der politischen und wissenschaftlichen Diskussion stehen. Da der Staat an den Motiven 
der Steuerumgehung nur relativ wenig ändern kann (Steuersenkungen sind nicht in beliebigem Umfange realisierbar, psychologische Faktoren nur bedingt manipulierbar), sollte die Bekämpfung der Steuerumgehung vor allem denjenigen Ansatz berücksichtigen, der in Politik und öffentlicher Auseinandersetzung die geringste Rolle spielt, aber die größten Erfolgsaussichten haben dürfte: Die meisten Gelegenheiten zur Steuerumgehung ließen sich relativ unproblematisch und ohne schädliche Nebenwirkungen durch eine grundlegende Steuerreform beseitigen. Politiker, Politikberater und Steuerjuristen täten jedenfalls gut daran, sich das notwendige ökonomische Fachwissen anzueignen, welches unerläßlich ist, um die Steuerwirkungen und die Ursachen von Steuerausweichhandlungen zu durchschauen, und die Gesetzgebung und Gesetzesanwendung danach auszurichten. ${ }^{1}$

Umgekehrt sollten aber auch die Ökonomen nicht den Fehler machen, die Erkenntnisse anderer Wissenschaften zu vernachlässigen. Eine restlose Beseitigung sämtlicher Gelegenheiten zur Steuerumgehung dürfte in der Praxis unerreichbar sein. Vielmehr ist eine Anti-Umgehungs-Politik dann am erfolgversprechendsten, wenn in einer Art konzertierter Aktion alle drei grundlegenden Methoden der Mißbrauchsbekämpfung eingesetzt werden:

Der erhebliche Rückgang der Steuerumgehung im Großbritannien der 80er Jahre dürfte darauf zurückzuführen sein, daß gleichzeitig der Spitzensatz der Einkommensteuer gesenkt, die Schedulensteuer bei Abschaffung diverser Steuervergünstigungen in Richtung auf eine synthetische Einkommensteuer reformiert wurde und flankierend der sog. new approach Eingang in die Rechtsprechung fand. ${ }^{2}$

Auch für die Bundesrepublik Deutschland wäre eine weniger steuerumgeherfreundliche Auslegung des $\S 42$ AO durch die Dritte Gewalt im Sinne der Gleichmäßigkeit der Besteuerung und gesamtgesellschaftlicher Verantwortung zweifellos wünschenswert.

Die Politik täte gut daran, die derzeitigen Steuerpläne (Abschaffung der betrieblichen Substanzsteuern, Ausdehnung der ESt-Bemessungsgrundlage) möglichst konsequent umzusetzen, die geplante Senkung des Spitzen- und des Eingangssatzes der Einkommensteuer hingegen zu überdenken. Die Grenzbelastung des unternehmerischen Einkommens sollte statt dessen durch Abschaffung auch der Gewerbeertragsteuer verringert werden; statt einer Senkung des ESt-Eingangssatzes empfiehlt sich zunächst eine Ausdehnung der Nullzone, langfristig sollte eine Abschaffung der direkten Progression bei Einfuihrung einer negativen Einkommensteuer angepeilt werden. Sich ergebende Mindereinnahmen bei den direkten Steuern ließen sich durch neue oder höhere indirekte Steuern kompensieren.

\footnotetext{
1 Ähnlich äußert sich SCHNEIDER (1985) S.355.

${ }^{2} \mathrm{Vgl}$. KAY/KIING (1990) S.60 und 103; NEVERMANN (1994) S. $67 \mathrm{f}$.
} 
Die Wirtschaftswissenschaft sollten dem Phänomen „Steuerumgehung“ weitere Forschungsarbeit widmen. Insbesondere sind Schätzungen seiner quantitativen Bedeutung, aber auch die empirische Überprüfung der in dieser Arbeit gewonnenen Ergebnisse eine wichtige Zukunftsaufgabe. Je mehr wirtschaftswissenschaftliche Erkenntnisse gewonnen werden können und je gesicherter diese Erkenntnisse sind, desto erfolgreicher werden sie sich verbreiten lassen, und desto weniger werden sich Politik und Rechtsprechung ihnen verschließen können. Steuerreformen wie die in dieser Arbeit vorgeschlagene dürften bei ausreichendem ökonomischen Wissen der maßgeblichen Politiker und Steuerrechtler nicht mehr an den bei jeder umfassenden Reform auftretenden lautstarken und zunehmend auch auf gerichtlichem Wege geäußerten Protesten der sich auf der Verliererseite wähnenden Interessengruppen scheitern. 


\section{Literaturverzeichnis}

Allingham, Michael G.; Sandmo, Agnar:

Income Tax Evasion: A Theoretical Analysis,

in: Journal of Public Economics 1 (1972), S. 323-338

Alm, James; McCallin, Nancy J.:

Tax Avoidance and Tax Evasion as a Joint Portfolio Choice, in: Public Finance, Vol. 45, No. 2/1990, S. 193-200

Andersen, Per: Tax Evasion and Labor Supply,

in: The Scandinavian Journal of Economics 79 (1977), S. 375-383

Asian-Pacific Tax and Investment Research Centre (ed.):

Tax Planning, Tax Avoidance, Tax Evasion

Singapore 1984

S. 1-10: Alun G. Davies:

The British Stance on Tax Evasion and Avoidance

S. 70-77: Jaap van Hoorn: How the Tax Authorities in Europe are Combatting Tax Avoidance Tactics

Ax, Rolf; Große, Thomas; Cämmerer, Johannes:

Abgabenordnung und Finanzgerichtsordnung,

Schäffer Verlag für Wirtschaft und Steuern GmbH Stuttgart,

14. Aufl. 1995

Barth, Rainer: Richterliche Rechtsfortbildung im Steuerrecht

Dissertation Westfälische Wilhelms-Universität zu Münster 1995

Schriften zum Steuerrecht Band 50

Duncker \& Humblot GmbH, Berlin 1996

Beisse, Heinrich: Verlagerung von Einküntten ins Ausland

Zur neueren Steuergesetzgebung und -rechtsprechung,

in: Die Information über Steuer und Wirtschaft, 32. Jg.,

Nr. 1/1978, S. 1-9

Beisse, Heinrich: Die wirtschaftliche Betrachtungsweise bei der Auslegung der Steuergesetze in der neueren deutschen Rechtsprechung, in: Steuer und Wirtschaft, 58. (11.) Jg., Nr. 1/1981, S. 1-14 
Bockelmann, Paul:

Strafe und Buße als Mittel der Erziehung zur Steuerehrlichkeit, in: Steuer-Kongreß-Report 1969, S. 291-318

Böhmer, Peter: Erfüllung und Umgehung des Steuertatbestandes,

Verlagsbuchhandlung des Instituts der Wirtschaftsprüfer $\mathrm{GmbH}$, Düsseldorf 1958

Boidman, Nathan: International Tax Avoidance: The Impact on Legal Systems, in: Bulletin for International Fiscal Documentation 35 (1981),

S. $435-447$

Bopp, Gerhard: Scheingeschäfte, mißbräuchliche Steuerumgehung und wirtschaftliche Betrachtungsweise, in: Günther Felix:

Von der Auslegung und Anwendung der Steuergesetze Festschrift für Armin Spitaler zum 60. Geburtstag

Carl Ernst Poeschel Verlag GmbH, Stuttgart 1958, S. 132-150

Bosch, Karl; Jensen, Uwe: Großes Lehrbuch der Mathematik für Ökonomen R. Oldenbourg Verlag GmbH, München/Wien 1994

Bracewell-Milnes, Barry:

Tax Avoidance and Evasion: The Individual and Society London 1979

Bracewell-Milnes, Barry: The Economics of International Tax Avoidance Political Power versus Economic Law

Rotterdam Institute for Fiscal Studies, International Series no. 4 Kluwer, Deventer/Boston/Antwerpen/London/Frankfurt 1980

Britschkat, Günter; Körner, Josef: Gesamtwirtschaftliche und einzelwirtschaftliche Auswirkungen eines Familiensplittings ifo-Studien zur Finanzpolitik Nr. 31, München 1984

Büchner, Heinz-Jürgen: Eine ökonomische Theorie der Steuerhinterziehung

Der Einfluß staatlicher Parameteränderungen auf das Verhalten von Individuen

Discussion Paper No. A - 33, Sonderforschungsbereich 303 „Information und die Koordination wirtschaftlicher Aktivitäten“, Rheinische Friedrich-Wilhelms-Universität Bonn 1985 
Büchner, Heinz-Jürgen: Ökonomische Theorien zur Steuerhinterziehung Inaugural-Dissertation Rheinische Friedrich-Wilhelms-Universität Bonn 1988

Bydlinski, Franz: Juristische Methodenlehre und Rechtsbegriff, Springer-Verlag Wien/New York, 2. Auflage 1991

Canaris, Claus-Wilhelm: Die Feststellung von Lücken im Gesetz Eine methodologische Studie über Voraussetzungen und Grenzen der richterlichen Rechtsfortbildung praeter legem Schriften zur Rechtstheorie Heft 3 Duncker \& Humblot, Berlin 1964

Cansier, Dieter: Cash-flow-Steuern: Neue Wege der Unternehmensbesteuerung?, in: Wirtschaftsdienst, 69. Jg., Nr. 1/1989, S. 49-56

Christiansen, Vidar: Two Comments on Tax Evasion, in: Journal of Public Economics 13 (1980), S. 389-393

Clotfelter, Charles T.:

Tax Evasion and Tax Rates: An Analysis of Individual Returns, in: The Review of Economics and Statistics, Vol. 65, No. 3/1983, S. 363-373

Collard, David; Lecomber, Richard; Slater, Martin (eds.):

Income Distribution: the Limits to Redistribution Bristol 1980

S. 135-148: John Alexander Kay: The Anatomy of Tax Avoidance

S. 148-149: G. Whittington: Discussion

S. 150-162: C. T. Sandford:

Tax Compliance Costs, Evasion and Avoidance

Collins, David J. (ed.): Tax Avoidance and the Economy

Australian Tax Research Foundation, Sydney 1984

S. vii-xi: David J. Collins: Introduction

S. 23-38: Peter D. Groenewegen:

Distributional and Allocational Effects of Tax Avoidance

S. 39-45: J. W. Nevile: Macro-Economic Effects of Tax Avoidance

S. 47-56: Peter L. Swan:

Reforming the System: An Economist's View 
Cowell, Frank A.: Tax Evasion with Labour Income, in: Journal of Public Economics 26 (1985), S. 19-34

Cowell, Frank A.: The Economic Analysis of Tax Evasion, in: John D. Hey, Peter J. Lambert:

Surveys in the Economics of Uncertainty, Basil Blackwell Ltd, Oxford 1987, S. 173-203 (ebenfalls veröffentlicht im Bulletin of Economic Research, Vol. 37, No. 3/1985, S. 163-193.)

Cowell, Frank A.: Cheating the Government The Economics of Evasion The MIT Press, Cambridge/London 1990

Cowell, Frank A.; Gordon, James P.F.: Unwillingness to Pay Tax Evasion and Public Good Provision in: Journal of Public Economics 36 (1988), S. 305-321

Cozian, Maurice: Les grands principes de la fiscalité des entreprises Litec Paris, 2. Aufl. 1986

Crane, Steven E.; Nourzad, Farrokh: Inflation and Tax Evasion: An Empirical Analysis, in: Review of Economics and Statistics 68 (1986), S. 217-223

Crane, Steven E.; Nourzad, Farrokh: Tax Rates and Tax Evasion: Evidence from California Amnesty Data, in: National Tax Journal, Vol. 43, No. 2/1990, S. 189-199

Crezelius, Georg: Kodifizierte und rechtsprechungstypisierte Umgehungen, in: Steuer und Wirtschaft, 72. (25.) Jg., Nr. 4/1995, S. 313-325

Cross, Rodney; Shaw, G. K.: On the Economics of Tax Aversion, in: Public Finance, Vol. 37, No. 1/1982, S. 36-47

Däke, Karl Heinz: Volkssport Steuer-Betrug, in: Die Woche Nr. 5 vom 27.1.1995, S. 8

Dannecker, Gerhard: Steuerhinterziehung im internationalen Wirtschaftsverkehr Dissertation Albert-Ludwigs-Universität Freiburg Schriften zum gesamten Wirtschaftsstrafrecht Band 6 Dr. Peter Deubner Verlag GmbH, Köln 1984 
Danzer, Jürgen: Die Steuerumgehung

Dissertation Ruhr-Universität Bochum Wintersemester 80/81

Dr. Peter Deubner Verlag GmbH, Köln 1981

Daumke, Michael: Grundriß der Abgabenordnung

Alfred Metzner Verlag, Frankfurt 1988

David, Cyrille; Latournerie, Marie-Aimée; Fouquet, Olivier:

Les grands arrêts de la jurisprudence fiscale

Sirey Paris, 2. Aufl. 1991

Debatin, Helmut: Rechtsmißbrauch im internationalen Steuerrecht im Lichte deutscher Rechtsprechung, in: Der Betrieb, 32. Jg., Nr. 4+5/1979, S. 181-183 und S. 229-234

Diebold, Urs: Der illegale Steuerwiderstand

Die verschiedenen Erklärungsansätze unter besonderer Berücksichtigung der Steuerdisziplin

Dissertation Universität Fribourg 1983

Zürich 1984

Dolzer, Rudolf; Vogel, Klaus (Hrsg.):

Bonner Kommentar zum Grundgesetz Band 8

C. F. Müller Juristischer Verlag Heidelberg, 75. Erg.-Lfg. 12/1995

Dornbach, Eike-Goetz: Die Bedeutung und Funktion der ,wirtschaftlichen Betrachtungsweise“ in der höchstrichterlichen Rechtsprechung Vergangenheit, Gegenwart und Zukunft, in: Deutsches Steuerrecht, 15. Jg., Nr. 1/1977, S. 3-13

Dubin, Jeffrey A.; Graetz, Michael J.; Wilde, Louis L.: Are We a Nation of Tax Cheaters? New Econometric Evidence on Tax Compliance, in: American Economic Review, Vol. 77, No. 2/1987, S. 240-245

Dubin, Jeffrey A.; Wilde, Louis L.: An Empirical Analysis of Federal Income Tax Auditing and Compliance, in: National Tax Journal, Vol. 41, No. 1/1988, S. 61-74

Eimermann, Dieter:

Die neuen U.S.-Verrechnungspreisrichtlinien - auf OECD-Kurs?, in: Internationales Steuerrecht, 3. Jg., Nr. 11/1994, S. 537-542 
Engel, Clemens L. J.: Konzerntransferpreise im Internationalen Steuerrecht Implikationen der Gewinnabgrenzung multinationaler Unternehmen unter besonderer Berücksichtigung der Konzerndienstleistungen Dissertation Universität Freiburg 1984

Schriftenreihe „Steuerwissenschaft“ Band 22

Dr. Peter Deubner Verlag GmbH, Köln 1986

Engelhardt, Gunther: Verhaltenslenkende Wirkungen der Einkommensteuer Ein Beitrag zum Problem der wirtschaftspolitischen Beratung Finanzwissenschaftliche Forschungsarbeiten Neue Folge Heft 38 Duncker \& Humblot, Berlin 1968

European Commission: Community action to combat international tax evasion and avoidance

Communication from the Commission to the Council and to the European Parliament

in: intertax No. $2 / 1985$, S. $52-57$

Falkinger, Josef: Tax Evasion and Equity: A Theoretical Analysis,

in: Public Finance, Vol. 43, No. 3/1988, S. 388-395

Feldman, J.; Kay, John Alexander: Tax avoidance,

in: Paul Burrows, Cento G. Veljanovski (eds.):

The Economic Approach to Law

Butterworth \& Co. Ltd.,

London/Boston/Sydney/Wellington/Durban/Toronto 1981,

S. 320-333

Felix, Günther: Gestaltungsmißbrauch und Steuerumgehung,

in: Handwörterbuch des Steuerrechts und der Steuerwissenschaften,

2. Auflage München/Bonn 1981, Erster Band A-J,

S. $647-650$

Fischer, Peter: Substanz und Form - oder:

„Das Steuergesetz kann nicht umgangen werden“

Zugleich Besprechung von Karsten Nevermann, Justiz und Steuerumgehung

in: Steuer und Wirtschaft, 72. (25.) Jg., Nr. 1/1995, S. 87-97 
Friedland, Nehemiah; Maital, Shlomo; Rutenberg, Aryeh:

A Simulation Study of Income Tax Evasion,

in: Journal of Public Economics 10 (1978), S. 107-116

Friedrich, Werner: Gedanken zur verschärfenden Analogie im Steuerrecht,

in: Der Bundesfinanzhof und seine Rechtsprechung

Grundfragen - Grundlagen

Festschrift für Hugo von Wallis, Bonn 1985, S. 151-165

Friemel, Rainer; Schiml, Kurt: Die Auslegung von Steuergesetzen,

in: Steuer und Studium, 2. Jg., Nr. 12/1981, S. 353-358, und 3. Jg., Nr. 1/1982, S. 6-10

Fullerton, Don; Karayannis, Marios: Tax evasion and the allocation of capital, in: Journal of Public Economics 55 (1994), S. 257-278

Gambier, Claude; Mercier, Jean-Yves: Les impôts en France Traité pratique de la fiscalité des affaires

Éditions Francis Lefebvre Paris, 22. Aufl. 1990

Gärtner, Wulf; Wenig, Alois (Hrsg.): The Economics of the Shadow Economy Springer-Verlag, Berlin/Heidelberg 1985

S. 227-244: Arne Jon Isachsen, Sven Ove Samuelsen, Steinar Strøm: The Behavior of Tax Evaders

S. 245-264: Yael Benjamini, Shlomo Maital: Optimal Tax Evasion and Optimal Tax Evasion Policy: Behavioral Aspects

S. 285-300: Ingemar Hansson: Tax Evasion and Government Policy

Geeroms, Hans; Wilmots, Hendrik:

An Empirical Model of Tax Evasion and Tax Avoidance,

in: Public Finance, Vol. 40, No. 2/1985, S. 190-209

Gnahs, Dieter; Janneck, Rainer: Das Problem des illegalen Steuerwiderstandes

Ein Versuch der Integration verschiedener Erklärungsansätze

Diskussionsschriften aus dem Institut für Finanzwissenschaft

(Universität Hamburg) Nr. 8, Hamburg 1978

(ebenfalls veröffentlicht in: Soziale Welt, 30. Jg., Nr. 2/1979,

S. 205-229) 
Gordon, James P.F.: Individual Morality and Reputation Costs as Deterrants to

Tax Evasion,

in: European Economic Review 33 (1989), S. 797-805

Graetz, Michael J.; Wilde, Louis L.:

The Economics of Tax Compliance: Fact and Fantasy, in: National Tax Journal, Vol. 38, No. 3/1985, S. 355-363

Gretschmann, Klaus: Wohlfahrtseffekte schattenwirtschaftlicher Aktivitäten?, in: K. Gretschmann, Rolf G. Heinze, Bernd Mettelsiefen (Hrsg.): Schattenwirtschaft

Wirtschafts- und sozialwissenschaftliche Aspekte, internationale Erfahrungen

Vandenhoeck \& Ruprecht, Göttingen 1984, S. 97-129

Grimm, Claus: Das Steuerrecht im Spannungsfeld zwischen wirtschaftlicher Betrachtungsweise und Zivilrecht, in: Deutsche Steuer-Zeitung Ausgabe A, 66. Jg., Nr. 15-16/1978, S. 283-290

Günther, Karl-Heinz: Mißbräuchliche Rechtsgestaltungen nach § 42 AO Ein Rechtsprechungsüberblick, in: Die steuerliche Betriebsprüfung Nr. 9/1987, S. 198-205

Haavelmo, Trygve: Multiplier effects of a balanced budget, in: Econometrica 13 (1945), S. 311-318

Haberstock, Lothar; Breithecker, Volker:

Einfuihrung in die Betriebswirtschaftliche Steuerlehre

Mit Fallbeispielen, Übungsaufgaben und Lösungen

S+W Steuer- und Wirtschaftsverlag Hamburg, 8. Auflage 1996

Hagedorn, Rolf: Die Quellensteuer auf Zinserträge und die Hinterziehung von

Einkommensteuern,

in: Finanzarchiv N.F. 47 (1989), S. 24-45 
Hagedorn, Rolf: Steuerhinterziehung und Finanzpolitik

Ein theoretischer Beitrag unter besonderer Berücksichtigung der

Hinterziehung von Zinserträgen

Dissertation Fernuniversität Hagen 1991

Finanzwissenschaftliche Schriften Band 44

Verlag Peter Lang GmbH, Frankfurt am Main/Bern/NewYork/Paris 1991

Hansson, Ingemar; Stuart, Charles: Taxation, Labor Supply, and Government Spending: A Diagrammatic Exposition, in: Economic Inquiry (21) 1983, S. 584-587

Hensel, Albert: Zur Dogmatik des Begriffs der „Steuerumgehung“ Bonner Festgabe für Ernst Zitelmann München/Leipzig 1923, S. 217-288

Hensel, Nikolaus: Zur verfassungsrechtlichen Problematik des $\S 6$ Steueranpassungsgesetz, dargestellt am Beispiel des Steueroasenerlasses der Finanzminister der Länder vom 14. Juni 1965 Inaugural-Dissertation Freie Universität Berlin 1974

Herzog, Roman: Leitlinien und Entwicklungstendenzen der Rechtsprechung des Bundesverfassungsgerichts in Steuerfragen, in: Steuerberater-Jahrbuch 1985/86, S. 27-45

Hess, Dieter: Analogieverbot und Steuerrecht

Ein methodologischer und rechtlicher Beitrag zu den Grenzen der Lückenausfüllung im Steuerrecht dargestellt am Beispiel der Analogie Inaugural-Dissertation Universität zu Köln 1974

Hirai, Genji: Finanzpsychologische Aspekte der Staatsfinanzen, in: Horst Zimmermann (Hrsg.): Die Zukunft der Staatsfinanzierung Wissenschaftliche Verlagsgesellschaft $\mathrm{mbH}$, Stuttgart 1988, S. 111-119

Hübschmann, Walter; Hepp, Ernst; Spitaler, Armin:

Abgabenordnung

Finanzgerichtsordnung

Kommentar

Verlag Dr. Otto Schmidt KG Köln, 10. Auflage 1995, 149. Erg.-Lfg. 07/1996 
Huither, Michael: Integrierte Steuer-Transfer-Systeme für die Bundesrepublik

Deutschland

Normative Konzeption und empirische Analyse

Dissertation Universität Gießen 1990

Volkswirtschaftliche Schriften Heft 400

Duncker \& Humblot, Berlin 1990

Institut „Finanzen und Steuern“, Bonn: Analogie im Steuerrecht

Zur Unzulässigkeit einer steuerbegründenden oder steuerverschärfenden Lückenausfüllung im Steuerrecht

„Grüner Brief“" Nr. 243, Bonn 1985

Institut „Finanzen und Steuern“, Bonn: Zur Rückwirkung im Steuerrecht Zugleich eine Kritik am Beschluß des Bundesverfassungsgerichts vom 14. Mai 1986

„Grüner Brief" Nr. 269, Bonn 1987

The Institute of Economic Affairs (ed.): Tax Avoision

The economic, legal and moral inter-relationships between avoidance and evasion

IEA Readings 22, London 1979

S. 1- 19: Arthur Seldon:

Avoision: The Moral Blurring of a Legal Distinction without an Economic Difference

S. 21- 40: A. R. Ilersic: The Economics of Avoidance/Evasion

S. 41- 57: D. R. Myddelton: Tax Avoision - Its Costs and Benefits

S. 59- 73: Christie Davies: Can High Taxation Be Enforced?

S. 75- 88: Anthony Christopher: The Law is the Law is the Law

S. 89- 99: Lord Houghton of Sowerby:

The Futility of Taxation by Menaces

S. 99-103: Lord Houghton of Sowerby:

The Case Against the Aggressive Taxman

S. 105-113: Barry Bracewell-Milnes: Is Tax Avoidance/Evasion a Burden on Other Taxpayers?

S. 115-125: Robert Miller: Evidence of Attitudes to Evasion From a Sample Survey

Irmler, Hermann: Die Mehrheit der Deutschen ist steuerehrlich

Anmerkungen zum Deutschen Steuerberatertag 1984 in Stuttgart, in: Die Steuerberatung, 28. Jg., Nr. 1/1985, S. 10 f. (Leserbrief) 
Isachsen, Arne Jon; Strøm, Steinar:

The Hidden Economy: The Labor Market and Tax Evasion, in: The Scandinavian Journal of Economics 82 (1980), S. 304-311

Jahrmarkt, Manfred: Steuervorteile durch Steuergestaltung

Taktik - Vorsorge - Wahlrecht

Rudolf Haufe Verlag Freiburg, 5. Auflage 1981

Janssen, Bernhard: Zur Gerechtigkeit in der Familienbesteuerung in Theorie und Praxis,

in: Deutsche Steuer-Zeitung, 79 Jg., Nr. 1-2/1991, S. 13-24

Junker, Christoph: Steuerflucht und Basisunternehmen in England

Europäische Hochschulschriften Reihe II Rechtswissenschaft

Bd. 290

Verlag Peter Lang GmbH, Frankfurt am Main/Bern 1982

Karl-Bräuer-Institut des Bundes der Steuerzahler:

Zur Neuregelung der Familienbesteuerung

Heft 55, Wiesbaden 1983

Kay, John Alexander; King, M. A.: The British Tax System

Oxford University Press New York, 5. Auflage 1990

Kinsey, Karyl A.: Theories and Models of Tax Cheating,

in: Criminal Justice Abstracts 1986, S. 403-425

Kirchhof, Paul: Die Planung der Rechtsnachfolge bei Personengesellschaften am Maßstab des Ertragsteuerrechts,

in: Deutsches Anwaltsinstitut e.V. Bochum (Hrsg.): Jahrbuch der Fachanwälte für Steuerrecht 1979/1980, Herne/Berlin 1979, S. 254-274

Kirchhof, Paul: Steuerumgehung und Auslegungsmethoden, in: Steuer und Wirtschaft, 60. (13.) Jg., Nr. 2/1983 S. 173-183

Klein, Franz; Orlopp, Gerd: Abgabenordnung - einschließlich Steuerstrafrecht -

C. H. Beck'sche Verlagsbuchhandlung München,

5. Aufl. 1995 
Klepper, Steven; Nagin, Daniel: The Anatomy of Tax Evasion,

in: Journal of Law, Economics, and Organization, Vol. 5, No. $1 / 1989$, S. $1-24$

Kluge, Volker: Die Basisgesellschaft

Betriebswirtschaftliche Bedeutung und steuerrechtliche Beurteilung,

in: Die Aktiengesellschaft, 22. Jg., Nr. 12/1977, S. 325-334

Koch, Karl; Scholtz, Rolf-Detlev: Abgabenordnung AO 1977

Karl Heymanns Verlag AG Köln/Berlin/Bonn/München,

4. Auflage 1993

Koskela, Erkki (JPE 1983):

A Note on Progression, Penalty Schemes and Tax Evasion, in: Journal of Public Economics 22 (1983), S. 127-133

Koskela, Erkki (PF 1983): On the Shape of Tax Schedule, the Probability of Detection, and the Penalty Schemes as Deterrents to Tax Evasion, in: Public Finance, Vol. 38, No. 1/1983, S. 70-80

Kottke, Klaus: Das unechte Tatbestandsmerkmal des ungewöhnlichen Weges in $\S 42$ der Abgabenordnung, in: Betriebs-Berater, 38. Jg., Nr. 18/1983, S. 1146-1151

Kottke, Klaus: Steuerersparung, Steuerumgehung, Steuerhinterziehung Eine Sammlung lehrreicher Grenzfälle Rudolf Haufe Verlag Freiburg, 10. Auflage 1994

Kruse, Heinrich Wilhelm: Steuerumgehung zwischen Steuervermeidung und Steuerhinterziehung, in: Steuerberater-Jahrbuch 1978/79, S. 443-460

Kruse, Heinrich Wilhelm: Lehrbuch des Steuerrechts

Band I: Allgemeiner Teil

C.H. Beck'sche Verlagsbuchhandlung, München 1991

Kühn, Rolf; Kutter, Heinz; Hofmann, Ruth:

Abgabenordnung; Finanzgerichtsordnung, Nebengesetze Schäffer Verlag für Wirtschaft und Steuern GmbH Stuttgart, 16. Aufl. 1990 
Lang, Ulrich: Die zwei Seiten der Steuermoral, in: Die Steuerberatung, 28. Jg., Nr. 4/1985, S. 96-99

Larenz, Karl: Methodenlehre der Rechtswissenschaft, Springer-Verlag Berlin/Heidelberg/New York, 6. Aufl. 1991

Leibholz, Gerhard; Rinck, Hans-Justus; Hesselberger, Dieter:

Grundgesetz für die Bundesrepublik Deutschland Band 2

Kommentar an Hand der Rechtsprechung des Bundesverfassungsgerichts

Verlag Dr. Otto Schmidt KG Köln, 7. Auflage 1993, 28. Erg.-Lfg. 12/1995

Lewis, Alan: An Empirical Assessment of Tax Mentality, in: Public Finance, Vol. 34, No. 2/1979, S. 245-257

Lücke, Wolfgang (Hrsg.): Investitionslexikon

Verlag Franz Vahlen GmbH, München 1975

Masters, Colin: Is There a Need for General Anti-Avoidance Legislation in the United Kingdom?,

in: British Tax Review 1994, S. 647-673

Maunz, Theodor; Dürig, Günter: Grundgesetz Band IV

Kommentar

C.H. Beck'sche Verlagsbuchhandlung, München 1993,

31. Erg.-Lfg. 05/1994

Medenbach, Wilhelm: Reich bleiben und werden durch Steuer-Oasen Karlsruhe 1988

Meincke, Jens Peter: Erbschaftsteuer- und Schenkungsteuergesetz

Kommentar

C.H. Beck'sche Verlagsbuchhandlung München, 10. Auflage 1994

Messner, Walter: Steueroasen: Existenz und Bekämpfung

Mit praktischen Anwendungsfällen

Service-Fachverlag Wien, 2. Auflage 1987 
Mettelsiefen, Bernd: Zur Theorie der Steuerhinterziehung - Ein Überblick, in: Peter de Gijsel, Hans-Günther Seifert-Vogt (Hrsg.):

Schattenwirtschaft und alternative Ökonomie Eine Herausforderung für die Politische Ökonomie? Transfer Verlag GmbH, Regensburg 1984, S. 66-87

Metze, Ingolf: Negative Einkommensteuer, in: Handwörterbuch der Wirtschaftswissenschaft Bd. 9, Stuttgart 1982, S. 788-799

Meyer, Ulrich: Schattenwirtschaft

Definition, Erfassung, Ursachen und Wirkungen, in: Jochen Schumann (Hrsg.): Der Staat in den Volkswirtschaften Polens und der Bundesrepublik Deutschland Deutsch-polnische wirtschaftswissenschaftliche Studien Band 8 Bock + Herchen Verlag, Bad Honnef 1989, S. 72-85

Mihatsch, Günther: Änderung, Rücknahme und Widerruf von Steuerverwaltungsakten

Systematische Darstellung der steuerlichen Korrekturvorschriften (Grundlagen und Praxis des Steuerrechts Band 27)

Erich Schmidt Verlag GmbH \& Co., Bielefeld 1988

Millett, Peter: Artificial Tax Avoidance

The English and American Approach, in: British Tax Review 1986, S. 327-339

Mitschke, Joachim: Ungereimtheiten der Steuer- und Umverteilungspolitik, in: Wirtschaftsdienst, 66. Jg., Nr. 6/1986, S. 314-320

Mittelsteiner, Karl-Heinz; Schaumburg, Harald: Abgabenordnung 1977 Materialien

Dr. Peter Deubner Verlag GmbH Köln, 2. Aufl. 1977

Mork, Knut Anton: Income Tax Evasion: Some Empirical Evidence, in: Public Finance, Vol. 30, No. 1/1975, S. 70-76

von Münch, Ingo (Hrsg.): Grundgesetz-Kommentar Band 3 (Art. 70 bis Art. 146 und Gesamtregister)

C.H. Beck'sche Verlagsbuchhandlung München, 2. Aufl. 1983 
Musgrave, Richard A.; Musgrave, Peggy B.; Kullmer, Lore:

Die öffentlichen Finanzen in Theorie und Praxis Band 2

J.C.B. Mohr (Paul Siebeck) Tübingen, 5. Auflage 1993

Nevermann, Karsten: Justiz und Steuerumgehung

Ein kritischer Vergleich der Haltung der Dritten Gewalt zu kreativer steuerlicher Gestaltung in Großbritannien und Deutschland Dissertation Universität Hamburg 1993

Schriften zum Steuerrecht Band 48

Duncker \& Humblot GmbH, Berlin 1994

Niemann, Ursula: Bericht über die Podiumsdiskussion:

Steuervermeidung, Steuerumgehung, Steuerhinterziehung,

in: Steuerberater-Jahrbuch 1972/73, S. 533-539

Niessen, Hans-Joachim: Jeder zweite betrügt, in: Die Zeit Nr. 4 vom 20.1.1995, S. 20 (Interview)

OECD (1987): International Tax Avoidance and Evasion

Four Related Studies

Issues in International Taxation No.1

Paris 1987

OECD (intertax 1987): Tax havens, in: intertax no. 4-5/1987, S. 122-124

Offerhaus, Klaus: Zur Analogie im Steuerrecht, in: Betriebs-Berater, 39. Jg., Nr. 16/1984, S. 993-997

o.V.: $\quad$ Steuerzahlerbund moniert eine irrefuihrende Neidkampagne, in: Handelsblatt vom 19.3.1996, S. 4

Papier, Hans-Jürgen: Die finanzrechtlichen Gesetzesvorbehalte und das grundgesetzliche Demokratieprinzip

Zugleich ein Beitrag zur Lehre von den Rechtsformen der Grundrechtseingriffe

Duncker \& Humblot Berlin 1973

Paulick, Heinz: Lehrbuch des allgemeinen Steuerrechts, Heymann Köln/Berlin/Bonn/München, 3. Aufl. 1977 
Pencavel, John H.: A Note on Income Tax Evasion, Labour Supply, and Nonlinear Tax Schedules, in: Journal of Public Economics 12 (1979), S. 115-124

Pettersson, Lennart: Explanatory Memorandum, in: Council of Europe:

Cooperation between Member States against International Tax Avoidance and Evasion, in: Intertax No. 6-8/1978, S. 251-260, 298-311 [253 ff.]

Pflugfelder, Peter: Das Analogieverbot im Steuerrecht unter Berücksichtigung der Rechtsprechung der obersten Finanzgerichte, in: Steuer und Studium, 5. Jg., Nr. 10/1984, S. 290-293

Piltz, Detlev Jürgen: Doppelbesteuerungsabkommen und Steuerumgehung unter besonderer Berücksichtigung des treaty-shopping Betriebs-Berater Beilage 14/1987 zu Heft 18/1987

Pommerehne, Werner W.: Was wissen wir eigentlich über Steuerhinterziehung? Institut für empirische Wirtschaftsforschung der Universität Zürich Diskussionsbeitrag Nr. 8404, Zürich 1984

Pommerehne, Werner W.; Weck-Hannemann, Hannelore:

Steuerhinterziehung: Einige romantische, realistische und nicht zuletzt empirische Befunde,

in: Zeitschrift furr Wirtschafts- und Sozialwissenschaft, Bd. 112 (1992), S. 433-466

Popkin, William D.: Judicial Anti-Tax Avoidance Doctrine in England:

A United States Perspective, in: British Tax Review No. 8/1991, S. 283-310

Poterba, James M.: Tax Evasion and Capital Gains Taxation, in: The American Economic Review

Papers and Proceedings of the Ninety-Ninth Annual Meeting of the American Economic Association, New Orleans/Louisiana, December 28-30, 1986, Vol. 77, No. 2/1987, S. 234-239

Raab, Martin: Steuerarbitrage - Formen legaler Steuervermeidung und ihre Folgen,

in: Jahrbuch für Sozialwissenschaft, 43. Jg., Nr. 3/1992, S. 416-431 
Radeck, Harald: Positive Theorie der Steuerhinterziehung

(Arbeitspapiere des Fachbereichs Wirtschaftswissenschaft der Universität-Gesamthochschule Wuppertal Nr. 114)

Wuppertal 1988

Rauer, Horst: Mißbrauch von Gestaltungsmöglichkeiten des Rechts durch

Einschaltung einer Basisgesellschaft,

in: Der Betrieb, 36. Jg., Nr. 43/1983, S. 2276-2281

Reinganum, Jennifer F.; Wilde, Louis L.:

Income Tax Compliance in a Principal-Agent Framework, in: Journal of Public Economics 26 (1985), S. 1-18

Reuter, Hans Peter: Internationale Steuerpolitik im Unternehmen, in: Die Aktiengesellschaft, 23. Jg., Nr. 8/1978, S. 228-232

Rice, Eric Marshall: Skirting the Law: Essays on Corporate Tax Evasion and Avoidance,

Dissertation Harvard University, Cambridge/Massachusetts 1990

Riedel, Jürgen: Die Steuerumgehung

Inaugural-Dissertation, vorgelegt 1968

Dissertationsdruck Blasaditsch Augsburg

Römer, Gustav: Gesetzesumgehung im deutschen Internationalen Privatrecht

Walter de Gruyter \& Co., Berlin 1955

Rosen, Harvey S.: Public Finance

Richard D. Irwin INC. Homewood/Boston, 3. Aufl. 1992

Sachverständigenrat zur Begutachtung der gesamtwirtschaftl. Entwicklung:

Zeit zum Handeln - Antriebskräfte stärken

Jahresgutachten 1993/94

Metzler-Poeschel, Stuttgart 1993

von Savigny, Friedrich Carl:

System des heutigen Römischen Rechts, Erster Band

Veit und Comp, Berlin 1840 
Schäfer, Wolf (Hrsg.): Schattenökonomie

Theoretische Grundlagen und wirtschaftspolitische Konsequenzen

Vandenhoeck \& Ruprecht, Göttingen 1984

S. 81-101: Hans-Georg Petersen: Staatstätigkeit, Leistungsanreize und Schattenwirtschaft

S. 122-156: Wolfgang Wiegard: Schwarzarbeit und Besteuerung

Schmid, Alfons: Die internationale Steuerflucht

Möglichkeiten und Bekämpfungsmethoden

Dissertation Handels-Hochschule St. Gallen

Veröffentlichungen der Handels-Hochschule St. Gallen Reihe A

Heft 59

Polygraphischer Verlag AG, Zürich und St. Gallen 1961

Schmölders, Günter: Finanzpsychologie,

in: Finanzarchiv N.F. 13 (1951/52), S. 1-36

Schneider, Dieter: Steuergerechtigkeit durch Regelungen gegen Steuervermeidung - ein „Gefangenendilemma“ des Steuerrechts,

in: Steuer und Wirtschaft, 62. (15.) Jg., Nr. 4/1985, S. 345-355

Schulze-Osterloh, Joachim: Unbestimmtes Steuerrecht und strafrechtlicher Bestimmtheitsgrundsatz,

in: Günter Kohlmann (Hrsg.):

Strafverfolgung und Strafverteidigung im Steuerstrafrecht

Grundfragen des Steuerstrafrechts heute

Verlag Dr. Otto Schmidt KG, Köln 1983, S. 43-66

Schwarz, Bernhard (Hrsg.): Abgabenordnung (AO)

Kommentar

Rudolf Haufe Verlag GmbH \& Co. KG, Freiburg 1976,

75. Erg.-Lfg. 06/1996

Seidl, Christian: Normative Theorien der Steuerdisziplin der Selbständigen

Eine Analyse des Zensitenverhaltens

Veröffentlichungen der Kommission für Sozial- und Wirtschaftswissenschaften $\mathrm{Nr} .2$

Verlag der Österreichischen Akademie der Wissenschaften,

Wien 1974 
Seuffert, Walter: „Lückenausfüllung“ und „Analogieschlüsse“ im Steuerrecht, in: Deutsches Steuerrecht, 23. Jg., Nr. 1-2/1985, S. 5-9

Shenfield, A. A.: The Political Economy of Tax Avoidance Harrison \& Son Ltd., London 1968

Slemrod, Joel: An Empirical Test for Tax Evasion, in: Review of Economics and Statistics 67 (1985), S. 232-238

Snelting, Martin: Übergangsgerechtigkeit beim Abbau von Steuervergünstigungen und Subventionen Untersuchung eines finanzwissenschaftlichen und staatsrechtlichen Problems unveröffentlichte Dissertation Universität Hamburg 1996, erscheint im Physica Verlag Heidelberg

Spicer, Michael W.: Civilization at a Discount: The Problem of Tax Evasion, in: National Tax Journal, Vol. 39, No. 1/1986, S. 13-20

Spicer, Michael W.; Hero, Rodney E.: Tax Evasion and Heuristics A research note, in: Journal of Public Economics 26 (1985), S. 263-267

Spicer, Michael W.; Lundstedt, S. B.: Understanding Tax Evasion, in: Public Finance, Vol. 31, No. 2/1976, S. 295-305

Srinivasan, T. N.: Tax Evasion: A Model, in: Journal of Public Economics 2 (1973), S. 339-346

Steuerreformkommission: Gutachten der Steuerreformkommission 1971 Schriftenreihe des Bundesministeriums der Finanzen Heft 17 Bonn 1971

Stiglitz, Joseph E.: The General Theory of Tax Avoidance, in: National Tax Journal, Vol. 38, No. 3/1985, S. 325-337

Stiglitz, Joseph E.; Schönfelder, Bruno: Finanzwissenschaft R. Oldenbourg Verlag GmbH München/Wien, 2. Auflage (1. deutschsprachige Auflage) 1989 
Tanzer, Michael: Das „Analogieverbot“ im Steuerrecht

Eine Wertbetrachtung auf der Grundlage des kritischen Rechtspositivismus,

in: Steuer und Wirtschaft, 58. (11.) Jg., Nr. 3/1981, S. 201-219

Teichmann, Arndt: Die Gesetzesumgehung

Göttinger Rechtswissenschaftliche Studien Band 46

Verlag Otto Schwartz \& Co., Göttingen 1962

Thoma, Gerhard: Die mißbräuchliche Steuerumgehung,

in: Steuerberater-Jahrbuch 1950, S. 57-74

Tiedemann, Klaus: Die Bekämpfung der Wirtschaftskriminalität als Aufgabe der Gesetzgebung am Beispiel der Steuer- und Subventionsdelinquenz, in: Goltdammer's Archiv für Strafrecht 1974, S. 1-14

Tilch, Horst (Redaktor): Münchener Rechts-Lexikon

Band 1 A-F

C.H. Beck'sche Verlagsbuchhandlung, München 1987

Tipke, Klaus: Systematisierung des allgemeinen Steuerrechts

Ein Alternativvorschlag zum Regierungsentwurf einer Abgabenordnung,

in: Steuer und Wirtschaft, 48. (1.) Jg., Nr. 2/1971, S. 95 ff.

Tipke, Klaus: Steuerrecht

Ein systematischer Grundriß

Verlag Dr. Otto Schmidt KG Köln, 5. Aufl. 1978

Tipke, Klaus: Steuergerechtigkeit in Theorie und Praxis:

Vom politischen Schlagwort zum Rechtsbegriff und zur prakti-

schen Anwendung

Verlag Dr. Otto Schmidt KG, Köln 1981

Tipke, Klaus: Über teleologische Auslegung, Lückenfeststellung und Lückenaus-

füllung,

in: Der Bundesfinanzhof und seine Rechtsprechung

Grundfragen - Grundlagen

Festschrift für Hugo von Wallis, Bonn 1985, S. 133-150 
Tipke, Klaus: Die Steuerrechtsordnung.

Band I: Wissenschaftsorganisatorische, systematische und grundrechtlich-rechtsstaatliche Grundlagen (S. 1-516)

Band II: Steuerrechtfertigungstheorie, Anwendung auf alle Steuerarten, sachgerechtes Steuersystem (S. 517-1050)

Band III: Föderative Steuerverteilung, Rechtsanwendung und

Rechtsschutz, Gestalter der Steuerrechtsordnung (S. 1051-1593)

Verlag Dr. Otto Schmidt KG, Köln 1993

Tipke, Klaus; Kruse, Heinrich Wilhelm:

Abgabenordnung, Finanzgerichtsordnung

Kommentar zur AO 1977 und FGO (ohne Steuerstrafrecht)

Verlag Dr. Otto Schmidt KG Köln, 16. Auflage 1996,

79. Erg.-Lfg. 08/1996

Tipke, Klaus; Lang, Joachim: Zur Reform der Familienbesteuerung,

in: Steuer und Wirtschaft, 61. (14.) Jg., Nr. 2/1984, S. 127-132

Tipke, Klaus; Lang, Joachim: Steuerrecht

Ein systematischer Grundriß

Verlag Dr. Otto Schmidt KG Köln, 14. Aufl. 1994

Tretter, Bertram: Die Steuermentalität

Ein internationaler Vergleich

Finanzwissenschaftliche Forschungsarbeiten Neue Folge Heft 45

Duncker \& Humblot, Berlin 1974

Ulmer, Eckhart: Steuervermeidung, Steuerumgehung, Steuerhinterziehung,

in: Deutsche Steuer-Zeitung, 74. Jg., Nr. 12/1986, S. 292-297

Urbas, Helmut: Die wirtschaftliche Betrachtungsweise im Steuerrecht

(Europäische Hochschulschriften: Reihe 5, Volks- und Betriebswirtschaft, Bd. 785)

Peter Lang GmbH, Frankfurt/Bern/New York/Paris 1987 
Vogel, Klaus: Resümee

zu den Vorträgen und Diskussionsbeiträgen der Teilnehmer an der Jahrestagung der Deutschen Steuerjuristischen Gesellschaft e.V. vom 8.-9.10.1984 in Heidelberg, in: Klaus Vogel (Hrsg.):

Grundfragen des internationalen Steuerrechts

Verlag Dr. Otto Schmidt KG, Köln 1985, S. 275-281

Vogel, Klaus: Doppelbesteuerungsabkommen

der Bundesrepublik Deutschland auf dem Gebiet der Steuern vom Einkommen und Vermögen

Kommentar auf der Grundlage der Musterabkommen

C.H. Beck'sche Verlagsbuchhandlung München, 3. Auflage 1996

Völker, Gerhard: Zum Ausfüllen von Gesetzeslücken im Steuerrecht

Eine Stellungnahme für die Praxis,

in: Deutsche Steuer-Zeitung, 77. Jg., Nr. 10/1989, S. 235-241

Wackernagel, Jacob: Die Steuerumgehung und ihre Verhütung unter besonderer Berücksichtigung des schweizerischen Rechts

Basel 1949

Wagner, Franz Wilhelm: Der gesellschaftliche Nutzen einer betriebswirtschaftlichen Steuervermeidungslehre, in: Finanzarchiv N.F. 44 (1986), S. 32-54

Wagner, Franz Wilhelm: Neutralität und Gleichmäßigkeit als ökonomische und rechtliche Kriterien steuerlicher Normkritik, in: Steuer und Wirtschaft, 69. (22.) Jg., Nr. 1/1992, S. 2-13

Wagner, Franz Wilhelm; Dirrigl, Hans: Die Steuerplanung der Unternehmung Gustav Fischer Verlag, Stuttgart/New York 1980

von Wallis, Hugo: Belastende Analogie im Steuerrecht?, in: NWB Nr. 31 vom 28.7.1986 Fach 2, S. 4679-4682

Walz, Wolfgang Rainer: Steuergerechtigkeit und Rechtsanwendung Grundlinien einer relativ autonomen Steuerrechtsdogmatik R. v. Decker's Verlag, G. Schenck GmbH, Heidelberg/Hamburg 1980 
Walz, Wolfgang Rainer: Richterliche Rechtsfindung im Steuerrecht der USA, in: Steuer und Wirtschaft, 59. (12.) Jg., Nr. 1/1982, S. 1-13

Wassermeyer, Franz: Erfahrungen mit dem Außensteuergesetz von 1972, in: Karl-Heinrich Hansmeyer (Hrsg.):

Staatsfinanzierung im Wandel

Schriften des Vereins für Socialpolitik N.F. Band 134

Duncker \& Humblot, Berlin 1983, S. 573-591

Westerhoff, Rudolf: Gesetzesumgehung und Gesetzeserschleichung Dissertation Universität Hamburg 1966

Will-Feld, Waltrud: Überfordert der Gesetzgeber den Steuerzahler und schwächt er damit die Steuermoral?, in: Die Steuerberatung, 28. Jg., Nr. 1/1985, S. 9 f.

Witte, Ann D.; Woodbury, Diane F.:

The Effect of Tax Laws and Tax Administration on Tax Compliance: The Case of the U.S. Individual Income Tax, in: National Tax Journal, Vol. 38, No. 1/1985, S. 1-13

Wrede, Matthias: Ökonomische Theorie des Steuerentzuges Steuervermeidung, -umgehung und -hinterziehung Dissertation Universität Bamberg Wirtschaftswissenschaftliche Beiträge 86 Physica-Verlag Heidelberg 1993

Yitzhaki, Shlomo: A Note on Income Tax Evasion: A Theoretical Analysis, in: Journal of Public Economics 3 (1974), S. $201 \mathrm{f}$.

Yitzhaki, Shlomo: On the Excess Burden of Tax Evasion, in: Public Finance Quarterly, Vol. 15, No. 2/1987, S. 123-137

Zimmermann, Horst; Henke, Klaus-Dirk: Finanzwissenschaft

Eine Einführung in die Lehre von der öffentlichen Finanzwirtschaft Verlag Franz Vahlen München, 7. Aufl. 1994 
Ralf Oberheide - 978-3-631-75185-5

Downloaded from PubFactory at 01/11/2019 07:21:58AM

via free access 


\section{Verzeichnis der zitierten Gerichtsentscheidungen}

\section{Deutschland}

Bundesfinanzhof:

BFH-Urteil vom

BFH-Urteil vom

8.1.1958

I $131 / 57 \quad U$

BStBl. 1958 III

S. 97

BFH-Urteil vom

16.9 .1958

I $351 / 56 \quad \mathrm{U}$

BStB1. 1958 III

S. 462

BFH-Urteil vom

22.1 .1960

V $52 / 56 \quad \mathrm{~S}$

BStB1. 1960

S. 111

BFH-Urteil vom

8.11 .1960

I $131 / 59 \mathrm{~S}$

BStBl. 1960

III

S. 513

BFH-Urteil vom

25.7 .1961

II $154 / 59$

BStB

S. 21

BFH-Urteil vom

14.3.1962

I $54 / 60$ U

BStB1. 1961

III

S. 422

BFH-Urteil vom

22.11 .1963

II $218 / 59$

BStB

S. 206

BFH-Urteil vom

14.10.1964

VI $178 / 62$ U

BStB

1962

III

II $175 / 61 \quad \mathrm{U}$

BStB

S. 74

BFH-Urteil vom 28.10.1964

I $198 / 62 U$

BStBl. 1965

III

S. 667

BFH-Urteil vom

2.3 .1966

II

$113 / 61$

BStBl. 1966

III

S. 119

BFH-Urteil vom

29.11 .1966

BFH-Urteil vom

15.11.1967

$216 / 64$

BStBl. 1967

S. 509

BFH-Urteil vom 28.11.1967

IV R $139 / 67$

BStB1. 1968

III

S. 392

BFH-Urteil vom

26.9.1968

II

$110 / 62$

BStBl. 1968

II

S. 152

BFH-Urteil vom

18.12 .1968

IV

$121 / 64$

BStBl. 1969

II

S. 216

BFH-Urteil vom

5.5 .1970

III

R $71 / 68$

BStBl. 1969

II S. 102

II R $\quad 98 / 69$

BStB1. 1970

II

S. 232

BFH-Beschl. vom

8.11.1971

GrS

$2 / 71$

BStBl. 1972

II

S. 757

BFH-Urteil vom

18.1.1972

VIII R $125 / 69$

BStB1. 1972

S. 63

BFH-Urteil vom

28.1.1972

III

R $108 / 70$

BStB1. 1972

S. 344

11.2.1972

III

29.5.1972

R $5 / 70$

BStB1. 1972

S. 414

BFH-Beschl. vom

6.6 .1973 GrS $\quad 4 / 71$

BStBl. 1973

S. 480

BFH-Urteil vom

16.1.1974

R $257 / 70$

BStBl. 1973

S. 5

BFH-Urteil vom

29.1.1975

R $176 / 72$

BStBl. 1974

S. 670

BFH-Urteil vom

21.1.1976

R $135 / 70$

BStB1. 1975

S. 294

BFH-Urteil vom

BFH-Urteil vom

29.7.1976 VIII

R 234/73

BStB1. 1976

S. 553

BFH-Urteil vom

27.1.1977

R $142 / 73$

BStB1. 1977

S. 513

BFH-Urteil vom

18.2.1977

R $46 / 76$

BStB1. 1977

S. 263

BFH-Urteil vom

16.3.1977

VI

R $177 / 75$

BStB1. 1977

S. 754

BFH-Urteil vom

4.8.1977

R 213/74

BStB1. 1977

S. 524

BFH-Urteil vom

31.5 .1978

IV

R $57 / 74$

BStB1. 1977

S. 414

BFH-Urteil vom

25.10.1979 VIII

R $53 / 76$

BStB1. 1978

S. 843

BFH-Urteil vom

13.2.1980

R $46 / 76$

BStBl. 1980

S. 577

BFH-Urteil vom

II R $\quad 18 / 75$

BStB1. 1980

S. 247

IV $\mathrm{R} \quad \mathbf{8 1 / 7 7}$

BStBl. 1981

II

S. 364

S. 223 


\begin{tabular}{|c|c|c|c|c|c|c|c|c|c|}
\hline FH-Urteil & vom & 14.10 .1981 & I & $\mathbf{R}$ & $34 / 80$ & StBl. & 1982 & II & S. \\
\hline FH-Urteil & vom & 29.10 .1981 & & & $89 / 80$ & BStBl. & 1982 & & S. \\
\hline FH-Urteil & vom & 12.1981 & & & $25 / 79$ & $\mathrm{tBl}$. & 1982 & & 618 \\
\hline FH-Beschl. & vom & 28.4.1982 & & $\mathbf{R}$ & $89 / 77$ & StBl. & 1982 & II & 556 \\
\hline H-Beschl. & vom & 29.11 .82 & \multicolumn{2}{|c|}{ GrS } & $1 / 81$ & 3StB1. & 1983 & II & 272 \\
\hline FH-Urteil & vom & 1.12 .1982 & I & $\mathbf{R}$ & $43 / 79$ & StBI. & 1985 & II & $\mathrm{C}$ \\
\hline H-Beschl. & vom & 1.2 .1983 & VIII & $\mathbf{R}$ & $30 / 80$ & StB1. & 1983 & & \\
\hline FH-Urteil & vom & 5.10 .1983 & II & R & $92 / 79$ & StBl. & 1984 & & 147 \\
\hline rteil & vom & 20.1 & IV & R & $175 / 79$ & Bl. & 1984 & & 221 \\
\hline rteil & vom & 83 & VIII & $\mathbf{R}$ & $3 / 83$ & & & & 428 \\
\hline rteil & vom & 15.1 & V & $\mathbf{R}$ & $69 / 75$ & StBl. & 1984 & II & 388 \\
\hline rteil & vom & & VIII & $\mathbf{R}$ & $134 / 81$ & Bl. & 1984 & & 705 \\
\hline H-Urteil & vom & & IX & $\mathbf{R}$ & $3 / 79$ & StBl. & 1985 & & 33 \\
\hline rteil & vom & 29.1 & V & $\mathbf{R}$ & $38 / 78$ & StBl. & 1985 & & S. 269 \\
\hline teil & vom & & II & $\mathrm{R}$ & $240 / 83$ & & & & 494 \\
\hline teil & vom & & I & $\mathrm{R}$ & & StB1. & 19 & & 680 \\
\hline treil & vom & & VII & $\mathrm{R}$ & $172 / 83$ & StBl. & 1985 & II & 636 \\
\hline rteil & vom & 29. & IX & $\mathrm{R}$ & $07 / 82$ & & 19 & 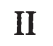 & 217 \\
\hline Urteil & vom & & I & $\mathbf{R}$ & $201 / 82$ & 3StBl. & 1986 & & $S$. \\
\hline eil & vom & & II & $\mathrm{R}$ & $22 / 84$ & StBl. & 198 & & 620 \\
\hline teil & vom & & IV & & $12 / 81$ & 31. & 19 & & 811 \\
\hline rteil & vom & & VII & $\mathbf{R}$ & $69 / 83$ & BStB1. & 19 & II & 821 \\
\hline teil & vom & & I & $\mathbf{R}$ & $202 / 82$ & 3StB1. & 1987 & II & 308 \\
\hline rteil & vom & & VIII & D & & StBl. & 19 & & S. \\
\hline teil & vom & & IX & R & $85 / 85$ & BStBl. & 198 & & 492 \\
\hline & & & III & $\mathbf{R}$ & $197 / 83$ & StBl. & 19 & & 603 \\
\hline teil & vom & & IX & R & $41 / 86$ & 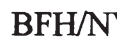 & V1987 & & 714 \\
\hline teil & vom & & IX & $\mathbf{R}$ & $7 / 83$ & $\mathrm{BSt}$ & 1987 & II & 814 \\
\hline & vom & & I & $\mathbf{R}$ & 149 & & & II & 25 \\
\hline eschl. & vom & & V & B & & Bl. & 19 & II & 756 \\
\hline iil & von & & IX & $\mathbf{R}$ & $163 / 83$ & BStBl. & 1989 & II & 702 \\
\hline & & & II & $\mathbf{R}$ & $145 / 85$ & BStBI. & 198 & 1 & 547 \\
\hline rteil & & & IX & $\mathbf{R}$ & $157 / 84$ & BStB1. & 1988 & I & 604 \\
\hline FH-Urteil & vom & & V & $\mathbf{R}$ & $183 / 83$ & BStB1. & 19 & II & 205 \\
\hline rteil & vom & & $\mathrm{X}$ & $\mathbf{R}$ & $27 / 86$ & BStB1. & 1988 & II & 629 \\
\hline & & & V & $\mathbf{R}$ & $115 / 83$ & BStBl. & 1988 & II & 916 \\
\hline & & & I & $\mathbf{R}$ & $2 / 85$ & BStBl. & 1989 & II & 473 \\
\hline & & & V & & $60 / 88$ & & & & 396 \\
\hline FH-Urteil & & & & & $46 / 85$ & BStBl. & & & 113 \\
\hline BFH-Urteil & & 13.7 .1989 & V & $\mathbf{R}$ & $8 / 86$ & BStBl. & 1990 & II & 100 \\
\hline BFH-Beschl. & & 27.11 .1989 & & UIS & $1 / 88$ & BStBl. & 1990 & II & S. 160 \\
\hline
\end{tabular}




$\begin{array}{lrrrrrllll}\text { BFH-Urteil vom } & 6.3 .1990 & \text { II } & \text { R } & 88 / 87 & \text { BStBl. } & 1990 & \text { II } & \text { S. } 446 \\ \text { BFH-Beschl. vom } & 4.7 .1990 & \text { GrS } & 2-3 / 88 & \text { BStBl. } & 1990 & \text { II } & \text { S. } 817 \\ \text { BFH-Urteil vom } & 17.1 .1991 & \text { IV } & \text { R } & 132 / 85 & \text { BStBl. } & 1991 & \text { II } & \text { S. } 607 \\ \text { BFH-Urteil vom } & 6.2 .1991 & \text { I } & \text { R } & 101 / 88 & \text { BStBl. } & 1991 & \text { II } & \text { S. } 851 \\ \text { BFH-Urteil vom } & 5.3 .1991 & \text { VIII } & \text { R } & 93 / 84 & \text { BStBl. } & 1991 & \text { II } & \text { S. } & 516 \\ \text { BFH-Urteil vom } & 23.10 .1991 & \text { I } & \text { R } & 40 / 89 & \text { BStBl. } & 1992 & \text { II } & \text { S. } 1026 \\ \text { BFH-Urteil vom } & 12.2 .1992 & \text { X } & \text { R } & 121 / 88 & \text { BStBl. } & 1992 & \text { II } & \text { S. } 468 \\ \text { BFH-Urteil vom } & 10.6 .1992 & \text { I } & \text { R } & 105 / 89 & \text { BStBl. } & 1992 & \text { II } & \text { S. } 1029\end{array}$

Bundesgerichtshof:

BGH-Beschl.vom

18.3.1952 - GSSt $2 / 51$ - BGHSt 2

S. 194

BGH-Urteil vom

27.1.1982 -3 StR 217/81 - DB 1982

S. 2676

Bundesverfassungsgericht:

$\begin{array}{lrllll}\text { BVerfG-Urteil vom } & 21.5 .1952 & -2 \mathrm{BvH} & 2 / 52- & \text { BVerfGE } & 1,299 \\ \text { BVerfG-Beschl. vom } & 17.5 .1960 & -2 \mathrm{BvL} & 11 / 59,11 / 60- & \text { BVerfGE } & 11,126 \\ \text { BVerfG-Beschl. vom } & 10.10 .1961 & -2 \mathrm{BvL} & 1 / 59- & \text { BVerfGE } & 13,153 \\ \text { BVerfG-Urteil vom } & 19.12 .1961 & -2 \mathrm{BvL} & 6 / 59- & \text { BVerfGE } & 13,261 \\ \text { BVerfG-Urteil vom } & 24.1 .1962 & -1 \mathrm{BvR} & 232 / 60- & \text { BVerfGE } & 13,318 \\ \text { BVerfG-Beschl. vom } & 10.6 .1963 & -1 \mathrm{BvR} & 345 / 61- & \text { BVerfGE } & 16,203 \\ \text { BVerfG-Beschl. vom } & 16.11 .1965 & -2 \mathrm{BvL} & 8 / 64- & \text { BVerfGE } & 19,187 \\ \text { BVerfG-Urteil vom } & 14.12 .1965 & -1 \mathrm{BvR} & 571 / 60- & \text { BVerfGE } & 19,253 \\ \text { BVerfG-Beschl. vom } & 13.12 .1966 & -1 \mathrm{BvR} & 512 / 65- & \text { BVerfGE } & 21,1 \\ \text { BVerfG-Beschl. vom } & 26.2 .1969 & -2 \mathrm{BvL} & 15,23 / 68- & \text { BVerfGE } & 25,269 \\ \text { BVerfG-Beschl. vom } & 10.3 .1971 & -2 \mathrm{BvL} & 3 / 68- & \text { BVerfGE } & 30,272 \\ \text { BVerfG-Beschl. vom } & 22.6 .1971 & -2 \mathrm{BvL} & 6 / 70- & \text { BVerfGE } & 31,222 \\ \text { BVerfG-Beschl. vom } & 11.2 .1976 & -2 \mathrm{BvL} & 2 / 73- & \text { BVerfGE } & 41,314 \\ \text { BVerfG-Urteil vom } & 8.2 .1977 & -1 \mathrm{BvR} & 79,278,282 / 70- & \text { BVerfGE } & 43,242 \\ \text { BVerfG-Beschl. vom } & 21.6 .1977 & -2 \mathrm{BvR} & 308 / 77- & \text { BVerfGE } & 45,363 \\ \text { BVerfG-Beschl. vom } & 19.4 .1978 & -2 \mathrm{BvL} & 2 / 75- & \text { BVerfGE } & 48,210 \\ \text { BVerfG-Beschl. vom } & 8.1 .1981 & -2 \mathrm{BvL} & 3,9 / 77- & \text { BVerfGE } & 56,1 \\ \text { BVerfG-Beschl. vom } & 22.3 .1983 & -2 \mathrm{BvR} & 475 / 78- & \text { BVerfGE } & 63,343 \\ \text { BVerfG-Beschl. vom } & 14.6 .1983 & -2 \mathrm{BvR} & 488 / 80- & \text { BVerfGE } & 64,208 \\ \text { BVerfG-Beschl. vom } & 10.4 .1984 & -2 \mathrm{BvL} & 19 / 82- & \text { BVerfGE } & 67,1 \\ \text { BVerfG-Beschl. vom } & 23.10 .1985 & -1 \mathrm{BvR} & 1053 / 82- & \text { BVerfGE } & 1,108 \\ \text { BVerfG-Beschl. vom } & 13.5 .1986 & -1 \mathrm{BvR} & 99,461 / 85- & \text { BVerfGE } & 72,175 \\ \text { BVerfG-Beschl. vom } & 6.5 .1987 & -2 \mathrm{BvL} & 11 / 85- & \text { BVerfGE } & 75,329 \\ \text { BVerfG-Beschl. vom } & 14.5 .1986 & -2 \mathrm{BvL} & 2 / 83- & \text { BVerfGE } & 72,200 \\ \text { BVerfG-Beschl. vom } & 31.5 .1988 & -1 \mathrm{BvR} & 520 / 83- & \text { BVerfGE } & 78,214 \\ \text { BVerfG-Beschl. vom } & 27.11 .1990 & -1 \mathrm{BvR} & 402 / 87- & \text { BVerfGE } & 83,130 \\ \text { BVerfG-Beschl. vom } & 25.9 .1992 & -2 \mathrm{BvL} & 5,8,14 / 91- & \text { BVerfGE } & 87,153\end{array}$


BVerfG-Beschl.vom 17.11.1992 -1 BvR 168,1509/89;

638,639/90- BVerfGE 87,363

BVerfG-Beschl.vom 22.6.1995 -2 BvL 37/91- $\quad$ NJW 1995, 2615

BVerfG-Beschl. vom 22.6.1995 -2 BvR 552/91- $\quad$ NJW 1995, 2624

Finanzgerichte:

FG Baden-Württemberg Urteil vom 11.3.1987 VII-K 396/84 EFG 1987

FG Baden-Württemberg Urteil vom 13.4.1989 II K 55/87 $\begin{array}{lll}\text { S. } 429 \\ \text { EFG } 1989\end{array}$

$\begin{array}{lllll}\text { FG Münster } & \text { Urteil vom } & 16.4 .1985 & \text { VI 670/85 } & \text { EFG } 1986\end{array}$

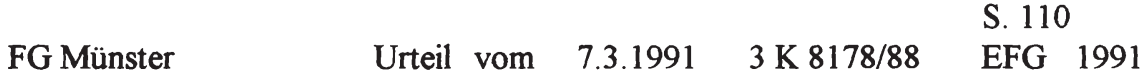

$\begin{array}{llll}\text { FG Nürnberg } & \text { Urteil vom 13.5.1977 } & \text { III 176/76 } 737 & \text { EFG } 1977\end{array}$

$\begin{array}{lllll}\text { FG Nümberg } & \text { Urteil vom 21.3.1979 } & \text { V 256/77 } & \text { EF } 1979\end{array}$

FG Rheinland-Pfalz Urteil vom $14.3 .1989 \quad 2$ K $316 / 88 \quad \begin{aligned} & \text { S. } 460 \\ & \text { EFG } 1989\end{aligned}$

S. 598

Reichsfinanzhof:

$\begin{array}{lllllllll}\text { RFH-Urteil vom } & 26.7 .1919 & \text { I } & \text { A } & 82 / 19 & \text { RFHE } & 2, & 183\end{array}$

RFH-Urteil vom 26.4.1921 II A $412 / 20$ RFHE 5, 247

RFH-Urteil vom 30.6 .1922 II A $132 / 22$ RFHE 10,65

RFH-Urteil vom 15.7 .1925 I A $18 / 25$ RFHE 17, 91

\section{Großbritannien}

Moodie vs. IRC [1993] 2 All ER S. 49 WLR v. 26.2.1993 S. 266 Fitzwilliam vs. IRC [1993] 3 All ER S. 184

\section{Frankreich}

Conseil d'État

Cour administrative d'appel de Nantes

Conseil d'État

$\begin{array}{llll}\text { v. } 23.2 .1979 & \text { RJF } & 1979 & \text { S. } 143 \\ \text { v. 19.4.1989 } & \text { RJF } & 1989 & \text { S. } 518 \\ \text { v. 15.1.1992 } & \text { DF } & 1992 & \text { S. } 1923\end{array}$




\section{FINANZWISSENSCHAFTLICHE SCHRIFTEN}

Band 1 Werner Steden: Finanzpolitik und Einkommensverteilung. Ein Wachstums- und Konjunkturmodell der Bundesrepublik Deutschland. 1979.

Band 2 Rainer Hagemann: Kommunale Finanzplanung im föderativen Staat. 1976.

Band 3 Klaus Scherer: Maßstäbe zur Beurteilung von konjunkturellen Wirkungen des öffentlichen Haushalts. 1977.

Band 4 Brita Steinbach: "Formula Flexibility" - Kritische Analyse und Vergleich mit diskretionärer Konjunkturpolitik. 1977.

Band 5 Hans-Georg Petersen: Personelle Einkommensbesteuerung und Inflation. Eine theoretisch-empirische Analyse der Lohn- und veranlagten Einkommensteuer in der Bundesrepublik Deutschland. 1977.

Band 6 Friedemann Tetsch: Raumwirkungen des Finanzsystems der Bundesrepublik Deutschland. Eine Untersuchung der Auswirkungen der Finanzreform von 1969 auf die Einnahmenposition der untergeordneten Gebietskörperschaften und ihrer regionalpolitischen Zieladäquanz. 1978.

Band 7 Wilhelm Pfähler: Normative Theorie der fiskalischen Besteuerung. Ein methodologischer und theoretischer Beitrag zur Integration der normativen Besteuerungstheorie in der Wohlfahrtstheorie. 1978.

Band 8 Wolfgang Wiegard: Optimale Schattenpreise und Produktionsprogramme für öffentliche Unternehmen. Second-Best Modelle im finanzwirtschaftlichen Staatsbereich. 1978.

Band 9 Hans P. Fischer: Die Finanzierung des Umweltschutzes im Rahmen einer rationalen Umweltpolitik. 1978.

Band 10 Rainer Paulenz: Der Einsatz finanzpolitischer Instrumente in der Forschungs- und Entwicklungspolitik. 1978.

Band 11 Hans-Joachim Hauser: Verteilungswirkungen der Staatsverschuldung. Eine kreislauftheoretische Inzidenzbetrachtung. 1979.

Band 12 Gunnar Schwarting: Kommunale Investitionen. Theoretische und empirische Untersuchungen der Bestimmungsgründe kommunaler Investitionstätigkeit in NordmeinWestfalen 1965-1972. 1979.

Band 13 Hans-Joachim Conrad: Stadt-Umland-Wanderung und Finanzwirtschaft der Kemstäđte. Amerikanische Erfahrungen, grundsätzliche Zusammenhänge und eine Fallstudie für das Ballungsgebiet Frankfurt am Main. 1980.

Band 14 Cay Folkers: Vermögensverteilung und staatliche Aktivität. Zur Theorie distributiver Prozesse im Interventionsstaat. 1981.

Band 15 Helmut Fischer: US-amerikanische Exportförderung durch die DISC-Gesetzgebung. 1981.

Band 16 Günter Ott: Einkommensumverteilungen in der gesetzlichen Krankenversicherung. Eine quantitative Analyse. 1981.

Band 17 Johann Hermann von Oehsen: Optimale Besteuerung. (Optimal Taxation). 1982.

Band 18 Richard Kössler: Sozialversicherungsprinzip und Staatszuschüsse in der gesetzlichen Rentenversicherung. 1982.

Band 19 Hinrich Steffen: Zum Handlungs- und Entscheidungsspielraum der kommunalen Investitionspolitik in der Bundesrepublik Deutschland. 1983.

Band 20 Manfred Scheuer: Wirkungen einer Auslandsverschuldung des Staates bei flexiblen Wechselkursen. 1983. 
Band 21 Christian Schiller: Staatsausgaben und crowding-out-Effekte. Zur Effizienz einer Finanzpolitik keynesianischer Provenienz. 1983.

Band 22 Hannelore Weck: Schattenwirtschaft: Eine Möglichkeit zur Einschränkung der öffentlichen Verwaltung? Eine ökonomische Analyse. 1983.

Band 23 Wolfgang Schmitt: Steuern als Mittel der Einkommenspolitik. Eine Ergänzung der Stabilitätspolitik? 1984.

Band 24 Wolfgang Laux: Erhöhung staatswirtschaftlicher Effizienz durch budgetäre Selbstbeschränkung? Zur Idee einer verfassungsmäßig verankerten Ausgabengrenze. 1984.

Band 25 Brita Steinbach-van der Veen: Steuerinzidenz. Methodologische Grundlagen und empirisch-statistische Probleme von Länderstudien. 1985.

Band 26 Albert Peters: Ökonomische Kriterien für eine Aufgabenverteilung in der Marktwirtschaft. Eine deskriptive und normative Betrachtung für den Allokationsbereich. 1985.

Band 27 Achim Zeidler: Möglichkeiten zur Fortsetzung der Gemeindefinanzreform. Eine theoretische und empirische Analyse. 1985.

Band 28 Peter Bartsch: Zur Theorie der längerfristigen Wirkungen 'expansiver' Fiskalpolitik. Eine dynamische Analyse unter besonderer Berücksichtigung der staatlichen Budgetbeschränkung und ausgewählter Möglichkeiten der öffentlichen Defizitfinanzierung. 1986.

Band 29 Konrad Beiwinkel: Wehrgerechtigkeit als finanzpolitisches Verteilungsproblem. Möglichkeiten einer Kompensation von Wehrungerechtigkeit durch monetäre Transfers. 1986.

Band 30 Woltgang Kitterer: Effizienz- und Verteilungswirkungen des Steuersystems. 1986.

Band 31 Heinz Dieter Hessler: Theorie und Politik der Personalsteuern. Eine Kritik ihrer Einkommens- und Vermögensbegriffe mit Blick auf die Leistungsfähigkeitstheorie. 1994.

Band 32 Wolfgang Scherf: Die beschäftigungspolitische und fiskalische Problematik der Arbeitgeberbeiträge zur Rentenversicherung. Eine Auseinandersetzung mit der Kritik an der lohnbezogenen Beitragsbemessung. 1987.

Band 33 Andreas Mästle: Die Steuerunion. Probleme der Harmonisierung spezifischer Gütersteuern. 1987.

Band 34 Günter Ott: Internationale Verteilungswirkungen im Finanzausgleich der Europäischen Gemeinschaften. 1987.

Band 35 Heinz Haller: Zur Frage der zweckmäßigen Gestalt gemeindlicher Steuern. Ein Diskussionsbeitrag zur Gemeindesteuerreform. 1987.

Band 36 Thomas Kuhn: Schlüsselzuweisungen und fiskalische Ungleichheit. Eine theoretische Analyse der Verteilung von Schlüsselzuweisungen an Kommunen. 1988.

Band 37 Walter Hahn: Steuerpolitische Willensbildungsprozesse in der Europäischen Gemeinschaft. Das Beispiel der Umsatzssteuer-Harmonisierung. 1988.

Band 38 Ulrike Hardt: Kommunale Finanzkraft. Die Problematik einer objektiven Bestimmung kommunaler Einnahmemöglichkeiten in der gemeindlichen Haushaltsplanung und im kommunalen Finanzausgleich. 1988.

Band 39 Jochen Michaelis: Optimale Finanzpolitik im Modell überlappender Generationen. 1989.

Band 40 Bernd Raffelhüschen: Anreizwirkungen der sozialen Alterssicherung. Eine dynamische Simulationsanalyse. 1989.

Band 41 Berend Diekmann: Die Anleihe- und Darlehenstransaktionen der Europäischen Gemeinschaften. 1990.

Band 42 Helmut Kaiser: Konsumnachfrage, Arbeitsangebot und optimale Haushaltsbesteuerung. Theoretische Ergebnisse und mikroökonometrische Simulation für die Bundesrepublik Deutschland. 1990. 
Band 43 Rüdiger von Kleist: Das Gramm-Rudman-Hollings-Gesetz. Ein gescheiterter Versuch der Haushaltskonsolidierung. 1991.

Band 44 Rolf Hagedorn: Steuerhinterziehung und Finanzpolitik. Ein theoretischer Beitrag unter besonderer Berücksichtigung der Hinterziehung von Zinserträgen. 1991.

Band 45 Cornelia S. Behrens: Intertemporale Verteilungswirkungen in der gesetzlichen Krankenversicherung der Bundesrepublik Deutschland. 1991.

Band 46 Peter Saile: Ein ökonomischer Ansatz der Theorie der intermediären Finanzgewalten Die Kirchen als Parafisci. 1992.

Band 47 Peter Gottfried: Die verdeckten Effizienzwirkungen der Umsatzsteuer. Eine empirische allgemeine Gleichgewichtsanalyse. 1992.

Band 48 Andreas Burger: Umweltorientierte Beschäftigungsprogramme. Eine Effizienzanalyse am Beispiel des "Sondervermögens Arbeit und Umwelt". 1992.

Band 49 Jeanette Malchow: Die Zuordnung verteilungspolitischer Kompetenzen in der Europäischen Gemeinschaft. Eine Untersuchung aufgrund einer Fortentwicklung der ökonomischen Theorie des Föderalismus. 1992.

Band 50 Barbara Seidel: Die Einbindung der Bundesrepublik Deutschland in die Europäischen Gemeinschaften als Problem des Finanzausgleichs. 1992.

Band 51 Ralph Wiechers: Markt und Macht im Rundfunk. Zur Stellung der öffentlich-rechtlichen Rundfunkanstalten im dualen Rundfunksystem der Bundesrepublik Deutschland. 1992.

Band 52 Klaus Eckhardt: Probleme einer Umweltpolitik mit Abgaben. 1993.

Band 53 Oliver Schwarzkopf: Die Problematik unterschiedlicher Körperschaftsteuersysteme innerhalb der EG. 1993.

Band 54 Thorsten Giersch: Bergson-Wohlfahrtsfunktion und normative Ökonomie. 1993.

Band 55 Li-Fang Chou: Selbstbeteiligung bei Arzneimitteln aus ordnungspolitischer Sicht. Das Beispiel der Bundesrepublik Deutschland. 1993.

Band 56 Harald Schlee: Einkommensteuerliche Behandlung von Transferzahlungen. Zur Neuordnung der Familienbesteuerung sowie der Besteuerung von Versicherungsleistungen und Sozialtransfers. 1994.

Band 57 Alexander Spermann: Kommunales Krisenmanagement. Reaktionen baden-württembergischer Stadtkreise auf steigende Sozialhilfekosten und Einnahmenausfälle (198092). 1993.

Band 58 Otto Roloff / Sibylle Brander / Ingo Barens / Claudia Wesselbaum: Direktinvestitionen und internationale Steuerkonkurrenz. 1994.

Band 59 Claudia Wesselbaum-Neugebauer: Internationale Steuerbelastungsvergleiche. 1994.

Band 60 Stephanie Miera: Kommunales Finanzsystem und Bevölkerungsentwicklung. Eine Analyse des kommunalen Finanzsystems vor dem Hintergrund der sich abzeichnenden Bevölkerungsentwicklung am Beispiel Niedersachsens unter besonderer Berücksichtigung des Landkreises Wolfenbüttel und seiner Gemeinden. 1994.

Band 61 Wolfgang Scherf: Die Bedeutung des kaldorianischen Verteilungsmechanismus für die gesamtwirtschaftlichen Wirkungen der staatlichen Neuverschuldung. 1994.

Band 62 Rainer Volk: Vergleich der Vergünstigungseffekte der verschiedenen investitionsfördernden Maßnahmen. 1994.

Band 63 Hans-Georg Napp: Kommunale Finanzautonomie und ihre Bedeutung für eine effiziente lokale Finanzwirtschaft. 1994. 2., unveränderte Auflage 1994.

Band 64 Bernd Rahmann / Uwe Steinborn / Günter Vornholz: Empirische Analyse der Autonomie lokaler Finanzwirtschaften in der Europäischen Gemeinschaft. 1994. 
Band 65 Carsten Kühl: Strategien zur Finanzierung der Altlastensanierung. 1994.

Band 66 Stephan Boll: Intergenerationale Umverteilungswirkungen der Fiskalpolitik in der Bundesrepublik Deutschland. Ein Ansatz mit Hilfe des Generational Accounting. 1994.

Band 67 Karl Justus Bernhard Neumärker: Finanzverfassung und Staatsgewalt in der Demokratie. Ein Beitrag zur konstitutionellen Finanztheorie. 1995.

Band 68 Christian Haslbeck: Zentrale versus dezentrale Internalisierung externer Effekte bei unvollständiger Information. 1995.

Band 69 Regina Müller: Horizontale oder vertikale Transfers zur Durchsetzung eines horizontalen Finanzausgleichs. 1995.

Band 70 Christian Hockenjos: Öffentliche Sportförderung in der Bundesrepublik Deutschland. Darstellung und finanztheoretische Analyse. 1995.

Band 71 Manfred Rosenstock: Die Kontrolle und Harmonisierung nationaler Beihilfen durch die Kommission der Europäischen Gemeinschaften. 1995.

Band 72 Christian Rüsch: Wohnungsbau- und Wohneigentumspolitik im Rahmen der Einkommensteuer. Eine Analyse unter steuersystematischen, verteilungspolitischen und fiskalischen Aspekten. 1996.

Band 73 Stephan Winters: Die kollektive Vorsorge für den Pflegefall im Alter. Eine Untersuchung am Beispiel der gesetzlichen Pflegeversicherung in den Niederlanden. 1996.

Band 74 Knut Blind: Allokationsineffizienzen auf Sicherheitsmärkten: Ursachen und Lösungsmöglichkeiten. Fallstudie: Informationssicherheit in Kommunikationssystemen. 1996.

Band 75 Barbara Petrick-Rump: Ökonomische Wirkungen von Steueramnestien. Untersuchung konkreter Erfahrungen ausgewählter Länder mit dem Einsatz von Steueramnestien anhand eines effizienten Steueramnestieprogramms. 1996.

Band 76 Georg Hirte: Effizienzwirkungen von Finanzausgleichsregelungen. Eine Empirische Allgemeine Gleichgewichtsanalyse für die Bundesrepublik Deutschland. 1996.

Band 77 Ulrike Kirchhoff: Die rheinland-pfälzischen Gemeinden im System des Finanzausgleichs. 1996.

Band 78 Kerstin Keil: Der soziale Mietwohnungsbau: Mängel und Alternativen. 1996.

Band 79 Bernhard Manzke: Kinderlastenausgleich versus verstärkte Einwanderung. Alternative Ansätze zur langfristigen Sicherung der Gesetzlichen Rentenversicherung. 1997.

Band 80 Hariolf M. Wenzler: Institutionenökonomik und öffentliche Finanzkontrolle. Eine Analyse am Beispiel der Europäischen Union. 1997.

Band 81 Joachim Nagel: Supply-Side Policy in den USA. Eine theoretische und empirische Analyse der angebotsorientierten Wirtschaftspolitik Reagans unter besonderer Berücksichtigung steuerlicher Aspekte. 1997.

Band 82 Heinz Lampert: Krise und Reform des Sozialstaates. 1997.

Band 83 Monika Hanswillemenke / Bernd Rahmann: Zwischen Reformen und Verantwortung für Vollbeschäftigung. Die Finanz- und Haushaltspolitik der sozial-liberalen Koalition von 1969 bis 1982. 1997.

Band 84 Berthold Fürst: Die Maastrichter Budgetkriterien im Konflikt mit der Verschuldungsautonomie der deutschen Gebietskörperschaften. 1997.

Band 85 Burkhard Pahnke: Einkommensorientierte Förderung des sozialen Mietwohnungsbaues. Bestandsaufnahme und Kritik. 1998. 
Band 86 Judith Safford: Staatsverschuldung im Vereinigten Königreich. Die öffentliche Verschuldung unter der Konservativen Regierung von 1979-1994. Ursachen und Auswirkungen. 1998.

Band 87 Ralf Oberheide: Die Bekämpfung der Steuerumgehung. 1998. 
Ralf Oberheide - 978-3-631-75185-5

Downloaded from PubFactory at 01/11/2019 07:21:58AM

via free access 